Louisiana State University

LSU Digital Commons

Faculty Publications

Department of Biological Sciences

$1-1-2016$

\title{
Comparison of electrophysiological auditory measures in fishes
}

\author{
Karen P. Maruska \\ Louisiana State University \\ Joseph A. Sisneros \\ University of Washington, Seattle
}

Follow this and additional works at: https://digitalcommons.Isu.edu/biosci_pubs

\section{Recommended Citation}

Maruska, K., \& Sisneros, J. (2016). Comparison of electrophysiological auditory measures in fishes.

Advances in Experimental Medicine and Biology, 877, 227-254. https://doi.org/10.1007/

978-3-319-21059-9_11

This Article is brought to you for free and open access by the Department of Biological Sciences at LSU Digital Commons. It has been accepted for inclusion in Faculty Publications by an authorized administrator of LSU Digital Commons. For more information, please contact ir@lsu.edu. 
Advances in Experimental Medicine and Biology 877

Joseph A. Sisneros Editor
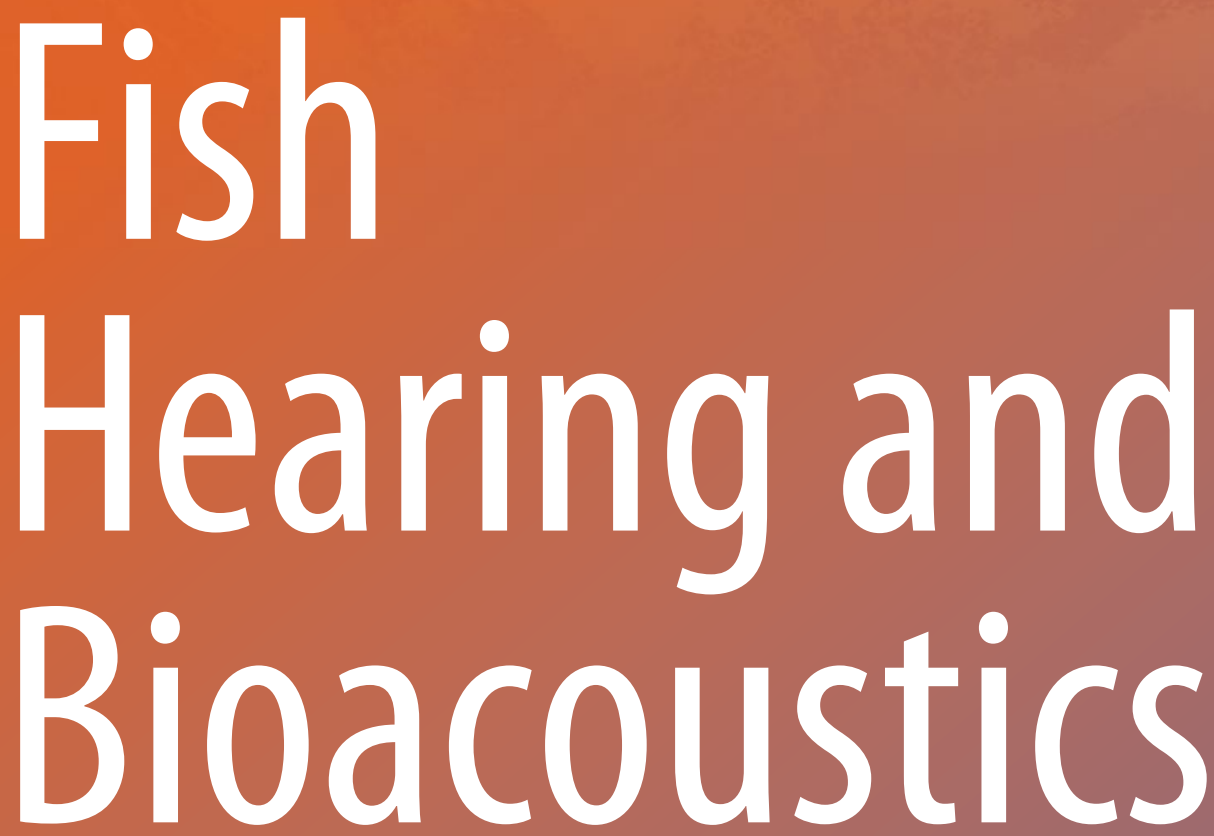

An Anthology in Honor of Arthur N. Popper and Richard R. Fay

$\underline{\underline{y}}$ Springer 


\section{Advances in Experimental Medicine and Biology}

Editorial Board:

IRUN R. COHEN, The Weizmann Institute of Science, Rehovot, Israel

ABEL LAJTHA, N.S. Kline Institute for Psychiatric Research, Orangeburg, NY, USA JOHN D. LAMBRIS, University of Pennsylvania, Philadelphia, PA, USA

RODOLFO PAOLETTI, University of Milan, Milan, Italy

More information about this series at http://www.springer.com/series/5584 

Joseph A. Sisneros

Editor

\section{Fish Hearing and Bioacoustics}

An Anthology in Honor of

Arthur N. Popper and Richard R. Fay

Springer 


\title{
Editor
}

\author{
Joseph A. Sisneros \\ Department of Psychology \\ University of Washington \\ Seattle, WA, USA
}

ISSN 0065-2598

ISSN 2214-8019 (electronic)

Advances in Experimental Medicine and Biology

ISBN 978-3-319-21058-2

ISBN 978-3-319-21059-9 (eBook)

DOI 10.1007/978-3-319-21059-9

\section{Library of Congress Control Number: 2015944316}

\section{Springer Cham Heidelberg New York Dordrecht London}

(c) Springer International Publishing Switzerland 2016

This work is subject to copyright. All rights are reserved by the Publisher, whether the whole or part of the material is concerned, specifically the rights of translation, reprinting, reuse of illustrations, recitation, broadcasting, reproduction on microfilms or in any other physical way, and transmission or information storage and retrieval, electronic adaptation, computer software, or by similar or dissimilar methodology now known or hereafter developed.

The use of general descriptive names, registered names, trademarks, service marks, etc. in this publication does not imply, even in the absence of a specific statement, that such names are exempt from the relevant protective laws and regulations and therefore free for general use.

The publisher, the authors and the editors are safe to assume that the advice and information in this book are believed to be true and accurate at the date of publication. Neither the publisher nor the authors or the editors give a warranty, express or implied, with respect to the material contained herein or for any errors or omissions that may have been made.

Printed on acid-free paper

Springer International Publishing AG Switzerland is part of Springer Science+Business Media (www.springer.com) 


\section{Prelude to the Anthology to Honor Arthur N. Popper and Richard R. Fay}

A special symposium was held on 25 May 2013 at the Mote Marine Laboratory in Sarasota, Florida, USA, to honor the long and illustrious careers of Drs. Richard R. Fay and Arthur N. Popper. During the past 38 years, Drs. Popper and Fay have made substantial research contributions to the field of fish hearing and bioacoustics, which include Richard Fay's elegant psychoacoustic and physiology experiments on fish hearing and Arthur Popper's seminal electron and light microscopy research on fish inner ear structure. The work of Fay and Popper spans multiple disciplines and topics including the ototoxicity, development and regeneration of hair cells, sound communication and directional hearing in fishes, and the effects of underwater noise on aquatic life. In addition to their many "classic" review papers, which had major impacts on the field of fish hearing, Popper and Fay have also made important contributions to the understanding of broader issues in the fields of animal bioacoustics and auditory neuroscience through the many conferences they have organized and books edited in the 50 plus volumes of the Springer Handbook of Auditory Research, of which Fay and Popper are the founding (and current) series editors.

At the formal one-day symposium in Sarasota, FL (Figs. 1, 2, 3, 4, 5, 6, 7, 8, 9, $10,11,12$, and 13), there were 12 presentations that covered a wide range of topics on fish bioacoustics and hearing including a number of presentations by former graduate students, postdocs, and colleagues who reviewed the historical contributions of "Art" Popper and "Dick" Fay and traced their academic heritage to Dick and Art in terms of both research and training. From the original talks and posters presented at the symposium plus a few additional contributions, an anthology of 15 book chapters were contributed for this volume in Advances in Experimental Medicine and Biology. We asked the authors of this volume to include in their chapters a significant review of their area of study and conclude with 3-5 "burning questions" that should be addressed in future studies. It is hoped that this anthology of papers will provide the inspiration and impetus for young (and old) scientists to continue the study of fish hearing and bioacoustics in future studies. 
The book chapters that follow the biographies of Dick Fay and Art Popper are divided into three categories: acoustic communication and behavior, sensory biology and physiology, and morphology and neuroanatomy. The first chapter in Part II on acoustic communication and behavior is by Tim Tricas and Jackie Webb in which they review the current knowledge of sound producing mechanisms, hearing capabilities, and the likely importance of the auditory and lateral systems, especially the laterophysic connection, in acoustic communication in butterflyfishes. Jeffrey Zeyl and associates then present a review of sound production in darters, sculpin, and gobioids in a phylogenetic context that details the efficacy of signal transmission from senders to receivers and evaluates the potential functional significance of sound attributes in relation to reproductive and territorial behaviors. Next, Joe Sisneros and Pete Rogers summarize the previous behavioral work on directional hearing and sound source localization in fishes and review the current theoretical models for fish sound localization. Ashwin Bhandiwad and Joe Sisneros then review some of the common methods used in fish psychoacoustic studies and discuss associative methods such as operant, avoidance, and classical conditioning and how they are used to construct audiograms, measure frequency selectivity,

\section{Years of Underwater Bioacoustics}

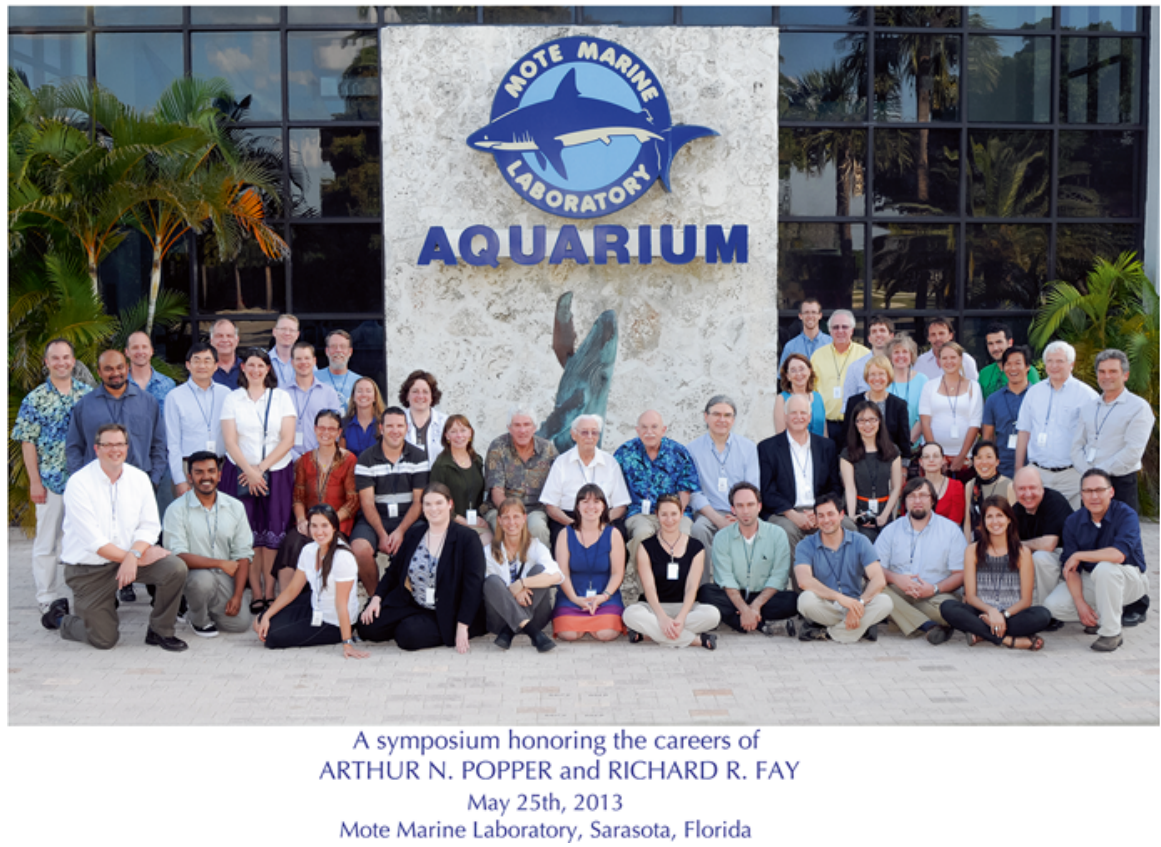

Fig. 1 Group photograph of the attendees at the symposium to honor Arthur N. Popper and Richard R. Fay in front of the aquarium at Mote Marine Laboratory in Sarasota, Florida on May 25, 2013 


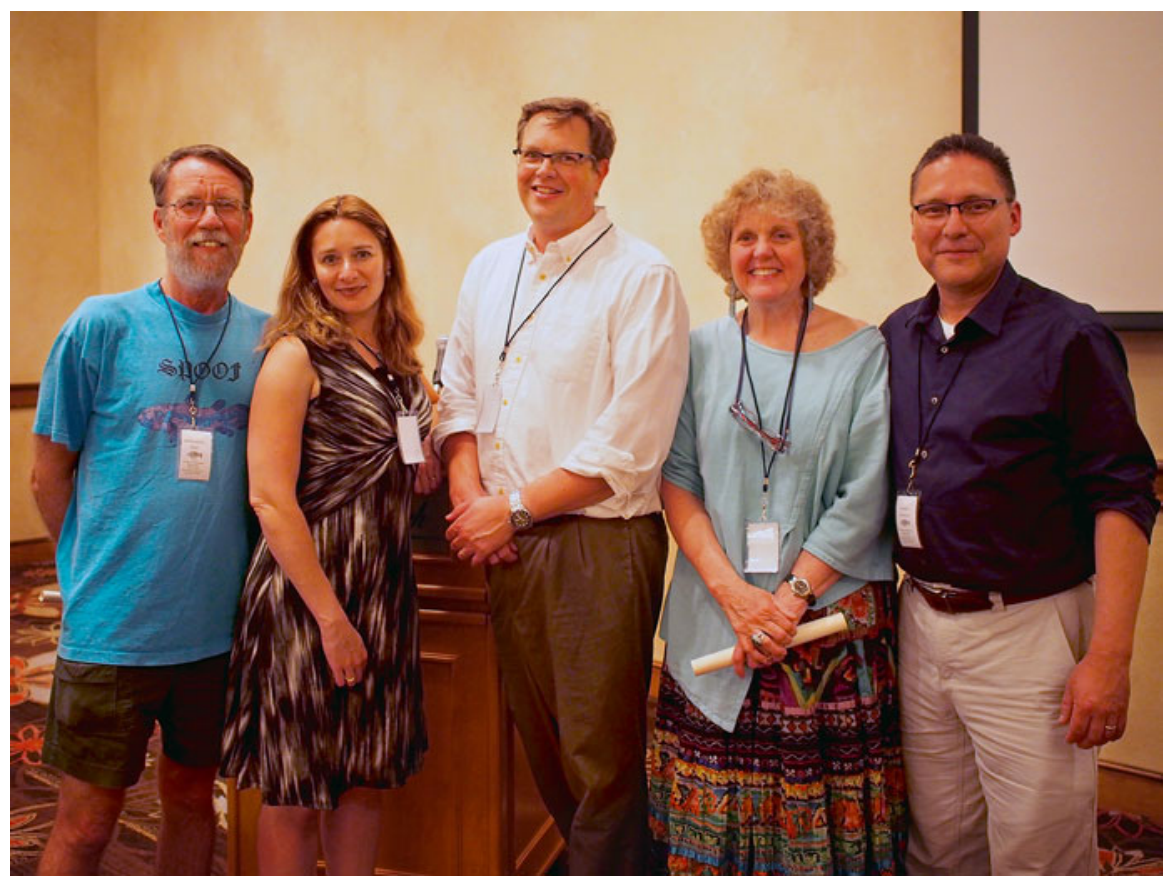

Fig. 2 The conference organizers at the reception following the symposium to honor the careers of Richard R. Fay and Arthur N. Popper at Mote Marine Laboratory. From left to right are Chris Platt, Alli Coffin, David Mann, Sheryl Coombs, and Joe Sisneros. Other conference organizer Pamela Lanford not shown

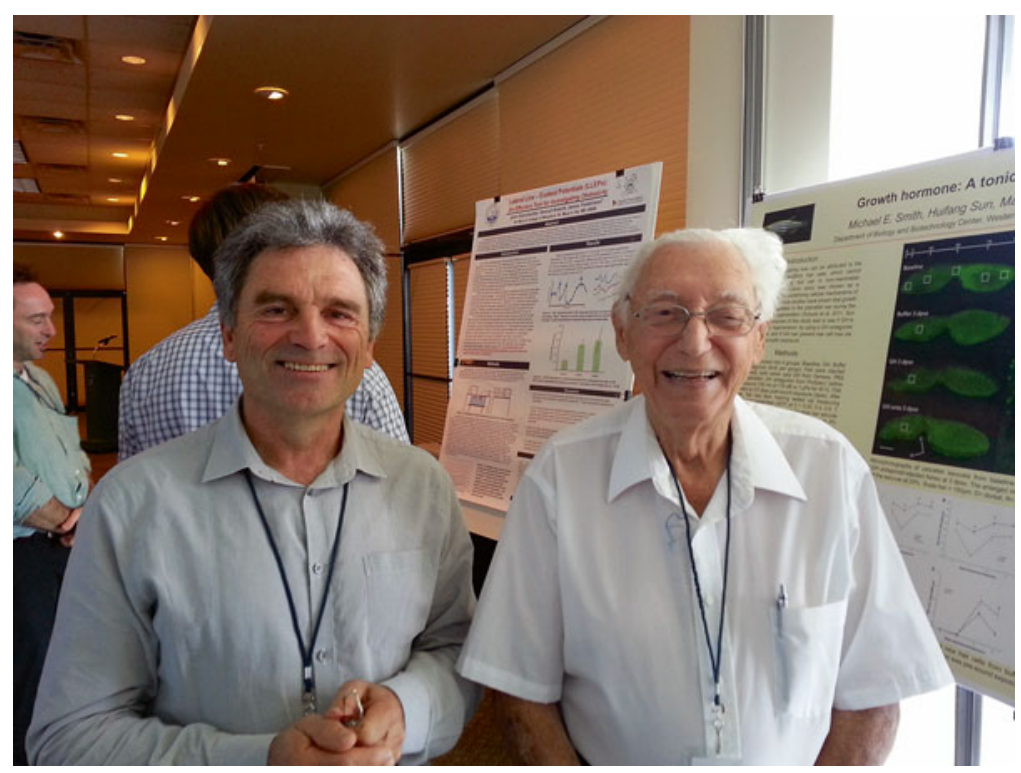

Fig. 3 Conference participants from near and far included from left to right John Montgomery (New Zealand) and Bill Tavolga (Sarasota, FL) 


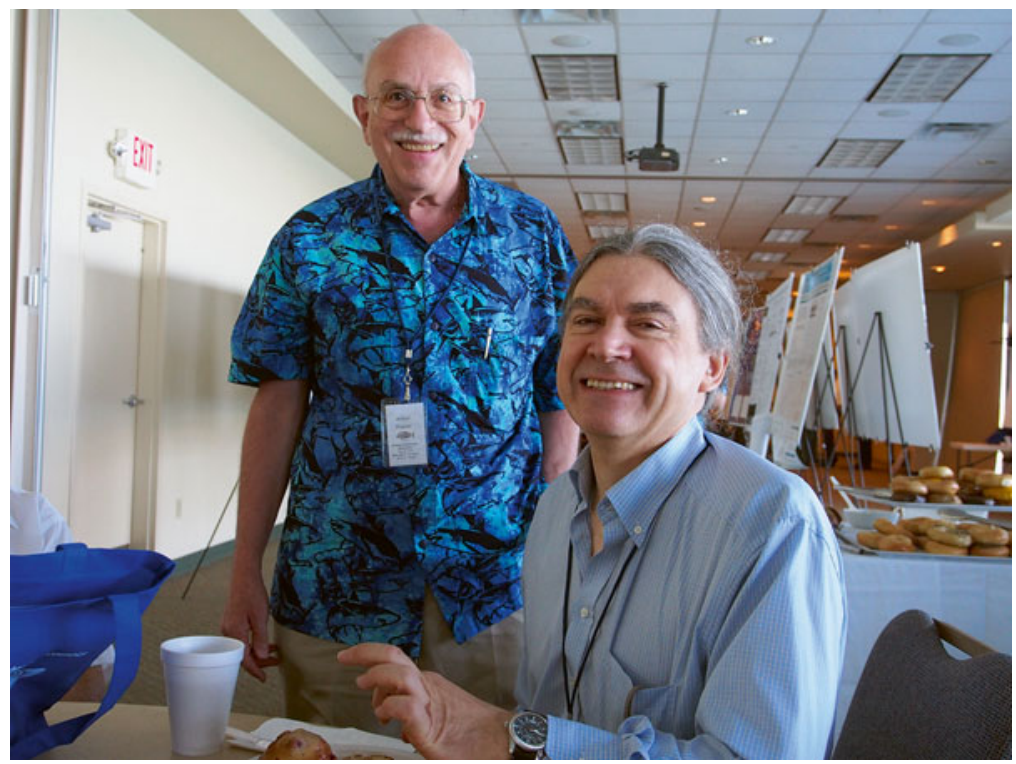

Fig. 4 During a break at the symposium to honor the outstanding careers of Arthur N. Popper and Richard R. Fay. From left to right are Art Popper and Fritz Ladich

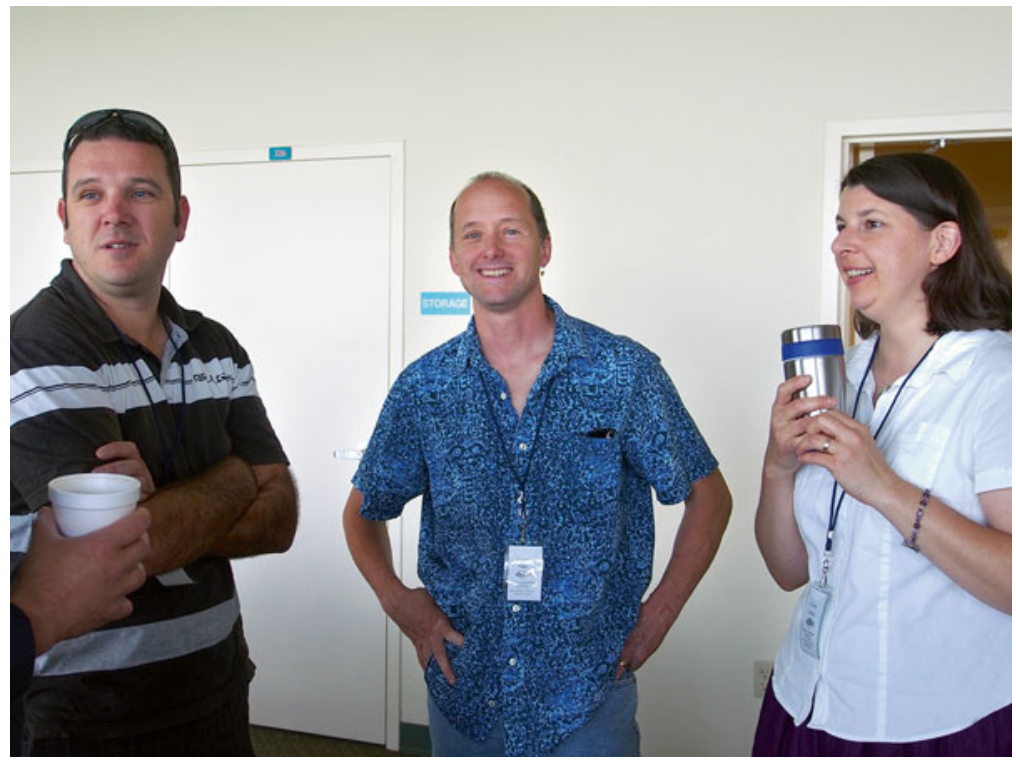

Fig. 5 Enjoy a break during the symposium to honor Richard R. Fay and Arthur N. Popper. From left to right are Craig Radford, Dennis Higgs, and Kirsten Poling 


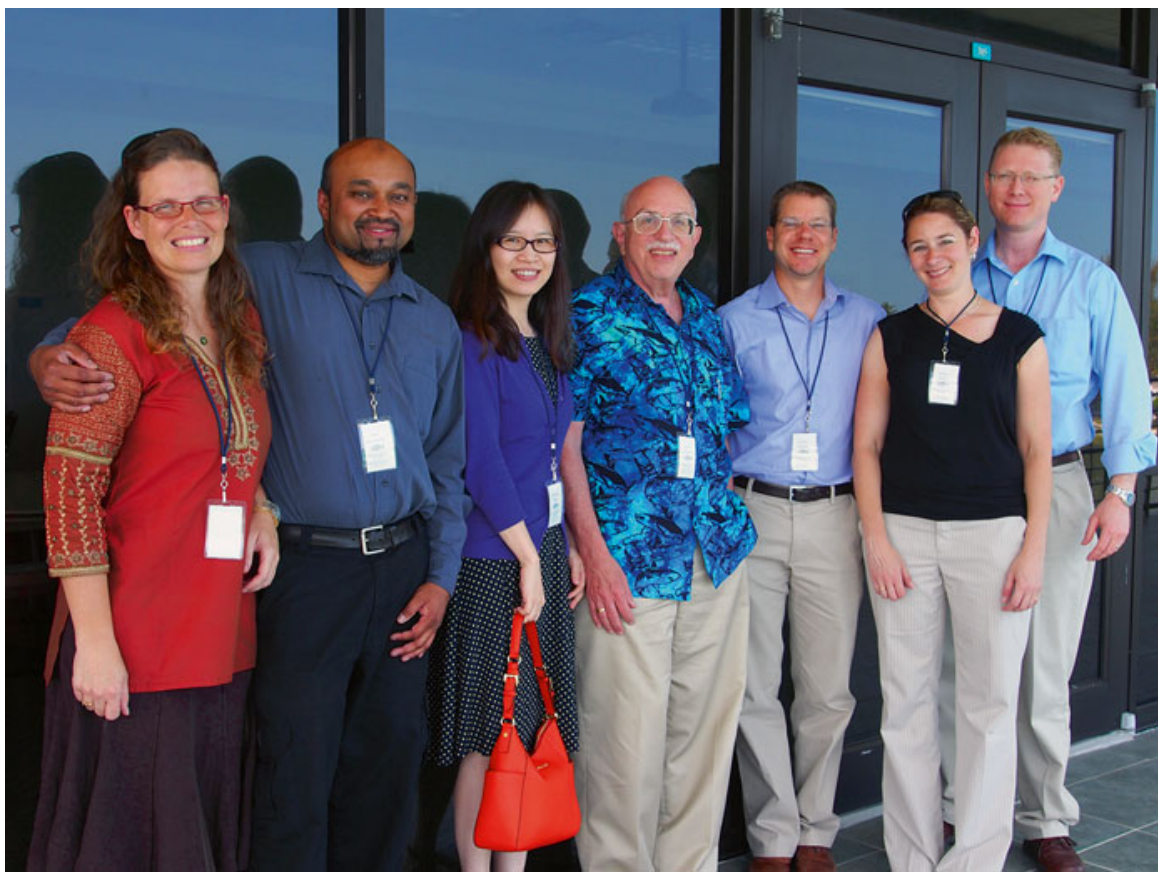

Fig. 6 The symposium to honor Arthur N. Popper and Richard R. Fay in Sarasota was attended by many of Art Popper's former postdocs, students, and advisees. From left to right are Daphne Soares, John Ramcharitar, Xiaohong Deng, Art Popper, David Zeddies, Alli Coffin, and Michael Smith

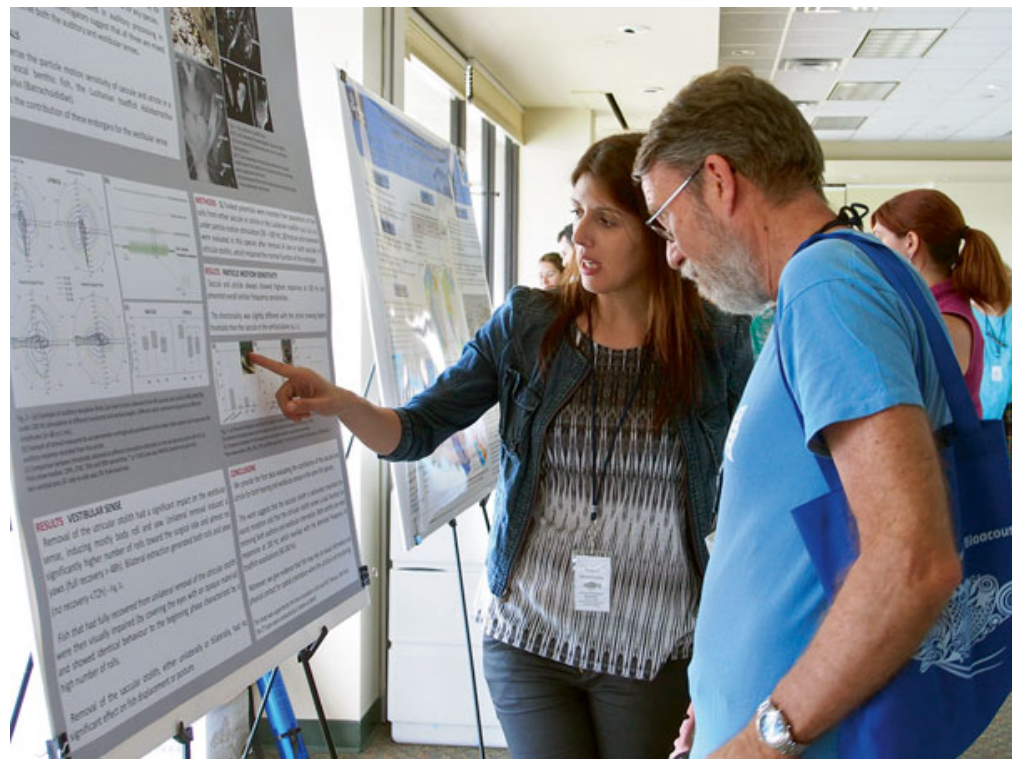

Fig. 7 During the poster session at the symposium to honor Richard R. Fay and Arthur N. Popper, Raquel Vasconcelos (left) explains her research on toadfish to Chris Platt (right) 


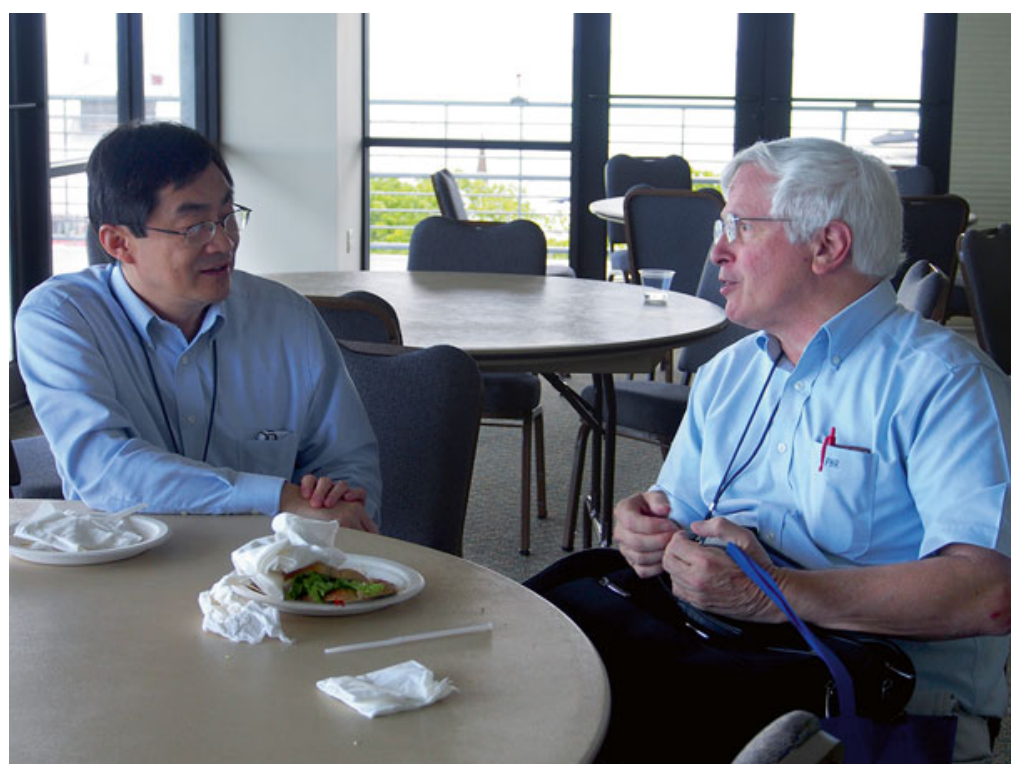

Fig. 8 During a lunch break, John Lu (left) and Peter Rogers (right) discuss fish hearing and bioacoustics

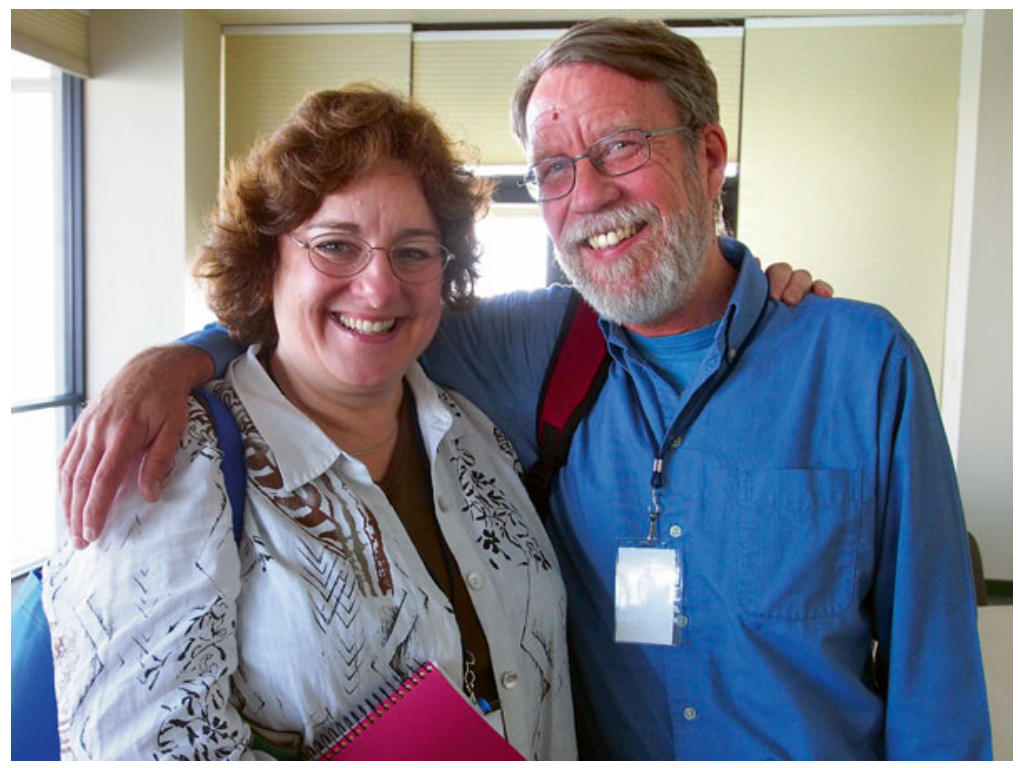

Fig. 9 During a symposium break, Jackie Webb (left) and Chris Platt (right) pose for a picture 


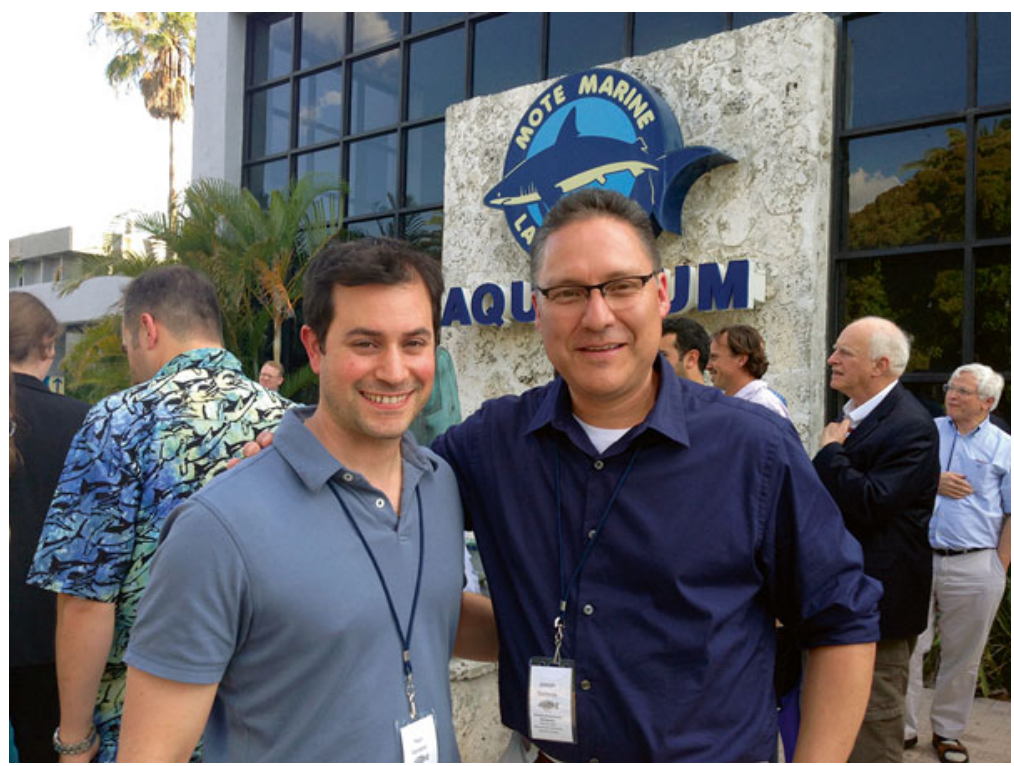

Fig. 10 After the symposium to honor Fay and Popper, Paul Forlano (left) and Joe Sisneros (right) pose for a picture outside the aquarium at Mote Marine Laboratory

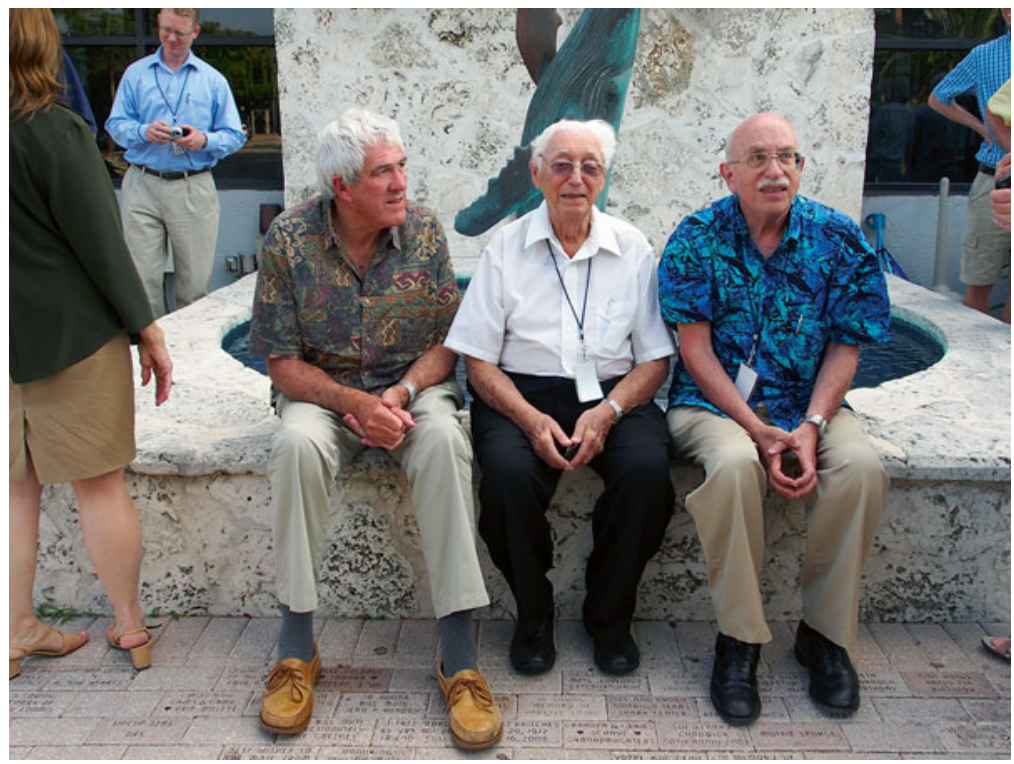

Fig. 11 Posing for pictures after the symposium to honor Popper and Fay in front of the Mote Marine Laboratory aquarium are (from left to right) Tony Hawkins, Bill Tavolga, and Art Popper 


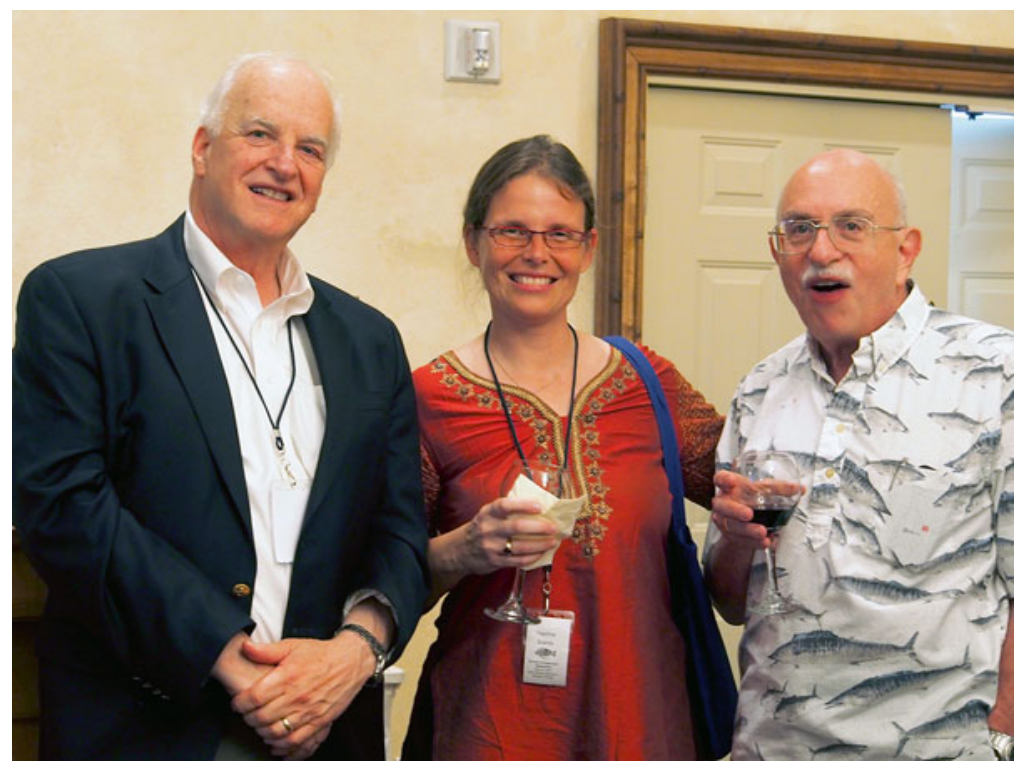

Fig. 12 Social hour after the Fay and Popper symposium. From left to right are Peter Narins, Daphne Soares, and Art Popper

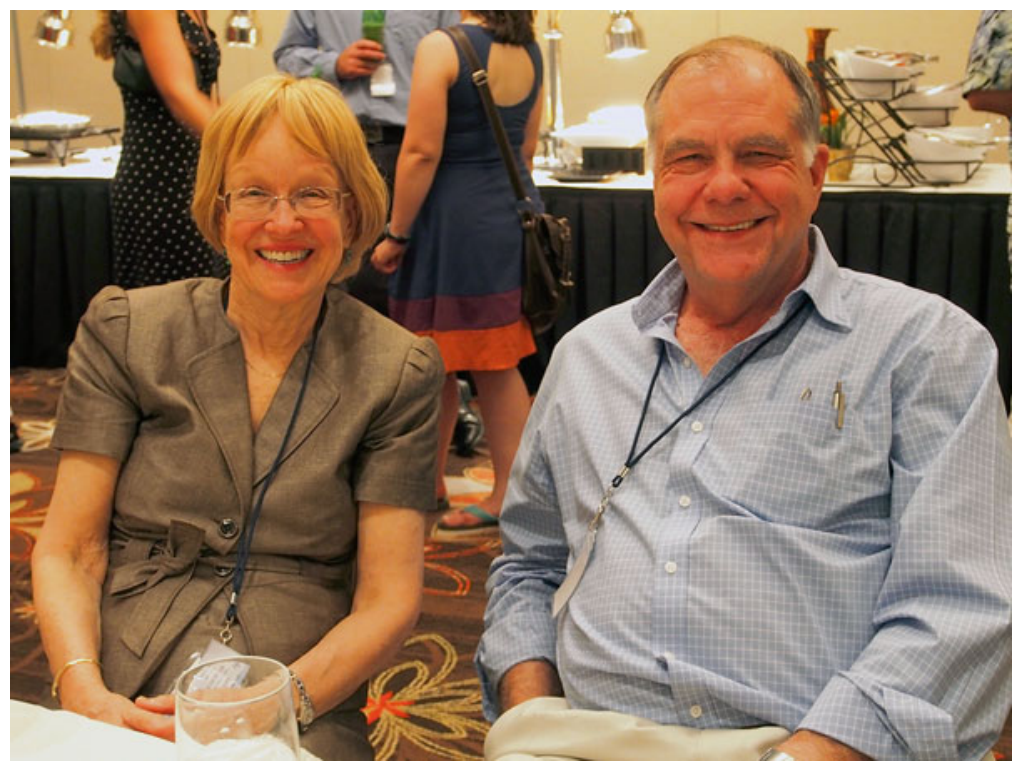

Fig. 13 Enjoying the reception following the Popper and Fay symposium are Norma Allewell (left) and Bob Dooling (right) 
and evaluate auditory stream segregation. They also present detailed considerations for experimental design with respect to stimulus presentation and threshold criteria and how these experimental variables can be used in future studies to investigate auditory perception in fishes. In Part III on sensory biology and physiology, Daphne Soares, Matthew Niemiller, and Dennis Higgs review the current knowledge on cavefish hearing, which has not been well studied, as hearing ability has only been examined in four species. These authors summarize their own studies on amblyopsid cavefishes and offer suggestions for future research on these fascinating fishes. In the next chapter, Peggy Edds-Walton summarizes her research completed during collaborations with both Art Popper and Dick Fay on how the toadfish ear and central nervous system encode and process biologically relevant sounds and what we have learned about what the toadfish ear tells the toadfish brain specifically about the particle motion component of sound. Karen Maruska and Joe Sisneros then provide one of the first comparisons of auditory threshold curves determined by different recording methods in a single fish species, the soniferous Hawaiian sergeant fish Abudefduf abdominalis, and review past studies on representative fish species with tuning curves determined by different methods. Next, Dennis Higgs and Craig Radford examine the potential overlapping roles of the inner ear and the lateral line for encoding acoustic stimuli in the context of sound communication and other acoustically driven behaviors. Al Mensinger summarizes the use of chronically implanted microwire electrodes and telemetry tags for exploring the sensory physiology and multimodal sensory input of the lateral line and inner ear, specifically the utricle, and discusses the need to determine how these sensory systems encode and integrate similar stimuli. Raquel Vasconcelos, Peter Alderks, and Joe Sisneros then review the current literature on the development of the fish inner ear and provide a systematic overview of how auditory sensitivity develops during ontogeny. In the fourth and final part on the morphology and neuroanatomy of the fish auditory system, Friedrich Ladich begins with a discussion of the peripheral hearing structures in catfishes and cichlids and to what degree the size of the swim bladder and the linkage to the inner ear affect hearing in these fishes. Tanja Schulz-Mirbach and Friedrich Ladich then provide a much needed update on the "state of the art" of inner ear diversity in teleost fishes and summarize the current hypotheses on the evolution of this inner ear diversity. Michael Smith and J.D. Monroe discuss the current knowledge regarding the causes and consequences of hair cell damage in teleost fishes from intense and/or long-term exposure to sound and ototoxic chemicals such as aminoglycoside antibiotics and antineoplasmic agents. Next Alli Coffin and John Ramcharitar also review ototoxicity effects in the inner ear and lateral line systems of fishes but with an emphasis on neuroethological research aimed at understanding fish sensory function and behavior and in the context of biomedical studies that may influence the clinical use of agents with demonstrated ototoxicity. Finally, Paul Forlano and Joe Sisneros summarize recent studies on the plainfin midshipman (Porichthys notatus) that have characterized catecholamine innervation in the central and peripheral auditory system and have tested hypotheses that innervation of the midshipman auditory system is seasonally plastic and that catecholaminergic neurons are activated in response to conspecific vocalizations. 
The editor would like to thank all the participants of the special symposium at Mote Marine Laboratory to honor Art and Dick and those who contributed book chapters in this printed volume. The symposium was made possible with support from Tucker-Davis Technologies, Springer, The Company of Biologists and the Association for Research in Otolaryngology. Special thanks to David Mann, Alli Coffin, Sheryl Coombs, Chris Platt, and Pamela Lanford in helping to organize this special symposium. We would also like to thank the more than 75 attendees at the meeting who helped make this a memorable symposium.

Seattle, WA, USA

Joseph A. Sisneros

30 April 2015 


\section{Contents}

\section{Part I Biographies and Soliloquy}

Fishy Hearing: A Short Biography of Arthur N. Popper, PhD

Allison B. Coffin

A Most Interesting Man of Science: The Life and Research of Richard Rozzell Fay

Joseph A. Sisneros

It Started in Hawai'i Kai: Reminiscences of 43 Years

(and Counting) of Collaboration and Friendship

Arthur N. Popper and Richard R. Fay

A Soliloquy for Art and Dick

Robert J. Dooling

Part II Acoustic Communication and Behavior

Acoustic Communication in Butterflyfishes: Anatomical Novelties, Physiology, Evolution, and Behavioral Ecology

Timothy C. Tricas and Jacqueline F. Webb

Convergent Aspects of Acoustic Communication in Darters,

Sculpins, and Gobies.

Jeffrey N. Zeyl, Stefano Malavasi, Daniel E. Holt, Patricia Noel,

Marco Lugli, and Carol E. Johnston

Directional Hearing and Sound Source Localization in Fishes

Joseph A. Sisneros and Peter H. Rogers

Revisiting Psychoacoustic Methods for the Assessment

of Fish Hearing

Ashwin A. Bhandiwad and Joseph A. Sisneros 


\section{Part III Sensory Biology and Physiology}

Hearing in Cavefishes

Daphne Soares, Matthew L. Niemiller, and Dennis M. Higgs

What the Toadfish Ear Tells the Toadfish Brain About Sound

Peggy L. Edds-Walton

Comparison of Electrophysiological Auditory Measures in Fishes.

Karen P. Maruska and Joseph A. Sisneros

The Potential Overlapping Roles of the Ear and Lateral Line

in Driving "Acoustic" Responses

Dennis M. Higgs and Craig A. Radford

Multimodal Sensory Input in the Utricle and Lateral Line

of the Toadfish, Opsanus tau

Allen F. Mensinger

Development of Structure and Sensitivity of the Fish Inner Ear

Raquel O. Vasconcelos, Peter W. Alderks, and Joseph A. Sisneros

\section{Part IV Morphology and Neuroanatomy}

Peripheral Hearing Structures in Fishes:

Diversity and Sensitivity of Catfishes and Cichlids

Friedrich Ladich

Diversity of Inner Ears in Fishes: Possible Contribution

Towards Hearing Improvements and Evolutionary Considerations

Tanja Schulz-Mirbach and Friedrich Ladich

Causes and Consequences of Sensory Hair Cell Damage and Recovery in Fishes

Michael E. Smith and J. David Monroe

Chemical Ototoxicity of the Fish Inner Ear and Lateral Line

Allison B. Coffin and John Ramcharitar

Neuroanatomical Evidence for Catecholamines as Modulators

of Audition and Acoustic Behavior in a Vocal Teleost

Paul M. Forlano and Joseph A. Sisneros

Index 
Part I

Biographies and Soliloquy 


\title{
Fishy Hearing: A Short Biography of Arthur N. Popper, PhD
}

\begin{abstract}
Allison B. Coffin
Abstract Biologist Dr. Arthur Popper's career spans decades, from his early work on comparative inner ear morphology in fishes to his recent interest in how underwater noise impacts aquatic vertebrates. Along the way Dr. Popper's research subjects span at least 19 vertebrate taxa, from lamprey to lungfish to humans, and he's had a profound influence in the field of fish bioacoustics. This brief biography describes some of Dr. Popper's many contributions to fish hearing research and highlights both some of his major discoveries and some of the biological mysteries he has yet to solve.
\end{abstract}

Keywords Fish • Bioacoustics $\bullet$ Hearing $\bullet$ Underwater sound $\bullet$ Sound localization

I joined Dr. Arthur Popper's lab in 2000, an eager young graduate student interested in studying sound source localization in fishes. Art welcomed me with open arms and a word of caution - sound localization was too hard a problem for a graduate thesis, or at least it would take longer to solve than most students wished to spend on their dissertations.

It turns out I wasn't the first graduate student enticed by the problem of how fish localize a sound. In the late 1960s Art began graduate study with Dr. William Tavolga at City College of the City University of New York. Art was interested in studying fish hearing but didn't know at first what angle he wished to take. Dr. Tavolga sent him home with a stack of papers to read, giving Art the freedom to select his dissertation topic, and after perusing the literature Art arrived at the question of sound source localization. The story is best told in Art's own words, "I suggested to Bill that I study sound localization, and his immediate response was that it would take 17 years to complete a study, and I signed on (although I did not believe it would take 17 years)... I won't continue the story with localization other than to say that Bill's 17 years were way off; even today, we really don't have a clear understanding of the mechanisms and capabilities of fishes for sound localization..." (Popper 2014).

\footnotetext{
A.B. Coffin $(\bowtie)$

Washington State University Vancouver, Vancouver, WA, USA

e-mail: Allison.coffin@wsu.edu 
Anim. Behav., 1970, 18, 552-562

\title{
AUDITORY CAPACITIES OF THE MEXICAN BLIND CAVE FISH (ASTYANAX JORDANI) AND ITS EYED ANCESTOR ( ASTYANAX MEXICANUS)
}

\author{
BY ARTHUR N. POPPER* \\ Department of Biology, City College of The City University of New York
}

Fig. 1 The title page from Art's dissertation study, published in Animal Behaviour in 1970

Since Art didn't want to spend 17 years in graduate school, he switched his dissertation topic to a comparative study of hearing between Mexican blind cavefish and their sighted sister taxa (now considered subspecies of Astyanax mexicanus), demonstrating that both groups had similar ear morphology and hearing capabilities (Popper 1970, 1971; see Fig. 1). After graduation in 1969, Art moved to the University of Hawaii as an assistant professor, where, in December 1971, he met a new postdoc working with Nobel Prize winner Georg von Békésy. That postdocDr. Richard Fay - was just as fascinated with fish hearing as Art, and their chance meeting at a barbeque has resulted in 25 papers (see essay by Popper in this volume), over 50 SHAR volumes (Springer Handbook of Auditory Research), and the growth of our field in fish bioacoustics. The first Popper and Fay paper was published in 1973 with the title "Sound detection and processing by fish: a critical review." I suspect this early review was more of a strategic planning move, giving them an excuse to review the literature so they could chart a course for the field over the next $40+$ years.

After launching his independent career in Hawaii, Art moved back to the east coast for a position at Georgetown University, then to the University of Maryland, where he retired as Professor Emeritus in 2013. Through his long career Art has slowly shifted his research focus from fundamental questions in comparative sensory biology to applied issues about the effects of underwater sound on fishes and other aquatic life. Much of Art's early work focused on comparative morphology between ears of fishes from different taxonomic groups, using scanning electron microscopy to describe variation in hair bundle morphology and bundle orientation both within an epithelium and between epithelia of different fishes (Popper 1976, 1977, 1978a, b, 1980). While several of these fishes had interesting differences in ear morphology, some (such as the lake whitefish, Coregonus clupeaformis) were also quite tasty. Institutional Animal Care and Use Committees were quite different back then, particularly where fish were concerned!

Over the years Art has published over 200 papers, with the vast majority of studies examining different aspects of fish hearing. His wide array of structural and functional studies form the basis for much of our understanding of fish hearing and the similarities and differences between different fishes. A true comparative biologist, Art's work spans many diverse fish phylogenetic and ecological groups. 
His dissertation work on cavefish marked the renewed interest in otophysan studies since the early days of Von Frisch. Otophysans are the group of fishes that include catfish, goldfish, and other fishes with specialized Weberian ossicles that enhance hearing via coupling of the swim bladder and inner ear (e.g., Popper 1972, 1974; Fay and Popper 1974; Popper and Clarke 1976; Popper and Tavolga 1981; Lanford et al. 1996; Edds-Walton and Popper 2000; Smith et al. 2006).

Other studies include comparative morphology of deep-sea fish ears (Popper 1980; Buran et al. 2005; Deng et al. 2011, 2013), comparative morphology and physiology in sound-producing sciaenid fishes (Ramcharitar et al. 2004, 2006), and a body of work on the oscar (Astronotus ocellatus), a cichlid used by the Popper Lab for a range of studies from behavioral auditory function to cell proliferation research (Yan and Popper 1992; Lombarte et al. 1993; Presson et al. 1993; Lu et al. 1996). Popper Lab research on hearing in clupeid fishes includes the striking discovery that some shad species can detect and behaviorally respond to ultrasound, likely as an adaptation for avoiding predation by echo-locating dolphins (Mann et al. 1997; Plachta and Popper 2003; Higgs et al. 2004). Art's work includes fishes that occupy key evolutionary nodes, such as research in cartilaginous elasmobranchs (sharks, skates, and rays, Fay et al. 1974), non-teleost actinopterygian fishes such as sturgeon (Acipenser spp.) (Meyer et al. 2010), bichir (Polypterus bichir) (Popper 1978a, b), and bowfin (Amia calva) (Popper and Northcutt 1983), and the sarcopterygian lungfish (Protopterus sp.) (Platt et al. 2004). Collectively, this body of work offers a broad evolutionary view of vertebrate hearing.

While I think Art considers himself a fish sensory biologist at heart, over the years he has pursued research questions as they are generated, often letting his students and postdocs follow their curiosity. This has led to publications on diverse vertebrate groups and research topics, such as amphibious hearing in alligators (Higgs et al. 2002), cell death in canary ears (Wilkins et al. 2001), and even the first work on sound localization in bottlenose dolphins (Tursiops truncates) (Renaud and Popper 1975). Figure 2 shows a vertebrate (albeit fish-centric) phylogeny indicating taxonomic groups where Art has published at least one study.

Art's recent work has taken a more applied bent to fish hearing. In the 1990s he became interested in the use of sound to control fish behavior, with possible applications for preventing fish from swimming into industrial piping or helping guide them through fish ladders (Popper and Carlson 1998). These considerations led to a new avenue of research about the impact that anthropogenic underwater noise may have on fishes and other aquatic organisms. Noise from seismic air guns used for oil and gas exploration, naval sonar in use by the military, or pile drivers employed for underwater construction output intense sounds at $198 \mathrm{~dB}$ (re $1 \mu \mathrm{Pa}$ ) or higher, which may have profound consequences for nearby aquatic life. Art's research in the last decade demonstrates that intense underwater sounds can cause inner ear damage, temporary hearing loss, and serious tissue damage to some fish species, with significant barotrauma seen in fishes with swim bladders (McCauley et al. 2003; Popper et al. 2005; Song et al. 2008; Casper et al. 2012, 2013; Halvorsen et al. 2012). These studies help set policy for underwater construction projects, including Art's consulting role on the Tappan Zee Bridge reconstruction project in 


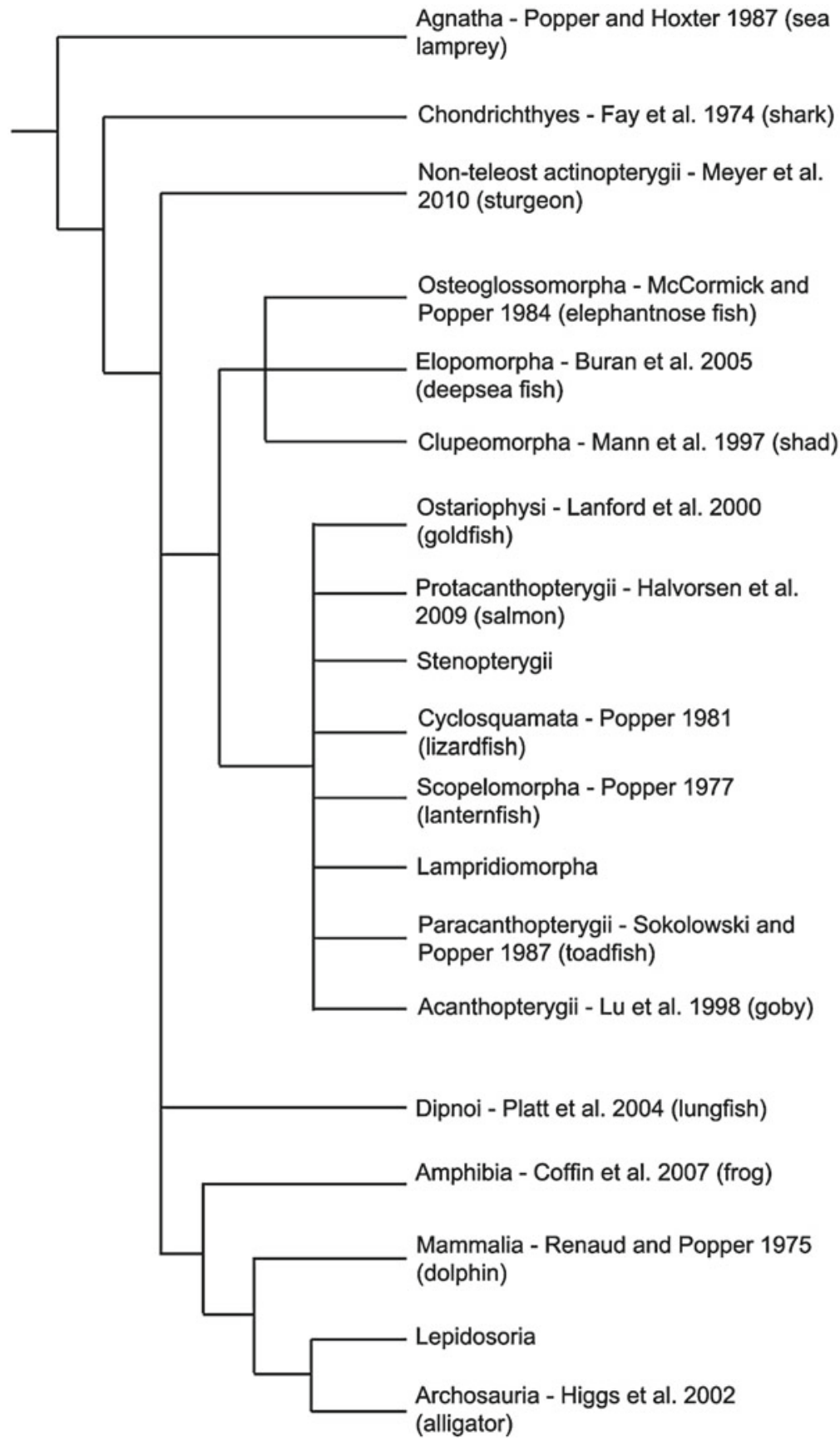

Fig. 2 Vertebrate phylogeny showing taxonomic groups where Art has published at least one study. Only select papers are shown to highlight the breadth of Art's comparative work. Taxonomic groups are shown as superorders or higher. Phylogeny based on Nelson (1994), lines are not drawn to scale 
New York. Tellingly, though, Art still approaches these applied projects with the eye (ear?) of a comparative biologist, as these studies compare the effects of noise trauma on different fishes that occupy diverse phylogenetic positions and possess different hearing sensitivities (e.g., Mann et al. 2007; Casper et al. 2013).

Research takes funding, of course, and Art is a shining example of funding success. Art has received continuous grant funding since 1972, including grants from the Office of Naval Research (ONR), the National Science Foundation (NSF), and the National Institutes of Health (NIH). When we approached the ONR with a conference grant proposal to help fund Art and Dick's Festschrift (celebration of their careers), the program officer told us that if Art would quit submitting (and receiving!) research proposals and instead actually retire, the ONR might have some money left to help fund the retirement celebration.

Art is a researcher, a teacher, and a mentor, and he takes all three roles very seriously. He's taught courses ranging from introductory freshman biology to graduate seminars on research ethics, and mentored or co-mentored 8 Master's students, 18 $\mathrm{PhD}$ students, and 18 postdocs, many of whom are featured as authors in this volume. Art has won awards recognizing his scholarly contributions (Outstanding Faculty Research Award, College of Life Sciences, University of Maryland), his excellence in teaching (Distinguished Scholar-Teacher Award, University of Maryland), and his commitment to mentoring (University System of Maryland Regent's Faculty Award for Mentoring). Other notable accomplishments include his election as a Fellow to the American Association for the Advancement of Science (AAAS) in 1983 and as an Acoustical Society of America Fellow in 1994. In 2012 Science Magazine published a delightful News Focus about Art and his lifetime of research, calling him the "godfather of fish bioacoustics" (Lee 2012).

One of Art's joys is bringing together scientists with diverse backgrounds and perspectives for focused research conferences. His recent interest in the impact of anthropogenic sound on aquatic life represents the perfect opportunity since basic researchers, policy-makers, and industry representatives all have acute interest in this issue but often want different information, or might use the same data for different purposes. He and his close friend and collaborator Dr. Tony Hawkins have organized a series of meetings with this exact purpose in mind, the International Conferences on the Effects of Noise on Aquatic Life. Planning these meetings also affords Art and his wife Helen the opportunity to travel, as the meetings are always in interesting locations (Cork, Ireland in 2010, Budapest, Hungary in 2013) and Art insists on personally surveying each meeting location to make sure it meets his standards. Even in his retirement he continues to organize these meetings, allowing him to combine his passion for research with his love of travel.

In addition to his contributions in research, teaching, and mentoring, Art has held many administrative positions. Art served on the Faculty Senate at both Georgetown University and the University of Maryland, including Chairing the University Senate at the University of Maryland. He was the Chair of the Biology Department at the University of Maryland and a Director of their Neuroscience and Cognitive Sciences (NACS) graduate program. He, along with his colleague and close friend Dr. Robert Dooling, founded and directed the Center for Comparative and 
Evolutionary Biology of Hearing at the University of Maryland. Much of Art's committee work stems from his commitment to teaching and mentoring, such as co-chairing the University of Maryland's Campus Task Force on Mentoring of Junior Faculty.

Despite an exhausting schedule, Art maintains a long and very happy marriage with Helen, and they manage to talk every day when he's on the road. Helen has also edited many of Art's papers through the years, so we have her to thank for the precise prose and proper grammar! Art is extremely proud of daughters Michelle and Melissa, son-in-laws Roman and Jeff, and grandchildren Ethan, Emma, and Sophie.

In his retirement Art plans to spend time with his family, continue traveling, consult on underwater construction projects, continue to develop and edit books in the Springer Handbook of Auditory Research series that he and Dick Fay founded over 20 years ago, edit Acoustics Today, the magazine of the Acoustical Society of America, and pursue the scientific questions that have fascinated him throughout his long and storied career. But he might not return to the issue of sound source localization in fishes any time soon. Art and Bill Tavolga were right. Almost 50 years after Art started his career, we still don't fully understand how fish determine the location of an acoustic signal. However, thanks to Art and Dick's work, and the cadre of fish bioacoustics researchers descended from their labs or influenced by their collaborations, we're closer than ever to solving the sound localization riddle. I invite you to read the chapter by Sisneros et al. in this volume to judge for yourself whether the past decades have yielded answers to this burning question in fish bioacoustics.

Author Note: For the phylogeny in Fig. 2 and throughout the text I cite many of Art's primary research papers. I based my citation selections on both taxonomic considerations and to demonstrate the multitude of talented researchers that Art has worked with over the years. Given that Art has published almost 200 primary research studies, I couldn't include most of his publication record, which means that many excellent studies are not included here, and I apologize if your favorite paper (or dissertation work) is not cited.

\section{References}

Buran BN, Deng X, Popper AN (2005) Structural variation in the inner ears of four deep-sea elopomorph fishes. J Morphol 265:215-225

Casper BM, Popper AN, Matthews F, Carlson TJ, Halvorsen MB (2012) Recovery of barotrauma injuries in Chinook salmon, Oncorhynchus tshawytscha from exposure to pile driving sound. PLoS One 7(6), e39593. doi:10.1371/journal.pone.0039593

Casper BM, Smith ME, Halvorsen MB, Sun H, Carlson TJ, Popper AN (2013) Effects of exposure to pile driving sounds on fish inner ear tissues. Comp Biochem Physiol A Mol Integr Physiol 166:352-360

Coffin AB, Dabdoub A, Kelley MW, Popper AN (2007) Myosin VI and VIIa distribution among inner ear epithelia in diverse fishes. Hear Res 224:15-26

Coombs S, Popper AN (1982) Structure and function of the auditory system in the clown knife fish, Notopterus chitala. J Exp Biol 97:225-239 
Deng X, Wagner H-J, Popper AN (2011) The Inner Ear and its Coupling to the Swim Bladder in the Deep-Sea Fish Antimora rostrata (Teleostei: Moridae). Deep Sea Res Part 1 Oceanogr Res Pap 58:27-37

Deng X, Wagner H-H, Popper AN (2013) Interspecific variations of inner ear structure in the seepsea fish family Melamphaidae. Anat Rec 296:1064-1082

Edds-Walton P, Popper AN (2000) Dendritic arbors on the saccule and lagena in the ear of the goldfish, Carassius auratus. Hear Res 141:229-242

Fay RR, Popper AN (1974) Acoustic stimulation of the ear of the goldfish (Carassius auratus). J Exp Biol 61:243-260

Fay RR, Kendall JI, Popper AN, Tester AL (1974) Vibration detection by the macula neglecta of sharks. Comp Biochem Physiol 47:1235-1240

Halvorsen MB, Wysocki LE, Stehr CM, Baldwin DH, Scholz NL, Popper AN (2009) Barging effects on sensory systems of Chinook salmon smolts. Trans Am Fish Soc 138:777-789

Halvorsen MB, Casper BM, Woodley CM, Carlson TJ, Popper AN (2012) Threshold for onset of injury in Chinook salmon from exposure to impulsive pile driving sounds. PLoS One 7(6), e38968. doi:10.1371/journal.pone.0038968

Higgs DM, Brittan-Powell EF, Soares D, Souza MJ, Carr CE, Dooling RJ, Popper AN (2002) Amphibious auditory responses of the American alligator (Alligator mississipiensis). J Comp Physiol A 188:217-223. doi:10.1007/s00359-002-0296-8

Higgs DM, Plachta DTT, Rollo AK, Singheise M, Hastings MC, Popper AN (2004) Development of ultrasound detection in American shad (Alosa sapidissima). J Exp Biol 207:155-163

Lanford PJ, Presson JC, Popper AN (1996) Cell proliferation and hair cell addition in the ear of the goldfish, Carassius auratus. Hear Res 100:1-9

Lanford PJ, Platt C, Popper AN (2000) Structure and function in the saccule of the goldfish (Carassius auratus): a model of diversity in the non-amniote ear. Hear Res 143:1-13

Lee JJ (2012) The sound in the silence: discovering a fish's soundscape. Science 337(6100):1290-1291

Lombarte A, Popper AN (1994) Quantitative analyses of postembryonic hair cell addition in the otolithic endorgans of the inner ear of the European hake, Merluccius merluccius (Gadiformes, Teleostei). J Comp Neurol 345:419-428

Lombarte A, Yan HY, Popper AN, Chang JS, Platt C (1993) Damage and regeneration of hair cell ciliary bundles in a fish ear following treatment with gentamicin. Hear Res 64:166-174

Lu Z, Popper AN, Fay RR (1996) Behavioral detection of acoustic particle motion by a teleost fish, Astronotus ocellatus: sensitivity and directionality. J Comp Physiol A 179:227-233

Lu Z, Song J, Popper AN (1998) Encoding of acoustic directional information by saccular afferents of the sleeper goby, Dormitator latifrons. J Comp Physiol A 182:805-815

Mann DA, Lu Z, Popper AN (1997) A clupeid fish can detect ultrasound. Nature 389:341

Mann DA, Cott PA, Hanna BW, Popper AN (2007) Hearing in eight species of northern Canadian freshwater fishes: implications for seismic surveys. J Fish Biol 70:109-120

Mathiesen C, Popper AN (1987) The ultrastructure and innervation of the ear of the gar, Lepisosteus osseus. J Morphol 194:129-142

McCauley RD, Fewtrell J, Popper AN (2003) High intensity anthropogenic sound damages fish ears. J Acoust Soc Am 113:638-642. doi:10.1121/1.1527962

McCormick CA, Popper AN (1984) Auditory sensitivity and psychophysical tuning curves in the elephant nose fish, Gnathonemus petersii. J Comp Physiol 155:753-761

Meyer M, Fay RR, Popper AN (2010) Frequency tuning and intensity coding of sound in the auditory periphery of the lake sturgeon, Acipenser fulvescens. J Exp Biol 213:1567-1578

Nelson JS (1994) Fishes of the World, 3rd edn. Wiley, New Jersey

Oxman DS, Barnett-Johnson R, Smith ME, Coffin AB, Miller DD, Josephson R, Popper AN (2007) The effect of vaterite deposition on otolith morphology, sound reception and inner ear sensory epithelia in hatchery-reared Chinook salmon (Oncorhynchus tshawytscha). Can J Fish Aquat Sci 64:1469-1478 
Plachta DTT, Popper AN (2003) Evasive responses of American shad (Alosa sapidissima) to ultrasonic stimuli. Acoust Res Lett Online 4:25-30

Platt C, Jørgensen JM, Popper AN (2004) The inner ear of the lungfish Protopterus. J Comp Neurol 471:277-278

Popper AN (1970) Auditory capacities of the Mexican blind cave fish Astyanax jordani and its eyed ancestor Astyanax mexicanus. Anim Behav 18:552-562

Popper AN (1971) The morphology of the Weberian ossicles in two species of Astyanax (Ostariophysi: Characidae). J Morphol 133:179-188

Popper AN (1972) Pure-tone auditory thresholds for the carp Cyprinus carpio. J Acoust Soc Am 52:1714-1717

Popper AN (1974) The response of the swim bladder of the goldfish (Carassius auratus) to acoustic stimuli. J Exp Biol 60:295-304

Popper AN (1976) Ultrastructure of the auditory regions in the inner ear of the lake whitefish. Science 192:1020-1023

Popper AN (1977) A scanning electron microscopic study of the sacculus and lagena in the ears of fifteen species of teleost fishes. J Morphol 153:397-418

Popper AN (1978a) A comparative study of the otolithic organs in fishes. Scan Electron Microsc 1984:405-416

Popper AN (1978b) Scanning electron microscopic study of the otolithic organs in the bichir (Polypterus bichir) and shovel-nose sturgeon (Scaphirhynchus platorynchus). J Comp Neurol 18:117-128

Popper AN (1980) Scanning electron microscopic studies of the sacculus and lagena in several deep-sea fishes. Am J Anat 157:115-136

Popper An (1981) Comparative scanning electron microscopic investigations of the sensory epithelia in the teleost sacculus and lagena. J Comp Neurol 200:357-374

Popper AN (2014) From cave fish to pile driving: a tail of fish bioacoustics. In: Popper AN, Fay RR (eds) Perspectives on auditory research. New York, Springer, pp 467-492

Popper AN, Carlson TJ (1998) Application of the use of sound to control fish behavior. Trans Am Fish Soc 127:673-707

Popper AN, Clarke NL (1976) The auditory system of the goldfish (Carassius auratus): effects of intense acoustic stimulation. Comp Biochem Physiol 53A:11-18

Popper AN, Fay RR (1973) Sound detection and processing by fish: a critical review. J Acoust Soc Am 53:1515-1529

Popper AN, Hoxter B (1987) Sensory and nonsensory ciliated cells in the ear of the sea lamprey, Petromyzon marinus. Brain Behav Evol 30:43-61

Popper AN, Northcutt RG (1983) Structure and innervation of the inner ear of the bowfin, Amia calva. J Comp Neurol 213:279-286

Popper AN, Platt C (1979) The herring ear has a unique receptor pattern. Nature 280:832-833

Popper AN, Tavolga WN (1981) Structure and function of the ear of the marine catfish, Arius felis. J Comp Physiol 144:27-34

Popper AN, Smith ME, Cott PA, Hanna BW, MacGillivray AO, Austin ME, Mann DA (2005) Effects of exposure to seismic airgun use on hearing of three fish species. J Acoust Soc Am 117:3958-3971

Presson JC, Jones M, Popper AN (1993) Modes of neuronal arbor enlargement in the ear of a postembryonic fish, Astronotus ocellatus. Cell Tissue Res 274:97-103

Ramcharitar JU, Deng X, Ketten D, Popper AN (2004) Form and function in the unique inner ear of a teleost fish: the silver perch (Bairdiella chrysoura). J Comp Neurol 475:531-539

Ramcharitar J, Higgs D, Popper AN (2006) Audition in Sciaenid fishes with different swim bladder-inner ear configurations. J Acoust Soc Am 119:439-443

Renaud DL, Popper AN (1975) Sound localization by the bottlenose porpoise, Tursiops truncatus. J Exp Biol 63:569-585

Saidel WM, Popper AN (1987) Sound reception in two anabantid fishes. Comp Biochem Physiol 88A:37-44 
Smith ME, Coffin AB, Miller DL, Popper AN (2006) Anatomical and functional recovery of the goldfish (Carassius auratus) ear following noise exposure. J Exp Biol 209:4193-4202

Sokolowski B, Popper AN (1987) The gross and ultrastructural development of the saccule of the toadfish, Opsanus tau. J Morphol 194:323-348

Song J, Matieu A, Soper RF, Popper AN (2006) Structure of the inner ear of bluefin tuna (Thunnus thynnus). J Fish Biol 68:1767-1781

Song J, Mann DA, Cott PA, Hanna BW, Popper AN (2008) The inner ears of northern Canadian freshwater fishes following exposure to seismic air gun sounds. J Acoust Soc Am 124:1360-1366

Tenold JL, Crowell DH, Jones RH, Daniel TH, McPherson DF, Popper AN (1974) Cepstral and stationary analysis of full-term and premature infants' cries. J Acoust Soc Am 56:975-980

Wilkins HR, Presson JC, Popper AN (1999) Proliferation of vertebrate inner ear supporting cells. J Neurobiol 39:527-535

Wilkins H, Presson JC, Popper AN, Ryals B, Dooling R (2001) Hair cell death in a hearingdeficient canary. J Assoc Res Otolaryngol 2:79-86

Wysocki LE, Davidson JW III, Smith ME, Frankel AS, Ellison WT, Mazik PM, Popper AN, Bebak $\mathrm{J}$ (2007) Effects of aquaculture production noise on hearing, growth, and disease resistance of rainbow trout Oncorhynchus mykiss. Aquaculture 272:687-697

Yan HY, Popper AN (1992) Auditory sensitivity of the cichlid fish Astronotus ocellatus (Cuvier). J Comp Physiol 171A:105-109 


\title{
A Most Interesting Man of Science: The Life and Research of Richard Rozzell Fay
}

\author{
Joseph A. Sisneros
}

\begin{abstract}
On May 25, 2013, a special symposium was held at the Mote Marine Laboratory in Sarasota, FL to honor the outstanding careers of Drs. Richard R. Fay and Arthur N. Popper, a "dynamic duo" of scientists who were pioneers in the field of contemporary fish hearing and bioacoustics. The present article details the research, academic life, and "other side" of Richard Rozzell Fay, a most interesting man of science who is known to all as a kind, gentle, wise, and introspective scientist.
\end{abstract}

Keywords Goldfish hearing • Psychoacoustics • Physiology • Von Békésy

Richard "Dick" Fay (Figs. 1 and 2) born on May 5th, 1944 in Holden, Massachusetts where he grew up and during his early years he attended Wachusett Regional High School. As Dick tells the story, he was not a "joiner" in high school which is why his English teacher advised him to participate in some extracurricular activities or he would not get into college. His teacher managed to get him appointed Editor of the High School Yearbook, an endeavor that Dick enjoyed very much despite the fact that he had to ride the bus over-an-hour to and from school every day. In addition to being an editor, Dick also began writing a column in the school newspaper on his true love ... "Jazz." A bit sophisticated for the average senior high school student but Duke Ellington, Sidney Bechet, and the "ultimate" Art Tatum came alive with Dick and for those students interested in jazz in 1962. Dick's early duties as a writer and editor would serve him well later in academia and as a co-editor of the Springer Handbook of Auditory Research series. Growing up in a rural isolated small town with a population of less than a thousand people in the middle of Massachusetts, Dick spent his free time pretty much as many others there did perfecting their shooting skills at the Eight Point Sportsman's Club. For the non-sportsman, "Eight points"

\footnotetext{
J.A. Sisneros $(\triangle)$

Departments of Psychology and Biology, University of Washington, Seattle, WA 98195, USA

e-mail: sisneros@uw.edu
} 
Fig. 1 Richard R. Fay in the laboratory (circa 1968)

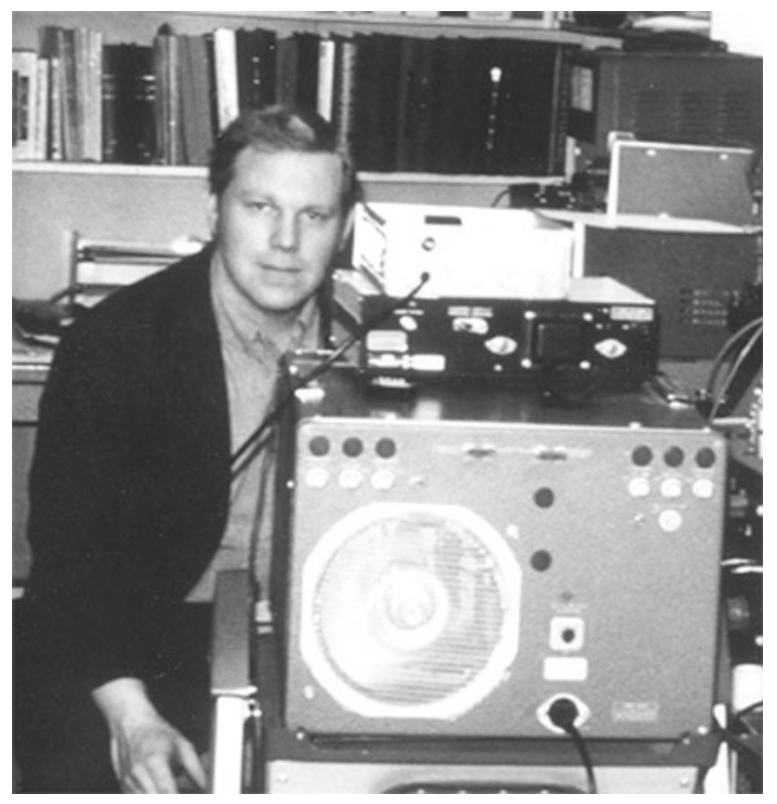

Fig. 2 Richard R. Fay at a scientific conference in Shanghai, China (circa 2007)

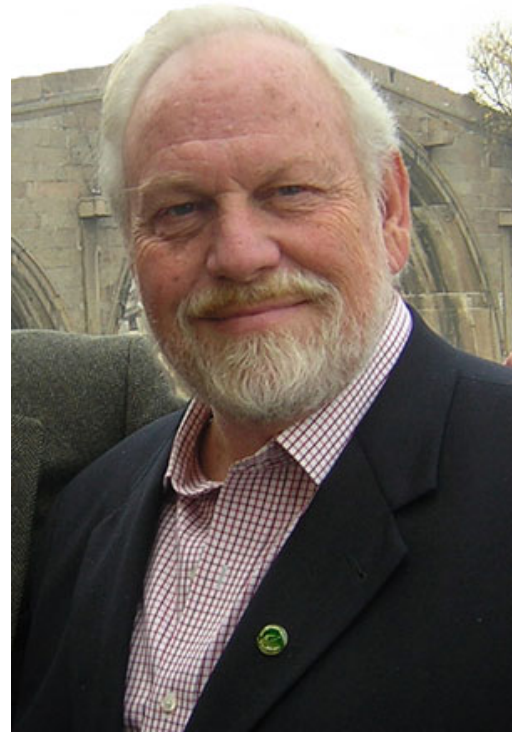

represents the number of points or spikes on the antlers of a large male deer. The Eight Point Sportsman's Club is where Dick perfected his shooting skills with many different types of rifles practicing target, skeet and trap shooting (but no hunting). Perhaps Dick's early interest in rifles stemmed from his father's hobby as an expert 
gun collector. Dick spent many hours with his father at gun dealers learning about the mechanisms, models, and bullets of guns used during the Revolutionary and Civil Wars as well as more modern guns. Dick still today showcases many of his historic guns at this home on Cape Cod in Falmouth, MA. I hear from Dick's wife Cathy Fay that their children Chris and Amanda, and even their grandkids Nate and Evan are excellent shots!

Dick's father, Charles Rozzell Fay was of great influence on Dick during his precollege years growing up in Massachusetts. Charles Fay was a descendant of John Fay who emigrated from England to Massachusetts on the Speedwell in 1620. Charles was a mechanical engineer who received his law degree from George Washington University and became a patent attorney. He practiced patent law in Worcester, MA with Dick's grandfather, Albert E. Fay, who was also a mechanical engineer and patent attorney. It was the firm of Fay, Fay and Hawley that patented many of early rocket designs of Robert F. Goddard, often recognized as the founding father of modern rocketry. As Dick often mentioned, Charles Fay loved his profession and was most enchanted with dealing with what he termed the "Yankee Ingenuity" of the creative New England inventors. Charles would entertain the family with humorous stories of the almost yearly patent applications for a "Perpetual Motion" machine. Dick spent many hours watching his father make intricate and precise mechanical drawings for the many patents over the years. Dick says his love for "precision" stemmed from seeing these early drawings and that he often attempted to replicate.

Charles R. Fay met and married Dick's mother Ingrid Clara Tellefsen, who was from Trondheim Norway, while working in the patent office in Washington DC. At the time Charles met Ingrid she was an assistant to the US Ambassador to Norway. Later, Dick's mother Ingrid Fay and aunt would buy a small island on Kezar Lake in Lovell, Maine as a summer getaway. The island soon became known as "Birch Island" by the Fay family. Dick would spend every summer there with his family swimming, boating, fishing and later working as a dishwasher at the Sunset Inn down the lake from the family camp. To this day Dick and his family still make their annual summer visit to Birch Island which is actually very close to the summer home of Stephen King, a famous American author of contemporary horror and supernatural fiction. I remember Dick telling me a great story about a young movie director named Monroe Mann who asked Dick if he could shoot part of his movie on the docks of Birch Island to make a low budget comedy horror film called "You can't kill Stephen King." Dick did grant permission and part of the movie was filmed on the docks of Dick's summer home on Birch Island. If you look carefully, you can still find this B-movie available on the web for rent or sale!

In 1962, Dick headed off to college in Brunswick, Maine where he attended Bowdoin College. According to Dick, he chose Psychology as his major because he found comparative psychology and especially "Behaviorism" an appealing concept and a topic he thought he would enjoy exploring. During his studies, we would later find that the approach of the early psychophysicists such as Ernst Weber, Gustav Fechner, Stanley Smith Stevens, Hermann von Helmholtz, Wilhelm Wundt and later Georg von Békésy were also worthy of study. It was at Bowdoin that Dick became 
lifelong friends with fraternity brothers Barry Timson, Maine Coastal Geologist and John Tarbell, New York Financier. Dick also became an avid downhill skier while at Bowdoin spending most weekends skiing in Maine until he graduated in 1966 with a BA in Psychology.

After graduating from Bowdoin College, Dick went on to pursue a master's degree at Connecticut College in New London, CT. Dick chose Connecticut College because it was one of the very few schools at that time to offer a degree in Physiological Psychology. It was during this time that Dick started working on goldfish hearing for his master's thesis titled "Auditory Sensitivity of the Goldfish within the Nearfield." According to Cathy Fay, one night in the lab at Connecticut College while Dick was working on determining hearing thresholds in goldfish using a behavioral method that utilized a conditioned suppression of heart rate, Dick noticed (while carefully observing the fish's behavior) that the goldfish was consistently exhibiting a conditioned suppression of respiration to the tones. This behavioral method would later be described in Dick's thesis and would subsequently be successfully used by Dick in his research for the next 45 years! While at Connecticut College Dick met and married classmate, Catherine Hill, who graduated a year before Dick in 1967. After graduation, Cathy worked as a Research Analyst at the Stanley Cobb Neuropsychiatric Laboratory at Mass General Hospital in Boston. During this time, Dick also became a research assistant of Paul Smith at the U.S. Navy Submarine Base in Groton, CT to continue his studies on goldfish hearing. Dick would then later graduate in 1968 with an MA in Physiology Psychology from Connecticut College and publish his first two papers based on his master's thesis work (Fay 1969a, Fay and MacKinnon 1969).

One side note about Dick: he has always had an interest in the history wrought by old American graveyards, and he spent a great deal of his time in college and high school visiting the many old New England graveyards and would make delicate "rubbings" of the gravestones. Cathy spent many "dates" rubbing gravestones with Dick in graveyards around New London CT and she still fondly remembers Dick's excitement and enthusiasm about his historic gravestone discoveries. The Fay children find this aspect of Dick's life very fascinating and they often marvel that this was what their dad was doing instead of going out partying or drinking.

After obtaining his master's degree, Dick decided to pursue a PhD degree at Princeton University in New Jersey. Dick chose Princeton University because he wanted to work with Ernest G. Wever who at the time was famous for his two books: Theories of Hearing (1949) and Physiological Acoustics (co-authored with M. Lawrence in 1954). While at Princeton, Dick continued his work in Wever's Auditory Research Laboratory on hearing in goldfish that culminated in a $\mathrm{PhD}$ thesis in 1970 titled "Hearing and Frequency Discrimination in the Goldfish (Carassius auratus)," which would be the basis for his next three papers (Fay 1969b, Fay 1970a, Fay 1970b). During this time, Dick and Cathy had their first child Christian Martin Fay who was born in November 1969. After receiving his PhD in 1970, Dick stayed on at Princeton working with Wever as a postdoc and the Fay family moved into faculty housing on Lake Carnegie in Princeton, which according to Cathy was a "beautiful spot." At Princeton, Dick met and remained lifelong friends with a 
number of Princeton colleagues that included Jim Simmons, George Gourevitch, Sam Ridgeway, Jerry Palin, Jim Saunders, and Jim McCormick.

During Dick's last year as a postdoc year at Princeton, Georg von Békésy visited Wever's lab in November 1971. Von Bekesy asked Wever to recommend a good candidate to come work with him at the Laboratory of Sensory Sciences in Honolulu. Von Békésy told Dick that Wever didn’t hesitate more than a second to name Dick Fay (...or "so Dick says" according to Cathy!). On November 23, the day before Thanksgiving, Dick asked Cathy if she would like to move to Honolulu. By December 28th, the Fays had sold their cars, furniture, and utensils and happily settled with their 2-year-old son Christian into a great location in Honolulu, HI (all within 5 weeks!). The Fays moved to the bottom floor of a large house almost twothirds up St Louis Heights on the edge of the Manoa Valley with a panoramic view of Waikiki Beach and the University of Hawaii-Manoa. According to Cathy, their back yard was replete with mangoes, lemons, papayas, guava, and passion fruit; it was so beautiful "they thought had died and gone to heaven." Dick settled into his research in von Békésy's Lab working on crayfish at von Békésy's behest and eventually published two of Dick's only papers on invertebrates, one on the multisensory interaction in control of eye-stalk rotation response in the crayfish (Fay 1973) and the other on the dynamic properties of the compensatory eye stalk rotation response in the crayfish (Fay 1975). Unfortunately, von Békésy died on June 13, 1972 less than 6 months after Dick joined von Békésy lab. There was a "silver lining" to the time spent in the von Békésy's lab, Dick met Art Popper. Dick was thrilled to meet and work with Art Popper who joined the Laboratory of Sensory Sciences shortly after Dick began working there. Dick and Art were kindred spirits with like minds and as many of us know eventually lead to great collaborations (as they say "the rest is history"). The Fay and Popper families became very good friends and as Cathy reminisced "the two families spent many great times together at University of Hawai'i parties, eating at Honolulu restaurants, and enjoying Passover Seders at the Popper home, and the Fay family loved every single minute of their Honolulu years."

During his time in the Laboratory of Sensory Sciences, Dick and Art went on a now rather famous trip in 1972 to the Enewetok Atoll, which had a mean elevation $10 \mathrm{ft}$ above sea level. Dick said that when he was not working he was either eating or watching a movie with the 40 other government employees on the island. The native Enewetokians had been evacuated and relocated because of the fallout from nuclear tests (a total of 43 nuclear tests were conducted on Enewetok from 1948 to 1958). During their stay on the atoll, Dick and Art witnessed the birth of four baby sharks in the lab pool and they managed to catch other sharks by hook and line to do some basic research on shark hearing. It was from this early collaboration that they were able to publish one of their first papers together from their work on Enewetok (Fay et al. 1974).

After Von Békésy passed away, members of the von Békésy Lab tried to continue their NIH grant without von Békésy but their efforts were not successful. After that in 1974, Dick and the family moved to North Carolina where he took a position as an assistant professor at Wake Forest University in the Bowman Gray School of 
Medicine located in Winston-Salem, NC. At the Bowman Gray School of Medicine, Dick joined his friend Jim McCormick in the Otolaryngology Department where Dick worked on writing grants and interviewing for a full-time faculty position. According to Cathy, she was not particularly enamored with the South and wanted to leave as soon as possible! As Cathy mentioned "any place after Honolulu would be a difficult adjustment at best." During his time in North Carolina, Dick interviewed at Rensellaer Polytech in Troy New York and at Loyola University in Chicago. Cathy said that she read that Chicago was the best place for a woman to find a job and that they would be moving to Chicago!

Soon after interviewing for full time faculty positions, Dick was offered a position as an Associate Professor of Psychology at Loyola University Chicago. Three months after leaving North Carolina, the Fays settled in Winnetka, IL and Dick began his faculty position at Loyola University Chicago where he would spend the next 36 years of his career. Cathy happily took a position at GD Searle Pharmaceutical Company and then later became Editor-in-Chief of the Travel Division at Simon \& Schuster in Chicago. A few years later, Dick and Cathy had their second child Amanda Hutchinson Fay who was born in April of 1979. Memorable highlights for the Fays included their hosting the annual Psychology Picnic in their backyard which continued for many years until the department grew too large and then the picnic had to be moved to a much larger, real picnic ground. While at Loyola University, Dick taught Physiological Psychology, Neuroscience and Statistics. He often mentioned that he very much enjoyed teaching students and that he preferred to teach rather than buy out of such responsibilities. Perhaps Dick greatest love at Loyola University Chicago was being part of the Loyola-endowed Parmly Hearing Institute. According to Cathy, Dick enjoyed every one of his days there working in his spacious lab and he was enormously fond of his highly respected and eminent colleagues, Bill Yost, Sheryl Coombs, Rich Bowen, Bill Shoffner, and Toby Dye.

Later in the mid 1990s, Dick began to take his research "on the road" and work as a summer scientist at the Marine Biological Laboratory (MBL) in Woods Hole, MA. He brought his "shaker system" to the MBL and continued many years of experiments with Peggy Edds-Walton, Steve Highstein, David Zeddies, and Joe Sisneros. In 1993, Dick and Cathy bought a big old barn on "Shearwater Farm" about a mile down the road from the MBL, and as Dick says, he put a lot of "sweat equity" into it over the last 22 years bringing it up to snuff (as well as up to code)! This research arrangement seemed to be ideal for Dick where he could teach and perform his goldfish hearing research in Chicago during the academic year and then spend the warm summers on Cape Cod with his family at their home in Falmouth and work at the MBL on toadfish hearing research.

Another side note about Dick is his love for art. No picture of Dick Fay is complete without acknowledging his abiding love and keen interest in art. His particular interest is in the moderns. Cathy says that he has an incredible memory for every detail of every artist's life and work and can expound on every artist and their contemporaries. Cathy says Dick has provided her with many art lessons for her to cherish throughout her life. 
In 2003, I was first introduced to Dick by his former postdoc David Zeddies while David and I were both Grass Fellows at the MBL. I was initially very nervous to meet the "great fish auditory physiologist" Richard Fay. I had read all his papers and was especially interested in his earlier elasmobranch hearing research with Art Popper. After initially meeting Dick, I was quickly put at ease when I realized how easy it was to talk with him about research and science in general. Right away we started to discuss possible projects regarding sound source localization with the "west coast toadfish," the plainfin midshipman. The following year David Zeddies, Dick Fay, and I set off to the UC Bodega Marine Lab in California to investigate the plainfin midshipman and sound source localization. We later successfully wrote an NSF grant to support our Bodega research on sound localization, which eventually led to four coauthored publications on the topic (Zeddies et al. 2010, 2011, 2012, Coffin et al. 2014). During this time, David and I looked forward to our annual "Bodega research adventure" with Dick. I had some of the best times of my science career working with Dick and David during those summers in Bodega. As Cathy once mentioned not only did Dick find the yearly trip to Bodega Bay to work with the "midshipman" invigorating, he also loved the beauty of the area and the fabulous meals they all managed to cook while "roughing" it.

In 2008, Cathy retired and started a hobby that turned into a small business that resulted in her building an arts and crafts studio on their Shearwater Farm. Her shop is full of all kinds of paintings along with decorated rugs, trays, boxes, and wastebaskets. As Cathy put it, her hobby/business "became a nice way for her to calm down and adjust to retirement after 20 deadline-driven years in the publishing business." In 2011, Dick joined Cathy in retirement and they both spent time travelling to Brazil and Ecuador to visit their daughter Amanda who was teaching in Quito. In April 2013, while on vacation in Brazil Dick suffered a stroke and he is now steadily improving and slowly regaining all his faculties. In 2014, the Fays spent 3 winter months in Old San Juan Puerto Rico enjoying the warm weather and not missing the very cold winter that gripped New England that year. They are definitely making plans to go back soon. Cathy tells me that Dick is feeling good about his career and in retirement is now happy to pursue writing a children's book on Hearing in Goldfish. I hear that Cathy is also very happy in retirement editing and illustrating his recent work. At this point in his life, Dick says he has some good advice that he would like to pass on: "Listen to Art Tatum, a genius jazz pianist whose music will amaze your mind and soothe your soul. Start with "Deep Night."”

Many thanks to Cathy Fay for sharing much of the information presented here that allowed me to tell you about Dick's “other side." Best "fishes"!

\section{The Publication List of Richard R. Fay}

1. Fay, R.R. (1969a) Auditory sensitivity of the goldfish within the near acoustic field. U.S. Naval Submarine Medical Center, Submarine Base, Groton, Connecticut, Report No. 605, 1-11.

2. Fay, R.R. and MacKinnon, J.R. (1969) A simplified technique for conditioning respiratory mouth movements in fish. Behav. Res. Meth. \& Instru. 1, 123-124. 
3. Fay, R.R. (1969b) Behavioral audiogram for the goldfish. J. Aud. Res. 9, 112-121.

4. Fay, R.R. (1970a) Auditory frequency generalization in the goldfish (Carassius auratus). J. Exp. Anal. Behav. 14, 353-360.

5. Fay, R.R. (1970b) Auditory frequency discrimination in the goldfish (Carassius auratus). J. Comp. Physiol. Psychol. 73, 175-180.

6. Fay, R.R. (1972) Perception of amplitude-modulated auditory signals by the goldfish. J. Acoust. Soc. Am. 52, 660-666.

7. Fay, R.R. (1973) Multisensory interaction in control of eye-stalk rotation response in the crayfish (Procambarus clarkii). J. Comp. Physiol. Psychol. 84, 527-533.

8. Fay, R.R. and Popper, A.N. (1973) Vibration isolation for small aquaria. Behav. Res. Meth. Instr. 5, 502-503.

9. Popper, A.N. and Fay, R.R. (1973) Sound detection and processing by teleost fishes: A critical review. J. Acoust. Soc. Am. 53, 1515-1529.

10. Fay, R.R., Kendall, J.I., Popper, A.N., and Tester, A.L. (1974) Vibration detection by the macula neglecta of sharks. Comp. Biochem. Physiol. 47, 1235-1240.

11. Fay, R.R. (1974) Sound reception and processing in the carp: saccular potentials. J. Comp. Biochem. Physiol. 49, 29-42.

12. Fay, R.R. (1974) Masking of tones by noise for the goldfish (Carassius auratus). J. Comp. Physiol. Psychol. 87, 708-716.

13. Fay, R. (1974) Auditory frequency discrimination in vertebrates. J. Acoust. Soc. Am. 56, 206-209.

14. Fay, R.R. Popper, A.N. (1974) Acoustic stimulation of the ear of the goldfish (Carassius auratus). J. Exp. Biol. 61, 243-260.

15. Fay, R.R. and Popper, A.N. (1975) Modes of stimulation of the teleost ear. J. Exp. Biol. 62, 379-387.

16. Fay, R.R. (1975) Dynamic properties of the compensatory eye-stalk rotation response of the crayfish (Procambarus clarkii). Comp. Biochem. Physiol. 51, 101-103.

17. Popper, A.N. and Fay, R.R. (1977) Structure and function of the elasmobranch auditory system. Amer. Zool. 17, 443-452.

18. Fay, R.R. (1978) Coding of information in single auditory-nerve fibers of the goldfish. J. Acoust. Soc. Amer. 63, 136-146.

19. Fay, R.R. Ahroon, W.A. and Orawski, A.A. (1978) Auditory masking patterns in the goldfish (Carassius auratus): Psychophysical tuning curves. J. Exp. Biol. 74, 83-100.

20. Fay, R.R. (1978) Sound detection and sensory coding by the auditory systems of fishes. In D. Mostofsky (Ed.) The Behavior of Fish and Other Aquatic Animals. Academic Press, New York, 197-236.

21. Fay, R.R. (1978) Phase-locking in goldfish saccular nerve fibres accounts for frequency discrimination capacities. Nature, 275, 320-322.

22. Labs, S.M. Gescheider, G.A. Fay, R.R. and Lyons, C.H. (1978) Psychophysical tuning curves in vibrotaction. Sensory Processes, 2, 231-247. 
23. Fay, R.R. and Olsho, L.W. (1979) Discharge patterns of lagenar and saccular neurones of the goldfish eighth nerve: Displacement sensitivity and directional characteristics. Comp. Biochem. Physiol. 62, 377-386.

24. Fay, R.R. (1980) Psychophysics and neurophysiology of temporal factors in hearing by the goldfish: Amplitude modulation detection. J. Neurophysiol. 44, 312-332.

25. Fay, R.R. and Popper, A.N. (1980) Structure and function in teleost auditory systems. In A.N. Popper and R.R. Fay (Eds.), Comparative Studies of Hearing in Vertebrates. Springer-Verlag, New York, pp. 3-42.

26. Fay, R.R. (1981) Coding of acoustic information in the eighth nerve. In W.N. Tavolga, A.N. Popper, and R.R. Fay (Eds.), Hearing and Sound Communication in Fishes. Springer-Verlag, New York, pp. 189-219.

27. Hall, L. Patricoski, M. and Fay, R. (1981) Neurophysiological mechanisms of intensity discrimination in the goldfish. In W.N. Tavolga, A.N. Popper, and R.R. Fay (Eds.), Hearing and Sound Communication in Fishes. SpringerVerlag, New York, pp. 179-186.

28. Fay, R.R. and Patricoski, M. (1980) Sensory mechanisms for low frequency vibration detection in fishes. In R. Buskirk (Ed.), Abnormal Animal Behavior Prior to Earthquakes, II. U.S. Geological Survey Open File Report 80-453, 63-91.

29. Lombard, R.E., Fay, R.R. and Werner, Y.L. (1981) Underwater hearing in the frog, Rana catesbeiana. J. Exp. Biol. 91, 57-71.

30. Fay, R.R., Hillery, C.M. and Bolan, K. (1982) Representation of sound pressure and particle motion information in the midbrain of the goldfish. Comp. Biochem. Physiol. 71, 181-191.

31. Fay, R.R. (1982) Neural mechanisms of an auditory temporal discrimination by the goldfish. J. Comp. Physiol. 147, 201-216.

32. Hillery, C.M. and Fay, R.R. (1982) Forward masking and suppression in the midbrain of the southern grey treefrog (Hyla chrysoscelis) J. Comp. Physiol. 146, 435-447.

33. Fay, R.R. and Passow, B. (1982) Temporal discrimination in the goldfish. J. Acoust. Soc. Amer. 72, 753-760.

34. Fay, R.R. and Coombs, S. (1983) Neural mechanisms in sound detection and temporal summation. Hearing Research, 10, 69-92.

35. Fay, R.R. Yost, W.A., and Coombs, S. (1983) Psychophysics and neurophysiology of repetition noise processing in a vertebrate auditory system. Hearing Research, 12, 31-55.

36. Fay, R.R. and Popper, A.N. (1983) Hearing in fishes: Comparative anatomy of the ear and the neural coding of auditory information. In R. Fay and G. Gourevitch (Eds.), Hearing and other Senses: Presentations in Honor of E.G. Wever. Amphora Press, Groton, Conn., pp. 123-148.

37. Fay, R.R. (1983) Effects of noise on acoustic detection and communication by fishes. 11th International Congress on Acoustics, vol. 8, 245-248.

38. Popper, A.N. and Fay, R.R. (1984) Sound detection and processing by teleost fish: A selective review. In L. Bolis, R.D. Keynes, and S.H.P. Maddrell (Eds.), 
Comparative Physiology of Sensory Systems, Cambridge University Press, Cambridge, UK, 67-101.

39. Fay, R.R. (1984) The goldfish ear codes the axis of acoustic particle motion in three dimensions. Science, 225, 951-954.

40. Fay, R.R. (1985) Temporal processing by the auditory system of fishes. In A. Michelsen (Ed.) Time Resolution in Auditory Systems, Springer-Verlag, Berlin, 28-57.

41. Fay, R.R. (1985) Sound intensity processing by the goldfish. J. Acoust. Soc. Amer. 78, 1296-1309.

42. Coombs, S. and Fay, R.R. (1985) Adaptation effects on amplitude modulation detection: Behavioral and neurophysiological assessment in the goldfish auditory system. Hearing Research, 19, 57-71.

43. Fay, R. and Popper, A. (1985) Functional morphology of the octavolateralis system. In M. Hildebrand, D.M. Bramble, K.F. Liem and D.B. Wake (Eds.) Functional Vertebrate Morphology, The Belknap Press, Cambridge, MA, pp. 291-316.

44. Fay, R.R. and Ream, T.J. (1986) Acoustic response and tuning in saccular nerve fibers of the goldfish (Carassius auratus). J. Acoust. Soc. Amer. 79, 1883-1895.

45. Fay, R.R. (1986) Frequency selectivity, adaptation, and suppression in goldfish auditory nerve fibers. In B.C.J. Moore and R. Patterson (Eds.) Auditory Frequency Selectivity. Plenum Publishing Corporation, New York, pp. 137-145.

46. Coombs, S.L. and Fay, R.R. (1987) Response dynamics of goldfish saccular fibers: Effects of stimulus frequency and intensity on fibers with different tuning, sensitivity, and spontaneous activity. J. Acoust. Soc. Amer. 81, 1025-1035.

47. Fay, R.R. and Feng, A.S. (1987) Directional hearing among nonmammalian vertebrates. In W.A. Yost and G. Gourevitch (Eds.), Directional Hearing, Springer-Verlag, New York, pp. 179-213.

48. Bowen, R. and Fay, R. (1987) "The Big Feed," Chicago Magazine, Feb.

49. Fay, R.R. (1987) Peripheral adaptations for spatial hearing in fish. In J. Atema, R.R. Fay, A.N. Popper, and W.N. Tavolga (Eds.), Sensory Biology of Aquatic Animals, Springer-Verlag, New York, pp. 711-731.

50. Fay, R.R. and Coombs, S.L. (1988) Psychophysics and neurophysiology of frequency selectivity and masking in the goldfish. In H. Duifhuis, W. Horst, and H. Wit (Eds) Basic Issues in Hearing, Groningen University Press, Groningen, The Netherlands, pp. 169-176.

51. Fay, R.R. (1988) Comparative psychoacoustics. Hearing Research, 34, 295-305.

52. Platt, C, Popper, A.N. and Fay, R.R. (1989) The ear as part of the octavolateralis system. In S.L. Coombs, P. Görner, and H. Münz (Eds.) The Mechanosensory Lateral Line: Neurobiology and Evolution. Springer-Verlag, New York, pp. 633-651. 
53. Fay, R.R. (1989) Intensity discrimination of pulsed tones by the goldfish (Carassius auratus). J. Acoust. Soc. Amer. 85, 500-502.

54. Fay, R.R. (1989) Frequency discrimination in the goldfish (Carassius auratus): Effects of roving intensity, sensation level, and the direction of frequency change. J. Acoust. Soc. Amer. 85, 503-505.

55. Coombs, S.L., Fay, R.R., and Janssen, J. (1989) Hot-film anemometry for measuring lateral line stimuli. J. Acoust. Soc. Amer. 85, 2185-2193.

56. Coombs, S.L., and Fay, R. (1989) The temporal evolution of masking and frequency selectivity in the goldfish (Carassius auratus). J. Acoust. Soc. Amer. 86, 925-933.

57. Fay, R.R. (1990) Suppression and excitation in auditory nerve fibers of the goldfish, Carassius auratus. Hearing Research, 48, 93-110.

58. Fay, R.R. (1991) Masking and suppression in auditory nerve fibers of the goldfish, (Carassius auratus). Hearing Research, 55, 177-187.

59. Fay, R.R. and Ream, T.J. (1992) The effects of temperature change and transient hypoxia on auditory nerve response in the goldfish (Carassius auratus). Hearing Research, 58, 9-18.

60. Fay, R.R. and Coombs, S.L. (1992) Psychometric functions for level discrimination and the effects of signal duration in the goldfish (Carassius auratus): Psychophysics and neurophysiology. J. Acoust. Soc. Amer., 92, 189-201.

61. Fay, R.R. (1992) Analytic listening by the goldfish. Hearing Research, 59, 101-107.

62. Fay, R.R. (1992) Structure and function in sound discrimination among vertebrates. In D. Webster, R.R. Fay, and A.N. Popper (Eds.), The Evolutionary Biology of Hearing, Springer-Verlag, New York, pp. 229-263.

63. Fay, R.R. (1992) Ernest Glen Wever: A brief biography and bibliography. In D. Webster, R.R. Fay, and A.N. Popper (Eds.), The Evolutionary Biology of Hearing, Springer-Verlag, New York, pp. xliii-li.

64. Popper, A.N., and Fay, R.R. (1993) Sound detection and processing by fish: Critical review and major research questions. Brain Behav. Evol., 41, 14-38.

65. Coombs, S., and Fay, R.R. (1993) Source level discrimination by the lateral line system of the mottled sculpin, Cottius bairdi. J. Acoust. Soc. Amer., 93, 2116-2123.

66. Lu, Z, and Fay, R.R. (1993) Acoustic response properties of single units in the torus semicircularis of the goldfish, Carassius auratus. J. Comp. Physiol, 173, 33-48.

67. Fay, R.R., Edds-Walton, P.L., and Highstein, S.M. (1994) Directional sensitivity of saccular afferents of the toadfish to linear acceleration at audio frequencies. Biol. Bull. 187, 258-259.

68. Fay, R.R. (1994) Comparative auditory research. In R.R. Fay, and A.N. Popper (Eds.) Springer Handbook of Auditory Research. Vol. 4. Comparative Mammalian Hearing. Springer-Verlag, New York, 1994, pp. 1-17.

69. Echteler, S.M., Fay, R.R., and Popper, A.N. (1994) Structure of the mammalian cochlea. In R.R. Fay, and A.N. Popper (Eds.) Springer Handbook of Auditory Research. Vol. 4. Comparative Mammalian Hearing. SpringerVerlag, New York, 1994, pp 134-171. 
70. Fay, R.R. (1994) Perception of temporal acoustic patterns by the goldfish (Carassius auratus). Hearing Research, 76, 158-172.

71. Fay, R.R. (1994) The sense of hearing in fishes: psychophysics and neurophysiology. Sensory Systems, 8, 222-232.

72. Fay, R.R. (1995) Psychoacoustical studies of the sense of hearing in the goldfish using conditioned respiratory suppression. In G. Klump, R. Dooling, R.R., Fay and W.C. Stebbins (Eds.) Methodology in Animal Psychophysics. Birkhauser Verlag, Berlin.

73. Fay, R.R. (1995) Physiology of primary saccular afferents of goldfish: Implications for Mauthner cell response. Brain, Behavior, and Evolution, 46, 141-150.

74. Fay, R.R. (1995) Comparative studies of sound source perception. In G.A. Manley, G.M. Klump, C. Köppl, H. Fastl, and H. Oeckinghaus (Eds.) Advances in Hearing Research, World Scientific Publishers, Singapore, pp. 183-197.

75. Lu, Z., and Fay, R.R. (1995) Acoustic response properties of single units in the central posterior nucleus of the thalamus of the goldfish (Carassius auratus). J. Comp. Physiol., 176, 747-760.

76. Fay, R.R. (1995) Perception of spectrally and temporally complex sounds by the goldfish (Carassius auratus). Hearing Research, 89, 146-154.

77. Edds-Walton, P., and Fay, R.R. (1995) Regional differences in directional response properties of afferents along the saccule of the toadfish (Opsanus tau). Biol. Bull., 189, 211-212.

78. Lu, Z., Popper, A., and Fay, R.R. (1996) Behavioral detection of acoustic particle motion by a teleost fish (Astronotus ocellatus): Sensitivity and directionality. J. Comp. Physiol., 179, 227-234.

79. Lu, Z. and Fay, R.R. (1996) Two-tone interaction in auditory nerve fibers and midbrain neurons of the goldfish, Carassius auratus. Auditory Neuroscience, 2, 257-273.

80. Fay, R.R., Chronopoulos, M. and Patterson, R.D. (1996) The sound of a sinusoid: Perception and neural representations in the goldfish (Carassius auratus). Auditory Neuroscience, 2, 377-392.

81. Fay, R.R., Edds-Walton, P.L., and Highstein, S.M. (1996) Tuning in saccular afferents of the toadfish revealed by the reverse correlation method. Biol. Bull., 191, 255-257.

82. Fay, R.R. (1997) Hearing and sound perception among vertebrate animals. In M. Crocker (Ed.) Handbook of Acoustics. John Wiley \& Sons, New York, pp. 1789-1797.

83. Fay, R.R. (1997) Frequency selectivity of saccular afferents of the goldfish revealed by revcor analysis. In E.R. Lewis, G.R. Long, R.F. Lyon, P.M. Narins, C.R. Steele, and E. Hecht-Poinar (Ed.) Diversity in Auditory Mechanics, World Scientific Publishers, Singapore, pp. 69-75.

84. Popper, A.N., and Fay, R.R. (1997) Evolution of the Ear and Hearing: Issues and Questions. Brain, Behavior, and Evolution, 50: 213-221. 
85. Fay, R.R. and Popper, A.N. (1997) Preface to special issue of Brain, Behavior, and Evolution on Evolution of Sensory Systems, 50, 1-2.

86. Fay, R.R. and Edds-Walton, P.L. (1997a) Directional response properties of saccular afferents of the toadfish, Opsanus tau. Hearing Research, 111: 1-21.

87. Fay, R.R., Edds-Walton, P.L. (1997b) Diversity in frequency response properties of saccular afferents of the toadfish (Opsanus tau). Hearing Research, 113: 235-246.

88. Fay, R.R. (1998) Perception of two-tone complexes by goldfish (Carassius auratus). Hear. Res. 120, 17-24.

89. Fay, R.R. (1998) Auditory stream segregation in goldfish (Carassius auratus). Hearing Research, 120, 69-76.

90. Edds-Walton, P.L., and Fay, R.R. (1998) Directional auditory responses in the descending octaval nucleus of the toadfish (Opsanus tau). Biol. Bull., 195, 191-192

91. Fay, R.R., and Popper, A.N. (1999) The auditory periphery in fishes. In R.R. Fay and A.N. Popper (Eds.) Springer Handbook of Auditory Research. Vol. 10. Hearing in Fishes and Amphibians. Springer-Verlag, New York, 43-100.

92. Fay, R.R., and Popper, A.N. (1999) Hearing in Fishes and Ambhibians: An Introduction. In R. Fay and A. Popper (Eds.) Springer Handbook of Auditory Research. Vol. 11. Hearing in Fishes and Amphibians. Springer-Verlag, New York, 1-14.

93. Fay, R.R., and Megela Simmons, A. (1999) The sense of hearing in fishes and amphibians. In R. Fay and A. Popper (Eds.) Springer Handbook of Auditory Research. Vol. 10. Hearing in Fishes and Amphibians. Springer-Verlag, New York, 269-318.

94. Edds-Walton, P.L., Fay, R.R., and Highstein, S.M. (1999) Dendritic arbors and central projections of auditory fibers from the saccule of the toadfish (Opsanus tau). J. Comp. Neurol., 411: 212-238.

95. Fay, R.R., and Edds-Walton, P.L. (1999). Sharpening of directional auditory responses in the descending octaval nucleus of the toadfish (Opsanus tau). Biol. Bull, 197: 240-241.

96. Fay, R.R. and Edds-Walton, P.L. (2000a). Directional encoding by fish auditory systems. Philosophical Transactions of the Royal Society London. B, 355: 1281-1284.

97. Fay, R.R. (2000) Frequency contrasts underlying auditory stream segregation in goldfish. Journ. Assoc. Res. Otolaryngol., 01: 120-128.

98. Fay, R.R. and Popper, A.N. (2000) Evolution of hearing in vertebrates: the inner ears and processing. Hear. Res., 149:1-10.

99. Fay, R.R. and Edds-Walton, P.L. (2000b) Frequency response of auditory brainstem units in toadfish (Opsanus tau). Biol. Bull., 199:173-174.

100. Fay, R.R. (2000) Hearing in Vertebrate Animals. In: McGraw-Hill Encyclopedia of Science and Technology.

101. Fay, R.R. (2001). Stream segregation in goldfish: Auditory scene analysis. In Breebaart, D.J., Houtsma, A.J.M., Kohlrausch, A., Prijs, V.F., and 
Schoonhoven, R. (Eds.) Physiological and Psychophysical Bases of Auditory Function: Proceedings of the XIIth Symposium on Hearing, Maastricht, The Netherlands: Shaker Publishing, pp. 485-491.

102. Fay, R.R., and Edds-Walton, P.L. (2001) Bimodal units in the torus semicircularis of the toadfish (Opsanus tau). Biol. Bull, 201, 280-281.

103. Fay, R.R. (2002) The sense of hearing in fishes. Bioacoustics, 12: 167-169.

104. Fay, R.R., Coombs, S., and Elepfandt, A. (2002) Response of goldfish otolithic afferents to a moving dipole sound source. Bioacoustics, 12: 172-173

105. Edds-Walton, P.L., and Fay, R.R. (2002) Directional auditory processing by the oyster toadfish, Opsanus tau. Bioacoustics, 12: 202-204

106. Ma, D. W.-L., and Fay, R.R. (2002) Neural representations of acoustic particle motion direction in the midbrain of the goldfish, Carassius auratus. Bioacoustics, 12: 207-208.

107. Popper, A., Webb, J., and Fay, R. (Eds.) (2002) Special Issue of Fish Bioacoustics, Bioacoustics, 12, 99-339.

108. Ma, W.-L., and Fay, R.R. (2002) Neural representations of the axis of acoustic particle motion in the auditory midbrain of the goldfish, Carassius auratus. J. Comp. Physiol. (A) 188: 301-313

109. Weeg, M., Fay, R.R., and Bass, A. (2002) Directional response and frequency tuning in saccular nerve fibers of a vocal fish, Porichthys notatus. J. Comp. Physiol., 188: 631-641.

110. Fay, R.R., and Edds-Walton, P. (2002) Preliminary evidence for interpulse interval selectivity of cells in the torus semicircularis of the oyster toadfish (Opsanus tau). Biol. Bull, 203: 195-196.

111. Braun, C., Coombs, S., and Fay, R. (2002) Multisensory interactions within the octavolateralis systems: What is the nature of multisensory integration? Brain, Behavior and Evolution, 59: 162-176.

112. Popper, A., Fay, R., Platt, C., and Sand, O. (2003) Sound detection mechanisms and capabilities of teleost fishes. In S. Colin and J. Marshall (Eds.) Sensory Processing in Aquatic Environments, New York: Springer-Verlag, pp. 3-38.

113. Edds-Walton, P., and Fay, R.R. (2004) Directional selectivity and frequency tuning of midbrain cells in the oyster toadfish, Opsanus tau. J. Comp. Physiol., 189: 527-543.

114. Lewis, ER and Fay RR (2004) Environmental variables and the fundamental nature of hearing. In: Springer Series on Auditory Research Vol. 22, Evolution of the Vertebrate Auditory System. New York: Springer-Verlag, pp 27-54.

115. Fay, R.R (2005) Sound Source Localization in Fishes. In R. Fay and A. Popper (Eds.) Springer Handbook of Auditory Research: Sound Source Localization. Springer-Verlag, New York, pp. 36-66.

116. Fay, R.R. and Popper, A.N. (2005) Introduction to sound source localization. In R. Fay and A. Popper (Eds.) Springer Handbook of Auditory Research: Sound Source Localization. Springer-Verlag, New York, pp. 1-5.

117. Zeddies, D Fay RR. (2005) Development of the acoustic startle response of zebrafish to tones. J. Exp. Biol., 208:1363-1372. 
118. Walton, P.L.E. and Fay, R.R. (2005) Projections known bimodal sites in the torus semicircularis of the toadfish (Opsanus tau). Brain Behavior and Evolution, 66, 73-87.

119. Fay, R.R. (2005) Pitch perception in goldfish. Hear. Res. 205: 7-20.

120. Edds-Walton, P. and Fay, RR (2005) Sharpening of Directional Responses along the Auditory Pathway of the Oyster Toadfish, Opsanus tau. J. Comp Physiol, 191, 1079-1086.

121. Fay, R.R. and Edds-Walton, P.L. (2007) Structures and Functions of the Auditory Nervous System of Fishes. In: Webb J, Popper AN, Fay RR (eds) Springer Handbook of Auditory Research: Fish Bioacoustics. New York: Springer-Verlag, 2008.

122. Fay, RR (2008) Fish Bioacoustics. In: Handbook of Signal Processing in Acoustics, Riquimaroux, H. (ed.), New York: Springer-Verlag.

123. Fay RR (2008) Evolution of middle ear and inner ear in vertebrates. In: Dallos P. and Oertel D. (Eds.) Audition. Handbook of the Senses. London: Elsevier.

124. Edds-Walton, P., and Fay, R.R. (2008). Directional and frequency response characteristics in the descending octaval nucleus of the toadfish (Opsanus tau), Jour. Comp. Physiol. (A). 194: 1013-1029.

125. Fay, R.R. (2008) Sound Source Perception and Stream Segregation in Nonhuman Vertebrate Animals. In: Yost, W., Popper, A., and Fay, R. (Eds.), Springer Handbook of Auditory Research. Vol. 29. Auditory Perception of Sound Sources. Springer-Verlag, New York, 2008.

126. Fay, R.R. (2009) Soundscape and the Sense of Hearing in Fish. Integrative Zoology, 4, 26-32.

127. Edds-Walton, P.L. and Fay, R.R. (2009) Physiological Evidence for Binaural Directional Computations in the Brainstem of the Oyster Toadfish, Opsanus tau. Journ. Exp. Biol, 212, 1483-1493.

128. Fay, R.R. (2009) Sound source segregation in goldfish: two simultaneous tones. Journ. Acoust. Soc. Amer. 125: 4053-4059.

129. Edds-Walton, P., Holstein, G.M, and Fay, R. (2009) $\gamma$-Aminobutyric acid is a neurotransmitter in the auditory pathway of toadfish, Opsanus tau. Hear. Res. 262, 45-55.

130. Meyer, M., Popper, A.N., and Fay, R.R. (2009) Frequency tuning and intensity coding of sound in the auditory periphery of the lake sturgeon, Acipenser fulvescens. Journ. Exp. Biology, 213, 1567-1578.

131. Zeddies, D.G., Fay, R.R., Alderks, P.W., Shaub, K.S., and Sisneros, J.A. (2010) Sound Source localization by the plainfin midshipman fish, Porichthys notatus. J. Acoust. Soc. Amer. 127, 3104-3113.

132. Coombs, S.L, Fay, R.R. and Elepfandt, (2010) Dipole source detection and tracking by the goldfish auditory system. J. Exp Biol. 213, 3536-3547.

133. Fay, R.R. (2011) Signal-to-noise ratio for source determination and for a comodulated masker in goldfish, Carassius auratus. J. Acoust. Soc. Amer., 129, 3367-3372.

134. Popper, A.N. and Fay, R.R. (2011) Rethinking sound detection by fishes. Hearing Research, 273, 25-36. 
135. Fay, R.R. (2011) What fish hear. In Farrell, AP (ed.), Encyclopedia of Fish Physiology: From Genome to Environment, volume 1, Elsevier.

136. Zeddies DG, Fay, R.R., and Sisneros, J.A. (2011) Sound Source Localization and Directional Hearing in Fishes. In Farrell, AP (ed.), Encyclopedia of Fish Physiology: From Genome to Environment, volume 1, Elsevier.

137. Meyer, M., Popper, A., Fay, R.R. (2011) Coding of sound direction in the auditory periphery of the lake sturgeon, Acipenser fulvescens. J Neurophysiol. 107:658-665.

138. Fay, R.R. (2011) Directional hearing in fishes. In Strumillo P. (Ed) Advances in Sound Localization. InTech, pp. 493-512.

139. Zeddies, D.G., Fay, R.R., Gray, M.D., Alderks, P.W., Acob, A., and Sisneros, J.A. (2012) Local acoustic particle motion guides sound source localization behavior in the plainfin midshipman fish (Porichthys notatus). Journ Exp. Biol. 215, 152-160.

140. Fay, R.R. (2012) Listening in noise. In: Popper, A., and Hawkins, A. The Effect of Noise on Aquatic Life. Springer: New York, pp. 129-134.

141. Manley, G.A., Narins, P.M., and Fay, R.R. (2012) Experiments in comparative hearing: Georg von Békésy and beyond. Hearing Research 293:44-50.

142. Christensen-Dalsgaard, J., Brandt, C., Willis, K.L., Christensen, C.B., Ketten, D., Edds-Walton, P., Fay, R.R., Madsen P.T., Carr, C.E. (2012) Specialization for underwater hearing by the tympanic middle ear of the turtle, Trachemys scripta elegans. Proc. R. Soc. B. 279:2816-2824.

143. Fay, R.R. and Popper, A.N. (2012) Fish hearing: new perspectives from two 'senior' bioacousticans. Brain Behav Evol 79:215-217.

144. Ladich, F. and Fay, R.R. (2013) Auditory evoked potential audiometry in fish. Rev. Fish Biol Fisheries 23:317-364.

145. Coffin, A.B., Zeddies, D.G., Fay, R.R., Brown, A.D., Alderks, P.W., Bhandiwad, A.A., Mohr, R.A, Gray, M.D., Rogers, P.H., Sisneros, J.A. (2014) Use of the swim bladder and lateral line in near-field sound source localization by fishes. J Exp Biol 217:2078-2088.

146. Popper, A.N., Hawkins, A.D., Fay, R.R., Mann, D.A., Bartol, S., Carlson, T.J., Coombs, S., Ellison, W.T., Gentry, R.L., Halvorsen, M.B., Løkkeborg, S., Rogers, P.H., Southall, B.L., Zeddies, D.G., Tavolga, W.N. (2014) Introduction. Sound Exposure Guidelines for Fishes and Sea Turtles: A Technical Report prepared by ANSI-Accredited Standards Committee S3/SC1 and registered with ANSI. ASA S3/SC1.4 TR-2014. Springer and ASA Press, Cham, Switzerland.

147. Popper, A.N., Hawkins, A.D., Fay, R.R., Mann, D., Bartol, S., Carlson, T., Coombs, S., Ellison, W.T., Gentry, R., Halvorsen, M.B., Løkkeborg, S., Rogers, P., Southall, B.L., Zeddies, D., Tavolga, W.N. (2014) Aquatic organisms of concern. Sound Exposure Guidelines for Fishes and Sea Turtles: A Technical Report prepared by ANSI-Accredited Standards Committee S3/ SC1 and registered with ANSI. ASA S3/SC1.4 TR-2014. Springer and ASA Press, Cham, Switzerland. 
148. Popper, A.N., Hawkins, A.D., Fay, R.R., Mann, D., Bartol, S., Carlson, T., Coombs, S., Ellison, W.T., Gentry, R., Halvorsen, M.B., Løkkeborg, S., Rogers, P., Southall, B.L., Zeddies, D., Tavolga, W.N. (2014) Hearing - a general overview. Sound Exposure Guidelines for Fishes and Sea Turtles: A Technical Report prepared by ANSI-Accredited Standards Committee S3/ SC1 and registered with ANSI. ASA S3/SC1.4 TR-2014. Springer and ASA Press, Cham, Switzerland.

149. Popper, A.N., Hawkins, A.D., Fay, R.R., Mann, D., Bartol, S., Carlson, T., Coombs, S., Ellison, W.T., Gentry, R., Halvorsen, M.B., Løkkeborg, S., Rogers, P., Southall, B.L., Zeddies, D., Tavolga, W.N. (2014) Classification of fishes and sea turtles with respect to sound exposure risk. Sound Exposure Guidelines for Fishes and Sea Turtles: A Technical Report prepared by ANSIAccredited Standards Committee S3/SC1 and registered with ANSI. ASA S3/ SC1.4 TR-2014. Springer and ASA Press, Cham, Switzerland.

150. Popper, A.N., Hawkins, A.D., Fay, R.R., Mann, D., Bartol, S., Carlson, T., Coombs, S., Ellison, W.T., Gentry, R., Halvorsen, M.B., Løkkeborg, S., Rogers, P., Southall, B.L., Zeddies, D., Tavolga, W.N. (2014) Effects of sound exposure. Sound Exposure Guidelines for Fishes and Sea Turtles: A Technical Report prepared by ANSI-Accredited Standards Committee S3/SC1 and registered with ANSI. ASA S3/SC1.4 TR-2014. Springer and ASA Press, Cham, Switzerland.

151. Popper, A.N., Hawkins, A.D., Fay, R.R., Mann, D., Bartol, S., Carlson, T., Coombs, S., Ellison, W.T., Gentry, R., Halvorsen, M.B., Løkkeborg, S., Rogers, P., Southall, B.L., Zeddies, D., Tavolga, W.N. (2014) The nature of man-man sound. Sound Exposure Guidelines for Fishes and Sea Turtles: A Technical Report prepared by ANSI-Accredited Standards Committee S3/ SC1 and registered with ANSI. ASA S3/SC1.4 TR-2014. Springer and ASA Press, Cham, Switzerland.

152. Popper, A.N., Hawkins, A.D., Fay, R.R., Mann, D., Bartol, S., Carlson, T., Coombs, S., Ellison, W.T., Gentry, R., Halvorsen, M.B., Løkkeborg, S., Rogers, P., Southall, B.L., Zeddies, D., Tavolga, W.N. (2014) Sound exposure guidelines. Sound Exposure Guidelines for Fishes and Sea Turtles: A Technical Report prepared by ANSI-Accredited Standards Committee S3/SC1 and registered with ANSI. ASA S3/SC1.4 TR-2014. Springer and ASA Press, Cham, Switzerland.

153. Popper, A.N., Hawkins, A.D., Fay, R.R., Mann, D., Bartol, S., Carlson, T., Coombs, S., Ellison, W.T., Gentry, R., Halvorsen, M.B., Løkkeborg, S., Rogers, P., Southall, B.L., Zeddies, D., Tavolga, W.N. (2014) Research recommendations. Sound Exposure Guidelines for Fishes and Sea Turtles: A Technical Report prepared by ANSI-Accredited Standards Committee S3/ SC1 and registered with ANSI. ASA S3/SC1.4 TR-2014. Springer and ASA Press, Cham, Switzerland.

154. Popper, A.N., Hawkins, A.D., Fay, R.R., Mann, D., Bartol, S., Carlson, T., Coombs, S., Ellison, W.T., Gentry, R., Halvorsen, M.B., Løkkeborg, S., Rogers, P., Southall, B.L., Zeddies, D., Tavolga, W.N. (2014) Summary and 
conclusions. Sound Exposure Guidelines for Fishes and Sea Turtles: A Technical Report prepared by ANSI-Accredited Standards Committee S3/ SC1 and registered with ANSI. ASA S3/SC1.4 TR-2014. Springer and ASA Press, Cham, Switzerland.

155. Edds-Walton, P.L., Arruda, J., Fay, R.R., Ketten D.R. (2014) Computerized tomography of the otic capsule and otoliths in the oyster toadfish, Opsanus tau. J Morph 276:228-240.

156. Fay, R.R. and Popper, A.N. (2014) A brief history of SHAR. In Popper A.N. and R.R. Fay (Eds.) Springer Handbook of Auditory Research: Perspectives on Auditory Research. Springer-Verlag, New York, pp. 1-8.

157. Fay, R.R. (2014) The sense of hearing in fishes. In Popper A.N. and R.R. Fay (Eds.) Springer Handbook of Auditory Research: Perspectives on Auditory Research. Springer-Verlag, New York, pp. 107-124. 


\title{
It Started in Hawai'i Kai: Reminiscences of 43 Years (and Counting) of Collaboration and Friendship
}

\author{
Arthur N. Popper and Richard R. Fay
}

\begin{abstract}
This paper discusses the 43+ year collaboration of Arthur Popper and Richard Fay. Over these years, we have co-authored over 30 papers and 55 books. The collaboration benefits from a strong friendship that includes our spouses and children. By any measure, our collaboration must be seen as being successful. The basis for this success is, we think, twofold. First, we have very complementary and overlapping research interests. This has enabled us to tackle issues, whether in research or in planning meetings or books, from different perspectives. Second, a hallmark of our successful collaboration has been our deep and close friendship and the extension of that friendship to our spouses and children. In this paper, we discuss some of the events that have shaped our collaboration, and some of the people who have impacted our lives.
\end{abstract}

Keywords Fish $\bullet$ Hearing $\bullet$ Localization $\bullet$ Springer Handbook $\bullet$ SHAR $\bullet$ Hawaii

Our collaboration started in 1971 and continues to this day. Together, we have published over 25 scientific papers, close to 60 books, and organized a number of meetings. Obviously, the collaboration has been productive, but it has also been one of close friendship between our families. We like to think that while each of us would have been productive had we never met, the "chemistry" of us together has benefited both of us and our discipline in many exciting and important ways that would not have occurred had we not collaborated.

Looking back on our careers, we have certainly been productive as collaborators. For example, we have coauthored 32 papers (see list at the end of this essay), coedited over 55 books, and shared students and postdocs who have gone on to be very productive scholars in their own right. We have co-organized eight scholarly meetings, all of which have resulted in publications.

\footnotetext{
A.N. Popper $(\square)$

Department of Biology, University of Maryland, College Park, MD 20742, USA

e-mail: apopper@umd.edu

R.R. Fay

Marine Biological Laboratory, Woods Hole, MA, USA
} 
Perhaps the hallmark of our collaboration is our strong friendship and our growing to know and work together so easily that, as our wives like to point out (and as many of our friends and colleagues have observed), the two of us finish each other's sentences and ideas. As a result, we often have no idea of the origin of any particular project. Projects arose from conversations where our thinking was so intertwined that it is impossible to know who originated the idea. In fact, our families learned early on that we would come up with some new book, meeting, or research project if left alone for more than a few minutes. At one point, two of our children, Christian Fay and Michelle Popper, actually plotted to not let us be alone to prevent us from coming up with a new project (by the way, they were never successful in their attempts).

In this essay, we will share anecdotes and vignettes that typify our shared careers and show how we have worked together for over 43 years. We have left out most of our shared science since that is reflected in other essays in this volume and in our scholarly publications.

\section{The Start of Our Collaboration}

Our collaboration started the day after Christmas 1971. Helen and Art Popper had been living in Hawai'i for about 2.5 years. Dick, Cathy, and 2-year-old Chris Fay came to Hawai'i around December 24th so that Dick could take up a postdoc position with Nobel Laureate Georg von Békésy. Art and Dick vaguely knew of one another ${ }^{1}$ but had never met. So the Poppers invited the Fays to a barbeque on December 26th. As the saying goes, "This was the start of a beautiful friendship."We "bonded" almost instantly. Even before the Fays left the barbeque, we had started to think about doing a research project at the Eniwetok Marine Biological Laboratory in the Marshall Islands and talked about starting some joint research projects.

Dick's lab was located in the Laboratory of Sensory Sciences while Art's was in the zoology building (Edmondston Hall). However, in mid-1972 Dr. von Békésy passed away. The University then decided to somewhat broaden the scope of faculty in Sensory Sciences and Art was invited to move his lab (to what became the Békésy Laboratory of Sensory Sciences ${ }^{2}$-Fig. 1). Thus, we had offices and labs near one another for the remainder of Dick's stay in Hawai'i.

\section{Digression 1}

It is interesting to note that Dick was the only postdoc (and only student) that Dr. von Békésy ever had. This came as a result of a meeting between Dr. von Békésy and Dick’s doctoral mentor Dr. E. Glenn Wever at Princeton in 1967 (they were close friends). Dr. von Békésy was interested in crayfish statocysts as vestibular organs and wanted someone to examine the vestibular physiology of these animals. Dr. Wever mentioned that he had a student (Dick) who would be perfect for this project. Although Dr. von Békésy passed away before Dick could complete the work, Dick continued it for several years and published his only invertebrate papers as a result of that project (Fay 1973, 1975). 


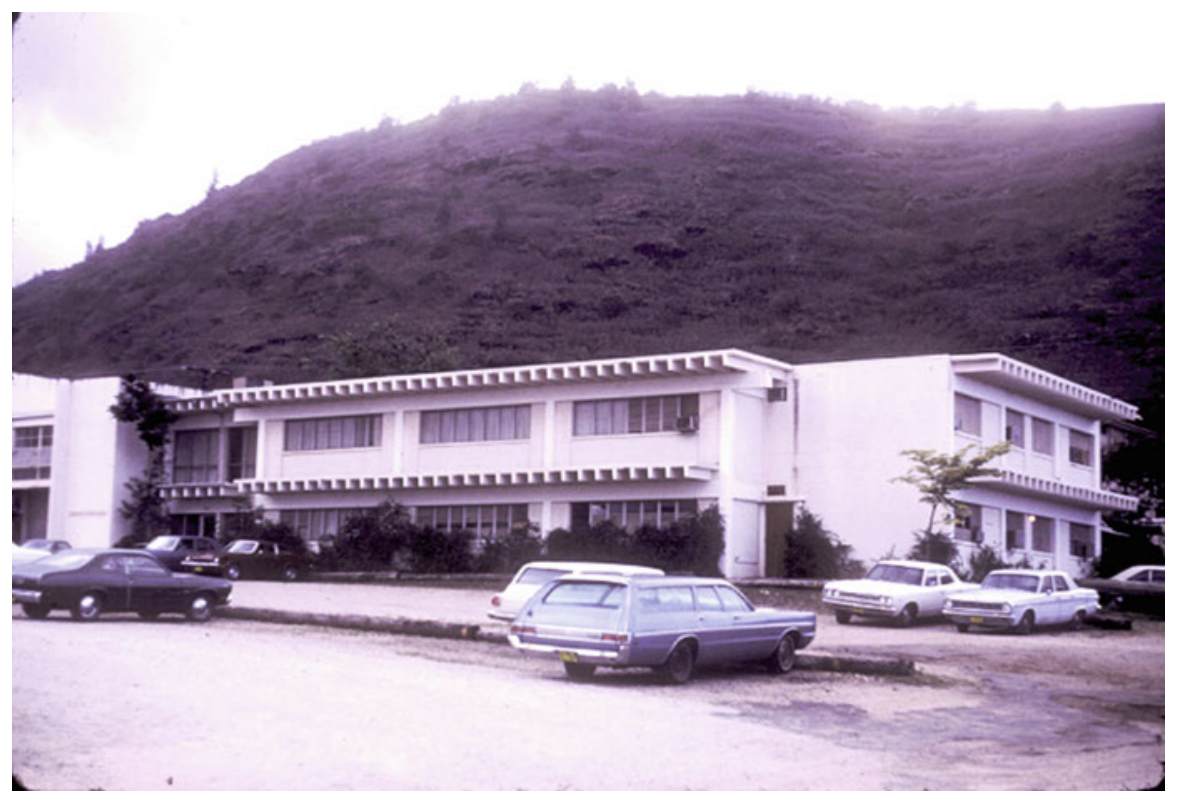

Fig. 1 Békésy Laboratory of Sensory Sciences about 1975

\section{Our First Paper and Its Descendants}

Our first joint project came about as we were leaving a meeting, the topic of which we cannot recall now. We started to discuss that it had been a some time since fish hearing had been reviewed, and we came up with the idea of doing a critical review to look at the field at that time (Fig. 2, left). "Sound Detection and Processing by Fish: A Critical Review" became our first paper together (Popper and Fay 1973). It appeared in the Journal of the Acoustical Society of America (a journal for which both of us ultimately became associate editors). We remember being quite concerned once the paper was accepted that we did not have funds for page charges so we talked Ian Cooke, then the director of the Békésy lab, into picking up the tab.

In thinking about that paper, two things stand out. First, the ideas expressed in the paper were hatched spontaneously, and we just fed off each other as ideas came pouring out about what it should include and the approach to take. This has been typical of our collaboration, and it is interesting to realize that our ease of collaboration started so early in our relationship. Second, 20 years after this paper was published, we had the opportunity to revisit the material in an article, "Sound Detection and Processing by Fish: Critical Review and Major Research Questions," in Brain, Behavior and Evolution (BBE) (Popper and Fay 1993). We recall being quite surprised that the gaps we identified in the literature back in 1973 had still not been fully filled. 
Reprinted from: The Journal of the Acoustical Society of America

\title{
Sound detection and processing by teleost fishes: a critical review*
}

\author{
Arthur N. Popper \\ Department of Zoology and Laboratory of Sensory Sciences, University of Hawaii, Honolulu, Hawaii 96822 \\ Richard R. Fay \\ Laboratory of Sensory Sciences, University of Hawaii, Honolulu 96822 \\ (Received 5 December 1972)

\begin{abstract}
The purpose of this critical review is to reevaluate the current experimental literature on fish audition based upon evaluation of structural, physiological and behavioral studies. The specific emphasis of the paper will be to (1) review the recent literature on the psychophysiology of hearing in fishes; (2) look at the subject of fish hearing from the standpoint of auditory mechanisms and their relationship to what is known about hearing in terrestrial vertebrates: and (3) emphasize some questions and areas of research which we fecl require more investigation. Based on the data reviewed in the paper we have tentatively concluded that the teleost auditory
\end{abstract} \\ system is well adapted as a temporal analyzer.
}

Subject Classification: $16.6 ; 3.4$.

\section{INTRODUCTION}

Although experimental studies of hearing in fishes have been undertaken for at least 100 years, the data generally have not been included in the main body of concepts comprising the area of sensory psychophysiology. However, in the past decade there has been an increasing interest in fishes as subjects for neuropsychological research ${ }^{1}$ and investigators interested in fish hearing have started to use the more sophisticated ideas and techniques which have developed around the study of the mammalian auditory system. Consequently, there has been an extensive increase in the experimental literature on hearing in fishes and this now has the potential of providing meaningful input to the field of psychological and physiological acoustics. It is our intention in this review to reevaluate the current literature on fish audition in order to point out its potential contribution to studies on hearing. Owing to space limitations we have had to limit our discussion to what we feel are the most significant papers. For the reader interested in more comprehensive and historical reviews of fish sound detection and production, there are several recent excellent reviews. ${ }^{2-9}$ Furthermore, valuable reviews of lateral-line function ${ }^{10.11}$ and the older literature $\mathrm{e}^{12-14}$ are also available.

The specific emphases of this paper will be to (1) critically review the recent literature on the psychophysiology of hearing in fishes; (2) look at the subject of fish hearing from the standpoint of auditory mechanisms and their relationship to what is known about hearing in terrestrial vertebrates; and (3) emphasize some questions and areas of research which we feel require more investigation.
This paper is divided into several parts, starting with discussions of underwater sound and sounddetecting mechanisms. This is followed by a discussion of the behavioral data presently available on several aspects of fish hearing. While the neurophysiology of the fish auditory system is not presented separately, discussions of recent studies are included within appropriate sections of the paper.

\section{UNDERWATER SOUND}

A major problem associated with investigations of sound detection by marine organisms is the understanding of the underwater sound stimulus. Sound in water follows the same physical laws as air-borne sounds but there are several aspects of the subject not often encountered by investigators working with terrestrial animals. As an introduction to the problem of underwater sound, and in order to provide several important definitions, we quote a discussion relevant to this subject from a recent paper $^{15}$ :

The physical characteristics of underwater sound itself have not been until recently completely understood by biologists. Sound consists of extremely small fluid motion which sets up two variables, pressure and particle velocity (displacement, the integral of particle velocity, is often used instead of particle velocity). Particle velocity is a vectorial quantity possessing direction (the direction may be a function of time and also of frequency). The ratio of sound pressure and the particle velocity in a traveling wave is called the characteristic impedence of the wave and in water is of the order of $150,000 \mathrm{cgs}$ units. Its exact value is a product of the density times the speed of sound or ' $\rho c$. ' As a point source of sound is

The Journal of the Acoustical Society of America

Fig. 2 Our first two collaborative papers. On left is Popper and Fay (1973) and on the right Fay and Popper (1974) 


\title{
ACOUSTIC STIMULATION OF THE EAR OF THE GOLDFISH (CARASSIUS AURATUS)
}

\author{
BY RICHARD R. FAY* \\ Laboratory of Sensory Sciences, University of Hawaii, Honolulu, \\ Hawaii 96822 , U.S.A. \\ AND \\ ARTHUR N. POPPER \\ Department of Zoology and Laboratory of Sensory Sciences, \\ University of Hawaii, Honolulu, Hawaii 96822 , U.S.A.
}

(Received 3 fanuary 1974)

SUMMARY

Microphonic potentials were recorded from the ears of the goldfish during acoustic stimulation in a situation where sound pressure and particle displacement could be varied. Microphonic potentials from fishes with the swim bladder intact were proportional to sound pressure. After removal of the swim bladder, sound pressure sensitivity declined by $20-35 \mathrm{~dB}$ and the response was generated in proportion to particle displacement. The ear's sensitivity to direct vibration of the head increases at between -3 and -6 $\mathrm{dB} /$ octave between 70 and $1500 \mathrm{~Hz}$ and is not affected by the removal of the swim bladder. It is concluded that the peripheral auditory system of the goldfish may function as a pressure detector or as a displacement detector, depending upon the impedance of the applied signal.

\section{INTRODUCTION}

The auditory portions of the inner ears of fishes are unique among vertebrates in that the simple hair cell macula is overlain by a solid calcareous otolith. Hair cell stimulation is presumed to occur as a result of relative shearing movements between the hair cell body and its ciliary hairs, which appear to be in contact with the overlying otolith (Hama, 1969).

The otolithic organs of most animals can be viewed as inertial devices such that movement transmitted within the body tissues is taken up by the dense otolith with an amplitude and phase which differs from that of the surrounding fluid and tissues. This view of auditory reception in fishes is attractive since under water sound energy is readily transmitted through the fish's body because of the close impedance match between water and tissue (Alexander, 1966; van Bergeijk, 1967, and others). In fact, it appears unavoidable that relative movement would occur as the result of the large difference in density between the otolith and adjacent tissues. In general, however, the

\footnotetext{
- Requests for reprints should be sent to Richard R. Fay, Department of Otolaryngology, The Bowman Gray School of Medicine, Wake Forest University, Winston-Salem, North Carolina 27103.
}

Fig. 2 (continued) 
And, to follow this thread in our publications, we learned in 2011 that this 1993 paper was one of the most cited in the history of BBE, and we were invited to revisit the paper, think back on what we had said in 1993, and review changes in the field. We are quite proud of "Fish Hearing: New Perspectives From Two 'Senior' Bioacousticians" (Fay and Popper 2012) because it allowed us both, as we were cogitating retirement, to look at the field of fish bioacoustics as it had evolved over our careers. But, again, 19 years after the first BBE paper and 39 years after our 1973 review, we still saw many open and exciting questions for the next generations of investigators to pursue.

\section{Modes of Hearing}

Our first research collaboration resulted in two papers in 1974 and 1975 (Fay and Popper 1974, 1975) (Fig. 2, right). These were inspired, as we recall, by some work done by Dick's mentor, Dr. Wever (also the discoverer of the Wever-Bray Effect, better known as cochlear microphonics; see Hallpike and Rawdon-Smith 1934). Dr. Wever was one of the first to suggest that fish hear with both particle motion and pressure, but there were, at that time, no experimental studies to demonstrate this possibility. (We did not know then that a number of our European colleagues were, using different approaches, asking the same questions; see the wonderful review by our close friend and colleague Tony Hawkins 2014.)

Thus, our first collaborative experimental studies (Fay and Popper 1974, 1975) involved placing fish in a tube and using evoked potentials to determine hearing sensitivity with and without air in the swim bladder. We examined goldfish (Carassius auratus) and a cichlid (Tilapia macrocephala) and concluded that the swim bladder was involved in hearing in the goldfish for higher frequencies but not in the cichlid. This led to our suggesting (but not using the terms) that there are "hearing specialists" and "hearing generalists." This differentiation, as we will get to below, came back to "haunt" us later in our careers.

\section{Eniwetok and Shark Hearing}

In the summer of 1972, we teamed up with two of the most remarkable people we have ever met, Drs. Albert Tester and James Kendall, to do a study on shark hearing (Fig. 3). Al Tester was one of the world's preeminent elasmobranch biologists and was on the faculty of the University of Hawai'i (UH) for decades. Jim Kendall moved to Hawai'i after retiring as a professor of biology at City College of New York (CCNY; he was also a retired colonel in the U.S. Air Force). When Jim moved to Hawai'i, he met $\mathrm{Al}$ and that led to a very deep friendship and a magnificent scientific collaboration. On thinking back on it, perhaps the collaboration and friendship we saw in Jim and $\mathrm{Al}$ rubbed off on us and could be the basis of our working together. 


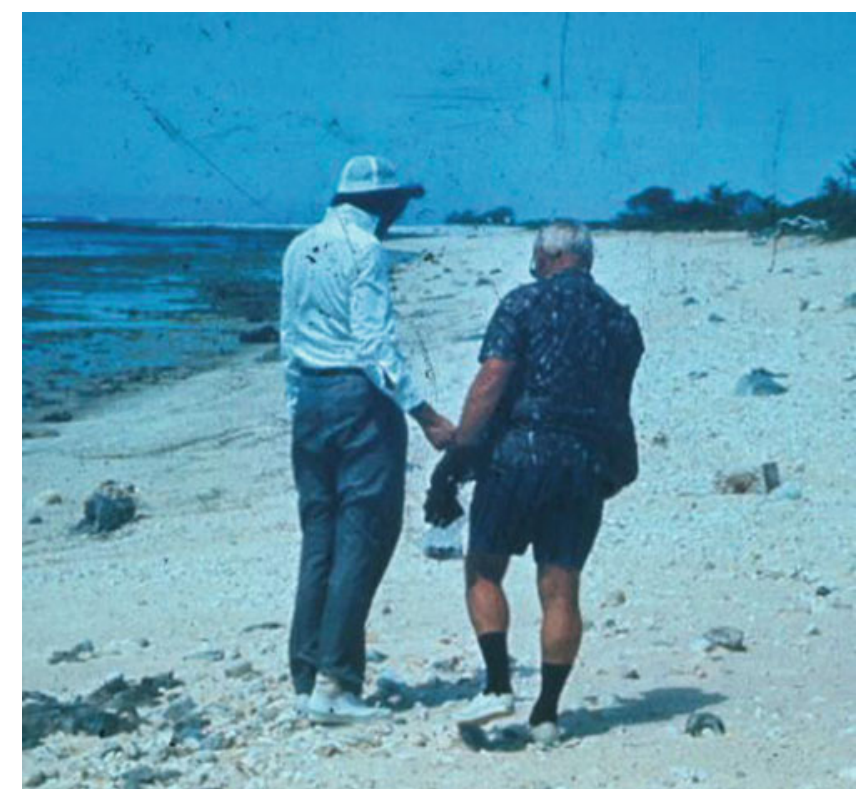

Fig. 3 The only picture we have of Jim Kendall (left) and Al Tester together. This was taken in 1972 on the beach in Eniwetok

\section{Digression 2}

When Art was a doctoral student at CCNY, he decided he wanted to do a postdoc on shark hearing. He wrote to $\mathrm{Al}$ who responded that he had no funds for a postdoc but that there was an open faculty position at UH teaching comparative anatomy. Art applied (as well as to postdocs with Dr. Arthur Myrberg and Dr. Wever) and was offered the position.

Back in those days, postdocs were not critical to getting jobs, and on the advice of Dr. Tavolga and several other mentors at City University of New York (including George Gourevitch, who Art later found out was a close friend of Dick's), he took the faculty position. Again, back in those days, interviews were rather less formal than now, and so rather than being invited to interview in Hawai' $i$, Art was interviewed at the annual meeting of the American Association for the Advancement of Science (AAAS) that took place in Dallas in December 1968. (This was Art and Helen's first trip to Texas and Art's first experience with Mexican food, something that resulted in heartburn for several days, only to be "cured" by his mother-in-law's chicken soup.) 


\section{Digression 3}

As mentioned above, Jim Kendall was a professor at CCNY where he taught histology but left before Art arrived there for graduate work. Jim retired just as Art's wife Helen, a CCNY undergraduate, was about to take the course. Helen then took histology with Bill Tavolga, little knowing that she would get to know Bill as her future husband's mentor and then as a close friend. In any case, Helen met Jim in Hawai'i and never let him forget that he left CCNY before she could take his class. Jim became not only Art's collaborator but also a very close personal friend. He was a very special and kind man and gave Helen a copy of the histology text he had written but never published.

Getting back to sharks! The study was to be conducted at the Eniwetok Atoll in the Marshall Islands, a marine lab run then by the Atomic Energy Commission to study the biology of the Eniwetok Atoll since they had tested nuclear bombs on various islands in the atoll. Getting to the Eniwetok Atoll itself was a challenge (Fig. 4). We were all supposed to fly on a military air cargo (MAC) flight to the island of Kwajalein in the mid-Pacific and then fly on to Eniwetok. However, at the last minute, Art and Dick got bumped from the flight (there was only one flight per week and some VIP had a higher priority) and were put on a commercial flight on Air Micronesia

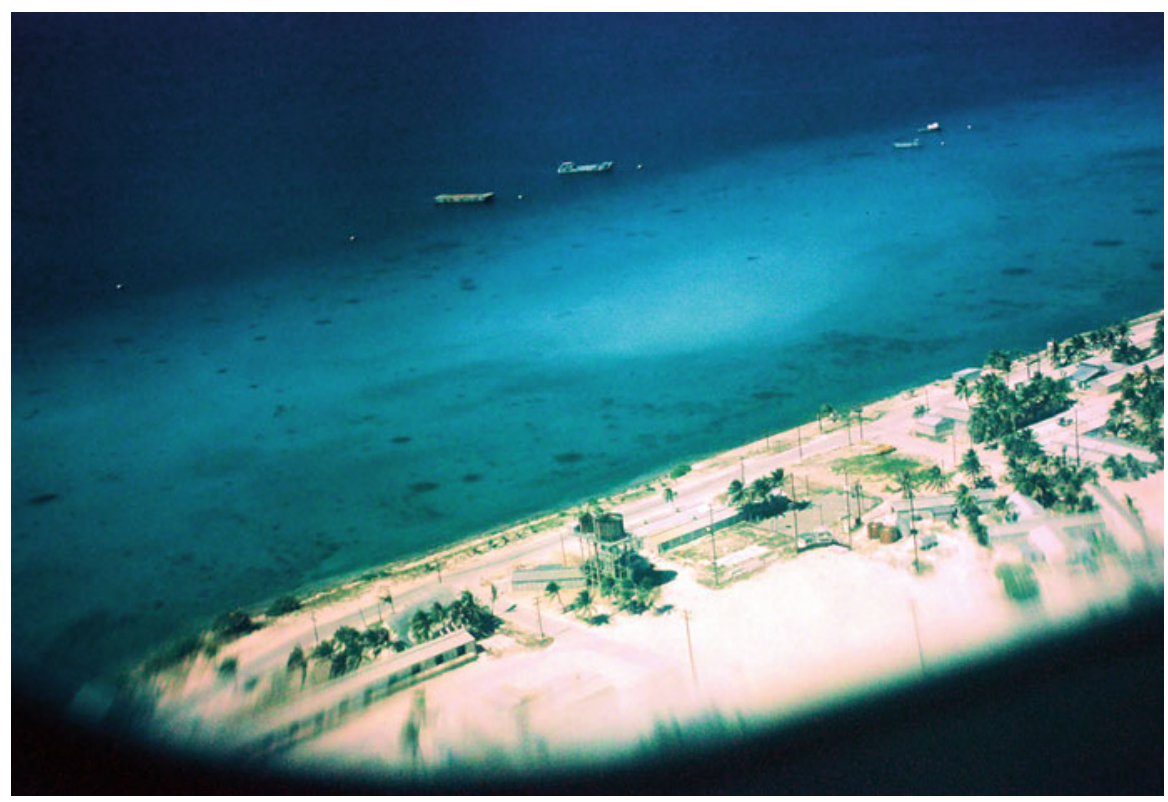

Fig. 4 A view of "Fred" and the Eniwetok Marine Laboratory from the air in 1972 
to Kwajalein to get on the MAC flight to Eniwetok (apparently the VIP got off in Kwajalein).

The Air Micronesia flight was quite interesting. We were told before takeoff that this was a unique Boeing 737 that had a special underbody so that the coral runways would not throw up material and damage the plane. The plane carried a spare engine and a mechanic to change engines if needed. Photos out of the plane were forbidden. The first stop was the island of Midway (of World War II fame) where we were ushered off the plane between lines of heavily armed guards and put into a waiting area until the plane refueled. We were then ushered back and flew to Kwajalein where we were again taken to a secure site. Trouble was that our Air Micronesia flight was late and the flight to Eniwetok was about to take off without us. However, Al Tester decided that he was going to change the schedule and, as we recall, he stood in front of the plane to keep it from moving until we were on board.

We arrived at the base in Eniwetok, on an island given the name of "Fred" by the military. ${ }^{3}$ We recall that we were in an air-conditioned dormitory that was quite nice. Food for the first part of each week was abundant and great, but by the end of the week, five or six days after the one weekly flight, the food got pretty boring and repetitive. And then the next plane arrived and food got great again. The island also had a bar ( 25 cents/drink) and movies every night. Trouble with the movies was that they were on film and sent from island to island in the South Pacific sequentially. And after the first few stops, all the sections that had any hint of sex were cut out and, rumor had it, compiled into films of only sexy scenes; we never saw those!

Fred also had a lab, part of which was just a shed and part was air-conditioned (keep in mind that Fred was $4^{\circ}$ north of the equator and we were there in summer, so the humidity was $100 \%$ and the temperature over $100{ }^{\circ} \mathrm{F}$ most of the time). There was also a nice outdoor aquarium facility with running sea water.

Our plan was to get small sharks and stimulate various parts of the head with a vibrator to test the hypothesis that $\mathrm{Al}$ and Jim had proposed that hearing was through the dorsal endolymphatic fossa that led directly into the ear (Tester et al. 1972). So, the first job we had was to get sharks! We figured this would be easy (and Al assured us it would be) because sharks abound in the Eniwetok Atoll.

Trouble is, the sharks may have known we were there and catching animals turned out to be a daunting task! We fished and fished and got nothing until after a few days of trying, we caught a female white-tipped shark. We took her back to the lab late in the morning, and she was clearly in bad shape. In fact, Al pronounced her dead just before lunch, and, dejected, we went to eat (food was still good early in the week). We returned to the lab and Al noticed that the sides of the shark were moving. He realized that she was pregnant (remember, many sharks are live bearers) and quickly set to work to do a cesarean section on the shark. He was successful and delivered 9 or 10 shark pups. This was an exciting event, but we had to get them

\footnotetext{
${ }^{3}$ Each island, despite having a name given by the Marshall Islanders, was given a name by some U.S. government agency. Thus, Eniwetok Island was Fred and Runit Island was called Yvonne. See http://www.dod.mil/pubs/foi/International_security_affairs/eniwetok_and_johnsonatolls/117. pdf.
} 
respiring or they would die. Thus, each of us took a shark pup and "walked" it around a tank, forcing water over the gills until it started to respire on its own (Fig. 5, top). We had, to our delight, a $100 \%$ success rate. While other animals became our experimental subjects and are commemorated in Fay et al. (1974), our friend Leo Demski (now at the University of South Florida campus in Sarasota) was also at Eniwetok and was able to use a few of the pups for a study on the ventricles of the shark brain.
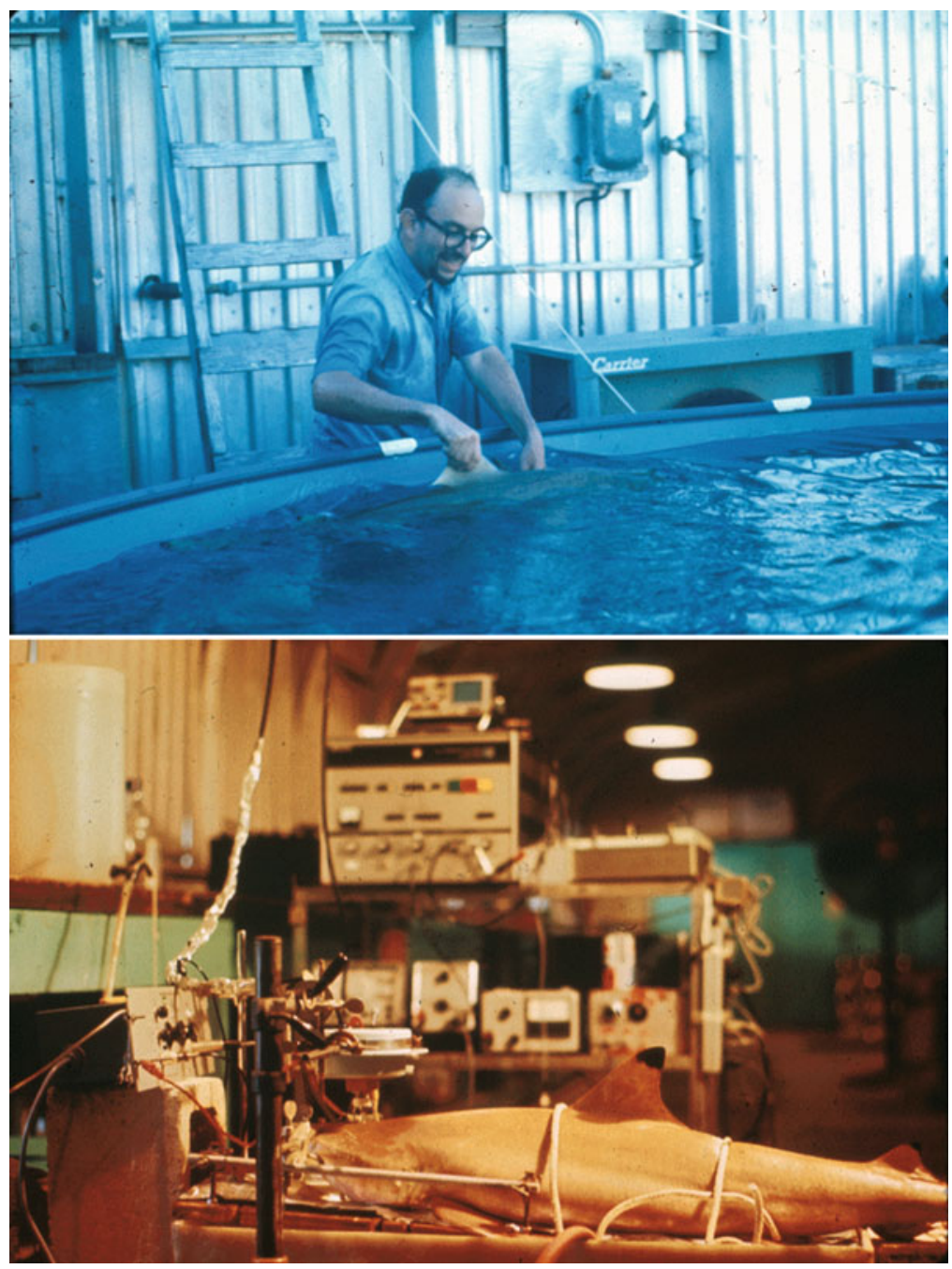

Fig. 5 Top: Art "walking" a newborn shark pup after Al Tester did a C-section on the mother. Bottom: Setup designed by Dick to measure the microphonic potentials from a shark. The large box toward the top was a circa 1971 signal average 
Now that we had the pups, we had to start the experiments. The two of us were in charge of physiology and we had brought cases of equipment, including a Tektronix 503 oscilloscope and a Tektronix preamplifier and power supply (Fig. 5, bottom). We got very frustrated over the first few days because the preamplifier and power supply would not work. We saw the whole study "going down the tubes" and finally wound up calling (by ham radio) our friend Howard Gillary who was coming the next week and asked him to bring working equipment. We feared that we had lost at least a week of work!

Out of frustration, we decided to test the equipment one more time. By chance, we first tried the equipment in the air-conditioned lab room and, to our amazement, all worked fine. We then took the equipment outside to the aquarium area and it worked! We were thrilled, and we had a sudden revelation. Eniwetok is very humid. Up until then, we had taken the equipment from the air-conditioned room to the outside and turned it on. This was in the days when much of the equipment used vacuum tubes and what was happening is that the moisture in the air was condensing on the cold connections in the preamplifier and power supply, shorting out the circuits when the power was applied. But, by first turning on and heating up the equipment in the lab, water did not condense and we were able to continue our work.

\section{Books}

A few years ago, while the Poppers were visiting the Fays on Cape Cod, we had a conversation about our scientific "legacy". We both realized that although we had published (what we like to think) good research papers that made substantial contributions to our discipline, the life of research papers is relatively short. Sure, some of our papers will still be cited 5, maybe 10, years from now, but the likelihood of their being used 15 or 20 years from now is low; just look at the outstanding papers by many other notable people in our field like Sven Dijkgraaf, Karl von Frisch, and William Tavolga.

What we also realized was that perhaps our real legacy is the books we have edited over the years. This is particularly the case for our Springer Handbook of Auditory Research (SHAR) series (discussed below). But, SHAR was not our first book.

In fact, the origin of our first book, Comparative Vertebrate Hearing, arose by chance (Popper and Fay 1980). We had agreed to organize a symposium at the 1979 meeting of the Acoustical Society of America (ASA) in Honolulu and invited a number of people, including Ted Bullock (who, until then, neither of us had ever met), to speak. Right before the ASA meeting, Art was at the Society for Neuroscience meeting and while wandering the exhibit halls got into a conversation with Dr. Mark Licker, an editor at Springer-Verlag (now just Springer), a major international scientific publisher. We don't recall the details of the conversation, but one thing led to another and the conversation turned to the ASA symposium and the idea of publishing it as a book. Our colleagues at the symposium agreed to write papers for the book. Thus, Mark became our first editor at Springer, and he was also our "tutor" in how to put together a book. Mark ultimately left Springer and became Vice President of Von Nostrand. He is now retired, but we continue to be in touch with him. 
Concurrent to getting the "book bug," we also discovered that we liked to organize symposia and went on to develop several other meetings (Table 1). The first, on fish hearing and bioacoustics, took place at the Mote Marine Lab in Sarasota, FL, partly because it is a good facility and partly because we wanted to collaborate with Bill Tavolga. Bill had retired from CCNY and was on the Mote staff. He had organized the two formative books in marine bioacoustics (Tavolga 1964, 1967) and we thought it would not only be fun to work with Bill but also to have the continuity with the earlier meetings (Fig. 6). The best part of this meeting was that it allowed us to invite colleagues from around the world, none of whom we had previously met, including Tony Hawkins, Olav Sand, Arie Schuijf, and Per Enger (many of whom have become good friends over the years).

Table 1 Major meetings organized by Richard Fay and Arthur Popper (this does not include a number of symposia and smaller workshops we also organized)

"Comparative Studies of Hearing in Vertebrates," November 1978, Honolulu, Hawaii, at a joint meeting of the Acoustical Societies of America and Japan

"Hearing and Sound Communication in Fishes," June, 1980, Sarasota, Florida (with W. N. Tavolga)

"Sensory Biology of Aquatic Animals," June 1985, Sarasota, Florida (with J. Atema and W. N. Tavolga)

"Comparative Evolutionary Biology of Hearing," May, 1990, Sarasota, Florida (with D. B. Webster)

Fish Bioacoustics: Sensory Biology, Behavior, and Practical Applications, Chicago, IL, May 30-June 2, 2001 (with J. Webb)

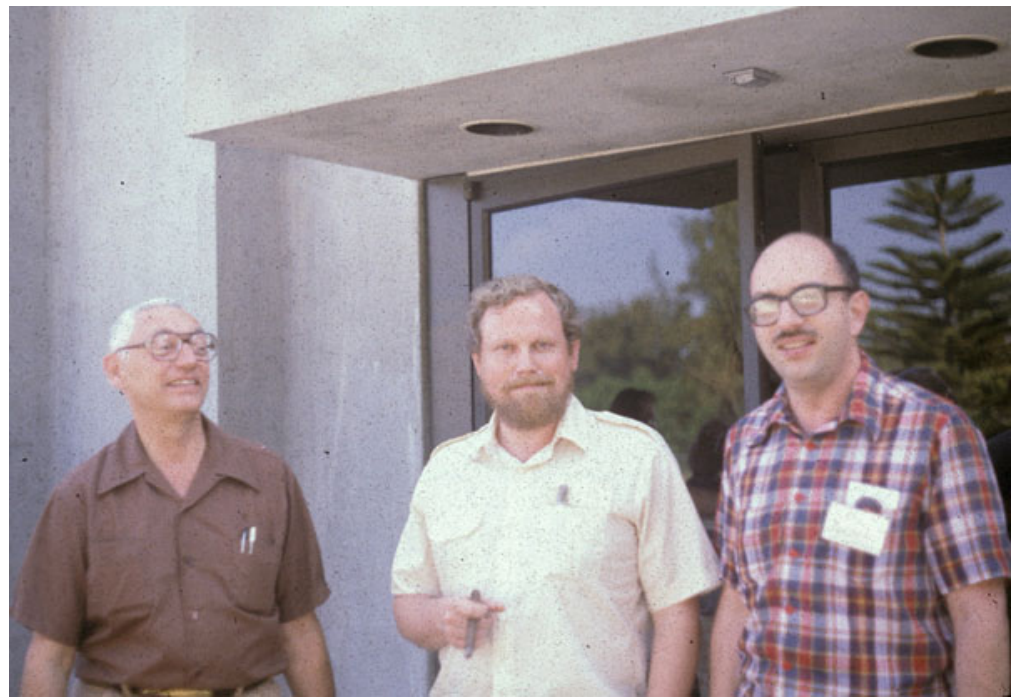

Fig. 6 Bill Tavolga, Dick Fay, and Art Popper at the 1980 meeting on fish bioacoustics 
Although it would be hard to pick out a "favorite" meeting, the one that everyone seems to recall best was our 1985 meeting on Sensory Biology of Aquatic Animals (Atema et al. 1988). The idea for this meeting arose one snowy Saturday morning at Art's home in Rockville, MD, during a visit by Dick. Helen had made French toast for breakfast (that has no significance other than we remember this trivial detail!) and we were sitting around before taking Dick to the airport. For some reason, we started to cogitate about the need for a meeting that would focus on all fish senses rather than just hearing and how valuable it would be to get people interested in different senses to share ideas, providing a much broader understanding of the sensory lives of fishes. Within an hour (and this is not an exaggeration), we had come up with the basic plan for the meeting, had ideas on funding, and decided we needed a collaborating organizer who was studying another sense. We decided that the ideal person would be someone neither of us knew well, Jelle Atema. We called Jelle the following Monday, he accepted the idea instantly, and, besides everything else, Jelle has become a close and very valued friend to both of us.

The meeting was a resounding success, bringing an exciting group of people to Mote for five days of sharing knowledge and ideas (Fig. 7). Everyone present felt

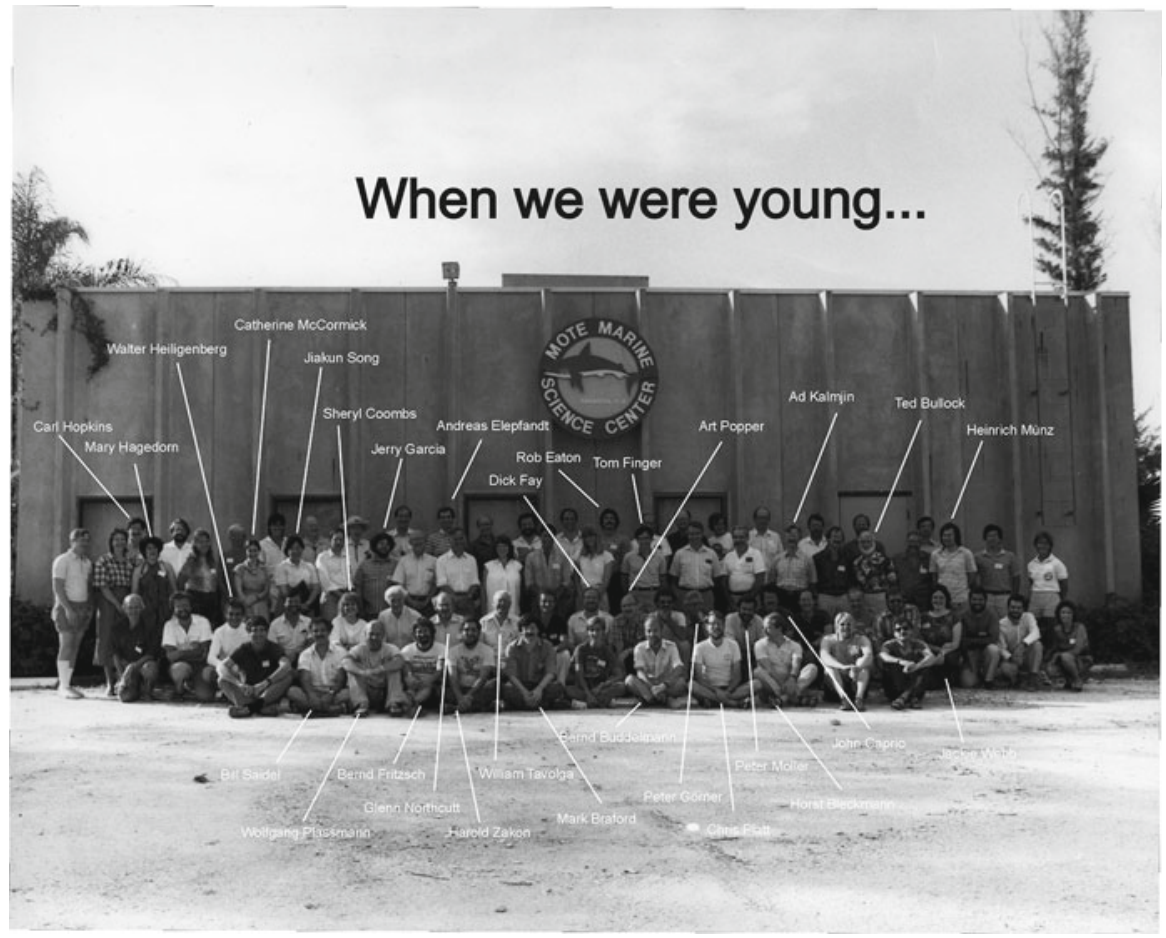

Fig. 7 Sensory Biology of Aquatic Animals meeting in 1985. We cannot recall who labeled this picture, and so we "apologize" to many of our colleagues and friends who are in the photo but not identified. Among those not specifically identified are: Jelle Atema. Perry Gilbert, Jim Kendall, Art Myrberg, Pete Rogers, Tony Hawkins (but see Fig. 8), Arie Schuijf, Olav Sand, Eric Denton, and John Gray 
that we really moved sensory biology forward with this meeting. But, the thing that every participant remembers in greatest detail was the FOOD!!!

This happened because we were given some private funding for the meeting and we decided that one of the best ways to foster interactions was to keep everyone together during lunch (rather than going to other sites). So, on Bill Tavolga's suggestion, we hired a local French chef, Alain Mons, to do lunch, breaks and the final banquet. We planned lunch every day, with only a light lunch on Thursday because participants had the afternoon off to relax. Well, each lunch was a culinary masterpiece, and the breaks were the best we have ever experienced (even to now!). And we accomplished our goal-everyone stayed around for long lunch breaks, and there were two hours of lively and exciting discussion each day in the company of brilliant food. And, on Thursday, when we figured people would "eat and run," the sandwiches were extraordinary and no one left.

The banquet was another experience! The food, as expected, was fantastic. But what we remember most vividly, during the closing "thank you's" for the meeting, the organizers got polite applause and some nice words were said about our organization skills. But, when Chef Mons was introduced, he got a five-minute standing ovation!!!

\section{SHAR}

One day, we were sitting around Dick's house in Falmouth, MA, and got into a conversation about various books in the field of auditory neuroscience. One thing led to another, and for some reason, we came up with the idea of editing a series of books on various aspects of hearing. We quickly came up with the idea for eight books and figured that would pretty much cover the field. We broached this idea with Dr. William Curtis, our Springer editor at that time (now president of Springer in the USA) and he immediately "bought" the idea and gave us considerable encouragement and support. We decided to start with just two books, one on anatomy and one on physiology. We realized that there are many areas in which neither of us is expert or even knew the major "players," so we decided to invite coeditors to work with us and guide the books using a model that we developed for the series.

We discuss the origin and evolution of SHAR in volume 50 of the series, Perspectives in Auditory Research (Fay and Popper 2014), so we won't repeat that here. We'll only say that the motivation to continue beyond volume 8 was the very positive responses we got to the first volumes from colleagues and friends, our growing understanding of the field, and the variety of topics open to review.

Much to our delight, SHAR has grown, with volume 51 having come out in 2014 and perhaps 10-15 volumes at various stages. In fall of 2012 we broached the idea of stopping the series, but Springer "rebelled" and said it has to go on; we assume they make some money from the series. So we have designated two young colleagues, Allison Coffin and Joseph Sisneros, as "heirs apparent," but you won't see them editing SHAR for a while because we enjoy the volumes so much. We will add 
that Springer is very supportive of our series, and although they "own" the series, they have treated it, and us, as if we are the owners and let us go in any direction we wish. We have worked with wonderful people at Springer and are grateful that Bill Curtis takes particular pride and interest in the series and makes its importance clear throughout the company.

\section{Students}

Over the years, each of us has had a number of graduate students and postdocs. They inevitably get to know both of us because we are together so often. In addition, there have been several students who moved from one of our labs to the other and one student who we co-mentored to her doctorate.

This started with Sheryl Coombs. Sheryl, now retired as a professor at Bowling Green State University in Ohio, joined Art as a graduate student in Hawai'i in 1975. She then followed Art to Georgetown University in 1978 (although she got her degree from Hawai'i). Sheryl worked on hearing in squirrelfish and made very important contributions to our understanding of comparative hearing. After receiving her doctorate, Sheryl decided to move to the Parmly Hearing Institute at Loyola University of Chicago to do a postdoc with Dick. Sheryl stayed on as a faculty member at Parmly for many years doing what has become some of the most exciting and important work on the function of the lateral line ever done. She remains a good friend of both of ours, and we share great pride in her accomplishments.

Sheryl was followed by Zhongmin (John) Lu who made the reverse trip from Parmly where he worked on the physiology of goldfish hearing with Dick to the University of Maryland to work with Art (who moved there in 1987) on sound localization. John is a very talented physiologist and he collaborated with both of us on individual and joint projects. John is now a tenured associate professor at the University of Miami.

The third "shared" student was Peggy Edds-Walton. Art met Peggy when he moved to Maryland where she was an instructor with a reputation as a stellar teacher. Art "persuaded" Peggy to pursue her doctorate, which she did. She did really lovely work on the anatomy of the auditory system in toadfish. Deciding she wanted to learn physiology, Peggy started a collaboration and postdoc with Dick that took place at the Marine Biological Laboratory in Woods Hole, MA (where Dick and Cathy now live). This collaboration has been immensely productive, with Peggy and Dick producing a seemingly endless series of important papers that combine anatomy and physiology of fish hearing.

The last student we shared was Michaela Meyer. Art met Michaela on a visit to Bonn, Germany, and invited her to come to Maryland for her doctorate. Michaela had a passion to do physiology of fish hearing and because that is not Art's expertise, we devised a scheme where we would co-mentor Michaela. This turned out to be great fun, and Michaela got to spend time both at Maryland and at Loyola. Indeed, she was great a real pleasure to co-mentor, and the three of us had many 
great discussions and good times together. Michaela did a wonderful dissertation on hearing in lake sturgeon, a very important and endangered species (but she used hatchery-raised animals that were, themselves, not endangered). Michaela has moved on and is now a postdoc at Harvard.

\section{Food}

Food has always been an integral part of our relationship, starting at that very first barbeque in 1971. As mentioned earlier, having good food has always been a major consideration as we organized meetings, but it has been a part of much of what we have done. It should be noted that Art readily admits that Dick is the chef of the two of us. Art's contribution will be wine or whisky, but he would never try to compete with Dick with respect in preparing a memorable meal. (Of course, it is worth remembering that Dick is also a published food critic with his much acclaimed Hot Dog Chicago, the basis of a film that won an Emmy ${ }^{4}$ on local public TV in Chicago.)

Perhaps our most memorable meal has become "legend" in our families. It took place in May 1974 at the Maile Room in Honolulu, HI. We went there to celebrate our birthdays (Art is 361 days older than Dick and so our birthdays are within 4 days of one another) and Helen and Cathy arranged a "surprise." The Maile Room was one of two restaurants in Hawai' $i$ that then required gentlemen to wear jackets and ties (the other was the Cannon Club, the military club on the slopes of Diamond Head that we went to several times with Jim Kendall). The first memory of that evening was that as we were leaving the Fay's home (having picked them up), Helen noticed that Dick was in a nice suit but, in true Hawaiian tradition, was wearing sandals and no socks!

So, we had a lovely dinner and were about to order dessert. Just as we were doing this, both of us noticed a birthday cake with candles being brought out and recall looking at one another and saying something about the poor fools who were about to be embarrassed by a cake. Needless to say, those two "fools" were us! But, someone messed up somewhere because the cake had Vick and Art on it!

\section{The "Curse" of the Hearing "Specialist"}

For the past 20 or 30 years, the term "hearing specialist" has been used to describe fishes that have structures that somehow enhance hearing capabilities compared with fishes without such specializations ("hearing generalists"). A number of years ago, we came to the conclusion that these terms were more confusing than helpful because there is so much overlap in fish hearing capabilities between various species. So we started to wonder where the terms came from. We searched the literature

${ }^{4}$ For non-US reads, an Emmy is the TV equivalent to Academy Awards in the U.S. 
and could not find a "start" to the terms. We wrote to perhaps 50 friends and colleagues in the field to see if anyone had an idea of where the terms arose.

Interestingly, the consensus appeared to be that no one was sure of the origin of the terms (or can find them in the literature), but many people "accused" the two of us of being the first to use the words. However, to "defend ourselves," we recently redid a search using Google Scholar and have come to the conclusion that the term "specialist" for some fishes predated even our being in college, much less our participation in the field. In our search, we found a quotation in a classic paper, Hearing in Bony Fishes, by Dr. Sven Dijkgraaf (1960) that says: "Roughly we can distinguish two groups of fishes: the 'specialists' in sound reception, and the 'normal' fishes (Von Frisch 1936; Dijkgraaf and Verheijen 1950). The sensitive specialists are mostly freshwater fishes. They all possess certain sound-reinforcing structures like the apparatus of Weber in the Ostariophysi or the gas chambers connected with the labyrinth..." (pp. 52-53). Dr. Dijkgraaf went on to say: "In the so-called "normal' fishes, including nearly all marine species, the upper limit of the auditory range is found at frequencies between 400 and $1000 \mathrm{c} / \mathrm{s}^{5}$ " (p. 53).

So, quite clearly, we are not the perpetrators of these words, but we did decide that they are not appropriate and that there needed to be a new way of thinking about fish hearing; the variation between species is more a "continuum" than a clear distinction between specialist and generalist (or, in Dijkgraaf's terms, "normal") fishes. We first presented this idea at a meeting of the Acoustical Society of America and, much to our amazement, had our talk interrupted by sustained applause by the audience. Clearly, many of our colleagues were as stymied by these terms as we and they were delighted that we had come up with a new concept for how to think about fish hearing. This work was published as Popper and Fay (2011) and the ideas seem to have become quickly accepted.

\section{End Note}

We will end with the hope that this essay provides a sense of who we are and the great satisfaction (even joy) we have had with our continued collaboration and friendship. We suspect that a collaboration of this length is rare in science, and we have been truly fortunate to have the opportunity to work together and to have a friendship that spans five decades. We are also truly fortunate that this friendship has extended to our wives (Fig. 8) and children, and we are very much looking forward to early 2015 when our grandchildren get to meet for the first time. Hopefully, they too will appreciate the closeness of our lives and perhaps one of our grandchildren will decide to follow us into science. But for now, this essay is dedicated to Emma Levit, Ethan and Sophie Levinsohn, and Evan, Nathaniel, and Stella Fay. We hope they someday read this essay and take pride in the friendship and closeness of their families and what their grandfathers have contributed to science.

${ }^{5}$ Cycles/second, now referred to as hertz. 


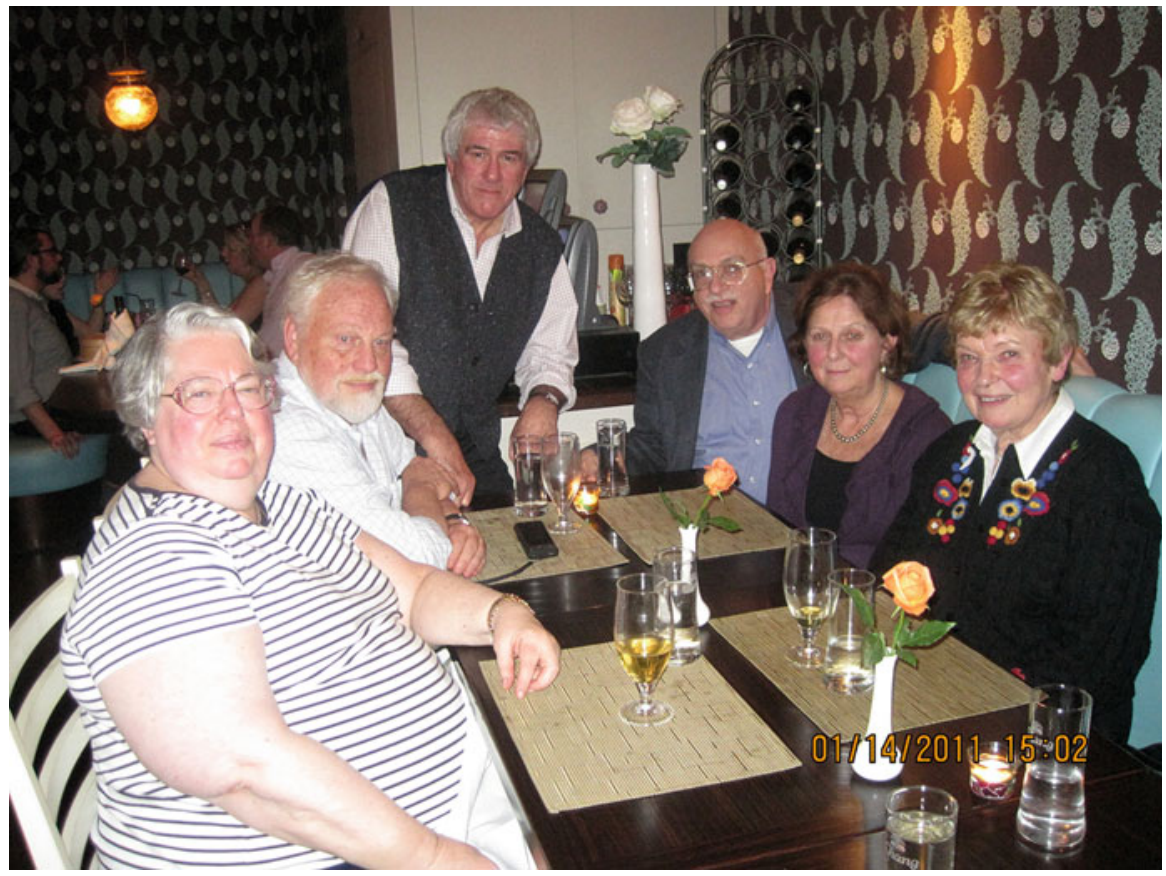

Fig. 8 Helen Popper, Dick Fay, Tony Hawkins, Art Popper, Cathy Fay, Sue Hawkins, 2011

\section{Our Collaborative Papers (in Chronological Order and Not including Our Books)}

1. Popper, A.N., and Fay, R.R. (1973). Sound detection and processing by fish: A critical review. J. Acoust. Soc. Am. 53:1515-1529.

2. Fay, R.R., and Popper, A.N. (1973). Vibration isolation for small aquaria. Behav. Res. Methods Instr. 5:502-503.

3. Fay, R.R., and Popper, A.N. (1974). Acoustic stimulation of the ear of the goldfish (Carassius auratus). J. Exp. Biol. 61:243-260.

4. Fay, R.R., Kendall, J.I., Popper, A.N., and Tester, A.L. (1974). Vibration detection by the macula neglecta of sharks. Comp. Biochem. Physiol. 47:1235-1240.

5. Fay, R.R., and Popper, A.N. (1975). Modes of stimulation of the teleost ear. J. Exp. Biol. 62:379-387.

6. Popper, A.N., and Fay, R.R. (1977). Structure and function of the elasmobranch auditory system. Am. Zool. 17:443-452.

7. Fay, R.R., and Popper, A.N. (1980). Structure and function in teleost auditory systems. In: Comparative Studies of Hearing in Vertebrates. (eds. A.N. Popper and R.R. Fay). Springer-Verlag, New York, pp. 3-42. 
8. Fay, R.R., and Popper, A.N. (1983). Hearing in fishes: Comparative anatomy of the ear and the neural coding of sensory information. In: Hearing and Other Senses: Presentations in Honor of E. G. Wever, (eds. R.R. Fay and G. Gourevitch), The Amorpha Press: Groton, CT. pp. 123-148.

9. Popper, A.N., and Fay, R.R. (1984). Sound detection and processing by teleost fish: A selective review. In: Comparative Physiology of Sensory Systems, (eds. L. Bolis, R.D. Keynes, and S.H.P. Maddrell). Cambridge University Press, Cambridge, UK, pp. 67-101.

10. Fay, R.R., and Popper, A.N. (1985). The octavolateralis system. In: Functional Vertebrate Morphology, (eds. M. Hildebrand, D. M. Bramble, K. F. Liem and D. B. Wake). Harvard Press: Cambridge, MA, pp. 291-316.

11. Platt, C., Popper, A.N., and Fay, R.R. (1989). The ear as part of the octavolateralis system. In: The Mechanosensory Lateral Line: Neurobiology and Evolution, (eds. S. Coombs, P. Görner, and H. Münz). Springer-Verlag, New York, pp. 663-651.

12. Popper, A.N., and Fay, R. R. (1993) Sound detection and processing by fish: Critical review and major research questions. Brain Behav. Evol. 41:14-38.

13. Echteler, S. M, Fay, R.R., and Popper, A. N. (1994). Structure of the mammalian cochlea. In: Comparative Hearing: Mammals, (eds. R.R. Fay, and A.N. Popper). Springer-Verlag, New York, pp. 134-171.

14. Lu, Z., Popper, A.N. and Fay, R.R. (1996). Behavioral detection of acoustic particle motion by a teleost fish, Astronotus ocellatus: sensitivity and directionality. J. Comp. Physiol. A 179:227-233.

15. Popper, A.N., and Edds-Walton, P.L. (1997). Bioacoustics of marine vertebrates. In Handbook of Acoustics (ed. M. Crocker). John Wiley and Sons, New York, pp. 1831-1836.

16. Fay, R.R., and Popper, A.N. (1997). Evolution of vertebrate sensory systems. Brain Behav. Evol. 50:187-188.

17. Popper, A.N., and Fay, R.R. (1997). Evolution of the ear and hearing: Issues and questions. Brain Behav. Evol. 50:213-221.

18. Fay, R.R., and Popper, A.N. (1999). Hearing in fishes and amphibians: An introduction. In: Comparative Hearing: Fish and Amphibians (eds. R.R. Fay and A.N. Popper). Springer-Verlag, New York, pp. 1-14.

19. Popper, A.N., and Fay, R.R. (1999). The auditory periphery in fishes. In: Comparative Hearing: Fish and Amphibians (eds. R.R. Fay and A.N. Popper). Springer-Verlag, New York, pp. 43-100.

20. Popper, A.N. (2000). Hair cell heterogeneity and ultrasonic hearing: Recent advances in understanding fish hearing. Phil. Trans. R. Soc. Lond. B Biol. Sci. 355:1277-1280.

21. Fay, R.R., and Popper, A.N. (2000). Evolution of hearing in vertebrates: The inner ears and processing. Hear. Res. 149:1-10.

22. Popper, A.N., Fay, R.R., Platt, C., and Sand, O. (2003). Sound detection mechanisms and capabilities of teleost fishes. In: Sensory Processing in Aquatic Environments (eds. S.P. Collin and N.J. Marshall). Springer-Verlag, New York, pp. 3-38. 
23. Fay, R. R. and Popper, A. N. (2005). Introduction to sound source localization. In: Sound Source Localization (Eds. A. N. Popper and R. R. Fay), Springer Science+Business Media, New York, pp. 1-5.

24. Meyer, M., Fay, R. R., and Popper, A. N. (2010). Frequency tuning and intensity coding of sound in the auditory periphery of the lake sturgeon, Acipenser fulvescens. J. Exp. Biol., 213:1567-1578.

25. Popper, A. N. and Fay, R. R. (2011). Rethinking sound detection by fishes. Hear. Res., 273: 25-36.

26. Meyer, M., Popper, A. N., and Fay, R. R. (2012). Coding of sound direction in the auditory periphery of the lake sturgeon, Acipenser fulvescens. J. Neurophysiol., 107:658-665.

27. Fay, R. R. and Popper, A. N. (2012). Fish hearing: New perspectives from two "senior" bioacousticians. Brain, Behaviour and Evolution 792:215-217. DOI: $10.1159 / 000338719$

28. Popper, A.N., Hawkins, A.D., Fay, R.R., Mann, D., Bartol, S., Carlson, T., Coombs, S., Ellison, W.T., Gentry, R., Halvorsen, M.B., Løkkeborg, S., Rogers, P., Southall, B.L., Zeddies, D., Tavolga, W.N. (2014) Sound Exposure Guidelines for Fishes and Sea Turtles: A Technical Report prepared by ANSIAccredited Standards Committee S3/SC1 and registered with ANSI. ASA S3/ SC1.4 TR-2014. Springer and ASA Press, Cham, Switzerland.

29. Fay, R. R., and Popper, A. N. (2014). A brief history of SHAR. In: Popper, A. N. and Fay, R. R. (eds.) Perspectives in Auditory Research, Springer Science+Business Media, New York.

30. Rogers, P. H., Hawkins, A. D., Popper, A. N., Fay, R. R., Gray, M. D. (2015). Parvulescu revisited: Small tank acoustics for bioacousticians. In: Popper, A. N., Hawkins, A. D. (eds.) Effects of Noise on Aquatic Life, II, Springer Science+Business Media, New York, in press.

31. Sisneros, J. A., Popper, A. N., Hawkins, A. D., Fay, R. R. (2015). Auditory evoked potential audiograms compared to behavioral audiograms in aquatic animals. In: Popper, A. N., Hawkins, A. D. (eds.) Effects of Noise on Aquatic Life, II, Springer Science+Business Media, New York, in press.

32. Gray, M. D., Rogers, P. H., Popper, A. N., Hawkins, A. D., Fay, R. R. (2015). "Large" tank acoustics: How big is big enough? In: Popper AN, Hawkins AD (eds.) Effects of Noise on Aquatic Life, II, Springer Science+Business Media, New York, in press.

\section{References}

Atema J, Fay RR, Popper AN, Tavolga WN (eds) (1988) Sensory biology of aquatic animals. Springer, New York

Dijkgraaf S (1960) Hearing in bony fishes. Proc Roy Soc Lond B Biol Sci 51-54.

Dijkgraaf S, Verheijen FJ (1950) NeueVersucheüber das Tonunterscheidungsvermögen der Elritze. ZeitschriftfürvergleichendePhysiologie 32(3):248-256 
Fay RR (1973) Multisensory interaction in control of eye-stalk rotation response in the crayfish (Procambarus clarkii). J Comp Physiol Psychol 84(3):527

Fay RR (1975) Dynamic properties of the compensatory eye-stalk rotation response of the crayfish Procambarus clarkii. Comp Biochem Physiol A Physiol 51(1):101-103

Fay RR, Popper AN (1974) Acoustic stimulation of the ear of the goldfish (Carassius auratus). J Exp Biol 61:243-260

Fay RR, Popper AN (1975) Modes of stimulation of the teleost ear. J Exp Biol 62:379-387

Fay RR, Popper AN (2012) Fish hearing: new perspectives from two "senior" bioacousticians. Brain Behav Evol 792:215-217. doi:10.1159/000338719

Fay RR, Popper AN (2014) A brief history of SHAR. In: Popper AN, Fay RR (eds) Perspectives in auditory research. Springer Science+Business Media, New York

Fay RR, Kendall JI, Popper AN, Tester AL (1974) Vibration detection by the macula neglecta of sharks. Comp Biochem Physiol 47:1235-1240

Hallpike CS, Rawdon-Smith AF (1934) The origin of the Wever and Bray phenomenon. J Physiol 83(2):243-254

Hawkins AD (2014) Examining fish in the sea: a European perspective on fish hearing experiments. In: Popper AN, Fay RR (eds) Perspectives in auditory research. Springer Science+Business Media, New York, pp 247-267

Popper AN, Fay RR (1973) Sound detection and processing by fish: a critical review. J Acoust Soc Am 53:1515-1529

Popper AN, Fay RR (eds) (1980) Comparative studies of hearing in vertebrates. Springer, New York

Popper AN, Fay RR (1993) Sound detection and processing by fish: critical review and major research questions. Brain Behav Evol 41:14-38

Popper AN, Fay RR (2011) Rethinking sound detection by fishes. Hear Res 273:25-36. doi:10.1016/j.heares.2009.12.023

Tavolga WN (ed) (1964) Marine bio-acoustics. Pergamon Press, Oxford, 413 p

Tavolga WN (ed) (1967) Marine bio-acoustics, II. Pergamon Press, Oxford, 353 pp

Tester AL, Kendall JI, Milisen WB (1972) Morphology of the ear of the shark genus Carcharhinus, with particular reference to the macula neglecta. Pac Sci 26:264-274

Von Frisch K (1936) Über den Gehörsinn der Fische. Biol Rev 11(2):210-246 


\title{
A Soliloquy for Art and Dick
}

\section{Robert J. Dooling}

\begin{abstract}
Art Popper and Dick Fay are probably the most prolific scientists in the history of auditory research. In fact, they should probably be listed among the most prolific authors anywhere given their number of Springer Handbook of Auditory Research volumes, alone, now reaching 51 volumes and still continuing! To give them their proper due, I channeled another very prolific author from years ago and produced a soliloquy to honor their contributions to us and our field of auditory science.
\end{abstract}

Keywords Dynamic duo $\bullet$ Goldfish $\bullet$ Generalist $\bullet$ Specialist

The following poem was presented by Robert Dooling at the banquet following the symposium to honor Drs. Arthur N. Popper and Richard R. Fay:

R.J. Dooling ( $(\square)$

Department of Psychology, University of Maryland, College Park, MD 20742, USA

e-mail: rdooling@umd.edu 


\section{$\mathscr{A}$ bolíloquy for Art and 五ick \\ Sarasota, fflay 25, 2013}

The "sea" or not the "\$ea": that was the question:

Whether "tis nobler in the mind to suffer the slime and odors of outragreous físbes, Or to take arms aqaingt this sea of troubles. And by opposing, ent them, and thoose a mammal or bird for auditory research instead?

To bear, to respond; 30 more; and by a response to say we ent the beart-ache and the thousand electrical shocks the goldfísh ts heir to, "tis a consummation veboutly to be wish'd.

To bear, to respond; To respond, perchance correctly: ap, there's the rub; Jor in that sleep after proposal submígsion, what oreams may come of 'qeneralísts' bersus 'specialists' exposed to antbropogentic noise in the ocean, must gibe us pause.

There's the regpect that makes calamity of so long careers; Ifor who would bear the whips and scorns of particle-motion theorists. The rebiewer's wrongs, the editor's insults, the pangs of despis-ed data, the publication Delaps, the insolence of the Itish \& Wildife serbice, and the spurns of mandatory rebistons required by the unworthy, when be bimself mitght bis qutetus make if be truly understood the function of the simin bladoer. 积ut, who would bear the cost of pet another summer at

To grunt and sweat under weary life, 杼ut that the iread of something after publication, the undiscobered, earlier paper, from whose data no scientist eber recobers, puzzles the will, And makes us rather bear those ills we babe as last author, than to fly to the first author posittion that we know not of?

Thus, hearing Does make scientists of $\mathfrak{u}$ all; Ant thus, the basic nature of Detection and discrimination is sicklied ober with a pale cast of attentional bariables, And enterpríges of great pitch and moment, such as structure-function relationships and anatomical spectalizations, on account of this, are turmed astive. Ant loge to molecular biology.

Soft you now! Thy faír Springer 五uo from Ant's and 敢'k's contributions remembered! 
Part II

Acoustic Communication and Behavior 


\title{
Acoustic Communication in Butterflyfishes: Anatomical Novelties, Physiology, Evolution, and Behavioral Ecology
}

\author{
Timothy C. Tricas and Jacqueline F. Webb
}

\begin{abstract}
Coral reef fishes live in noisy environments that may challenge their capacity for acoustic communication. Butterflyfishes (Family Chaetodontidae) are prominent and ecologically diverse members of coral reef communities worldwide. The discovery of a novel association of anterior swim bladder horns with the lateral line canal system in the genus Chaetodon (the laterophysic connection) revealed a putative adaptation for enhancement of sound reception by the lateral line system and/or the ear. Behavioral studies show that acoustic communication is an important component of butterflyfish social behavior. All bannerfish (Forcipiger, Heniochus, and Hemitaurichthys) and Chaetodon species studied thus far produce several sound types at frequencies of $<1$ to $>1000 \mathrm{~Hz}$. Ancestral character state analyses predict the existence of both shared (head bob) and divergent (tail slap) acoustic behaviors in these two clades. Experimental auditory physiology shows that butterflyfishes are primarily sensitive to stimuli associated with hydrodynamic particle accelerations of $\leq 500 \mathrm{~Hz}$. In addition, the gas-filled swim bladder horns in Chaetodon are stimulated by sound pressure, which enhances and extends their auditory sensitivity to 1700-2000 Hz. The broadband spectrum of ambient noise present on coral reefs overlaps with the frequency characteristics of their sounds, thus both the close social affiliations common among butterflyfishes and the evolution of the swim bladder horns in Chaetodon facilitate their short-range acoustic communication. Butterflyfishes provide a unique and unexpected opportunity to carry out studies of fish bioacoustics in the lab and the field that integrate the study of sensory anatomy, physiology, evolution, and behavioral ecology.
\end{abstract}

Keywords Acoustic behavior - Coral reef fish - Communication - Evolution • Hearing $\bullet$ Lateral line $\bullet$ Laterophysic connection $\bullet$ Soundscape

\footnotetext{
T.C. Tricas $(\triangle)$

Department of Biology, Hawai'i Institute of Marine Biology, University of Hawai'i at Manoa, 2538 The Mall, Edmondson Hall, Honolulu, HI 96822, USA

e-mail: tricas@hawaii.edu

J.F. Webb

Department of Biological Sciences, University of Rhode Island, 120 Flagg Road, Kingston, RI 02881, USA
} 


\section{Introduction}

The butterflyfishes (Family Chaetodontidae) are a conspicuous, speciose, and highly social family of coral reef fishes. The family includes four genera of coralfishes (Amphichaetodon, Chelmon, Chelmonops, Coradion), four genera of bannerfishes (Forcipiger, Hemitaurichthys, Heniochus, Johnrandallia), and a clade composed of the genera Prognathodes and Chaetodon, the latter of which represents approximately $70 \%$ of the species in the family (Blum 1988; Smith et al. 2003; Fessler and Westneat 2007; Bellwood et al. 2010). The butterflyfishes are diverse in their feeding habits and they include species that are planktivores, obligate and facultative corallivores, benthic invertebrate predators, and omnivores (reviewed by Cole and Pratchett 2014). Individuals are rarely solitary and several types of social relationships are found among species (Hourigan 1989; Yabuta and Berumen 2014). Many species form monogamous pairs that are maintained for several years (or for life) in which the same two individuals carry out all of their daytime activities in close proximity to one another (separated by only a few body lengths) while foraging over large home ranges, or defending a feeding territory (Reese 1975; Fricke 1986; Tricas 1989; Roberts and Ormond 1992). Other species form long-term haremic associations that consist of a single male and multiple females. During daylight hours some species form larger groups, shoals, or schools that feed on plankton in the water column above the reef. Their highly conspicuous species-specific color patterns and behavioral displays are used to visually mediate many social interactions such as the recognition of conspecifics (Zumpe 1965; Boyle and Tricas 2014), identification of mates (Reese 1975; Yabuta 2002), defense of territories (Tricas 1985, 1989; Roberts 1992; Wrathall et al. 1992; Kosaki 1999), avoidance of predators (Motta 1984; Neudecker 1989), and determination of behavioral state (Hamilton and Peterman 1971). However, the more recent discoveries of novel anatomical features associated with the lateral line system and the discovery of sound production have refocused attention on butterflyfish bioacoustic behavior in relation to their behavioral ecology and evolution, which is the focus of this chapter.

The laterophysic connection (LC; Figs. 1 and 2) is a unique anatomical feature in the genus Chaetodon that is defined by the presence of cylindrical, anterior swim bladder horns in proximity to a medial opening in the lateral line canal in the supracleithral bone, located at the posterior margin of the skull. This unique feature was proposed to facilitate the transmission of sound pressure stimuli to the lateral line canal system and to the ear (Webb 1998; Webb et al. 2006). Behavioral studies in the lab and field demonstrate that sound is produced in all Chaetodon species and in representatives of other butterflyfish genera studied thus far (summarized in Tricas and Boyle 2015a). The tendency for Chaetodon species to form monogamous pairs and other close social associations is consistent with their use of both the auditory and lateral line systems for the perception of acoustic signals at short distances. This may be especially important on coral reefs in which the soundscape is characterized by high intensity, broadband, ambient noise levels that 


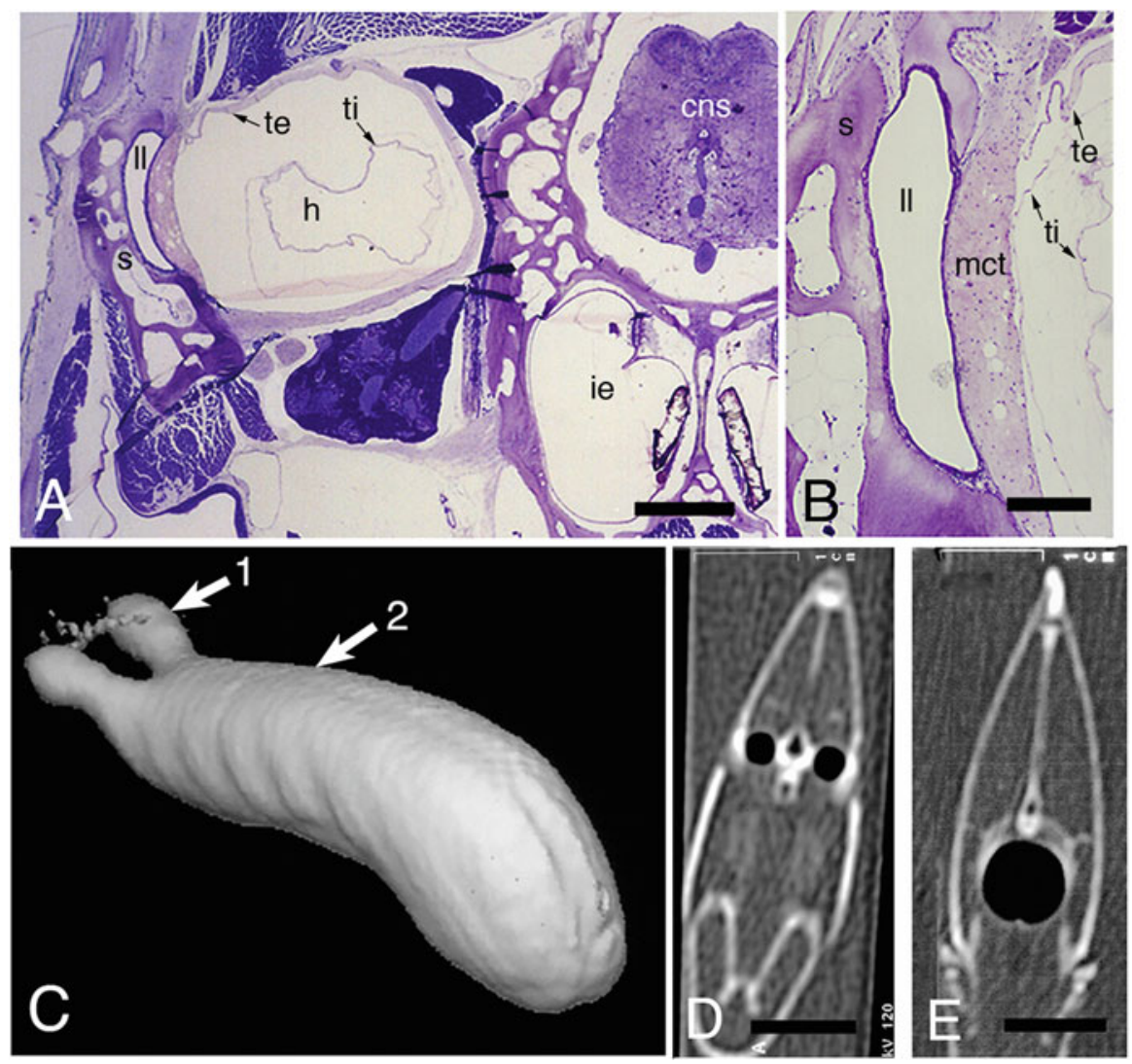

Fig. 1 Histological sections and CT images of the laterophysic connection (LC) and swim bladder in Chaetodon species. (a) Transverse section through LC in C. octofasciatus. Scale bar $=500 \mu \mathrm{m}$ (modified from Webb 1998). (b) Close-up of laterophysic tympanum in C. octofasciatus. Scale bar $=200 \mu \mathrm{m}$. (c) 3-D reconstruction (CT) of the air volume in the swim bladder and swim bladder horns in C. ephippium. (d) Transverse CT slice at level of arrow 1 (swim bladder horns) in c. (e) Transverse CT slice at level of arrow 2 (body of swim bladder) in $\mathbf{c}$. In $\mathbf{d}$ and $\mathbf{e}$ white represents high density bone (cranium, vertebral column, fin supports), and scales covering body. Soft tissue is grey, like the water surrounding the fish. Scale bar in $\mathbf{d}$ and $\mathbf{e}=10 \mathrm{~mm}$. cns central nervous system, $h$ horn, ie inner ear, $l l$ lateral line canal, $m c t$ mucoid connective tissue, $s$ supracleithrum, te tunica externa, $t i$ tunica interna (from Smith et al. 2003, Reproduced with permission by John Wiley \& Sons)

overlap the frequency range for both hearing and sound production and may present a challenge for the extraction of biologically relevant acoustic information. In this chapter we review the comparative anatomy of the laterophysic connection (in Chaetodon species), ear, and swim bladder, which may all be involved in the reception of acoustic field stimuli (Sect. 2). We review the current (but still limited) knowledge of the diversity of butterflyfish sounds and sound production mechanisms, and examine the evolution of their acoustic behaviors (Sect. 3). We describe 
a

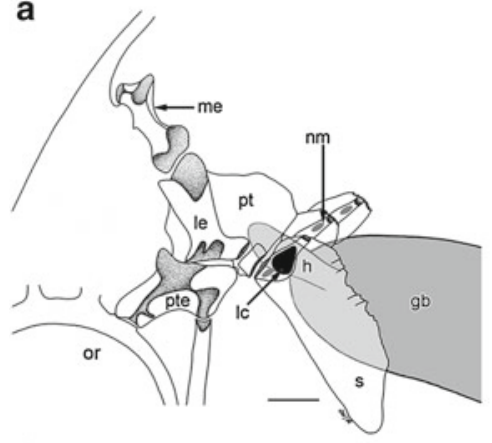

C

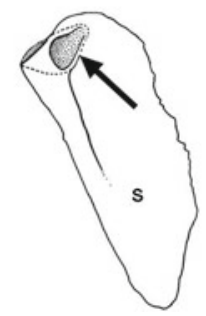

b

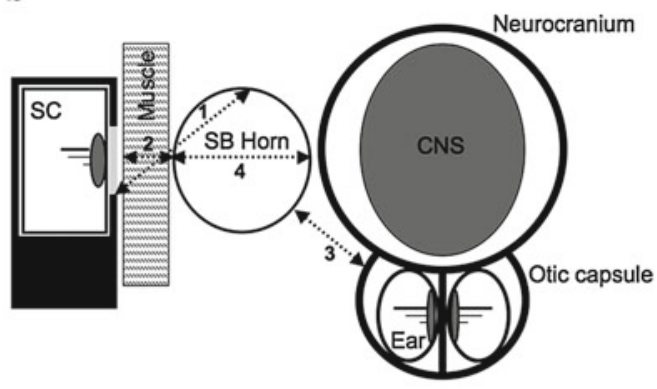

d

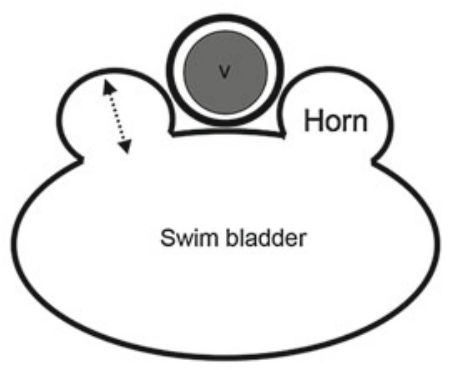

Fig. 2 Laterophysic connection in Chaetodon. (a) Drawing (lateral view, rostral to right) of the bones just behind the left orbit in C. octofasciatus. The anterior swim bladder horn (shaded) sits deep to the medial opening in the lateral line (LL) canal in the supracliethrum (black teardrop, $=$ site of the laterophysic connection), and in the vicinity of several canal neuromasts within the LL canals (grey ovals). (b) Medial view of the right supracleithrum (in same orientation as a). Arrow points to the posterior terminal pore of the short LL canal (lumen is shaded), which is illustrated as a black oval in a. $g b$ gas bladder (swim bladder), $h$ swim bladder horn, $l c$ site of laterophysic connection (black teardrop), le lateral extrascapular, me medial extrascapular, $\mathrm{nm}$ neuromast (grey oval), or orbit, pt post-temporal, pte pterotic, $s$ supracleithrum. Scale bar $=1 \mathrm{~mm}$. (c) Schematic representation (in transverse view) of the spatial relationships of the LL canal in the supracleithrum, the swim bladder horn and the otolithic organs of the ear in C. ocellatus. The left LL canal is in the supracleithrum (sc), the medial opening in the canal (light grey gap in canal wall) and the neuromast that sits on the tissue filling the opening, muscle tissue that sits deep to the opening, the cylindrical swim bladder horn, and the skull containing the central nervous system (CNS) and beneath it, the ear, with the sensory macula of the sacculus on the medial wall in the midline (see also Fig. 7). "1-4" indicate distances measured to describe spatial relationships of ear and horns in Webb et al. (2012). (d) Transverse view of the relationship of the body of the swim bladder, and the bilateral swim bladder horns (in C. ocellatus) showing that the horns are outpocketings of the swim bladder that emerge dorsally (arrow) on either side of the vertebral column (v) (from Webb et al. 2006, 2012, reprinted with permission of John Wiley \& Sons)

butterflyfish hearing capabilities and the likely importance of both the auditory and lateral line systems in acoustic communication (Sect. 4). We also consider how acoustic communication during social behaviors may enhance individual fitness (Sect. 5), and discuss the ecological implications for acoustic communication by different butterflyfish species on noisy coral reefs (Sect. 6). 


\section{Anatomy Associated with the Reception of Acoustic Stimuli}

Butterflyfishes have a well-developed lateral line canal system on the head and trunk and have an ear that is typical of those teleost fishes that lack otophysic connections (a swim bladder-ear connection). The laterophysic connection, a unique feature of the genus Chaetodon, demonstrates a considerable degree of variation among species, and the morphology of the swim bladder is correlated with that of the laterophysic connection.

\subsection{The Laterophysic Connection}

The "laterophysic connection" (LC), the association of anterior swim bladder horns with an opening in the lateral line canal contained within the supracleithral bone, was named to draw attention to its apparent structural and putative functional similarity to otophysic connections found in other fishes. Webb (1998) suggested that the LC is the site of transduction of pressure oscillations generated by sound pressure waves in the air-filled swim bladder and swim bladder horns into fluid movements in the lateral line canal in the supracleithral bone, which are capable of stimulating canal neuromasts just rostral and caudal to the LC. It was hypothesized that the presence of an LC in Chaetodon would thus make the lateral line system, in addition to the inner ear (by virtue of the proximity of the swim bladder horns to the otic capsule), sensitive to sound pressure, thus expanding its functional repertoire. It was further suggested that novel interactions of lateral line and auditory input would enhance the interpretation of acoustic stimuli (Webb 1998; Webb et al. 2006), and the reception of acoustic communication stimuli produced by Chaetodon in their natural coral reef habitats (Tricas et al. 2006; see Sect. 3).

LC morphology varies interspecifically but, like the external body features of butterflyfishes, is not sexually dimorphic (Webb and Smith 2000). Two LC types are found among Chaetodon species (Figs. 3 and 4): (1) a Direct LC, characterized by direct contact of the lateral wall of the cylindrical anterior swim bladder horns with the medial opening in the supracleithrum, and (2) an Indirect LC, defined by the presence of muscle or kidney tissue between the lateral wall of the anterior swim bladder horn and the medial opening in the supracleithrum (Webb and Smith 2000). Two variants on a direct LC (Dir1 and Dir2) and four variants on an indirect LC (Ind1-Ind4) were found among 22 Chaetodon species in the 11 Chaetodon subgenera (Smith et al. 2003; Webb et al. 2006, Figs. 3 and 4; Table 1). These variants are defined by the type(s) of tissues found between the swim bladder horns and the supracleithrum (presence or absence of mucoid connective tissue in the medial opening), the length and diameter of the swim bladder horns (long [ 1.5-3.5 mm] vs. short [ $<1 \mathrm{~mm}]$ horns, wide [ 1-3 mm] vs. narrow [<1 mm] horns; Fig. 4), and the presence or absence of an external constriction (ductus communicans) of the 

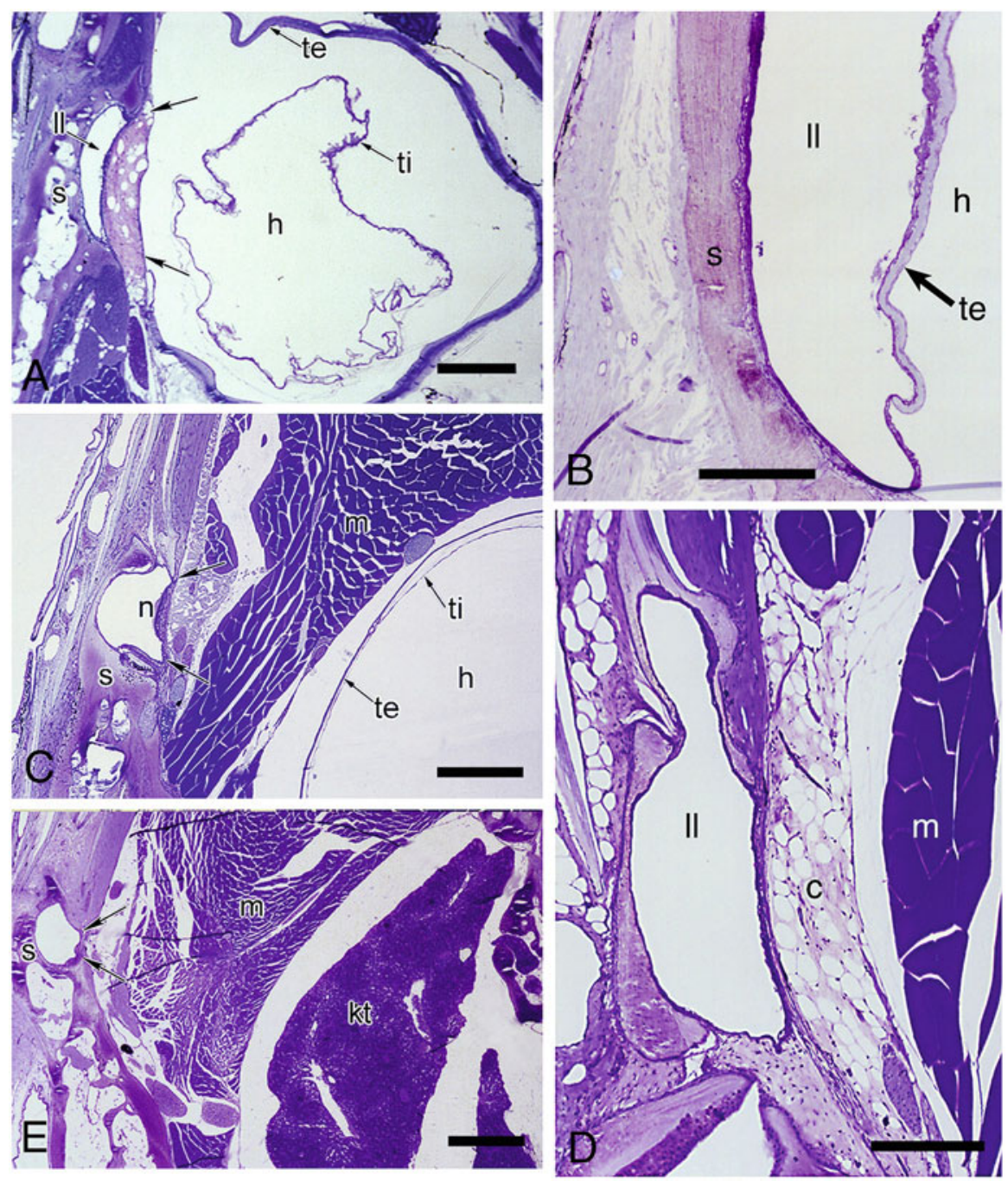

Fig. 3 Laterophysic connection (LC) variants among Chaetodon species represented schematically in Fig. 4. (a) Dirl - direct LC with mucoid connective tissue (arrows) in Chaetodon octofasciatus. Scale bar $=500 \mu \mathrm{m}$. (b) Dir2 - direct LC without mucoid connective tissue in Chaetodon plebeius. Scale bar $=200 \mu \mathrm{m}$. (c) Ind2 -indirect LC with no mucoid connective tissue in Chaetodon multicinctus. Scale bar $=500 \mu \mathrm{m}$. (d) Indl -indirect LC (arrows) with mucoid connective tissue in Chaetodon kleinii. Scale bar $=200 \mu \mathrm{m}$. (e) Ind3-indirect LC with short horns in Chaetodon ornatissimus. Note that the swim bladder horns are not present in this section (at the level of the LC), and instead the space occupied by long horns in other species is filled by muscle (m) and kidney tissue (kt). Scale bar $=500 \mu \mathrm{m}$. Arrows indicate the dorsal and ventral extent of the tissues that separate the LL canal from the swim bladder horn in a, c, and e. c mucoid connective tissue (as in d), $h$ swim bladder horn, $k t$ kidney tissue, $l l$ lateral-line canal, $m$ muscle, $n$ neuromast, $s$ supracleithrum, te tunica externa, $t i$ tunica interna (from Smith et al. 2003, reprinted with permission of John Wiley \& Sons) 

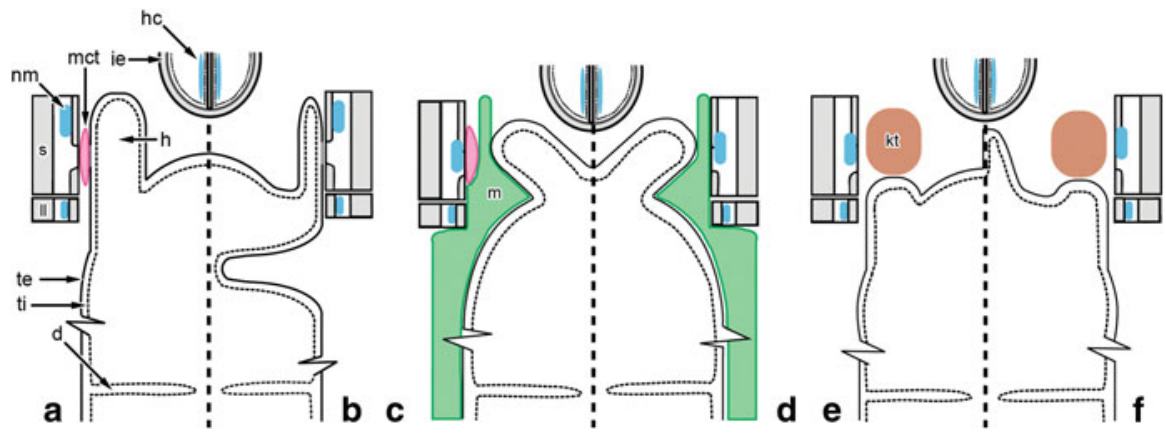

Fig. 4 Schematic representation of the six LC variants in dorsal view (rostral to top) among Chaetodon species (see Table 2 for more information). (a) Dirl - direct LC with mucoid connective tissue (pink) deep to opening in supracleithral lateral line canal containing neuromast (blue), wide horns, and one-chambered swim bladder (e.g., Chaetodon auriga). (b) Dir2 - direct LC without mucoid connective tissue, with narrow horns, and a two-chambered swim bladder (e.g., C. plebeius). (c) Indl -indirect LC with mucoid connective tissue (pink) deep to opening in supracleithral lateral line canal, with muscle (green) lateral to wide horns, and one-chambered swim bladder (e.g., C. kleinii). (d) Ind2 - indirect LC without mucoid connective tissue, with muscle (green) lateral to wide horns, and one-chambered swim bladder (e.g., C. multicinctus). (e) Ind3-indirect LC with short horns (which do not reach the level of the opening in the supracleithral canal, and a one-chambered swim bladder (e.g., C. ornatissimus). (f) Ind4 - indirect LC with short horns, a onechambered swim bladder, and a medial anterior extension of swim bladder (e.g., C. meyeri). $d$ diaphragm (transverse) in tunica interna, $h$ swim bladder horn, $h c$ sensory macula, $e$ ear in otic capsule, $k t$ kidney tissue, $l l$ 1st lateral-line scale, $m$ muscle, $m c t$ mucoid connective tissue, $n m$ neuromast, $s$ supracleithrum, te tunica externa of swim bladder (solid line), $t i$ tunica interna of swim bladder (dotted line). (From Webb et al. 2006, reprinted with permission of John Wiley \& Sons)

external wall (tunica externa) of the swim bladder (Webb et al. 2006; Fig. 4). Only one LC variant is found in each of the 11 Chaetodon subgenera, with the exception of the subgenus Citharoedus in which two short horn variants (Ind3 and Ind4) are found.

\subsection{The Swim Bladder}

Butterflyfishes have a euphysoclistous swim bladder that sits just below the vertebral column and is typically $30 \%$ of the length of the body. The swim bladder wall is composed of a thicker collagenous tunica externa and a thinner, epithelial tunica interna (Woods 2006; Woods et al. 2006). The gas exchange structures in the tunica interna (the secretory rete mirabile and resorptive oval) are well developed. A transverse diaphragm pierced by a central opening is formed by the infolding of the tunica interna and divides the swim bladder into anterior and posterior chambers (in Chaetodon and Forcipiger, and presumably other chaetodontid genera). The morphology of the diaphragm tissue suggests that the size of the opening can be changed, perhaps in order to control relative gas pressure in the two compartments 
Table 1 Taxonomic placement of butterflyfishes, morphology of the Laterophysic Connection (LC variants, see Sect. 2.1), and feeding habit of Chaetodon species

\begin{tabular}{|c|c|c|c|c|}
\hline & Species $^{\mathrm{a}}$ & Subgenus ${ }^{\mathrm{b}}$ & LC Var. $^{\mathrm{c}}$ & Feeding habit \\
\hline Clade 1 & C. robustus & & & \\
\hline \multirow[t]{13}{*}{ Clade 2} & C. tinkeri & Roaops & Ind3 & \\
\hline & C. argentatus & Exornator & $?$ & Omnivore $^{\mathrm{d}}$ \\
\hline & C. fremblii & Exornator & Ind2 & Omnivore $^{\mathrm{d}}$ \\
\hline & C. blackburnii & Exornator & $?$ & \\
\hline & C. citrinellus & Exornator & Ind2 & $\begin{array}{l}\text { Corallivore } \\
\text { Omnivore }^{\mathrm{d}}\end{array}$ \\
\hline & C. quadrimaculatus & Exornator & Ind2 & $\begin{array}{l}\text { Corallivore } \\
\text { Omnivore }^{\mathrm{d}}\end{array}$ \\
\hline & C. miliaris & Exornator & Ind2 & Planktivore $^{\mathrm{d}}$ \\
\hline & C. santaehelenae & Exornator & $?$ & \\
\hline & C. sedentarius & Exornator & Ind2 & \\
\hline & C. multicinctus & Exornator & Ind2 & Corallivore $^{e}$ \\
\hline & C. interruptus & Lepidochaetdon & $?$ & Corallivore $^{\mathrm{e}}$ \\
\hline & C. unimacualtus & Lepidochaetodon & Ind1 & Corallivore $^{e}$ \\
\hline & C. kleinii & Lepidochaetodon & Ind1 & Planktivore $^{\mathrm{d}}$ \\
\hline \multirow[t]{13}{*}{ Clade 3} & C. aureofasciatus & Discochaetodon & Dir1 & Corallivore $^{\mathrm{e}}$ \\
\hline & C. rainfordi & Discochaetodon & Dir1 & Corallivore $^{e}$ \\
\hline & Parach-aetodon ocellatus & Megaprototon $^{\mathrm{f}}$ & $?$ & \\
\hline & C. baronessa & Gonochaetodon & Dir1 & Corallivore $^{\mathrm{e}}$ \\
\hline & C. bennetti & Tetrachaetodon & Dir2 & Corallivore $^{\mathrm{e}}$ \\
\hline & C. plebeius & Tetrachaetodon & Dir2 & Corallivore $^{\mathrm{e}}$ \\
\hline & C. tricinctus & Discochaetodon & $?$ & Corallivore $^{\mathrm{d}}$ \\
\hline & C trifascialis & Megachaetodon & Dir2 & Corallivore \\
\hline & C. lunulatus & Corallochaetodon & $?$ & Corallivore $^{\mathrm{e}}$ \\
\hline & C. trifasciatus & Corallochaetodon & Ind2 & Corallivore $^{\mathrm{e}}$ \\
\hline & C. meyeri & Citharoedus & Ind4 & Corallivore ${ }^{\mathrm{e}}$ \\
\hline & C. ornatissimus & Citharoedus & Ind3 & Corallivore $^{\mathrm{e}}$ \\
\hline & C. reticulatus & Citharoedus & $?$ & Corallivore $^{e}$ \\
\hline \multirow[t]{12}{*}{ Clade 4} & C. auriga & Rhabdophorus & Dir1 & Omnivore $^{\mathrm{d}}$ \\
\hline & C. auripes & Rhabdophorus & $?$ & Corallivore $^{\mathrm{d}}$ \\
\hline & C. collare & Rhabdophorus & $?$ & Corallivore $^{\mathrm{d}}$ \\
\hline & C. lunula & Rhabdophorus & $?$ & Omnivore $^{\mathrm{d}}$ \\
\hline & C.lineolatus & Rhabdophorus & $?$ & Omnivore $^{\mathrm{d}}$ \\
\hline & C. ulietensis & Rhabdophorus & $?$ & Omnivore $^{\mathrm{d}}$ \\
\hline & C. ephippium & Rhabdophorus & Dir1 & Omnivore $^{\mathrm{d}}$ \\
\hline & C. capistratus & Chaetodon & $?$ & Corallivore $^{\mathrm{d}}$ \\
\hline & C. striatus & - & Dir1 & \begin{tabular}{|l|} 
Corallivore $^{\mathrm{d}}$ \\
Omnivore $^{\mathrm{d}}$
\end{tabular} \\
\hline & C. humeralis & Chaetodon & $?$ & Omnivore $^{\mathrm{d}}$ \\
\hline & C. ocellatus & Chaetodon & Ind2 & \\
\hline & C. melannotus & Rhabdophorus & - & Corallivore $^{f}$ \\
\hline
\end{tabular}

aPlacement of species in Chaetodon clades (1-4) is based on Bellwood et al. (2010)

${ }^{b}$ Subgeneric placement is from Smith et al. (2003)

${ }^{c} \mathrm{LC}$ type and variant is from Webb et al. (2006)

${ }^{\mathrm{d}}$ From Hourigan (1989) - in Hawaiian waters

${ }^{\mathrm{e}}$ Corallivore $=$ obligate corallivore, from Bellwood et al. (2010)

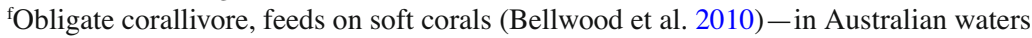

?LC variant not determined histologically, but LC type (Direct, Indirect) can be inferred from swim bladder morphology or subgeneric placement (Webb et al. 2006) 
(Woods 2006; Woods et al. 2006; Webb et al. 2006). The swim bladder is bounded dorsally by the vertebral column, laterally by the ribs, and ventrally by the peritoneum that lines the abdominal cavity. This configuration limits the overall shape and volume of the swim bladder as indicated by the obvious indentations in the volume of air created by the ribs (Webb et al. 2006; Fig. 1c). Neither extrinsic nor intrinsic sonic muscles are found in association with the swim bladder, so the swim bladder likely functions as a sound resonator, which is stimulated by the physical motion of other adjacent sound production mechanisms (Sect. 3 below).

Variation in the morphology of the swim bladder may have implications for both bioacoustic reception and sound production. The gross morphology of the swim bladder varies among Chaetodon species (such variation within a genus is unusual and thus notable), and is correlated with LC type (Direct, Indirect; with a few minor exceptions; Webb 1998; Webb and Smith 2000; Smith et al. 2003; Fig. 4). Chaetodon species with a Direct LC (e.g., C. auriga, C. octofasciatus) have a swim bladder with a distinct "kink" in its long axis, such that the anterior half of the swim bladder and swim bladder horns is relatively horizontal, whereas the posterior half of the swim bladder is more vertical in orientation. The thick tunica externa is composed of multiple layers of collagen and is somewhat thicker dorsally than it is ventrally (Woods 2006). The ventral surface of the swim bladder is covered by a thin peritoneum (lining of the abdominal cavity) that wraps tightly around the swim bladder's posterior end (a "free" swim bladder; Smith et al. 2003). The thickness of the lateral wall of the swim bladder horns decreases quite dramatically near the medial opening in the supracleithrum (Woods 2006), which may allow pressure-induced movement of the tissue covering the opening resulting in movements of fluids in the canal. Sound production by Chaetodon species with a direct LC is so far quantified only in $C$. auriga (very low frequency pulse sounds; Sect. 3). In addition, the enhanced auditory sensitivity of $C$. auriga appears to depend more on the swim bladder horns rather than on the body of the swim bladder (Sect. 4).

In contrast, Chaetodon species with an Indirect LC (e.g., C. multicinctus, $C$. unimaculatus, C. kleinii, C. ornatissimus), and species in non-Chaetodon genera (Forcipiger, Heniochus and Hemitaurichthys) have a swim bladder that is more smoothly contoured (lacking a "kink"). The tunica externa in these species is much thinner overall (and translucent) when compared to that in species with a direct LC. It is thinner dorsally than it is ventrally, but its thickness does not vary along the length of the swim bladder or along the horns as in species with a Direct LC (Woods 2006). In contrast to species with Direct LC, a thick, opaque peritoneum covers the ventral surface of the swim bladder and attaches laterally to the ribs (an "attached" swim bladder; Smith et al. 2003; Webb et al. 2006). In several Chaetodon species with an indirect LC, as well as several non-Chaetodon species, sound production includes both low and high frequency pulsed sounds with a stronger contribution of the body of the swim bladder for auditory sensitivity (see Sects. 3 and 4 below).

The swim bladder of teleost fishes is also quite important for the control of buoyancy, which makes the study of its adaptive evolution rather complex. The euphysoclistic swim bladder of chaetodontids (and other "advanced" teleosts) regulates its air volume physiologically (by active secretion and passive resorption of gases). 
Chaetodon species are known to sometimes make quick excursions along reef walls from 2 to $8 \mathrm{~m}$ in only $5-15 \mathrm{~s}$ during which they experience rapid pressure changes close to $1 \mathrm{~atm}$ (Tricas, unpublished observations). The ability to precisely control gas pressure in the swim bladder would also enable fishes to consistently and accurately monitor sounds produced by mates, conspecifics, and competitors (see Sect. 3 ). The fine control of buoyancy may also facilitate precise maneuvers made with paired fins during paired swimming and interactions, which is when sounds are produced (Sect. 3). Finally, swim bladder shape and the presence of anterior swim bladder horns may alter the center of gravity or center of buoyancy in Chaetodon. This may help to control posture, especially when feeding on benthic invertebrate prey (Woods 2006), an ability also suggested in other fishes (Parmentier et al. 2011). Thus, the evolution of swim bladder morphology is likely the result of responses to a range of selective pressures involved with sound production, hearing, locomotion, and/or feeding behavior.

\subsection{The Ear and Its Proximity to the Swim Bladder}

Prior to the discovery of the LC, the structure and function of swim bladder horns defining the otophysic connection was explored to some extent in holocentrid fishes, which provide a useful context for interpreting the LC in Chaetodon. The holocentrid, Myripristis kuntee, has robust anterior swim bladder horns that make contact with a thinned otic capsule wall, and a saccular macula (sensory epithelium) that is modified in shape relative to that in Sargocentron (another holocentrid) and in other percormorph fishes that lack an otophysic connection (Nelson 1955; Popper 1977; Fig. 5b). Myripristis also has higher sensitivity to sound stimuli over a broader frequency range, when compared to Sargocentron (Coombs and Popper 1979; Fig. 5a). In his analysis of the ears of Hawaiian fishes, Popper (1977) described the sensory epithelium of the sacculus and lagena in one chaetodontid, C. miliaris, and found that it was similar to that in other teleosts that lack an otophysic connection. However, we now know that $C$. miliaris has an indirect LC (see Sect. 2.1) and is not representative of all chaetodotid species. Thus, Webb et al. (2010) examined ear morphology in Chaetodon species with different LC types and in Forcipiger flavissimus in light of the hypothesized acoustic functions of the LC and the known correlation of swim bladder and LC morphology among Chaetodon species (Sect. 2.2). Ear morphology was found to be similar in all chaetodontid species examined. The otic capsule sits ventral to the hindbrain, the left and right ears share a common wall in the midline of the otic capsule (Figs. 1a and 2c), and the shape of the sensory maculae of the lagenar, saccular, and utricular otolithic organs was similar in Chaetodon and Forcipiger, and in other perciform fishes that lack swim bladder horns or an otophysic connection (discussed in Webb et al. 2010). Thus, swim bladder morphology in butterflyfishes is in direct contrast to that in holocentrids, which demonstrates a correlation between the presence of swim bladder horns, modified 


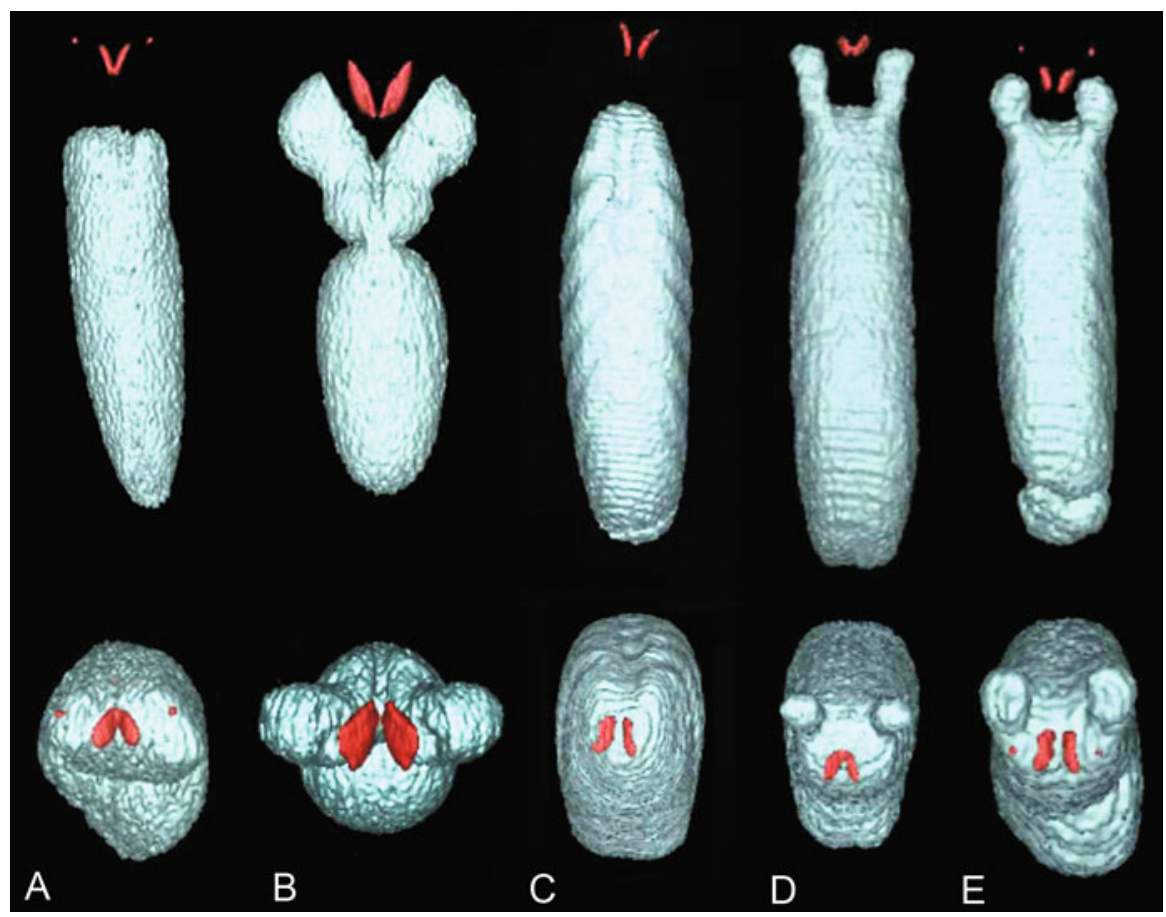

Fig. 5 3-D reconstruction of CT data illustrating the relationship of otoliths (red) to the volume of air within the swim bladder (white; swim bladder diameter $=\sim 1 \mathrm{~cm}$ ) in dorsal (top) and frontal (bottom) views of two species of holocentrids $(\mathbf{a}, \mathbf{b})$ and three species of chaetodontids (c-e). (a) Sargocentron sp. (Holocentridae: Holocentrinae)-no swim bladder horns, (b) Myripristis sp. (Holocentridae: Myripristinae)-swim bladder horns extend rostrally and wrap around the otic capsules containing the very large saccular otoliths, (c) Forcipiger flavissimus, (d) Chaetodon auriga, (e) Chaetodon multicinctus. In the two species of Chaetodon (d, e) the air-filled cylindrical horns extend rostrally, but are dorsal and lateral to the otic capsules that contain the otoliths. The large otoliths are the saccular otoliths and the smaller otoliths [visible in a, e] are the utricular otoliths. (From Webb et al. 2010, reprinted with permission of John Wiley \& Sons)

otic capsule, and modified ear morphology (and enhanced hearing capabilities). It is apparent in Chaetodon, that the LC evolved and diversified among species without apparent morphological modification of the ear or otic capsule (Webb et al. 2010).

In adult Chaetodon, the swim bladder horns extend rostrally and approach the ear to within 1-2 mm (Webb et al. 2010; Fig. 5). In species with a direct LC (e.g., C. auriga; Fig. 5d) the swim bladder horns sit further from the otic capsule (and closer to the laterally placed supracleithral bones) than the swim bladder horns in species with an indirect LC (e.g., C. multicinctus; Fig. 5e). The anterior end of the swim bladder of Forcipiger (which has no horns or LC) sits at approximately the same distance from the ear as do the horns of Chaetodon species with a direct LC (Webb et al. 2010; Fig. 5c). This close juxtaposition of the volume of gas in the 
swim bladder or swim bladder horns to the ear is now known to enhance the hearing sensitivity and frequency range during social communication in adult Chaetodon species (see Sect. 4.2). In the tholichthys larvae of $C$. ocellatus the distance between the swim bladder and the ear increases to about $1.2 \mathrm{~mm}$ as fish grow. This distance does not increase after transformation to the juvenile stage (with continuing increases in fish size) as the long swim bladder horns increase in length with no significant change in hearing sensitivity (Webb et al. 2012) suggesting that the distance between the air within the horns and the ear is of functional importance even in early life history stages.

\subsection{Evolution of the Laterophysic Connection in Chaetodon}

Blum (1988) determined that the medial opening in the supracleithrum is a synapomorphy that defines the genus Chaetodon. Webb (1998) then defined the LC as an association of swim bladder horns with the medial opening in the supracleithrum. Webb et al. (2006) defined two Direct LC variants (Fig. 4a, b) and four Indirect LC variants (Fig. 4c-f) among Chaetodon species. Smith et al. (2003) mapped LC characters on a new hypothesis of phylogenetic relationships based on morphological characters and suggested that Chaetodon ancestor had a Direct LC. This was surprising given the correlation of swim bladder morphology with LC type among Chaetodon species and because Chaetodon species with an Indirect LC have a swim bladder that is quite similar to those non-Chaetodon genera in lack an LC (e.g., Forcipiger, Hemitaurichthys; Fig. 5).

More recent phylogenetic analyses (using molecular evidence) identified four Chaetodon clades (Fessler and Westneat 2007; Bellwood et al. 2010). A Direct LC is found in Clades 3 and 4, but an Indirect LC is found in Clades 2, 3, and 4. Data are not available for any species in Clade 1 (Table 1). In contrast to the mapping of LC type in Smith et al. (2003), a mapping of LC variants on a molecular phylogeny (Fessler and Westneat 2007), in which Clade 2 is considered to be the sister group to Clades $3+4$, suggests that an Indirect LC is the ancestral LC type in Chaetodon. Unfortunately, the mapping of LC variants on a more recent molecular phylogeny (Bellwood et al. 2010) sheds no light on the identity of the ancestral LC condition because it shows Clades 2, 3, and 4 as an unresolved trichotomy. Regardless, the occurrence of one LC variant in each of the Chaetodon subgenera, which are intact within the four clades, substantiates the value of the subgenera as taxonomic units that presumably evolved in response to different selective pressures associated with LC structure, and presumably function. The distribution of LC variants among subgenera reveals that most of the variants evolved at least two times within the genus Chaetodon (Table 1).

It was hypothesized that ecological correlates (e.g., feeding habit) might shed light on the functional significance of the evolution of LC morphology (Webb and Smith 2000). However, of the 15 Chaetodon species now known to be obligate corallivores that are monogamous and territorial (Table 1), seven have a Direct LC and 
eight have an Indirect LC (Webb et al. 2006). Thus, LC type is not correlated with corallivory, which is thought to be a major ecological factor in the evolution of Chaetodon species. The drivers of the evolutionary diversification of the LC have yet to be identified, but it has been shown experimentally that the presence of long swim bladder horns enhances auditory capabilities (threshold, frequency range) in Chaetodon species regardless of other defining features of LC variation (Sect. 3).

\section{Diversity and Evolution of Sound Production in Butterflyfishes}

The discovery of the LC in Chaetodon led to the hypothesis that these highly social fishes produce sounds for acoustic communication during social interactions. Subsequent field and laboratory investigations on several species show that sound production is used by Chaetodon and representatives of other genera during their social interactions.

\subsection{Acoustic Behavior and Sound Production Mechanisms}

Sound production is now known for eight Chaetodon species and for all of the species of Forcipiger, Heniochus, and Hemitaurichthys studied so far. The names for most acoustic behaviors (and sound types) are derived from the most prominent observable motor pattern that occurs during the sound production event (Table 2). Lab and field studies show that as a group, these fishes produce a large repertoire of pulsed sounds and pulse trains that are generated by: (1) multiple sound production mechanisms associated with subtle movements of various body parts (e.g., head bob, jaw protrusion, body motion, buckling of the anterior body wall), and (2) hydrodynamic stimuli generated by movement of the whole body during a stereotyped locomotor tail slap in Chaetodon. Several sound production mechanisms appear to be shared among species studied, which generate sounds across a broad range of frequencies (Table 2).

Kinematic and electromyographic analyses indicate the presence of at least three sound production mechanisms in non-Chaetodon bannerfish species, which produce sounds with peak frequencies of $27-170 \mathrm{~Hz}$ (Table 2). The head bob sound is produced by the two known species of Forcipiger and is associated with a rapid and prominent vertical motion of the head (Fig. 6). The head bob acoustic behavior is driven by epaxial muscle action on the skull and a ventral linkage between the head and pectoral girdle, which is maintained by simultaneous activity of the adductor mandibulae and sternohyoideus muscles (Boyle and Tricas 2011). This results in the anterior motion of the pectoral girdle, ribs, and rostral swim bladder before the head is released and rotated dorsally (and also contributes to apparent passive motions of 


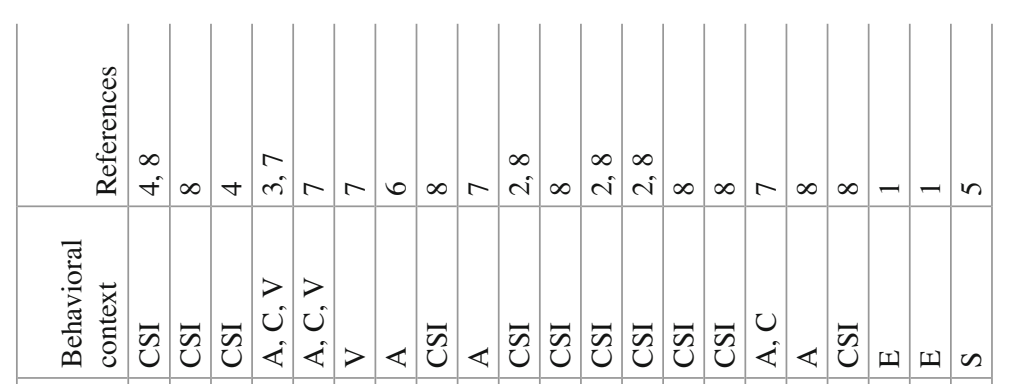

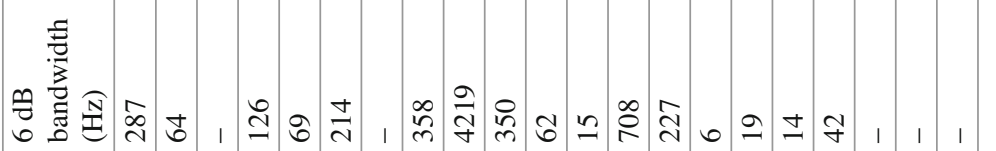

م.

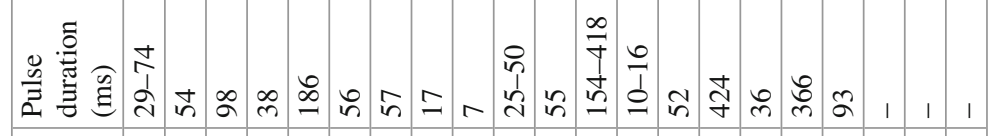

$\stackrel{\circ}{0}$

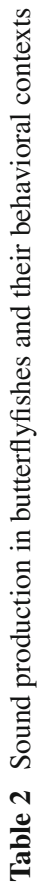

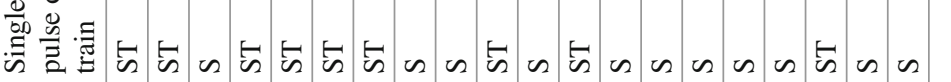

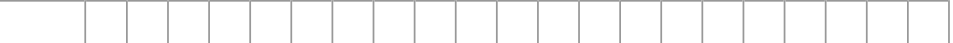

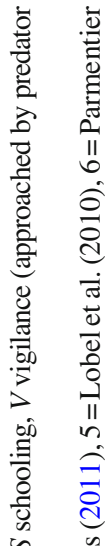

(

|

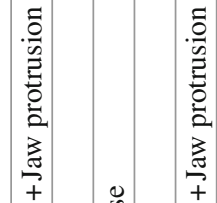

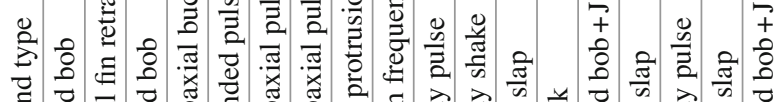

苛芯

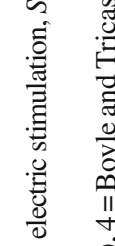

ฉి

焉

苛

苟

氙 命

亟

o 0

के ट्टे

造 它

$\frac{\frac{\pi}{\pi}}{\mathrm{U}}$

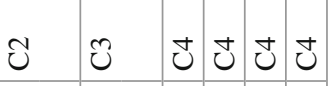

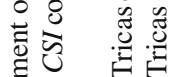

बु. 에 II

늘 $\stackrel{2}{2}$

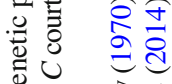

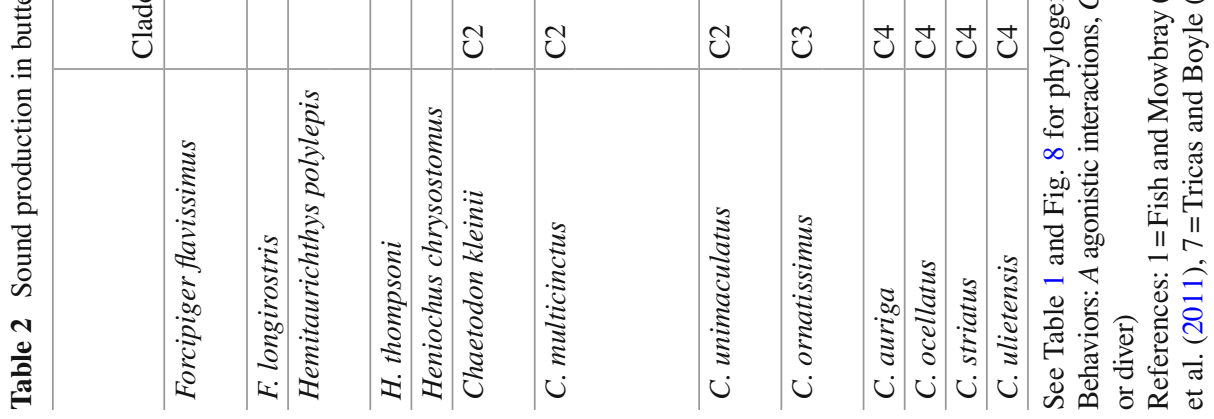


the jaws). These motions stimulate the adjacent swim bladder to produce a pulsed sound with peak frequency in the range of 100-200 Hz (Boyle and Tricas 2011; Boyle et al. 2013; Tricas and Boyle 2014, 2015a). The anal fin retract sound is also produced by $F$. flavissimus and has a much lower peak frequency $(27 \mathrm{~Hz}$ ) (Fig. 6; Tricas and Boyle 2015a). These two acoustic behaviors in Forcipiger are not yet reported for the other bannerfish genera studied so far.

In contrast, the bannerfishes Hemitaurichthys polylepis and H. thompsoni produce loud pulse sounds that do not involve a head bob motion, but instead produce sounds that are associated with a buckling of the anterior body wall caused by contraction of the hypaxial musculature lateral to the anterior portion of the swim bladder (Boyle and Tricas 2010; Tricas and Boyle 2014). This mechanism is similar to that demonstrated in Heniochus chrysostomus, which likely involves the contraction of the lateral subdivision of the hypaxial musculature (Parmentier et al. 2011). Thus the head bob sound in Forcipiger is produced by the action of the epaxial, adductor mandibula and sternohyoideus muscles, and their musculoskeletal linkages. The anal-fin spine-retraction sound is produced by the action of the anal fin erector and retractor muscles and their associated linkages. The pulsed sounds of Heniochus and Hemitaurichthys are driven primarily by the action of the hypaxial musculature.

Several acoustic behaviors of Chaetodon (including some for which the sound production mechanisms are not yet confirmed) clearly vary among species and clades, and span a wider range of frequencies than those produced by the bannerfishes (Table 2; Tricas and Boyle 2015a). A prominent head bob behavior that is similar to that seen in Forcipiger occurs in both $C$. unimaculatus (Clade 2) and $C$. auriga (Clade 4), but also includes a prominent and active protrusion of the jaws (Fig. 6). In comparison, pulsed sounds produced by the blacklip butterflyfish, $C$. kleinii, (Clade 2) involves jaw protrusion without a prominent head bob motion. The possibility that the jaw motion found among Clade 2 species causes the relatively high average peak frequency pulsed sounds (e.g., C. kleinii $=516 \mathrm{~Hz}$, C. unimaculatus $=1031 \mathrm{~Hz}$ ) needs to be tested and examined in more species. In addition, the causal factors for the head-bob jaw-protrusion sound in $C$. auriga and its lower peak frequency $(23 \mathrm{~Hz})$ need to be resolved. Furthermore, the common sound produced by $C$. multicinctus (also in Clade 2) does not involve a visible head bob or jaw protrusion, but instead is a body motion pulse sound (average peak frequency $=137 \mathrm{~Hz}$ ) similar to that described for Hemitaurichthys and Heniochus. Additional detailed electromyographic studies are needed to confirm or reject the presence of similar internal kinematic patterns (see Tricas and Boyle 2015a). A similar body motion acoustic behavior occurs in $C$. ornatissimus (Clade 3 ), but that pulsed sound has a much lower peak frequency $(10 \mathrm{~Hz})$. Collectively, the head bob, jaw protrusion, and body motion sounds produced by Chaetodon species studied thus far span a greater frequency range than sounds produced by members of other butterflyfish genera, and involve several sound production mechanisms.

Several species of Chaetodon also produce a very low frequency hydrodynamic stimulus known as the tail slap, which has peak frequencies that range from $<1$ to $69 \mathrm{~Hz}$ and a significant component in the infrasound $(<20 \mathrm{~Hz})$ range (sensu Sand 


$$
<30 \mathrm{~Hz}
$$

a Forcipiger flavissimus

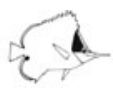

b C. kleinii<smiles>C1=CCCCCC1</smiles>

C C. unimaculatus

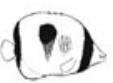

C. multicinctus

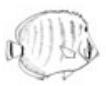

C. ornatissimus

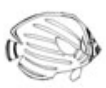

f C. auriga

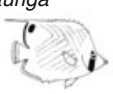

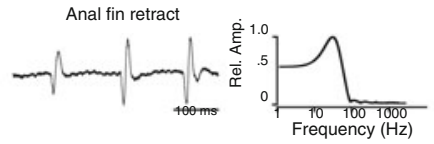

$>100 \mathrm{~Hz}$
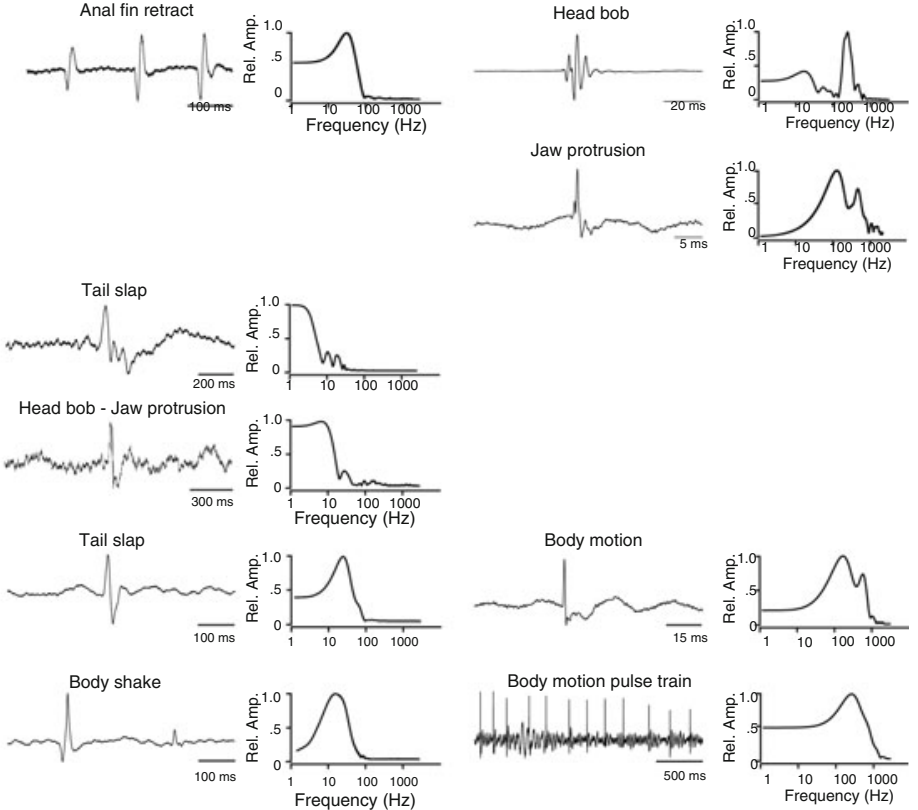
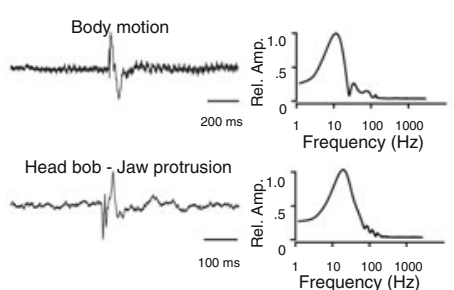

Fig. 6 Representative waveforms and spectra of sounds produced by five species of Chaetodon and by Forcipiger flavissimus during social interactions with conspecifics. Sounds are categorized as those with peak frequencies near infrasound $(<30 \mathrm{~Hz})$ and with peak frequencies $>100 \mathrm{~Hz}$. (a) F. flavissimus produced a low frequency pulse sound associated with erection of the anal fin and a higher frequency pulse sound associated with the head bob-jaw protrusion behavior. (b) C. kleinii produced a short pulse sound during protrusion of the jaw with average peak frequency near $500 \mathrm{~Hz}$. (c) C. unimaculatus produced pulse sounds with peak frequency $<10 \mathrm{~Hz}$ during slap behavior or protrusion of the jaw. (d) $C$. multicinctus produced low frequency pulse sounds from 10 to $30 \mathrm{~Hz}$ during tail slap and body shake acoustic behaviors. Single and trains of pulses were produced during the body motion sound and had a higher average peak frequency of $137 \mathrm{~Hz}$. (e) C. ornatissimus produced low frequency pulse sounds near $10 \mathrm{~Hz}$ during both tail slap and body motion acoustic behaviors. (f) C. auriga produced the head bob-jaw protrusion sound which had a low average peak frequency near $20 \mathrm{~Hz}$. Fast Fourier transforms of sound waveforms show relative amplitude (Rel. Amp.) of example peak frequencies. From Tricas and Boyle (2015a) 
and Karlsen 2000). This sound is generated by a tail slap locomotor behavior during agonistic interactions with conspecifics (Fig. 6; Tricas et al. 2006; Tricas and Boyle 2015a). The tail slap is a stereotyped motion of the body that follows other aggressive movements, such as a rapid approach or intense lateral display, which is described in detail by Dewan and Tricas (2011). Swift movements of the lateral body surface and tail creates a hydrodynamic acceleration that may produce complex vortices that impinge on the lateral body surface of the receiver fish (Hanke et al. 2008), and at high intensities can displace a receiver's body (Tricas et al. 2006). Whole body acceleration directly stimulates the ear of the receiver, but the associated sound pressure wave is thought to produce only relatively small displacements of the wall of the swim bladder and swim bladder horns relative to hydrodynamic motions from the source at frequencies $<10 \mathrm{~Hz}$, as modeled in the cod swim bladder (Sand and Hawkins 1973). The tail slap behavior is most commonly observed in paired, monogamous, and territorial species such as $C$. multicinctus and $C$. ornatissimus, which aggressively defend food resources and mates. The tail slap behavior is not commonly observed in planktivorous species such as C. miliaris or C. kleinii, and is not yet described for other butterflyfish genera. These differences in aggressive behavior and the production of the tail slap sound among butterflyfish species are also associated with differential expression of arginine vasotocin neuropeptide by neurons that project to the forebrain (Dewan et al. 2008, 2011; Dewan and Tricas 2011, 2014). Further neuroanatomical and physiological investigations are required to determine the proximate mechanisms responsible for the central neural control of aggressive acoustic behaviors in butterflyfishes.

\subsection{The Broad Palette of Butterflyfish Sound Characteristics}

The acoustic stimuli produced by Chaetodon species during social interactions span a frequency range of at least four decades $(<1$ to $>1000 \mathrm{~Hz})$. Extreme low frequency sounds with an average peak frequency of $<10 \mathrm{~Hz}$ and long duration (400 ms) are associated with the tail slap behavior in $C$. ornatissimus, $C$. multicinctus, and $C$. unimaculatus (Tricas and Boyle 2015a), and this sound is also produced by $C$. auriga in the field but is not yet quantified (Tricas and Boyle unpublished observations). Other low frequency pulse sounds in the $\sim 10-30 \mathrm{~Hz}$ range are produced by C. multicinctus, C. ornatissimus, C. auriga, and Forcipiger via different mechanisms. Sounds with higher peak frequencies of $100-1000 \mathrm{~Hz}$ are also readily produced during social interactions in the lab by $C$. kleinii, C. unimaculatus, C. multicinctus, and Forcipiger. These have pulse durations of $\leq 50 \mathrm{~ms}$ and are similar with respect to frequency and bandwidth characteristics. There is also great variation in the frequency range of sounds produced by different species (Tricas and Boyle 2014, 2015a). For example, each Chaetodon species (with the exception of C. kleinii) produces at least one sound type with a peak frequency of $1-30 \mathrm{~Hz}$ and another sound type at $10-100 \mathrm{~Hz}$. Sounds with peak frequency in the $10-100 \mathrm{~Hz}$ band can include several sound types, and the 6 or $10 \mathrm{~dB}$ bandwidth of these sounds often 
extends to higher frequencies. These comparisons show that the sound characteristics of a single species may span a wide range of frequencies and are not made by a single sound production mechanism or behavior. Thus the acoustic repertoire for some species covers a wide range of frequencies as the result of the production of several sound types (as in $C$. unimaculatus and $C$. multicinctus), whereas the number and frequency range of sounds produced by other species may be more limited.

\subsection{Evolution of Sound Production in Butterflyfishes}

The evolutionary interpretations of the diversity of acoustic behaviors and sound production mechanisms in butterflyfishes are in the very early phases of analysis, but some patterns are beginning to emerge. Characters defined by acoustic behaviors that are mapped onto a molecular phylogeny of butterflyfishes shows that the head bob and body motion behaviors may be shared among some members of the bannerfish and Chaetodon clades, whereas the tail slap acoustic behavior may be a character only of Chaetodon (Fig. 7, Tricas and Boyle 2015a). The prominent head bob acoustic behavior in Forcipiger, which is driven by several muscles and a ventral linkage between the head and pectoral girdle (see Sect. 3.1), is not yet known in Hemitaurichthys or Heniochus (see Sect. 3.1). The head bob behavior in C. unimaculatus (Clade 2) and C. auriga (Clade 4) includes a prominent and active protrusion of the jaws, whereas $C$. kleinii (Clade 2) only demonstrates the prominent jaw protrusion and not the head bob. The apparent variation in the occurrence of the head bob and associated jaw actions among Chaeotodon species leaves the question of the ancestral character state of the head bob behavior open to interpretation (Fig. 8a). The head bob behavior is apparently lacking in both C. multicinctus (also Clade 2) and in C. ornatissimus (Clade 3). In addition, preliminary EMG experiments on C. multicinctus demonstrate activity of the ventral portion of the anterior epaxial muscles lateral to the anterior swim bladder horns during the production of the body motion sound (Boyle and Tricas, unpublished data). This muscle activity pattern appears to be most similar to that observed for the nearby region of the hypaxial muscles in both Hemitaurichthys (Boyle and Tricas 2010) and Heniochus (Parmentier et al. 2011). Further kinematic, anatomical, and electromyographic analyses are needed to test the hypotheses that the head bob sound is a shared trait nested deep within the butterflyfish phylogeny, that it was lost at least once in the bannerfishes and twice in Chaetodon, or that it has evolved in parallel in these groups.

In contrast to the head bob behavior, the most distinctive acoustic behavior in Chaetodon is the tail slap, which is not yet reported in the bannerfishes. Statistical models that use currently available data to reconstruct the ancestral character states for the tail slap behavior show that this character may have existed in the ancestors of the Chaetodon clade (Tricas and Boyle 2015a). However, the existence of the tail slap behavior in the common ancestor of both the bannerfishes and Chaetodon can- 


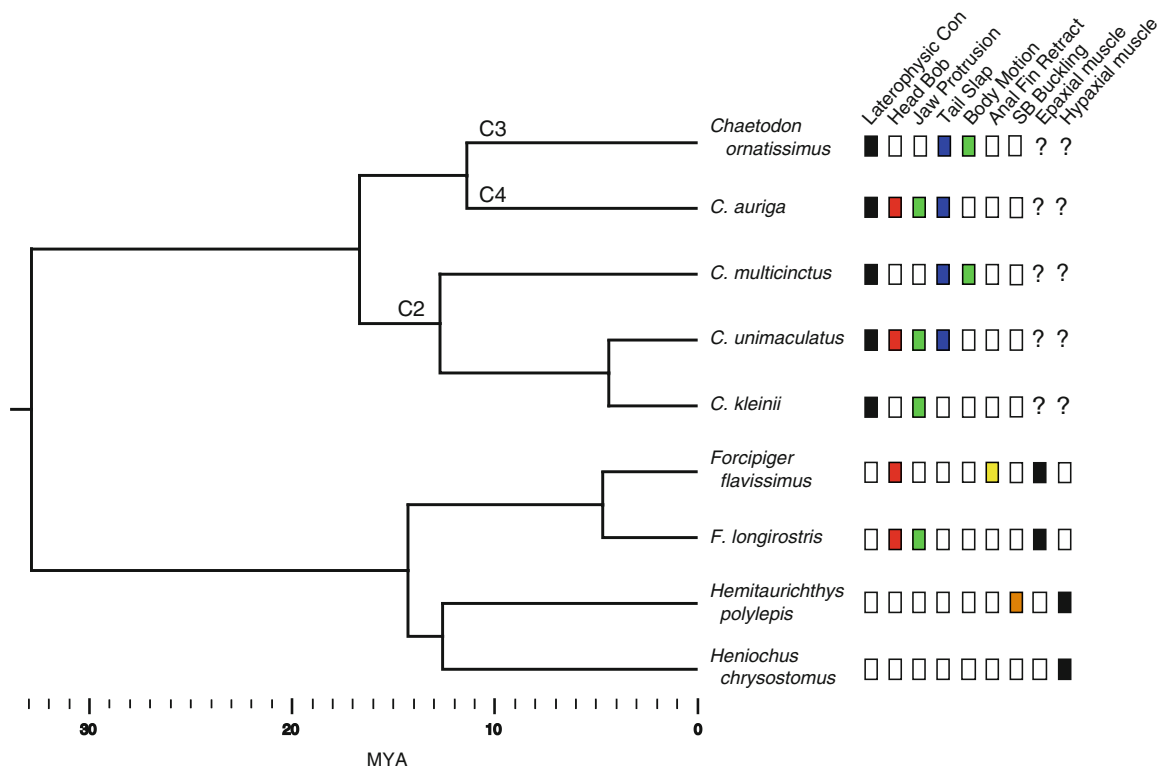

Fig. 7 Character states associated with sound production for nine species in the two major butterflyfish clades. In the bannerfish clade (bottom), the head bob sound is known so far only for Forcipiger and involves epaxial muscle activity. In contrast, sound production by Heniochus and Hemitaurichthys does not include the head bob motion and involves the hypaxial muscles. A pronounced head bob sound occurs in Chaetodon species (top), including clade 4, not clade 3, and was variable among species in clade 2 . Note the frequent but not consistent linkage between the head bob and jaw protrusion movements. Of note, the tail slap behavior is found only in Chaetodon and is represented in clades $2-4$. The box matrix below the sound character traits indicate the presence (filled) or lack (open) for each species. ? verification of muscle activity remains to be tested, $C$ clade, Con Connection, MYA million years ago. Supplemental data from other sources are included for the laterophysic connection (Smith et al. 2003), Forcipiger (Boyle and Tricas 2011), Hemitaurichthys (Boyle and Tricas 2010), and Heniochus (Parmentier 2011). The phylogeny and clock estimates were taken from Bellwood et al. (2010). From Tricas and Boyle (2015a)

not be predicted without data from more species (Fig. 8b). This points to the need for studies on Prognathodes (the sister genus to Chaetodon), coralfishes (Amphichaetodon, Coradion, Chemonops, and Chelmon), and chaetodontid outgroups such as the pomacanthids (angelfishes) and ephippids (spadefishes).

\section{The Butterflyfish Ear and Lateral Line in the Reception of Acoustic Stimuli}

The discovery and characterization of natural sounds produced by chaetodontids make it possible to form and test hypotheses about how these stimuli are encoded by the ear and/or lateral line, and to evaluate the effect of the swim bladder horns on 
a

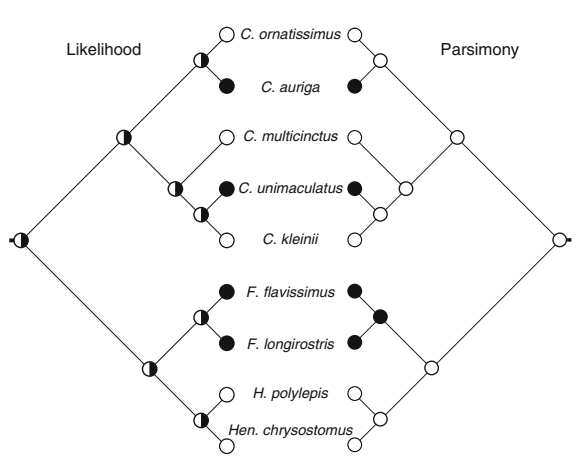

b

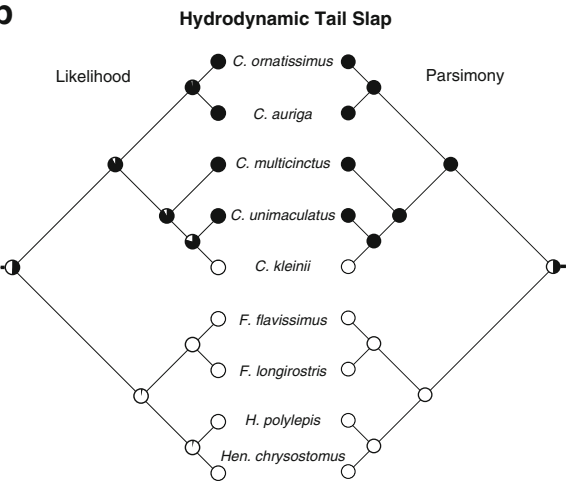

Fig. 8 Ancestral state reconstruction of two acoustic behaviors used during social interactions in butterflyfishes. (a) The head bob acoustic behavior occurs in both Chaetodon and Forcipiger with an equivocal likelihood for it as the ancestral state (left), and the possible independent evolution among clades in the parsimony model (right). (b) The tail slap behavior is so far observed during social interactions only by Chaetodon species and produces a very low frequency acoustic stimulus that is directed towards the receiver fish. It is not yet documented in the bannerfish clade and both the likelihood (left) and parsimony (right) models are equivocal on the presence of this trait in the common ancestor. The darkened portion of the circles indicates the probability that the trait is present at each node. C Chaetodon, F. Forcipiger, H. Hemitaurichthys, Hen. Heniochus. From Tricas and Boyle (2015a)

hearing sensitivity in Chaetodon species. Butterflyfishes are diurnally active in the clear waters of coral reefs and exhibit numerous forms of complex social and mating behaviors that include monogamous pairing, haremic mating systems, solitary behavior, and aggregation or schooling (Reese 1975; Hourigan 1989; Yabuta and Berumen 2014). A recent field study shows that while visual signals are used for recognition of conspecifics and other behaviors in these colorful fishes (see Sect. 1), chemical cues are also required for the discrimination of mates from non-mates (Boyle and Tricas 2014). In this section, we first review the basic features of underwater acoustic fields and how they are likely encoded by the fish auditory and lateral line systems. We then interpret in more detail how the butterflyfish ear and lateral line systems likely encode their biologically relevant acoustic signals that they produce during social interactions.

\subsection{The Acoustic Field: Hydrodynamic Particle Motion and Sound Pressure Stimuli}

The acoustic field of an underwater sound includes a hydrodynamic flow component in close proximity to the source that can accelerate the body of a nearby receiver and directly stimulate the inner ear (Kalmijn 1988; Braun and Grande 2008). During the 
production of sounds such as the tail slap, head bob or body pulse in Chaetodon, and the head bob or anal fin pulse in Forcipiger (see Sect. 3), a local hydrodynamic flow is generated by the displacement of the adjacent water mass. Directional motions of the body produce a polar hydrodynamic flow field that could generate a whole body acceleration of a nearby fish and thus stimulate its ear depending on the amplitude, direction, and distance of the acoustic source. At very short distances of a few body lengths, the hydrodynamic flow also produces a pressure gradient across the surface of the receiver fish that may stimulate the lateral line system to provide additional information about stimulus direction and intensity (Schellart and Popper 1992; Hawkins 1993; Webb 1998; Braun and Coombs 2010). At greater distances, sound pressure waves penetrate the body of a receiving fish and may set into motion the walls of the gas-filled swim bladder and swim bladder horns of Chaeotodon, which secondarily induce local particle motions in the ear (Fletcher and Crawford 2001; Schellart and Popper 1992; Tricas and Boyle 2015b) and presumably in the lateral line canals in the vicinity of the LC (Webb et al. 2006).

\subsection{Stimulation of the Ear in Chaetodon and the Effect of the Swim Bladder Horns}

Several lines of evidence from data obtained in the laboratory by the auditory evoked potential (AEP) technique (which estimates hearing sensitivity thresholds to short tone stimuli) indicate that all butterflyfishes species tested to date are sensitive to the hydrodynamic flow component (particle acceleration) of an acoustic field, and that the auditory sensitivity of Chaetodon is enhanced by coincident sound pressure stimuli that are mediated by the gas-filled swim bladder horns (Tricas and Boyle 2015b). Sensitivity to hydrodynamic particle acceleration is indicated for Forcipiger (which lacks swim bladder horns) by higher stimulus thresholds at all frequencies compared to that for all tested Chaetodon species, and these curves converge at the lowest stimulus frequency of $100 \mathrm{~Hz}$ (Fig. 9). The best frequency sensitivity of Forcipiger to particle acceleration was at the lowest test frequency of $100 \mathrm{~Hz}$ (Fig. 9b), which is predicted for particle acceleration sensitive species (see Ladich and Fay 2013 for discussion). None of the hearing thresholds for Forcipiger increased (or changed) following deflation of its gas-filled swim bladder, which would be required for the transduction of sound pressure stimuli to stimulate the ear (Fig. 10a). A relatively low absolute sensitivity to sound pressure for all butterflyfishes is indicated by their apparently much higher AEP thresholds compared to species with anatomical specializations for reception of sound pressure stimuli such as the Weberian apparatus (Kenyon et al. 1998; Ladich 1999; Amoser and Ladich 2005; Lechner and Ladich 2008), anterior swim bladder horns and otic bullae, or a suprabranchial organ (Ladich and Yan 1998). Further, the lowest particle acceleration threshold levels in this low frequency band for butterflyfishes ranged from 
about $70-85 \mathrm{~dB}$ re: $1 \mu \mathrm{m} \mathrm{s}^{-2}$ (Fig. 9b), which is similar to that reported for a marine damselfish (Chromis) and goby (Gobius) that lack auditory specializations for sound pressure sensitivity (Wysocki et al. 2009).

Comparison of butterflyfish audiograms also shows evidence for sensitivity to sound pressure and the resultant enhanced hearing capabilities in Chaetodon. The maximum response frequency of $1000 \mathrm{~Hz}$ for some $F$. flavissimus (which lacks swim bladder horns) is considerably less than the $1700-2000 \mathrm{~Hz}$ maximum observed for Chaetodon species (which have swim bladder horns and an LC, Fig. 9). An extended upper frequency range of hearing is common for pressure sensitive fishes (see Ladich and Fay 2013). Recent comparative AEP experiments on cichlid genera show that species with anterior swim bladder horns have improved auditory sensitivities of 20-40 dB (SPLs) at frequencies of 0.5 to $1 \mathrm{kHz}$ (Schulz-Mirbach et al. 2012), which is higher than the improvement in hearing sensitivity for Chaetodon (10-15 dB) compared to Forcipger. In addition, the frequency of lowest hearing thresholds (best frequency) in species sensitive to sound pressure is predicted to be greater than $100-200 \mathrm{~Hz}$ (Ladich and Fay 2013) and this is best seen at $600 \mathrm{~Hz}$ for C. multicinctus (Figs. 9 and 10c). Experimental displacement of gas from the swim bladder horns (by the injection of gel) in both C. multicinctus (LC variant Ind1) and C. auriga (LC variant Dir1) decreased auditory sensitivity (increased thresholds) in the low pass $200-600 \mathrm{~Hz}$ frequency range and variably among species at higher frequencies (Fig. 10c, d). Removal of gas from the swim bladder horns and body in Chaetodon species increases their hearing thresholds much closer to that of Foripiger (Fig. 10b-d). Combined, these findings support the hypothesis that all butterflyfishes are primarily sensitive to hydrodynamic particle acceleration and that hearing sensitivity and frequency range are enhanced by the transduction of sound pressure stimuli mediated by the swim bladder horns in Chaetodon species with either Direct or Indirect LC's.

Enhanced frequency sensitivity in Chaetodon may facilitate acoustic communication. The frequency band of best sensitivity to sound pressure stimuli at $200-600 \mathrm{~Hz}$ overlaps the frequency spectrum of the body motion pulse in $C$. multicinctus and $C$. ornatissiumus, the head bob-jaw protrusion pulse of $C$. unimaculatus, and the jaw protrusion pulse sound of C. kleinii (Fig. 6, Table 2, Tricas and Boyle 2015b). This match provides evidence that the swim bladder horns can enhance the perception of biologically relevant acoustic signals used in social interactions. However, enhanced

Fig. 9 (continued)measured as total sound pressure level (SPL) are similar among Chaetodon species with lower thresholds and an extended response range to $1700 \mathrm{~Hz}$ for all species and to $2000 \mathrm{~Hz}$ for C. ornatissimus. (b) Thresholds measured as particle acceleration level (PAL) show similar curve shapes to SPL audiograms. The accelerometer was not calibrated at $2000 \mathrm{~Hz}$, thus that data point is lacking for $C$. ornatissimus. $N=$ sample size of fish tested at each frequency. Fractions indicate the proportion of tested fish that showed a response. Audiograms are means and SE for thresholds for all fish tested at a given frequency in that study in order to increase sample size, increase frequency resolution and to reduce variation for overlaying of the comparative audiogram plots. From Tricas and Boyle (2015b) 


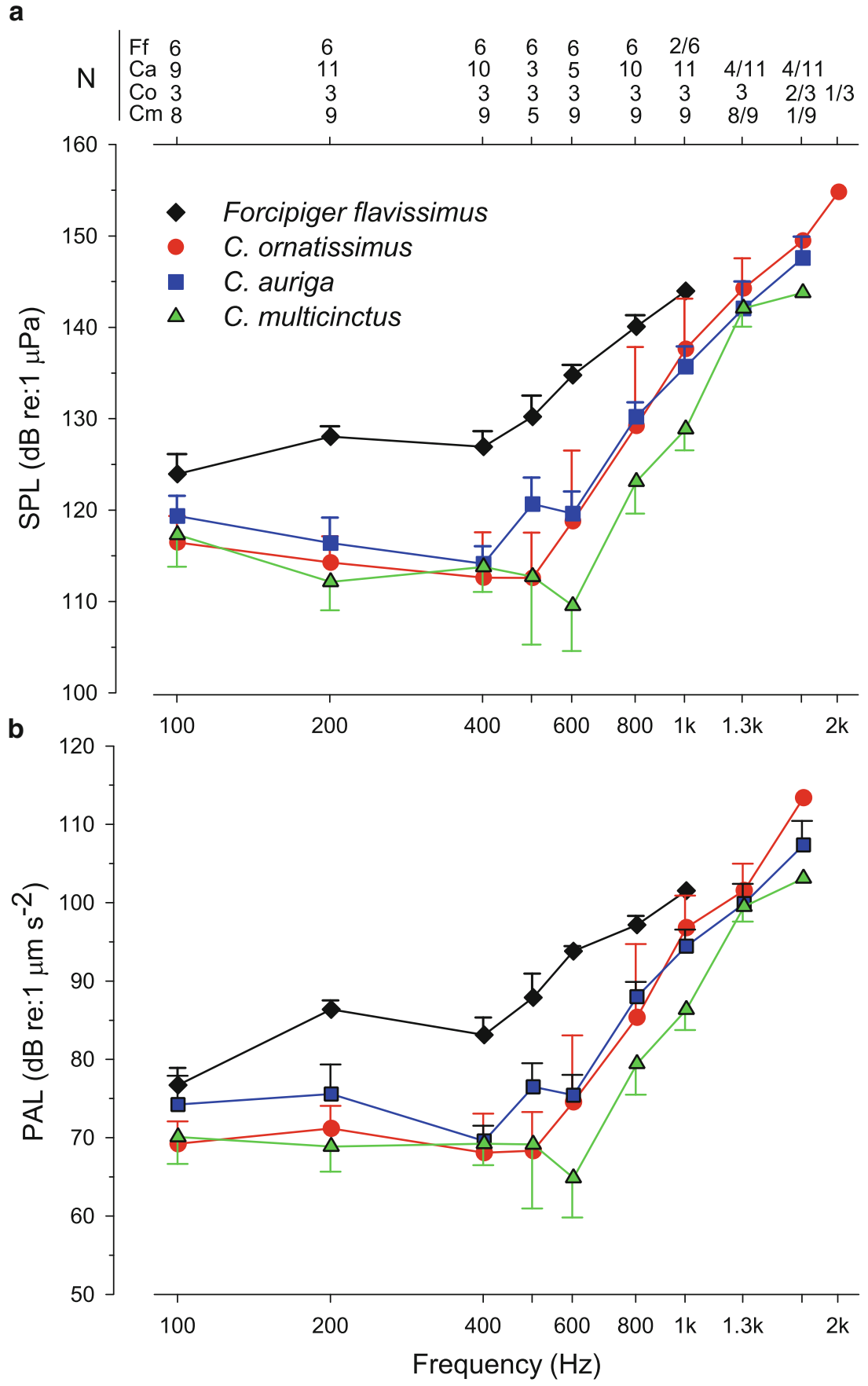

Fig. 9 Comparative hearing threshold audiograms for adult Forcipiger flavissimus and three Chaetodon species as measured by the auditory evoked potential technique. (a) Hearing thresholds 

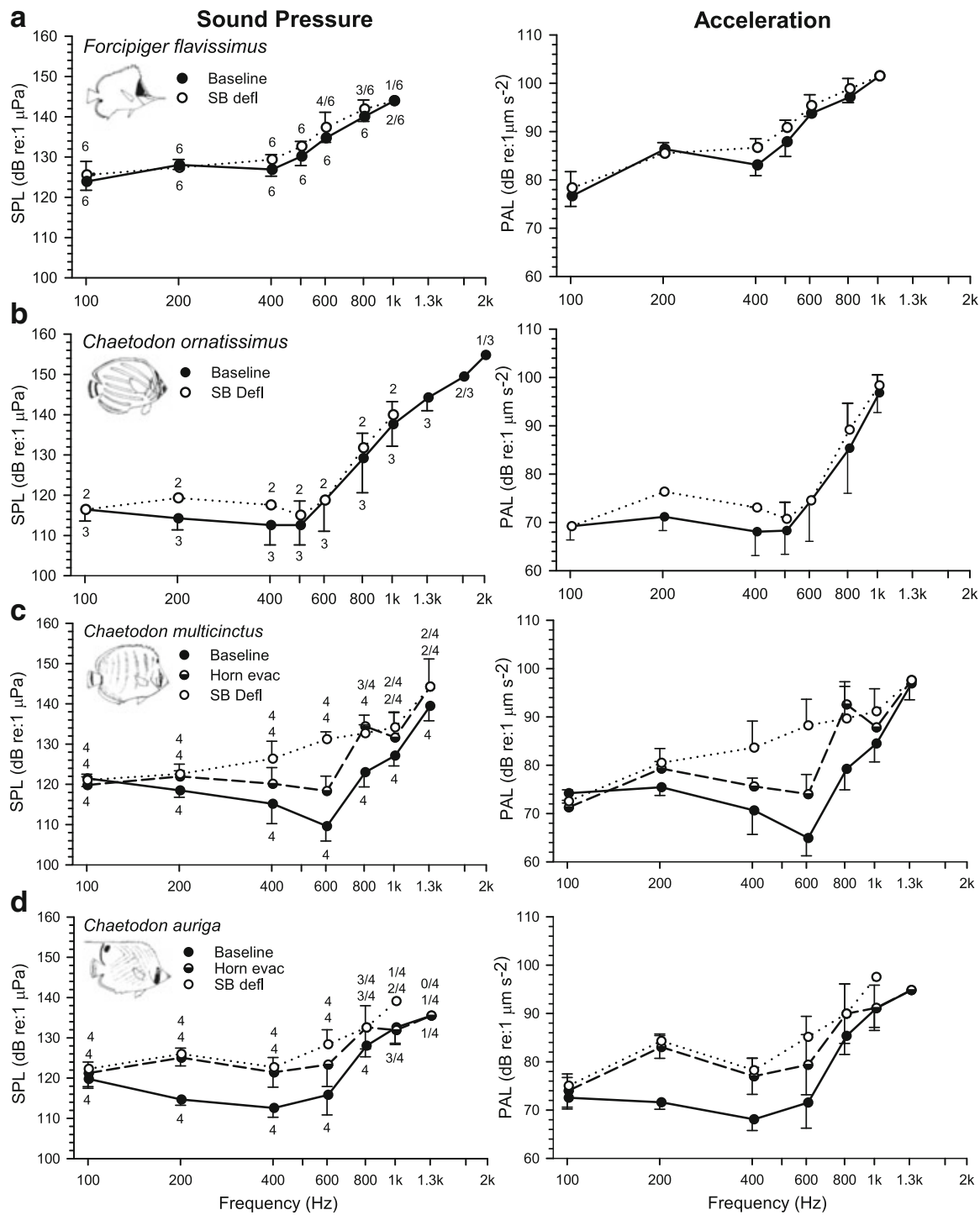

Fig. 10 The effect of the gas-filled swim bladder horns and chamber on hearing sensitivity in Chaetodon with different LC morphologies as determined by the auditory evoked potential (AEP) technique. (a) Forcipiger flavissimus, which lacks an LC and swim bladder horns (see Fig. 5c) shows little change in normal AEP threshold (solid circles) following deflation of the swim bladder (open circles). (b) C. ornatissimus has short swim bladder horns with an indirect connection to the LC (see Fig. 4c) that we were not able to manipulate. The baseline thresholds extended to $2000 \mathrm{~Hz}$ and appear to increase by approximately $5 \mathrm{~dB}$ in the $200-400 \mathrm{~Hz}$ band following deflation of the swim bladder. (c) C. multicinctus has long swim bladder horns with an indirect connection to the LC (see Fig. 5e). Baseline thresholds increased in the $200-600 \mathrm{~Hz}$ band after gas was evacuated from the swim bladder horns (half-filled circles) with a maximum increase of $10 \mathrm{~dB}$ at $600 \mathrm{~Hz}$. 
hearing sensitivity in $C$. auriga does not match the lower frequency band of the only sound (head-bob jaw-protrusion) recorded to date for this species in the laboratory. It is possible that higher frequency sounds are produced in the field by $C$. auriga as observed in C. ornatissimus (Tricas and Boyle 2014). In addition, a biological function, if any, for the extended frequency range of hearing (up to $2 \mathrm{kHz}$ ) for some Chaetodon sound types remains to be demonstrated. In addition, the $200-300 \mathrm{~Hz}$ band of best sensitivity in late larval and juvenile spotfin butterflyfish, C. ocellatus (Webb et al. 2012), is also well below the upper $1-3 \mathrm{kHz}$ range reported for species highly sensitive to sound pressure (reviewed by Ladich and Fay 2013), thus the potential use of sound pressure stimuli by larval butterflyfish may be more limited in bandwidth.

Detailed morphological studies of the ear in Forcipiger flavissimus and in several Chaetodon species with different LC variants confirm that there is no intimate association of the swim bladder horns with the otic capsule, or notable modification of the ear (Webb et al. 2010). However, the swim bladder horns of both $C$. auriga and $C$. multicinctus are long and have similar lengths when corrected for body size (Woods 2006). Further, the swim bladder horns of C. multicinctus are closer to the ear $(1 \mathrm{~mm})$ than those in $C$. auriga $(2 \mathrm{~mm})$. The proximity of the horns to the ear and the shape of the swim bladder horns in species with Indirect LC variants may explain the stronger effect of the horns on auditory sensitivity in $C$. multicinctus (and likely other species with Indirect LC variants) than in C. auriga (and other species with Direct LC variants, Woods 2006). Subsequent evacuation of gas from the swim bladder further reduced hearing sensitivity in C. multicinctus, but not in C. auriga (Fig. 10; Tricas and Boyle 2015b). Of particular interest is that the highest frequency sensitivity found among butterflyfishes $(2 \mathrm{kHz})$ was observed in $C$. ornatissimus, a species with short swim bladder horns (LC variant Ind2) that approach the ear to within a distance of about $1 \mathrm{~mm}$ (Woods 2006). Further modeling and experiments are needed to demonstrate the frequency-dependent displacement amplitudes of the swim bladder horns in three axes that are caused by sound pressure stimuli, and to determine their physical contribution to the extended hearing sensitivity and frequency range of Chaetodon.

Fig. 10 (continued) Subsequent deflation of the swim bladder demonstrated further threshold increases most notable at $600 \mathrm{~Hz}$. (d) C. auriga has long swim bladder horns with a direct connection to the LC. Baseline thresholds increased by about $10 \mathrm{~dB}$ at $200-600 \mathrm{~Hz}$ after gas was evacuated from the swim bladder horns and swim bladder. AEP threshold data are provided in relation to sound pressure (left column) and particle acceleration (right column). Data are means and SE among individuals. Numbers at circles indicate sample size at each test frequency, or fraction of test subjects for which an AEP response was recorded. From Tricas and Boyle (2015b) 


\subsection{Stimulation of the Lateral Line System in Chaetodon and the Potential Effect of the Swim Bladder Horns and $L C$}

Body motions that generate sound produce dipole or higher order hydrodynamic flow fields that can be directed towards a receiver fish. Butterflyfishes have a well-developed set of cranial and trunk lateral line canals (and presumably superficial neuromasts on the head and trunk) that can respond to these hydrodynamic stimuli. In addition to stimulating the ear by whole body accelerations (as described above), such hydrodynamic flows generated by body motions produce steep pressure gradients across the skin of the receiver that can stimulate the lateral line system at distances within a few body lengths (Coombs and Montgomery 1999). Weak tail slaps by Chaetodon multicinctus create slow fluid vortices that impinge on the skin of the receiver fish (Hanke et al. 2008) and potentially provide information on the intensity and frequency components of water velocity via superficial neuromasts and acceleration via canal neuromasts (as defined by Kroese and Schellart 1992; Weeg and Bass 2002). The somatotopic organization of these hydrodynamic mechanoreceptors can potentially provide direction and distance information for social stimuli as demonstrated for the detection of stimuli generated by prey (Coombs et al. 1996). During territory border conflicts that occur among pairs in several butterflyfish species (Hourigan 1989; Tricas 1989; Tricas et al. 2006) such lateral-line mediated directional information may be complementary to visual and auditory cues and provide unambiguous directional information, as proposed by Braun et al. (2002) and Coffin et al. (2014). In addition, the mechanosensory lateral line system may also be activated by sound pressure that is transduced by the LC (see Sect. 2.1). Thus, coincident sound pressure information may be received by both the ear and a portion of the lateral line canal system in the vicinity of the LC, while different features of the hydrodynamic flow field are detected by the ear and the greater lateral line system. However, the transduction of sound pressure stimuli to the mechanosensory lateral line via the LC awaits experimental confirmation. Experiments that involve the pharmacological or physical ablation of neuromasts are also needed to determine the relative contribution of the lateral line and auditory systems to the perception of an acoustic field (Higgs and Radford 2013).

\section{The Behavioral Ecology of Acoustic Communication in Butterflyfishes}

Sound production provides important information for social interactions in a wide range of fish species (Myrberg and Lugli 2006, reviewed by Ladich and Myrberg 2006). Honest signals provide accurate information about the condition of the signaler (Fitch and Hauser 2002) and can contribute to a dependable assessment of the quality of an opponent. Evidence is accumulating that the acoustic stimuli generated by butterflyfishes contain reliable information about the size or motivation of the signaler, which may be important for decision-making in social contexts as reported 
for other fishes (Ladich and Fine 2006; Amorim 2006). For instance, the low frequency (9-69 Hz) aggressive tail slap and body pulse (137-184 Hz) sounds produced by $C$. multicinctus during social interactions increase in intensity with body size (Tricas and Boyle 2015a), and a similar relationship between sound intensity and body size was reported for the head bob sound in F. flavissimus (Boyle and Tricas 2011). A preliminary independent contrast analysis of the continuous variables that define sound characteristics (duration, peak frequency, median frequency, bandwidth, and intensity) produced by the tail slap in Chaetodon and other sound types in Forcipiger shows evidence for correlated changes between sound duration and sound pressure intensity (Tricas and Boyle 2015a). This indicates a possible evolutionary trend for the generation of loud and long pulse sounds by butterflyfishes, although data on additional species are needed. Members of both Forcipiger and Chaetodon engage in contests over territories to protect mates and food resources, so signals that convey information on body size may reduce the risk of injury (e.g., lacerations, lost scales, broken spines) that commonly occur during escalated disputes. Reinforcement of information on relative body size conveyed by visual and acoustic signals may also be used to maintain low levels of aggression, as commonly seen among neighbors in stable territories (Hourigan 1989; Tricas 1989; Roberts and Ormond 1992). In $C$. multicinctus, acoustic information that is correlated with body size may also benefit individuals because body size is correlated with the size of a feeding territory (Tricas 1989). Thus, sounds and other sensory cues may be important indicators of resource-holding potential and be factors in the evolution of their social behavior.

In summary, sound production between mates and between conspecific competitors is common in Chaetodon and appears to be widespread among butterflyfishes. Single pulse or pulse train sounds are produced during non-aggressive interactions with mates, initial social interactions with unfamiliar conspecifics, aggressive interactions with competitors and during courtship. Several species produce multiple sound types with a frequency range from infrasound to $>1 \mathrm{kHz}$. Analysis of kinematics correlated with sound production indicates that sound production mechanisms vary substantially among chaetodontid taxa. These sounds are likely to provide useful information about size or quality of the individual and have critical implications for butterflyfish ecology and fitness. Additional kinematic and electromyographic analyses of sound production in other butterflyfish genera (e.g., Amphichaetodon, Coradion and Chelmon) and angelfishes (family Pomacanthidae, a hypothesized sister group to Chaetodontidae) are needed to more completely address the origin and evolutionary diversification of sound production in butterflyfishes.

\section{The Acoustic Soundscape of Coral Reefs and Implications for Butterflyfish Acoustic Communication}

Ambient acoustic noise is common in both freshwater and marine habitats and can decrease the ability to detect biologically relevant sounds especially in taxa that possess anatomical specializations for enhancement of hearing sensitivity and frequency range (see review by Ladich 2013). The coral reef environment is replete 
with acoustic noise from abiotic and biotic sources that spans the frequency range of butterflyfish sounds and their auditory sensitivity.

\subsection{Sources of Ambient Noise}

Low frequency background noise $(<10-100 \mathrm{~Hz})$ originates primarily from abiotic sources such as wind, waves, and tidal streaming (Wenz 1962; Urick 1983). The complex physical structure of a coral reef also contributes to multiple sources, forms and features of acoustic noise within the sub-habitats inhabited by different butterflyfish species. For example, wind-driven ocean swells with surface chop pass over the outer reef where planktivorous butterflyfishes feed in the water column during daylight hours, and where corallivores and other benthic invertebrate feeding butterflyfish species forage in long-term territories and in larger home ranges on the bottom. Onshore swells break onto the shallow outer reef crest and impact the substrate with severe broadband acoustic noise, substrate vibrations, and strong low frequency hydrodynamic turbulence that can affect resident butterflyfish species that inhabit shallower areas of the reef. Wave action and surge then flow over the reef flat into back reef lagoons where other butterflyfish species have long-term home ranges. Thus, ambient noise (from both hydrodynamic and sound pressure sources) is expected to vary considerably among different habitats and will have differential effects on the perception of sounds produced for social communication. In addition, ambient noise at the higher end of the hearing range of butterflyfishes (e.g., 100 to $>1000 \mathrm{~Hz}$ ) is generated by biological sources such as other reef fishes (Cato and McCauley 2002; McCauley and Cato 2000; Tricas and Boyle 2014), snapping shrimp, and other invertebrates (Cato 1978; Lammers et al. 2008). Seasonal ambient sounds generated by migratory marine mammals such as the humpback whale in offshore Hawaiian waters have intense fundamental frequencies (reviewed in $\mathrm{Au}$ and Hastings 2008) that are also in the hearing frequency range of butterflyfishes. Thus both abiotic and biotic sources of ambient noise are expected to vary across time in intensity and spectra among different habitats on a coral reef, and to have potential effects on butterflyfish acoustic communication.

\subsection{Ambient Noise, Sound Production and Hearing in Butterflyfish Territories}

Acoustic recordings on Hawaiian reefs show that the intensity of ambient noise near the substrate on the outer reef overlaps in the frequency domain with sounds used for communication by butterflyfishes (Tricas and Boyle 2015b). Field measurements of average ambient noise levels during an afternoon with modest onshore winds were 10-15 dB higher in shallow water territories of $C$. multicinctus (at $<6 \mathrm{~m}$ 
deep) compared to those in deeper waters (Fig. 11). This difference in total noise with depth was most notable at frequencies of $10-500 \mathrm{~Hz}$, which overlaps with the low frequency spectra of representative tail slap, body shake, and body pulse sounds produced by $C$. multicinctus, as well as with several low frequency sounds produced by other species (e.g., C. ornatissimus and F. flavissimus) that live on the same reef (see Fig. 5). Calculated sound pressure levels in the frequency band of the tail slap sound decrease with depth whereas ambient noise in the higher frequency band of the body pulse sound did not (Fig. 12a). Subsequent estimation of the signal to noise ratio (SNR) of each sound band at different territory sites showed an increase in SNR with increased territory depth for the tail slap sound, but not for the body

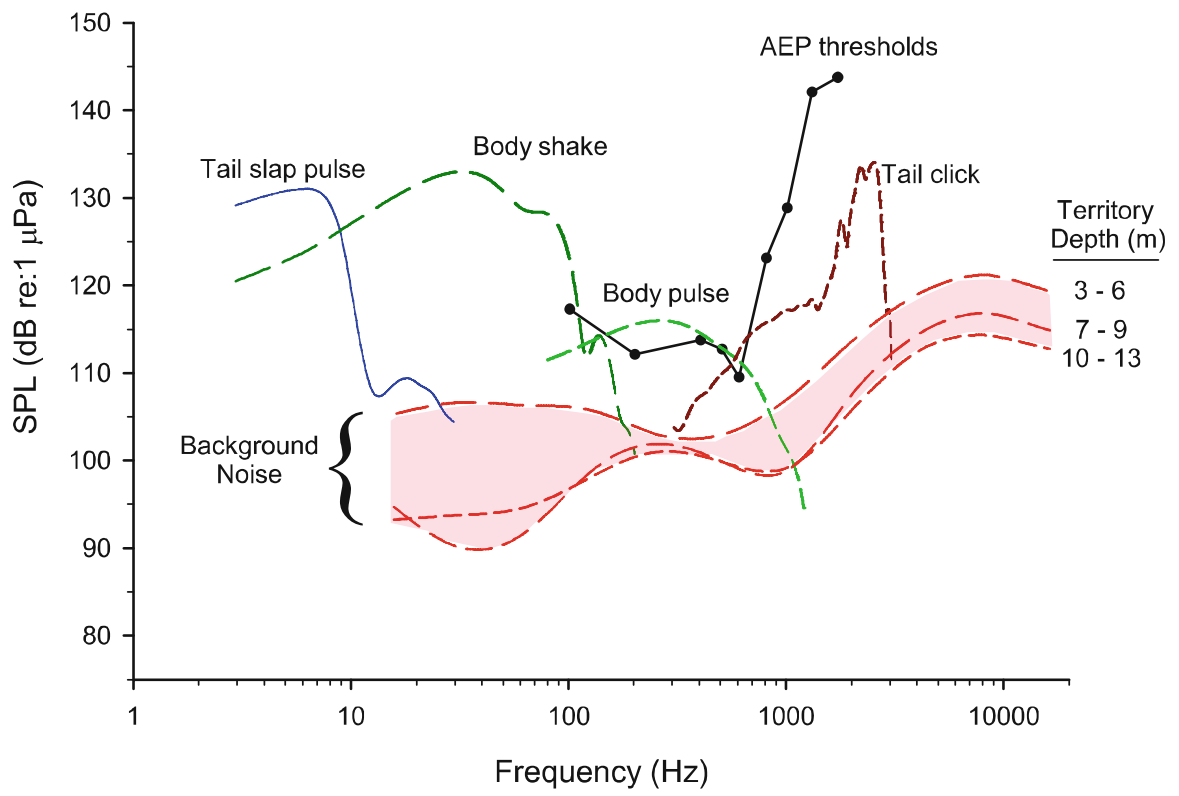

Fig. 11 Hearing thresholds, four representative vocalization intensities and the ambient background noise environment for acoustic social communication by Chaetodon multicinctus, in coral reef territories at Puako Reef, Hawai'i. Fish AEP thresholds to tone stimuli from 100 to $2000 \mathrm{~Hz}$ were determined in the lab and show a low pass sensitivity below $600 \mathrm{~Hz}$ (black solid dots). Curves for the power spectrum of four representative sounds (tail slap, body shake, body pulse, and tail click) were determined by fast Fourier transforms of sound waveforms. The low frequency band of best hearing sensitivity is nearest to the band of the body pulse sound used commonly in close social interactions (light green dashed curve). The infrasound tail slap (solid blue line curve) and body shake (dark green dashed curve) pulses are produced during agonistic interactions and have peak frequencies $<100 \mathrm{~Hz}$, but sensitivity to these low frequency stimuli remain to be experimentally determined. The high frequency tail click sound (dark red dashed curve) is likely beyond their hearing capabilities. The range of average ambient background octave noise band (red shaded area) is shown for 11 territories at depths from 2.5 to $12.8 \mathrm{~m}$ and illustrate the general higher background noise levels that occur within territories in shallow habitats $\leq 6 \mathrm{~m}$ deep. The background noise levels in the band $<20 \mathrm{~Hz}$ remain to be characterized for most coral reef environments. From Tricas and Boyle (2015b) 


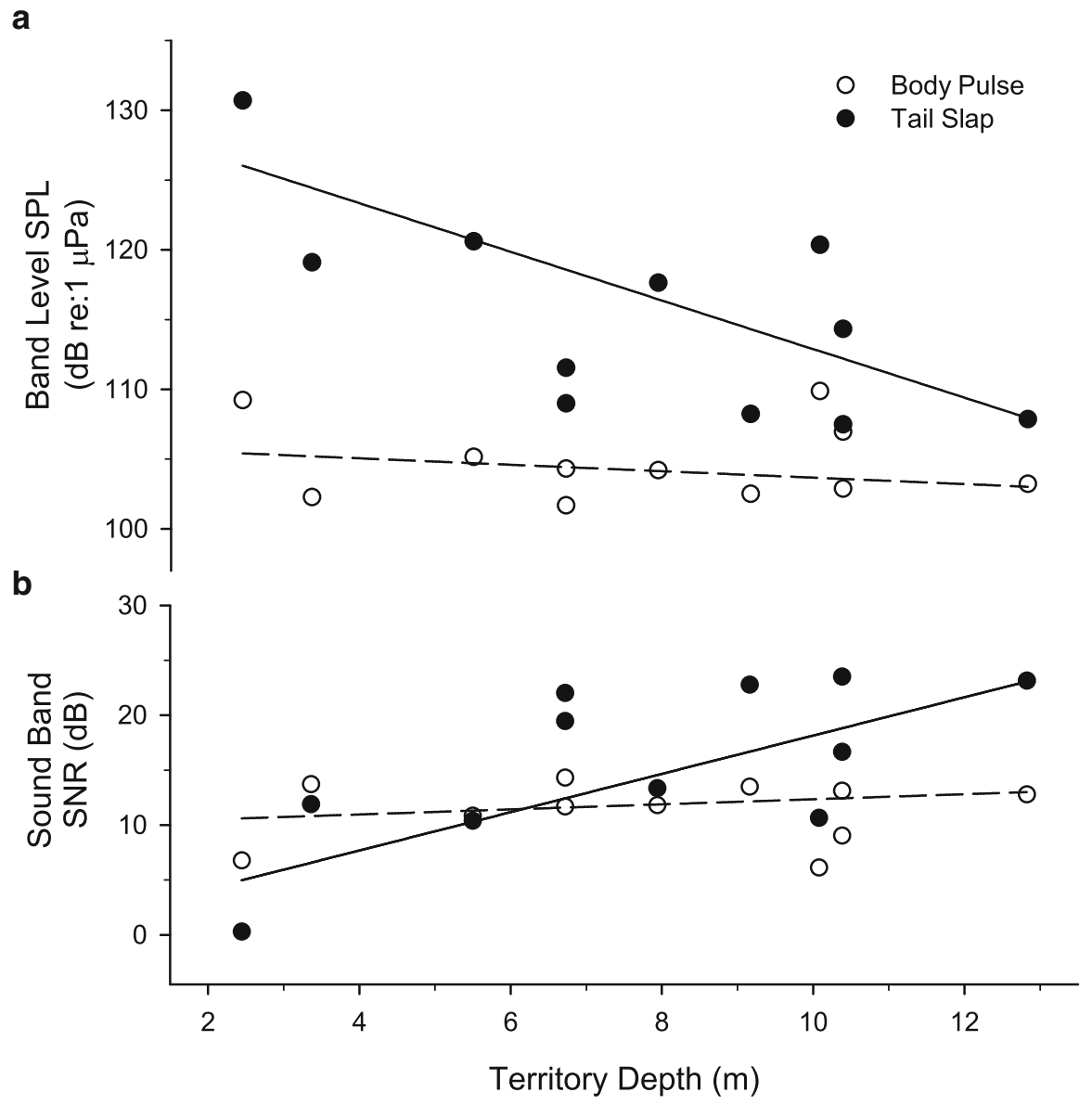

Fig. 12 The potential impact of sound-band-specific ambient noise on the transmission of communication sounds in coral reef territories of Chaetodon multicinctus, at Puako Reef, Hawai'i. (a) Background noise band level sound pressure within the predominate frequency range (top $6 \mathrm{~dB}$ of the power spectrum) of the body pulse $(21-414 \mathrm{~Hz})$ and tail slap sounds $(2-18 \mathrm{~Hz})$ indicate that the background noise levels change with territory depth for the tail slap but not for the body pulse sound. (b) Signal-to-noise ratio of signal sound amplitudes near the source to ambient noise levels for the frequency bands of the body pulse and tail slap sounds at different territory depths. Perception of the tail slap but not the body pulse sound should improve at deeper territory locations. From Tricas and Boyle (2015b)

motion sound (Fig. 12b). These estimations indicate that the tail slap sound, which is used in agonistic interactions with conspecifics, may be a more effective communication signal in deeper territories. Deeper areas of a reef may provide higher quality food (coral) resources and a quieter environment (with lower swell and wave action) that would benefit acoustic communication used in defense of food resources. It remains to be demonstrated how the distances required for effective acoustic communication among conspecifics may be affected by ambient noise, and whether any 
masking effects occur given their apparent low absolute hearing sensitivity (see Sect. 3). Nonetheless, effective acoustic communication is degraded at large distances in a noisy reef environment and the signal to noise ratio is enhanced at the short distances of separation found among individuals of most butterflyfish species (Tricas and Boyle 2015b).

This analysis is founded on the interpretation of acoustic communication within the butterflyfish's natural habitat. However, more studies of sensory ecology are needed in which local ambient noise levels and frequency spectra are considered across different time scales (diel, lunar, season, annual), among sub-habitats, and with respect to natural acoustic signals and hearing capabilities of butterflyfishes in order to determine the nature of the constraints on acoustic communication. For example, higher signal-to-noise ratios at lower frequencies of $<1-100 \mathrm{~Hz}$ are expected to occur on leeward reefs, which normally experience low wind velocity and wave conditions when compared to windward reefs, which are subject to stronger and continuous trade winds. Furthermore, recordings of ambient noise levels made on reefs (e.g., Simpson et al. 2005; Radford et al. 2014; Tricas and Boyle 2015 b) have not yet distinguished between the hydrodynamic (surge/water turbulence) and sound pressure components of ambient sounds, which will also differ, respectively, with habitat and depth. In addition, distinct spectral and intensity signatures are found in different coastal habitats, and it is suggested that these may provide important navigational cues for larval reef fishes (Kennedy et al. 2010; Radford et al. 2014). However, it should be noted that the swim bladder horns of $C$. ocellatus, which impart sound pressure sensitivity in adult Chaetodon, do not develop until larvae have already moved into potential settlement areas. Thus, they do not likely play a role in interpreting acoustic stimuil that may be inolved in finding suitable settlement sites (Webb et al. 2012).

\section{Conclusions and Future Work}

The study of the ecology and social behavior of butterflyfishes has provided an exciting context for the discovery and interpretation of auditory anatomy, auditory physiology, and the evolution of sound production and sensory systems. Some important questions that should guide future research are detailed below.

1. Sound production and hearing, in addition to vision and chemoreception, are important in the complex social behavior of butterflyfishes. The head bob acoustic behavior appears to be a shared character of several species in the bannerfish and Chaetodon clades, whereas the tail slap acoustic behavior appears to be a derived character in Chaetodon. The occurrence of sound production and sound communication in butterflyfish genera other than Chaetodon indicates that these capabilities evolved in the family prior to the evolutionary origin of Chaetodon and the LC, which is a defining character of that genus. Furthermore, the evolution of swim bladder horns and the laterophysic connection (LC) in Chaetodon was not 
accompanied by modification of the ear or otic capsule. Thus, the evolution of acoustic anatomy, physiology, and behavior has a complex and interesting history that deserves more study. Future studies on sound production in other chaetodontid genera and outgroups are needed to better understand the evolution of butterflyfish acoustic behaviors.

2. The sounds produced by butterflyfishes are diverse in form, frequency and with respect to their correlated kinematic (motor) patterns. This indicates that a variety of sound production mechanisms are present that are open for more investigation. In addition, the production of very low frequency sounds $(<1-30 \mathrm{~Hz})$ requires that the role and reception of "infrasound" for social communication be further considered in butterflyfishes and other fish taxa.

3. All butterflyfishes are sensitive to the hydrodynamic flow component of an acoustic field. In Chaetodon, the swim bladder horns also respond to sound pressure stimuli that enhances their auditory sensitivity from 100 to $600 \mathrm{~Hz}$ and extends their absolute hearing range up to $2 \mathrm{kHz}$. Studies on sound pressure sensitivity are needed on more species to define the potential roles of LC types and variants in the enhancement of hearing.

4. The physical motion of the wall of the swim bladder horns at the medial opening of the supracleithrum (which defines the LC) and the resultant activation of adjacent canal neuromasts (hypothesized by Webb 1998; Webb et al. 2006) remain to be determined.

5. The importance of the swim bladder horns in affecting auditory sensitivity and frequency range in Chaetodon begs the question of what other groups of fishes, and coral reef fishes in particular, may have evolved adaptations for the enhancement of auditory capabilities in noisy reef habitats.

6. The coral reef environment is replete with abiotic and biotic noise that overlaps with the spectrum of butterflyfish sounds and their auditory sensitivity. The close affiliative social behaviors demonstrated by most butterflyfishes facilitate acoustic communication in these noisy coral reef environments and indicate that the non-visual sensory environment may influence the evolution of behavior in these fishes.

7. Studies are needed to determine the amplitude of sound pressure and hydrodynamic stimuli in the many sub-habitats of the coral reef, which are occupied by different butterflyfish species, in order to better understand the constraints on acoustic communication imposed by the soundscape.

8. The relative contributions of the ear and lateral line in the detection of different components of hydrodynamic and acoustic stimuli generated at close range (especially at low frequencies, $<1-100 \mathrm{~Hz}$ ) need to be determined. In addition, neuroanatomical and neurophysiological analyses of the central neural pathways that integrate diverse auditory (direct or via the swim bladder) and lateral line (direct or via the laterophysic connection) inputs will likely to provide novel insights into the function of these complementary acoustic modalities.

Acknowledgments The authors would like to thank Drs. Arthur Popper and Richard Fay for intellectual inspiration, scientific and editorial advice and collaboration, for their mentorship, and in their roles as luminaries in the field of fish bioacoustics. Art Popper told JFW, then a young 
graduate student, to run with her lateral line project (it was initially a "side project"), which she did. He followed this up with a generous invitation to visit his lab to do extensive SEM work, which formed the basis for a chapter of her $\mathrm{PhD}$ dissertation, and inspiration for lateral line studies over the next several decades. JFW was asked by Art Popper and Dick Fay to co-organize a key conference on fish bioacoustics (2001), which was a great experience. They shared their invaluable editorial expertise in the course of preparing the co-edited 2008 SHAR volume on Fish Bioacoustics - their wisdom, collegiality, and mentorship will be long remembered. JFW thanks former graduate students Dr. W. Leo Smith, J. Luke Herman, and Christopher Woods (whose unpublished MS Thesis is cited herein), undergraduates Ryan Walsh, Nicole Cicchino, and Natasha Kelly, and Drs. Brandon Casper, Darlene Ketten, and David Mann for their contributions to our work on butterflyfishes.

TCT thanks Art Popper for giving him his first job as a doctoral student building wire-wrap amplifier circuits for hearing experiments at the Univeristy of Hawai'i, and also for sparking his interest to understand how and why fish hear in their natural environments. TCT thanks Dick Fay for his inspiration and friendship during his early days of neurobiology investigations at Washington University in St. Louis and Woods Hole. TCT also thanks his former undergraduate students Jon Dale and Emily Donham, and graduate students Kelly Boyle, Adam Dewan and Karen Maruska for their many hours together investigating the adaptive functions of hearing and sound production in coral reef fishes; and he thanks JFW, Whitlow Au, Marc Lammers, Joe Sisneros, David Mann, and John Allen III for many lively discussions on fish acoustic behaviors and hearing.

Research in the Webb Lab was supported by a HHMI grant to Villanova University (for support of undergraduates) and NSF grants IBN-9603896 and IBN-0132607. Research in the Tricas Lab was supported by NSF grant IBN-0137883; NOAA's Undersea Research Program and Coral Reef Conservation Program, and the Hawai'i Undersea Research Laboratory under NOAA award NA05OAR4301108.

\section{References}

Amorim MCP (2006) Diversity of sound production in fish. In: Ladich F, Collin SP, Moller P, Kapoor BG (eds) Communication in fishes, vol I. Science Publishers, Enfield, pp 71-104

Amoser S, Ladich F (2005) Are hearing sensitivities of freshwater fish adapted to the ambient noise in their habitats? J Exp Biol 208:3533-3542

Au WWL, Hastings MC (2008) Principles of marine bioacoustics. Springer, New York

Bellwood DR, Klanten S, Cowman PF, Pratchett MS, Konow S, Van Herwerden L (2010) Evolutionary history of the butterflyfishes (f: Chaetodontidae) and the rise of coral feeding fishes. J Evol Biol 23:335-349

Blum SD (1988) Osteology and phylogeny of the Chaetodontidae (Pisces: Perciformes). Dissertation, University of Hawaii at Manoa, $356 \mathrm{p}$

Boyle KS, Tricas TC (2010) Pulse sound generation, anterior swim bladder buckling, and associated muscle activity in the pyramid butterflyfish, Hemitaurichthys polylepis. J Exp Biol 213:3881-3893

Boyle KS, Tricas TC (2011) Sound production in the longnose butterflyfishes (genus Forcipiger): cranial kinematics, muscle activity and honest signals. J Exp Biol 214:3829-3842

Boyle KS, Tricas TC (2014) Discrimination of mates and intruders: visual and olfactory cues for a monogamous territorial coral reef butterflyfish. Anim Behav 92:33-43

Boyle KS, Dewan AK, Tricas TC (2013) Fast drum strokes: novel and convergent features of sonic muscle ultrastructure, innervation, and motor neuron organization in the pyramid butterflyfish (Hemitaurichthys polylepis). J Morphol 274:377-394

Braun CB, Coombs S (2010) Vibratory sources as compound stimuli for the octavolateralis systems: dissection of specific stimulation channels using multiple behavioral approaches. J Exp Psychol Anim Behav Process 36:243-257 
Braun CB, Grande T (2008) Evolution of peripheral mechanisms for the enhancement of sound reception. In: Webb JF, Fay RR, Popper AN (eds) Fish bioacoustics. Springer, New York, pp 100-144

Braun CB, Coombs S, Fay RR (2002) What is the nature of multisensory interaction between octavolateralis sub-systems? Brain Behav Evol 59:162-176

Cato DH (1978) Marine biological choruses observed in tropical waters near Australia. J Acoust Soc Am 64:736-743

Cato DH, McCauley RD (2002) Australian research in ambient sea noise. Acoust Aust 30:13-20

Coffin AB, Zeddies DG, Fay RR, Brown AD, Alderks PW, Bhandiwad AA, Mohr RA, Gray MD, Rogers PH, Sisneros JA (2014) Use of the swim bladder and lateral line in near-field sound source localization by fish. J Exp Biol 217:2078-2088

Cole AJ, Pratchett MS (2014) Diversity in diet and feeding behaviour of butterflyfishes: reliance on reef corals versus reef habitats. In: Pratchett MS, Berumen ML, Kapoor BG (eds) Biology of butterflyfishes. CRC, Boca Raton, pp 107-139

Coombs S, Montgomery, JC (1999) The enigmatic lateral line system. In: Fay RR, Popper AN (eds) Comparative hearing: fish and amphibians. Springer, New York, pp 319-362

Coombs S, Popper AN (1979) Hearing differences among Hawaiian squirrelfishes (family Holocentridae) related to differences in the peripheral auditory system. J Comp Physiol A 132:203-207

Coombs S, Hasting M, Finneran J (1996) Modeling and measuring lateral line excitation patterns to changing dipole source locations. J Comp Physiol A 178:359-371

Dewan AK, Tricas TC (2011) Arginine vasotocin neuronal phenotypes and their relationship to aggressive behavior in the territorial monogamous multiband butterflyfish, Chaetodon multicinctus. Brain Res 1401:74-84

Dewan AK, Tricas TC (2014) Cytoarchitecture of the telencephalon in the coral reef multiband butterflyfish (Chaetodon multicinctus: Perciformes). Brain Behav Evol 84:31-35

Dewan AK, Maruska KP, Tricas TC (2008) Arginine vasotocin neuronal phenotypes among congeneric territorial and shoaling reef butterflyfishes: species, sex and reproductive season comparisons. J Neuroendocrinol 20:1382-1394

Dewan AD, Ramey ML, Tricas TC (2011) Arginine vasotocin neuronal phenotypes, telencephalic fiber varicosities, and social behavior in butterflyfishes (Chaetodontidae): potential similarities to birds and mammals. Horm Behav 59:56-66

Fessler JL, Westneat MW (2007) Molecular phylogenetics of the butterflyfishes (Chaetodontidae): taxonomy and biogeography of a global coral reef fish family. Mol Phylogenet Evol 45:50-68

Fish MP, Mowbray WH (1970) Sounds of western north Atlantic fishes. Baltimore, Johns Hopkins Univ. Press.

Fitch WT, Hauser MD (2002) Unpacking 'honesty': vertebrate vocal production and the evolution of acoustic signals. In: Simmons AM, Fay RR, Popper AN (eds) Acoustic communication. Springer, New York, pp 65-137

Fletcher LB, Crawford JD (2001) Acoustic detection by sound producing fishes (Mormyridae): the role of gas-filled tympanic bladders. J Exp Biol 204:175-183

Fricke HW (1986) Pair swimming and mutual partner guarding in monogamous butterflyfish (Pisces, Chaetodontidae): a joint advertisement of territory. Ethology 73:307-333

Hamilton WJ III, Peterman RJ (1971) Countershading in the colourful reef fish Chaetodon lunula: concealment, communication, or both? Anim Behav 19:357-364

Hanke W, Boyle K, Tricas TC (2008) Flow measurements during the multimodal communication in Hawaiian butterflyfish. In: Ruck B, Leder A, Dophedide D (eds) Lasermethoden in der Strömungsmesstechnik). German Association for Laser Anemometry, Karlsruhe, pp 53.1-53.6

Hawkins AD (1993) Underwater sound and fish behavior. In: Pitcher TJ (ed) Behaviour of teleost fishes. Chapman Hall, London, pp 129-160

Higgs DM, Radford CA (2013) The contribution of the lateral line to 'hearing' in fish. J Exp Biol 216:1484-1490

Hourigan TF (1989) Environmental determinants of butterflyfish social systems. Environ Biol Fishes 25:61-78 
Kalmijn AJ (1988) Hydrodynamic and acoustic field detection. In: Atema J, Fay RR, Popper AN, Tavolga WN (eds) Sensory biology of aquatic animals. Springer, New York, pp 83-130

Kennedy EV, Holderied MW, Mair JM, Guzman HM, Simpson SD (2010) Spatial patterns in reefgenerated noise relate to habitats and communities: evidence from a Panamanian case study. J Exp Mar Biol Ecol 395:85-92

Kenyon TN, Ladich F, Yan HY (1998) A comparative study of hearing ability in fishes: the auditory brainstem response approach. J Comp Physiol A 182:307-318

Kosaki RK (1999) Behavioral mechanisms of coexistence among coral-feeding butterflyfishes. Unpublished PhD Dissertation, University of Hawaii at Manoa, $179 \mathrm{p}$

Kroese ABA, Schellart NAM (1992) Velocity- and acceleration-sensitive units in the trunk lateral line of the trout. J Neurophysiol 68:2212-2221

Ladich F (1999) Did auditory sensitivity and vocalization evolve independently in otophysan fishes? Brain Behav Evol 53:288-304

Ladich F (2013) Effects of noise on sound detection. In: Brumm H (ed) Animal communication and noise, animal signals and communication 2. Springer, Berlin, pp 65-90

Ladich F, Fay RR (2013) Auditory evoked potential audiometry in fish. Rev Fish Biol Fish 23:317-364

Ladich F, Fine ML (2006) Sound-generating mechanisms in fishes: a unique diversity in vertebrates. In: Ladich F, Colin SP, Moller P, Kapoor BG (eds) Communication in fishes, vol I. Science Publishers, Enfield, pp 3-43

Ladich F, Myrberg AA Jr (2006) Agonistic behavior and acoustic communication. In: Ladich F, Colin SP, Moller P, Kapoor BG (eds) Communication in fishes, vol I. Scientific Publishers, Enfield, pp 121-148

Ladich F, Yan HY (1998) Correlation between auditory sensitivity and vocalization in anabantoid fishes. J Comp Physiol A 182:737-746

Lammers MO, Brainard RE, Au WWL, Mooney A, Wong K (2008) An ecological acoustic recorder (EAR) for long-term monitoring of biological and anthropogenic sounds on coral reefs and other marine habitats. J Acoust Soc Am 123:1720-1728

Lechner W, Ladich F (2008) Size matters: diversity in swim bladders and Weberian ossicles affects hearing in catfishes. J Exp Biol 211:1681-1689

McCauley RD, Cato DH (2000) Patterns of fish calling in a nearshore environment in the Great Barrier Reef. Philos Trans R Soc Lond B Biol Sci 355:1289-1293

Motta PJ (1984) Response of potential prey to coral reef predators. Anim Behav 31:1257-1259

Myrberg AA Jr, Lugli M (2006) Reproductive behavior and acoustical interactions. In: Ladich F, Colin SP, Moller P, Kapoor BG (eds) Communication in fishes, vol 1. Scientific Publishers, Enfield, pp 149-1176

Neudecker S (1989) Eye camouflage and false eyespots: chaetodontid responses to predators. Env Biol Fish 25:143-157

Nelson EM (1955) The morphology of the swimbladder and auditory bulla in the Holocentridae. Fieldiana (Zoology) 37:121-130

Parmentier E, Boyle KS, Berten L, Brié C, Lecchini D (2011) Sound production and mechanism in Heniochus chrysostomus (Chaetodontidae). J Exp Biol 214:2702-2708

Popper AN (1977) A scanning electron microscopic study of the sacculus and lagena in the ears of fifteen species of teleost fishes. J Morphol 153:397-418

Radford CA, Stanley JA, Jeffs AG (2014) Adjacent coral reef habitats produce different underwater sound signatures. Mar Ecol Prog Ser 505:1928

Reese ES (1975) A comparative field study of the social behavior and related ecology of reef fishes of the family Chaetodontidae. Z Tierpsychol 37:37-61

Roberts CM, Ormond RFG (1992) Butterflyfish social behaviour, with special reference to the incidence of territoriality: a review. Environ Biol Fishes 31:79-93

Sand O, Hawkins AD (1973) Acoustic properties of the cod swim bladder. J Exp Biol 58:797-820

Sand O, Karlsen HE (2000) Detection of infrasound and linear acceleration in fishes. Philos Trans R Soc Lond B 355:1295-1298 
Schellart NAM, Popper AN (1992) Functional aspects of the evolution of the auditory system of actinopterygian fish. In: Webster DB, Fay RR, Popper AN (eds) The evolutionary biology of hearing. Springer, New York, pp 295-322

Schulz-Mirbach T, Metscher B, Ladich F (2012) Hearing abilities-a case study on Asian and African cichlids. PLoS One 7:1-14

Simpson SD, Meekan M, Montgomery J, McCauley R, Jeffs A (2005) Homeward sound. Science 308:221

Smith WL, Webb JF, Blum SD (2003) The evolution of the laterophysic connection with a revised phylogeny and taxonomy of butterflyfishes (Teleostei: Chaetodontidae). Cladistics 19:287-306

Tricas TC (1985) The economics of foraging in corallivorous butterflyfishes of Hawaii. Proceedings of the 5th international coral reef congress 5:409-414

Tricas TC (1989) Determinants of feeding territory size in the corallivorous butterflyfish, Chaetodon multicinctus. Anim Behav 37:830-841

Tricas TC, Boyle KS (2014) Acoustic behaviors in Hawai'i coral reef fish communities. Mar Ecol Prog Ser 511:1-16

Tricas TC, Boyle KS (2015a) Diversity and evolution of sound production in the social behavior of Chaetodon butterflyfishes. J Exp Biol 218:1572-1584

Tricas TC, Boyle KS (2015b) Sound pressure enhances the hearing sensitivity of Chaetodon butterflyfishes on noisy coral reefs. J Exp Biol 218:1585-1595

Tricas TC, Kajiura SM, Kosaki RK (2006) Acoustic communication in territorial butterflyfish: test of the sound production hypothesis. J Exp Biol 209:4994-5004

Urick RJ (1983) Principles of underwater sound. McGraw Hill, New York

Webb JF (1998) Laterophysic connection: a unique link between the swimbladder and the lateral line system in Chaetodon (Perciformes: Chaetodontidae). Copeia 1998:1032-1036

Webb JF, Smith WL (2000) The laterophysic connection in chaetodontid butterflyfish: morphological variation and speculations on sensory function. Philos Trans R Soc Lond B 355:1125-1129

Webb JF, Smith WL, Ketten DR (2006) The laterophysic connection and swim bladder of butterflyfishes in the genus Chaetodon (Perciformes: Chaetodontidae). J Morphol 267:1338-1355

Webb JF, Herman JL, Woods CF, Ketten DR (2010) The ears of butterflyfishes: "Hearing generalists" on noisy coral reefs? J Fish Biol 77:1434-1451

Webb JF, Walsh RM, Casper BM, Mann DA, Kelly N, Cicchino N (2012) Development of the ear, hearing capabilities and laterophysic connection in the spotfin butterflyfish (Chaetodon ocellatus). Environ Biol Fishes 95:275-290

Weeg MS, Bass AH (2002) Frequency response properties of lateral line superficial neuromasts in a vocal fish, with evidence for acoustic sensitivity. J Neurophysiol 88:1252-1262

Wenz GM (1962) Acoustic ambient noise in the ocean: spectra and sources. J Acoust Soc Am 34:1936-1956

Woods CF (2006) Swim bladder morphology in chaetodontids butterflyfishes with a discussion of its acoustic significance. Unpublished MS Thesis, Villanova University, $126 \mathrm{p}$

Woods CF, Webb JF, Ketten DR (2006) The physoclistous swim bladder of chaetodontid butterflyfishes: implications for acoustic function. J Acoust Soc Am 120:3326

Wrathall TJ, Roberts CM, Ormond RFG (1992) Territoriality in the butterflyfish Chaetodon austriacus. Environ Biol Fishes 34:305-308

Wysocki LE, Codarin A, Ladich F, Picciulin M (2009) Sound pressure and particle acceleration audiograms in three marine fish species from the Adriatic Sea. J Acoust Soc Am 126:2100-2107

Yabuta S (2002) Uncertainty in partner recognition and the tail-up display in a monogamous butterflyfish. Anim Behav 63:165-173

Yabuta S, Berumen ML (2014) Social structures and spawning behavior of Chaetodon butterflyfishes. In: Pratchett MS, Berumen ML, Kapoor BG (eds) Biology of butterflyfishes. CRC, Boca Raton, pp 200-225

Zumpe D (1965) Laboratory observations on the aggressive behaviour of some butterfly fishes (Chaetodontidae). Z Tierpsychol 22:226-236 


\title{
Convergent Aspects of Acoustic Communication in Darters, Sculpins, and Gobies
}

\author{
Jeffrey N. Zeyl, Stefano Malavasi, Daniel E. Holt, Patricia Noel, \\ Marco Lugli, and Carol E. Johnston
}

\begin{abstract}
Darters (Perciformes, Percidae), sculpins (Perciformes, Cottidae), and gobioids (Gobiiformes, Gobioidei) exhibit convergent life history traits, including a benthic lifestyle and a cavity nesting spawning mode. Soniferous species within these taxa produce pulsed and/or tonal sounds with peak frequencies below $200 \mathrm{~Hz}$ (with some exceptions), primarily in agonistic and/or reproductive contexts. The reduced or absent swim bladders found in these taxa limit or prevent both hearing enhancement via pressure sensitivity and acoustic amplification of the contracting sonic muscles, which are associated with the skull and pectoral girdle. While such anatomies constrain communication to low frequency channels, optimization of the $\mathrm{S} / \mathrm{N}$ (signal-to-noise) ratio in low frequency channels is evident for some gobies, as measured by habitat soundscape frequency windows, nest cavity sound amplification, and audiograms. Similar S/N considerations are applicable to many darter and sculpin systems. This chapter reviews the currently documented diversity of sound production in darters, sculpins, and gobioids within a phylogenetic context, examines the efficacy of signal transmission from senders to receivers (sound production mechanisms, audiograms, and masking challenges), and evaluates the potential functional significance of sound attributes in relation to territorial and reproductive behaviours.
\end{abstract}

Keywords Etheostoma • Cottidae • Gobioidei • Fish hearing • Fish sound production

J.N. Zeyl $(\bowtie) \bullet$ D.E. Holt • P. Noel • C.E. Johnston

Fish Biodiversity Lab, School of Fisheries, Aquaculture and Aquatic Sciences,

Auburn University, Auburn, AL 36849, USA

e-mail: jnz0002@tigermail.auburn.edu

S. Malavasi

Dipartimento di Scienze Ambientali, Informatica e Statistica, Center for Estuarine,

CoastAL Marine Sciences (CEMAS), Università Ca' Foscari Venezia,

Castello 2737/b, 30122 Venice, Italy

M. Lugli

Department of Neurosciences, University of Parma, Parma, Italy 


\section{Introduction}

Soniferous darters (Perciformes, Percidae), sculpins (Perciformes, Cottidae), and many gobioids (Gobiiformes, Gobioidei) have convergent life history traits, including a benthic lifestyle and the cavity nesting spawning mode (current phylogeny by Bentacur et al. 2013). These taxa produce low frequency sounds with dominant frequencies below $200 \mathrm{~Hz}$ (with some notable exceptions) in agonistic and reproductive contexts. While low frequency sounds and acoustic signaling in agonistic and reproductive contexts is a widespread characteristic of teleost acoustic communication (Bass and McKibben 2003; Amorim 2006; Ladich 2014), a few additional characteristics shared by the soniferous members of these groups make their integrative study informative for understanding the selective pressures and constraints on acoustic communication in fishes. This chapter examines the currently documented diversity of sound production in these taxa, the design efficacy of signals (i.e., acoustic characteristics of sounds, signal propagation within soundscapes, and receiver audiograms) (Endler 1992), and the potential functional significance of sound attributes in relation to territorial and reproductive behaviours.

These fishes have reduced or absent swim bladders, which limits or prevents hearing enhancement via pressure sensitivity and drumming amplification via swim bladder motion (Demski et al. 1973; Popper and Fay 1993, 2011). Swim bladder drumming sounds are a widespread sound production mechanism in fishes (Ladich and Fine 2006), but sound production in darters, gobies, and sculpins does not appear to involve the swim bladder. Swim bladders are absent in adult sculpins and either absent or reduced more broadly in Etheostomatine darters, but absent in the soniferous Catonotus darters (Evans and Page 2003; Nelson 2006). The phylogenetic distribution of the swim bladder in gobies has not yet been thoroughly examined (Hesthagen and Koefoed 1979), though both species possessing a swim bladder (e.g. Padogobius bonelli, Pomatoschistus minutus, Gobius cruentatus) and species lacking a swim bladder (e.g. Padogobius nigricans, Neogobius melanostomus) have been found to be soniferous. Experimental manipulations in gobies have not supported involvement of the swim bladder in sound production (Lugli et al. 2003; Parmentier et al. 2013). The similar cranial-pectoral muscular anatomies of gobies and sculpins (Parmentier et al. 2013; Colleye et al. 2013) and the observed "nodding" and/or pectoral fin motion during sound production in all three taxa suggest similar sound production mechanisms involving of cranial-pectoral muscle contraction (Parmentier et al. 2013; Colleye et al. 2013; DEH pers. obs.).

The efficacy of signaling within the shallow water habitats occupied by many members of these groups is also examined. Soniferous gobies have adapted to marine, transitional, and freshwater habitats, while currently described soniferous darters and Cottus are stream inhabitants (Page 1985; Ladich 1989; Nelson 2006; Kierl and Johnston 2010; Colleye et al. 2013). In the shallow stream and coastal habitats, low frequency sounds are limited in propagation due to cutoff frequencies (Rogers and Cox 1988; Mann 2006). However, within these constraints, research on gobies indicates that low frequencies could optimize signal-to-noise $(\mathrm{S} / \mathrm{N})$ ratio as a result of two 
factors: (1) low frequency acoustic windows in the ambient noise frequency spectrum (Lugli et al. 2003; Lugli 2010), and (2) nest cavity amplification of low frequency content (Lugli 2012, 2013, 2014). Shared habitats and nest cavity spawning are expected to produce similar effects on $\mathrm{S} / \mathrm{N}$ ratio in darters and sculpins, but further study is required (Speares et al. 2011).

Territoriality and mate attraction are significant factors associated with evolution of acoustic communication of fishes (Ladich and Myrberg 2006; Myrberg and Lugli 2006; Ladich 2014). Therefore, the similar reproductive life histories of sculpins, darters, and gobies are of evolutionary interest in terms of sexual selection on acoustic signals. Early phylogenetic examinations of sound production in darters and gobies support associations between cavity building and sound production (CEJ unpublished; Gkenas et al. 2010). Several authors have previously reviewed sound production in gobies (Lugli et al. 1997; Bass and McKibben 2003; Myrberg and Lugli 2006), but there is a body of novel work in gobies that could be critically reviewed, and a comprehensive review of acoustic communication in sculpins and darters is currently lacking.

\subsection{Reproductive Ecologies}

Soniferous darters, sculpins, and gobies share a benthic cavity spawning pattern with male paternal care (Morris 1954; Page 1985; Torricelli et al. 1985; Knouft et al. 2003). Generally, males compete for nest sites under rocks, logs, or other stable debris and court females to spawn and attach eggs to the inner nest surfaces. After spawning, males defend the nest and court additional females (Page 1985; Lindström and Hellström 1993; Whang and Janssen 1994). Sounds are most commonly observed during three categories of behaviour: agonistic contests, attracting females to spawn in the nest (pre-spawning), and/or during spawning itself (Lugli et al. 1997; Lugli and Torricelli 1999; Johnston and Johnson 2000; Myrberg and Lugli 2006; Kierl and Johnston 2010). These signals do not propagate far in the shallow water habitats of these fishes and are not used for long range advertisement, as is found in toadfishes.

Sound production has been described for six darter species within the Catonotus subgenus of Etheostoma (Table 1). Catonotus darters occupy headwater streams in eastern North America, utilizing an "egg clustering" spawning technique involving placement of eggs as a single layer onto the cavity ceiling, which is typically a flat rock (Page 1985). Females prefer nests with eggs, and alloparental care has been documented in this group (Knapp and Sargent 1989). Both agonistic and courtship activities elicit sound production by males (Johnston and Johnson 2000; Speares and Johnston 2011).

While coastal marine sculpins in the Northern Hemisphere constitute the bulk of sculpin diversity, most of our knowledge about sound production in this taxon has been gathered from freshwater species of the genus Cottus $(n=6)$ and a few coastal marine species: Myoxocephalus $(n=3)$ and Leptocottus $(n=1)$ (Table 1). 


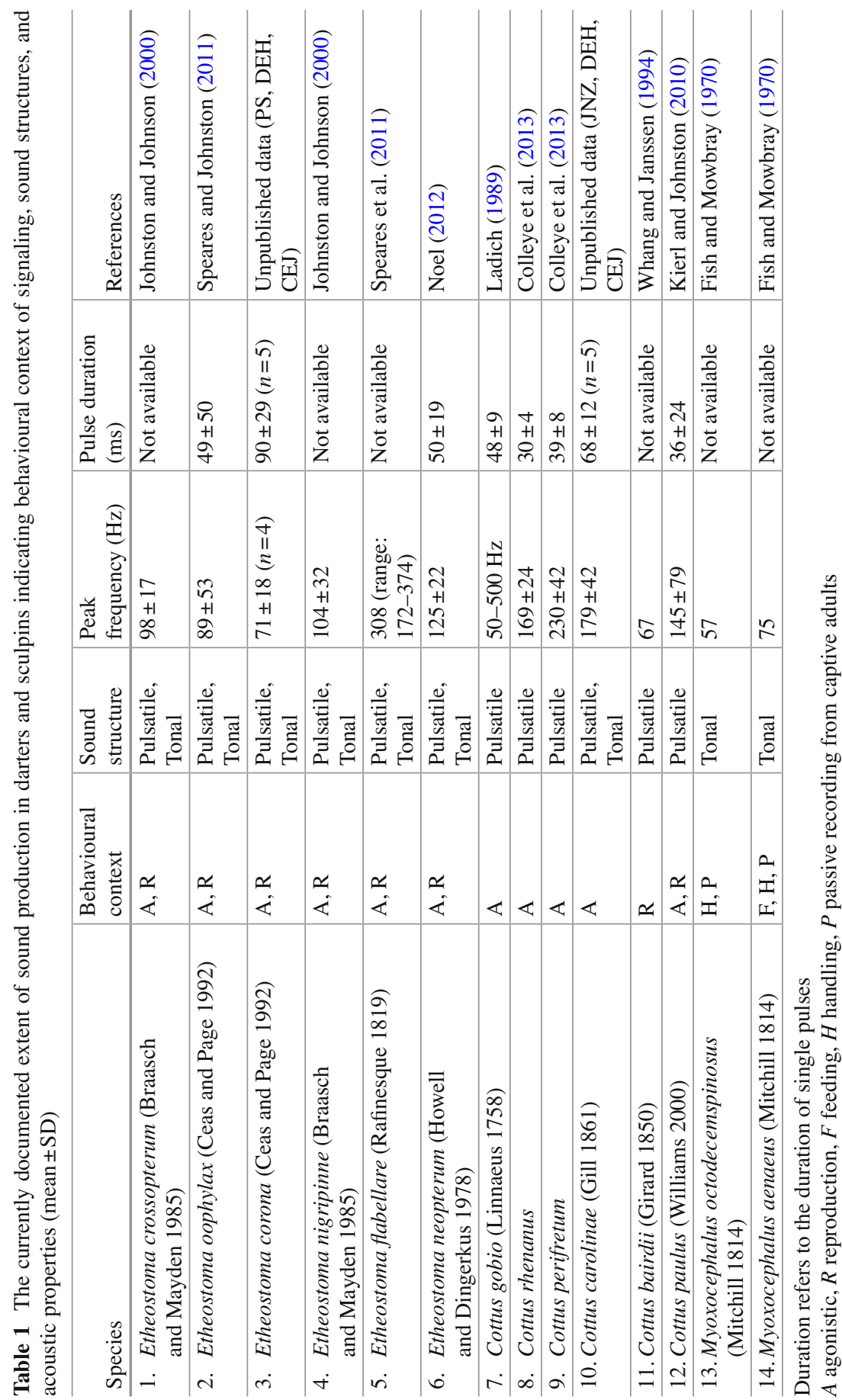


Male Cottus typically excavate nest cavities beneath rocks and guard the developing eggs after spawning (Morris 1954; Downhower and Brown 1980; Goto 1993). Cottus sounds have been primarily observed in agonistic contexts as a mechanism to deter intruders (Ladich 1989; Colleye et al. 2013), though it is unclear whether the prevalence of agonistic sound observations reflects context-specific signaling rates or rather the difficulty of observing spawning in the laboratory (but see Kierl and Johnston 2010). Marine sculpins exhibit a diversity of spawning modes, but soniferous Myoxocephalus scorpius males are known to guard crevice-laid eggs until hatching (Ennis 1970). The presence of paternal care in the soniferous Myoxocephalus octodecemspinous and Myoxocephalus aenaeus is uncertain. Male Myoxocephalus jaok and M. brandti guard eggs (Panchenko 2001a, b), but their acoustic behaviour has not been tested.

The gobiid pattern of reproduction is quite stereotyped in its basic scheme across species: the male selects and occupies a nest cavity below a hard object, often excavating or at least adjusting this cavity, and defends it by patrolling the area surrounding the nest (Tavolga 1956; Torricelli et al. 1985). The hard object varies greatly within and between species, but commonly includes lamellibranch or gastropod valves, stones, reedstand, or artificial objects. Once a ripe female is in a male's visual field, the male swims towards her, attempting to lead the female into the nest cavity with stereotyped swimming movements ("approaching-leading behaviours"). Sounds are typically emitted throughout this courtship sequence, which occurs primarily outside the nest. Once in the nest and ready to spawn, the female inverts her position to release eggs onto the nest ceiling. At this stage the male may emit the so-called pre-spawning sounds before inverting to release sperm. Upside-down behaviours of both partners, male sound emission and patrol of the nest entrance are alternated throughout the duration of spawning (Lugli et al. 1997; Lugli and Torricelli 1999; Malavasi et al. 2008).

Gobiid sounds are mainly documented in agonistic and/or reproductive contexts. In eight species the vocal behaviour was shown to be associated with both contexts (Table 2): Padogobius bonelli (formerly P. martensii), Gobius paganellus, Gobius niger, Zosterisessor ophiocephalus, Pomatoschistus canestrinii, Pomatoschistus pictus, Bathygobius fuscus, Gobiosoma bosci. For some of the remaining species, the occurrence of sounds in only one context could result from a lack of deeper investigation rather than the real absence of acoustic signaling in a given context; reproductive behaviour is difficult to achieve in captivity in some species (e.g. mudskippers). Despite the high prevalence of sound production among gobies, detailed descriptions of sound production and associated behaviours are available for only a few species: P. bonelli (Lugli et al. 1995, 1997), Pomatoschistus minutus (Lindström and Lugli 2000), P. canestrinii (Malavasi et al. 2009), and P. pictus (Amorim and Neves 2007). Within the reproductive context, these species' sounds are associated with pre-spawning and/or courtship phases. 

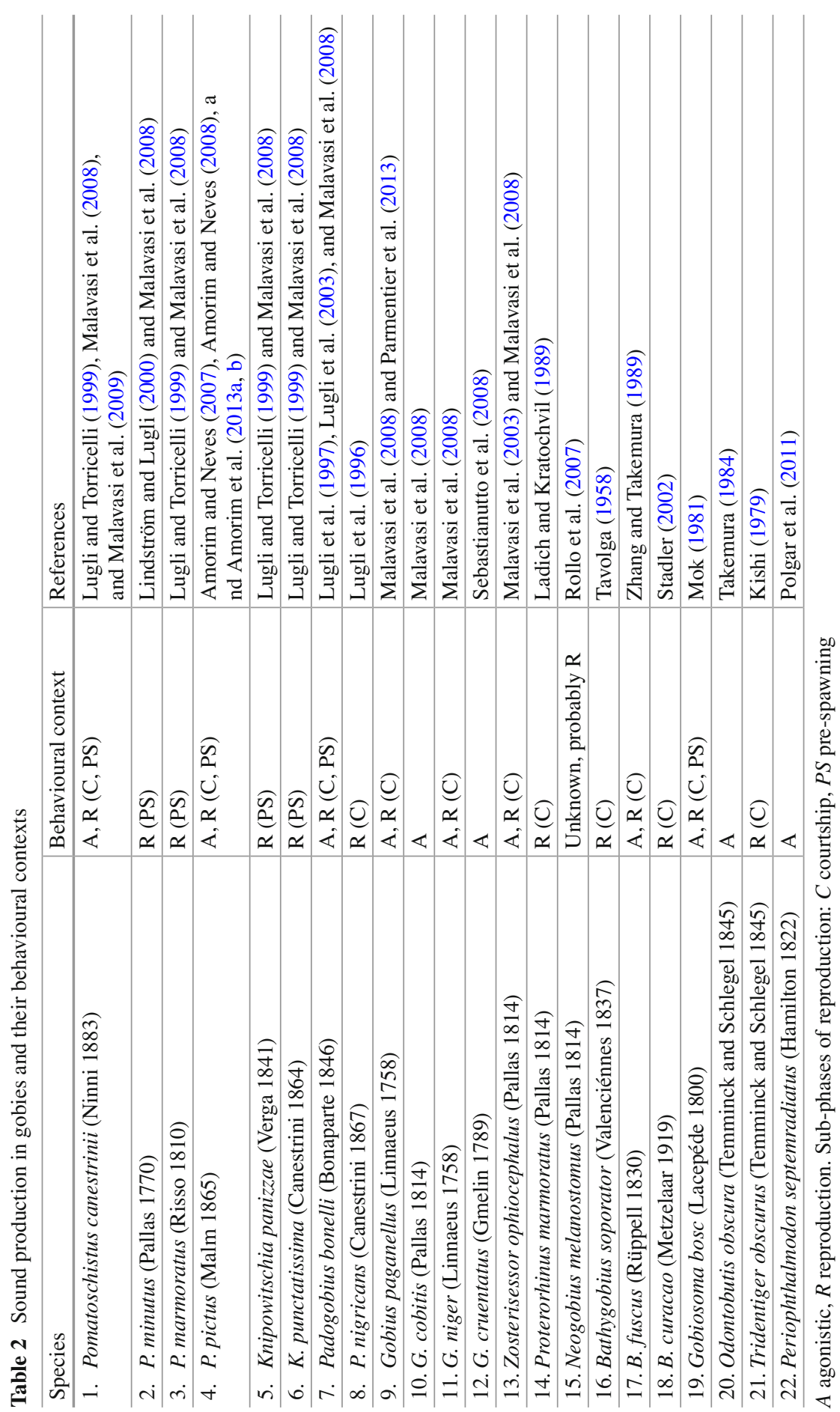


\section{Diversity of Sound Types with Phylogenetic Considerations}

The acoustic repertoires of darters, gobies, and sculpins are constructed from pulsed units with dominant frequencies below $200 \mathrm{~Hz}$ (Fig. 1, Tables 1 and 3). The variety of sound structures that have been classified are generated from variation in the temporal spacing of pulse repetition. At one end of the continuum, pulses are produced with long, irregular inter-pulse intervals where each "knock" or "pulse" is clearly distinguishable to the human ear (e.g., Cottus carolinae). Pulses may also be strung closer together into coherent pulse train bursts with regular repetition rates (i.e., "drumming", "purrs", or "grunt" sounds) (e.g., Etheostoma corona). In the repertoires of some sculpins, some gobies, and all of the currently tested darters, pulses may resolve to tonal structures at a high repetition rate. For the purposes of comparison, we classify the first two sound types (single pulses and structured pulse trains) as "pulsatile" and the third as "tonal". In gobies, sounds that possess both tonal and drumming components within the same burst have been classified as "complex" (Lugli et al. 1997). Darters exhibit similar continuities between pulse trains and tonal sounds (e.g., Fig. 1 a, b).

\subsection{Darters}

All of the soniferous darters tested to date have repertoires that include both pulsatile and tonal sounds, which have been classified into three sound structures: isolated pulsatile "knocks", pulse train "purrs", and harmonic "drums" (Fig. 1a, b). Drums typically exhibit a rise and fall of the frequency contour structure (Johnston and Johnson 2000; Speares and Johnston 2011), although additional inflection points are possible. A particularly high degree of frequency modulation is evident in Etheostoma flabellare (Fig. 1a) (previously unpublished data). Darters can exhibit considerable variation in the drum duration and degree of frequency modulation within the same individuals.

Despite a significant survey across darter phylogeny, sound production has only been found in the Catonotus clade, suggesting that it may be a derived condition in this group. Within Catonotus, sound production appears to be absent in the barcheek group (Etheostoma smithi and Etheostoma virgatum, CEJ unpublished data). Outside Catonotus, a number of darters have been tested and found to be silent during spawning. These species can be distinguished from Catonotus in utilizing eggburying and egg-attaching spawning modes, where eggs are abandoned after spawning: Percina palmaris, Etheostoma luteovictum (egg-buriers), Etheostoma parvipinne, Etheostoma prolarie, Etheostoma blennius, Etheostoma simoterum, and Etheostoma duryi, (egg attachers, CEJ unpublished data) (Page 1985). Such an association between territoriality and sound production is interesting given that communication commonly occurs in territorial contexts in other taxa (Bradbury and 
a

Etheostoma flabellare

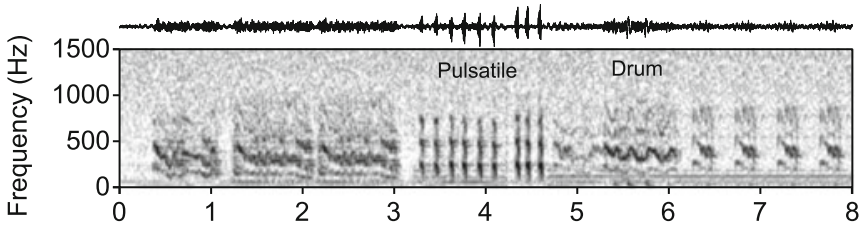

b

\section{Etheostoma corona}

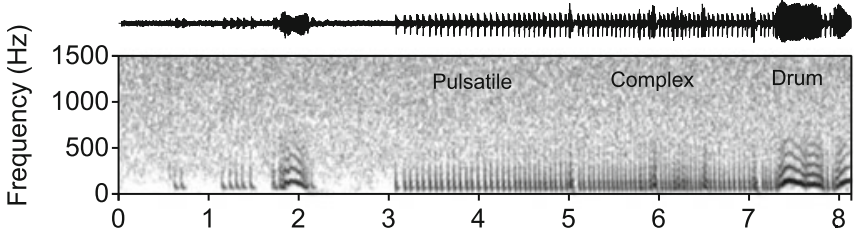

C Myoxocephalus octodecemspinosus

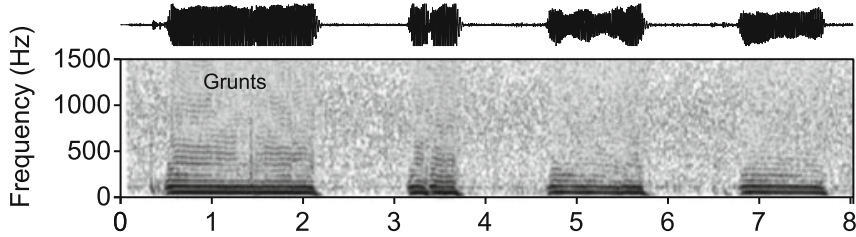

d

Cottus carolinae
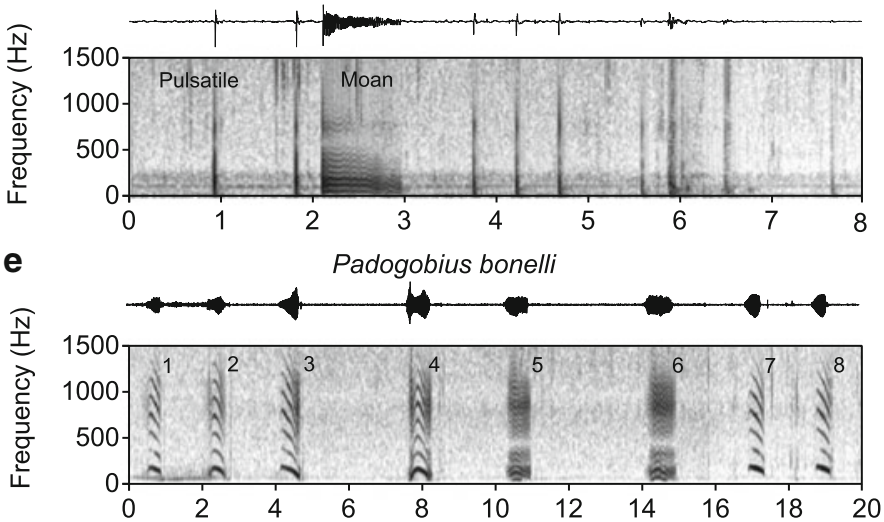

f Periophthalmodon septemradiatus

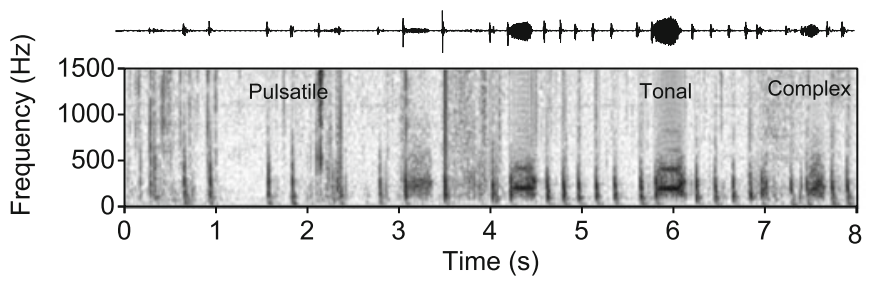

Fig. 1 Waveforms and spectrograms highlighting the diversity of acoustic signals in darters, sculpins, and gobies. (a) A composite sound highlighting the various sound types of Etheostoma flabellare. (b) An uninterrupted sequence of Etheostoma corona pulsatiles and tonal sounds. 
Vehrencamp 1998; Davies et al. 2012). An exception to this association between egg-clustering and sound production occurs in the Boleosoma clade, where eggclustering species were found to lack sound production (Etheostoma olmstedi and Etheostoma nigrum, CEJ unpublished data). Another distinguishing characteristic of the soniferous Catonotus is that they are virtually the only group lacking bright male breeding coloration within Etheostoma (Page 1985). Additionally, the silent barcheek group within Catonotus lacks sound production but has bright breeding coloration (Page 1985).

Since all soniferous darters documented to date produce all three sound types, a comparative analysis on the evolutionary origin of particular sound types within Catonotus is not possible. However, one notable phylogenetic association warranting further investigation is the divergent signals of Etheostoma flabellare, which are in higher dominant frequencies and have a more complex pulse repetition rate than the soniferous darters belonging to the more phylogenetically distant Etheostoma squamiceps clade (Fig. 1a; Speares et al. 2011) (see Page et al. 2003 for a recent phylogeny).

\subsection{Sculpins}

The sound descriptions for marine sculpins are mostly anecdotal. Myoxocephalus "growls" are sustained, harmonic sounds of variable duration with a fundamental frequency near $60 \mathrm{~Hz}$ (Fig. 1c; Fish and Mowbray 1970) (Table 1). Fish and Mowbray (1970) collected Myoxocephalus aenaeus and M. octodecemspinosus sounds passively from several adults together in an aquarium, and M. octodecemspinosus also produced sounds during feeding and handling. The neurophysiology of sound production in Myoxocephalus scorpius and Leptocottus armatus has been investigated without description of behaviours or acoustic parameters (Bass and Baker 1991).

All Cottus species produce pulsed "knocks" ( $40 \mathrm{~ms}$ pulse duration, peak frequencies: 50-300 Hz), some species produce structured "knock trains", and at least one species produces a tonal "moan" (Cottus carolinae, Fig. 1d). The acoustic

Fig. 1 (continued) (c) An uninterrupted sequence of Myoxocephalus octodemospinosus "grunts" (from the CD archive companion to Fish and Mowbray 1970). (d) An uninterrupted sequence of Cottus carolinae distinct pulsatile knock and tonal "moan" sounds. (e) An uninterrupted sequence of Padogobius bonelli breeding sounds recorded in stream Stirone and emitted by a male (with eggs) from the nest hollow (under a stone) toward a caged ripe female placed in front of the nest. The $P$. bonelli sounds grade from purely tonal $(1,7,8)$ to purely grunt-like $(5,6)$, three of them $(2,3,4)$ being a mix of the two types. This sequence shows how modulation of the pulse rate can change the spectral representation of the sound on the spectrogram. (f) An uninterrupted sequence of the mudskipper Periophthalmodon septemradiatus, indicating pulsatile, tonal, and complex sound types. All spectrograms were computed with the following parameters: window length: 0.05 s, maximum frequency: $1500 \mathrm{~Hz}$, time step: $0.002 \mathrm{~s}$, frequency step: $20 \mathrm{~Hz}$, window: Hamming 
Table 3 Sound structure and acoustic properties of sounds produced by the 22 confirmed soniferous gobies, as documented in the literature (References as in Table 2)

\begin{tabular}{|c|c|c|c|c|c|c|}
\hline Species & $\begin{array}{l}\text { Sound } \\
\text { structure }\end{array}$ & Type & $\begin{array}{l}\text { Duration } \\
(\mathrm{ms})\end{array}$ & $\mathrm{PF}(\mathrm{Hz})$ & PRR (Hz) & $\begin{array}{l}\text { Body size } \\
(\max , \mathrm{cm})\end{array}$ \\
\hline $\begin{array}{l}\text { 1. Pomatoschistus } \\
\text { canestrinii }\end{array}$ & Pulsatile & 2 & 600 & 140 & 37 & 5.5 \\
\hline 2. P. minutus & Pulsatile & 1 & 583 & 99 & 27 & 11.0 \\
\hline 3. P. marmoratus & Pulsatile & 1 & 694 & 125 & 26 & 8.0 \\
\hline 4. P. pictus & Pulsatile & 2 & $\begin{array}{l}692 \\
(\text { drum) }\end{array}$ & 83.2 & 42 (drum) & 6.0 \\
\hline $\begin{array}{l}\text { 5. Knipowitschia } \\
\text { panizzae }\end{array}$ & Pulsatile & 1 & 1019 & 187 & 38 & 5.5 \\
\hline 6. K. punctatissima & Pulsatile & 1 & 856 & 128 & 27 & 4.5 \\
\hline $\begin{array}{l}\text { 7. Padogobius } \\
\text { bonelli }\end{array}$ & $\begin{array}{l}\text { Pulsatile, } \\
\text { Tonal, } \\
\text { Complex }\end{array}$ & 3 & 600 & 165 & $\begin{array}{l}35 \text { (pulse) } \\
165 \text { (tonal) }\end{array}$ & 8.6 \\
\hline 8. P. nigricans & Tonal & 1 & 261 & 89 & 76 & 12.5 \\
\hline $\begin{array}{l}\text { 9. Gobius } \\
\text { paganellus }\end{array}$ & \begin{tabular}{|l} 
Tonal, \\
Pulsatile
\end{tabular} & 2 & 351 & 97 & 90 & 12.0 \\
\hline 10. G. cobitis & Pulsatile & 1 & 330 & 124 & 49 & 27.0 \\
\hline 11. G. niger & Pulsatile & 1 & 397 & 106 & 43 & 18.0 \\
\hline 12. G. cruentatus & $\begin{array}{l}\text { Pulsatile, } \\
\text { Tonal, } \\
\text { Complex } \\
\end{array}$ & 4 & 480 & 125 & $\begin{array}{l}80 \text { (drum) } \\
15 \text { (tonal) }\end{array}$ & 18.0 \\
\hline $\begin{array}{l}\text { 13. Zosterisessor } \\
\text { ophiocephalus }\end{array}$ & Pulsatile & 1 & 260 & 220 & 37 & 25.0 \\
\hline $\begin{array}{l}\text { 14. Proterorhinus } \\
\text { marmoratus }\end{array}$ & Tonal & 1 & 263 & 100 & 100 & 11.5 \\
\hline $\begin{array}{l}\text { 15. Neogobius } \\
\text { melanostomus }\end{array}$ & Pulsatile & 1 & 2270 & 180 & 6.5 & 24.6 \\
\hline $\begin{array}{l}\text { 16. Bathygobius } \\
\text { soporator }\end{array}$ & Pulsatile & 1 & 225 & 150 & $\begin{array}{l}\text { Not } \\
\text { available }\end{array}$ & 15.0 \\
\hline 17. B. fuscus & Pulsatile & 1 & 500 & 450 & $\begin{array}{l}\text { Not } \\
\text { available }\end{array}$ & 12.0 \\
\hline 18. B. curacao & Pulsatile & 2 & 1000 & 200 & 11 & 7.5 \\
\hline $\begin{array}{l}\text { 19. Gobiosoma } \\
\text { bosc }\end{array}$ & Pulsatile & 1 & $\begin{array}{l}27 \text { (single } \\
\text { pulse) }\end{array}$ & 3000 & 30 & 6.0 \\
\hline $\begin{array}{l}\text { 20. Odontobutis } \\
\text { obscura }\end{array}$ & Pulsatile & 1 & 240 & 400 & 40 & 12.0 \\
\hline $\begin{array}{l}\text { 21. Tridentiger } \\
\text { obscurus }\end{array}$ & Pulsatile & 1 & $\begin{array}{l}\text { Not } \\
\text { available }\end{array}$ & $100-500$ & $\begin{array}{l}\text { Not } \\
\text { available }\end{array}$ & 14.0 \\
\hline $\begin{array}{l}\text { 22. Periophthalmodon } \\
\text { septemradiatus }\end{array}$ & $\begin{array}{l}\text { Complex, } \\
\text { Pulsatile }\end{array}$ & 2 & $\begin{array}{l}461 \\
58 \text { (single } \\
\text { pulse) }\end{array}$ & $\begin{array}{l}194 \\
60 \text { (pulse) }\end{array}$ & $\begin{array}{l}185 \text { (tonal) } \\
8 \text { (pulse) }\end{array}$ & 10.0 \\
\hline
\end{tabular}

Duration indicates total duration of a train of pulses or a single tonal sound, unless otherwise indicated. The type column indicates the number of sound types recognised by the authors of the paper (though sound type criteria are variable across studies). Note that recordings of Gobiosoma bosc, with the unusually high dominant frequency, were recorded under a high noise floor, masking low frequency components under $\sim 750 \mathrm{~Hz}$. $P F$ peak frequency, $P R R$ pulse repetition rate 
repertoire of Cottus gobio, Cottus perifretum, and Cottus rhenanus consists predominantly of single knocks and occasional structured knock trains (Ladich 1989; Colleye et al. 2013). Cottus gobio knocks have been documented in agonistic contexts and are also presumed to be involved in courtship, since "head nods" were visually observed during courtship and head nods are always accompanied by knocks (Morris 1954; Ladich 1989). Cottus bairdii and Cottus paulus produce knocks and knock trains in both agonistic and courtship contexts (Whang and Janssen 1994; Kierl and Johnston 2010). The tonal moan of Cottus carolinae is produced in agonistic contexts but is produced at a lower rate relative to "knocks" (DEH, unpublished).

Knocks have been described in several distinct clades across the Cottus phylogeny (in phylogenetic order from Kinziger et al. 2005): Cottus clade: Cottus gobio (Ladich 1989), C. perifretum, C. rhenanus (Colleye et al. 2013); Uranidea clade: $C$. carolinae, C. bairdii (Whang and Janssen 1994), C. paulus (Kierl and Johnston 2010); Bailkalian clade: Cottocemephorus grewingkii (Whang 1992, see Whang and Janssen 1994). The prevalence of the knock sound may indicate that it is an ancestral sound type within Cottus and that the moan of C. carolinae is a derived condition. However, the ancestral sound type of Cottidae more broadly remains an open question because of a lack of data. Myoxocephalus, with its harmonic "growls", is basal to both Cottus and Leptocottus (Yokoyama and Goto 2005). Acoustic signaling is likely widespread in Scorpaeniformes, as both single pulses and harmonic sounds have also been found in rockfishes (Širović and Demer 2009) and sea robins (Amorim 2006). Hallacher (1974) identified swim bladder-associated drumming muscles in many Sebastes rockfishes.

\subsection{Gobies}

Sound production has been documented in 22 species of goby (Table 2), which is a large number within a soniferous group, but a small proportion of the 1950 goby species described (Nelson 2006). In fact, less than $2 \%$ of the entire group have been acoustically tested. In 16 of the 22 goby species described to date, sound structures are strictly pulsatile. In the remaining six species, tonal components have been recorded either as the exclusive repertoire or combined with pulsatile components into "complex" sounds (Lugli et al. 1997) (Table 3). Regardless of temporal structure, the average peak frequency of sounds emitted by gobies is low $(\sim 100-150 \mathrm{~Hz})$ with few exceptions reaching the 300-450 Hz range. Mok (1981) described sound energy above $1 \mathrm{kHz}$ in Gobiosoma bosc, though the sound recording likely masked most sounds below $\sim 750 \mathrm{~Hz}$. The only goby species for which no sound production has been detected despite thorough investigation is Economidichthys pygmaeus (Gkenas et al. 2010), a small freshwater species which lacks burrowing behaviour, instead using naturally occurring reedstand cavities. This was interpreted as a secondary loss of sound production, due probably to the peculiar ecological conditions that characterized the evolution of this species (Gkenas et al. 2010). 


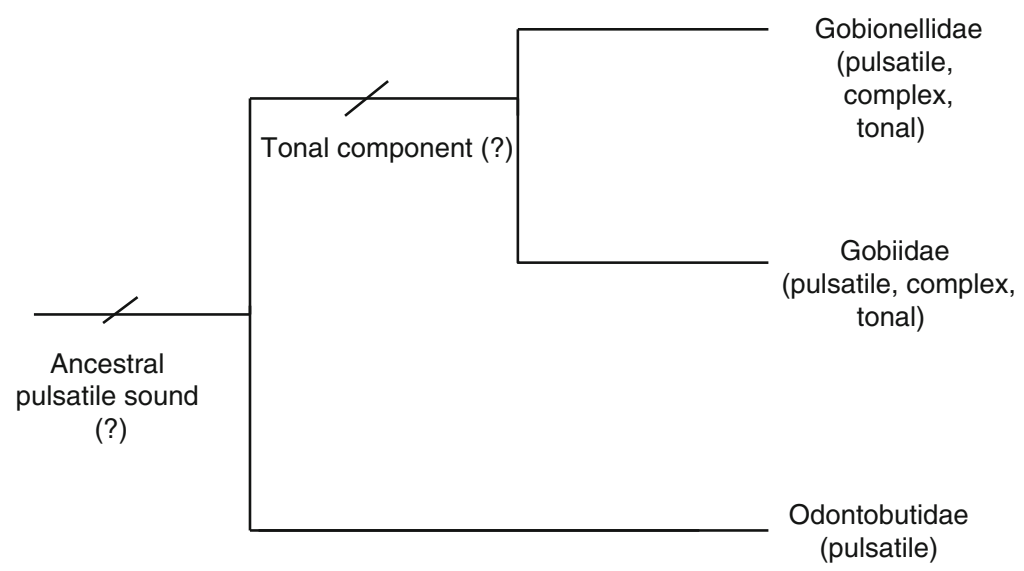

Fig. 2 Phylogenetic hypothesis on the evolution of goby sound production. Sound production is mapped onto the phylogeny adapted from Thacker $(2003,2009)$ and Thacker and Roje (2011)

This correspondence between cavity nesting and sound production is a similar pattern to darters, indicating another potential aspect of convergence.

Several goby species utilize distinct sound types during distinct spawning phases, and in at least two sand goby species (Knipowitschia punctatissima, K. panizzae,) the male, while silent during courtship outside of the nest, produces drumming sounds exclusively while a female is in the nest (Lugli et al. 1997; Lugli and Torricelli 1999). Padogobius bonelli courtship sounds are tonal $\left(f_{\mathrm{o}} \sim 100 \mathrm{~Hz}\right.$, duration $500 \mathrm{~ms}$ ), whereas spawning sounds are pulse trains or "complex" (Lugli et al. 1997) (Fig. 1e). Similar sequence-specific sound types occur in $P$. canestrinii, where courtship sounds emitted outside the nest are "thumps" consisting of single, short pulses repeated within a burst of 10-20 pulses (Malavasi et al. 2009), whereas prespawning sounds emitted in the nest with the onset of spawning are long pulse trains (>1 s duration in some cases) (Lugli and Torricelli 1999; Malavasi et al. 2009). A similar thump-pulse train sequence was described for the closely related Pomatoschistus pictus (Amorim and Neves 2007). Since the genera Padogobius and Pomatoschistus are relatively distant clades (Huyse et al. 2004; Malavasi et al. 2008), the utilization of two distinct sound types for courtship and pre-spawning function could represent convergent evolution.

According to the most recent goby phylogeny (Thacker 2009; Thacker and Roje 2011), the soniferous gobies occur in two main families: Gobiidae (Mediterranean and Ponto-Caspian gobies, and inshore gobies) and Gobionellidae (mudskippers and perhaps sand gobies, according to Thacker and Roje 2011) (Fig. 2). Furthermore, the production of pulsatile sounds by the sleeper Odontobutis obscura (Odontobutidae) (Takemura 1984), a basal group within Gobioidei (Thacker 2009; Agorreta et al. 2013), suggests a deeper sound production ancestry. The pulsatile sound structures of this species and the wider prevalence of strictly pulsed repertoires in the soniferous gobies investigated to date suggest that the tonal sounds are 
derived, as was hypothesised for Mediterranean gobies (Malavasi et al. 2008). Tonal sounds are observed in Gobius paganellus, Padogobius nigricans, and Proterorhinus marmoratus, with the acoustic repertoires of $P$. nigricans and $P$. marmoratus being strictly tonal (Ladich and Kratochvil 1989; Lugli et al. 1996). Complex sounds are found in Gobius cruentantus, Padogobius bonelli, and Periophthalmodon septemradiatus.

Interestingly, mudskippers (subfamily: Oxudercinae) converge with the other two Mediterranean species, Gobius cruentatus and Padogobius bonelli, in using complex sounds during agonistic interactions, despite the great differences in both phylogeny and ecology. The mudskipper Periophthalmodon septemradiatus emits sounds while out of water, which are transmitted through the wet muddy substratum (Polgar et al. 2011; Fig. 1f). In addition to complex sounds, mudskippers also produce single, distinctly spaced pulses, similar in some respects to the "thump" or "stutter" sounds recorded for Pomatoschistus canestrinii, Pomatoschistus pictus, and Bathygobius curacao (Table 3).

Currently, the only wide comparative analysis of acoustic diversity within gobies is provided by the work of Malavasi et al. (2008) on Mediterranean gobies belonging to two related but distinct clades: the sand gobies (genus Pomatoschistus and Knipowitschia) and the Gobius-Padogobius complex. The results of this study suggested that the temporal patterning of sounds, mainly duration and pulse rate, are the acoustical properties that are most effective in discriminating between species, whereas frequency appears to be more constrained, converging to mean values around $100-200 \mathrm{~Hz}$.

In Mediterranean gobies, duration is negatively related to body size at the interspecific level (Malavasi et al. 2008). This pattern could be applied more broadly to the whole 22 soniferous gobies known to date. However, extending the correlative analysis between body size and duration within the entire gobioid group of soniferous species so far investigated is a difficult task, partly due to the limited number of data collected for many species. However, if the negative correlation between sound duration and body size will be confirmed by future investigations, this would suggest a possible morphological constraint related to the sound production mechanism (see Parmentier et al. 2013, Sect. 7.2 in this chapter). A comparative look at the means and variation of the main acoustical properties of gobioids indicates that sound duration is an extremely variable property (ranging from $\sim 200 \mathrm{~ms}$ to $>4 \mathrm{~s}$ ) (Table 3).

\section{Sound Production Mechanisms}

While drumming muscles inserting on the swim bladder are involved in sound production in many fishes (Ladich and Fine 2006), similar sounds are produced by darters, sculpins, and darters without an apparent involvement of the swim bladder. Investigations into sound production mechanisms of sculpins and gobies have found that sounds are generated from contraction of muscles originating on the skull and inserting on the pectoral girdle (Barber and Mowbray 1956; Parmentier et al. 2013; 
Colleye et al. 2013). Myoxocephalus sounds are associated with obvious vibrations of the pectoral girdle when handled (Fish and Mowbray 1970), and an electromyography study found that cranioclavicular muscles contract in association with sound production in Myoxocephalus octodecemspinosus (Barber and Mowbray 1956). In Cottus spp., behavioural observations support a similar cranio-pectoral muscle mechanism; head abduction and/or pectoral girdle adduction have been observed repeatedly in association with sounds (Ladich 1989; Kierl and Johnston 2010; Colleye et al. 2013). The levator pectoralis is a candidate muscle that could generate a forward displacement of the pectoral girdle in Cottus spp. (Colleye et al. 2013).

The levator pectoralis muscles of Gobius paganellus are contracted during sound production (Parmentier et al. 2013). These muscles exhibit ribbon-like myofibril structure, a mitochondria dense core, and well-developed sarcoplasmic tubules characteristics typically found in specialized sonic muscle (Parmentier et al. 2013). In both Myoxocephalus and Gobius, muscles on both sides are contracted simultaneously, and the contraction rate is equal to the pulse repetition rate of the sound produced (Bass and Baker 1991; Parmentier et al. 2013), as has been found more broadly for sonic drumming mechanisms in fishes (Ladich and Fine 2006). Sounds were still produced after experimental deflation of the swim bladder in Padogobius bonelli, a species of goby possessing a swim bladder, suggesting the lack of a role of the swim bladder in sound production for this species (Lugli et al. 2003).

Hydrodynamic expulsion of water through the gills was proposed by Tavolga (1958) as a sound production mechanism for Bathygobius, which was supported in a separate study by the similar sound structure produced by the expulsion of water from a loaded pipette underwater (Stadler 2002). Such a forced water expulsion mechanism was not supported in Gobius paganellus, since experimentally cutting the opercula and hyohyoideus muscle, which would prevent water retention and forceful expulsion from the buccal cavity, did not eliminate sound production (Parmentier et al. 2013). Presently, no attempts have been made to investigate the mechanics of sound production in darters, but our observations of "head nodding" movements during sound production in Etheostoma corona (DEH, unpublished) point to a similar cranial-pectoral muscle contraction.

\section{Audiograms}

These fishes have reduced or absent swim bladders, thus limiting or preventing any hearing enhancement via pressure sensitivity (Popper and Fay 1993, 2011). In gobies that do possess a swim bladder, it does not appear to play a significant role in sound detection. As a group, the auditory sensitivities of gobies possessing a swim bladder (i.e. Padogobius bonelli, Pomatoschistus minutus, and Gobius cruentatus) do not differ significantly from those lacking it (i.e. Neogobius melanostomus and Padogobius nigricans). Additionally, experimentally puncturing the swim bladder of P. bonelli did not affect auditory sensitivity (Lugli et al. 2003). 
Results from auditory evoked potential (AEP, or "auditory brainstem response") studies indicate that the tuning curves of darters, sculpins, and gobies are similar in profile (Fig. 3). The common pattern is a hearing range effectively below $1 \mathrm{kHz}$, with maximum sensitivity below $300 \mathrm{~Hz}$ and declining sensitivity with increasing frequency. In general, the audiograms are consistent with data collected for other fishes lacking ancillary auditory specializations (Popper and Fay 1993; Ladich and Fay 2013). We report here novel AEP audiograms for Etheostoma neopterum, Etheostoma flabellare, and Etheostoma oophylax (Noel 2012; Noel unpublished; Fig. 3a, b). Lowest thresholds occurred at $100-200 \mathrm{~Hz}$ at $65-80 \mathrm{~dB}$ re $1 \mu \mathrm{m} / \mathrm{s}^{2}$, which is comparable in both sensitivity and bandwidth to the AEP audiograms collected for another percid, Perca fluviatilis (Amoser and Ladich 2005). In gobies, pressure audiograms have been collected from Padogobius bonelli and Padogobius nigricans (Lugli et al. 2003), Neogobius melanostomus (Belanger et al. 2010; Zeyl et al. 2013), and Pomatoschistus pictus (Bolgan et al. 2012; Fig. 3c, d). The particle motion audiograms available for Gobius cruentatus (Wysocki et al. 2009) and $N$. melanostomus found best sensitivities at $100-200 \mathrm{~Hz}$ at $\sim 70 \mathrm{~dB}$ re $1 \mu \mathrm{m} / \mathrm{s}^{2}$. Cottus audiogram contours and bandwidths are similar to darters and gobies but thresholds are lower (Fig. 3e, f). Best sensitivities occur at 100-200 Hz at $\sim 50 \mathrm{~dB}$ re $1 \mu \mathrm{m} / \mathrm{s}^{2}$ $(\sim 90 \mathrm{~dB}$ re $1 \mu \mathrm{Pa})$, and increase with increasing frequency, although Cottus ricei exhibits a slight decrease in threshold above $800 \mathrm{~Hz}$.

\section{Signaling Efficacy Within Soundscapes}

For acoustic signals to effectively transmit information, sound frequencies must be detectable by receivers. Many vocalizing fishes produce low frequency sounds, and fishes lacking pressure detection abilities have best hearing sensitivity at frequencies less than $500 \mathrm{~Hz}$ (Popper and Fay 1993, 2011; Amorim 2006). Darters, sculpins, and gobies follow this pattern. However, within these phylogenetic constraints, low frequency signals of gobies optimize $\mathrm{S} / \mathrm{N}$ ratio via (1) a correspondence between sound dominant frequency and ambient noise acoustic window (Lugli et al. 2003; Lugli 2010), and (2) amplification of low frequencies by nest objects, stones, and bivalve shells (Lugli 2012, 2013, 2014). In addition to the dominant frequencies in the freshwater gobies Padogobius bonelli and Padogobius nigricans matching the ambient acoustic noise window $(70-150 \mathrm{~Hz})$, their audiogram best sensitivities at $100 \mathrm{~Hz}$ correspond with the lowest spectrum level of ambient noise (Lugli et al. 2003). While soundscape analysis is likely an important selective pressure on hearing in both soniferous and non-soniferous fishes (Schellert and Popper 1992; Popper and Fay 1993; Fay and Popper 2000; Ladich 2014), the evolution of sound production traits is expected to be constrained by the efficacy of information transfer in relation to both soundscapes and receiver hearing characteristics (Endler 1992).

Catonotus darters, most Cottus spp., and freshwater gobies often inhabit lotic stream habitats, where geophysical factors such as water depth, velocity, flow obstructions, and sediment load dictate the soundscape. Stream areas with an unbro- 
a

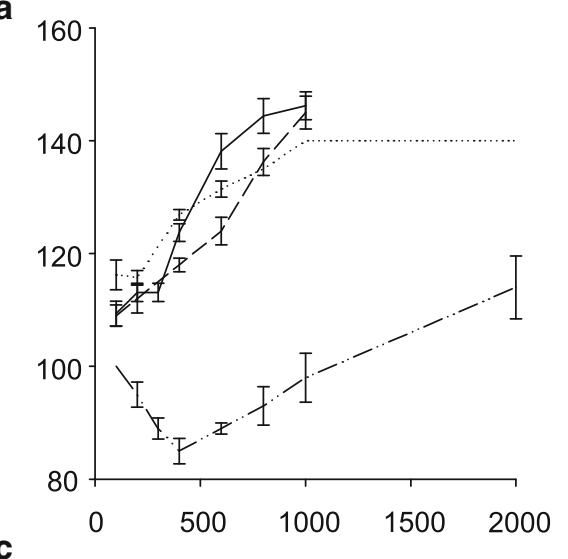

C

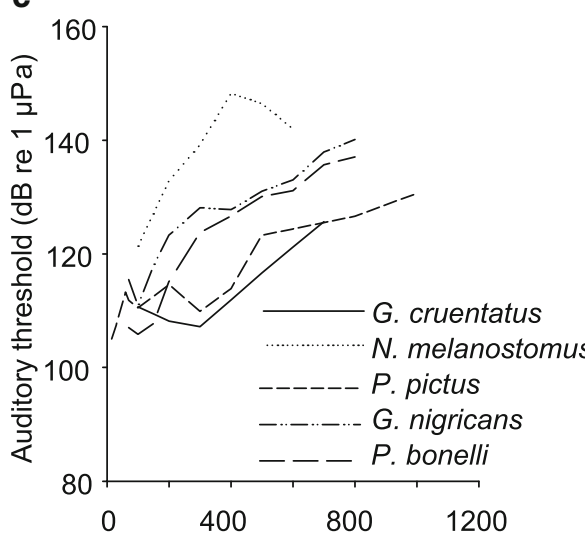

e

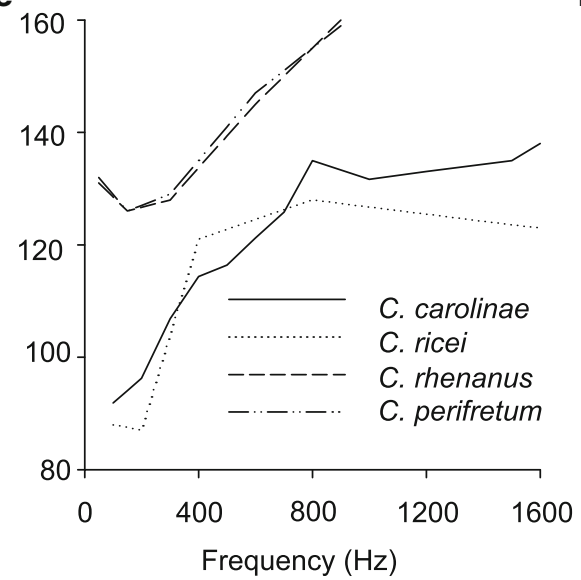

b

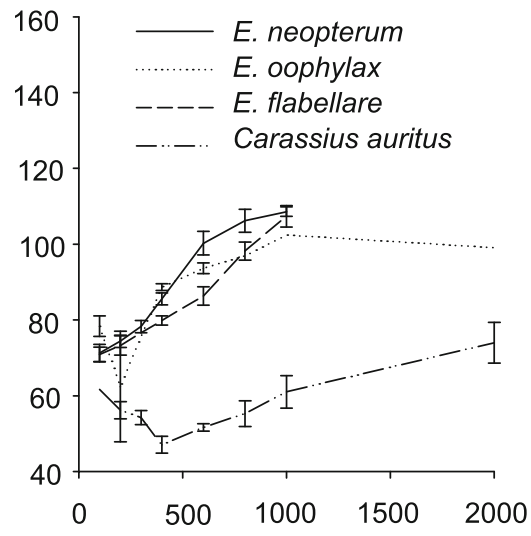

d

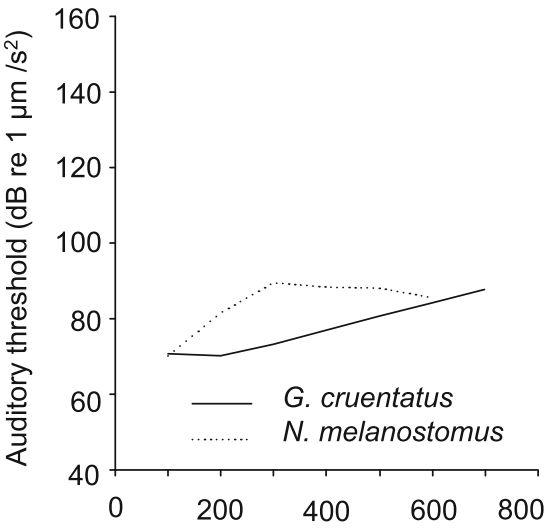

f

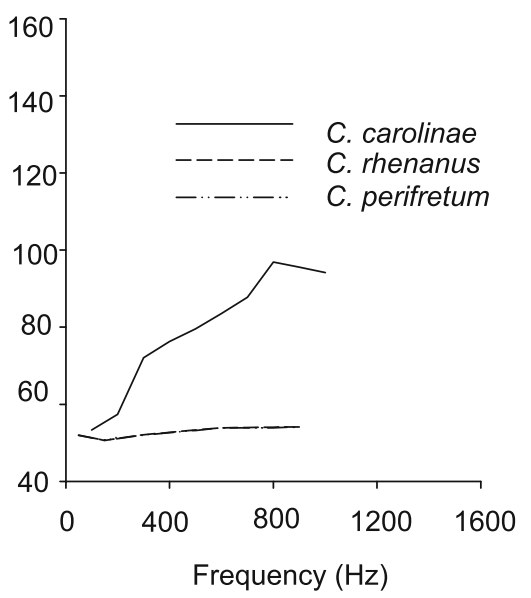

Fig. 3 Mean auditory evoked potential tone audiograms for darters $(\mathbf{a}, \mathbf{b})$, gobies $(\mathbf{c}, \mathbf{d})$, and sculpins $(\mathbf{e}, \mathbf{f})$ expressed in terms of pressure $(\mathbf{a}, \mathbf{c}, \mathbf{e})$ and particle acceleration $(\mathbf{b}, \mathbf{d}, \mathbf{f})$. Darter data are novel $($ mean $\pm \mathrm{SD})$ : Etheostoma oophylax $(n=8)$, Etheostoma neopterum $(n=8)$, Etheostoma 
ken surface are relatively quiet with a constant spectral peak at very low frequencies $(\sim 30 \mathrm{~Hz})$, regardless of flow velocity, water depth, or substrate composition (Lugli and Fine 2003; Speares et al. 2011). However, when the water surface becomes turbulent and air bubbles are trapped below the water surface, broadband spectral energy emerges between 100 and $2000 \mathrm{~Hz}$ (Lugli and Fine 2003; Wysocki et al. 2007; Tonolla et al. 2009, 2010). The frequency range of the second spectral peak is variable, but does not typically overlap with the low frequency peak of the unbroken surface waters, leaving a quiet window in a variety of freshwater and coastal habitats (Lugli and Fine 2003; Amoser and Ladich 2005; Wysocki et al. 2007; Tonolla et al. 2010). Shallow coastal habitats can generate similar low frequency quiet windows (Lugli 2010; but see Coers et al. 2008). Sources of ambient noise in freshwater and shallow marine habitats are reviewed in more detail by others (Shellert and Popper 1992; Myrberg and Lugli 2006; Lugli 2010). Given the local variability in ambient noise in freshwater habitats, further quantification of relationships between ambient noise spectra, sound spectra, and auditory sensitivity will advance our understanding of the general question, "what are fish listening to" in their respective environments, and to what extent masking has significant effects on behaviour (Fay and Popper 2012).

In addition to ambient noise, there is considerable transmission loss of low frequency sounds in shallow freshwater and coastal habitats, since sound energies are well below the cutoff frequencies of most stream habitats $(0.8 \mathrm{kHz}$ for water depth of $50 \mathrm{~cm}$ over a rigid bottom, Officer 1958; Rogers and Cox 1988). Field measurements of courtship sound transmission in Padogobius bonelli indicate an attenuation of 15-20 dB over $20 \mathrm{~cm}$ at depths of about $50 \mathrm{~cm}$ (Lugli and Fine 2003, 2007), which is more rapid decay than spherical or cylindrical spreading. The result is small active spaces for acoustic communication, with sound production often occurring when individuals are within decimeters of each other.

Absolute sound levels measured close to the fish (i.e. within $10 \mathrm{~cm}$ ) are 110-125 $\mathrm{dB} \mathrm{dB}$ re $1 \mu \mathrm{Pa}$ for Cottus species (Ladich 1989; Colleye et al. 2013), 100-138 for gobies (Lugli et al. 1995, 1997; Lindström and Lugli 2000; Stadler 2002), and 80-90 dB for darters (Speares et al. 2011). Signal-to-noise ratios within the quiet window were $40 \mathrm{~dB}$ greater than average environmental noise levels in the stony stream habitats of $P$. nigricans and $P$. bonelli and $50 \mathrm{~dB}$ greater for Knipowitschia punctatissma residing in spring habitats (Lugli 2010). In darters, Speares et al. (2011) found a 20-30 dB difference between the ambient noise and dominant

Fig. 3 (continued) flabellare $(n=5)$ (P. Noel, unpublished). A goldfish (Carassius auratus) audiogram collected under the same experimental setup is shown for comparison $(n=5)$. Goby audiogram sources include: Pomatoschitus pictus (Bolgan et al. 2012), Padogobius bonelli (formerly P. martensii) and Padogobius nigricans (Lugli et al. 2003), Gobius cruentatus (Wysocki et al. 2009), and Neogobius melanostomus (males and females averaged, Zeyl et al. 2013). Sculpin audiogram sources include: Cottus rhenanus and Cottus perifretum (Colleye et al. 2013), Cottus ricei (Mann et al. 2007), and Cottus carolinae (mean, $n=8$, JNZ unpublished). Acceleration values incorporate three orthogonal axes: $\sqrt{\left(x^{2}+y^{2}+z^{2}\right)}$. Data from Bolgan et al. (2012) and Lugli et al. (2003) were extracted from figures using Plot Digitizer (version 2.6.3) 
frequency of $E$. crossopterum, which resides in relatively quiet pools, but only about a $10 \mathrm{~dB}$ difference for $E$. flabellare, which inhabits noisier riffles.

\section{Communicative Value of Acoustic Attributes}

In addition to efficacy of information transfer, acoustic communication trait evolution is influenced by its adaptive function to the signaler and/or receiver (Davies et al. 2012). In vertebrate and non-vertebrate animals, sound production can affect reproductive success by informing female choice, facilitating male detection, and facilitating male-male resource competition (Searcy and Andersson 1986). In fishes also, sound production may be significant in influencing reproductive success (Myrberg et al. 1986; Amorim and Neves 2007; Vasconcelos et al. 2012). Specifically, sounds have been linked to female attraction and mate choice (Myrberg et al. 1986; McKibben and Bass 1998; Lindström and Lugli 2000; Amorim and Neves 2007), and intruder deterrence and threat assessment in the context of territoriality (reviews by Amorim 2006; Ladich and Myrberg 2006). More broadly, intraspecific variations in fish sounds have been related to motivation, individual variation, social context, and species identity (Amorim 2006). This section explores how acoustic parameters may be honest indicators of male quality, may reflect social context, and may reflect species identity in darters, sculpins, and gobies. Current evidence indicates that these characteristics can be encoded by sound amplitude, dominant frequency, duration, and call rate, as has been described for other fishes (Bass and McKibben 2003).

\subsection{Size and Somatic Condition}

Fish body size is predictive of success in male-male interactions and territory defense (Torricelli et al. 1988) and is often strongly correlated to reproductive success (e.g., Downhower and Brown 1980; Marconato et al. 1989). Thus, acoustic signals that are indices of male size are predicted to provide useful informative to both potential mates and territorial rivals. In courtship signaling contexts of cavity spawning fishes, more specifically, females may gain a reproductive advantage by attending to reliable indicators of successful nest defense and a low likelihood of cannibalizing eggs (Manica 2004). Thus, informative acoustic signals in these fishes could also include indices of male somatic condition that predict quality care of offspring (e.g., high fat reserves) (Amorim et al. 2009, 2010).

Sound pressure level and pulse dominant frequency are reliable indices of body size in a number of soniferous fishes (e.g., Myrberg et al. 1993; Connaughton et al. 2000; Amorim et al. 2008). These relationships have also been demonstrated in some sculpins and gobies, with larger individuals producing sounds with higher sound pressure levels (Cottus gobio: Ladich 1989; P. minutus, Lindström and Lugli 
2000; Zosterisessor opiocephalus, Malavasi et al. 2003; Pomatoschistus pictus, Pedroso et al. 2013) and lower dominant frequencies (C. gobio, Ladich 1989; Z. ophiocephalus, Malavasi et al. 2003). The mechanical basis for the amplitude relationship is that sonic muscle size determines the force of contraction and correlates positively with body size (Connaughton et al. 2000). Lower dominant frequency of larger individuals can be explained by longer contraction durations of larger muscles (Connaughton et al. 2000).

However, size does not always predict sound dominant frequency; no relationship is found between dominant frequency and male size in the gobies $P$. pictus, $P$. minutus, and P. bonelli (Torricelli et al. 1990; Amorim and Neves 2008; Pedroso et al. 2013). Where sounds are sustained and harmonic, the dominant frequency may be determined by the pulse repetition rate, which is controlled by central pattern generators, and may therefore be less sensitive to body size influences than sounds in which pulses can be individually distinguished (Bass and McKibben 2003). Similarly, harmonic plainfin midshipman hums and Mormyrid "moans" show no correlation between dominant frequency and size (Crawford et al. 1997; Bass and McKibben 2003).

Calling rate has been linked to female mate choice in benthic cavity spawning fishes. Two recent sets of studies conducted on Pomatoschistus gobies and the Lusitanian toadfish (Halobatrachus didactylus) found that call rates were correlated with male size and/or somatic condition, and were also predictive of female mate choice. Condition factor (Fulton's K) was related positively to total drumming sound output in Pomatoschistus pictus and Pomatoschistus minutus (Amorim et al. 2013a; Pedroso et al. 2013), and female P. pictus mated with males presenting high courtship effort, which corresponds with a high number of drumming sounds (Amorim et al. 2013a, b). Similarly, Halobatrachus didactylus calling rate and calling effort were correlated with male size, lipid stores, and liver mass (Amorim et al. 2010; Vasconcelos et al. 2012) and positively predicted number of eggs in the nest (Vasconcelos et al. 2012). Sonic muscle mass is strongly related to body size and liver size in H. didactylus (Amorim et al. 2009), and similar relationships have been found between drumming muscles mass and body size and condition in cod, Gadus morhua (Rowe and Hutchings 2004).

\subsection{Social Context}

In addition to internal predictors of acoustic variation, the social context may elicit changes in sound duration and dominant frequency; however, the patterns of association between these parameters and social context are variable across species. More generally in fishes, call durations are longer and pulse repetition rate is higher in courtship contexts than agonistic contexts (Amorim 2006). In the goby Pomatoschistus pictus, drum durations were longer in agonistic contexts than courtship contexts, although drumming rates were higher in courtship than agonistic contexts (Bolgan et al. 2013). Similarly, Padogobius bonelli aggressive sounds were longer in duration 
than courtship sounds (Torricelli et al. 1990). By contrast, "purr" and "knock" train durations of Etheostoma oophylax and Cottus paulus, respectively, were longer in courtship contexts than agonistic contexts (E. oophylax: $55 \mathrm{~ms}$ longer, Speares and Johnston 2011; C. paulus: 200 ms longer, Kierl and Johnston 2010).

Dominant frequencies of Padogobius bonelli courtship sounds were higher than aggressive sounds, after controlling for effects of water temperature (Torricelli et al. 1990), whereas opposite associations have been found for darters. Dominant frequencies of Etheostoma nigripinne drums and knocks were lower in courtship contexts than aggressive contexts (Johnston and Johnson 2000). Similarly, the Etheostoma oophylax purr fundamental frequency was lower in courtship relative to aggressive contexts (38 vs. 96 Hz, Speares and Johnston 2011). Despite differences in the direction of acoustic parameter variation across species, these findings indicate that males modify acoustic output based on the social context. Male evaluation of the social context in Padogobius bonelli is at least partially mediated by chemical cues, where female odour cues are necessary to elicit sounds in response to playbacks of male conspecific sounds (Lugli et al. 2004). Chemical signals stimulating courtship have been identified in Bathygobius soporator (Tavolga 1956).

\subsection{Species Identity}

For related species in sympatry, determining species identity can be an important discrimination task in the reproductive context. Species identity could be encoded by acoustic signals (Myrberg et al. 1978; Spanier 1979; Crawford et al. 1997; Lobel 1998). Selected studies of gobies and sculpins have supported findings from other fishes (i.e., Centrachidae, Mormyridae, Pomacentridae, and Cichlidae) (Kihslinger and Klimley 2002; Amorim et al. 2008) that pulse rate is a reliable species identifier. Sympatric sand gobies Pomatoschistus minutus and Pomatoschistus pictus, and sculpins Cottus perifretum and Cottus rhenanus differ in pulse repetition rate (Pedroso et al. 2013; Colleye et al. 2013). Both of these studies also found dominant frequency to effectively distinguish the sympatric species. The link between pulse dominant frequency and body size in sculpins makes this a poor species identity attribute, whereas it could be a reliable indicator in sand gobies, since there are no such body size-dominant frequency relationships in these species (Pedroso et al. 2013).

\section{Future Directions}

\subsection{How Do Acoustic Signals Modulate Spawning Physiology?}

The observation that certain sound types are restricted to when a female has entered the nest (e.g., Pomatoschistus and Knipowitschia, Lugli et al. 1997), the low sound intensity of many species, and observations of escalated sound output as spawning draws near (Lugli et al. 1997) indicate that acoustic signals may not be selected 
strictly for long-range detection and localization purposes in these taxa. One possible proximate function of acoustic signaling in vertebrates is rapid modulation of the neuroendocrine profile (e.g., Cheng et al. 1998; Remage-Healey and Bass 2005), and sculpins, darters, and gobies would be useful taxa for investigations in that direction. Exposing Etheostoma crossopterum females to male courtship sounds lead to a decline in circulating oestrogen (Noel 2012), suggesting that sounds were capable of inducing ovulation, since teleost ovulation is characterized by oestrogen decline concurrent with maturation steroid elevation (Kime 1993).

\subsection{What Selective Pressures and Constraints Affect Changes in Acoustic Repertoire?}

Darters, gobies, and sculpins could inform future investigations into the evolution of acoustic repertoire expansion in fishes because these taxa include members that exemplify the continuum of simple pulse sounds to complex and harmonic sounds, which is more broadly characteristic of fish sound diversity involving drumming mechanisms (Amorim 2006). The problem of the emergence of tonal sounds and of the relative role of tonal vs pulsatile components is a complex issue involving numerous factors; some basic constraints that may apply to the production of pulsatile versus tonal sounds and their efficacy of reception by receivers are discussed here.

Pulsatile and tonal signals could have different energetic and production costs. While fast twitch sonic muscle is highly metabolically active tissue (Parmentier and Diogo 2006), $\mathrm{O}_{2}$ consumption was not significantly elevated in toadfishes after prolonged muscle contraction, suggesting negligible energetic cost for sound production as a proportion of the total energy budget (Amorim et al. 2002). However, sound duration may be still be limited by fatigue (Mitchell et al. 2008). Rapidly contracting muscles producing tonal sounds are designed for contraction speed, which involve a suite of physiological adaptations (reviewed by Parmentier and Diogo 2006), but contraction speed can come with costs to power and/or endurance (Rome and Lindstedt 1998; Mitchell et al. 2008). Long duration tonal sounds are expected to generate fatigue more quickly than sparse pulsed sounds; trade-offs between call duration and call rate have been supported in the boatwhistles of Gulf toadfish, Opsanus beta (Thorson and Fine 2002).

Pulsatile and tonal sounds may differ in transmission in the environment and in salience in the receiver auditory system. Tonal sounds could facilitate larger active spaces than pulse trains, since tonal, frequency modulated sounds are more generally characteristic of long range signals in vertebrates (Wiley and Richards 1982; Lugli and Fine 2007). Frequency modulated sounds could increase detectability by stimulating a wider range of frequency filters in receivers (Wiley and Richards 1980). For example, tonal sounds may have evolved in association with territoriality in highly territorial Padogobius spp., where longer detection ranges would be an advantage. Differences in receiver auditory sensitivity to pulse intervals could also result in differential encoding of pulsed versus tonal sounds (e.g., Crawford 1997). 
In gobies, the relative occurrence of tonal versus pulsatile sound types can vary geographically. In a Venetian population of the rock goby Gobius paganellus, tonal sound production is the predominant sound type, with fewer pulsatile sounds, while a French population of the same species more commonly exhibits pulsatile sounds (Malavasi et al. 2008; Parmentier et al. 2013). Body size cannot be ruled out as a limiting factor explaining this geographic difference, since the French rock gobies sampled were smaller than Venetian rock gobies (Parmentier et al. 2013). At the interspecific level, tonal sounds are clearly less common than pulsatile sounds within the gobioid fishes and are found in species of maximum body size above $8.6 \mathrm{~cm}$ (Table 3); tonal sounds are absent in the smaller sized species, such as the sand gobies (genus Pomatoschistus and Knipowitschia; Table 3). However, such a size constraint seems unlikely in darters, where the relatively small Etheostoma flabellare produces sounds of high contractile rate.

\section{Conclusions}

Darters, sculpins, and gobies share similar acoustic repertoires, reproductive behaviours, sound generation mechanisms, auditory sensitivities, and soundscapes. These shared characteristics suggest evolutionary histories marked by common selective pressures on both the efficacy and information value of acoustic communication. Future comparative studies contrasting these taxa could help us to understand mechanisms of acoustic communication evolution in fishes.

Acknowledgements We are grateful for the contributions of Drs. Fay and Popper to fish bioacoustics, which have undoubtedly enhanced our study of fish acoustic communication. Their body of work on fish hearing has provided a critical resource for integrating our work on sound production into a larger context. While we have not worked directly with them, PN and JNZ were advised for their Masters degrees by Dr. Dennis Higgs, Dr. Popper's former post-doc.

\section{References}

Agorreta A, San Mauro D, Schliewen U, Van Tassell JL, Kovačić M, Zardoya R, Rüber L (2013) Molecular phylogenetics of Gobioidei and phylogenetic placement of European gobies. Mol Phylogenet Evol 69:619-633. doi:10.1016/j.ympev.2013.07.017

Amorim MCP (2006) Diversity of sound production in fish. In: Ladich F, Collin SP, Moller P, Kapoor BG (eds) Communication in fishes, vol I. Science Publishers, Enfield, pp 71-105

Amorim MCP, McCracken ML, Fine ML (2002) Metabolic costs of sound production in the oyster toadfish, Opsanus tau. Can J Zool 80:830-838. doi:10.1139/z02-054

Amorim MCP, Neves ASM (2007) Acoustic signalling during courtship in the painted goby, Pomatoschistus pictus. J Mar Biol Assoc UK 87:1017-1023. doi:10.1017/S0025315407056822

Amorim MCP, Neves ASM (2008) Male painted goby (Pomatoschistus pictus) vocalise to defend territories. Behaviour 145:1065-1083 
Amorim MCP, Simões JM, Fonseca PJ, Turner GF (2008) Species differences in courtship acoustic signals among five Lake Malawi cichlid species (Pseudotropheus spp.). J Fish Biol 72:1355-1368. doi:10.1111/j.1095-8649.2008.01802.x

Amorim MCP, Simões JM, Mendonça N, Bandarra NM, Almada VC, Fonseca PJ (2010) Lusitanian toadfish song reflects male quality. J Exp Biol 213:2997-3004. doi:10.1242/jeb.044586

Amorim MCP, Pedroso SS, Bolgan M, Jordão JM, Caiano M, Fonseca PJ (2013a) Painted gobies sing their quality out loud: acoustic rather than visual signals advertise male quality and contribute to mating success. Funct Ecol 27:289-298. doi:10.1111/1365-2435.12032

Amorim MCP, da Ponte AN, Caiano M, Pedroso SS, Pereira R, Fonseca PJ (2013b) Mate preference in the painted goby: the influence of visual and acoustic courtship signals. J Exp Biol 216:3996-4004. doi:10.1242/jeb.088682

Amorim MCP, Vasconcelos RO, Parreira B (2009) Variability in the sonic muscles of the Lusitanian toadfish (Halobatrachus didactylus): acoustic signals may reflect individual quality. Can J Zool 87:718-725. doi:10.1139/Z09-067

Amoser S, Ladich F (2005) Are hearing sensitivities of freshwater fish adapted to the ambient noise in their habitats? J Exp Biol 208:3533-3542. doi:10.1242/jeb.01809

Barber SB, Mowbray WH (1956) Mechanism of sound production in the sculpin. Science 124:219-220. doi:10.1126/science.124.3214.219

Bass A, Baker R (1991) Evolution of homologous vocal control traits. Brain Behav Evol 38: 240-254. doi:10.1159/000114391

Bass AH, McKibben JR (2003) Neural mechanisms and behaviours for acoustic communication in teleost fish. Prog Neurobiol 69:1-26. doi:10.1016/S0301-0082(03)00004-2

Belanger AJ, Bobeica I, Higgs DM (2010) The effect of stimulus type and background noise on hearing abilities of the round goby Neogobius melanostomus. J Fish Biol 77:1488. doi:10.1111/j.1095-8649.2010.02773.x

Betancur-R. R, Broughton RE, Wiley EO, Carpenter K, López JA, Li C, Holcroft NI, Arcila D, Sanciangco M, Cureton II JC, Zhang F, Buser T, Campbell MA, Ballesteros JA, Roa-Varon A, Willis S, Borden WC, Rowley T, Reneau PC, Hough DJ, Lu G, Grande T, Arratia G, Ortí G (2013) The tree of life and a new classification of bony fishes. PLoS Curr. doi:10.1371/currents.tol.53ba26640df0ccaee75bb165c8c26288

Bolgan M, Pedroso SS, Vasconcelos RO, Jordão JM, Amorim MCP, Fonseca PJ, Fonseca PJ (2012) Hearing sensitivity of the painted goby, Pomatoschistus pictus. In: Popper AN, Hawkins A (eds) The effects of noise on aquatic life. Springer, New York, pp 109-111

Bolgan M, Pedroso SS, Picciulin M, Fonseca PJ, Amorim MCP (2013) Differential investment in acoustic communication during social interactions in two closely-related sand goby species. Behaviour 150(2):133-152. doi:10.1163/1568539X-00003041

Bradbury JW, Vehrencamp SL (1998) Principles of Animal Communication. Sinauer Associates, Sunderland

Cheng M-F, Peng JP, Johnson P (1998) Hypothalamic neurons preferentially respond to female nest coo stimulation: demonstration of direct acoustic stimulation of luteinizing hormone release. J Neurosci 18:5477-5489

Connaughton MA, Taylor MH, Fine ML (2000) Effects of fish size and temperature on weakfish disturbance calls: implications for the mechanism of sound generation. J Exp Biol 203:1503-1512

Colleye O, Ovidio M, Salmon A, Parmentier E (2013) Contribution to the study of acoustic communication in two Belgian river bullheads (Cottus rhenanus and C. perifretum) with further insight into the sound-producing mechanism. Frontiers Zool 10:71. doi:10.1186/1742-9994-10-71

Coers A, Bouton N, Vincourt D, Slabbekoorn H (2008) Fluctuating noise conditions may limit acoustic communication distance in the rock-pool blenny. Bioacoustics 17:63-65. doi:10.1080 /09524622.2008.9753765

Crawford JD (1997) Hearing and acoustic communication in Mormyrid electric fishes. Mar Fresh Behav Physiol 29:65-86. doi:10.1080/10236249709379001 
Crawford JD, Cook AP, Heberlein AS (1997) Bioacoustic behavior of African fishes (Mormyridae): potential cues for species and individual recognition in Pollimyrus. J Acoust Soc Am 102: 1200-1212. doi:10.1121/1.419923

Davies NB, Krebs JR, West SA (2012) An introduction to behavioural ecology. Wiley, West Sussex, UK

Demski LS, Gerald JW, Popper AN (1973) Central and peripheral mechanisms of teleost sound production. Am Zool 13:1141-1167

Downhower JF, Brown L (1980) Mate preferences of female mottled sculpins, Cottus bairdi. Anim Behav 28:728-734. doi:10.1016/S0003-3472(80)80132-1

Endler JA (1992) Signals, signal conditions, and the direction of evolution. Am Nat 139:S125-S153

Ennis GP (1970) Reproduction and associated behaviour in the shorthorn sculpin, Myoxocephalus scorpius in Newfoundland waters. J Fish Res Board Can 27:2037-2045. doi:10.1139/f70-227

Evans JD, Page LM (2003) Distribution and relative size of the swim bladder in Percina, with comparisons to Etheostoma, Crystallaria, and Ammocrypta (Teleostei: Percidae). Environ Biol Fishes 66:61-65. doi:10.1023/A:1023238125892

Fay RR, Popper AN (2000) Evolution of hearing in vertebrates: the inner ears and processing. Hear Res 149:1-10. doi:10.1016/S0378-5955(00)00168-4

Fay RR, Popper AN (2012) Fish hearing: new perspectives from two "senior" bioacousticians. Brain Behav Evol 79:215-217

Fish MP, Mowbray WH (1970) Sounds of Western North Atlantic fishes. A reference file of biological underwater sounds. Johns Hopkins Press, Baltimore

Gkenas C, Malavasi S, Georgalas V, Leonardos ID, Torricelli P (2010) The reproductive behaviour of Economidichthys pygmaeus: secondary loss of sound production within the sand goby group? Environ Biol Fishes 87:299-307. doi:10.1007/s10641-010-9597-x

Goto A (1993) Male mating success and female mate choice in the river sculpin, Cottus nozawae (Cottidae). Environ Biol Fishes 37:347-353. doi:10.1007/BF00005202

Hallacher LE (1974) The comparative morphology of extrinsic gasbladder musculature in the scorpionfish genus Sebastes (Pisces, Scorpaenidae). Proc Calif Acad Sci 40:59-86

Hesthagen IH, Koefoed JH (1979) A note on the existence of a well-developed swimbladder in the bottom-living goby Pomatoschistus minutus. J Fish Biol 14:225-228. doi:10.1111/j.10958649.1979.tb03513.x

Huyse T, Van Houdt J, Volckaert AM (2004) Paleoclimatic history and vicariant speciation in the 'sand goby' group (Gobiidae, Teleostei). Mol Phylogenet Evol 32:324-336

Johnston CE, Johnson DL (2000) Sound production during the spawning season in cavity-nesting darters of the subgenus Catonotus (Percidae: Etheostoma). Copeia 2000:475-481. doi:10.1643/0045-8511(2000)000[0475:SPDTSS]2.0.CO;2

Kierl NC, Johnston CE (2010) Sound production in the pygmy sculpin Cottus paulus (Cottidae) during courtship and agonistic behaviours. J Fish Biol 77:1268-1281. doi:10.1111/j.1095-8649.2010.02745.x

Kihslinger RL, Klimley PA (2002) Species identity and the temporal characteristics of fish acoustic signals. J Comp Psychol 116:210-214. doi:10.1037/0735-7036.116.2.210

Kime DE (1993) "Classical” and "non-classical" reproductive steroids in fish. Rev Fish Biol Fish 3:160-180. doi:10.1007/BF00045230

Kinziger AP, Wood RM, Neely DA, Douglas ME (2005) Molecular systematics of the genus Cottus (Scorpaeniformes: Cottidae). Copeia 2005:303-311. doi:10.1643/CI-03-290R1

Kishi Y (1979) Social behaviour of the goby Tridentiger obscurus. Hiyoshi Sci Rev 15:127-429 (English summary)

Knapp RA, Sargent RC (1989) Egg-mimicry as a mating strategy in the fantail darter, Etheostoma flabellare: females prefer males with eggs. Behav Ecol Sociobiol 25:321-326

Knouft JH, Page LM, Plewa MJ (2003) Antimicrobial egg cleaning by the fringed darter (Perciformes: Percidae: Etheostoma crossopterum): implications of a novel component of parental care in fishes. Proc Biol Sci 270:2405-2411. doi:10.1098/rspb.2003.2501 
Ladich F (1989) Sound production by the river bullhead, Cottus gobio L. (Cottidae, Teleostei). J Fish Biol 35:531-538. doi:10.1111/j.1095-8649.1989.tb03004.x

Ladich F (2014) Fish bioacoustics. Curr Opin Neurobiol 28:121-127. doi:10.1016/j. conb.2014.06.013

Ladich F, Fay RR (2013) Auditory evoked potential audiometry in fish. Rev Fish Biol Fisheries 23:317-364. doi: 10.1007/s11160-012-9297-z

Ladich F, Fine ML (2006) Sound-generating mechanisms in fishes: a unique diversity in vertebrates. In: Ladich F, Collin SP, Moller P, Kapoor BG (eds) Communication in fishes, vol I. Science Publishers, Enfield, pp 3-43

Ladich F, Kratochvil H (1989) Sound production by the marmoreal goby Proterorhinus marmoratus (Pallas) (Gobiidae, Teleostei). Zool Jb Physiol 93:501-504

Ladich F, Myrberg A (2006) Agonistic behavior and acoustic communication. In: Ladich F, Collin S, Moller P, Kapoor B (eds) Communication in fishes. Vol I. Science Publishers, New Hampshire, pp 121-148

Lindström K, Hellström M (1993) Male size and parental care in the sand goby, Pomatoschistus minutus. Ethol Ecol Evol 5:97-106. doi:10.1080/08927014.1993.9523117

Lindström K, Lugli M (2000) A quantitative analysis of the courtship acoustic behaviour and sound patterning in male sand goby, Pomatoschistus minutus. Environ Biol Fish 58:411-424. doi:10.1023/A:1007695526177

Lobel PS (1998) Possible species specific courtship sounds by two sympatric cichlid fishes in Lake Malawi, Africa. Environ Biol Fish 52:443-452. doi:10.1023/A:1007467818465

Lugli M (2010) Sounds of shallow water fishes pitch within the quiet window of the habitat ambient noise. J Comp Physiol A 196:439-451. doi:10.1007/s00359-010-0528-2

Lugli M (2012) Acoustics of fish shelters: frequency response and gain properties. J Acoust Soc Am 132:3512-3524. doi:10.1121/1.4754581

Lugli M (2013) Sand pile above the nest amplifies the sound emitted by the male sand goby. Environ Biol Fish 96:1003-1012. doi:10.1007/s10641-012-0097-z

Lugli M (2014) Acoustics of fish shelters: background noise and signal-to-noise ratio. J Acoust Soc Am 136:3382-3388

Lugli M, Fine ML (2003) Acoustic communication in two freshwater gobies: ambient noise and short-range propagation in shallow streams. J Acoust Soc Am 114:512-521. doi: $10.1121 / 1.1577561$

Lugli M, Fine ML (2007) Stream ambient noise, spectrum and propagation of sounds in the goby Padogobius martensii: Sound pressure and particle velocity. J Acoust Soc Am 122:2881-2892. doi:10.1121/1.2783113

Lugli M, Torricelli P (1999) Prespawning sound production in Mediterranean sand-gobies. J Fish Biol 54:691-694

Lugli M, Pavan G, Torricelli P, Bobbio L (1995) Spawning vocalizations in male freshwater gobiids (Pisces, Gobiidae). Environ Biol Fish 43:219-231. doi:10.1007/BF00005853

Lugli M, Torricelli P, Pavan G, Miller PJ (1996) Breeding sounds of male Padogobius nigricans with suggestions for further evolutionary study of vocal behaviour in gobioid fishes. J Fish Biol 49:648-657

Lugli M, Torricelli P, Pavan G, Mainardi D (1997) Sound production during courtship and spawning among freshwater gobiids (Pisces, Gobiidae). Mar Freshw Behav Physiol 29:109-126. doi:10.1080/10236249709379003

Lugli M, Yan HY, Fine ML (2003) Acoustic communication in two freshwater gobies: the relationship between ambient noise, hearing thresholds and sound spectrum. J Comp Physiol A 189:309-320. doi:10.1007/s00359-003-0404-4

Lugli M, Pavan G, Torricelli P (2004) The response of the male freshwater goby to natural and synthetic male courtship sound playback following exposure to different female sexual stimuli. Ethol Ecol Evol 16:55-70. doi:10.1080/08927014.2004.9522654 
Malavasi S, Torricelli P, Lugli M, Pravoni F, Mainardi D (2003) Male courtship sounds in a teleost with alternative reproductive tactics, the grass goby, Zosterisessor ophiocephalus. Environ Biol Fish 66:231-236. doi:10.1023/A:1023923403180

Malavasi S, Collatuzzo S, Torricelli P (2008) Interspecific variation of acoustic signals in Mediterranean gobies (Perciformes, Gobiidae): Comparative analysis and evolutionary outlook. Biol J Linn Soc 93:763-778. doi:10.1111/j.1095-8312.2008.00947.x

Malavasi S, Valerio C, Torricelli P (2009) Courtship sounds and associated behaviours in the Canestrini's goby Pomatoschistus canestrinii. J Fish Biol 75:1883-1887

Manica A (2004) Parental fish change their cannibalistic behaviour in response to the cost-tobenefit ratio of parental care. Anim Behav 67:1015-1021. doi:10.1016/j.anbehav.2003.09.011

Mann DA (2006) Propagation of fish sounds. In: Ladich F, Collin S, Moller P, Kapoor B (eds) Communication in fishes. Vol I. Science Publishers, New Hampshire, pp 107-120

Mann DA, Cott PA, Hanna BW, Popper AN (2007) Hearing in eight species of northern Canadian freshwater fishes. J Fish Biol 70:109-120. doi:10.1111/j.1095-8649.2006.01279.x

Marconato A, Bisazza A, Marin G (1989) Correlates of male reproductive success in Padogobius martensi (Gobiidae). J Fish Biol 34:889-899. doi:10.1111/j.1095-8649.1989.tb03372.x

McKibben JR, Bass AH (1998) Behavioral assessment of acoustic parameters relevant to signal recognition and preference in a vocal fish. J Acoust Soc Am 104:3520-3533. doi:10.1121/ 1.423938

Mitchell S, Poland J, Fine ML (2008) Does muscle fatigue limit advertisement calling in the oyster toadfish Opsanus tau? Anim Behav 76:1011-1016. doi: 10.1016/j.anbehav.2008.03.024

Mok HK (1981) Sound production in the naked goby Gobiosoma bosci (Pisces, Gobiidae) - a preliminary study. In: Tavolga WN, Popper AN, Fay RR (eds) Hearing and sound communication in fishes. Springer, New York, pp 447-456

Morris D (1954) The reproductive behaviour of the river bullhead (Cottus gobio L.), with special reference to the fanning activity. Behaviour 7:1-32. doi:10.1163/156853955X00012

Myrberg AA, Lugli M (2006) Reproductive behavior and acoustical interactions. In: Ladich F, Collin SP, Moller P, Kapoor BG (eds) Communication in fishes, vol I. Science Publishers, Enfield, pp 149-176

Myrberg AA, Spanier E, Ha SJ (1978) Temporal patterning in acoustical communication. Contrasts in behavior. Wiley, New York, pp 137-179

Myrberg AA Jr, Mohler M, Catala JD (1986) Sound production by males of a coral reef fish (Pomacentrus partitus): its significance to females. Anim Behav 34:913-923. doi:10.1016/ S0003-3472(86)80077-X

Myrberg AA Jr, Ha SJ, Shamblott MJ (1993) The sounds of bicolor damselfish (Pomacentrus partitus): predictors of body size and a spectral basis for individual recognition and assessment. J Acoust Soc Am 94:3067-3070. doi:10.1121/1.407267

Nelson JS (2006) Fishes of the world. Wiley, Hoboken, New Jersey

Noel PS (2012) Acoustic communication, reproduction and hormone modulation in the Catonotus darters. Auburn University Dissertation

Officer CB (1958) Introduction to the theory of sound transmission. McGraw-Hill, New York

Page LM (1985) Evolution of reproductive behaviours in percid fishes. Bull Ill Nat Hist Surv 33:275-295

Page LM, Hardman M, Near TJ, Buth DG (2003) Phylogenetic relationships of barcheek darters (Percidae: Etheostoma, Subgenus Catonotus) with descriptions of two new species. Copeia 2003:512-530. doi:10.1643/CI-02-259R

Panchenko VV (2001a) Reproduction peculiarities of plain sculpin Myoxocephalus jaokin Peter the Great Bay, Sea of Japan. Russ J Mar Biol 27:111-112. doi:10.1023/A:1016651415508

Panchenko VV (2001b) Reproduction of snowy sculpin Myoxocephalus brandti (Cottidae) in Peter the Great Bay, Sea of Japan. Russ J Mar Biol 27:329-332. doi:10.1023/A:1012560816492

Parmentier E, Diogo R (2006) Evolutionary trends of swimbladder sound mechanisms in some teleost fishes. In: Ladich F, Collin SP, Moller P, Kapoor BG (eds) Communication in fishes, vol I. Science Publishers, Enfield, pp 71-105 
Parmentier E, Kéver L, Boyle K, Corbisier Y, Sawelew L, Malavasi S (2013) Sound production mechanism in Gobius paganellus (Gobiidae). J Exp Biol 216:3189-3199. doi:10.1242/ jeb.087205

Pedroso SS, Barber I, Svensson O, Fonseca PJ, Amorim MCP et al (2013) Courtship sounds advertise species identity and male quality in sympatric Pomatoschistus spp. gobies. PLoS One 8:e64620. doi:10.1371/journal.pone.0064620

Polgar G, Malavasi S, Cipolato G, Georgalas V, Clack JA, Torricelli P (2011) Acoustic communication at the water's edge: Evolutionary insights from a mudskipper. PLoS One 6:e21434. doi:10.1371/journal.pone.0021434

Popper AN, Fay RR (1993) Sound detection and processing by fish: critical review and major research questions. Brain Behav Evol 41:14-38. doi:10.1159/000113821

Popper AN, Fay RR (2011) Rethinking sound detection by fishes. Hear Res 273:25-36. doi:10.1016/j.heares.2009.12.023

Remage-Healey L, Bass AH (2005) Rapid elevations in both steroid hormones and vocal signaling during playback challenge: a field experiment in Gulf toadfish. Horm Behav 47:297-305. doi:10.1016/j.yhbeh.2004.11.017

Rogers PH, Cox M (1988) Underwater sound as a biological stimulus. In: Fay RR, Popper AN, Tavolga WN, Atema J (eds) Sensory biology of aquatic animals. Springer, New York, pp 131-149

Rollo A, Andraso G, Janssen J, Higgs D (2007) Attraction and localization of round goby (Neogobius melanostomus) to conspecific calls. Behaviour 144:1-21. doi:10.1163/156853907779947391

Rome LC, Lindstedt SL (1998) The quest for speed: muscles built for high-frequency contractions. News Physiol Sci 13:261-268

Rowe S, Hutchings JA (2004) The function of sound production by Atlantic cod as inferred from patterns of variation in drumming muscle mass. Can J Zool 82:1391-1398. doi:10.1139/ z04-119

Schellart NAM, Popper AN (1992) Functional aspects of the evolution of the auditory system of Actinopterygian fish. In: Webster DB, Popper AN, Fay RR (eds) The evolutionary biology of hearing. Springer New York, pp 295-322

Searcy WA, Andersson M (1986) Sexual selection and the evolution of song. Ann Rev Ecol Syst 17:507-533. doi:10.1146/annurev.es.17.110186.002451

Sebastianutto L, Picciulin M, Costantini M, Rocca M, Ferrero E (2008) Four types of sounds from one winner: vocalizations during territorial behaviour in the red-mouthed goby Gobius cruentatus (Pisces, Gobiidae). Acta Ethol 11:115-121

Šrović A, Demer DA (2009) Sounds of captive rockfishes. Copeia 2009:502-509. doi:10.1643/ CP-08-121

Spanier E (1979) Aspects of species recognition by sound in four species of damselfishes, genus Eupomacentrus (Pisces: Pomacentridae). Z Tierpsychol 51:301-316. doi:10.1111/j.14390310.1979.tb00691.x

Speares P, Johnston C (2011) Sound production in Etheostoma oophylax (Percidae) and call characteristics correlated to body size. Environ Biol Fish 92:461-468. doi:10.1007/ s10641-011-9863-6

Speares P, Holt D, Johnston C (2011) The relationship between ambient noise and dominant frequency of vocalizations in two species of darters (Percidae: Etheostoma). Environ Biol Fish 90:103-110. doi:10.1007/s10641-010-9722-x

Stadler JH (2002) Evidence for a hydrodynamic mechanism of sound production by courting males of the notchtongue goby, Bathygobius curacao (metzelaar). Bioacoustics 13:145-152. doi:10.1080/09524622.2002.9753492

Takemura A (1984) Acoustical behaviour of the freshwater goby Odontobutis obscura. Bull Jpn Soc Sci Fish 50:561-564

Tavolga WM (1956) Visual, chemical and sound stimuli as cues in the sex discriminatory behaviour of the gobiid fish Bathygobius soporator. Zoologica 41:49-65 
Tavolga WN (1958) The significance of underwater sounds produced by males of the gobiid fish, Bathygobius soporator. Physiol Zool 259-271

Thacker CE (2003) Molecular phylogeny of the gobioid fishes (Teleostei, Perciformes, Gobioidei). Mol Phylogen Evol 26:354-368

Thacker CE (2009) Phylogeny of Gobioidei and placement within Acantomorpha with a new classification and investigation of diversification and character evolution. Copeia 2009:93-104

Thacker CE, Roje DM (2011) Phylogeny of Gobiidae and identification of gobiid lineages. Syst Biodivers 9:329-347

Thorson RF, Fine ML (2002) Crepuscular changes in emission rate and parameters of the boatwhistle advertisement call of the gulf toadfish, Opsanus beta. Environ Biol Fish 63:321-331. doi:10.1023/A:1014334425821

Tonolla D, Lorang MS, Heutschi K, Tockner K (2009) A flume experiment to examine underwater sound generation by flowing water. Aquat Sci 71:449-462

Tonolla D, Acuña V, Lorang MS, Heutschi K, Tockner K (2010) A field-based investigation to examine underwater soundscapes of five common river habitats. Hydrol Process 24:3146-3156

Torricelli P, Lugli M, Gandolfi G (1985) A quantitative analysis of the fanning activity in the male Padogobius martensi (Pisces: Gobiidae). Behaviour 92:288-301

Torricelli P, Parmigiani S, Lugli M, Gandolfi G (1988) Intermale aggression in Padogobius martensi (günther) (pisces Gobiidae): effect of size and prior residence. Monit Zoolog Ital - Ital. J Zool 22:121-131. doi:10.1080/00269786.1988.10736547

Torricelli P, Lugli M, Pavan G (1990) Analysis of sounds produced by male Padogobius martensi (pisces, Gobiidae) and factors affecting their structural properties. Bioacoustics 2:261-275. doi $: 10.1080 / 09524622.1990 .9753141$

Vasconcelos RO, Carriço R, Ramos A, Modesto T, Fonseca PJ, Amorim MCP (2012) Vocal behavior predicts reproductive success in a teleost fish. Behav Ecol 23:375-383. doi:10.1093/beheco/ $\operatorname{arr} 199$

Whang, A (1992) Hydromechanical communication during re- productive behavior in three species of sculpin (Cottidae). MS Thesis, Loyola University of Chicago, Chicago. 54 pp.

Whang A, Janssen J (1994) Sound production through the substrate during reproduction in the mottled sculpin, Cottus bairdi (Cottidae). Environ Biol Fish 40:141-148. doi:10.1007/ BF00002540

Wiley RH, Richards DG (1982) Adaptations of acoustic communication in birds: sound transmission and signal detection. Acoustic communication in birds. Academic Press, New York, pp 131-278

Wysocki LE, Amoser S, Ladich F (2007) Diversity in ambient noise in European freshwater habitats: noise levels, spectral profiles, and impact on fishes. J Acoust Soc Am 121:2559-2566. doi:10.1121/1.2713661

Wysocki LE, Codarin A, Ladich F, Picciulin M (2009) Sound pressure and particle acceleration audiograms in three marine fish species from the Adriatic Sea. J Acoust Soc Am 126:2100 2107. doi: $10.1121 / 1.3203562$

Yokoyama R, Goto A (2005) Evolutionary history of freshwater sculpins, genus Cottus (Teleostei; Cottidae) and related taxa, as inferred from mitochondrial DNA phylogeny. Mol Phylogen Evol 36:654-668. doi:10.1016/j.ympev.2005.06.004

Zeyl JN, Love OP, Higgs DM (2013) Condition-dependent auditory processing in the round goby (Neogobius melanostomus): links to sex, reproductive condition and female estrogen levels. J Exp Biol 216:1075-1084. doi:10.1242/jeb.076935

Zhang G, Takemura A (1989) Acoustic behaviour of brown goby Bathygobius fuscus. Bull Fac Fish Nagasaki University 66:21-30 (in Japanese) 


\title{
Directional Hearing and Sound Source Localization in Fishes
}

\author{
Joseph A. Sisneros and Peter H. Rogers
}

\begin{abstract}
Evidence suggests that the capacity for sound source localization is common to mammals, birds, reptiles, and amphibians, but surprisingly it is not known whether fish locate sound sources in the same manner (e.g., combining binaural and monaural cues) or what computational strategies they use for successful source localization. Directional hearing and sound source localization in fishes continues to be important topics in neuroethology and in the hearing sciences, but the empirical and theoretical work on these topics have been contradictory and obscure for decades. This chapter reviews the previous behavioral work on directional hearing and sound source localization in fishes including the most recent experiments on sound source localization by the plainfin midshipman fish (Porichthys notatus), which has proven to be an exceptional species for fish studies of sound localization. In addition, the theoretical models of directional hearing and sound source localization for fishes are reviewed including a new model that uses a time-averaged intensity approach for source localization that has wide applicability with regard to source type, acoustic environment, and time waveform.
\end{abstract}

Keywords Particle motion • Sound pressure • Inner ear • Phonotaxis • Hair cell

\section{Introduction}

The underwater acoustic environment consists of dynamic and complex soundscapes where animals must be able to behave appropriately toward all objects and events in order to survive and reproduce. Part of this requirement for appropriate

\footnotetext{
J.A. Sisneros $(\varangle)$

Department of Psychology, University of Washington, Seattle, WA 98195, USA

Department of Biology, University of Washington, Seattle, WA 98195, USA

e-mail: sisneros@uw.edu

P.H. Rogers

George W. Woodruff School of Mechanical Engineering, Georgia Institute of Technology,

Atlanta, GA 30332, USA
} 
behavior is the capacity to assign all acoustic components to their appropriate sources, and not to confuse the components from multiple independent sources with a single source. This capability is known as the capacity for "source segregation" as specifically demonstrated for humans (Bregman 1990), European starlings (Hulse et al. 1997), and goldfish (Fay 1998, 2000). Source segregation is a fundamental component of "auditory scene analysis," a proposed model for the basis of auditory perception where the listener parses the "acoustic ambience" or the mixtures of sounds into specific, independent sources (biotic and abiotic alike), analogous to a visual scene (Bregman 1990). By definition, everything in the auditory scene is biologically significant to the extent that the components of abiotic noise, for example, must be segregated from biotic communication sounds in order for the communication signals to be properly interpreted.

A component of source segregation is sound source localization. Evidence suggests that the capacity for sound source localization is common to mammals, birds, reptiles, and amphibians (Grothe et al. 2010). Sound source localization gives the scene a spatial dimension, making it comparable to the visual scene. Surprisingly, it is not known whether fishes locate sound sources in the same manner (e.g., combining binaural and monaural cues) or what computational strategies they use for successful source localization (Fay 2005). Sound source localization has been difficult to conceive of for fishes because they are assumed not to use the same binaural acoustic cues as terrestrial animals for the localization of sound sources. In fish, the two ears (e.g., saccules, which are the main organ of hearing in most fishes) are not stimulated independently and the interaural time difference (ITD) and interaural level difference (ILD) cues are too small to be utile for source localization. Furthermore, acoustic particle motion, not sound pressure, is required to stimulate the ears of fish directly and in a directional manner (Fay 1984; Edds-Walton et al. 1999). In addition to these considerations, the dominant theories for sound source localization by fishes, e.g., the "phase" model by Schuijf (1975) and the computational model by Rogers et al. (1988), are rather complex and many fish species seem to lack the ability to detect the acoustic cues (i.e., sound pressure) that are theoretically necessary (see Sect. 3 in Models of Directional Hearing and Sound Localization). Thus, the question of how fish locate sound sources remains an open one. Directional hearing and sound source localization in fishes continues to be important topics in the neuroethology and evolutionary biology of hearing, but the empirical and theoretical work on these topics have been contradictory and obscure for decades.

This review summarizes the previous behavioral work on directional hearing and sound source localization in fishes and the most recent experiments on source localization in the plainfin midshipman fish, Porichthys notatus, which has proven to be an exceptional species for fish studies of sound localization. In addition, we also review the theoretical models of directional hearing and sound source localization in fishes, and discuss new directions for future research. 


\subsection{Underwater Sound and the Acoustic Cues Available to Fish}

Sound is a mechanical disturbance that propagates as a longitudinal wave through a medium (e.g., air, water, or other material, see Beranek 1954). When a disturbance occurs, energy is radiated away from the source in the form of sound pressure and particle motion. In water close to the source, the pressure is high and the particle motion is large due to incompressible fluid flow. Away from the source, the pressure remains relatively large with small but finite particle motion. Sound pressure is a scalar quantity that conveys the magnitude of pressure fluctuations relative to the ambient pressure at a fixed point of measurement. Pressure is the component of sound that we are most accustomed because it is the component that most terrestrial ears sense and is what is measured using a microphone or hydrophone. Sound pressure sensors only convey the amplitude and time course of pressure fluctuations and not information related to sound source directionality. In contrast, particle motion is the actual displacement of the particles constituting the medium and is a vector quantity having both magnitude and direction. Particle motion sensors can thus convey information about source direction and angle. In air, particle motion decays to small values very rapidly and we rarely are subject to it, but due to the higher density and correspondingly longer wavelengths of underwater sound, it remains at relatively high amplitudes at greater distances from the underwater sound source (particle motion predominates within about a wavelength from the source). For example, in water the wavelength of $100 \mathrm{~Hz}$ (a frequency similar to the fundamental frequency of the male plainfin midshipman's advertisement call) is approximately $15 \mathrm{~m}$. Thus, particle motion may provide fish with salient acoustic cues at large distances from sound sources and offer directional information to fish that they may be able to exploit for sound source localization. Conversely, traditional "terrestrial" localization cues, i.e., the ITDs and ILDs computed via the comparison of the pressure waveform at two different pressure sensors (e.g., left and right eardrums), are thought to be negligible for most fish. This, in part, is due to the speed of underwater sound which is nearly five times faster in water than in air, reducing underwater ITDs by $\sim 80 \%$ (relative to terrestrial ITDs). Thus, the maximum ITD experienced by a fish with an interaural distance of less than $3 \mathrm{~cm}$ should be $30 \mu \mathrm{s}$ or less, which is at or near the threshold ITD of the most sensitive terrestrial vertebrates (Grothe et al. 2010). Furthermore, because fish are approximately the same density as water there is little or no attenuation of sound as it travels from one ear through the head to the other ear (i.e., ILDs are also $\sim 0 \mathrm{~dB}$ ). However, in fish the orthogonal orientation of the left and right saccule with their complementary hair cell orientations could 
theoretically provide robust and uniquely underwater binaural cues for sound localization.

\subsection{Fish Inner Ears and Modes of Hearing}

The inner ear of fishes includes three semicircular canals that encode angular momentum in each plane (vestibular function) and three otolithic end organs (saccule, lagena, and utricle) that may serve an auditory and/or vestibular (positional) function (Platt and Popper 1981; Popper and Fay 1993). Each end organ has a distinct pattern of sensory hair cell orientations that are arranged in different planes, which provide the potential for three-dimensional encoding of the vector of particle motion for sound source localization. Of the three otolithic end organs, the saccule is the end organ most often implicated for use in hearing in teleost fishes (Popper and Fay 1993). The possible acoustic functions of the utricle and lagena are not well understood, but previous studies suggest that both the utricle and lagena are capable of coding acoustic particle motion (Lu et al. 2003, 2004; Meyer et al. 2010, 2012).

Fishes have evolved at least two modes of hearing: (1) a pressure-mediated mode, found in derived teleost species (e.g., otophysans) with special morphological adaptations for transducing the pressure-induced vibrations of the swim bladder to inner ear acoustic end organs (e.g., Weberian ossicles or gas-filled vesicles in close proximity to the inner ear) that can be used to enhance pressure detection although some fish (e.g., the cod and midshipman) can sense acoustic pressure from pressure-induced swim bladder vibration even in the absence of any special morphological adaptations (Sand and Enger 1973; Chapman and Sand 1974; Tytler and Blaxter 1977) and (2) an inertial mode, thought to be shared by all fishes, which results from the relative motion of the high-density otoliths and underlying sensory hair-cell epithelium in the inner ear end organs due to acoustic particle motion (de Vries 1950; Popper and Fay 1993). The inner ear end organs essentially function as inertial accelerometers, and thus respond to acoustic particle motion (de Vries 1950; Dijkgraaf 1960; see above). In this ancestral inertial mode of hearing, the fish's body moves with the same displacement, direction, and phase as water due to similar acoustic properties (i.e., the fish has little or no difference in impedance to that of water). However, because otoliths are denser than water, they move with smaller amplitude and lag in phase relative to the fish's body, which results in the net movement of the otolith relative to the sensory macula and results in the deflection of the end organ's hair cells in the sensory macula (Fig. 1). At the level of the hair cell, the deflection of the hair bundle toward the longest cilium, caused by particle motion along the axis to which the hair bundle is intrinsically "tuned" (by its geometry), leads to hair cell depolarization and the release of excitatory neurotransmitter. Sufficient neurotransmitter release initiates action potentials in the innervating primary auditory afferents that then propagate via the VIIIth cranial nerve to the auditory hindbrain and central auditory pathway. Hair cells are inherently directionally 


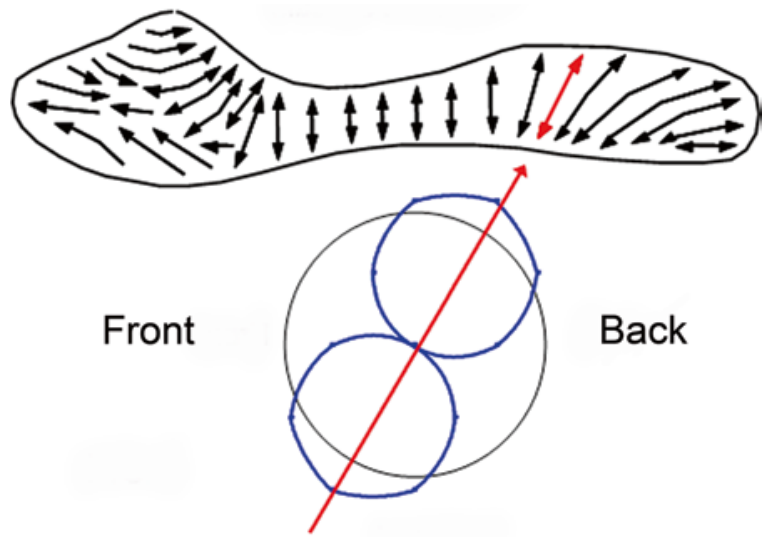

\section{Ventral}

Fig. 1 Movement of the otolith in response to sound in one direction maximally activates only a portion of the hair cells on the sensory macula. The red arrow shows the group of hair cells maximally activated by the movement of the otolith along the axis indicated by the red arrow. The directional response pattern of a nerve cell and hair cell (blue line) with a directional orientation (best axis) equal to the red arrow. This cell will respond best when the direction of particle motion is along the pathway indicated by the red arrow and it will not respond when the motion is $90^{\circ}$ or orthogonal to the arrow

sensitive with their axes of best directional sensitivity varying along the sensory macula. This is the basic mechanism of auditory transduction and the first substrate of directional sensitivity in all fish (e.g., Popper and Fay 1993).

\section{Behavioral Studies of Directional Hearing and Sound Source Localization in Fishes}

\subsection{Early Negative Results}

The question of whether fish locate sound sources has been of interest since the early part of the last century when the first experiments on sound source localization in fishes were performed using the European minnow (Phoxinus laevis) by Reinhardt (1935) in a laboratory setting and by von Frisch and Dijkgraaf (1935) in a more natural field setting. In the now more famous field experiment, Karl von Frisch and his student Sven Dijkgraaf carried out experiments using appetitive conditioning methods in an attempt to attract a natural population of European minnows to an underwater acoustic horn in a shallow lake. Von Frisch and Dijkgraaf tried to train minnows to swim to one of four feeding stations that were randomly paired with the activation of a waterproofed automobile horn (klaxon). The sound stimulus produced by the horn was described as having a pitch similar to an "e1" musical note. 
The horn was activated for 2 min and then cut pieces of earthworms were then dropped onto the feeding station next to the horn. The trials were then repeated again approximately every $10 \mathrm{~min}$. After 55 trials over several days, the researchers failed to observe any fish moving toward the feeding station that was paired with the sound stimulus even though many of the fish clearly demonstrated a conditioned arousal response to the acoustic stimulus. Based on their results, von Frisch and Dijkgraaf concluded that these fish could not localize underwater sound sources and they postulated that fish in general were incapable of sound source localization due to two major reasons. First, von Frisch and Dijkgraaf contended that the dominant view of sound source localization in humans was that the determination of extremely small ITDs (e.g., on the order of several microseconds) was required for source localization in the azimuth. Such processing of minute ITDs seemed "hardly imaginable" in fish according to von Frisch and Dijkgraaf (1935) because the inner ear acoustic end organs are very close together separated by only millimeters in fish compared to an ear separation greater than 10-15 cm in humans. Furthermore, because sound travels nearly five times faster underwater than in air the ITDs for fish underwater would be almost infinitesimal. Second, von Frisch and Dijkgraaf also pointed out that the European minnow was a pressure-sensitive otophysan fish that detects sound pressure indirectly via the swim bladder, which vibrates (oscillates) in response to a sound pressure stimulus. The pressure-induced vibrations of the swim bladder would stimulate both left and right acoustic endorgans equally via the inner ear projections of the Weberian ossicles, which are a series of specialized bones that are linked to the swim bladder. The simultaneous stimulation of both ears by the Weberian ossicles would occur equally regardless of sound source direction. Thus, von Frisch and Dijkgraaf were left to conclude that fish were unable to detect sound direction and locate sound sources even though they knew that their conclusions might not satisfy biologists.

\subsection{Re-evaluation of Directional Hearing and Source Localization}

The initial negative results of the sound source localization experiments by von Frisch and Dijkgraaf (1935) came to dominate the expectations that fish were unable to locate underwater sound sources. However, questions regarding the ability of fish to discriminate sound direction and locate sound sources arose again with van Bergeijk's $(1964,1967)$ influential analysis of directional hearing in fishes. As did von Frisch and Dijkgraaf (1935), van Bergeijk maintained that fish were unable to resolve sound direction in the far field due to the fact the fish's swim bladder acts as a pressure-to-displacement transformer and therefore in capable of discriminating sound direction. Thus, fish must use some other sensory system to guide directional hearing and sound source localization behavior. Earlier Harris and van Bergeijk (1962) showed that the mechanosensory lateral line organs of the killifish (Fundulus heteroclitus) responded in proportion to the near field particle motion 
generated by a vibrating dipole source. Because the mechanoreceptive organs of the lateral line are distributed over the fish's head and body, van Bergeijk reasoned that the lateral line system would be ideally suited to discriminate the near field particle motion generated by a sound source and function in sound localization. In addition, van Bergeijk (1967) also believed that lateral line organs were derived from the same developing tissue (anlage) as the inner ear labyrinth and thus proposed that the lateral line and inner ear should be considered singular parts of an "acoustico-lateralis" system. Based on these erroneous assumptions, van Bergeijk (1967) introduced the "acoustic-lateralis" hypothesis in which he maintained that the lateral line system and the inner ear otolithic end organs functioned together in fish hearing, but only the lateral line was responsible for directional orientation and source localization behaviors in fish.

At about this time, Moulton and Dixon (1967) reported an interesting set of observations regarding the role of the inner ear in the escape response of the goldfish (Carassius auratus), which is similar to the minnow Phoxinus in that its swim bladder is connected to the inner ear via Weberian ossicles. Goldfish innately exhibit a rapid tail-flip escape reflex in response to an acoustic startle stimulus. In a series of experiments, Moulton and Dixon (1967) conditioned goldfish using a food reward to change the direction of the tail-flip escape response, which naturally occurs in the opposite direction relative to the sound source. This orienting escape reflex was assumed to be mediated by Mauthner cells located in the brain stem (Furshpan and Furukawa 1962) but it was not experimentally confirmed. Fish were conditioned to perform the tail-flip response toward the sound source for a food reward. Pure tone signals of 100,150 , and $1500 \mathrm{~Hz}$ were used and the fish were observed to perform the tail-flip response toward the sound source for all three frequencies. Moulton and Dixon cleverly designed their experiments so that at $1500 \mathrm{~Hz}$ the sound source distance to the fish would be in the far field and well beyond the extent of the near field as defined by Harris and van Bergeijk (1962). When the authors severed the saccular and lagenar nerve (auditory inputs) on one side, the conditioned fish responded as if the sound source was on the same side of the intact nerve. Moulton and Dixon concluded that directional hearing is possible using the inner ear end organs in the far field and that both ears (i.e., the binaural processing of input from primarily the saccule and possibly the lagena) were required for the directional tail-flip response.

\subsection{Directional Hearing and Minimum Audible Angles}

During the 1970s, Hawkins, Schuijf, Sand, Chapman, and their colleagues established behavioral evidence that a number of fish species were capable of directional hearing and that fish could be conditioned to discriminate between sources of sound that were spatially separated, and from opposing directions (Schuijf et al. 1971, 1977; Chapman 1973; Chapman and Johnstone 1974; Schuijf 1975; Schuijf and Buwalda 1975; Hawkins and Sand 1977; Buwalda et al. 1983; Schuijf and Hawkins 
1983). It was a time of experimental innovations and major advancements in the theories of directional hearing and sound source localization in fishes. Some of the best early behavioral evidence for directional hearing in fishes comes from a series of experiments that were initiated by Schuijf et al. (1971), in which they carried out psychoacoustic conditioning experiments on the Ballan wrasse (Labrus berggylta) in a deep fjord near Bergen, Norway. In this free-field environment, fish were appetitively conditioned to respond to one of two sound sources separated in the azimuth by two angles of $10^{\circ}$ or $71^{\circ}$. For each angle, the conditioning trial consisted of switching a train of continuous $115 \mathrm{~Hz}$ tone bursts (with a burst duration of $1500 \mathrm{~ms}$ ) from one speaker to the other speaker. The positive responses of the fish at both source angle differences were interpreted by the authors to indicate that the fish could detect the tone bursts switching from one speaker to the other, which was assumed to be the result of a perceptional change in sound source direction. As the authors pointed out, this demonstration essentially shows that fish can be conditioned to discriminate between sources of sound that were spatially separated, but it represents a weak demonstration of sound source localization because the discrimination may have been made on the basis of cues associated with each source (e.g., a timbre difference) and may not necessary represent effective cues for source location.

Schuijf (1975) later demonstrated that the cod (Gadus morhua) could be conditioned to discriminate between two sound sources in the horizontal plane with an accuracy of $22^{\circ}$ and that two ears (each with the saccule and lagena) were required for this discrimination. The minimum audible angle of $22^{\circ}$ in the cod was determined by Schuijf using two- and four-alternative spatial choice experiments that required the fish to swim toward the active sound source for a food reward. As Schuijf pointed out, the fish could have solved this task by identifying each sound source based on differences in timbre cues and not necessarily knowing the locations of the sound sources. Hawkins and Sand (1977) had shown earlier for the cod the smallest discriminable change in elevation to be approximately $16^{\circ}$ and Sand (1974) also suggested that the two ears were required for directional hearing in the cod based on saccular potential recordings. Taken together, these experiments are perhaps the best evidence for directional hearing in fishes.

\subsection{Direction-Dependent Masking}

Direction-dependent masking has been observed in several species including haddock (Melanogrammus aeglefinus), pollock (Pollachius pollachius), ling (Molva molva), and cod (Gadus morhua) (Chapman 1973; Chapman and Johnstone 1974; Hawkins and Sand 1977). Chapman (1973) examined the ability of directional hearing in the haddock, pollock, and ling by investigating directional unmasking, a technique that determines tone detection thresholds in the presence of masking noise. This technique is similar to measuring the masking level difference studied in humans (Hirsh 1948). In his experiments, Chapman confined fish in a free-field 
acoustic testing range in midwater about $21 \mathrm{~m}$ deep and cardiac conditioned them to detect pure tone signals in the presence of masking noise in the horizontal plane. Chapman found that masking thresholds were highest when the angular separation of the stimulus tone and noise sources were within $10^{\circ}$ of one another in the azimuth, but a significant release of masking $(7.7 \mathrm{~dB})$ occurred when the signal and noise sources were separated by $85^{\circ}$ or more.

Directional unmasking was reinvestigated for the haddock and cod by Chapman and Johnstone (1974) using the same testing range, location and protocol used by Chapman (1973). In these experiments, Chapman and Johnstone (1974) observed a significant release of masking $(6.4-7.7 \mathrm{~dB})$ for haddock and cod when the signal and noise source separation was $45^{\circ}$ or more. Hawkins and Sand (1977) later demonstrated similar directional unmasking results for the cod in the median vertical plane. Chapman and Johnstone (1974) also found that haddock and cod could discriminate a change in the direction of a pulsed tone switched between two source locations when the angular separations in the azimuth were $20^{\circ}$ or more. In sum, these experiments imply that fish are capable of directional hearing in a free field and that they utilize spatial filtering for signal detection in noise.

\subsection{Sound Source Distance Discrimination}

Schuijf and Hawkins (1983) investigated the capacity for sound source distance discrimination in the cod using classical cardiac conditioning. Cod were conditioned to discriminate between two sound sources at two distances with $0^{\circ}$ azimuth and $0^{\circ}$ elevation. Evidence suggests that the fish were able to resolve the source distance using the distance-dependent phase angle between sound pressure and particle motion within the near-field. The authors suggested that source distance discrimination could also be determined by simultaneously comparing the amplitude ratios between sound pressure and particle motion. In addition, the authors also suggested that characteristic patterns of amplitude modulation between these two acoustic components may be generated at different distances as the result of the reflection of sound by the surface and seafloor, which could provide important distance cues far from a source. The observations by Schuijf and Hawkins (1983) are consistent with the hypothesis that fish are well able to determine the direction and distance of low-frequency sound sources, but these experiments along with all the other previous psychophysical-type experiments on source discrimination did not definitively demonstrate sound source localization because these experiments did not actually show that fish could locate sound sources in three-dimensional space. 


\subsection{The $180^{\circ}$ Ambiguity Problem}

Directional hearing in fishes is thought to be dependent on the direct stimulation of the accelerometer-like otoliths and underlying mechanically tuned hair cells of the inner ear by acoustic particle motion (de Vries 1950; Dijkgraaf 1960; Fay 1984). Based on afferent nerve recordings, the saccule is known to be sensitive to low frequency displacements as small as $0.1 \mathrm{~nm}$ rms, which is equivalent to the displacement produced by a $100 \mathrm{~Hz}$ sound wave propagating in the far field at $100 \mathrm{~dB}$ re $1 \mu \mathrm{Pa}$ (e.g., Fay 1984; Fay and Edds-Walton 1997). The axis of particle motion sensitivity of the acoustic end organ varies with the axis of optimal hair cell sensitivity along the sensory epithelium (Popper and Fay 1993). Although the neural mechanism(s) is not clearly understood, the fish's brain is thought to calculate the sound direction by vector weighing the input from different hair cell epithelia regions. This process has been called "vector detection" (Schuijf and Buwalda 1975) and is the basis for all current models of directional hearing in fish. However, there is a problem with the "vector detection" approach for resolving sound source direction; namely, that the axis of sound propagation does not in itself indicate bearing to the source. For a simple acoustic disturbance, a "particle" of fluid undergoes a small linear displacement in which its particle motion vector alternately points towards and away from the acoustic source for equal amounts of time. This particle motion vector does not indicate which direction a fish should travel to reach the source because the axis of propagation will cause the hair cells to oscillate both toward and away from the incident source. The bidirectional information conveyed by the hair cells and their corresponding auditory afferents will be largely ambiguous, a problem long recognized as the " $180^{\circ}$ ambiguity" problem.

The $180^{\circ}$ ambiguity problem has dominated most of the theoretical and empirical work on directional hearing in fishes since the 1970s and all new experiments on sound source localization in fish must confront this problem. Schuijf (1975) and Schuijf and Buwalda (1975) conceived a possible solution to this problem that entailed processing the phase relations between sound pressure and particle motion and their solution has become known as the "phase" model (see Sect. 3 in Models of Directional Hearing and Sound Localization). However, there are potential problems with Schuijf's solution because it seems to require sinusoidal signals and because some fish seem to lack the ability to detect the sound pressure cues that are theoretically necessary for this model to work.

\subsection{Phonotaxis Experiments}

In many vocal fish species, males often produce advertisement or mate calls to attract females for courtship and spawning (Fine et al. 1977; Myrberg 1981; Bass and McKibben 2003; Ladich and Myrberg 2006; Myrberg and Lugli 2006). The use of these calls in playback studies has been effective in determining the species response specificity and differential phonotaxis to such calls. Tavolga (1958) showed that in the goby (Bathygobius soporator) both females and males will 
increase their activity and approach a speaker broadcasting male courtship signals. Playback studies with cyprinids (Notropis sp.), sunfish (Lepomis sp.), Hawaiian squirrelfish (Myripristus berndti), and bicolor damselfish (Eupomacentrus partitus) showed greater attraction to the sounds of conspecifics than to those of heterospecifics (Delco 1960; Gerald 1971; Myrberg and Spires 1972; Popper et al. 1973). Winn (1972) showed that reproductive female oyster toadfish (Opsanus tau) will exhibit phonotaxis to the playback of the male's "boatwhistle" signal. Similar to its Atlantic relative, the plainfin midshipman fish (Porichthys notatus) is also known to exhibit similar phonotaxis responses. Ibara et al. (1983) and McKibben and Bass (1998) showed that gravid female midshipman (full of eggs) will exhibit robust phonotaxis to the playback of pre-recorded advertisement calls or pure tones $(80-115 \mathrm{~Hz})$ that were similar to the fundamental frequencies of natural advertisement calls or "hums." The frequency preferences based on female phonotaxis were found to be linearly related to water temperature that increased approximately $5 \mathrm{~Hz} /{ }^{\circ} \mathrm{C}$ and was about $100 \mathrm{~Hz}$ at $16{ }^{\circ} \mathrm{C}$ (Brantley and Bass 1994; McKibben and Bass 1998). McKibben and Bass (1998) used one-choice tests to determine call recognition and two-choice tests to evaluate signal preferences based on differences in harmonics, fundamental frequency, amplitude, frequency modulation, and beat stimuli. The results from their study and another (McKibben and Bass 2001) are perhaps the best and clearest evidence that fishes are able to locate sound sources in three-dimensional space. Until recently it was unclear what sound cues and search strategies midshipman used to locate sound sources. For example, do female midshipman locate sources by "climbing up" the intensity gradient (klinotaxis), or approach the source using a strategy analogous to the "light compass reaction" (Fraenkel and Gunn 1961) where the local particle motion vectors play the role of the sun to which the fish maintains a constant orientation angle to reach the source similar to Kalmijn's guided approach hypothesis (Kalmijn 1997), or do females already "know" where the source is and have already determined the source location at the initial time of release? These were just some of the questions that have persisted after the initial observations of phonotaxis by female midshipman.

Recently Zeddies et al. $(2010,2012)$ performed new phonotaxis experiments using the plainfin midshipman to investigate how these fish locate sound sources in relatively simple and complex sound fields. The experiments were performed in the same testing arena used previously by McKibben and Bass $(1998,2001)$. In the first set of experiments, Zeddies et al. (2010) investigated how female midshipman localized a sound source in the relatively simple geometry of a monopole sound field. A US Navy J9 sound projector was used to generate a monopole sound field in a large outdoor tank at the UC Bodega Marine Laboratory that allowed the researchers to observe female phonotaxis behavior in a controlled environment where the sound field could be easily measured. The projector was suspended from a beam and positioned in the center of the tank where it broadcasted an acoustic stimulus of a $90 \mathrm{~Hz}$ tone, which was similar to the fundamental frequency of the male advertisement call. During the playback experiments, an opaque plastic tarp was positioned in front, but not touching, the sound projector to remove any visual cues that could potential affect the sound source localization behavior of midship- 
Fig. 2 Drawing of the hydrophone array probe used to measure sound pressure and determine pressure gradients. The probe holds eight hydrophones at separation distances of $5 \mathrm{~cm}$ in the $x$, $y$, and $z$ directions. Adapted from Zeddies et al. (2010)
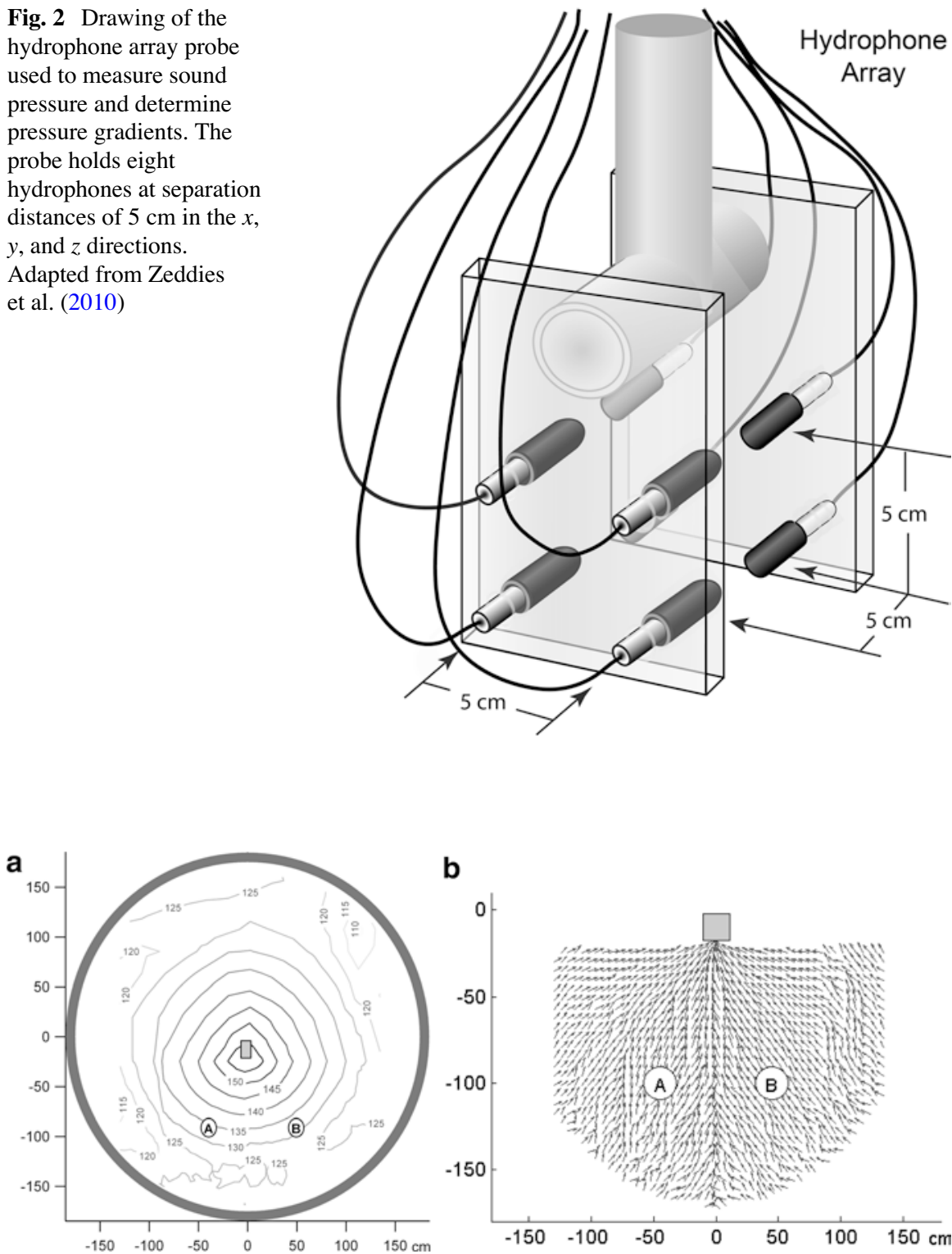

Fig. 3 Sound fields of sound pressure and particle motion produced by a J9 projector. (a) Contour plot of the peak sound pressure level (SPL dB re $1 \mu \mathrm{Pa}$ ) produced by the projector in the center of the tank. Sound pressure was measured with the hydrophones array probe at $9.5 \mathrm{~cm}$ above the tank bottom. (b) Particle displacement vector fields in the XY plane as measured at $4.5 \mathrm{~cm}$ above the tank floor. Particle displacement vector was also measured at $9.5 \mathrm{~cm}$ above tank floor (not shown). The axes in (a) and (b) are the distance from the center of the tank in cm. "A" and "B" denote the animal release sites during the playback experiments. Adapted from Zeddies et al. (2010) 
a

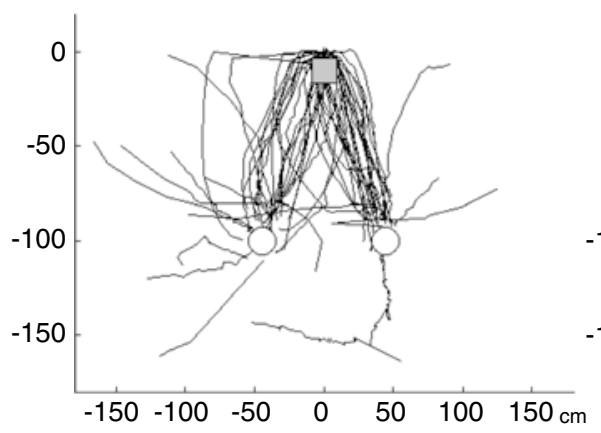

b

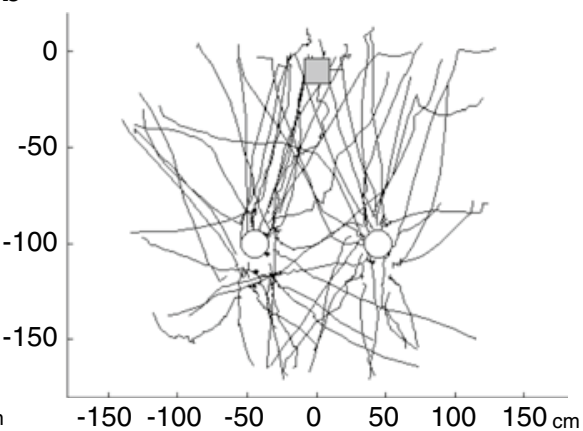

Fig. 4 Response pathways of the test (a, sound playback of a simulated midshipman advertisement call) and control (b, no sound) to naïve female plainfin midshipman. The phonotaxic responses of gravid females in the test (sound on) group displayed primarily straight to slightly curved paths to the sound source. Adapted from Zeddies et al. (2010)

man. The sound level at the release site was adjusted each night before behavioral tests to $130 \mathrm{~dB}$ re $1 \mu \mathrm{Pa}$, which is consistent with sound levels that nesting type I males produce within or near their nests (Bass and Clark 2003). The acoustic pressure gradients of the sound field were measured directly using an eight minihydrophone array that formed a cube, $5 \mathrm{~cm} \times 5 \mathrm{~cm}$ on each side (Fig. 2). This arrangement of the hydrophones permitted particle motion to be calculated in the $x$, $y$, and $z$ directions from the pressure gradient measurements between adjacent hydrophones, which were then used to create a map of the sound fields produced by the $\mathrm{J} 9$ sound projector in terms of sound pressure and particle motion (Fig. 3).

Behavioral tests occurred at night after sunset in the large outdoor testing tank. Female midshipman that were used in these experiments were collected by hand from the intertidal zone where midshipman nest and spawn during the summer reproductive season. All animals were collected during the morning low tides and then were tested later at night on the same day of collection. The behavioral tests began with an individual gravid female being placed in a $30 \mathrm{~cm}$ diameter plastic mesh cylinder that was positioned $109 \mathrm{~cm}$ away from the sound projector. Fish were then released from the cylinder while the $\mathrm{J} 9$ sound projector was continuously playing the $90 \mathrm{~Hz}$ stimulus tone. The phonotaxic responses of the gravid females consisted primarily of straight to slightly curved paths to the monopole sound source. Once at the sound source, females would then precede to either directly touch the face and/or underside of the sound projector. The majority ( $73 \%$ ) of the tested gravid females showed robust phonotaxis and localization of the monopole sound source (Fig. 4). In contrast, none of the gravid females in the control (sound-off) group localized the projector or made physical contact with it. The study by Zeddies et al. (2010) was significant because it was the first to compare the paths fish take to a sound source with a description of the available directional cues in the form of local particle motion vectors. Zeddies et al. confirmed that gravid females exhibit highly directional pho- 
a

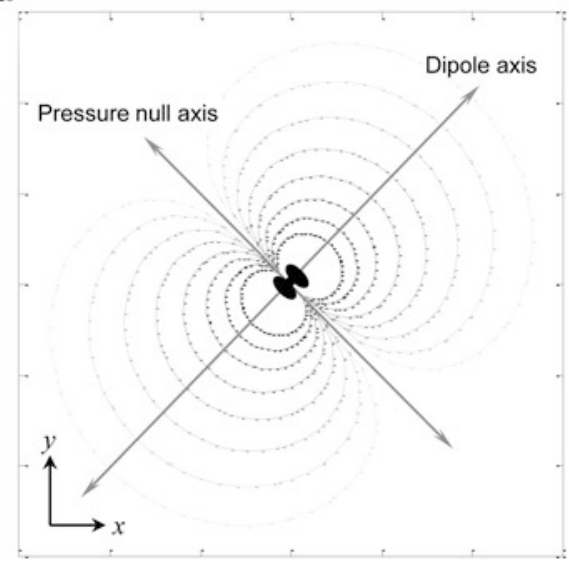

b

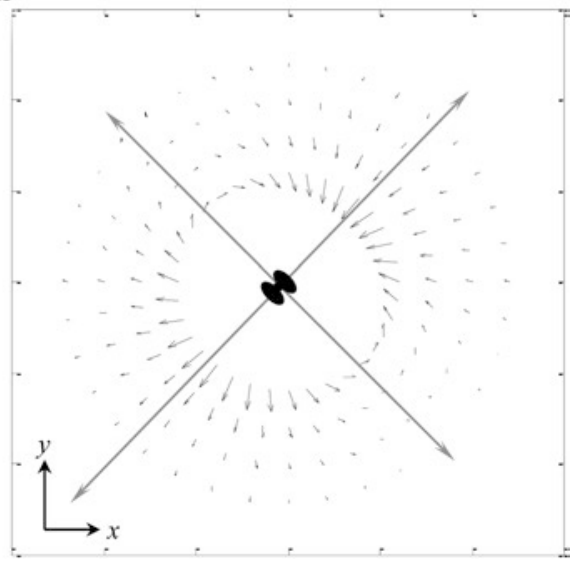

Fig. 5 Spatial projections of acoustic pressure and acoustic particle motion fields for an ideal dipole projector. (a) Contour plot of the pressure field surrounding a dipole projector. The pressure field is bi-lobed with areas of high pressure along the dipole axis, and a pressure null orthogonal to the dipole axis. (b) Particle motion vectors surrounding the dipole source with vectors along the dipole axis pointing towards (or away from) the source, whereas particle motion vectors along the pressure-null axis are parallel to the dipole axis. Note that moving from the pressure-null to the dipole axis, the particle motion direction gradually changes from parallel to the dipole axis to pointing towards or away from the source

notaxis to the sound source even at initial release, and that females swim along the axis of the particle motion vectors in a monopole sound field.

Monopoles with omnidirectional sound radiation are common biological sound sources in the natural environment including, for example, the pulsating swim bladder which is the typical sound source for a vocal fish. Not all biologically relevant sources are represented as monopoles. Kalmijn (1997) argued that many biological sound sources act like dipole or multipoles. For example, whole body accelerations radiate like dipoles. The sound field created by a dipole is more complex in nature than a monopole and can be modeled as a vibrating sphere that does not change volume. Its radiation pattern has an axisymmetric shape with a bi-lobed, figure eight pattern (Fig. 5a). Along the dipole axis, the particle motion vectors point toward and away from the source, but in the direction orthogonal to the dipole axis the particle motion vectors are parallel to the dipole axis and the sound pressure is zero (Fig. 5b). In other words, most particle motion vectors surrounding a dipole do not point toward or away from the sound source (as for monopoles), but are oriented at various angles that gradually changes from parallel to the dipole axis near the pressure null to pointing towards or away from the source along the dipole axis.

In a second set of experiments, Zeddies et al. (2012) investigated the phonotaxic responses of gravid female midshipman to a dipole sound source. These experiments offered researchers the opportunity to observe sound source localization behavior when fish were in locations where the particle motion vectors did not point 


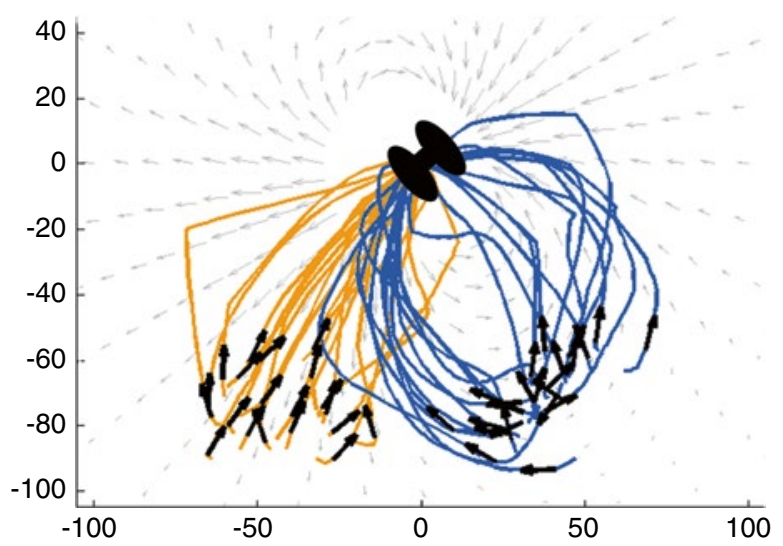

Fig. 6 Response pathways of the naïve female midshipman (Porichthys notatus) as they approach the dipole sound source. Orange traces are females released from site A; blue traces are females released from site B. Gray arrows indicate the particle velocity vectors and black arrows indicate the initial direction of the released fish from A and B sites. Adapted from Zeddies et al. (2012)

toward or away from the sound source. In these experiments, Zeddies et al. (2012) described the phonotaxic pathways of gravid females that localized a dipole sound source when: (1) females were released along the dipole axis where the sound pressure is high and the particle motion vectors point to and from the source, and (2) when the females were released at a point along a line orthogonal to the dipole axis where sound pressure is low and the particle motion vectors do not point towards or away from the source. Because the local sound field differed at the release sites, the researchers hypothesized that the pathways the fish would take to the source from these alternative release sites would also differ if the local particle motion vectors were crucial sensory cues that fish used for locating sound sources. The dipole sound field, which was created using two monopole sound sources back-to-back to yield a push pull action, was characterized via measurements of sound pressure using hydrophones and acoustic particle motion using an underwater accelerometer. The test tank and the procedures used in the phonotaxis experiments were similar to the previous monopole experiments (Zeddies et al. 2010). After characterizing the dipole sound field, the phonotaxic responses of 44 gravid females to the dipole source from two alternative release sites were recorded, analyzed, and compared with the sound field. As mentioned previously, one release site was approximately on the vibratory axis of the dipole source while the other release site was approximately orthogonal to the vibratory axis. When the females were released along the dipole vibratory axis they responded by taking essentially straight paths to the source. However, when females were released approximately $90^{\circ}$ to the source's vibratory axis 19 out of the 24 females took highly curved paths to the source that were more-or-less in line with the local particle motion vectors (Fig. 6). This behavior roughly corresponds to Kalmijn's guided approach hypothesis for fish sound 
source localization, but with a significant exception in that the fish adopted a constant $0^{\circ}$ orientation angle with respect to the local particle motion vector and not an arbitrary orientation angle that was constantly maintained. Zeddies et al. (2012) conclude that for a dipole source, midshipman fish do not appear to "know" where the source is, but it can use the acoustic cues of local particle motion vectors as a guide to determine the direction to the sound source. This conclusion, however, is not entirely justified since, as can be seen in Fig. 6, five of the females swam directly toward the source and apparently did "know" where it was. How the fish could know where the source was in this situation is discussed in Sect. 4.

\subsection{Role of the Swim Bladder and Lateral Line in Near-Field Sound Source Localization}

Recently Coffin et al. (2014) investigated the roles of the swim bladder and the lateral line system in sound source localization behavior in the plainfin midshipman. In the first set of experiments, gravid females underwent surgical deflation of the swim bladder soon after collection and then were tested later that night in a monopolar sound source localization task. Females with nominally "deflated" swim bladders exhibited similar phonotaxic responses to that of sham-deflated controls
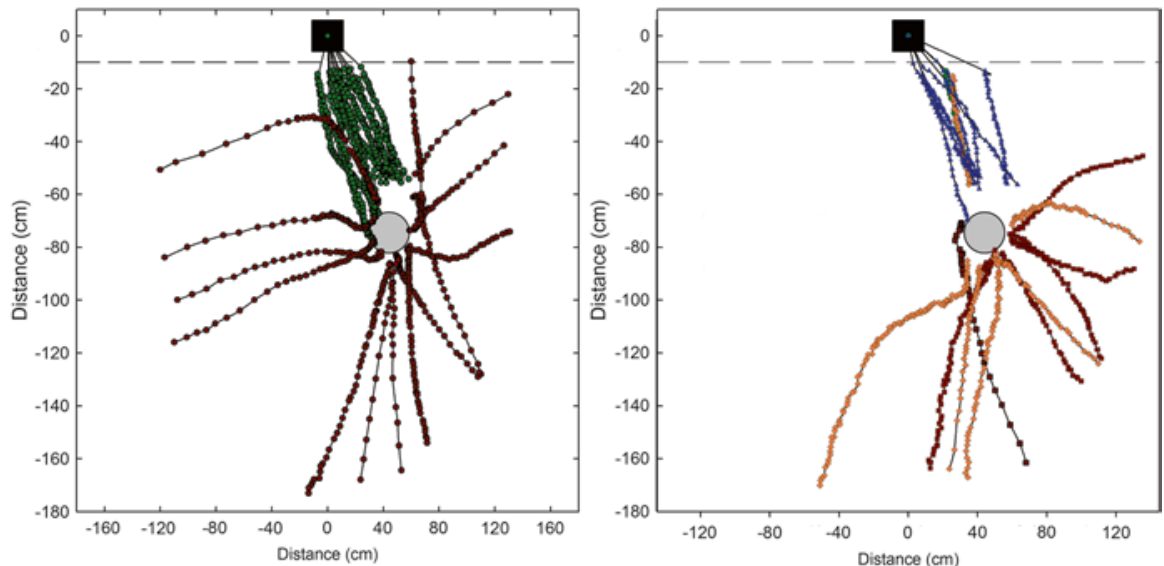

Fig. 7 Phonotaxic response pathways of gravid female midshipman that underwent swim bladder deflation surgery. Response pathways of females with sham-deflated swim bladders (left plot) that exhibited positive (green circle) phonotaxis and negative (red circle) responses to the simulated advertisement call stimulus. Response pathways of females with deflated and re-inflated swim bladders (right plot) that exhibited positive phonotaxis with either deflated (green circle) or reinflated (blue triangle) swim bladders and negative responses with either deflated (red square) or re-inflated (orange diamond) swim bladders. The axes are the distance from the center of the tank in $\mathrm{cm}$ where the monopole $\mathrm{J} 9$ speaker (black square) was located and the dotted line represents the position of the opaque screen. Adapted from Coffin et al. (2014) 
(Fig. 7). However, post-experiment examination of swim bladder deflation revealed that the majority ( $88 \%$ ) of the "deflated" females that displayed positive phonotaxis had partially re-inflated swim bladders. In total, 21 of the 22 tested fish (95\%) that localized the sound source had at least partially inflated swim bladders which indicated that pressure reception was likely required for sound source localization.

In a separate experiment, Coffin et al. (2014) found that midshipman could solve the $180^{\circ}$ ambiguity of source direction in the shallow water test tank, which was similar in depth to their natural nesting environment. The authors found that there were no differences in the positive phonotaxic response rates when fish were allowed to swim in any direction upon release using an "unbiased" release cage versus when fish were directed toward the sound source upon release using a "biased" release cage. The positive phonotaxic response rate was greater than $60 \%$ in both release cases. If the gravid females were unable to solve the $180^{\circ}$ ambiguity, then biasing their release toward the source would have increased the positive phonotaxic response rate relative to the unbiased release condition because the "unbiased" released fish would have been expected to be unable to determine "front" from "back" and would therefore swim away from the source in about half of trials. The researchers did not observe any fish to exit away from the sound source and then correctly turn and move to the source (Fig. 7). While it is true that a subset of fish tested failed to localize the sound source, the majority of the non-responding fish did not swim $180^{\circ}$ in the opposite direction, as would be expected if they were motivated to locate the source but could not solve the $180^{\circ}$ ambiguity. Thus, based on these observations the authors posited that midshipman could effectively resolve the $180^{\circ}$ ambiguity problem during sound source localization.

In a final set of experiments (Coffin et al. 2014), gravid female midshipman underwent ablation of the lateral line system soon after field collection and then were tested within $36 \mathrm{~h}$ after treatment in a monopolar sound source localization task. In preliminary lateral line ablation experiments, fish were initially treated with $0.001 \%$ gentamicin sulfate for $24 \mathrm{~h}$ (after Van Trump et al. 2010) or $0.05 \%$ streptomycin sulfate for $3 \mathrm{~h}$ (after Montgomery et al. 1997) in an attempt to chemically ablate both the canal and superficial neuromasts of the lateral line system (Brown et al. 2011). Treated and untreated females were then labeled with the fluorescent vital dyes DASPEI and FM1-43 to assess the extent of aminoglycoside-induced hair cell death and hair cell survival by fluorescence microscopy. Extensive neuromast survival was evident in both cases after the antibiotic treatments. Brown et al. (2011) then subsequently probed the effect of higher aminoglycoside concentrations on the midshipman lateral line system, treating additional fish in seawater containing doubled concentrations of gentamicin $(0.002 \%)$ for $24 \mathrm{~h}$ or streptomy$\operatorname{cin}(0.1 \%)$ for $3 \mathrm{~h}$. As before, extensive neuromast survival was evident but because comorbid nonsensory effects have been associated with exposure to high concentrations of aminoglycosides (Kaus 1987; see Janssen 2000), the researchers elected to abandon aminoglycosides altogether as a means of lateral line ablation, eventually selecting a physical method of ablation-direct application of a liquid nitrogenchilled probe to mechanosensory superficial neuromasts and surgically exposed 
canal neuromasts that enabled the cryoablation of the lateral line system of midshipman females for the subsequent sound source localization experiments.

Coffin et al. (2014) observed no difference in the proportion of females exhibiting positive phonotaxis with cyroablated- $(37 \%)$ and sham-ablated (47\%) lateral line systems, though complete ablation was not achieved because some of the mechanosensory neuromasts were incompletely damaged when the liquid nitrogenchilled probe was not properly applied. In addition, the authors reported that the mean approach angle to the sound source was significantly different for females with ablated lateral line systems (mean approach angle $=39^{\circ}$ ) compared to females with sham-ablated lateral line systems (mean approach angle $=15^{\circ}$ ). Based on these results, the authors suggested that the lateral line system is likely not required for sound source localization, but it may be important for fine-tuning the approach to the sound source.

\section{Models of Directional Hearing and Sound Localization}

Over the past five decades, a number of models have been proposed to account for directional hearing in fish. In the mid-1960s, van Bergeijk $(1964,1967)$ proposed one of the first influential such models, later known as the "acoustic-lateralis" model. Van Bergeijk hypothesized that pressure sensitivity in the inner ear (via the swim bladder or another gas bubble acting as a displacement-to-pressure transformer) allowed for sound source detection, but that mechanisms of the inner ear alone were insufficient to account for source localization. He instead theorized that the functionally similar lateral line system must supply directional information to the auditory system via unspecified channels (Harris and van Bergeijk 1962; van Bergeijk 1967). While some functional overlap of lateral line and auditory modalities has since been demonstrated and empirical measurements have not definitively ruled out lateral line contributions to sound localization behavior, Van Bergeijk's hypothesis has largely fallen out of favor in recent years. Most especially, it has become clear that the inner ear is intrinsically sensitive to source directionality, by virtue of the accelerometer-like otoliths and underlying mechanically tuned hair cells. In fact, saccular afferent particle displacement detection thresholds at low frequencies can approach $0.1 \mathrm{~nm}$ (Fay 1984; Fay and Edds-Walton 1997).

During the 1970s, Schuijf and his colleagues established behavioral (conditioning) evidence that was consistent with sound localization by several species of fish (Schuijf et al. 1977; Buwalda et al. 1983; Schuijf and Hawkins 1983). Fish could be conditioned to discriminate between sources of sound that were spatially separated, and from opposing directions. The investigators developed a complex mathematical/acoustical model that became known as the "phase model" to account for their experimental data (e.g., Schuijf 1975; Schuijf and Buwalda 1975; Chapman and Hawkins 1973). There are two essential components of the phase model. The first is a determination of the axis of acoustic particle motion impinging on the ears, which is thought to be accomplished through a process of resolving the axis of particle 
motion ("vector detection") by populations of differently oriented hair cells. The second component is a resolution of "the $180^{\circ}$ ambiguity" problem, i.e. disambiguation of the inherent ambiguity in the directionality of an oscillating particle. Schuijf (1975) conceived of a clever solution to this problem that entailed determining the phase angle between particle motion and sound pressure. This "phase model" requires that both the sound pressure and particle motion waveforms be encoded by the inner ear, and that appropriate central computations take place, exploiting the relative phase or timing relations to extract the true direction of incidence. While we ourselves have provided some empirical support for a role of pressure sensitivity via the swim bladder in midshipman localization (e.g., Coffin et al. 2014), the phase model (and pressure sensitivity) does not sufficiently explain sound localization in all scenarios. For example, particle motion-pressure relationships are easily predicted for monopolar sound sources (e.g., an expanding and contracting gas bubble), but many underwater sound sources are dipolar at least. Dipolar sources (e.g., a vibrating sphere with a constant volume) produce complex sound fields in which the particle motion vectors do not always point toward and away from the sound source, and the particle motion-pressure relationship does not reliably correspond to any one direction. A more serious empirical challenge to the phase model is that sharks and other elasmobranchs are able to locate sound sources from relatively far distances (Nelson and Gruber 1963; Nelson and Johnson 1972) despite their probable lack of pressure sensitivity (elasmobranchs lack a swim bladder or other inner ear-associated gas bubble). Thus, sharks are apparently able to localize sound on the basis of acoustic particle motion alone. Another difficulty with the phase model is that it requires the use of sinusoidal signals while broadband signals such the clicks transmitted by cod and haddock, which are far more common than sinusoidal signals in nature, cannot be used with the phase model.

Approximately over the past three decades, models of directional hearing in fish have proliferated, often focusing on improved solutions to the $180^{\circ}$ ambiguity problem. Recent models have included (1) an "orbital" model by Schellart and de Munck (1987; but also see de Munck and Schellart 1987) in which sound pressure and particle motion together cause the otolith orbits to rotate either clockwise or counterclockwise depending on whether the source is to the left or right, (2) a computational model by Rogers et al. (1988) that also requires both pressure and particle motion sensitivity, (3) a more algorithmic approach proposed by Kalmijn (1997) in which fish maintain a constant angle with respect to the axis of vibration even if the axis of vibration does not point toward the source, and (4) a "multipole" model by Rogers and Zeddies (2008) which applies the theory of multipole sensors to the fish ear, specifically the concept of an uncovered hair cell with no overlying otolith that responds to sound as a lateral quadrupole capable of resolving the $180^{\circ}$ ambiguity when coupled to otolith-covered hair cells that act as dipole detection mechanisms. Interestingly, the model by Rogers and Zeddies (2008) is one of the few that addresses how the $180^{\circ}$ ambiguity might be resolved for fish without a gas bubble, but this may only be possible in the far field.

All of the phase models of sound localization that have been proposed (Schuijf 1975; Schellart and de Munck 1987; Rogers et al. 1988) require that a fish be able 
to detect both sound pressure and particle motion, which has been well established (e.g., Buwalda 1981 and more recently Coffin et al. 2014). Unfortunately, the phase models by Schuijf (1975) and Schellart and de Munck (1987) represent only a very restrictive special case of the broader physical principle, namely point sources (or plane waves), in the free-field and then only for acoustic sinusoidal signals. In addition, the "directionalization" or the determination of the direction of the vector that points from the receiver to the source is not always possible, but in most cases the direction of energy flow (i.e., the acoustic intensity) can be determined and provide information as to the direction of the sound source. This is true in the free-field for monopoles and for dipoles, and it is even true for most non-free-field propagation conditions as well. In the next section, we describe a more general approach to the problem of directionalization that encompasses the phase model formulated on the concept of time-average acoustic intensity. It has the advantage of applying to both sinusoidal and broadband signals.

\section{Physics of Directionalization}

Directionalization is the determination of the direction of the vector that points from the receiver to the source. Most significant underwater sound sources are monopole (omnidirectional) in nature. All fish are thought to be capable of sensing a particle motion vector such as the acoustic particle velocity (de Vries 1950; Popper and Fay 1993). For simple point monopoles, in an infinite medium, the direction of the vector to the source is aligned with the acoustic particle velocity. However, the oscillatory nature of the motion of the fluid makes it impossible for the particle velocity alone to unambiguously determine the direction to the source since it alternately points towards then away from the source. If a fish aligns its body axis with the acoustic particle velocity, it cannot be sure whether it is facing directly towards or directly away from the source. This ambiguity presents a serious problem since the appropriate response to a relevant sound is to move towards it (e.g., towards a mate or prey) or away from it (e.g., away from a predator). In order to resolve this ambiguity, knowledge of a second variable such as acoustic pressure, which is scalar, is required. The motion vector quantity could be particle displacement, velocity or acceleration, all of which are aligned in the same direction. The scalar quantity in principle could be acoustic pressure, density, or temperature. We will assume for simplicity that the measured quantities are acoustic pressure and acoustic particle velocity, since all of the motion quantities can be obtained from one another by differentiation or integration, which can be performed by the CNS and the various scalar quantities are proportional to one another. The (ambiguous) line of bearing to the source can be determined either by aligning with the maximum particle velocity or by separately determining the velocity components in orthogonal directions and utilizing an arctangent algorithm to derive the source direction (Rogers et al. 1988). 
Most of the theoretical and experimental work on directionalization has involved several simplifications of the problem, some of which are more justifiable than others:

1. The source is acoustically small, i.e. much smaller than a wavelength. This is usually true. The sound speed in water is $1500 \mathrm{~m} / \mathrm{s}$, so the wavelength at $50 \mathrm{~Hz}$ is $30 \mathrm{~m}$ and even at $1 \mathrm{kHz}$ is $1.5 \mathrm{~m}$. The source, often the swim bladder is of the order of only a few centimeters in extent. One exception is ultrasonic hearing exhibited by some clupeids (Mann et al. 1997, 1998) where the wavelength is of the order of $1 \mathrm{~cm}$ and the presumed source, an echolocating dolphin, encompasses much of the head of the dolphin.

2. The source is monopole (omnidirectional) in character. Since all natural sources within the hearing range of fish are acoustically small, significant sound can only arise from monopole sources. Such sources generate sound by an oscillatory change in volume which generally requires the presence of an air bubble. Wholebody acceleration of a fish produces dipole radiation, but it is very low in frequency and/or very small in amplitude (but see item 4 below for an important exception).

3. The signal is sinusoidal. This mathematical and experimental convenience is rarely appropriate. While some fish calls are near sinusoidal (e.g., midshipman fish (Porichthys notatus) Bass et al. 1999; Bass and McKibben 2003) most fish sounds consist of a sequence of broadband click-like sounds. Sinusoidal sounds in the ocean are usually anthropogenic, natural oceanic noise is broadband.

4. The medium is unbounded. While for many pelagic fish the ocean boundaries play no significant role in sound propagation, the bottom plays a significant role for fish located close to the bottom or for very shallow water (Rogers and Cox 1988) The ocean surface, which presents a pressure-release boundary condition, can effect sound propagation via the filtering Lloyd's mirror effect or, if the source is close enough to the surface by transforming a monopole source into a vertically oriented dipole source (Urick 1967, p. 110).

Proposed mechanisms for resolving the $180^{\circ}$ ambiguity have focused on phase relationship between the acoustic pressure and particle velocity (Schuijf 1975; Schellart and de Munck 1987; Rogers et al. 1988). It is known that for plane waves or for spherical waves in the far field, pressure and acoustic particle velocity are in phase for waves propagating in the $+x$ or $+r$ direction and $180^{\circ}$ out of phase for waves propagating in the opposite direction. In the near field of a monopole source the ambiguity can be resolved by analysis of the phase between the pressure and particle velocity and this has been proposed, by some (e.g., Schuijf 1975; Schellart and de Munck 1987), as the mechanism used by fish. A principal difficulty with this hypothesis is that it only applies only to sinusoidal sources away from the surface. A more general approach to the problem of directionalization, which encompasses the phase model, can be formulated based on the concept of time-averaged acoustic intensity. Consideration of energy conservation in acoustics leads to the concept of acoustic intensity (see Pierce 1981, Section 1-11 for a derivation of Eqs. 1-5): 


$$
\mathbf{I}(\mathbf{r}, t)=p(\mathbf{r}, t) \mathbf{v}(\mathbf{r}, t)
$$

The acoustic intensity, $\mathbf{I}(\mathbf{r}, t)$, is a vector which equals the acoustic power per unit area at the point $\mathbf{r}$. The intensity $\mathbf{I}(\mathbf{r}, t)$ points in the direction of instantaneous power flow. Thus, the power passing through a surface $A$ is given by

$$
\Pi=\iint_{A} \mathbf{I}\left(\mathbf{r}_{\mathrm{s}}, t\right) \cdot \mathbf{n}\left(\mathbf{r}_{\mathrm{s}}\right) d S
$$

where $\mathbf{r}_{\mathrm{s}}$ is a point on the surface and $\mathbf{n}\left(\mathbf{r}_{S}\right)$ is a unit vector normal to the surface $A$. The intensity contains two components, a reactive oscillatory part and a resistive part which has a nonzero time average. The reactive part represents energy sloshing back and forth through the surface and thus indicates nothing about the direction of the source. The nonzero-time-average part of the intensity represents energy permanently passing from one side of the surface to the other and thus suggests that the source is on the side of the surface from which the energy comes. Thus,

$$
\langle\mathrm{I}(\mathbf{r}, t)\rangle=\frac{\int_{0}^{T} p(\mathbf{r}, t) \mathbf{v}(\mathbf{r}, t) d t}{T}
$$

is the actual power per unit area at $\mathbf{r}$ which is flowing in the direction of $\langle\mathrm{I}(\mathbf{r}, t)\rangle$. Under most circumstances one would expect that the source is located in the opposite direction. If $p$ and $\mathbf{v}$ are sinusoidal with frequency $f$, the product will consist of a constant term and a term with frequency $2 f$. The part of $p$ which is in phase with $\mathbf{v}$ produces the constant term (as well as part of the $2 f$ term). An arbitrary sinusoidal quantity can be represented in complex notation by

$$
A \cos (\omega t+\phi)=\operatorname{Re}\left(\widehat{A} e^{-i \omega t}\right) \text { with } \widehat{A}=A e^{-i \phi} .
$$

Using this notation it is easy to show that

$$
\langle\mathbf{I}(\mathbf{r})\rangle=\frac{1}{2} \operatorname{Re}\left(\hat{p} \hat{\mathbf{v}}^{*}\right)
$$

For a monopole source located at the origin (Pierce 1981; see Ch 4)

$$
\begin{gathered}
\hat{p}(\mathbf{r})=\hat{p}_{0} \frac{r_{0} e^{i k r}}{r} \\
\hat{\mathbf{v}}(\mathbf{r})=\left(1-\frac{1}{i k r}\right) \frac{\hat{p}_{0}}{\rho c} \frac{r_{0} e^{i k r}}{r} \mathbf{e}_{\mathbf{r}}
\end{gathered}
$$


where $\mathbf{e}_{\mathbf{r}}$ is a unit vector in the radial direction so the time-averaged intensity is given by

$$
\langle\mathbf{I}(\mathbf{r})\rangle=\frac{1}{2} \operatorname{Re}\left(\hat{p} \hat{\mathbf{v}}^{*}\right)=\frac{\left|\hat{p}_{0}\right|^{2}}{2 \rho c}\left(\frac{r_{0}}{r}\right)^{2} \mathbf{e}_{\mathbf{r}}
$$

The time-averaged intensity always points in the radial direction, i.e. away from the source. The fish, however, measures particle velocity in its own body-centered coordinate system. If we assume the positive direction in the fish's coordinate system is towards its head, the time-average value of the product of $p$ and $\mathbf{v}$ will be positive if the source is behind the fish and negative if it is in front of the fish. In the near field $(k r \ll 1)$, the term in $\hat{p} \hat{\mathbf{v}}^{*}$ involving $1 / i k r$ which would be much larger than the other term but it does not contribute to $\langle\mathbf{I}(\mathbf{r})\rangle$ because it is imaginary. The timeaveraged intensity, $\langle\mathbf{I}(\mathbf{r})\rangle$, is proportional to $1 / r^{2}$ so the total power passing through a spherical surface centered on the source, at any range from the source is constant as is required by conservation of energy. For the field of a point monopole which has arbitrary time dependence

$$
p(\mathbf{r}, t)=\frac{r_{0} p\left(t-\frac{r}{c}\right)}{r} \text { and } \mathbf{v}(\mathbf{r}, t)=\left[\frac{p\left(t-\frac{r}{c}\right)}{\rho c}-\frac{\int p\left(t-\frac{r}{c}\right) d t}{r \rho}\right] \mathbf{e}_{r}
$$

From Eq. (3), the time-averaged intensity is

$$
\begin{aligned}
\langle\mathbf{I}(\mathbf{r})\rangle & =\left[\frac{\int_{0}^{t} p(\mathbf{r}, t)^{2} d t}{\rho c T}-\frac{\int_{0}^{t} p(\mathbf{r}, t)\left(\int p(\mathbf{r}, t) d t\right) d t}{r \rho T}\right] \\
& =\left[\frac{\int_{0}^{t} p(\mathbf{r}, t)^{2} d t}{\rho c T}-\frac{\left.\left(\int p(\mathbf{r}, t) d t\right)^{2}\right|_{0} ^{T}}{r \rho T}\right] \mathbf{e}_{\mathbf{r}} \\
& =\frac{\int_{0}^{t} p(\mathbf{r}, t)^{2} d t}{\rho c T} \mathbf{e}_{\mathbf{r}}
\end{aligned}
$$

The second term in the brackets is zero because the pressure is zero before the wave arrives and after it leaves and in any case decreases with increasing $T$. The first term in the brackets is always positive so, again, if the time-average value of the product 
of $p$ and $\mathbf{v}$ is negative (positive) the source is in front of (behind) the fish. By using time-averaged intensity, the fish could process non-oscillatory input to ascertain unambiguous vector components of the source direction vector. Note that, as in the sinusoidal case (Eq. 7), in general case (Eq. 9), $\langle\mathbf{I}(\mathbf{r})\rangle$ is proportional to $1 / r^{2}$ as required by conservation of energy. Note also that the instantaneous intensity (before time averaging) does not have this property since it contains a term which is proportional to $1 / r^{3}$.

Dipole sources at audible frequencies are not common in nature but provide some interesting insights into how fish process directional information. For sinusoidal signals, the acoustic pressure and particle velocity for a point dipole oriented in the $z$ direction are given by (Pierce 1981, see Section 4-2)

$$
\begin{gathered}
\hat{p}_{\text {dip }}=\hat{p}_{d 0} \frac{r_{0} e^{i k r}}{r} \cos \theta\left(1-\frac{1}{i k r}\right) \\
\hat{\mathbf{v}}_{\mathrm{dip}}=\frac{\hat{p}_{d 0}}{\rho c} \frac{r_{0} e^{i k r}}{r}\left[\cos \theta\left(1+\frac{2 i}{k r}\left(1-\frac{1}{i k r}\right)\right) \mathbf{e}_{\mathbf{r}}+\sin \theta\left(1-\frac{1}{i k r}\right) \frac{i}{k r} \mathbf{e}_{\mathbf{r}}\right]
\end{gathered}
$$

Note that for dipoles the pressure and the particle velocity have a near field and that the particle velocity has components in both the radial $\left(\mathbf{e}_{\mathbf{r}}\right)$ and theta $\left(\mathbf{e}_{\theta}\right)$ directions. The $1 / r^{3}$ terms dominate the particle velocity close to in the source so that only at $\theta=0$ is the velocity vector aligned with the direction to the source and at $\theta=\pi / 2$ it is orthogonal to it. In the far field $(k r \gg 1)$ the particle velocity is oriented in the radial direction.

The product $\hat{p}_{\mathrm{dip}} \hat{\mathbf{v}}^{*}$ is given by

$$
\left.\hat{p}_{\mathrm{dip}} \hat{\mathbf{v}}_{\mathrm{dip}}^{*}=\frac{\left|\hat{p}_{d 0}\right|^{2}}{\rho c}\left(\frac{r_{0}}{r}\right)^{2} \cos \theta\left[\begin{array}{l}
\cos \theta\left(1-i\left(\frac{1}{k r}+\frac{2}{(k r)^{3}}\right)\right) \\
\mathbf{e}_{\mathbf{r}}-\sin \theta i\left(\frac{1}{k r}+\frac{1}{(k r)^{3}}\right)
\end{array}\right] \mathbf{e}_{\theta}\right]
$$

The time averaged intensity is one-half the real part of this quantity which is simply

$$
\left\langle\mathbf{I}(\mathbf{r})_{\text {dip }}\right\rangle=\frac{1}{2} \operatorname{Re}\left(\hat{p}_{d i p} \mathbf{v}_{d i p} *\right)=\frac{\left|\hat{p}_{d 0}\right|^{2}}{2 \rho c}\left(\frac{r_{0}}{r}\right)^{2} \cos ^{2} \theta \mathbf{e}_{\mathbf{r}}
$$

Importantly, $\left\langle\mathbf{I}(\mathbf{r})_{\text {dip }}\right\rangle$ is in the radial direction and so points directly away from the source, at any range and any angle, even though the acoustic particle velocity does not. These results are illustrated in Fig. 8 for the monopole source and for the dipole source in Fig. 9. In each of these figures the location of source is indicated by the small "o" and the axis of rotation is indicated by the dashed line. 


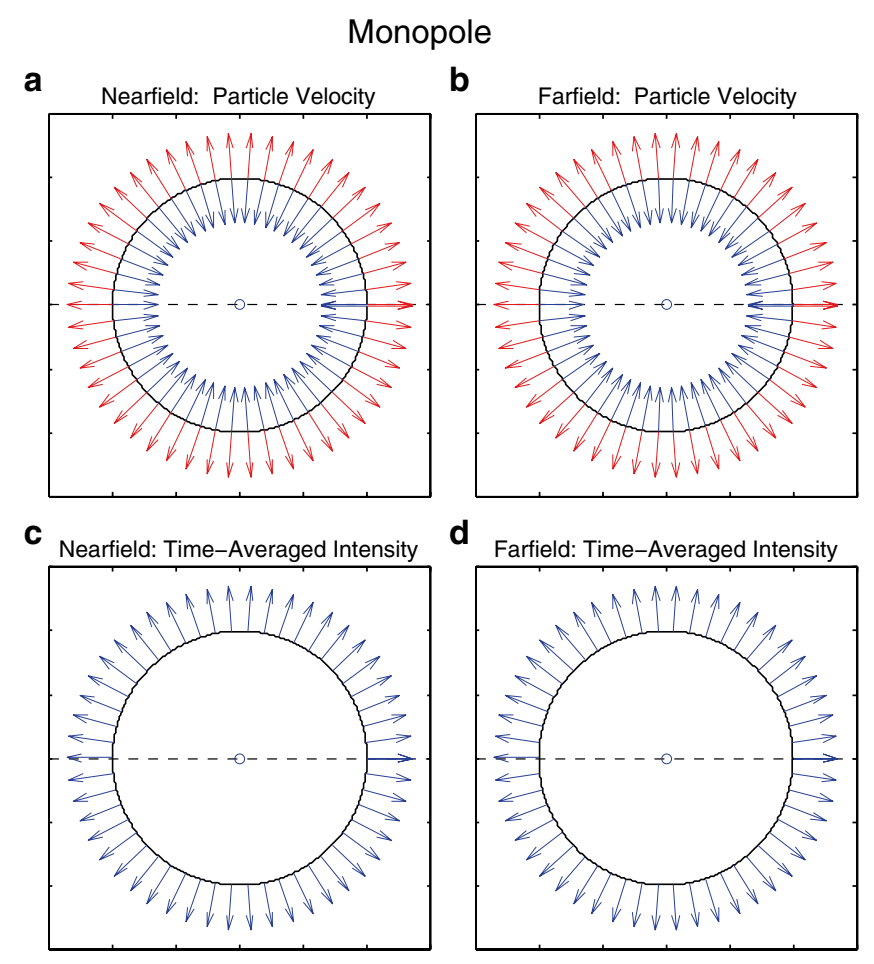

Fig. 8 Direction of acoustic particle velocity and time averaged intensity for a point monopole source. (a) and (c) are particle velocity and intensity, respectively, in the near field $(k r=0.001)$. (b) and (d) are particle velocity and intensity, respectively, in the far field $(k r=1000)$. The small "o" is the location of the source and the horizontal dashed line is the symmetry axis. When both red and blue arrows are present it indicates the vector is oscillating. The vectors are normalized to the largest value in each case and the vectors are a million times further from the source in the far-field cases. The intensity vector points directly away from the source at all distances

Figure 8a shows the direction and relative amplitude of particle velocity for a point monopole source in the near field $(k r=0.001)$. Figure $8 \mathrm{~b}$ shows the direction and relative amplitude of particle velocity for a monopole in the far field $(k r=1000)$. The two plots are seen to be identical. The presence of both red and blue arrows indicates the particle velocity is oscillating with the velocity alternating between pointing directly towards and directly away from the source. Figure $8 \mathrm{c}$, d shows the direction and relative of the time-averaged intensity for a point monopole source in the near field and far field, respectively. In both cases the time-averaged intensity is seen to point unambiguously away from the source.

The dipole is oriented in the horizontal direction with the rotational axis given by the dashed line. Figure $9 \mathrm{a}$ shows the direction and amplitude of the acoustic particle velocity for the dipole in the near field $(k r=0.001)$. The oscillating particle velocity vectors only point towards or away from the source along the dipole axis and, in fact, are orthogonal to the source direction for $\theta=\pi / 2$. In the far field $(k r=1000)$, 


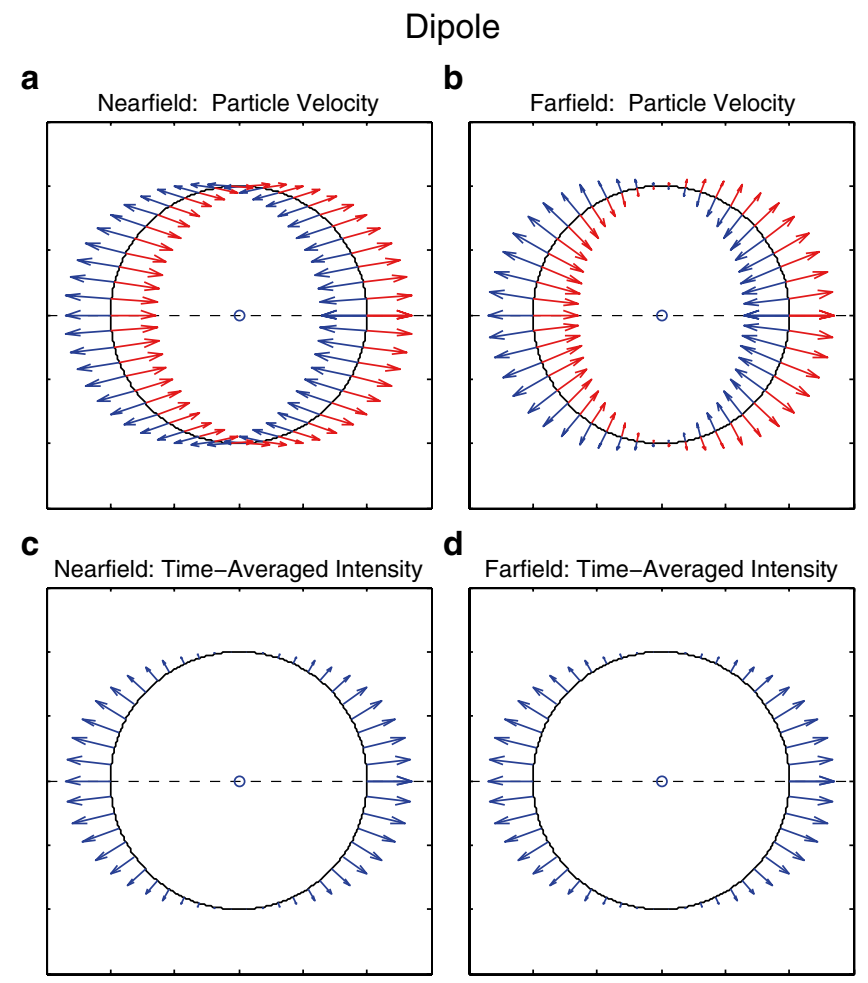

Fig. 9 Direction of acoustic particle velocity and time averaged intensity for a point dipole source. (a) and (c) are particle velocity and intensity, respectively, in the near field $(k r=0.001)$. (b) and (d) are particle velocity and intensity, respectively, in the far field $(k r=1000)$. The small "o" is the location of the dipole and the horizontal dashed line is the symmetry axis of the dipole. When both red and blue arrows are present it indicates the vector is oscillating. The vectors are normalized to the largest value in each case and the vectors are a million times further from the source in the farfield cases. The intensity vector points directly away from the source at all distances

shown Fig. 9b, however, the oscillating particle velocity always points directly towards or away from the source.

Figure $9 \mathrm{c}, \mathrm{d}$ shows the direction and relative of the time-averaged intensity for a point dipole source in the near field and far field, respectively. The plots are identical. In both cases the time-averaged intensity is seen to point unambiguously away from the source.

Kalmijn (1997) and Zeddies et al. (2012) have hypothesized that fish are not able to determine the direction to a dipole source but are none-the-less able to approach the source by following the local fluid velocity. There is, however, some evidence in the Zeddies et al. (2012) data on the midshipman fish (Porichthys notatus) that suggests fish were able to sense the true direction to the source. In the Zeddies et al. experiment, gravid females were motivated to approach the source, which emitted a low frequency $(80-90 \mathrm{~Hz})$ sinusoidal signal that simulated the advertisement call of the male. The females were released from site "A" which was located near the main 
pressure-response axis of the source where the particle velocity is nearly aligned with the direction to the dipole source or site " $\mathrm{B}$ " which was located near the direction of the pressure node where the local particle velocity was nearly orthogonal to the direction of the source. For the 44 females that exhibited a positive phonotaxic response, the paths to the source were traced and analyzed (see Figures 7, 8, and 9 in Zeddies et al. (2012)). For the 20 females released from the "A" site, females followed "straight to slightly curved tracks to the sound source." This is consistent with either hypothesis. For the 24 females that were released from the " $\mathrm{B}$ " site where the initial local acoustic particle velocity was orthogonal to the source direction, 19 females followed curved paths that more-or-less followed the local velocity vectors but 5 females swam directly to the source. The authors concluded, principally from the B site results, that gravid females did not know the direction to the source and followed the local velocity vectors. It is evident from Eq. (12) that for a dipole source the oscillatory part of the intensity (the imaginary terms in Eq. 12) is much larger than the steady part (the real term in Eq. 12) since $k r \approx 0.3$ near the release points. This results in a large signal but with ambiguous sign aligned with the local acoustic velocity and a small but steady signal pointing away from the source. It is not unreasonable to assume that the fish would be influenced by both type signals. It is hypothesized here that the females were making use of the timeaveraged intensity in their approach to the source. Consider the following:

1) Five gravid females released from site " $B$ " swam directly to the source, ignoring the orientation of the dominant local particle velocity. Apparently, they knew the direction to the source, and the only way they could have known it was from direction of $\langle\mathbf{I}\rangle$.

2) In support of their conclusions, the authors state that the fish's path to the source in general oscillate randomly about the particle velocity field lines. However, the data from Figure 9 in Zeddies et al. (2012) seems to indicate that on average the deviations from the field direction show a definite bias with respect to zero while according to the authors' hypothesis there would be should be no bias. The paper does not precisely define the direction of the variations between the path and the field lines so it is not possible to tell whether the bias is towards or away from the source but in all three cases (release from A, release from B going to the right and release from $\mathrm{B}$ going to the left) the bias, with respect to the direction to the source is the same. Ascertaining the size and direction of the bias and its statistical significance would require a complete reanalysis of the data or, if necessary, a repeat of the experiment. A statistically significant bias, especially toward the source would indicate that the fish "knew" the direction to the source.

The time-averaged intensity vector points directly away from the source for freefield point monopole and point dipole sources at all ranges. It turns out that this does not apply to all point sources. A point cardioid source provides a counterexample. A point cardioid consists of a point monopole and collocated point dipole. The amplitude of the dipole is adjusted to equal that of the monopole in the far-field of one of its main response directions at a certain frequency. This combination of sources produces a cardioid shaped beam pattern with an amplitude twice that of the mono- 


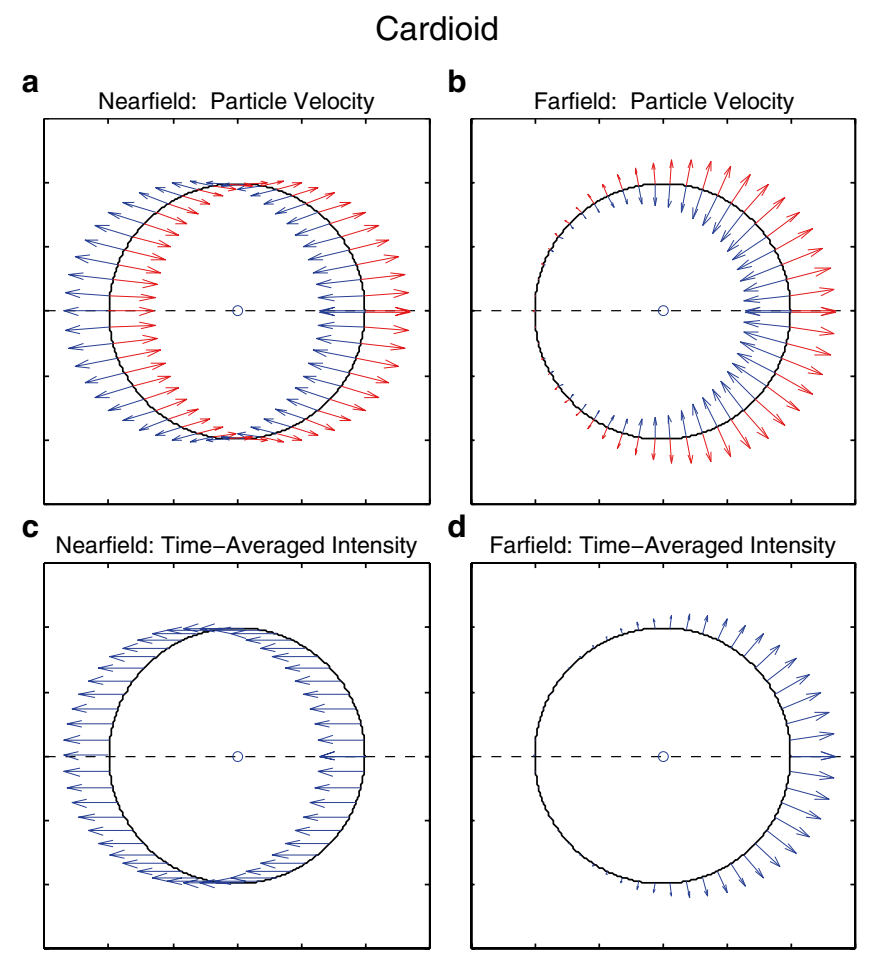

Fig. 10 Direction of acoustic particle velocity and time averaged intensity for a point cardioid source. (a) and (c) are particle velocity and intensity, respectively, in the near field $(k r=0.001)$. (b) and (d) are particle velocity and intensity, in the far field $(k r=1000)$. The small "o" is the location of the source and the horizontal dashed line is the symmetry axis. When both red and blue arrows are present it indicates the vector is oscillating. The vectors are normalized to the largest value in each case and the vectors are a million times further from the source in the far-field cases. The intensity vector points directly away from the source only in the far field

pole in one direction and zero in the opposite direction. The pressure and particle velocity of the cardioid can be calculated from the results we obtained for the component monopole and dipole (Eqs. 6 and 10). The result is shown in Fig. 10, which is in the same format as Figs. 8 and 9. Figure 10a, b shows the acoustic particle velocity vectors for a cardioid source in the near field and far field, respectively.

As with the dipole source (see Fig. 9) the near-field particle velocity vectors do not point towards or away from the source except along the source axis whereas the far-field velocity vectors do, but with an indeterminate sign. The near-field and far-field time-averaged intensity vectors for are shown in Fig. 10c, d, respectively. In the far field, Fig. 3d, the time-averaged intensity always points unambiguously in the direction opposite to the source. In the near field $(k r=0.001)$ the time-averaged intensity oddly points in the negative $z$ direction at all angles (Fig. 10c).

It is also of interest to consider whether the presence of boundaries can effect directionalization. One obvious example would be a monopole source at some distance from the pressure release ocean surface. If the distance between the source 


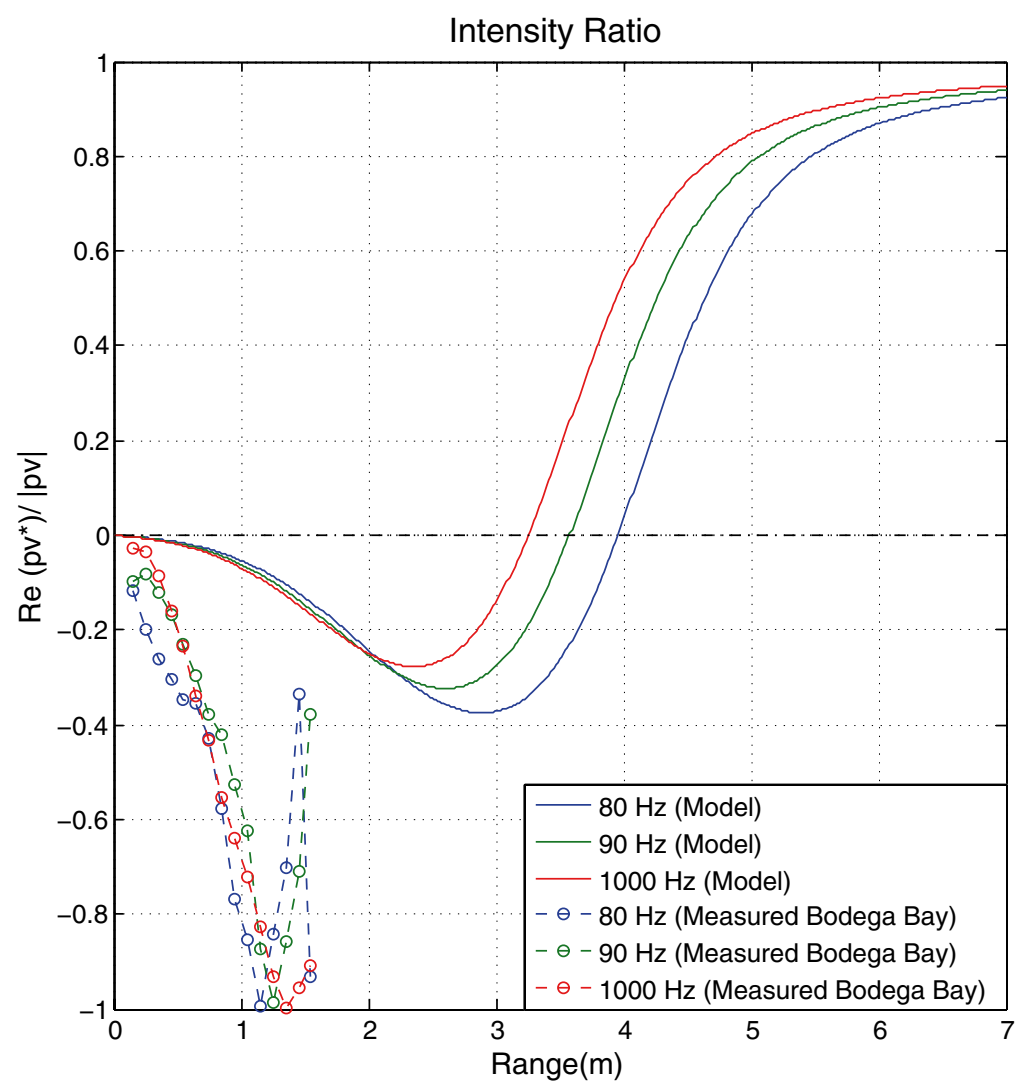

Fig. 11 Plot of the ratio of the time averaged intensity to $\frac{1}{2} 2$ the absolute value of the intensity. This ratio is always a real number between -1 and 1 . For a monopole or dipole source in a free field, a positive value indicates an outwardly propagating wave. The solid lines are values for a simplified model of the Bodega Bay directional hearing experiment (Coffin et al. 2014) which considers only the direct, bottom-reflected, surface-reflected and surface-bottom-reflected contribution to the field. The frequencies are $80 \mathrm{~Hz}$ (blue), $90 \mathrm{~Hz}$ (green), and $100 \mathrm{~Hz}$ (red). The water depth is $50 \mathrm{~cm}$, the source is $6 \mathrm{~cm}$ and the receiver $5 \mathrm{~cm}$ from the bottom. The dashed lines are the values for the ratio measured in the Bodega Bay tank

and the surface is much smaller than a wavelength, then the source and its negative image source create a dipole. From our analysis of dipole sources it follows that the time averaged intensity vector will usually point not away from the source but away from a point on the surface directly above the source which is the center of the dipole. The azimuth angle will be correct but the elevation angle will not be. For sources at larger distance the same thing is true with the elevation angle being correct when the field point is close to the source and moving towards the surface as the field point approaches the surface.

The very shallow water $(\sim 0.5 \mathrm{~m})$ where the midshipman fish nest is an extremely unusual and difficult acoustic environment to model for sound propagation, especially at the male's advertisement frequency of $70-100 \mathrm{~Hz}$ (wavelength 
15-20 m). In a tank experiment on midshipman directionalization (Coffin et al. 2014) intended to approximate that environment, it was observed that females were generally able to resolve the $180^{\circ}$ ambiguity and localize the sound source. Acoustic field measurements in the tank and a method-of-images propagation model for the natural environment indicated that the time average intensity pointed in the wrong direction (i.e., towards the source) from a distance of $1 \mathrm{~cm}$ from the source out to a distance beyond the release point, a meter from the source. This conclusion however is called into question because the propagation model that was used has been determined to be invalid for a source and receiver so close to the bottom in such shallow water. The field measurements in the Bodega Bay tank also indicated reversal of the direction of the time averaged intensity vector but an erroneous phase in such measurements is always a possibility. Thus the question of whether the sign of the timeaveraged intensity could point in the wrong direction due to boundary conditions direction remains moot. It is evident from the result shown for the point cardioid that the sign of the time-averaged intensity can change as the field point moves along the main response axis. Note that the intensity vector for a cardioid source points to the left on both sides of the source in the near field (Fig. 10c) implying that a fish approaching the source along the axis from the left would correctly determine the direction to the source but a fish approaching from the right would think the source was behind it. The question remains however whether such a reversal could occur for a point monopole source due to propagation conditions alone. The typical natural environment for the midshipman fish directionalization problem consists of a source (the male midshipman) and receiver (the female) both located close to the bottom in 50-100 cm depth water. This condition was generally mimicked in the Bodega Bay experiment but the actual boundary conditions at the bottom are unknown in both cases. The field at the receiver consists of the direct signal and signals from multiple reflections from the surface and bottom. This problem is extremely difficult to model because neither ray models nor normal mode models can be used. Ray acoustics are inappropriate because the wavelength is much longer than any other characteristic length involved and normal mode solutions cannot be used because the waveguide has no propagating modes. The four largest terms in the solution are the direct signal, its surface and bottom reflections, and the signal which is reflected twice, first by the surface and then by the bottom. For a fluid-like bottom the sum of these signals can be determined analytically (Jensen et al. 2011, pp. 87-101). Although this solution is, at best, an approximation for the actual problem it is a solution to a real problem (two vertically aligned sources with opposite signs, over a realizable fluid-like half-space).

Predicted values the time-averaged intensity for this model, $\langle\mathbf{I}\rangle=\frac{1}{2} \operatorname{Re}\left(\hat{p} \hat{\mathbf{v}}^{*}\right)$, normalized by $\frac{1}{2}|\hat{\mathbf{I}}|=\frac{1}{2}|\hat{p} \hat{\mathbf{v}}|$ versus distance from the source, are shown in Fig. 4 for frequencies of 80,90 , and $100 \mathrm{~Hz}$. The acoustic properties of the bottom are similar to those of concrete, $c=3400 \mathrm{~m} / \mathrm{s}, \rho=1800 \mathrm{~kg} / \mathrm{m}^{3}$. The water depth is $50 \mathrm{~cm}$ with the source $6 \mathrm{~cm}$ from the bottom and the receiver $5 \mathrm{~cm}$ from the bottom. The plotted quantity, the dimensionless ratio $\Gamma=\frac{\operatorname{Re}\left(\hat{p} \hat{\mathbf{v}}^{*}\right)}{|\hat{p} \hat{\mathbf{v}}|}$ must always fall between -1 and +1 . 
For a monopole or dipole source in a free field $\Gamma$ would always be positive. In Fig. 11, for all three frequencies $\Gamma$ is initially negative but becomes positive at a distance of 3-5 $\mathrm{m}$ from the source. The ratio $\Gamma$ approaches +1 at large distances as would be expected.

Time averaged intensity provides a physics based approach to source localization with wide applicability with regard to source type, acoustic environment, and time waveform. While it won't work for all possible sources and environments it may well work for all situations where localization from point measurements is possible.

\section{Conclusion and Future Directions}

Numerous observations of acoustical behaviors in multiple fish species strongly suggest that fish have the capacity for sound source localization. However, there are no good examples of sound localization capacities in a single species that provide a comprehensive theoretical explanation. There remain a number of important questions that should be addressed in future work on sound source localization by fishes, several of which are briefly detailed below:

1) Which end organs are utilized by fish in sound source localization? All teleost fishes possess three inner ear end organs (the saccule, utricle, and lagena) that contain functionally similar hair cells with functional overlap in both auditory and vestibular modalities, but their respective contributions to sound localization remain largely unclear.

2) Is binaural integration essential for sound source localization in teleost fishes? The importance of binaural input from the end organs in sound source localization has not been rigorously tested. Also, to what extent is sound source localization possible with a single ear? Can the $180^{\circ}$ ambiguity be resolved with just a single ear in a non-otophysan fish? Most models for pressure detection require two ears.

3) Under what controlled conditions can sharks and other fish without a gas bladder resolve the $180^{\circ}$ ambiguity and if so how? Sharks and other elasmobranch fishes are able to locate sound sources from relatively far distances despite their probable lack of pressure sensitivity and thus are apparently able to localize sound on the basis of acoustic particle motion alone.

4) Are fish cognizant of sound source location when local particle motion vectors do not point toward the sound source? A recent preliminary reanalysis of the results from the midshipman dipole localization by Zeddies et al. (2012) suggests that fish could potential use a time-average intensity approach for locating sound sources. This area of research warrants further study to determine how fish may use this information as well as determine under what potential acoustic environments the time averaged intensity does point away from the direction of the sound source. 
5) What are the effects of noise on the capabilities of sound source localization in fishes? This question may have a practical application in determining the effects of anthropogenic noise on the acoustically behaviors of fish. More midshipman sound localization experiments should be performed especially those in situ to determine the effects of noise on the ability of females to localize the advertisement call of males. In recent decades, sound levels have greatly increased in oceanic waters due to anthropogenic sources such as shipping, construction (e.g., pile driving), seismic exploration, and sonar. These sounds can be heard by fish and may interfere, or mask, biologically relevant acoustic signals that fish rely upon. Currently the consequences of such masking and its potential impact on the reproductive success of affected individuals are unknown.

Acknowledgements The authors would like to thank Drs. Arthur Popper and Richard Fay for their support, mentorship, and collegiality over the course of our collective careers. Both of the authors (JAS and PHR) have had the privilege to work with Dick and Art through various projects and conferences and we are very grateful for their guidance and patience.

Art Popper has been a good friend and biology guru to PHR for over 35 years. (It could have been over 50 years since Art and PHR attended the same NYC high school at the same time.) Back in 1980 Art contacted John Munson, the Superintendent of the NRL Acoustics Division, seeking some help with a tank-acoustics issue. As fate would have it, of the some 200 acousticians at NRL, Munson chose PHR to help with Art's problem. When PHR visited his lab at Georgetown University, Art explained how a fish's ear consisted of orthogonal dipole sensors and a collocated monopole sensor. PHR immediately recognized this as being identical to a Navy DIFAR sonar and PHR became obsessed with the idea that since fish were apparently 600 million years ahead of the Navy in sonar design that perhaps they had come up with other concepts that the Navy had yet to discover. From then on PHR was hooked on fish bioacoustics.

Dick Fay has been a great friend and mentor to JAS ever since the first day JAS met Dick outside the Rowe Laboratory at the Marine Biological Laboratory (MBL) in Woods Hole, MA during a smoking break in the summer of 2003. Dick provided the mentorship that allowed JAS to co-PI an NSF grant to investigate sound source localization by the midshipman fish at the Bodega Marine Lab from 2007 to 2011. In addition, JAS had the fortunate opportunity to collaborate with Dick at the Parmly Hearing Institute in Chicago, IL during the spring of 2008 and 2010 and at the MBL in Woods Hole, MA during the summers of 2011 and 2012. During these wonderful times of collaboration, JAS learned from Dick not only how to become a better scientist but also how to appreciate fine food and music, especially the jazz music of Art Tatum.

Research in the Sisneros Lab was supported by an NSF grant (IOS 0642214).

\section{References}

Bass AH, Clark CW (2003) The physical acoustics of underwater sound communication. In: Simmons AM, Fay RR, Popper AN (eds) Acoustic communication. Springer, New York, pp 1-64

Bass AH, McKibben JR (2003) Neural mechanisms and behaviors for acoustic communication in teleost fish. Prog Neurobiol 69:1-26

Bass AH, Bodnar D, Marchaterre MA (1999) Complementary explanations for existing phenotypes in an acoustic communication system. In: Hauser MD, Konishi M (eds) The design of animal communication. MIT Press, Cambridge, pp 493-514

Beranek LL (1954) Acoustics. McGraw-Hill, New York 
Brantley RK, Bass AH (1994) Alternative male spawning tactics and acoustic signals in the plainfin midshipman fish Porichthys notatus. Girard (teleostei, Batrachoididae). Ethology 96:212-232

Bregman AS (1990) Auditory scene analysis. The perceptual organisation of sound. MIT Press, Cambridge

Brown AD, Mussen TD, Sisneros JA, Coffin AB (2011) Reevaluating the use of aminoglycoside antibiotics in behavioral studies of the lateral line. Hear Res 272:1-4

Buwalda RJA (1981) Segregation of directional and nondirectional acoustic information in the cod. In: Tavolga WN, Popper AN, Fay RR (eds) Hearing and sound communication in fishes. Springer, New York, pp 139-171

Buwalda RJA, Schuijf A, Hawkins AD (1983) Discrimination by the cod of sounds from opposing directions. J Comp Physiol A 150:175-184

Chapman CJ (1973) Field studies of hearing in teleost fish. Helgoländer wiss Meeresunters 24:371-390

Chapman CJ, Hawkins AD (1973) A field study of hearing in the cod, Gadus morhua L. J Comp Physiol 85:147-167

Chapman CJ, Johnstone ADF (1974) Some auditory discrimination experiments on marine fish. J Exp Biol 61:521-528

Chapman CJ, Sand O (1974) Field studies of hearing in two species of flatfish Pleuronectes platessa (L.) and Limanda limanda (L.) (family pleuronectidae). Comp Biochem Physiol A 47:371-385

Coffin AB, Zeddies DG, Fay RR, Brown AD, Alderks PW, Bhandiwad AA, Mohr RA, Gray MD, Rogers PH, Sisneros JA (2014) Use of the swim bladder and lateral line in near-field sound source localization by fishes. J Exp Biol 217:2078-2088

de Vries HL (1950) The mechanics of the labyrinth otoliths. Acta Otolaryngol 38:262-273

Delco EA (1960) Sound discrimination by males of two cyprinid fishes. Tex J Sci 12:48-54

Dijkgraaf S (1960) Hearing in bony fishes. Proc R Soc B 152:51-54

Edds-Walton PL, Fay RR, Highstein SM (1999) Dendritic arbors and central projections of auditory fibers from the saccule of the toadfish (Opsanus tau). J Comp Neurol 411:212-238

Fay RR (1984) The goldfish ear codes the axis of acoustic particle motion in three dimensions. Science 225(951):954

Fay RR (1998) Auditory stream segregation in goldfish (Carassius auratus). Hear Res 120:69-76

Fay RR (2000) Frequency contrasts underlying auditory stream segregation in goldfish. J Assoc Res Otolaryngol 1:20-128

Fay RR (2005) Sound source localization in fishes. In: Fay RR, Popper AN (eds) Springer handbook of auditory research: sound source localization. Springer, New York, pp 36-66

Fay RR, Edds-Walton PL (1997) Directional response properties of saccular afferents of the toadfish, Opsanus tau. Hear Res 111:1-21

Fine ML, Winn HE, Joest L, Perkins PJ (1977) Temporal aspects of calling behavior in the oyster toadfish, Opsanus tau. Fish Bull 75:871-874

Fraenkel GS, Gunn DL (1961) The orientation of animals. Dover, New York

Furshpan EJ, Furukawa T (1962) Intracellular and extracellular responses of the several regions of the Mauthner cell of the goldfish. J Neurophysiol 25:732-771

Gerald JW (1971) Sound production during courtship in six species of sunfish (Centrachidae). Evolution 25:75-87

Grothe B, Pecka M, McAlpine D (2010) Mechanisms of sound localization in mammals. Physiol Rev 90:983-1012

Harris GG, van Bergeijk WA (1962) Evidence that the lateral line organ responds to near-field displacements of sound sources in water. J Acoust Soc Am 34:1831-1841

Hawkins AD, Sand O (1977) Directional hearing in the median vertical plane by the cod. J Comp Physiol A 122:1-8

Hirsh IJ (1948) The influence of interaural phase on interaural summation and inhibition. J Acoust Soc Am 20:536-544 
Hulse SH, MacDougall-Shackleton SA, Wisniewski AB (1997) Auditory scene analysis by songbirds: stream segregation of birdsong by European starlings (Sturnus vulagris). J Comp Psychol 111:3-13

Ibara RM, Penny LT, Ebeling AW, van Dykhuizen G, Cailliet G (1983) The mating call of the plainfin midshipman fish, Porichthys notatus. In: Noakes DGL, Lindquist DG, Helfman GS, Ward JA (eds) Predators and prey in fishes. Junk Press, The Hague, pp 205-212

Janssen J (2000) Toxicity of Co2+: implications for lateral line studies. J Comp Physiol A 186:957-960

Jensen FB, Kuperman WA, Porter MB, Schmidt H (2011) Computational ocean acoustics, 2nd edn. Eq. 2.205. Springer, New York

Kalmijn AJ (1997) Electric and near-field acoustic detection, a comparative study. Acta Physiol Scand 161(Suppl 638):25-38

Kaus S (1987) The effect of aminoglycoside antibiotics on the lateral line organ of Aplocheilus lineatus (Cyprinodontidae). Acta Otolaryngol 103:291-298

Ladich F, Myrberg AA (2006) Agonistic behaviour and acoustic communication. In: Ladich F, Collin SP, Moller P, Kapoor BG (eds) Communication in fishes. Science Publishers, Enfield, pp 122-148

Lu Z, Xu Z, Buchser WJ (2003) Acoustic response properties of lagenar nerve fibers in the sleeper goby, Dormitator latifrons. J Comp Physiol A 189:889-905

Lu Z, Xu Z, Buchser WJ (2004) Coding of acoustic particle motion by utricular afferents of the sleeper goby, Dormitator latifrons. J Comp Physiol A 190:923-938

Mann DA, Lu Z, Popper AN (1997) Ultrasound detection by a teleost fish. Nature 389:341

Mann DA, Lu Z, Hastings MC, Popper AN (1998) Detection of ultrasonic tones and simulated dolphin echolocation clicks by a teleost fish, the American shad (Alosa sapidissima). J Acoust Soc Am 104:562-568

McKibben JR, Bass AH (1998) Behavioral assessment of acoustic parameters relevant to signal recognition and preference in a vocal fish. J Acoust Soc Am 104:3520-3533

McKibben JR, Bass AH (2001) Effects of temporal envelope modulation on acoustic signals in a vocal fish: harmonic and beat stimuli. J Acoust Soc Am 109:2934-2943

Meyer M, Fay RR, Popper AN (2010) Frequency tuning and intensity coding of sound in the auditory periphery of the lake sturgeon, Acipenser fulvescens. J Exp Biol 213:1567-1578

Meyer M, Popper AN, Fay RR (2012) Coding of sound direction in the auditory periphery of the lake sturgeon, Acipenser fulvescens. J Neurophysiol 107:658-665

Montgomery JC, Baker CF, Carton AG (1997) The lateral line can mediate rheotaxis in fish. Nature 38:960-963

Moulton JM, Dixon RH (1967) Directional hearing in fishes. In: Tavolga WN (ed) Marine bioacoustics, vol 2. Pergamon Press, New York, pp 187-228

Myrberg AA (1981) Sound communication and interception in fishes. In: Tavolga WN, Popper AN, Fay RR (eds) Hearing and sound communication in fishes. Springer, New York, pp 395-426

Myrberg AA, Lugli M (2006) Reproductive behavior and acoustical interactions. In: Ladich F, Collin SP, Moller P, Kapoor BG (eds) Communication in fishes, vol 1. Science Publishers, Enfield, NH, pp 149-176

Myrberg AA, Spires JY (1972) Sound discrimination by the bicolor damselfish, Eupomacentrus partitus. J Exp Biol 57:727-735

Nelson DR, Gruber SH (1963) Sharks: attraction by low-frequency sounds. Science 142:975-977

Nelson DR, Johnson RH (1972) Acoustic attraction of pacific reef sharks: effect of pulse intermittency and variability. Comp Biochem Physiol A 42:85-90

Pierce AD (1981) Acoustics: an introduction to its physical principles and applications. McGrawHill, NY

Platt C, Popper AN (1981) Fine structure and function of the ear. In: Tavolga WN et al (eds) Hearing and sound communication in fishes. Spring-Verlag, New York, pp 3-38 
Popper AN, Fay RR (1993) Sound detection and processing by fish: critical review and major research questions. Brain Behav Evol 41:14-38

Popper AN, Salmon A, Parvulescu A (1973) Sound localization by the Hawaiian squirrelfishes, Myripristis berndti and M. argyromus. Anim Behav 21:86-97

Reinhardt F (1935) Uber Richtungswharnehmung bei Fischen, besonders bei der Elritze (Phoxinus laevis L.) und beim Zwergwels (Amiurus nebulosus Raf.). Z Vergl Physiol 22:570-603

Rogers PH, Cox M (1988) Underwater sound as a biological stimulus. In: Atema J, Fay RR, Popper AN, Tavolga WN (eds) Sensory biology of aquatic animals. Springer Verlag, New York, pp 131-149

Rogers PH, Zeddies DG (2008) Multipole mechanisms for directional hearing in fish. In: Webb JF, Popper AN, Fay RR (eds) Fish bioacoustics. Springer, New York, pp 233-252

Rogers PH, Popper AN, Cox M, Saidel WM (1988) Processing of acoustic signals in the auditory system of bony fish. J Acoust Soc Am 83:338-349

Sand O (1974) Directional sensitivity of microphonic potentials from the perch ear. J Exp Biol 60:881-899

Sand O, Enger PS (1973) Evidence for an auditory function of the swimbladder in the cod. J Exp Biol 59:405-414

Schellart NAM, de Munck JC (1987) A model for directional and distance hearing in swim bladder-bearing fish based on the displacement orbits of the hair cells. J Acoust Soc Am 82:822-829

Schuijf A (1975) Directional hearing of cod (Gadus morhua) under approximate free field conditions. J Comp Physiol A 98:307-332

Schuijf A, Buwalda RJA (1975) On the mechanism of directional hearing in cod (Gadus morhua). J Comp Physiol A 98:333-344

Schuijf A, Hawkins AD (1983) Acoustic distance discrimination by the cod. Nature 302:143-144

Schuijf A, Baretta JW, Wildschut JT (1971) A field investigation on the discrimination of sound direction in Labrus berggylta (Pisces: Perciformes). Netherl J Zool 22:81-105

Schuijf A, Visser C, Willers A, Buwalda RJ (1977) Acoustic localization in an ostariophysine fish. Experientia 33:1062-1063

Tavolga WN (1958) The significance of underwater sounds produced by males of the gobiid fish, Bathygobius soporator. Physiol Zool 31:259-271

Tytler P, Blaxter JHS (1977) The effect of swimbladder deflation on pressure sensitivity in the saithe Pollachius virens. J Mar Biol Assoc UK 57:1057-1064

Urick R (1967) Principles of underwater sound for engineers. McGraw Hill, New York

van Bergeijk WA (1964) Directional and nondirectional hearing in fish. In: Tavolga WA (ed) Marine bioacoustics. Pergamon Press, London, pp 269-301

van Bergeijk WA (1967) The evolution of vertebrate hearing. In: Neff WD (ed) Contributions to sensory physiology, vol 2. Academic, New York, pp 1-49

Van Trump WJ, Coombs S, Duncan K, McHenry MJ (2010) Gentamicin is ototoxic to all hair cells in the fish lateral line system. Hear Res 261:42-50

von Frisch K, Dijkgraaf S (1935) Can fish perceive sound direction? Z Vergl Physiol 22:641-655

Winn HE (1972) Acoustic discrimination by the toadfish with comments on signal systems. In: Winn HE, Olla BL (eds) Behavior of marine animals volume 2: vertebrates. Plenum, New York, pp 361-385

Zeddies DG, Fay RR, Alderks PW, Shaub KS, Sisneros JA (2010) Sound source localization by the plainfin midshipman fish, Porichthys notatus. J Acoust Soc Am 127(5):3104-3113

Zeddies DG, Fay RR, Gray MD, Alderks PW, Acob A, Sisneros JA (2012) Local acoustic particle motion guides sound source localization behavior in the plainfin midshipman fish, Porichthys notatus. J Exp Biol 215:152-160 


\title{
Revisiting Psychoacoustic Methods for the Assessment of Fish Hearing
}

\author{
Ashwin A. Bhandiwad and Joseph A. Sisneros
}

\begin{abstract}
Behavioral methods have been critical in the study of auditory perception and discrimination in fishes. In this chapter, we review some of the common methods used in fish psychoacoustics. We discuss associative methods, such as operant, avoidance, and classical conditioning, and their use in constructing audiograms, measuring frequency selectivity, and auditory stream segregation. We also discuss the measurement of innate behavioral responses, such as the acoustic startle response (ASR), prepulse inhibition (PPI), and phonotaxis, and their use in the assessment of fish hearing to determine auditory thresholds and in the testing of mechanisms for sound source localization. For each psychoacoustic method, we provide examples of their use and discuss the parameters and situations where such methods can be best utilized. In the case of the ASR, we show how this method can be used to construct and compare audiograms between two species of larval fishes, the threespined stickleback (Gasterosteus aculeatus) and the zebrafish (Danio rerio). We also discuss considerations for experimental design with respect to stimulus presentation and threshold criteria and how these techniques can be used in future studies to investigate auditory perception in fishes.
\end{abstract}

Keywords Behavior - Psychoacoustics - Conditioning • Reflex responses • Stimulus presentation

\footnotetext{
A.A. Bhandiwad $(\square)$

Department of Psychology, University of Washington, Seattle, WA 98103, USA

e-mail: bhandiwa@u.washington.edu

J.A. Sisneros

Department of Psychology, University of Washington, Seattle, WA 98103, USA

Department of Biology, University of Washington, Seattle, WA 98103, USA 


\section{Introduction}

Interest in teleost audition dates back to Aristotle's observation that "fishes undoubtedly hear...For they are observed to run away from any loud noise, such as would be made by the rowing of a galley, so as to become easy of capture in their holes; for though a sound be very slight in the open air, it has a loud and alarming resonance to creatures that hear under water" (for translation of Aristotle's original text see Barnes 1984). However, the formal study of hearing in fishes began at the turn of the twentieth century after Retzius (1881) published his study of the structure of inner ears of 48 species of fishes, which spawned interests in studying the mechanisms and processes underlying fish hearing. Parker (1903) was the first to quantitatively show that these inner ears were functional and that fish possess a sense of hearing. Working with the killifish (Fundulus heteroclitus), Parker performed a relatively simple experiment in which he attached a viol string to an aquarium wall (Fig. 1), vibrated the string, and observed that fish responded to acoustic stimuli by moving their pectoral fins in $96 \%$ of the trials. These movements were also observed when the lateral line nerves were cut $(94 \%)$, but rarely when the acoustic division of the VIIIth nerve was cut (18\%). Parker then replaced the viol string with a $128 \mathrm{~Hz}$ tuning fork and observed the same pectoral fin movements in response to acoustic stimuli, but only when the fork was both in motion and touching the aquarium wall. Since Parker's first experiments, behavioral methods have become a fundamental tool used to study the bioacoustics and hearing of fishes.

Because they are not invasive, behavioral methods are often a preferred method used to measure auditory capabilities in fishes. In some cases, behavioral methods

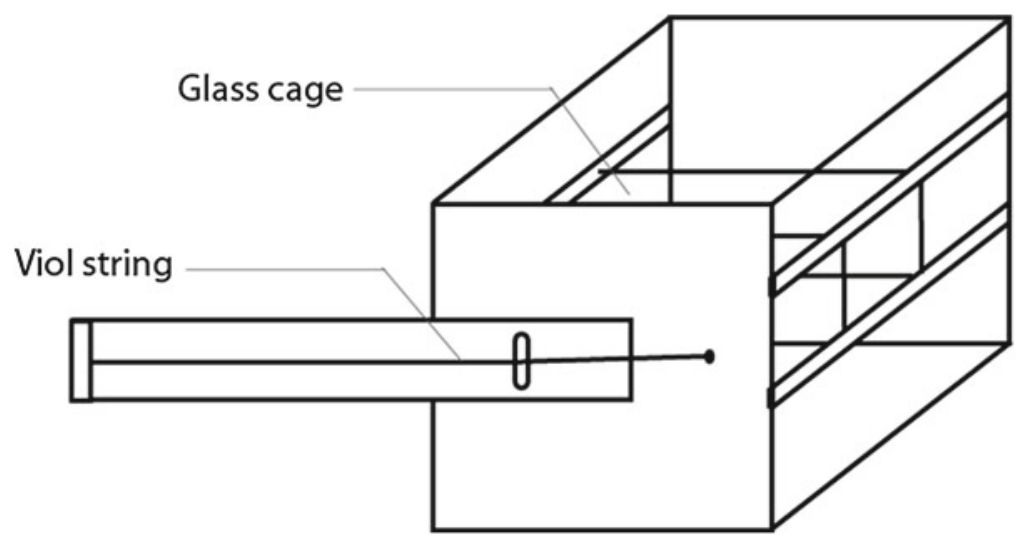

Fig. 1 Diagram of the experimental tank and testing apparatus used by Parker (1903) to test whether the killifish (Fundulus heteroclitus) could detect acoustic stimuli. A wooden board with an attached viol string was secured to one end of the tank. The fish was suspended in the center of a tank in a glass cage in order to stabilize it; during the experiment the viol string was plucked $\left(F_{0}\right.$ : $40 \mathrm{~Hz}$ ) and the presence of a suite of behaviors was measured (most commonly pectoral fin movement) to determine whether the fish detected the acoustic stimulus. Adapted from Parker (1903) 
may be the only means available to study hearing because alternative methods such as auditory electrophysiology require surgical preparation; this preparation prevents the use of many species that are sensitive and less stress tolerant to the surgery required for invasive auditory physiology experiments. Another advantage of using, noninvasive behavioral methods is that they can be used to test hearing capabilities of fish in longitudinal studies, which is useful in determining the onset and development of hearing in a given species. Finally, auditory evoked behaviors require the integration of multiple circuits and higher order auditory processing to produce a reliable and behaviorally relevant response. Thus, the use of auditory evoked behaviors provides an inherently sensitive way to assess hearing.

Why are behavioral methods important in understanding auditory function in fishes? Because hearing capability is often directly related to a behaviorally relevant function of an animal, it should follow that any stimulus that can evoke a behavioral change is a "relevant" stimulus to that animal. When considering the use of behaviorally relevant stimuli, researchers must use auditory stimulus parameters that take into account the hearing range of the species of interest. For example, in determining an audiogram for a fish species with no known hearing specializations, the use of stimulus frequencies greater than $2 \mathrm{kHz}$ (roughly the upper frequency limit of sound-pressure sensitive fish) would often be superfluous, except in cases where fishes might be sensitive to ultrasound $(>20 \mathrm{kHz})$. However, researchers should also be cautious to keep stimulus parameters relatively broad in order to conservatively assess the complete range of auditory capability in a given species. As Popper and Fay (1993) stated in their influential review on sound detection and processing in fish "...we could say that all objects that may produce or scatter sound simultaneously are equally 'biologically significant', in the sense that no source can be identified or localized without significant processing of the simultaneous sounds from the other sources."

In general, electrophysiology has been the most commonly used technique during the past 30 years to assess the auditory capabilities of fishes. Techniques such as single neuron recordings, auditory evoked potential (AEPs, also referred to in previous literature as the auditory brainstem response, or ABR), and microphonic potential recordings have been instrumental in understanding various auditory capabilities of fishes including temporal encoding (Fay 1978a; Fay and Coombs 1983; Bodnar and Bass 1997; Kozloski and Crawford 2000), frequency selectivity (Fay and EddsWalton 1997; Weeg et al. 2002), auditory plasticity (Sisneros and Bass 2003; Sisneros 2009), directional sensitivity (Enger et al. 1973; Lu et al. 1996; Fay and Edds-Walton 2000; Edds-Walton and Fay 2003), and the role of inhibition in shaping frequency tuning properties and phase locking ability (Fay 1978b; Fay 1995; Kawasaki and Guo 1998; McKibben and Bass 1999; Maruska and Tricas 2009). These methods are rapid and precise compared to behavioral methods, and as a result, they have been the technique of choice to investigate the hearing abilities of fish since the early 1960s (Enger 1963; Furukawa and Ishii 1967).

Although electrophysiological methods are critical in the study of fish hearing, they do have some limitations. First, some methods, like single auditory neuron and microphonic potential recordings, are technically difficult to perform, can involve 
invasive surgeries, and require physical restraint of the animal. Even noninvasive methods, such as the AEP recording technique, which has been used in over 100 fish species (Ladich and Fay 2013), require the animal to be physically restrained. Unfortunately, some fish species are difficult to test using electrophysiological methods due to a reduced tolerance for restraint, surgery, or other invasive methods. Second, electrophysiological methods are often difficult to perform on small animals, especially those that are early in development and less stress-tolerant. Although microphonic potentials have been recorded from larval fish (Lu and DeSmidt 2013; Inoue et al. 2013), most other electrophysiological recording methods are technically challenging to perform on embryonic and larval fishes. This limitation reduces the ontogenetic stages and the age/size ranges that can be compared and makes developmental physiology studies more difficult to perform. Third, electrophysiological methods such as the AEP recording technique that are used to measure auditory thresholds are difficult to compare to behavioral measures of hearing and are even more difficult to interpret in the context of natural auditory driven behaviors (Ladich and Fay 2013; Sisneros et al. 2015). Microphonic potentials of the fish inner ear, for example, can only inform us of hair cell activity, but not whether this activity results in an auditory percept for these fishes. Thus, there is a gap in our understanding of the relationship between behavioral and electrophysiological thresholds; although some correlations have been described for electrophysiological and behavioral thresholds, these correlations have only been made for goldfish (Carassius auratus) with no single representative relation between behavioral and physiological measures of auditory sensitivity (Ladich and Fay 2013). Variation of auditory thresholds obtained by electrophysiological measures can often be related to such factors such as electrode placement, morphology of the inner ear and skull, and the threshold criteria used.

This review primarily focuses on behavioral methods that are commonly used to assess the hearing capabilities of fishes. We discuss the use of associative (conditioning) methods and reflex (innate) responses in psychoacoustic studies of fish hearing. While many variants of these methods exist, we wish to convey the general techniques used to assess hearing in fishes and highlight the principles underlying these techniques. We also discuss the benefits and limitations of various psychoacoustic methods used to assess fish hearing and emphasize the techniques that are appropriate for investigating fundamental processes related to the sense of hearing in fishes.

\section{Associative Methods}

\subsection{Operant Conditioning}

Operant conditioning methods were used to study audition in fishes soon after Parker (1903) published his findings that fish could detect acoustic stimuli. Operant conditioning (also called instrumental conditioning) is a technique by which a 
behavior is either enhanced (through reinforcement) or suppressed (through punishment), before and/or after a cued stimulus. This form of conditioning can either enhance or suppress voluntary behaviors; continued behavioral reinforcement eventually leads to an association of the behavior and a consequence for that behavior. A similar apparatus to Parker (1903) was used to show that minnows (Pimepheles notatus; McDonald 1922), mudminnows (Umbia limi; Westerfield 1922), and wrasses (Crenilabrus melops; Bull 1928) could be conditioned using an auditory stimulus, and therefore demonstrated that these fishes could detect auditory stimuli and thus possessed a sense of hearing. Operant conditioning methods were later used by von Frisch (1936) in an attempt to train minnows to localize sound for a food reward and thereby establish whether fish could localize sound sources. Von Frisch tried to modify the "feeding reflex" of European minnows using an operant conditioning paradigm wherein minnows were trained to approach one of multiple available feeding stations when they heard a loud sound (the conditioned stimulus) that was produced by an underwater horn positioned under one of the feeding stations. Von Frisch was unsuccessful in his training of the fish and eventually he (incorrectly) concluded that fish could not localize sound sources, but the use of operant conditioning methods persisted and were later successfully used in subsequent fish hearing studies. For example, Schuijf (1975) used a forced choice conditioning method to successfully show that acoustic directional sensitivity in fish was mediated by the inner ear and not the lateral line. For a more complete review of the behavioral experiments used to investigate directional hearing and sound source localization in fishes see Hawkins (1981) and Sisneros et al. (in this volume).

Operant conditioning methods using feeding (positive) reinforcement have been successfully used in the studies of vision in fish (Yager and Thorpe 1970; Allen and Fernald 1985), but these methods have not been extensively used in the study of fish hearing. One excellent use of an operant conditioning paradigm was that used by Yan and Popper (1991), who developed an automated positive reinforcement system in which fish could be trained to respond to a piezo-pressure paddle via a feeding reflex when it heard a particular sound (Fig. 2). Goldfish (C. auratus) were trained to strike an observation paddle to initiate the trial after which they would strike a second "report" paddle if they heard a sound. Correct responses were rewarded with food, whereas false positive responses resulted in a punishment with the lights being turned off removing any possibility of successful prey capture. During the testing phase, sounds of varying frequencies and intensities were played, and responses were recorded, but not rewarded/punished. This paradigm was used to measure audiograms in goldfish, and was later used for intensity discrimination (Yan and Popper 1993), and in measuring audiograms in the cichlid Oscar (Astronotus ocellatus; Yan and Popper 1992).

There are three primary reasons why operant conditioning methods are rarely used in fish hearing studies. First, operant condition methods require the fish to be unrestricted and free-swimming. Most studies use a speaker to deliver acoustic stimuli, and a freely moving fish would likely encounter different aspects of the sound field at different points within the testing arena or apparatus, which makes it 


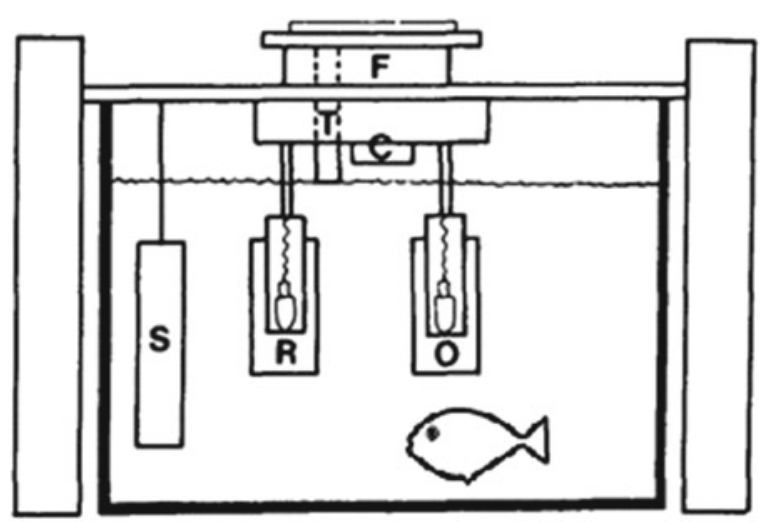

Fig. 2 Cross-section diagram of the apparatus used for operant conditioning by Yan and Popper (1992) to determine the hearing capability of the oscar (Astronotus ocellatus). Fish were trained to press the observation paddle $(\mathrm{O})$ and attend to a sound played through an underwater speaker $(\mathrm{S})$. If they perceived a sound stimulus, they were trained to press the response paddle (R). Correct responses were rewarded with a food pellet delivered from an automatic feeder $(\mathrm{F})$ through a tube (T). Incorrect responses resulted in the ceiling light (C) being switched off. Modified from Yan and Popper (1992)

difficult for the researcher to control the playback stimuli. This is a major problem when trying to determine auditory thresholds to acoustic playback stimuli or in behavioral tasks that involve sound-level discrimination. Second, operant conditioning methods require significant motivation of the animal being tested; feeding assays are only effective in cases where the reinforced reward has a strong biological significance to the animal (e.g., a food reward to a food-restricted animal). This may significantly impact the training time required for learning. For example, using this method, goldfish can be trained within 1-2 days, whereas oscars (A. ocellatus) can take 12-14 days to train (Yan and Popper 1992). Finally, the operant conditioning paradigm requires the use of an unconditioned stimulus that is biological relevant to the animal's unconditioned response. In the case of a food reward, the unconditioned stimulus would require modification of a feeding reflex. In the Yan and Popper (1991) conditioning paradigm, this required a species specialized for strike-feeding with the striking motion being conditioned to the auditory stimulus. Since not all fish have the same mode of prey capture, this may make a similar operant conditioning paradigm difficult to use in comparative studies.

\subsubsection{Avoidance Conditioning}

Avoidance conditioning is a variant of the operant conditioning paradigm that has been successfully used to determine the audiograms of a number of fish species. Tavolga and Wodinsky (1963) were the first to perform an exhaustive comparative study of the auditory capacities of nine species of fishes using avoidance 
conditioning. In this study, the authors trained fish to cross a barrier upon hearing a tone that was quickly followed by an electric shock (Fig. 3). The unconditioned stimulus was the electric shock that provided negative reinforcement and a successful barrier crossing resulted in a cessation of that shock. After training, the fish crossed the barrier very quickly after hearing the sound stimulus to avoid the unconditioned shock. Using this paradigm, the authors were able to determine auditory thresholds at various frequencies and construct audiograms for the nine species of fish. This method, though useful, requires a very long training period, up to 30 days in the case of the cichlid Tilapia macrocephala (Tavolga 1974).

Avoidance conditioning has been used very effectively in studies of frequency selectivity using maskers. McCormick and Popper (1984) used avoidance conditioning with maskers to determine the auditory thresholds of elephant nose fish (Gnathonemus petersii), and conditioned fish to avoid a $500 \mathrm{~Hz}$ test tone. The authors presented the test tone in the presence of an acoustic masker that varied in frequency between 100 and $800 \mathrm{~Hz}$ and then were able to measure the animal's frequency tuning and its tuning sharpness or $Q_{10}$, the ratio of test frequency to the bandwidth $10 \mathrm{~dB}$ above threshold. This application of the avoidance conditioning technique demonstrated that $G$. petersii had a tuning curve with a $Q_{10}$ similar to the filter shape in goldfish. Avoidance conditioning continues to be a promising method that can be used to study similar questions about directional hearing, frequency selectivity, and masking in future studies of fish hearing.

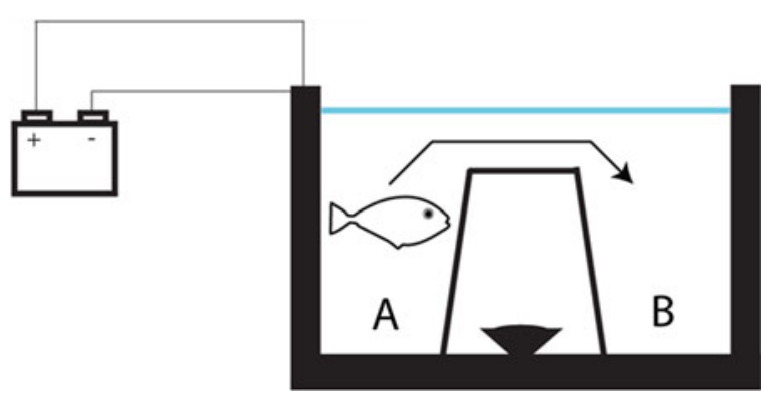

Fig. 3 Cross-section diagram of the apparatus used by Tavolga and Wodinsky (1963) to test the hearing ability of fishes using avoidance conditioning. Fish were initially placed in the left compartment of the chamber (A) separated from right compartment (B) by a raised barrier in the center of the tank. Fish were conditioned to cross from one compartment (A) into the other compartment (B) when they heard a tone that was followed quickly by an electric shock. Acoustic stimuli were played via a speaker (placed below the barrier) and the electric shock was produced by a DC battery that had terminal contacts embedded in the tank wall. Correct responses consisted of the fish crossing over the barrier into the other compartment of the tank. After conditioning, fish crossed from (A) to (B) upon hearing the sound stimulus alone 


\subsection{Classical Conditioning}

Classical conditioning is the most commonly used technique in the study of fish hearing. Classical conditioning, also called Pavlovian or respondent conditioning, is an associative learning paradigm in which a conditioned stimulus (CS, e.g. tone) is paired with an unconditioned stimulus (US, e.g. taste of food) and an unconditioned response (UR, e.g. salivation); after repeated pairings, the CS (tone) alone can invoke the UR (salivation). This technique has been used in fish hearing studies to determine audiograms (Buerkle 1967; Fay 1969; Popper et al. 1973), frequency discrimination (Fay 1970; Chapman and Johnstone 1974), sound source discrimination (Buwalda et al. 1983; Lu et al. 1996), and for auditory scene analysis (Fay 1992, 1998). This form of conditioning has become a powerful tool because it uses an innate response to a biologically potent stimulus that does not require voluntary movement. After Bull (1928) showed that eels (Anguilla vulgaris) could be conditioned to vibratory stimuli using electric shock, many other studies showed that this type of conditioning was generalizable. All of these methods use a form of a reflexive response, such as a defense response (Kenyon et al. 1998) or a suppression of ventilation or cardiac activity (Fay 1969; Buwalda et al. 1983; Lu et al. 1996). In the case of ventilation suppression (measured as a suppression of mouth or opercular movements), a tone-shock paradigm is used with the unconditioned response measured as a temporary reduction in the frequency of opercular ventilation movements; this response is robust and easy to measure in most fish, especially goldfish (Otis et al. 1957; Fay 1972, 1988, 1998). During the conditioning period, the fish begins to associate the tone with a shock and in subsequent trials starts to suppress ventilatory movements in the anticipation of the shock when the tone is heard. After conditioning, the fish will suppress its ventilatory movements upon hearing the tone alone, even in the absence of a shock. The stimulus tone can be altered with respect to frequency or intensity to determine the fish's frequency selectivity or absolute hearing threshold.

In almost all species tested, classical conditioning methods have yielded the lowest auditory thresholds compared to other methods that measure auditory thresholds including auditory physiology. The lower auditory threshold measures produced by behavioral methods are, in part, likely due to higher order processing and integration of auditory information required for whole animal behaviors. However, classical conditioning methods also have some potential limitations. Although training time is relatively short compared to the operant and avoidance conditioning paradigms, initial classical conditioning can still take $40-50$ trials for some fish species (Fay 2009). Furthermore, because the unconditioned stimulus is often an electrical shock, this might preclude the use of particular species that are sensitive to stressors, like certain cichlid species (Tavolga 1974; Allen and Fernald 1985). Classical conditioning also requires constant retraining during the testing phase. Finally, animals can only be conditioned a limited number of times, which then reduces the number of stimulus parameters that can be investigated, and subsequent stimulus parameter training requires additional subjects and/or longer test times. 
Perhaps the most powerful use of classical conditioning methods has been in the study of auditory scene analysis in goldfish (C. auratus), in particular auditory stream segregation. Utilizing a ventilation suppression reflex, Fay (1998) trained goldfish to suppress ventilation when presented with a complex acoustic stimulus that was paired with a mild electric shock. During conditioning, the goldfish learned to anticipate the shock paired with the acoustic stimulus by suppressing their ventilatory movements, functionally measured as the rate of mouth openings (Otis et al. 1957). The pairing of the conditioned acoustic stimulus and an unconditioned shock stimulus led to an association of the conditioned stimulus with an unconditioned response, the involuntary suppression of ventilatory movements of the goldfish, within 40 trials. Fish were placed in the training apparatus (Fig. 4) and conditioned to suppress their ventilation to a complex stimulus of pulse trains of two separable frequencies presented at two discernibly different rates. Each pulse train was independently played back and the ventilation rate was measured. Ventilation was suppressed when each pulse train was presented at the same frequency and pulse period as it was during the training phase. Furthermore, fish suppressed ventilation to single components of the complex stimulus, indicating that the two components of the complex conditioning stimulus were analyzed independently, as if they were from two separable sources and suggested that the fish were capable of auditory

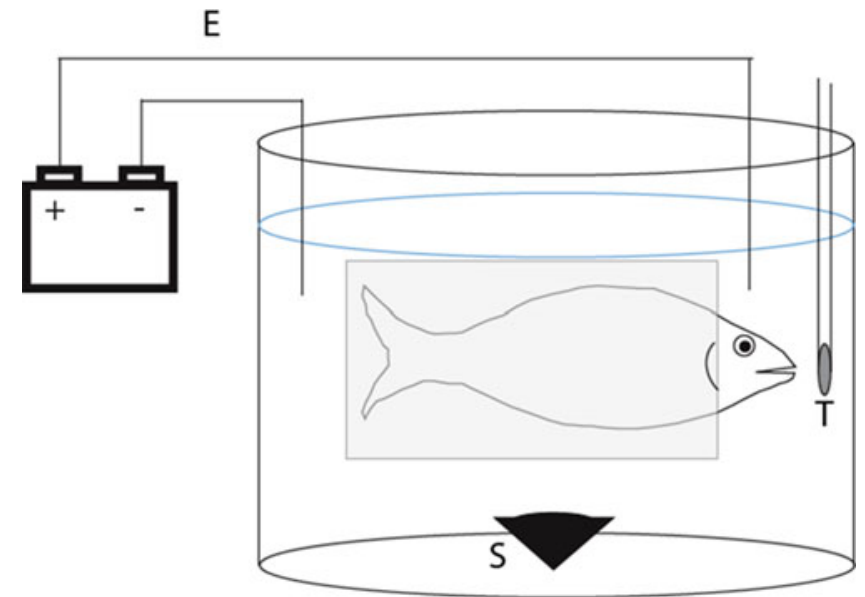

Fig. 4 Diagram of the apparatus described by Fay (1995) to measure frequency discrimination thresholds in goldfish (Carassius auratus) using classical conditioning. Fish were restrained in a cloth bag with their mouth and gills exposed and positioned $2 \mathrm{~cm}$ below the surface of the water in the center of the tank. Sound was produced by an underwater speaker (S) on the bottom of the tank and paired with a shock delivered through electrical leads positioned near the head and tail of the animal (E). Changes in ventilatory movements of the fish were measured using a thermistor (T), which registered a change in temperature when water was moved past the sensor 
stream segregation. Similar conditioning protocols using a complex stimulus and analysis of the components have also been used to study pitch perception in goldfish (Fay 1995).

\section{Use of Innate Behavioral Responses in Psychoacoustic Studies of Fish Hearing}

Many psychoacoustic studies of fish hearing have taken advantage of using innate behavioral responses to assess the auditory capabilities of fishes. Innate behavioral responses are regarded as genetically programmed responses to external stimuli. These stereotyped innate responses can often be used to probe an animal's perceptual world or "umwelt" and characterize an animal's sensory capabilities. Simple reflex responses and the more coordinated movement of reflexive locomotion are two broad categories of innate behavioral responses that have been successfully used to assess hearing in fishes.

\subsection{Reflex Responses}

Reflexes are involuntary movements in response to a sensory stimulus. Innate reflex responses are often used in psychoacoustic studies of hearing because they are stereotyped, repeatable and do not require conditional behavioral training in order to evoke them. Furthermore, these conserved innate responses serve a behaviorally relevant function, and are therefore robust and can be elicited easily. This allows for very fast and efficient measures of auditory capability.

\subsubsection{Acoustic Startle Response}

The most common reflex response described across multiple species is the auditory startle response (ASR). Although variants of the ASR have been described since Aristotle, Wilson (1959) was the first to show that the "tail-flip" startle response in fish was driven by Mauthner cells (M-cells), giant neurons found in the fourth segment of the reticulospinal formation of the hindbrain (R4). This stereotyped startle response is described in mammals (Parham and Willott 1988), anurans (Cioni et al. 1989), and urodeles (Marini et al. 1991). In fish, as well as anurans and urodeles, the M-cell circuitry is relatively simple (Zottoli and Faber 2000). Briefly, afferent neurons of the VIIIth nerve synapse onto the lateral dendrite of the M-cell. The M-cells cross-over and innervate the motor neurons on the contralateral side of the fish. When activated, an M-cell fires a single spike that activates all the motor neurons on the contralateral side of the fish, causing the fish to bend and accelerate away from the direction of the stimulus. The startle-escape response was later formalized as the 
"C-start" response, so called because of the conformation of the body to from a "C" at the apex of the response when all the muscles of that side are contracted (Kimmel et al. 1974). The authors used an experimental paradigm in which they dropped a metal ball into the tank containing zebrafish (Danio rerio) from varying heights (a greater height would correspond to a larger intensity) and recorded the startle behavior of the fish using a video camera. Using this, they were able to show that the startle response is present in both larval and adult zebrafish, it could be elicited with auditory or tactile stimuli, and it could be described using a psychometric function. The latter finding is important because it shows that the M-cells have intensitydependent firing probability (Neumeister et al. 2008). This property allows for model fitting of this response to a psychometric function, and allows for interpolation of threshold from discrete responses.

The ASR has been used most prominently in studies of the development of hearing in larval zebrafish (Kimmel et al. 1980; Zeddies and Fay 2005), but in most other studies it has served only as a test to determine whether or not the auditory system is functional. Zeddies and Fay (2005) were the first to use acoustic startlelike responses to construct audiograms in larval zebrafish. In this study, the authors stimulated larval zebrafish aged 5 days post-fertilization (dpf) using a onedimensional shaker (Fig. 5) and measured responses using a standard video camera. Using the shaker, the authors were able to provide pure-tone particle motion stimuli and measure the acoustically evoked behavioral responses (AEBR) to the particle motion stimuli. The AEBRs were defined as any acoustically mediated event that resulted in the movement of the fish and a difference in pixel distribution after frame subtraction in two consecutive video frames; if the number of differing pixels was two standard deviations above pixel differences during a no-stimulus trial, the fish

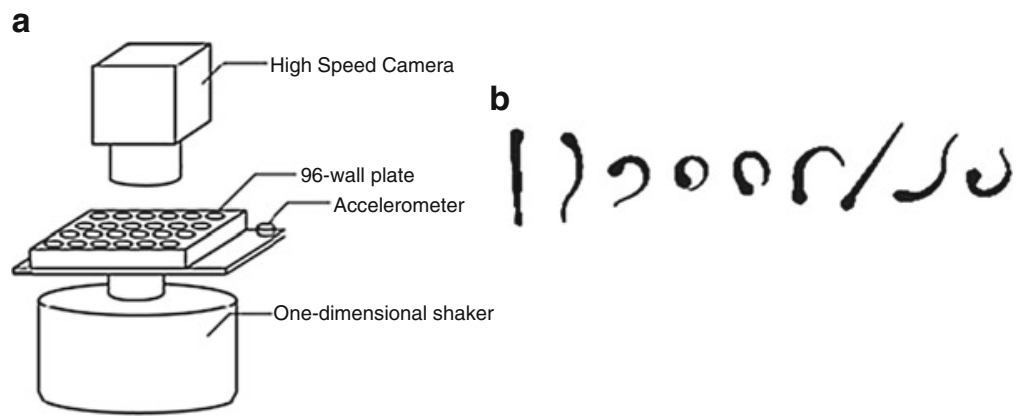

Fig. 5 (a) Apparatus used to measure auditory thresholds in larval zebrafish (Danio rerio) and sticklebacks (Gasterosteus aculeatus) using acoustic startle response and prepulse inhibition assays, as used in Bhandiwad et al. (2013). A 96-well plate was mounted on an acrylic plate attached to a one-dimensional shaker. Particle motion stimuli were delivered through the shaker to larvae placed in individual wells of the 96-well plate. An accelerometer measured stimulus level and the resulting ASRs were recorded using a high-speed video camera at 1000 frames per second. (b) Diagram of representative Mauthner-cell mediated ASR, digitized from data. Successive frames are $4 \mathrm{~ms}$ apart. Note that the characteristic " $\mathrm{C}$ " shape of the startle response can be seen in panel 4 
was determined to have performed an AEBR. AEBRs served as proxies for the ASR when using a non-high-speed camera to record the responses because the ASR occurs on the timescale of $\sim 5-10 \mathrm{~ms}$ and standard (30 frames per second) cameras have a temporal resolution of $\sim 33 \mathrm{~ms}$. The authors were able to use this technique to show group-level absolute thresholds for larval zebrafish in early development (from 5 to 26 days dpf).

We have used the ASR to determine how auditory thresholds differ during early development in two distantly related species of fish. Zebrafish (D. rerio, order Cypriniformes) have specialized accessory structures for hearing, whereas the three-spined sticklebacks (Gasterosteus aculeatus, order Gasterosteiformes) are non-specialists that lack specialized accessory hearing structures. Fishes with hearing specializations generally have greater auditory sensitivity and frequency bandwidth detection than fish species that do not (Popper and Fay 2011). However, whether these differences are present before the development of hearing specializations is not known. The ASR is a useful method to probe an animal's auditory system in terms of auditory sensitivity and frequency detection capability at hearing onset because it is rapid and can be retested over time.

Using the apparatus described by Bhandiwad et al. (2013), we presented pure tone stimuli to larval three-spined sticklebacks and zebrafish. We first used the kinematics of the startle response to determine whether startle responses of larval sticklebacks were similar to those found in larval zebrafish (Fig. 6). Sticklebacks that were tested consisted of Japan Pacific, Paxton Lake Limnetic, and Paxton Lake Benthic species and were chosen due to their morphological differences in lateral line and therefore represented the diversity of stickleback species (Wark and Peichel 2010). We show that the kinematics of the startle response in both zebrafish and sticklebacks are essentially the same, although the maximal bend angle is much smaller in sticklebacks (Fig. 7). Because both species' startle responses are on the same timescale, we posited that they are both mediated by the M-cell pathway.

Next, we tested groups of larval stickleback fish daily from the day they became free swimming until they exhibited the ASR. In zebrafish, the onset of the ASR to pure tones is $5 \mathrm{dpf}$ (Zeddies and Fay 2005; Bhandiwad et al. 2013), but ASRs can be evoked earlier by an acoustic broadband stimulus at $4 \mathrm{dpf}$ (Fig. 8). In contrast, sticklebacks begin to exhibit ASRs to broadband acoustic stimuli at 9 days post hatch (dph) and showed frequency-specific differences in ASR onset. Post-hatch days were more accurate measures of development in sticklebacks due to the long duration and variability of the embryonic period; in comparison, all zebrafish larvae hatched at $3 \mathrm{dpf}$. Low frequency stimuli (e.g., $45 \mathrm{~Hz}$ ) evoked ASRs in sticklebacks at $12 \pm 2 \mathrm{dph}($ mean $\pm \mathrm{SD}$ ), but higher frequency stimuli (e.g., $90 \mathrm{~Hz}$ ) did not evoke ASRs until $15 \pm 1 \mathrm{dph}$. These data suggest that there may be an ontogenetic change in frequency sensitivity of larval sticklebacks during early development from 9 to $16 \mathrm{dph}$. ASRs evoked by either pure tones or broadband stimuli were all-or-none response in both zebrafish and sticklebacks.

Auditory thresholds on the day of hearing onset also differed between larval zebrafish and sticklebacks. Because there were frequency-dependent differences in ASR onset, sticklebacks were tested between 24 and $31 \mathrm{dph}$. No significant differ- 


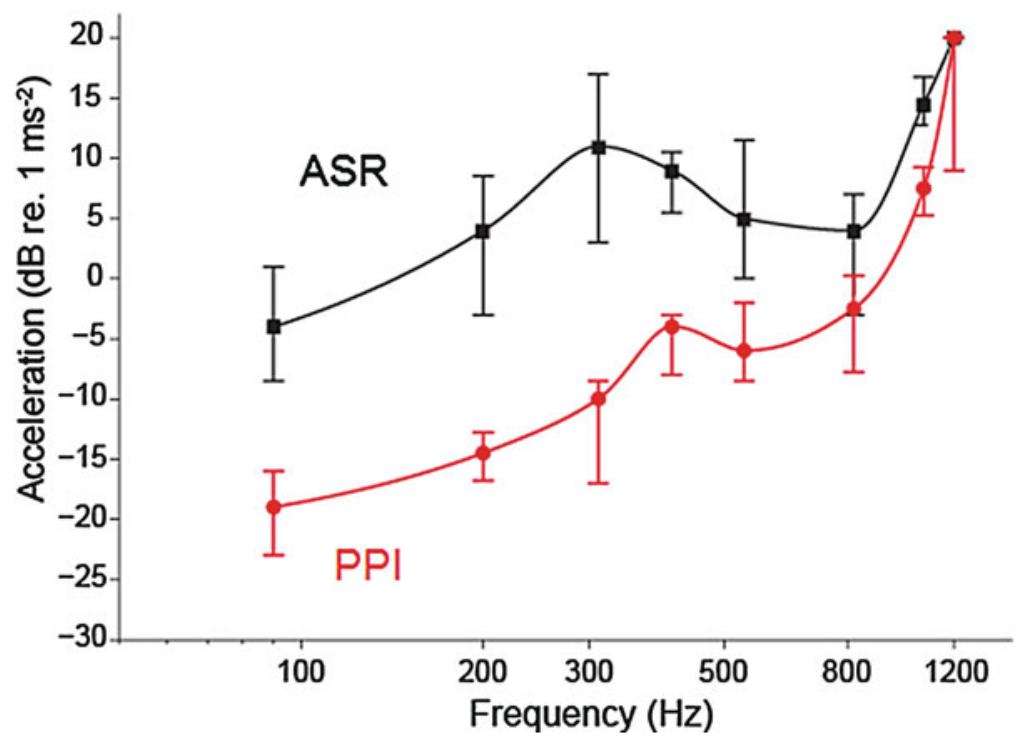

Fig. 6 Comparison of ASR (black squares) and PPI (red circles) audiograms in 5 day postfertilization zebrafish (Danio rerio) to particle motion stimuli. Threshold is defined as a $5 \%$ probability of startle for ASR assay or $5 \%$ inhibition of startle from the paired catch trials in the PPI assay. Both studies were performed on the same population of fish ( $n=10$ plates of 24 fish for both assays). Data presented as median \pm 1 quartile and lower numbers indicate higher sensitivities. The results show that auditory sensitivity determined using the PPI method are much lower than ASR thresholds

ences were observed in the thresholds across $24-31 \mathrm{dph}$; therefore, the thresholds were pooled for all sticklebacks tested. Zebrafish were tested at $5 \mathrm{dpf}$. At the onset of the auditory startle response, sticklebacks had much higher startle thresholds (up to $25 \mathrm{~dB}$ at $30 \mathrm{~Hz}$ ) than larval zebrafish (Fig. 9). Furthermore, zebrafish exhibited ASRs to acoustic frequencies as high as $320 \mathrm{~Hz}$, whereas sticklebacks only showed ASR to frequencies $\leq 180 \mathrm{~Hz}$ (Fig. 9).

Reflex responses like the ASR also have certain limitations. The first, and most prominent, is the habituation of the reflex response to repeated auditory stimuli. Habituation is a non-associative learning process by which an organism decreases the strength of its response after repeated presentations. Although the effects of habituation can be reduced by increasing the inter-stimulus interval between stimulus presentations (Zeddies and Fay 2005), there is an upper limit of approximately 15 stimulus presentations before the response rate is degraded (Roberts et al. 2011; Bhandiwad et al. 2013). Another potential problem with the ASR assay is that a very intense acoustic stimulus is required to facilitate the startle response. The threshold for the ASR is very high because it is often evoked by a predatory attack and requires a large energetic output for the response. Thus, repeated presentations of high intensity stimuli can often lead to habituation very quickly. Furthermore, the sound levels necessary to evoke the ASR are significantly higher than auditory 

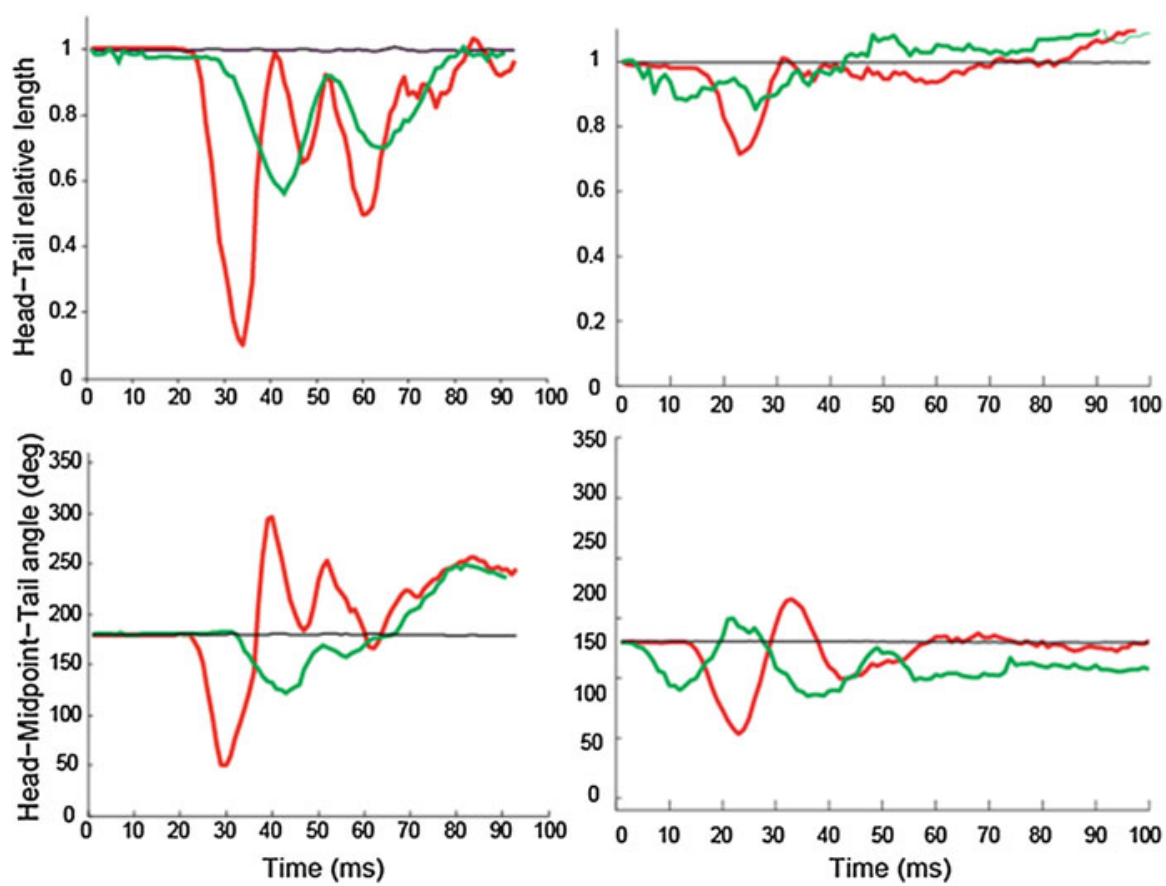

Fig. 7 Comparison of representative kinematics of the ASR as measured by the head-to-tail Euclidean distance (top) and the head-midpoint-tail angle (bottom) in 5- to 7-day-old zebrafish larvae (Danio rerio; left) and 17- to 27-day-old stickleback larvae (Gasterosteus aculeatus; right). M-cell based acoustic startle responses are uniquely identifiable (red trace) when compared to non-startle motion (green trace) and non-response (black trace) in both species analyzed. In all four panels, onset of startle response is highly correlated $(r=0.78)$ and is characterized by a large, rapid bend in one direction, followed by a series of refractory bends. Though the magnitude of the bends are different between zebrafish and stickleback larvae, the time course and magnitude relative to non-startle bends is conserved

thresholds obtained from electrophysiological measures, such as microphonic potentials or AEPs, suggesting that it greatly underestimates the hearing ability of fishes. Finally, although startle responses can occur with other reticulospinal neural networks, an M-cell pathway is necessary for the "fast-startle" responses currently described. Therefore, the ASR can only be reliably tested in fish species that exhibit the characteristic fast "C-start" startle response mediated by the M-cell pathway.

\subsubsection{Prepulse Inhibition}

One variant of the ASR paradigm is the use of reflex suppression in order to determine auditory sensitivity. Reflex suppression has been used to determine sensitivity of sensory systems since the early twentieth century when Yerkes (1903) used it to 

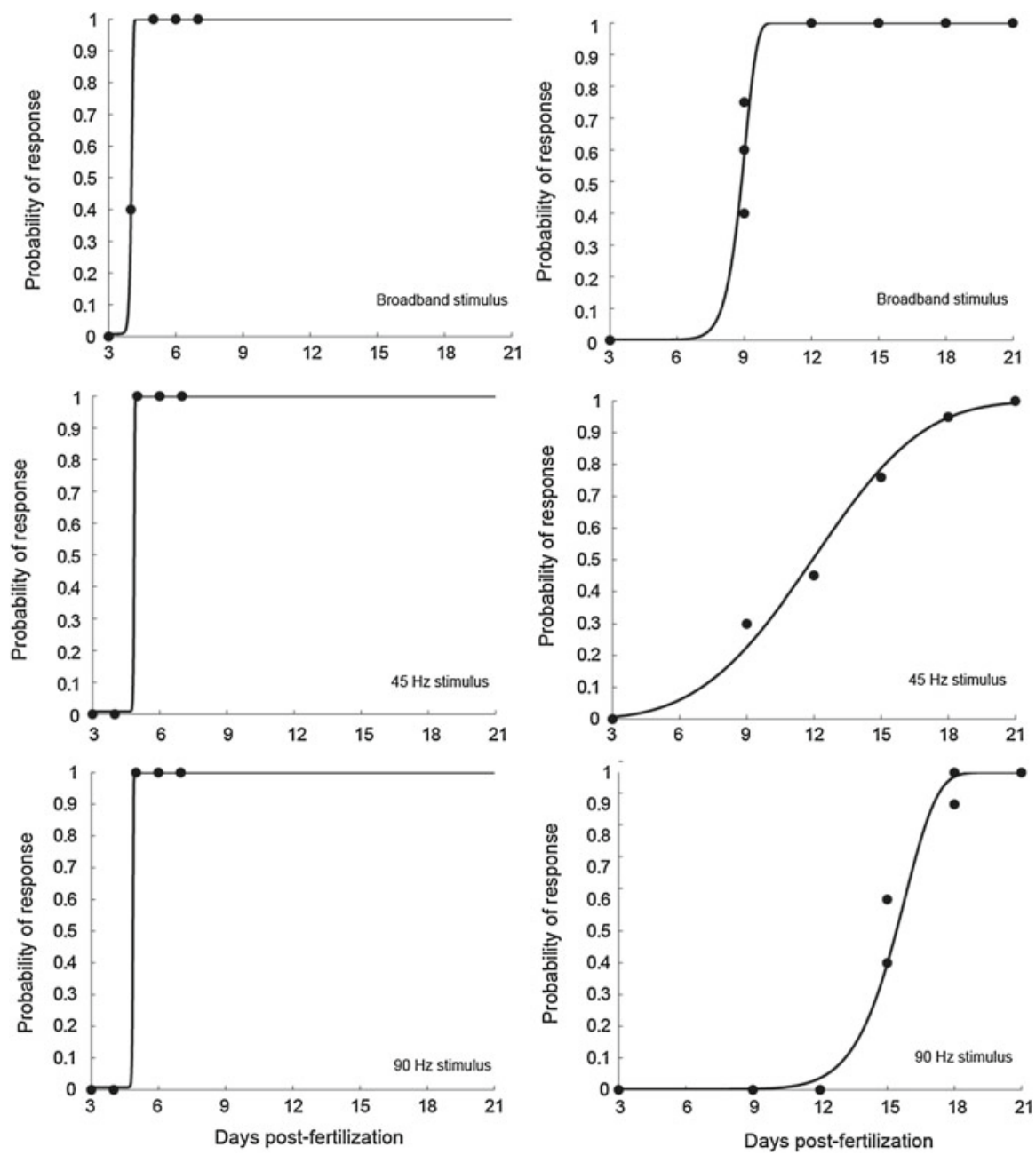

Fig. 8 Ontogeny of the startle response for larval zebrafish (Danio rerio; $N=24$; left) and larval sticklebacks (Gasterosteus aculeatus; $N=11$; right). The probability of observing a startle response for a cohort of fish was tested using a repeated measures design. Fish were tested daily after hatching for the presence of the ASR to broadband acoustic stimuli (top) and pure tone stimuli of $45 \mathrm{~Hz}$ (middle), and $90 \mathrm{~Hz}$ (bottom). Zebrafish had a rapid onset of ASR at $\sim 5 \mathrm{dpf}$. However, sticklebacks did not show the ASR until 8-13 dpf with frequency-specific differences in ASR onset

study the effect of touch on tactile reflexes. Reflex suppression was later applied to study the sensitivity of the mammalian auditory system by Russo (1979). Conditioning paradigms in combination with the suppression of ventilation and cardiac reflexes have also been successfully used in fishes to determine auditory sensitivity. Recently the suppression of the ASR using a prepulse inhibition (PPI) paradigm was shown to yield lower auditory thresholds than the ASR assay alone (Bhandiwad et al. 2013; Fig. 6). 


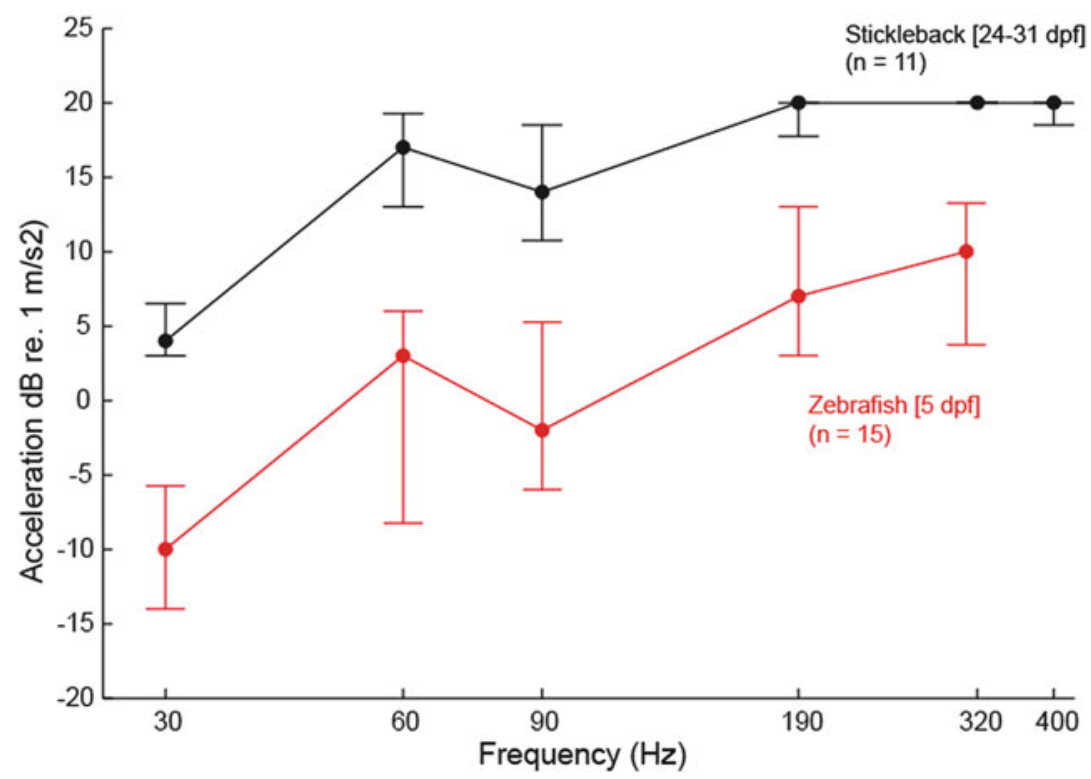

Fig. 9 ASR thresholds for 5-day-old zebrafish (Danio rerio; $N=8$ groups of 24 fish) and 24 to 31-day-old sticklebacks ( $N=11$ groups of 9 fish) to particle motion stimuli. Thresholds were defined as a $5 \%$ probability of startle. Note: data are presented as median \pm 1 quartile, and lower threshold values indicate higher sensitivity. At all frequencies tested, larval zebrafish have significantly greater sensitivity to particle motion stimuli than larval sticklebacks, with the greatest difference at low frequencies $(\sim 16 \mathrm{~dB}$ difference at $30 \mathrm{~Hz})$

PPI is a phenomenon by which the response evoked by a high intensity stimulus can be suppressed by the prior presentation of a lower intensity stimulus (the prepulse). In the case of inhibiting the ASR, the prepulse can be operationalized as a low intensity tone presented prior to a startle-inducing tone, which then acts to reduce the probability of the ASR. PPI has been used to study auditory sensitivity in rodents (Willott et al. 1994; McCaughran et al. 1999), but only recently it has been use to characterize the sensitivity of the teleost auditory system. The circuitry for PPI in teleosts has also been well studied (Neumeister et al. 2008; Weiss et al. 2006; Korn and Faber 2005; Burgess and Granato 2007; Kohashi et al. 2012). Briefly, the M-cells are inhibited not only by the contralateral M-cells but also by a set of neurons near the body and axon hillock of the M-cells. The most prominent of these is the passive hyperpolarization (PHP) cell, which also receives input from the VIIIth nerve afferents and hyperpolarizes the axon hillock of the M-cell, leading to a suppression of firing probability in the M-cell (Medan and Preuss 2014). This suppression happens at stimulus intensities too low to activate the M-cell, and is presumably a mechanism that prevents unnecessary firing of the M-cell.

The use of PPI to determine auditory thresholds has recently been used in larval zebrafish (Bhandiwad et al. 2013). In this study, the authors determined that an acoustic stimulus of $820 \mathrm{~Hz}$ at $20 \mathrm{~dB}$ re $1 \mathrm{~m} / \mathrm{s}^{2}$ was a reliable startle stimulus and sufficient to produce an $80-90 \%$ startle response probability for a plate of 24 larval 
zebrafish mounted on a shaker system (Fig. 5). After determining the baseline startle response probability, a set of acoustic stimuli ranging from 90 to $1200 \mathrm{~Hz}$ at sub-startle threshold levels were used as prepulse stimuli. Startle response probabilities were measured, and the change in probability of evoking the ASR was quantified. Auditory threshold was determined as the prepulse sound level that effectively reduced the ASR probability by $5 \%$ from the baseline response probability. Using this method, the authors were able to show that auditory thresholds in 5 dpf zebrafish were $10-15 \mathrm{~dB}\left(\mathrm{re} .1 \mathrm{~m} / \mathrm{s}^{2}\right)$ lower than was previously shown by just using an ASR assay (Fig. 6).

The PPI assay has similar limitations to ASR assays. Habituation to PPI can be reduced, but it still imposes an upper limit on the number of stimulus presentations that can be effectively performed. The use of PPI also requires the presence of the M-cell circuitry and the associated PHP cells, which are known to occur in zebrafish and goldfish (Neumeister et al. 2008; Medan and Preuss 2011). Future work in this field should investigate whether the PPI of the startle response can be implemented to study of auditory function in species that lack Mauthner cells.

PPI is potentially a powerful tool to study ontogenetic changes in auditory sensitivity, particularly in larval fishes. In this context, electrophysiological methods can be too invasive, conditioning methods can be too time-consuming, and ASR assays are not sensitive enough to study the auditory capabilities of larval fishes. PPI assays are sensitive enough to determine changes in auditory sensitivity of the animal during development and the same animals can be tested again at different stages of development. Furthermore, the acquired threshold estimates can be just as or more sensitive than those derived from electrophysiological methods. Studies using the Mongolian gerbil (Meriones unguiculatus) have shown that auditory thresholds determined by PPI are equivalent to thresholds determined using an ABR approach (Walter et al. 2012). Future work on PPI will inform us whether this finding can be generalized in larval and adult teleosts.

\subsection{Phonotaxis}

Phonotaxis is a reflexive locomotor response toward (positive) or away from (negative) an external auditory stimulus. This innate response is associated with a biologically relevant function, and as a result can only be elicited with a specific stimulus. Stimuli that "release" phonotaxis can be biogenic (in the case of conspecific advertisement calls) or produced by physical features of the environment (e.g., reef sounds that attract pelagic fish larvae; Pijanowski et al. 2011). Such acoustic "sign" stimuli are known to have unique spectral and temporal features (Amorim 2006) that are strongly stereotyped, complex, and behaviorally relevant to the animal. Many fish species have inherent behaviors that are evoked by specific acoustic stimuli including acoustic signals used for communication. Courtship and agonistic/ distress sounds have been recorded in mormyrid fish (Gnathonemus petersii; Rigley and Marshall 1973), cod (Gadus morhua; Hawkins and Chapman 1966), toadfishes 
(family Batrachoididae; Gray and Winn 1961; Cohen and Winn 1967), searobins (Prionotus carolinus; Fish 1954), cichlids (family Cichlidae; Lobel 2001), damselfishes (Chromis viridis; Amorim 1996), gobies (family Gobiidae; Fish and Mowbray 1970), and catfishes (families Pimelodidae, Mochokidae, and Doradidae; Ladich 1997). Behaviors that are evoked by particular acoustic signals can be in the context of aggression (Myrberg 1981; Ladich 1997) or affiliative behavior (Fine 1978; Brantley and Bass 1994). These characterized behaviors to specific stimuli can be used to measure properties of the auditory system for these species. For example, behavioral studies of female midshipman fish (Porichthys notatus) have used the advertisement call of males to investigate the salient acoustic cues (e.g., pressure and particle motion) used in sound source localization by females (Zeddies et al. 2010, 2012). In these studies, the authors played an acoustic stimulus similar to the fundamental frequency of the male midshipman's advertisement call to females released approximately $100 \mathrm{~cm}$ from the sound source and then tracked the females' paths to the source. The authors showed that midshipman use particle motion cues to localize sound sources. Using this method, the same research group was able to determine in subsequent studies (Coffin et al. 2014) that pressure reception via the swim bladder is likely important for sound source localization but the lateral line system may not be required for localizing sound sources.

Because positive phonotaxis is robust in gravid female midshipman, the use of this behavior has become a powerful tool to understand how fish localize simple and complex sound sources. However, these phonotaxis behaviors are often diverse and species-specific and therefore may not be useful for all fish species.

\section{Experimental Design Considerations for Psychoacoustics Experiments}

The experimental design and the appropriate use of behavioral methods are important considerations in the study of fish audition. Conditioning and PPI are two of the most sensitive behavioral methods that have been used to investigate fish hearing, but both of these methods come with certain advantages and disadvantages as mentioned previously. Conditioning methods have been very effective in determining absolute hearing thresholds and frequency discrimination in a number of fish species. Both conditioning and PPI are useful in studies of noise exposure and comparative hearing because they are precise and such mechanisms are conserved across taxa. However, one must also consider how acoustic stimuli are presented during behavioral experiments. Issues of tank acoustics, sound generation, and the characterization of pressure/particle motion stimuli have been discussed elsewhere (Popper and Fay 1973, 1993), but how acoustic stimuli are presented has been and continues to be a very important consideration (reviewed in Hawkins 1981). 


\subsection{Stimulus Presentation Considerations}

The stimulus presentation protocol is an important experimental design consideration in determining the appropriate techniques to be used to assess fish hearing. The number of stimulus presentations required to accurately determine thresholds or positive responses differs between stimulus presentation methods. Unlike electrophysiological methods such as the AEP recording technique, which can show changes in response amplitude or rate, behavioral methods often have binomial outcomes (response or no response). Therefore, the appropriate stimulus presentation method used will be important in order to minimize the number of trials required to accurately estimate the parameters of interest (e.g., auditory threshold). The three major classes of stimulus presentation methods are the method of constant stimuli, the method of limits, and adaptive procedures (Gescheider 1997). Although the theory behind these techniques is beyond the scope of this chapter, we invite the reader to consider the underlying assumptions of these procedures before implementation (Jesteadt 1980; Fay 1988).

\subsection{Method of Constant Stimuli}

The oldest and most common presentation paradigm currently used in fish hearing studies is the method of constant stimuli, characterized by a randomized set of parameters (in the case of absolute thresholds, these would be sound level and frequency). This method helps span the entire range of testable parameters and the full range of the psychometric function required to estimate auditory threshold, but unfortunately this method often requires a large number of stimulus presentations. In the larval zebrafish ASR and PPI experiments, the method of constant stimuli has been used to explore the entire frequency detection bandwidth (Zeddies and Fay 2005; Bhandiwad et al. 2013). This method works because the large number of fish (replicates) being tested at one time reduces the number of total trials required to determine the probability of an evoked response, but requires a relatively large number of individuals. This method has also been used in studies of frequency discrimination (Fay 1992). For example, fish conditioned to one frequency can be given a randomized frequency from a set of test frequencies and the probability of observing the unconditioned response can be modeled using a psychometric function.

\subsection{Method of Limits}

The method of limits is a paradigm by which stimuli are presented in an ascending or descending order until the behavior of interest is either present or absent, respectively. This procedure is repeated multiple times and the derived thresholds are 
averaged to estimate the true absolute threshold. The method of limits has been used to assess fish hearing in psychoacoustic studies that use cardiac conditioning (Fay 1970), avoidance conditioning (Tavolga and Wodinsky 1963), and operant conditioning (Casper et al. 2003). The advantage of using this stimulus presentation method over the method of constant stimuli is that only a subset of stimuli is required to determine threshold. However, in psychoacoustic studies using the ASR where habituation is an issue, the method of limits is problematic. In the descending method of limits, repeated presentations of the same stimulus can lead to habituation with an earlier than expected cessation of response, which can lead to an incorrect estimation of auditory threshold.

\subsection{Adaptive Procedures}

Adaptive procedures are experimental stimulus presentation paradigms where the stimulus parameter presented is dependent on the response of the animal being tested to the previous stimulus. Unlike the methods of limits and constant stimuli, adaptive procedures allow for testing of a range of parameters (e.g., frequency and sound level) that has not previously been specified. For example, in the case of absolute threshold determination, the experimenter can begin the testing procedure at any sound level and converge onto a threshold. Adaptive procedures are also robust and less susceptible to sequential errors that occur with the method of constant stimuli or the method of limits (Woodworth and Schlosberg 1972). Sequential errors, or errors of perseverance, are errors committed by over-responding to a sequence of stimuli. For example, using the descending method of limits may result in some false positive sub-threshold responses simply because of repeated responses to previous supra-threshold stimuli.

\subsubsection{Staircase Method}

The staircase method has been a stimulus presentation method in use in fish studies since the 1960s (e.g., see Tavolga and Wodinsky 1963), but is used less often than the methods of limits and constant stimuli. The staircase method was developed for audiometric testing in humans (Békésy 1947) and has been adapted for use with fish to determine auditory thresholds (Popper 1972), frequency discrimination (Jacobs and Tavolga 1968), and auditory masking (Popper and Clarke 1979).

The procedure begins with a presentation of a high intensity stimulus, similar to the descending method of limits. The stimulus intensity is lowered until the evoked behavioral response ceases, at which point the stimulus intensity reverts to the previous stimulus intensity presented (reversal of staircase). Staircases are reversed each time there is a shift from a series of evoked responses to a non-response. There are multiple variants of the staircase procedure that determine when to reverse stimuli. These follow an " $N$ up, one down" framework, where $N$ is the number of correct 
responses in a row which makes the stimulus less detectable and the one nonresponse makes the stimulus more detectable. It is important to determine the most appropriate framework with respect to the number of presented trials (fixed or variable), threshold characterization (discussed later in this chapter), and psychometric model used to estimate threshold (Garćia-Pérez 1998). The staircase methods can be a very useful tool in behavioral methods in cases where trial number is restricted because the adaptive procedure mainly samples at or near threshold. This allows for the greatest confidence around the threshold estimate and reduces the number of trials by down sampling at the tails of the psychometric function. The staircase method is only effective for binomial response choices and is problematic in use for multinomial responses (for example, in operant feeding assays with multiple locations). Furthermore, real-time feedback and analysis about behavioral outputs are required for adaptive tracking. That is, experimenters are required to analyze whether the response outcome is positive or negative in the time between stimulus presentations.

\subsubsection{Other Adaptive Procedures}

Other adaptive stimulus presentation procedures like QUEST (Watson and Pelli 1983) and ML-PEST (Harvey 1996) can also be used in behavioral testing (as reviewed by Treutwein 1995). Unlike the previously discussed methods, these procedures rely on a Bayesian framework and use an estimation of threshold (from electrophysiological data, for example) as a prior probability of stimulus detection and weight stimulus presentations around the previously estimated threshold. These adaptive procedures could be useful in behavioral studies with fish species that have low evoked response rates to acoustic stimuli.

\subsection{Threshold Criteria}

Auditory threshold criteria can vary widely across behavioral studies and are an important consideration when comparing thresholds between different species or conditions (Hawkins 1981). Because there is a continuous distribution of response probability, accurate characterization of a threshold is important to understanding the auditory sensitivity and capability of animals. However, because we do not fully understand the mechanisms underlying how the probability of auditory evoked responses changes across animals, auditory thresholds determined using different criteria are very difficult to compare within and across species.

Auditory thresholds obtained using the method of constant stimuli often have the greatest variability and are least accurate in threshold characterization (Fay 1974; Lu et al. 1996; Yan and Popper 1993; Zeddies and Fay 2005). Thresholds obtained by this method are often defined as a 0.5 probability of response, a positive response greater than three standard deviations above the mean expected response probability 
in the absence of a stimulus (Zeddies and Fay 2005), or as a probability of response that results in a repeatable non-zero probability of response (Bhandiwad et al. 2013).

Auditory threshold criteria used with the method of limits are more well defined than threshold criteria for the method of constant stimuli. Because the method of limits uses multiple stimulus presentation trials to sequentially reduce stimulus parameters, each trial ends at threshold estimation. By definition, the threshold is described as the point at which the animal changes its pattern of response to the delivered stimulus. The estimated threshold for the subject population is determined by averaging the thresholds of multiple stimulus presentation sequences. The only free parameter between experimenters is whether the ascending method of limits (each stimulus step increases the intensity level until the animal responds once) or the descending method (each stimulus step decreases intensity level until the animal ceases to respond) is used. Although we assume thresholds obtained using these methods should be identical, there is no a priori reason that establishes equivalency between these two methods.

Auditory threshold criteria used with the staircase method are more well defined than the stimulus presentation parameters discussed above. The adaptive quality of stimulus presentation procedure allows for a greater sampling at or near threshold, which can be mathematically determined. Earlier procedures defined threshold similar to the method of limits, where the threshold was estimated from the averaged samples taken at the "reversal," i.e., the sound level where the increasing or decreasing stimulus level was reversed to estimate threshold (Jesteadt 1980). However, this procedure is no longer used as the best measure for threshold determination (García-Pérez 1998). The total number of reversals, however, is still used as a stopping condition. Threshold for an " $N$-down, one up" protocol is defined as the probability of getting $N$ trials correct by chance. For example, in a protocol where two "correct" answers result in the stimulus parameter becoming more difficult; threshold is defined as the point at which the probability of getting two correct answers in a row is 0.5 . Threshold is therefore the square root of 0.5 , or 0.71 (71\% correct). In the case of a three down, one up protocol, threshold is defined as the cube root of 0.5 , or $79 \%$ correct. In the mathematical limit (i.e. as the number of presentations approach infinity), threshold can be conceptualized as the point at which the adaptive procedure is equally likely to increase or decrease after each trial.

\section{Conclusion and Future directions}

Behavioral measures of hearing remain the best methods to investigate the perceptual hearing ability of an organism (Ladich and Fay 2013). Conditioning methods in particular are powerful tools and should continue to be used in studies of fish hearing. However, we suggest that more studies should utilize innate behavioral responses where appropriate, particularly the use of PPI assays to determine auditory sensitivity. Although this method has been used for larval fish, it can easily be 
adapted for adult fish and juveniles, allowing for the better understanding of how auditory capabilities change during ontogeny. In addition, the PPI assay is also potentially useful in comparative hearing studies that examine closely related species and species that possess hearing specializations. We suggest that future researchers explore the use of psychoacoustic methods to assess fish hearing and consider the following areas of research mentioned briefly below.

1. In order to maximize the efficiency and accuracy of fish psychoacoustic studies, we suggest researchers should carefully consider the most appropriate associative (conditioning) method and stimulus presentation method available in order to assess the hearing capability of a given fish species. We also highly recommend the use of adaptive stimulus presentation methods, such as the staircase method, whenever possible to determine auditory threshold estimations, in order to minimize the number of stimulus presentations and reduce habituation of the measured behavioral response.

2. Future psychoacoustic fish studies should incorporate the latest automated methods to measure and analyze the movements/responses of animals. Video-based automation and tracking have been utilized to measure long-term locomotor behavior in rodents (Noldus et al. 2001), Drosophila (Branson et al. 2009), and larval zebrafish (Fontaine et al. 2008). Application of these tracking methods and their use with behavioral psychoacoustic paradigms to assess fish hearing can provide rapid data collection, analysis, and allow for more dynamic behavioral experiments that may provide a better understanding of auditory capabilities and perception in fishes.

3. Our psychoacoustic data from larval D. rerio and G. aculeatus suggest that auditory sensitivity is different across taxa, even before the development of accessory auditory structures in species that are "hearing specialists." The use of behavioral methods, particularly PPI assays can be useful in understanding how development of the auditory system and perceptual ability differ within and across species. Many species of larval fish use sound as a settlement cue (Simpson et al. 2004), but the hearing ability of such species has not been well characterized; the PPI assay could be a potential tool used to determine which pelagic larval fish are capable of hearing abiotic and biotic sound cues and provide a way to characterize the auditory sensitivity of various pelagic larval fishes.

4. Behavioral methods can inform us about auditory perception in fish species that are too delicate to investigate by other methods such as electrophysiology. In addition, psychoacoustic methods can be applied and used in longitudinal studies to investigate the effects of seasonal differences in auditory perception, discrimination of relevant vs. non-relevant stimuli, and auditory stream segregation. Longitudinal studies can also be used to assess auditory development and sensitivity within the same individuals using the same technique.

5. A prominent question in fish hearing is the effect of anthropogenic sound on fishes. Anthropogenic sounds can act as maskers, which may change the perceptual environment of fishes, or can be loud enough to have profound short- and long-term effects on the auditory systems such as causing short-term temporary 
threshold shifts. The extent to which these processes affect changes in auditory perception in fishes is not known; behavioral methods can be used to investigate such short- and long-term effects.

6. Top-down auditory attention effect on hearing (defined as an endogenous and selective concentration on one stimulus) in fishes remains largely unexplored. How does attention affect the perception of sound in fishes? Although many species attend to conspecific vocalizations, a generalized framework for auditory attention and mechanisms underlying it have not been investigated.

Acknowledgements The authors would like to thank Drs. Arthur Popper and Richard Fay for inspiration and guidance, both directly and indirectly. Much of the work highlighted in this chapter draws from the influential research studies of Drs. Popper and Fay and has been a source of inspiration for AAB's dissertation research. AAB and JAS have had the pleasure of working with Dick Fay directly in sound localization studies of the plainfin midshipman fish at the UC Bodega Marine Laboratory. It was during these studies that AAB first met Dick as a first-year graduate student, and received some of his wisdom and advice about how to conduct psychoacoustic studies of fish hearing. We would like to thank and acknowledge Drs. Richard Fay and David Zeddies, as the first to propose the idea of using prepulse inhibition to measure auditory function in fishes. Although we have not directly collaborated with Dr. Arthur Popper, his influence has been a significant force through not only his research, but through his legacy of former students and post-docs.

AAB thanks Drs. David Raible, Edwin Rubel, and Catherine Peichel for support and advice. We would also like to thank Drs. Allison Coffin, Kelly Owens, Peter Alderks, and Liz Whitchurch for discussions of auditory systems and hearing in fishes.

AAB's research has been supported in part by NIH grant 2T32DC005361-11.

\section{References}

Allen EE, Fernald RD (1985) Spectral sensitivity of the African cichlid fish, Haplochromis burtoni. J Comp Physiol A 157(2):247-253

Amorim MCP (1996) Sound production in the blue-green damselfish, Chromis viridis (Cuvier, 1830) (Pomacentridae). Bioacoustics 6(4):265-272

Amorim MCP (2006) Diversity of sound production in fish. In: Ladich F, Collin SP, Moller P, Kapoor BG (eds) Communication in fishes. Science Publishers, Plymouth

Aristotle (1984) The complete works of Aristotle: revised Oxford edition. English Edition: Barnes J. Princeton University Press, Princeton, NJ

Békésy GV (1947) A new audiometer. Acta Otolaryngol 35:411-422

Bhandiwad AA, Zeddies DG, Raible DW et al (2013) Auditory sensitivity of larval zebrafish (Danio rerio) measured using a behavioral prepulse inhibition assay. J Exp Biol 216:3504-3513

Bodnar DA, Bass, AH (1997) Temporal coding of concurrent acoustic signals in auditory midbrain. J Neurosci 17(19):7553-7564

Branson K, Robie AA, Bender J et al (2009) High-throughput ethomics in large groups of Drosophila. Nat Methods 6(6):451-457

Brantley RK, Bass AH (1994) Alternative male spawning tactics and acoustic signals in the plainfin midshipman fish Porichthys notatus Girard (Teleostei, Batrachoididae). Ethology 96(3):213-232

Buerkle U (1967) An audiogram of the Atlantic Cod, Gadus morhua L. J Fish Res Board Can 24(11):2309-2319 
Bull HO (1928) Studies on conditioned responses in fishes. Part I. J Mar Biol Assoc UK 15(02):485-533

Burgess HA, Granato M (2007) Modulation of locomotor activity in larval zebrafish during light adaptation. J Exp Biol 210(14):2526-2539

Buwalda RJA, Schuijf A, Hawkins AD (1983) Discrimination by the cod of sounds from opposing directions. J Comp Physiol A 150(2):175-184

Casper BM, Lobel PS, Yan HY (2003) The hearing sensitivity of the little skate, Raja erinacea: a comparison of two methods. Environ Biol Fish 68(4):371-379

Chapman CJ, Johnstone AD (1974) Some auditory discrimination experiments on marine fish. J Exp Biol 61(2):521-528

Cioni C, De Palma F, Stefanelli A (1989) Morphology of afferent synapses in the Mauthner cell of larval Xenopus laevis. J Comp Neurol 284(2):205-214

Coffin AB, Zeddies DG, Fay RR et al (2014) Use of the swim bladder and lateral line in near-field sound source localization by fishes. J Exp Biol. doi:10.1242/jeb.093831

Cohen MJ, Winn HE (1967) Electrophysiological observations on hearing and sound production in the fish, Porichthys notatus. J Exp Zool 165(3):355-369

Edds-Walton PL, Fay, RR (2003). Directional selectivity and frequency tuning of midbrain cells in the oyster toadfish, Opsanus tau. J Comp Phys A 189(7):527-543

Enger PS (1963) Single unit activity in peripheral auditory system of a teleost fish. Acta Physiol Scand 59:9

Enger PS, Hawkins AD, Sand O et al (1973) Directional sensitivity of saccular microphonic potentials in the haddock. J Exp Biol 59(2):425-433

Fay RR (1969) Behavioral audiogram for the goldfish. J Aud Res 9(2):112-121

Fay RR (1970) Auditory frequency discrimination in the goldfish (Carassius auratus). J Comp Physiol Psychol 73(2):175

Fay RR (1972) Perception of amplitude-modulated auditory signals by the goldfish. J Acoust Soc Am 52(2):660-666

Fay RR (1978a) Coding of information in single auditory-nerve fibers of the goldfish. J Acoust Soc Am 63(1):136-146

Fay RR (1978b) Sound detection and sensory coding by the auditory systems of fishes. The behavior of fish and other aquatic animals, 197-236

Fay RR (1988) Hearing in vertebrates: a psychophysics databook. Hill-Fay Associates, Winnetka, IL

Fay RR (1992) Structure and function in sound discrimination among vertebrates. In: The evolutionary biology of hearing. Springer, New York, pp 229-263

Fay RR (1995) Perception of spectrally and temporally complex sounds by the goldfish (Carassius auratus). Hear Res 89(1):146-154

Fay RR (1998) Auditory stream segregation in goldfish (Carassius auratus). Hear Res 120(1):69-76

Fay RR (2009) Sound source segregation by goldfish: two simultaneous tones. J Acoust Soc Am 125:4053-4059

Fay RR, Coombs S (1983) Neural mechanisms in sound detection and temporal summation. Hear res 10(1):69-92

Fay RR, Edds-Walton PL (1997) Diversity in frequency response properties of saccular afferents of the toadfish, Opsanus tau. Hear Res 113(1):235-246

Fay RR, Edds-Walton PL (2000) Directional encoding by fish auditory systems. Philos Trans R Soc Lond B Biol Sci 355(1401):1281-1284

Fine ML (1978) Seasonal and geographical variation of the mating call of the oyster toadfish Opsanus tau L. Oecologia 36(1):45-57

Fish MP (1954) The character and significance of sound production among fishes of the western North Atlantic. Bingham Oceanographic Laboratory

Fish MP, Mowbray WH (1970) Sound of western North Atlantic fishes. The Johns Hopkins Press, Baltimore 
Fontaine E, Lentink D, Kranenbarg S et al (2008) Automated visual tracking for studying the ontogeny of zebrafish swimming. J Exp Biol 211(8):1305-1316

Furukawa T, Ishii Y (1967) Neurophysiological studies on hearing in goldfish. J Neurophysiol 30(6):1377-1403

García-Pérez MA (1998) Forced-choice staircases with fixed step sizes: asymptotic and smallsample properties. Vision Res 38(12): 1861-1881

Gescheider GA (1997) Psychophysics: the fundamentals. LEA, London

Gray GA, Winn HE (1961) Reproductive ecology and sound production of the toadfish, Opsanus tau. Ecology 42(2):274-282

Harvey LO (1996) Efficient estimation of sensory thresholds with ML-PEST. Spat Vis 11(1):121-128

Hawkins AD (1981) The hearing abilities of fish. In: Tavolga WN, Popper AN, Fay RR (eds) Hearing and sound communication in fishes. Springer, New York

Hawkins AD, Chapman CJ (1966) Underwater sounds of the haddock, Melanogrammus aeglefinus. J Mar Biol Assoc UK 46(2):241-247

Inoue M, Tanimoto M, Oda Y (2013) The role of ear stone size in hair cell acoustic sensory transduction. Sci Rep 3:2114

Jacobs DW, Tavolga WN (1968) Acoustic frequency discrimination in the goldfish. Anim Behav 16(1):67-71

Jesteadt W (1980) An adaptive procedure for subjective judgments. Atten Percept Psychophys 28(1):85-88

Kawasaki M, Guo, YX (1998) Parallel projection of amplitude and phase information from the hindbrain to the midbrain of the African electric fish Gymnarchus niloticus. J Neurosci 18(18): 7599-7611

Kenyon TN, Ladich F, Yan HY (1998) A comparative study of hearing ability in fishes: the auditory brainstem response approach. J Comp Physiol A 182(3):307-318

Kimmel CB, Patterson J, Kimmel RO (1974) The development and behavioral characteristics of the startle response in the zebra fish. Dev Psychobiol 7(1):47-60

Kimmel CB, Eaton RC, Powell SL (1980) Decreased fast-start performance of zebrafish larvae lacking Mauthner neurons. J Comp Physiol A 140:343-350

Kohashi T, Nakata N, Oda Y (2012) Effective sensory modality activating an escape triggering neuron switches during early development in zebrafish. J Neurosci 32(17):5810-5820

Korn H, Faber DS (2005) The Mauthner cell half a century later: a neurobiological model for decision-making? Neuron 47(1): 13-28

Kozloski J, Crawford, JD (2000) Transformations of an auditory temporal code in the medulla of a soundproducing fish. J Neurosci 20(6):2400-2408

Ladich F (1997) Agonistic behaviour and significance of sounds in vocalizing fish. Mar Freshw Behav Physiol 29(1-4):87-108

Ladich F, Fay RR (2013) Auditory evoked potential audiometry in fish. Rev Fish Biol Fish 23:317-364

Lobel PS (2001) Acoustic behavior of cichlid fishes. J Aquaricult Aquat Sci 9:167-186

Lu Z, DeSmidt AA (2013) Early development of hearing in zebrafish. J Assoc Res Otolaryngol 14(4):509-521

Lu Z, Popper AN, Fay RR (1996) Behavioral detection of acoustic particle motion by a teleost fish (Astronotus ocellatus): sensitivity and directionality. J Comp Physiol A 179(2):227-233

Marini M, Trevisan P, Dondi MA et al (1991) The mauthner neurons in salamandra. Ital J Zool 58(1):43-48

Maruska KP, Tricas, TC (2009) Encoding properties of auditory neurons in the brain of a soniferous damselfish: response to simple tones and complex conspecific signals. J Comp Phys A 195(11):1071-1088

McCaughran J, Bell J, Hitzemann R (1999) On the relationships of high-frequency hearing loss and cochlear pathology to the acoustic startle response (ASR) and prepulse inhibition of the ASR in the BXD recombinant inbred series. Behav Genet 29(1):21-30 
McCormick CA, Popper AN (1984) Auditory sensitivity and psychophysical tuning curves in the elephant nose fish, Gnathonemus petersii. J Comp Physiol A 155(6):753-761

McDonald HE (1922) Ability of Pimephales notatus to form associations with sound vibrations. J Comp Psychol 2(3):191

McKibben JR, Bass, AH (1999) Peripheral encoding of behaviorally relevant acoustic signals in a vocal fish: single tones. J Comp Phys A 184(6):563-576

Medan V, Preuss T (2011) Dopaminergic-induced changes in Mauthner cell excitability disrupt prepulse inhibition in the startle circuit of goldfish. J Neurophysiol 106(6):3195-3204

Medan V, Preuss T (2014) The Mauthner-cell circuit of fish as a model system for startle plasticity. J Physiol Paris 108(2):129-140

Myrberg AA (1981) Sound communication and interception in fishes. In: Hearing and sound communication in fishes. Springer, New York, pp 395-426

Neumeister H, Szabo TM, Preuss T (2008) Behavioral and physiological characterization of sensorimotor gating in the goldfish startle response. J Neurophysiol 99(3):1493-1502

Noldus LP, Spink AJ, Tegelenbosch RA (2001) EthoVision: a versatile video tracking system for automation of behavioral experiments. Behav Res Methods Instrum Comput 33(3):398-414

Otis LS, Cerf JA, Thomas GJ (1957) Conditioned inhibition of respiration and heart rate in the goldfish. Science 126:263-264

Parham K, Willott JF (1988) Acoustic startle response in young and aging C57BL/6J and CBA/J mice. Behav Neurosci 102(6):881-886

Parker GH (1903) The sense of hearing in fishes. Am Nat 37:185-204

Pijanowski BC, Villanueva-Rivera LJ, Dumyahn SL et al (2011) Soundscape ecology: the science of sound in the landscape. BioScience 61(3):203

Popper AN (1972) Pure-tone auditory thresholds for the carp, Cyprinis carpio. J Acoust Soc Am 52(6): 1714-1717

Popper AN, Clarke NL (1979) Non-simultaneous auditory masking in the goldfish, Carassius auratus. J Exp Biol 83(1):145-158

Popper AN, Fay RR (1973) Sound detection and processing by teleost fishes: a critical review. J Acoust Soc Am 53(6):1515-1529

Popper AN, Fay RR (1993) Sound detection and processing by fish: critical review and major research questions. Brain Behav Evol 41(1):14-25

Popper AN, Fay RR (2011) Rethinking sound detection by fishes. Hear Res 273(1):25-36

Popper AN, Chan AT, Clarke NL (1973) An evaluation of methods for behavioral investigations of teleost audition. Behav Res Methods Instrum 5(6):470-472

Retzius G (1881) Das Gehörorgan der Wirbelthiere: Das Gehörorgan der Fische und Amphibien. Samson \& Wallin, Stockholm

Rigley L, Marshall JA (1973) Sound production by the elephant-nose fish, Gnathonemus petersi (Pisces, Mormyridae). Copeia 1973:134-135

Roberts AC, Reichl J, Song MY et al (2011) Habituation of the C-start response in larval zebrafish exhibits several distinct phases and sensitivity to NMDA receptor blockade. PLoS One 6(12), e29132

Russo JM (1979) Sensation in the rat and mouse: evaluation by reflex modification. Doctoral dissertation, Department of Psychology, University of Rochester

Schuijf A (1975) Directional hearing of cod (Gadus morhua) under approximate free field conditions. J Comp Physiol 98(4):307-332

Simpson SD, Meekan MG, McCauley RD et al (2004). Attraction of settlement-stage coral reef fishes to reef noise. Mar Ecol Prog Ser 276(1):263-268

Sisneros JA (2009) Seasonal plasticity of auditory saccular sensitivity in the vocal plainfin midshipman fish, Porichthys notatus. J Neurophysiol 102(2):1121-1131

Sisneros JA, Bass AH (2003) Seasonal plasticity of peripheral auditory frequency sensitivity. J Neurosci 23(3):1049-1058

Sisneros JA, Popper AN, Hawkins AD, Fay RR (2015) Auditory evoked potential audiograms compared to behavioral audiograms in aquatic animals. In: Popper AN, Hawkins AD (eds) 
Effects of noise on aquatic life II, advances in experimental medicine and biology. Springer, New York

Tavolga WN (1974) Signal/noise ratio and the critical band in fishes. J Acoust Soc Am 55(6):1323-1333

Tavolga WN, Wodinsky J (1963) Auditory capacities in fishes: pure tone thresholds in nine species of marine teleosts. Bull AMNH 126:2

Treutwein B (1995) Adaptive psychophysical procedures. Vision Res 35(17):2503-2522

von Frisch K (1936) Über den Gehörsinn der Fische. Biol Rev 11(2):210-246

Walter M, Tziridis K, Ahlf S et al (2012) Context Dependent Auditory Thresholds Determined by Brainstem Audiometry and Prepulse Inhibition in Mongolian Gerbils. Open J of Acoust 2(1):34-49

Wark AR, Peichel CL (2010) Lateral line diversity among ecologically divergent threespine stickleback populations. J Exp Biol 213(1):108-117

Watson AB, Pelli DG (1983) QUEST: a Bayesian adaptive psychometric method. Percept Psychophys 33(2):113-120

Weeg M, Fay RR, Bass AH (2002) Directionality and frequency tuning of primary saccular afferents of a vocal fish, the plainfin midshipman (Porichthys notatus). J Comp Physiol A 188(8):631-641

Weiss SA, Zottoli SJ, Do SC et al (2006) Correlation of C-start behaviors with neural activity recorded from the hindbrain in free-swimming goldfish (Carassius auratus). J Exp Biol 209(23):4788-4801

Westerfield F (1922) The ability of mudminnows to form associations with sounds. J Comp Psychol 2(3):187-190

Willott JF, Carlson S, Chen H (1994) Prepulse inhibition of the startle response in mice: relationship to hearing loss and auditory system plasticity. Behav Neurosci 108(4):703-713

Wilson DM (1959) Function of giant Mauthner's neurons in the lungfish. Science 129(3352):841-842

Woodworth RS, Schlosberg H (1972). Experimental Psychology, 3rd Edition. Holt, Rinehart, and Winston

Yager D, Thorpe S (1970) Investigations of goldfish color vision. In: Animal psychophysics: the design and conduct of sensory experiments. Springer, pp. 259-275

Yan HY, Popper AN (1991) An automated positive reward method for measuring acoustic sensitivity in fish. Behav Res Methods Instrum Comput 23(3):351-356

Yan HY, Popper AN (1992) Auditory sensitivity of the cichlid fish Astronotus ocellatus (Cuvier). J Comp Physiol A 171(1):105-109

Yan HY, Popper AN (1993) Acoustic intensity discrimination by the cichlid fish Astronotus ocellatus (Cuvier). J Comp Physiol A 173(3):347-351

Yerkes RM (1903) The instincts, habits and reactions of the frog. Psychol Rev 4(1):579-638

Zeddies DG, Fay RR (2005) Development of the acoustically evoked behavioral response in zebrafish to pure tones. J Exp Biol 208(7):1363-1372

Zeddies DG, Fay RR, Alderks PW et al (2010) Sound source localization by the plainfin midshipman fish, Porichthys notatus. J Acoust Soc Am 127(5):3104-3113

Zeddies DG, Fay RR, Gray MD et al (2012) Local acoustic particle motion guides sound-source localization behavior in the plainfin midshipman fish, Porichthys notatus. J Exp Biol 215(1):152-160

Zottoli SJ, Faber DS (2000) The Mauthner cell: what has it taught us? Neuroscientist 6(1):26-38 
Part III

Sensory Biology and Physiology 


\title{
Hearing in Cavefishes
}

\author{
Daphne Soares, Matthew L. Niemiller, and Dennis M. Higgs
}

\begin{abstract}
Caves and associated subterranean habitats represent some of the harshest environments on Earth, yet many organisms, including fishes, have colonized and thrive in these habitats despite the complete absence of light, and other abiotic and biotic constraints. Over 170 species of fishes are considered obligate subterranean inhabitants (stygobionts) that exhibit some degree of troglomorphy, including degeneration of eyes and reduction in pigmentation. To compensate for lack of vision, many species have evolved constructive changes to non-visual sensory modalities. In this chapter we review hearing in cavefishes, with particular emphasize on our own studies on amblyopsid cavefishes. Hearing in cavefishes has not been well studied to date, as hearing ability has only been examined in four species. Two species show no differences in hearing ability relative to their surface relatives, while the other two species (family Amblyopsidae) exhibit regression in the form of reduced hearing range and reduction in hair cell densities on sensory epithelia. In addition to reviewing our current knowledge on cavefish hearing, we offer suggestions for future avenues of research on cavefish hearing and discuss the influence of Popper and Fay on the field of cavefish bioacoustics.
\end{abstract}

Keywords Acoustic $\bullet$ Auditory $\bullet$ Evolution $\bullet$ Fish $\bullet$ Subterranean

\section{Introduction}

Caves have been shown to be rewarding environments for the study of ecology, evolution, and speciation (Poulson and White 1969; Culver 1976, 1982; Christman and Culver 2001; Christman et al. 2005; Niemiller et al. 2008). Yet, subterranean

\author{
D. Soares $(\bowtie)$ \\ Biological Sciences, New Jersey Institute of Technology, Newark, NJ 07102, USA \\ e-mail: soares@NJIT.edu \\ M.L. Niemiller \\ Illinois Natural History Survey, University of Illinois, Champaign, IL 61820, USA \\ D.M. Higgs \\ Biological Sciences, University of Windsor, Windsor, ON, Canada, N9B 3P4
}


organisms remain the most poorly understood fauna on the planet and little is known about their sense of hearing. Animals that thrive in a cave not only have evolved cave-specific morphological specializations but also have selective behaviors that allow for their survival in complete darkness. Cavefishes (obligate cave-dwelling fishes) are replicate ecological and evolutionary experiments in adaptation to this extreme environment. Because the direction of evolution is known (i.e., surface to subterranean), the colonization of a subterranean environment affords us the opportunity to examine species that have survived similar evolutionary pressures in parallel and converging ways.

Of the approximately 32,000 fish species globally, over 300 species have been reported to live in subterranean habitats with more than 170 described species living obligate underground with some degree of troglomorphy (features related to cave adaptation; Proudlove 2006, 2010). The phylogenetic diversity of cavefishes representing 10 orders and 21 families distributed on every continent but Europe and Antarctica (Fig. 1) and the assortment of aquatic subterranean habitats from fast flowing streams and waterfalls to quiet phreatic waters provide excellent examples for the study of independent responses to subterranean environments. Many species are monotypic and their relationships to surface forms are unknown; in other cases cave forms are grouped together based on convergent morphologies (Niemiller and Poulson 2010; Niemiller et al. 2013). However, the surface ancestors of all cavefish species had to adapt to the strict constraints imposed by caves, particularly perpetual darkness and limited energy resources. As a result, a suite of unique phenotypes associated with subterranean adaptation has emerged, with loss of pigmentation and eyes being the most conspicuous. Cavefishes, however, are outcomes of not just regressive evolution but also constructive adaptation. For example, several cavefishes exhibit enhancement of the mechanosensory lateral line system relative to their surface relatives (Culver and Pipan 2009; Soares and Niemiller 2013), and a cave catfish, Astroblepus pholeter, has adapted skin-teeth to sense water flow (Haspel et al. 2012). Despite the obvious power of using cavefish as a natural experiment, to date there have been few comparative studies in cavefish ecology and sensory biology (Trajano 1991, 1997, 2001; Niemiller et al. 2013; Soares and Niemiller 2013).

There is strong selection to develop and enhance non-visual sensory modalities in subterranean habitats, with enhanced hearing ability being one possible modification (see below for a review on possible lateral line enhancement). Lower auditory thresholds and greater frequency ranges in subterranean habitats should be adaptive for several reasons, including integrating with other non-visual senses to detect prey, predators, or conspecifics. However, hearing sensitivity and range, and acoustic communication for that matter, have received little attention in cavefishes - with studies limited to just three groups. Popper (1970) found no differences in hearing sensitivities between cave and surface forms of the characid Astyanax mexicanus. Both forms had sensitivities comparable to other otophysan (Actinopterygii: Teleostei: Ostariophysi) fishes with a threshold at $1000 \mathrm{~Hz}$. The best-studied cavefish with respect to hearing are cave and surface ecotypes of the Atlantic Molly (Poecilia mexicana). Schulz-Mirbach et al. (2008) documented pronounced 


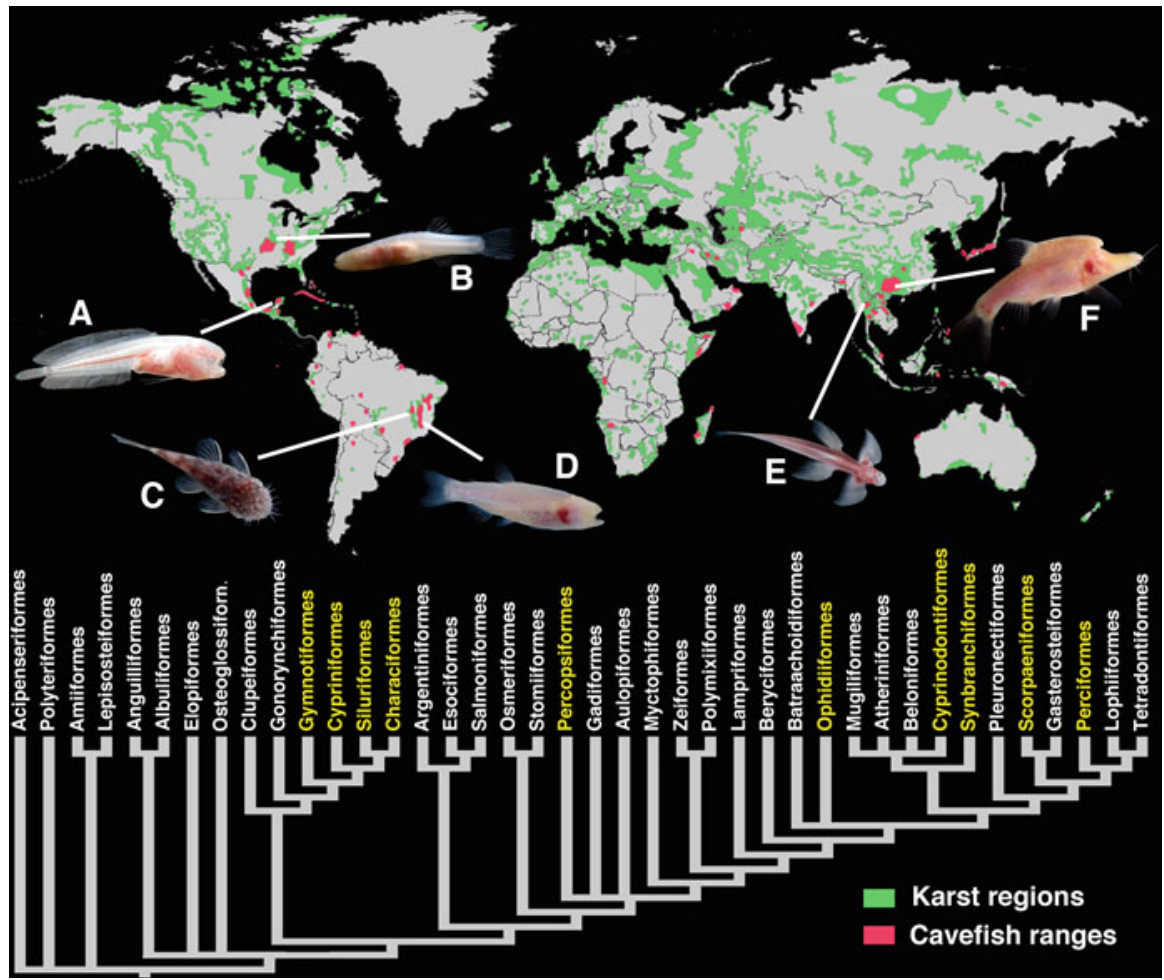

Fig. 1 Cavefishes are known from 10 teleost fish orders (highlighted in yellow) and occur on every continent but Europe and Antarctica: (a) Typhliasina pearsei (Ophidiiformes: Bythitidae) from Mexico. (b) Troglichthys rosae (Percopsiformes: Amblyopsidae) from the USA. (c) Ancistrus cryptophthalmus (Siluriformes: Loricariidae) from Brazil. (d) Stygichthys typhlops (Characiformes incertae sedis) from Brazil. (e) Cryptotora thamicola (Cypriniformes: Balitoridae) from Thailand. (f) Sinocyclocheilus furcodorsalis (Cypriniformes: Cyprinidae) from China. Sources: The karst regions were modified from those in Williams and Ford (2006), and the phylogenetic relationships are based on those in Li et al. (2008). Photographs: Thomas M Iliffe (a) Dante B. Fenolio (b-f). Modified from Soares and Niemiller (2013)

morphological differences between the sagittal otoliths of cave- and surface-dwelling mollies, with cave forms having heavier otoliths and a deeper auditory sulcus than surface forms. In a follow-up study, Schulz-Mirbach et al. (2010) examined the morphology of all three inner ear otoliths (saccule, utricle, and lagena) and hearing sensitivities between cave and surface ecotypes and found differences in shape of all three otoliths between the cave and surface form, while the otoliths of the lagena and utricle were heavier in the cave form. The first microanatomical study of the inner ear by Schulz-Mirbach et al. (2011a) using a combination of micro-CT analyses, scanning electron microscopy and immunocytochemical methods also revealed differences between cave and surface ecotypes, including the shape and curvature of the macula lagenae, curvature of the macula sacculi, and a much thicker otolith membrane housed in a deep sulcus of the sagittae. However, hearing sensitivities, 
based on auditory evoked potentials (AEPs), were similar between the two ecotypes with greatest sensitivities between 200 and $300 \mathrm{~Hz}$. The authors found no evidence for intra-specific acoustic communication in both cave and surface ecotypes. Differences in otolith morphology between ecotypes may reflect metabolic differences but had minimal influence on hearing sensitivity or acoustic behavior (Schulz-Mirbach et al. 2010).

Schulz-Mirbach et al. (2011b) compared otolith morphology of several locally adapted populations of $P$. mexicana living in surface and cave habitats that differed in levels of hydrogen sulfide $\left(\mathrm{H}_{2} \mathrm{~S}\right)$ and darkness. Asterisci, lapilli, and sagittae from a non-sulfidic cave were larger than those from the sulfidic cave, and generally larger than otoliths from surface habitats (sulfidic and non-sulfidic). As noted previously, cavefish had thicker otoliths with deep furrows housing the sensory epithelium. Schulz-Mirbach et al. (2011b) also examined inner ear size and brain morphology. The length and width of the optic tectum were smaller in fish from the two cave populations compared to fish from surface habitats. However, inner ear size and length of the sacculus were similar between cave and surface forms. Although the populations studied showed clear differentiation in otolith morphologies, no clear directional pattern of trait divergence along the two environmental gradients (darkness and hydrogen sulfide concentration) was discernible. Similar hearing sensitivities despite differences in otolith morphology between cave and surface fish may reflect the role of hearing for orientation (Popper et al. 2005; Popper and Schilt 2008) or other structures, such as the sensory epithelia, may have co-evolved with otolith changes to maintain inner ear function (Schulz-Mirbach et al. 2011b).

Our own studies have examined hearing ability between related cave and surface fishes in the family Amblyopsidae (Niemiller et al. 2013) (Fig. 2). Specifically, we compared hearing sensitivities between the related, surface-dwelling Forbesichthys agassizii and cave-dwelling Typhlichthys subterraneus and Amblyopsis spelaea. Forbesichthys is the sister group to a clade of subterranean genera, including Amblyopsis, Typhlichthys and Speoplatyrhinus (Niemiller et al. 2013). We used AEPs and showed that all three species exhibited similar hearing sensitivities at frequencies lower than $800 \mathrm{~Hz}$, consistent with previous studies in other cavefishes (Popper 1970; Schulz-Mirbach et al. 2010). Unexpectedly, the two cave species were unable to hear above $800 \mathrm{~Hz}$, whereas surface-dwelling F. agassizii exhibited a response up to $2 \mathrm{kHz}$, the maximum frequency tested in our experimental design. Eigenmann and Yoder (1899) noted no gross anatomical changes in the inner ear of Amblyopsis; however, we noted significant differences in saccular hair cell densities. The cave species, Typhlichthys subterraneus and A. spelaea, had lower hair cell densities compared to surface $F$. agassizii. The reduction in hair cell density suggests peripheral involvement in high-frequency hearing loss in the cave species.

Loss of high frequency hearing in Typhlichthys and Amblyopsis to our knowledge represents the first report of regressive evolution of hearing in a subterranean organism. In addition to testing hearing ability, we characterized aquatic environmental sound profiles in cave and surface habitats inhabited by each amblyopsid cavefish and the surface F. agassizii (Niemiller et al. 2013). Audio recordings from 


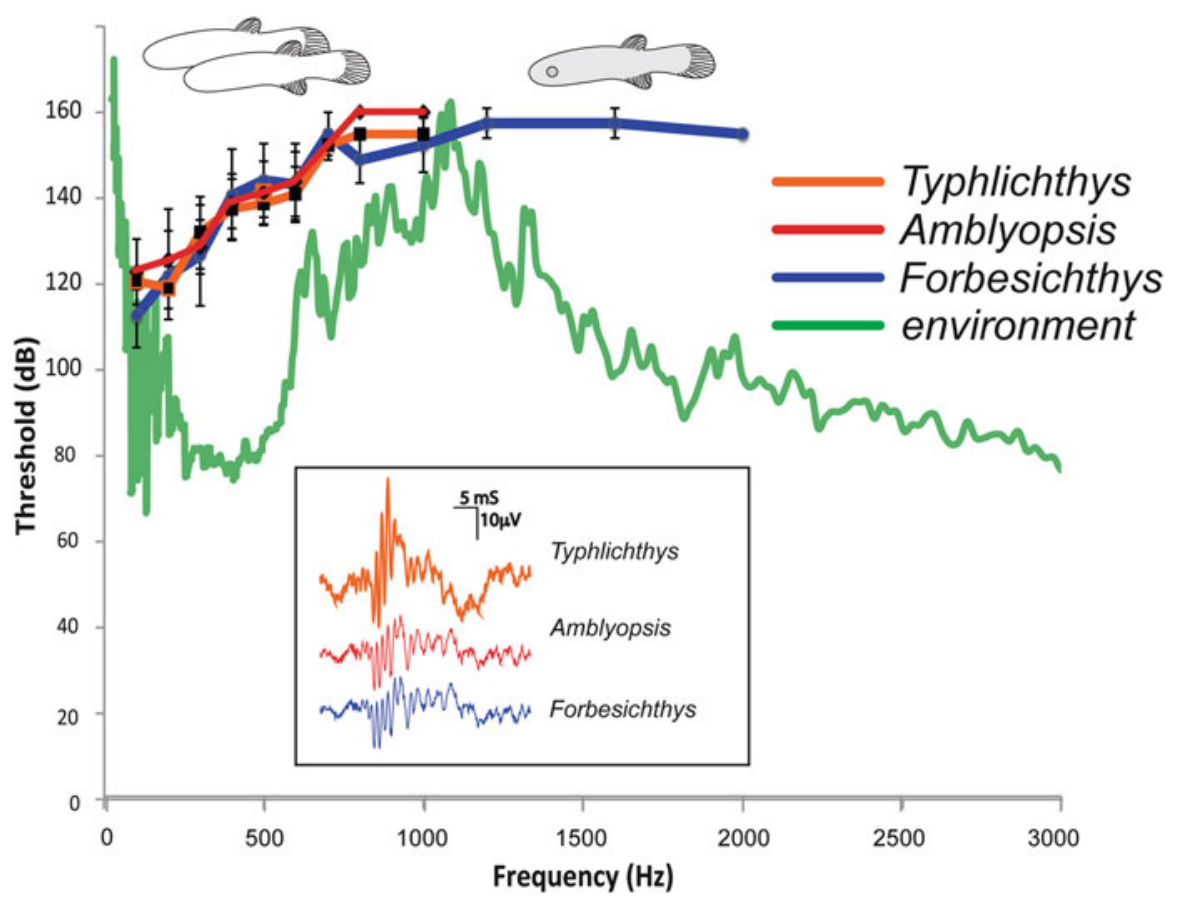

Fig. 2 Auditory thresholds of amblyopsid fishes. Values are means \pm standard errors. The surface fish Forbesichthys (blue) reaches up to $2 \mathrm{kHz}$ while the cave fish Typhlichthys (1) and Amblyopsis (2) are limited to $1 \mathrm{kHz}$. Fast Fourier Transformation (FFT, green line) of sound recorded in a cave pool, Pulaski Co., Kentucky, USA. The pool was carved in bedrock by a small stream. The recording was made $0.5 \mathrm{~m}$ deep and approximately $1 \mathrm{~m}$ from a small waterfall. The ceiling of the cave was also dripping into the pool. Insert: Auditory evoked potential traces of all species to a $400 \mathrm{~Hz}$ tone burst at $60 \mathrm{~dB}$. Modified from Niemiller et al. (2013)

native cave habitats revealed that riffles in cave streams and water droplets dripping from the ceiling into pools create loud high-frequency background noise generally above $800 \mathrm{~Hz}$; such background noise was absent in surface recordings. We therefore hypothesized that cave amblyopsids may have lost hearing at high frequencies in response to living in loud cave environments. However, it remains to be determined what factors contribute most to high background noise levels in aquatic cave habitats and the evolutionary mechanisms (i.e., neutral loss or selection) behind auditory regression.

\section{Lateral Line in Cavefishes}

Recently, Higgs and Radford (2012) showed that the lateral line contributes to AEPs of the brainstem of fishes. Their results suggest that auditory responses to sound should not be considered as a measurement of hearing ability alone but rather a 
multimodal mechanosensory response driven by both the ear and the lateral line system. With this in mind, it is interesting to re-examine the body of literature of cavefish mechanosensation. Most of our knowledge of cavefish lateral line systems comes from studies of the Mexican cavefish Astyanax mexicanus, and this species has made important contributions to understanding lateral line systems in general (Montgomery et al. 2001). The cave forms of Astyanax not only have many more neuromasts than their surface counterparts (Montgomery et al. 2001; Windsor et al. 2008; Yoshizawa et al. 2010) but also have enhanced behavioral sensitivity in feeding and navigation tasks (Sharma et al. 2009; Yoshizawa et al. 2010). Astyanax has also evolved a form of active sensing in which they use a kick and glide swimming style to generate a relatively stable, dipole-like flow signal during the glide phase of the swimming cycle (Sharma et al. 2009; Patton et al. 2010). With this strategy Astyanax use the distortions of nearby obstacles in the self-generated flow field and spend more time gliding when investigating a new object (Patton et al. 2010). Cave amblyopsid species, the second most studied cavefishes, also have more superficial neuromasts that are larger with longer cupulae that their surface relatives, which allow the detection of moving prey at a greater distance compared their surface relatives (Poulson 1963; Niemiller and Poulson 2010). Thus, the mechanosensory neuromasts have also undergone adaptive evolution, and, in conjunction with auditory hair cells, allow enhanced non-visual detection of prey, predators, and obstacles in their natural environment.

\section{Influence of Arthur Popper and Richard Fay on Cavefish Bioacoustics}

While Arthur Popper obviously influenced this specific research topic by being the first to study hearing in cavefish (Popper 1970), the influence of both Popper and Fay goes well beyond any individual research papers. The entire question of for what, precisely, fish are using their sense of hearing (i.e., what fish are listening to) remains largely unsolved, and Popper and Fay have repeatedly pushed the field to properly address this question (Popper and Fay 1973, 1993, 1997; Fay and Popper 2012). Their hypothesis of the ear evolving in response to "auditory scene analysis," while largely untested, was a central reason for us to test the acoustic soundscape of the cave and surface environments in our work and formed the underpinnings of much of what we were trying to assess. In addition, their longstanding interest in the evolution of fish hearing greatly influenced all three of us to use the cave- and surface-dwelling species as a natural experiment to test hypotheses first laid out in the seminal papers of these two senior bioacousticians (Fay and Popper 2012). Both have also served a personal mentoring role for two of the authors of this current work, as they have done for the vast majority of researchers in this field. 


\section{Future Directions}

Cavefishes have evolved an integrated suite of behavioral, morphological, and physiological adaptations to cope with the abiotic and biotic challenges associated with subterranean habitats. The close similarity of phenotypes among diverse fish taxa around the world suggests that cave adaptation may be a general process resulting from similar selective pressures. Some of the more notable adaptations include the degeneration of eyes, reduction in pigmentation, enhancement of mechanoreception, lower metabolism, and increased longevity. However, our understanding of sensory biology, including hearing, and ecology of cavefishes is largely limited to just a handful of species, particularly the characid Astyanax and amblyopsid cavefishes. While these groups have been invaluable models in the study of hearing in cavefishes, several important questions remain. For example, have different cavefish lineages evolved similar if not the same adaptive strategies to hearing specialization or regression? Hearing ability has only been examined in four of the over 170 cave obligate fishes known globally. Two species show no differences in hearing ability relative to their surface relatives, while the other two species exhibit regression.

Another important question is whether any cavefishes exploit acoustic communication, which plays an important role in agonistic and mating behaviors in many fishes. Acoustic communication may be important in the darkness of caves in some species, but the only study to examine acoustic communication in cave taxa found no evidence for the production of species-specific sounds in lab-reared cave- or surface-dwelling molly Poecilia mexicana (Schulz-Mirbach et al. 2010). The authors hypothesized that the enhancement of the cephalic lateral line system may compensate for the lack of visual communication in caves, but noted that cavefish might produce sounds in their natural habitats. Evidence for acoustic communication in cavefishes remains to be found.

Acknowledgements Apart from their enduring contributions to the field of fish sensory biology through published works, extensive reviews, and symposium organization, Drs. Popper and Fay have also had an enduring personal contribution to the careers of most of the researchers in the field of fish acoustic. DH entered the Popper lab as a postdoctoral fellow, despite knowing little about hearing and less about neurophysiology, and was immediately taken under Art's tutelage. Art not only offered invaluable training in the discipline but also served as a true mentor to $\mathrm{DH}$ in all aspects of scientific citizenship and mentoring. DH also owes a tremendous debt to Fay for patiently explaining the most basic principles of neurophysiology as well as being a constantly positive source of review and encouragement in this field. DS is also grateful for the mentoring and support received by Popper throughout the years. Although she was not in the Popper lab, she benefited from "hanging around" during her graduate years.

\section{References}

Culver DC (1976) The evolution of aquatic cave communities. Am Nat 110:945-957

Culver DC (1982) Cave life: evolution and ecology. Harvard University Press, Cambridge, MA

Culver DC, Pipan T (2009) The biology of caves and other subterranean habitats. Oxford University Press, New York 
Christman and Culver (2001) The relationship between cave biodiversity and available habitat. J Biogeogr 28(3):367-380

Christman MC, Culver DC, MK, White D (2005) Patterns of endemism of the eastern North American cave fauna. J Biogeogr 32(8):1441-1452

Eigenmann CH, Yoder AC (1899) The ear and hearing of the blind fishes. Proc Indiana Acad Sci 1899:242-247

Fay RR, Popper AN (2012) Fish hearing: new perspectives from two "senior" bioacousticians. Brain Behav Evol 792:215-217

Haspel G, Schwartz A, Streets A, Camacho DE, Soares D (2012) By the teeth of their skin, cavefish find their way. Curr Biol 22:R629-R630

Higgs DM, Radford CA (2012) The contribution of the lateral line to 'hearing' in fish. J Exp Biol 216:1484-1490

Li C, Lu G, Orti G (2008) Optimal data partitioning and a test case for ray-finned fishes (Actinopterygii) based on ten nuclear loci. Systemat Biol 57:519-539

Montgomery JC, Coombs S, Baker CF (2001) The mechanosensory lateral line system of the hypogean form of Astyanax fasciatus. Environ Biol Fishes 62:87-96

Niemiller ML, Fitzpatrick BM, Miller BT (2008) Recent divergence-with-gene-flow in Tennessee cave salamanders (Plethodontidae: Gyrinophilus) inferred from gene genealogies. Mol Ecol 17:2258-2275

Niemiller ML, Poulson TL (2010) Studies of the amblyopsidae: past, present, and future. In: Trajano E, Bichuette ME, Kapoor BG (eds) The biology of subterranean fishes. Science Publishers, Enfield, NH, pp 169-280

Patton P, Windsor S, Coombs S (2010) Active wall following by Mexican blind cavefish (Astyanax mexicanus). J Comp Physiol A Neuroethol Sens Neural Behav Physiol 196:853-867

Popper AN (1970) Auditory capacities of the Mexican blind cave fish (Astyanax jordani) and its eyed ancestor (Astyanax mexicanus). Anim Behav 18:552-562

Popper AN, Fay RR (1973) Sound production and processing by teleost fishes: a critical review. J Acoust Soc Am 53:1515-1529

Popper AN, Fay RR (1993) Sound detection and processing by fish: critical review and major research questions. Brain Behav Evol 41:14-38

Popper AN, Fay RR (1997) Evolution of the ear and hearing: issues and questions. Brain Behav Evol 50:213-221

Popper AN, Schilt CR (2008) Hearing and acoustic behavior: basic and applied considerations. In: Webb JF, Fay RR, Popper AN (eds) Fish bioacoustics. Springer, New York, pp 17-48

Popper AN, Ramcharitar JU, Campana SE (2005) Why otoliths? Insights from inner ear physiology and fisheries biology. Mar Freshw Res 56:497-504

Poulson TL (1963) Cave adaptation in amblyopsid fishes. Am Midl Nat 70:257-290

Poulson T, White W (1969) The cave environment. Science 165:971-981

Proudlove GS (2006) Subterranean fishes of the world: an account of the subterranean (hypogean) fishes described to 2003 with a bibliography 1541-2004. International Society for Subterranean Biology, Moulis

Proudlove GS (2010) Biodiversity and distribution of the subterranean fishes of the world. In: Trajano E, Bichuette ME, Kapoor BG (eds) The biology of subterranean fishes. Science Publishers, Enfield, NH, pp 41-63

Schulz-Mirbach T, Stransky C, Schlickeisen J, Reichenbacher B (2008) Differences in otolith morphologies between surface- and cave-dwelling populations of Poecilia mexicana (Teleostei, Poeciliidae) reflect adaptations to life in an extreme habitat. Evol Ecol Res 10:537-558

Schulz-Mirbach T, Ladich F, Riesch R, Plath M (2010) Otolith morphology and hearing abilities in cave and surface-dwelling ecotypes of the Atlantic molly, Poecilia mexicana (Teleostei: Poeciliidae). Hear Res 267:137-148

Schulz-Mirbach T, Hess M, Plath M (2011a) Inner ear morphology in the Atlantic molly Poecilia mexicana - first detailed microanatomical study of the inner ear of a cyprinodontiform species. PLoS One 6, e27734 
Schulz-Mirbach T, Riesch R, Garcia de Leon FJ, Plath M (2011b) Effects of extreme habitat conditions on otolith morphology - a case study on extremophile livebearing fishes (Poecilia mexicana, P. sulphuria). Zoology (Jena) 114:321-334

Sharma S, Coombs S, Patton P, de Perera T (2009) The function of wall-following behaviors in the Mexican blind cavefish and a sighted relative, the Mexican tetra Astyanax. J Comp Physiol A Neuroethol Sens Neural Behav Physiol 195:225-240

Soares D, Niemiller ML (2013) Sensory adaptations of fishes to subterranean environments. Bioscience 63:274-283

Trajano E (1991) Population ecology of Pimelodella kronei, troglobitic catfish from Southeastern Brazil (Siluriformes, Pimelodiae). Environ Biol Fishes 30:407-421

Trajano E (1997) Population ecology of Trichomycterus itacarambiensis, a cave catfish from eastern Brazil (Siluriformes, Trichomycteridae). Environ Biol Fishes 50:357-369

Trajano E (2001) Ecology of subterranean fishes: an overview. Environ Biol Fishes 62:133-160

Williams PW, Ford DC (2006) Global distribution of carbonate rocks. Zeitschrift für Geomorphologie 147 (suppl.): 1-2

Windsor SP, Tan D, Montgomery JC (2008) Swimming kinematics and hydrodynamic imaging in the blind Mexican cave fish (Astyanax fasciatus). J Exp Biol 211:2950-2959

Yoshizawa M, Goricki S, Soares D, Jeffery WR (2010) Evolution of a behavioral shift mediated by superficial neuromasts helps cavefish find food in darkness. Curr Biol 20:1631-1636 


\title{
What the Toadfish Ear Tells the Toadfish Brain About Sound
}

\author{
Peggy L. Edds-Walton
}

\begin{abstract}
Of the three, paired otolithic endorgans in the ear of teleost fishes, the saccule is the one most often demonstrated to have a major role in encoding frequencies of biologically relevant sounds. The toadfish saccule also encodes sound level and sound source direction in the phase-locked activity conveyed via auditory afferents to nuclei of the ipsilateral octaval column in the medulla. Although paired auditory receptors are present in teleost fishes, binaural processes were believed to be unimportant due to the speed of sound in water and the acoustic transparency of the tissues in water. In contrast, there are behavioral and anatomical data that support binaural processing in fishes. Studies in the toadfish combined anatomical tract-tracing and physiological recordings from identified sites along the ascending auditory pathway to document response characteristics at each level. Binaural computations in the medulla and midbrain sharpen the directional information provided by the saccule. Furthermore, physiological studies in the central nervous system indicated that encoding frequency, sound level, temporal pattern, and sound source direction are important components of what the toadfish ear tells the toadfish brain about sound.
\end{abstract}

Keywords Descending octaval nucleus $\bullet$ Hearing $\bullet$ Saccule $\bullet$ Torus semicircularis

P.L. Edds-Walton $(\bowtie)$

Biology Department, Woods Hole Oceanographic Institution, Woods Hole, MA 02543, USA

Science Education and Enrichment, 6864 Rycroft Drive, Riverside, CA 9250, USA

e-mail: seewalton@gmail.com 


\section{Introduction}

When considering the vast work on fishes conducted by Arthur Popper and Richard Fay, the obvious theme is a better understanding of how (and what) fish hear. However, each took a different approach. Much of Popper's fish research was driven by an interest in the organization and functions of the sensory hair cells, what one might call a "bottom-up approach." Much of Fay's research used psychophysical methods to investigate and define the limits of the sense of hearing in fishes, using a comparative approach and methods previously used for other vertebrates, particularly mammals, which one might call a "top-down approach."

Popper revealed an unexpected diversity of orientations for sensory hair cells (e.g., Fig. 1a, b) on the otolithic endorgans of fishes (e.g., Popper 1977). Of the three otolithic endorgans that may be involved in hearing (the lagena, the saccule, and the utricle), it was the saccule that showed the greatest variety among species that he

a Fish hair cell - top view of apical surface

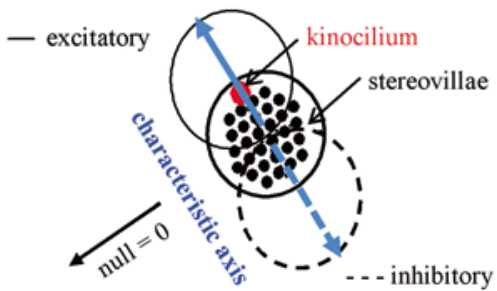

b Hair cell orientations on $O$. tau saccule

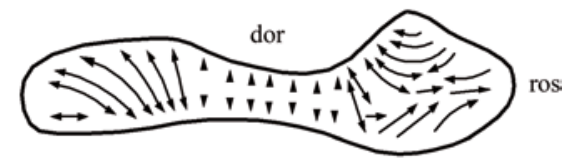

C Left saccular otolith from $O$. $t a u$

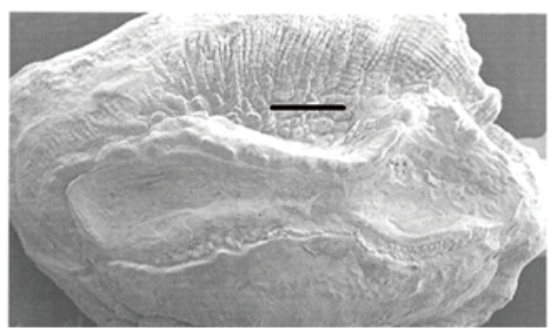

Fig. 1 Sensory hair cells on the toadfish saccule. (a) Apical view of morphological and physiological polarity of hair cell. The hair cell has a cosine response function, shown as a polar plot. The hair cell is excited by particle motion that bends the stereovillae toward the kinocilium (solid blue arrow), which results in excitation of the primary afferent. Hair cell activity is inhibited when the apical structures move in the opposite direction (dashed blue arrow) and there is a null (thick black arrow) along an axis perpendicular to the characteristic axis (blue line). (b) Hair cell orientations for regions on the epithelium are illustrated by an arrow indicating the excitatory direction [like solid blue arrow in (a)]. All orientations are opposed by a $180^{\circ}$ counterpart, but the point of orientation reversal varies in the regions where the arrows are connected. In the middle of the saccule, the opposition line is generally along the center of the epithelium. (c) Scanning electron micrograph of the saccular otolith illustrating the location of the smaller epithelium along the sculptured otolith surface. A gelatinous layer connects the epithelium to the otolith (not shown). Note the curvature along the edges of the saccular depression. Scale bar $=1 \mathrm{~mm}$ (modified from EddsWalton et al. 1999) 
and others examined. Popper (1981) proposed a broad classification system for saccular hair cell orientation "patterns," and Coombs and Popper (1979) suggested a functional hypothesis for some of the diversity, based on their studies of Hawaiian squirrelfish species with different audiograms and different hair cell orientation patterns. Although that hypothesis has not proven to be a valid generalization for all fishes, those studies led to major questions about the functional significance of the variations observed among the saccules of teleosts (Popper and Coombs 1982). Work by Flock (1971) and Hudspeth and Corey (1977) on the physiological polarity of vertebrate hair cells provided the basis for a variety of hypotheses on the potential role that hair cell orientations might play in encoding the direction of a sound source (e.g., Moulton and Dixon 1967; Schuijf 1975, 1976; Saidel and Popper 1983; Schellart and deMunck 1987; Rogers and Zeddies 2008). Documented variations in the apical structures (a single kinocilium and a stair-step array of stereovillae) on individual hair cells also stimulated research on frequency response and the potential for regional response differences along the saccular epithelium (e.g., Furukawa and Ishii 1967; Sugihara and Furukawa 1989).

Around that time, Fay (1984) conducted a landmark study that introduced the field of fish bioacoustics to his three-dimensional particle motion stimulus system, which allowed him to collect the data that proved all three otolithic endorgans of the goldfish (Carassius auratus) had overlapping frequency responses. In addition, each endorgan encoded the axis of particle motion as predicted, based on the orientation of the endorgan and the orientations of the hair cells on each sensory epithelium. Fay went on to study many aspects of the sense of hearing in goldfish by classical conditioning (respiration or heart rate) and various psychophysical procedures (see Fay 1988 for details), first obtaining a response to a stimulus the fish could easily detect and then determining whether the fish could detect another stimulus with a difference in frequency content, intensity, or temporal parameters, or a stimulus in the presence of various types of "noise." The reader is referred to Fay (2014), wherein he summarized his contributions to our understanding of the sense of hearing in goldfish, especially as it compares to the sense of hearing in humans. It is important to note here that the goldfish is a nonvocal teleost fish that nonetheless has specializations of the auditory pathway (Weberian ossicles) that provide increased sensitivity to higher frequencies (e.g., $500 \mathrm{~Hz}$ to about $5000 \mathrm{~Hz}$ ) than the majority of fish species investigated to date, which lack similar specializations and hear only lower frequencies (e.g., below 500 Hz; Popper and Fay 1999). The importance of Fay's work with goldfish was in revealing what the goldfish "knows" about the sounds (or noise) around it, including the concept of "auditory scene" analyses (introduced by Bregman 1990) or the "soundscape," which Fay has often addressed in his papers and presentations (Fay 2009, 2014).

As a beginning graduate student in the Popper lab, I was struck by the volume of information known about auditory processing in the non-vocal goldfish and the relative lack of information about auditory processing in vocal fish, particularly with regard to sound source localization. The oyster toadfish, Opsanus tau (Linnaeus 1766) was my first marine research subject as an undergraduate working in the lab of the famous "shark lady," Eugenie Clark, where I studied their shelter-seeking 
behavior and social interactions. I also had become familiar with their vocal behavior (Tavolga 1958, 1964). The locally available species was an obvious choice in which to address questions about how a fish locates a vocalizing conspecific. Arthur Popper approved, and thus began more than 20 years of research on auditory processing in oyster toadfish.

This review of research completed during collaborations with Arthur Popper and Richard Fay not only summarizes some of the important contributions to understanding what toadfish (and other teleosts) hear but also reflects their influence on the questions asked, the hypotheses generated, and the interpretation of the data obtained. None of this research would have taken place without them.

The focus of my research has been on how the toadfish ear and central nervous system encode and process sounds of biological significance. Sound consists of the alternating compression and rarefaction of the medium through which sound travels, producing both a pressure wave and particle motion. Although some fish can detect the pressure component of sound through an indirect mechanism (involving an internal, gas-filled structure), all fish ears respond directly to the particle motion component (Popper and Fay 2011). Lu (2011) provides an excellent introduction to auditory processing in fishes in general and Radford et al. (2012) provide an experimental comparison of particle motion and pressure stimulation among three teleost species that differ in the presence or absence of an association between the ear and the gas bladder. The physiological research that we conducted on toadfish has investigated only how the toadfish ear responds to particle motion and how the vector of particle motion is encoded in the central nervous system as the basis for determining the location of a sound source.

As in other vertebrates, the ear in fishes has three orthogonal semi-circular canals and three otolithic endorgans that provide information about the position and movement of the head (orientation with respect to gravity, linear acceleration, angular acceleration). The reader is referred to Straka and Baker (2011) for a general introduction to the vestibular (or positional) sense, which is fairly consistent across species and is applicable to what the toadfish ear tells the toadfish brain with regard to position. Unlike other vertebrates, one or more of the three otolithic endorgans in fishes encode the particle motion component of sound. The otolithic endorgan acts as an inertial accelerometer: the sensory hair cells are stimulated by the shearing motion caused by relative motion of the sensory epithelium with respect to the much denser, calcareous otolith. The sensory hair cells are oriented in various directions on the endorgan, resulting in response characteristics across the endorgan that could be used to compute the direction of the sound source in 3-dimensional space (see Sect. 3.1). The focus of this paper will be what we have learned about what the toadfish ear tells the toadfish brain about the particle motion component of sound.

The behavioral repertoire of oyster toadfish includes the establishment of reproductive territories around a nest site constructed by males, sound production in both agonistic and reproductive contexts, and behavioral responses to conspecific sounds by both sexes (Gray and Winn 1961; Winn 1972; Fish 1972). Behavioral observations confirm that multiple reproductive males do not occupy the same nest sites, and that females are attracted to nest sites with vocal males (Gray and Winn 1961; 
Fish 1972). Detailed observations of the natural behavior of the Lusitanian toadfish, a member of the same family (Batrachoididae) with similar reproductive behaviors, revealed that males avoid sites where a vocalizing male is present (Vasconcelos et al. 2010). Therefore, we have good indications that both sexes "listen" to conspecific vocalizations. In general, the agonistic sounds produced by both sexes are broadband pulses rapidly produced in brief bursts $(<150 \mathrm{~ms})$ that sound like a "grunt" (Winn 1972). The reproductive advertisement call is a sustained pulsing (up to $500 \mathrm{~ms}$ ) called a "boatwhistle" with a harmonic structure that is a function of the pulse repetition rate (Watkins 1967). The harmonic structure of the boatwhistle varies somewhat among individuals and populations (Fine 1978; Edds-Walton et al. 2002); however, behavioral studies by Winn (1967) revealed that toadfish respond equally well to pure-tone sounds around 100-200 Hz. Therefore, the majority of our research on auditory processing in toadfish has used tonal stimuli rather than pulsed sounds. There is no doubt that the physiological data collected in our lab reflect normal auditory processing that functions during natural behavior.

\section{Overview of Methods}

\subsection{Oyster Toadfish}

The majority of the fish used for these studies were obtained from the waters around Woods Hole, MA or Cape Cod, MA by the Marine Resources Center (MRC) at the Marine Biological Laboratory (MBL). The fish were maintained in large cement tanks with flow-through local seawater at ambient temperatures in the MRC until removed to be research subjects. Toadfish chosen for experimentation were placed in plastic tubs with flow-through, filtered and chilled local seawater (usually 16-18 C) for at least two weeks. Fish were fed twice weekly with small fish or clam chunks obtained from the MRC. Fish were not fed for one week prior to use to ensure complete digestion of food to prevent regurgitation and fouling of the gills during anesthesia and to reduce fouling of the water during the experiments.

When local toadfish availability was limited, individuals were obtained from New Jersey waters by the MRC. Although believed to be the same species, the New Jersey toadfish were used only for anatomical experiments because their physiology appeared to differ from the local toadfish (e.g., they required more anesthesia and metabolized the anesthesia more quickly, possibly due to the warmer temperatures of their home waters). Therefore, we never used New Jersey toadfish for experiments in which we obtained auditory threshold data. In addition, Massachusetts toadfish were sometimes retained over the winter in the MRC for use in the spring months before local toadfish were being caught. Those "overwintered fish" were used one summer due to a total lack of appropriately sized local fish. The physiological data (e.g., hearing thresholds) from the overwintered fish differed significantly from the data obtained from freshly caught, local fish (unpublished data); thus, only anatomical (e.g., recording site) and tract-tracing data from overwintered toadfish 
were included in data sets. The care and use of the toadfish during experimentation was approved by the IACUC at the MBL and at Loyola University Chicago, Parmly Hearing Institute.

\subsection{Tract-Tracing}

The tract-tracing studies included a variety of methods and labels, including DiI (1,1 dio-octadecyl 3,3,3,3 tetramethyl-indocarbocyanine-perchlorate, Sigma), biotinylated dextran amines (rhodamine, fluoroscein, cascade blue; 3000 and 10,000 MW, Molecular Probes), and neurobiotin (Molecular Probes). Details of the neuranatomical methods may be found in Edds-Walton (1998a, b), Edds-Walton et al. (1999), and Edds-Walton and Fay (2005a).

\subsection{Physiology}

All physiological studies were conducted using stimuli produced by the "shaker system" designed by Fay and described in detail in Fay and Edds-Walton (1997a, b). This unique stimulus system provides a particle-motion dominated sound field that is well controlled and predictable. The shaker system consists of a vibrationisolated, open cylinder attached to a single vertical shaker (beneath the cylinder) and paired mini-shakers (front-back and side-side stimulation). The shaker system is programmed (and calibrated daily) to provide particle motion stimulation at specified frequencies $(50-300 \mathrm{~Hz})$ along designated axes in the horizontal and midsagittal planes $\left(0^{\circ}, 30^{\circ}, 60^{\circ}, 90^{\circ}, 120^{\circ}, 150^{\circ}\right)$. Particle motion is a vector quantity with direction, frequency, and magnitude, and it is the component of sound to which all fish ears respond (Fay 2005; Popper and Fay 2011; Radford et al. 2012). Simply, each stimulus (500 ms duration, $20 \mathrm{~ms}$ rise, fall; repeated 8 times) consisted of controlled movement along a single axis in a single plane (see Fig. 3 in Edds-Walton and Fay 2008) to simulate particle motion produced by a sinusoid at a single frequency and designated level $(\mathrm{dB}$ re: $1 \mathrm{~nm})$. Displacement was measured by three orthogonally positioned accelerometers mounted on the cylinder. Stimulation with the mini-shakers did not permit determination of the excitatory direction along the designated axis, so all directional response pattern (DRP) illustrations consist of the best axis without regard to the excitatory versus inhibitory segment. In other words, although the DRPs for cells look like the cosine function of a single hair cell (Fig. 1a), the actual excitatory direction is not known, only the best axis (see Fay and Edds-Walton 1997a for a detailed explanation of the DRPs).

The fish was positioned in a custom head-holder within the cylindrical dish containing chilled seawater at a depth sufficient to submerge the gills. The dorsal surface of the fish was covered with a paper towel in contact with the water surface so that the entire body was kept moist, but the surgical area was free of water. An 
injection of pancuronium bromide (0.1-0.4 mg in toadfish saline, dependent on fish size) in the tail musculature prevented swimming movements of the tail, but the opercula moved and aerated the gills normally. Opercular movements did not interfere with the recording of auditory afferent activity, but could modulate the activity of lateral line cells in the medulla or bimodal cells (lateral line and auditory responses) in the midbrain. Water temperature and oxygen levels were maintained by replacing half of the water in the cylinder at $2 \mathrm{~h}$ intervals.

The shaker system produced movement of the entire dish in nanometer amounts, simulating particle motion stimulation at biologically relevant levels. The attachment of the head-holder to the dish ensured that the fish moved with the dish, and no water movement was induced around the fish by the stimuli. Thus, there was no hydrodynamic flow around the fish and the lateral line system was not stimulated unless we produced water movement around the fish using a glass pipette (to test for lateral line responsiveness, see Edds-Walton and Fay 2005a).

The experiments that will be summarized in this chapter included physiological recordings from (1) primary afferents as they exited the saccule, cells in (2) the descending octaval nucleus (DON) and (3) the magnocellular octaval nucleus (MON) in the medulla, and cells in (4) the auditory nucleus centralis (and the lateral line nucleus ventrolateralis (NVL)) in the torus semicircularis of the midbrain (Fig. $2 b, c)$. Although the surgical approach varied somewhat for each recording site, the surgical procedures included the same initial steps. The dorsal skin and musculature were removed and the dorsal braincase was scraped with dental tools until thin enough to remove without damaging the underlying tissues or blood supply. The required region of the otic capsule or the brain was exposed carefully and fluids around the ear and brain were replaced by a clear, inert fluorocarbon (FC-77). Pulled glass electrodes were mounted on a 3D micromanipulator and lowered into a branch of the VIIIth cranial nerve, an octaval nucleus of the medulla, or the midbrain (based on surface landmarks and confirmed by neurobiotin injections at recording sites). For more details about the methods, please see the original papers (e.g., EddsWalton et al. 1999; Edds-Walton and Fay 2005b; Edds-Walton and Fay 2008).

\section{Anatomy and Physiology of the Toadfish Auditory System}

As noted earlier, the insights into auditory processing by oyster toadfish were obtained over more than 20 years. The work that is summarized here is organized anatomically from the periphery to the medulla to the midbrain. The peripheral investigations were limited to the saccule, whose inputs to auditory processing sites in the medulla had been confirmed anatomically by Highstein et al. (1992) and Edds-Walton (1998a, b). Systematic investigations of auditory responsiveness were not conducted on the utricle or the relatively small lagena due to technical difficulties in reaching their afferents consistently without altering their normal orientations in the otic capsule or encountering afferents from the semicircular canal cristae that are also associated with those branches of VIII (see Fig. 3 in Edds-Walton 

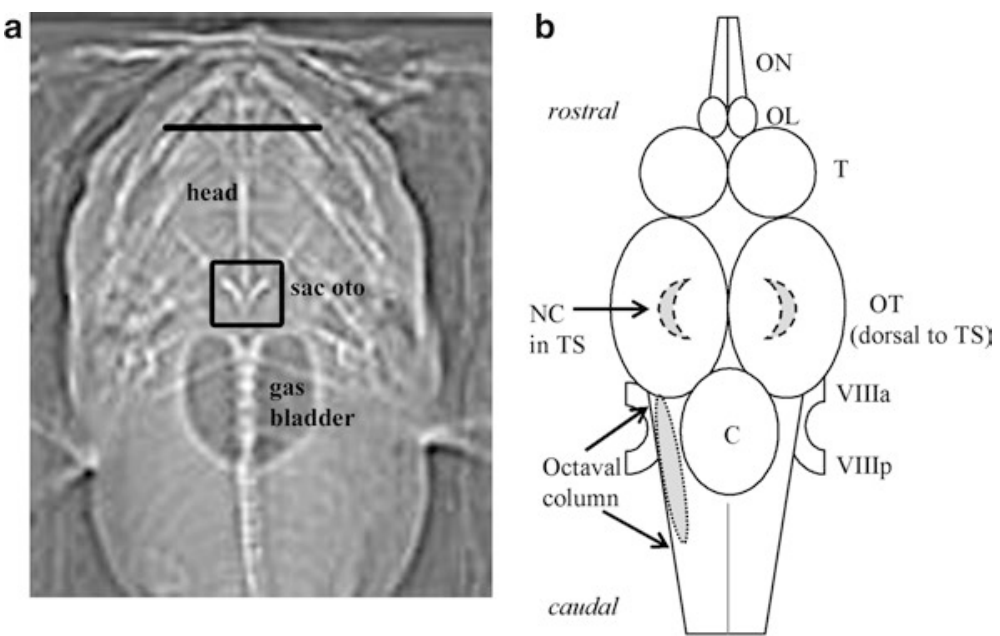

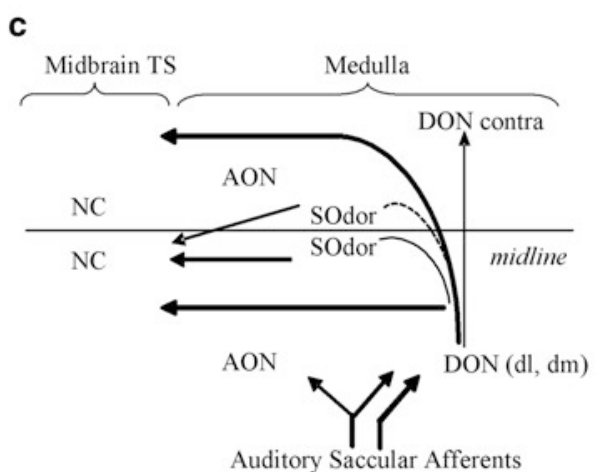

Fig. 2 Auditory structures and sites described in text. (a) Topogram of toadfish, revealing saccular otoliths (sac oto in the otic capsule, enclosed in box). The bi-lobed gas bladder is visible caudal to the otoliths; scale bar is $3.5 \mathrm{~cm}$. (b) Cartoon of Opsanus tau brain: dorsal view showing general location of auditory regions. The octaval column consists of the five nuclei receiving input from VIII, which lie deep to the surface of the medulla, indicated by the grey oval surrounded by the broken line. The auditory nucleus in the midbrain (nucleus centralis, dashed outline) is beneath the ventricle in the midbrain (below the optic tectum). Drawing not to scale. (c) Auditory circuit in toadfish defined by anatomical and physiological studies. Confirmed auditory afferents from the saccule project to AON and dorsal DON, with some bifurcating fibers that project to both octaval nuclei. Auditory projections from DON to SOdor and from SOdor to the auditory midbrain (NC) were obtained anatomically, without physiological confirmation that SOdor has auditory response characteristics. Dashed line indicates limited evidence for projection from DON to contralateral SOdor. Abbreviations: $A O N$ anterior octaval nucleus, $C$ cerebellum, $C C$ crista cerebellaris, contra contralateral, $d l$ dorsolateral, $d m$ dorsomedial, $D O N$ descending octaval nucleus, $N C$ nucleus centralis, $O L$ olfactory lobe, $O N$ olfactory nerve, $O T$ optic tectum, SOdor dorsal secondary octaval nucleus, $T$ telencephalon (forebrain), $T S$ torus semicircularis (midbrain), VIIIa anterior branch of acoustic cranial nerve, VIIIp posterior branch of acoustic cranial nerve (topogram by D. Ketten, CSI Lab, Woods Hole Oceanographic Institution) 
1998a). Therefore, while we have learned much about the contribution of the saccule to auditory processing, we do not know all that the ear tells the brain about sound (see Sect. 5). In each of the studies described here, auditory processing was evaluated in sexually mature toadfish of both sexes that were obtained during their spring and early summer breeding season.

\subsection{The Ear of the Toadfish}

Each of the otolithic endorgans consists of the sensory epithelium, a calcareous otolith, and a gelatinous substance that mechanically links the epithelium to the otolith in a fluid-filled sac within the otic capsule. The saccule is the largest of the otolithic endorgans in oyster toadfish. The saccular otolith is a dense, highly sculptured structure that is curved in both the vertical and horizontal planes (Figs. 1c and 2a). The sensory epithelium on which the hair cells are located is smaller in area than the otolith, but both are intricately associated such that the greater relative motion of the epithelium (e.g., from particle motion in a sound field) causes deflection of the apical structures on the hair cells.

As shown in Fig. 1, maximum excitation occurs along a central axis, toward the single kinocilium. The hair cell response is inherently directional with a single maximum excitatory direction (solid blue line in Fig. 1a), decreasing responsiveness along other axes and a null perpendicular to the best axis (modeled as a cosine function of relative activity versus angle of stimulation; Fig. 1a). The hair cell orientations on the sensory epithelium dictate the directional responsiveness of the endorgan. In toadfish, the saccule is oriented in the dorsal-ventral plane, with a sweeping hair cell orientation on both the rostral and caudal saccule, and a region of vertically oriented hair cells in the middle (Fig. 1b). Thus the hair cells on the saccule can respond to a particle motion stimulus at any angle in the vertical plane; however, the responsiveness in the horizontal plane is restricted by the angle of the endorgan with respect to the midline of the fish and the orientation of the endorgan on the curved otolith (Fig. 1c).

Like all components of the ear, the saccule is a paired endorgan. The saccular otoliths are heavily calcified and are obvious on X-rays, lying on either side of the midline (Fig. 2a) in the otic capsule. The rostral saccular otoliths lie at approximately $\pm 35^{\circ}$ with respect to the midline of the fish, and the caudal end is curved to lie adjacent to the midline in the otic capsule. This angled orientation is important because the left and the right saccules "point" into different regions of acoustic space, and their directional responses will be different, though complimentary. Nonparallel orientation of the saccules is also seen in other fishes that are not closely related to the toadfish (e.g., perch, Sand 1974; cod, Dale 1976; trout, Schellart and Buwalda 1990; sleeper goby, Lu and Xu 2002). The functional significance of the non-parallel orientation may lie in the location-dependent binaural contributions for encoding the direction of a sound source (see Enger et al. 1973; Schuijf and Buwalda 1975; Schellart and deMunck 1987; Schellart and Buwalda 1990). 


\subsection{Circuits: What Goes Where}

The "acoustic nerve," cranial VIII, includes afferents from the sensory epithelia in the endorgans of the ear: the three canal cristae and the otolithic endorgans (the lagena, saccule, and utricle). Efferent axons (from the paired efferent nuclei in the midline of the medulla) are also found in VIII as they travel to their peripheral projection sites. Afferent axons from the peripheral endorgans send their input to the octaval column in the medulla (Fig. 2b, c). The octaval column has five nuclei in toadfish (and all teleosts): the anterior octaval nucleus (AON), the MON, the DON, the tangential octaval nucleus (TON), and the posterior octaval nucleus (PON), as reported in detail by Highstein et al. (1992).

\subsubsection{Saccular Inputs}

Labeling of the entire saccular nerve bundle revealed projections to four of the five octaval nuclei in the medulla, in order of greatest to fewest projections: DON, AON, MON, and minimal input to TON. Distinct neuron bundles from the rostral, middle, and caudal saccule were labeled individually and in pairs to evaluate the organization of input from hair cells with different orientations (compare regions in Fig. 1b) in the two nuclei believed to be involved in auditory processing, the DON (dorsal division, which includes both medial and lateral subdivisions) and AON (EddsWalton 1998a, b). The hypotheses tested included (1) a topographic organization with afferent input in DON and/or AON reflecting the rostral-caudal organization of the saccule; (2) vector organization, representing hair cell orientations, and (3) extensive overlap of inputs consistent with analyses of the pattern of activity across the entire saccule.

The regional labeling of saccular afferents as they exited the sensory epithelium was designed to provide comparable projection data from (1) the afferents of the vertically oriented hair cells $\left(90^{\circ}\right.$, dorsal and ventral with regard to the fish) in the middle of the saccule, (2) from the rostral sweeping hair cell orientations $\left(0-90^{\circ}\right.$ in the vertical plane), and (3) from the caudal sweeping orientations (also $0-90^{\circ}$ in the vertical plane; Fig. 1b). The regional analyses revealed that there is great overlap in the primary afferent projections that represent different hair cell orientations (but see Fig. 6 in Edds-Walton 1998a for parallel input from the middle saccule). In other words, there was no evidence for a simple topographic or vector map in either the elongate DON or the much smaller AON. The data indicate that primary afferents from different hair cell orientations on the saccule converge in the lateral to medial axis and in the rostral to caudal axis of the dorsal region of the DON $(=\mathrm{dDON}$, above the descending tract of cranial V), as well as throughout the medial AON. From the viewpoint of determining the direction of a sound source, the computations in the DON are likely to consist of "weighting" of multiple inputs that converge onto the dendrites of the principal cells (although some axosomatic endings were seen in dDON; Edds-Walton 1998a). 
More specific projection data were obtained from physiologically characterized saccular afferents that were injected with neurobiotin (see Physiology below). Auditory afferents sometimes bifurcated and sent a process rostrally to AON and caudally to the dorsal subdivision of DON, indicating that the same auditory input can go to both nuclei (Edds-Walton et al. 1999). However, more afferents went exclusively to the $\mathrm{dDON}$, and the input had a distinctive lateral to medial organization. Individual primary afferent fibers projected along the length (rostral to caudal) of the DON, with medial projections bearing bouton-like endings at multiple sites along the length of DON (Edds-Walton et al. 1999). These anatomical data indicate that there is redundancy in the input from the saccule that occurs along the length of the dDON, which may reflect a computational axis for directional analyses. Additional studies have shown that there are topographic commissural connections between the left and right DONs that would permit binaural computations (EddsWalton 1998b; and see Physiology below).

Lastly, examination of the afferent branches from the saccular epithelium during the labeling study reported by Edds-Walton (1998a) revealed interesting variations in afferent organization that may provide clues to the location(s) of hair cells with response characteristics consistent with vestibular functions (e.g., tilt perception) on the saccule. In all toadfish, a small but distinct bundle of afferents (distinguished from efferents by the presence of somata in the periphery) exited the rostral tip of the saccule and merged with the anterior and horizontal canal cristae and utricular inputs, rather than with the rostral bundle of saccular afferents. In some toadfish, a small bundle of afferents exited vertically from the caudal saccule and joined VIII with afferents from the lagena and posterior canal crista (see Fig. 2A in Edds-Walton 1998a). These anatomical data suggest that if hair cells with vestibular response characteristics are present on the saccule, their distribution may be limited to the most rostral and most caudal sites along the saccular epithelium.

\subsubsection{The DON}

The organization of the DON is interesting in that the pattern of inputs across species indicates that DON has both vestibular and auditory roles (McCormick 2011). In toadfish, as in other teleosts, the dorsal regions receive inputs primarily from the otolithic endorgans (Fig. 3a); the ventro-lateral region of DON receives inputs primarily from the semicircular canal cristae (Highstein et al. 1992). Utricular afferents project to dorsolateral sites in DON (Highstein et al. 1992; unpublished data) where they may overlap with saccular inputs, but there is also substantial input from the utricle to the ventrolateral region (Highstein et al. 1992). The distribution of utricular inputs in DON is consistent with both auditory and vestibular (orientation) roles for that endorgan.

As noted previously, Fay (1984) provided physiological evidence that utricular and lagenar afferents in goldfish responded to $140 \mathrm{~Hz}$ with directional response characteristics consistent with the orientation of each endorgan and its hair cell orientation pattern, providing evidence that both endorgans could contribute to 
a

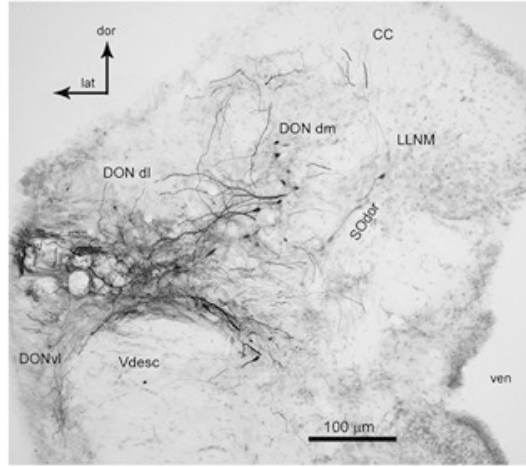

b

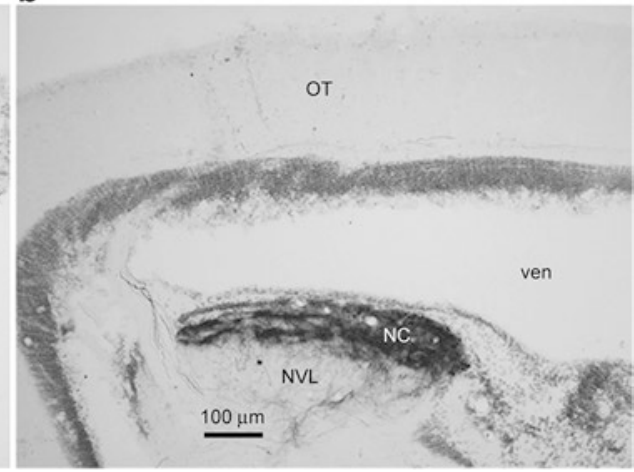

Fig. 3 Auditory processing regions in (a) the descending octaval nucleus in the medulla and (b) nucleus centralis of the midbrain torus semicircularis following injections of neurobiotin at physiologically confirmed auditory sites. Note the lack of auditory cells in ventrolateral DON $(v l)$, which receives input from semicircular canal cristae. Some efferent fibers pass through DONvl. A subset of cells in the dorsolateral $(d l)$ and/or dorsomedial $(d m)$ region of DON project to the secondary octaval dorsal nucleus (SOdor); both $\mathrm{dl}$ and dm project to NC. The midbrain torus semicircularis has a dorsal auditory region (NC) and an underlying lateral line processing area where bimodal cells are also located (nucleus ventrolateralis, NVL). Other abbreviations: dor dorsal, lat lateral, LLNM lateral line nucleus medialis, OT optic tectum, Vdesc descending tract of cranial V, ven ventricle (a was modified from Edds-Walton et al. 2010)

directional computations along with the saccule. McCormick and Wallace (2012) conducted an elegant study in goldfish in which they were able to show that all three otolithic endorgans send projections to identified auditory projection cells in DON. Although the saccule contributed the most input to the auditory cells in the goldfish DON, most often with bouton-like endings on the somata, McCormick and Wallace found evidence that the utricle or lagena also provided input to some of those auditory projection cells (see Table 2, McCormick and Wallace 2012). The anatomy indicates convergence of the otolithic endorgan inputs in the dorsal regions of the DON, but the physiological response properties of the DON projection cells receiving those inputs are unknown. Given that the goldfish has an otophysic connection that mechanically links movement of the gas bladder to the fluids in the ear, resulting in enhanced reception of the pressure component of sound, input from the endorgan encoding the indirect particle motion from the gas bladder (presumed to be the saccule in goldfish) may be parceled in some way for phase comparisons with input from an endorgan receiving only direct particle motion.

If the organization of $\mathrm{dDON}$ in goldfish includes a division for phase comparisons, projections from otolithic afferent input to the dDON in a fish lacking an otophysic connection may reveal a different organization of inputs. Tomchik and Lu (2005) examined the central projections of afferents from all three otolithic endorgans in the "non-otophysic" sleeper goby, in which, like the goldfish, the saccule, utricle, and lagena have overlapping frequency responses and distinct directionality. They found inter-digitating projection sites for the three otolithic endorgans in the 
octaval nuclei, including dDON. Therefore, convergence of otolithic inputs in the dDON may be common among fishes, including those with different peripheral anatomy.

\subsubsection{Medulla to Midbrain}

Injections of neurobiotin into physiologically characterized auditory sites in the midbrain nucleus centralis (NC in Figs. 2b, c and 3b) revealed the sites in the medulla that are components of the ascending auditory pathway. Inputs to the auditory midbrain originate primarily in the contralateral DON, with smaller contributions from the ipsilateral DON and secondary octaval (SO) nuclei in the medulla, which may receive input from both the ipsilateral and contralateral DONs (EddsWalton and Fay 2005a) (Figs. 2c and 3b).

The function of AON in the auditory circuit of toadfish remains to be revealed. Cells in AON receive substantial saccular input (Edds-Walton et al. 1999) and respond to auditory frequencies (Edds-Walton, unpublished data), but the connectivity of AON is not known. A small number $(<5)$ of retrogradely filled cells were present in AON in some, but not all, investigations of inputs to nucleus centralis (Edds-Walton 1998a; Edds-Walton and Fay 2005a). The scarcity of these fills suggests either that AON contributes little to the ascending auditory pathway or that AON contributes indirectly, via intermediate nuclei, such as the secondary octaval nuclei. For the second scenario, the retrograde fills in AON would have been due to trans-synaptic retrograde spread of the low molecular weight label (3000 mw dextran amine) from the dorsal SO nucleus (SOdor) to AON during incubation. Thus far, those two possibilities have not been investigated. Injections of label into AON (without involving other medullary nuclei or tracts) for anterograde transport that would reveal the target(s) of AON projection cells have not been successful. In addition, evaluating the origins of inputs to the SO nuclei is challenging due to the location and small size of the nuclei, which make discrete labeling of only those nuclei extremely difficult. However, it is critical to characterize the role that each may have in binaural processing of sound.

Although the MON and TON do not send projections to the auditory processing regions of the midbrain, the possibility remains that saccular projections to MON/ TON reflect inputs for orientation and reflex responses to sound (see Physiology below). The utricle also provides input to these two nuclei, along with substantial inputs from the semi-circular canal cristae (Highstein et al. 1992). Extracellular recording followed by injection of neurobiotin at the recording site revealed that a subset of MON cells (in M2, M3 subnuclei designated by Highstein et al. 1992) respond to particle motion stimuli (mostly $\leq 100 \mathrm{~Hz}$ ) and others (in M3) respond to both particle motion and lateral line stimuli (water motion), consistent with lateral line input to M3 (Highstein et al. 1992). The auditory and bimodal cells responded best to sounds in the horizontal plane, potentially reflecting inputs from the rostral or caudal saccule (Fig. 1b) or from the horizontally oriented utricle (Edds-Walton et al. 2013). In addition, ipsilateral label injections into auditory sites in MON also 
filled contralateral somata in MON, indicating that there is a commissural tract that provides the potential for integration of auditory (and lateral line) inputs from the left and right sides of the fish (Edds-Walton et al. 2013). These data are consistent with other studies of circuits that regulate body position in space (e.g., pitch and roll), which also could include rapid responses to sound (discussed in Straka and Baker 2011).

Although this review focuses on the directional hearing circuit, it is worth noting that auditory input is combined with lateral line input in the midbrain of oyster toadfish. Application of label to regions in the midbrain torus semicircularis (TS) revealed sites where lateral line and auditory inputs converged (Edds-Walton and Fay 2005b) and retrogradely filled projection cells were present in both DON and the lateral line nucleus medialis. Consistent with the anatomy, physiological studies confirmed bimodal cells in the TS that responded well to auditory particle motion around $100 \mathrm{~Hz}$, and to lateral line stimuli (water movement) ipsilaterally, or contralaterally, or on both sides of the fish (Fay and Edds-Walton 2001; Edds-Walton and Fay 2005a). An additional finding was the presence of cells for which lateral line stimulation inhibited the spiking activity during auditory stimulation (Edds-Walton and Fay 2005a). Therefore, there are potentially interesting interactions between these two sensory systems in toadfish, as well as other fishes (Braun and Sand 2014). The lateral line may be involved in orientation during the "final approach" within centimeters of a sound source, rather than sound source localization from a distance. A carefully conducted behavioral study with the closely related midshipman fish (Porichthys notatus, Batrachoididae) revealed that the lateral line is not required for sound source localization by free-swimming females approaching a speaker that projected male reproductive calls (Coffin et al. 2014).

\subsection{Physiology: What the Ear Hears}

Fay (1984) showed that all three otolithic endorgans in the goldfish responded to particle motion at $140 \mathrm{~Hz}$ and each had directional responses that reflect the hair cell orientations of that endorgan. Lu et al. (1998, 2003, 2004) also showed that all three otolithic endorgans in the sleeper goby (Dormitator latifrons) can respond to similar frequencies, however, the sound levels required to stimulate each endorgan varied to the extent that all three are unlikely to be stimulated simultaneously.

Fay and Edds-Walton have focused on understanding auditory processing of the saccule in the oyster toadfish, although an auditory role for the utricle or the lagena have not been ruled out, nor have our physiological studies ruled out a potential role for the saccule in orientation or equilibrium common for the vestibular systems of other vertebrates. The potential for each otolithic endorgan to respond to low frequency linear acceleration associated with "vestibular" function and frequencies in the auditory range, the "mixed function" hypothesis (Platt and Popper 1981; Popper and Fay 1993), remains an intriguing possibility.

In 2011, Vasconcelos worked with another member of the Batrachoididae, the Lusitanian toadfish (Halobatrachus didactylus), and used the shaker system to com- 
pare the relative sensitivity of the saccule and the utricle to particle motion at auditory frequencies. In addition, Vasconcelos removed the otolith from the endorgan (unilaterally or bilaterally) to assess the role of the saccule and the utricle in body posture and movement following recovery from the surgery. The results of those behavioral experiments indicated that the utricle functions both as an auditory and vestibular endorgan in the Lusitanian toadfish (Vasconcelos et al. 2012). Although the auditory responsiveness for the saccule was consistent with previous work on auditory processing in this species, the results of the postural experiments were less clear, and additional research is being done. Therefore, although likely that the toadfish brain receives both auditory and vestibular information from the utricle and the saccule, more work is required to delineate the specific contributions of each to orientation, auditory processing, and sound source localization.

The third otolithic endorgan, the lagena, is the smallest of the otolithic endorgans in toadfishes, difficult to access in vivo, and its association with the posterior semicircular canal indicates a vestibular role. In goldfishes, the lagena is nearly equivalent in area to the saccule (Edds-Walton and Popper 2000), lies directly adjacent to the saccule (Platt 1977), and the nerve bundle from the lagena joins the saccular bundle prior to joining the other components of VIII, all of which are consistent with a similar sensory role for the saccule and lagena in that species (for physiological comparisons, see Coombs et al. 2010; Dailey and Braun 2011). Therefore, clarification of the role of the lagena in toadfishes would be of interest, but it was not included in any of the studies by Fay and Edds-Walton.

As described above (Sect. 3.2.1), saccular afferents often occur in bundles that reflect their site of origin on the epithelium: rostral, middle, caudal. Fay and EddsWalton (1997a, b; Edds-Walton et al. 1999) evaluated afferents from those regions of the saccule and concluded that (1) in general, primary afferents are broadly tuned with most afferents responding best to the $100 \mathrm{~Hz}$ stimulus; (2) there is no evidence for a frequency map along the rostral-caudal axis of the saccule; (3) the majority of afferents are directional in that their responses reflect responses from a single hair cell orientation (producing a cosine response almost identical to that of a single hair cell; Fig. 1a); (4) the saccule provides information about the axis of stimulation for all angles in the vertical plane $\left(0-90^{\circ}\right)$, consistent with the hair cell orientation pattern described by Edds-Walton and Popper (1995); in the horizontal plane, responses are consistent with the orientation of the saccule in the otic capsule (Fig. 2a).

The variations in the saccular data also provided interesting insights into the auditory system. The best response directions (best stimulus axis) among saccular afferents that were filled with neurobiotin (to identify the location of their dendritic arbors on the saccular epithelium) did not always coincide with the predicted best direction based on the hair cell orientation drawing. Edds-Walton et al. (1999) provided evidence that the epithelium does not lie flat against the otolith, and the unexpected best directions (in particular, low elevations of cells along the edge of the epithelium) are likely to be due to curvature of the epithelium where it lies along the sculptured otolith (see Fig. 1c). Fay and Edds-Walton (1997a) also noted that some afferents (about $20 \%$ ) are nearly omnidirectional, lacking a null in the directional response plot. They hypothesized that those afferents contacted hair cells with two different orientations, based on a simple model (see Fig. 11 in Fay and Edds-Walton 
1997a), and that those afferents could function as simple sound detectors. Alternatively, those cells may reflect a step in the maturation of the synaptic connections on the sensory epithelium. New hair cells and new connections develop as the endorgan grows throughout the life of the fish; some of those connections may be temporary, particularly if correlated activity is favored for maintaining synaptic contacts between an afferent and multiple hair cells.

Thresholds among saccular afferents varied between 300 and $0.1 \mathrm{~nm}$ rms, similar to saccular afferents of the goldfish (Fay and Ream 1986; Fay and Edds-Walton 2000). These data were important because they showed that the otophysic connection (mechanically connecting the ear and gas bladder) in goldfish does not provide substantial improvement in sensitivity to particle motion at lower frequencies (below $200 \mathrm{~Hz}$ ) when compared to the toadfish, which lacks the otophysic connection. The most sensitive afferents (sensitivity is the inverse of threshold) rival mammalian cochlear afferents. Also, similarly to mammalian cochlear afferents, toadfish afferents with low spontaneous (or background) activity tended to have higher thresholds than those with higher spontaneous activity, though there was a continuum (not a dichotomy) of responses in all three locations investigated along the saccule (Fig. 5 in Fay and Edds-Walton 1997a).

Additionally, a subset of afferents located all along the saccule, with 0-2 spikes/s spontaneous activity, exhibited consistent level-dependent phase shifts with increasing stimulus levels (mean slope \pm s.e.m.: $3.7^{\circ} / \mathrm{dB} \pm 0.16^{\circ}$ ). Although the phase shift may seem inconsequential, for a $5 \mathrm{~dB}$ difference in stimulus level, there could be a $20 \mathrm{deg}$ shift in the occurrence of a phase-locked spike (Fig. 4). For a biologically relevant frequency such as $100 \mathrm{~Hz}$, a $5 \mathrm{~dB}$ difference would translate to a $55 \mathrm{~ms}$ temporal difference in the spiking activity of an afferent that exhibits phase-advance (Fig. 4d) versus a phase-locked afferent that does not exhibit phase-advance (Fig. 4b). If we look at an octaval cell that receives input from both of the above cells, the phase-advanced afferent representing the louder sound would provide its "information" earlier to a cell that receives both inputs. Taken together, the directional response data and phase-advance data provide evidence that computations of interaural level differences are possible, and a binaural comparison of the activity from the nonparallel saccules could contribute to sound source localization. These results led to the investigation of response characteristics within the medullary nucleus of the octaval column (Fig. 2b) that receives the majority of input from the saccule: the dorsal division of the descending octaval nucleus (dDON).

\subsection{Physiology: What the Brain "Knows"}

A key question to address is what the brain does with the information from the ear. Our studies of the dDON in the medulla and its midbrain target, nucleus centralis (NC), revealed that the auditory circuits perform various computations that "improve" the information about frequency, temporal pattern, and the axis of particle motion of a sound source from the information provided by the auditory endorgans of the ear. At this point, we cannot state which endorgans of the ear contribute 

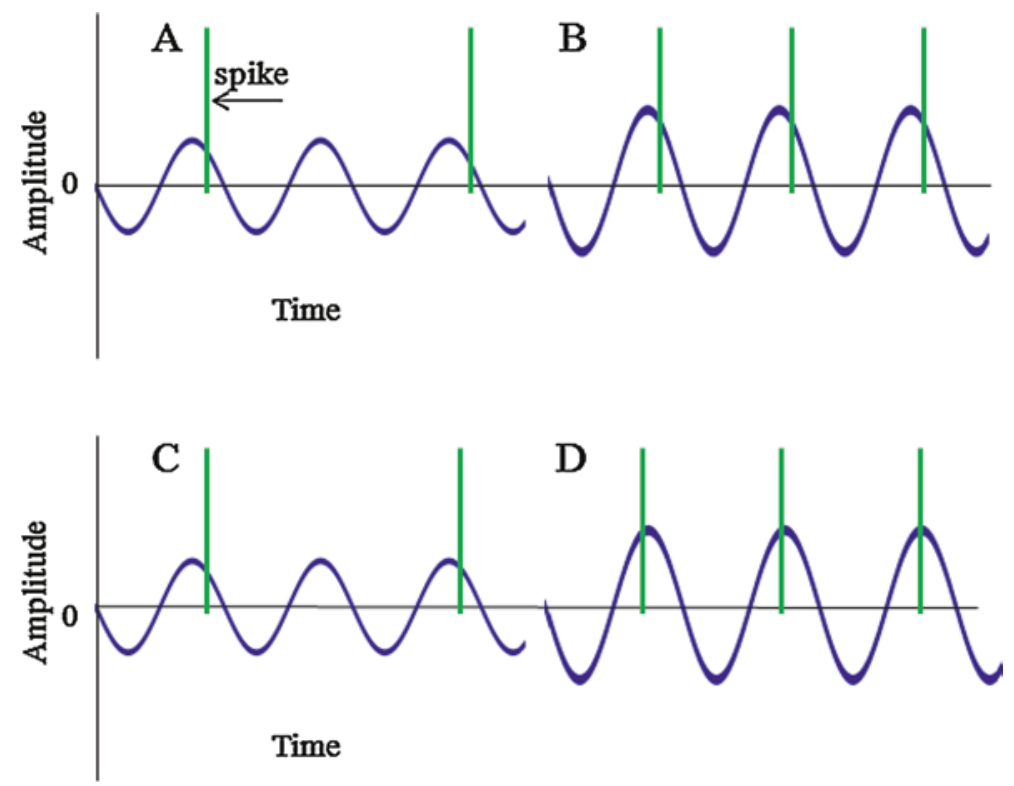

Fig. 4 Phase-locking in auditory afferents. (a) Spikes (green vertical lines) produced by a phaselocked afferent consistently occur at the same phase of a sinusoidal stimulus (blue line). At lower sound levels, the spikes do not occur during every cycle. At sound levels well above threshold for the same afferent, a spike will be produced for every cycle of the stimulus at the same phase, as shown in (b). (c) Spikes from an afferent that exhibits a level-dependent phase shift also occur at a particular phase of the sinusoid, but as sound levels increase, a spike consistently occurs earlier in the sinusoid, as shown in (d). The advance in the phase response results in earlier spike times (compare $\mathbf{d}$ to $\mathbf{b}$ ) that could be a mechanism for sound level comparisons

all of the information that the brain uses. As noted previously, we have focused on the saccule. Our data indicate that convergence of saccular input could be "sufficient" for the fish to determine the location of a sound source, but we have not investigated the possibility that the horizontally oriented utricle and/or vertically oriented lagena contribute important information (gravistatic, postural or auditory) that facilitate behavioral responses to biologically relevant sounds. Projections from the utricle overlap with those of the canal cristae (particularly the horizontal canal cristae) at multiple sites in the octaval column in a variety of fishes, which ultimately contribute to circuits that control posture and coordinate head and eye movements (Straka and Baker 2011).

\subsubsection{The Roles of DON}

As noted in Sect. 3.2.3, retrograde transport of label injected into the torus semicircularis to fill the somata of projection cells in the medulla consistently labeled primarily the $\mathrm{dDON}$ with contralateral predominance. The medial region of the AON (where bifurcating saccular afferents sometimes terminated; Edds-Walton et al. 
1999) and the secondary octaval populations (that project to the auditory midbrain) were located in medial areas of the medulla that were obscured by a large blood sinus, and we were never able to confirm auditory recordings in any of those sites. Therefore, we have focused our studies on the dDON (Fig. 3a). The research questions addressed in the dDON included: how are the response characteristics different from the saccular afferent responses? Is there evidence for convergence of inputs and directional computations?

Edds-Walton and Fay (2008) found similarities and differences in the auditory response characteristics of $\mathrm{dDON}$ cells when compared with saccular afferents. The frequency response of dDON cells was similar to that of saccular afferents (best frequencies of 84-185 Hz for $79 \%$ of cells), however bandwidth of the responses varied greatly, which was not a characteristic of saccular afferents. Most of the dDON cells had iso-level frequency response functions with an inverted-V shape (with various slopes), indicating narrowing of the frequency response (= tuning) when compared to saccular afferents. However, given the breadth of the bandwidths measured at $50 \%$ of maximum response, the majority of afferents in dDON could not be considered sharply tuned (see Figs. 4 and 6 in Edds-Walton and Fay 2008). Thus, we conclude that the brain is capable of processing broadband sounds such as the pulsed sounds produced by conspecifics. In addition, the observed responses to pure tones (Winn's behavioral studies and our physiological studies) can be attributed to the broad nature of tuning in the ear (Edds-Walton and Fay 2008). For example, many dDON cells not tuned to $100 \mathrm{~Hz}$ will respond well to it.

The majority of cells in dDON exhibited good phase-locking. As in saccular afferents, Edds-Walton and Fay (2008) found a subset of cells for which phaselocking was level-dependent (improved with increasing levels above threshold). Another subset of dDON cells phase-locked consistently at all levels and exhibited level-dependent phase shifts (mean $2.7^{\circ} / \mathrm{dB}$, maximum of $6^{\circ} / \mathrm{dB} ; \mathrm{Fig}$. 4) as was seen in saccular afferents. However, there was not a dichotomy of phase-locking accuracy in $\mathrm{dDON}$, but rather an array of variations in the strength of phase-locking and the degree of phase advance in the cells that exhibited it. Edds-Walton and Fay (2008) concluded that within dDON there appears to be the potential for the generation of parallel computational pathways: one pathway in which phase is encoded independent of level, and another pathway that could contribute to stimulus level comparisons. Both of these pathways would contribute to soundscape analyses and, potentially, to sound source localization.

Edds-Walton and Fay (2005b) determined that the convergence of auditory inputs in the dorsal division of DON does not result in a loss of directional information. On the contrary, the majority of cells in dDON exhibited DRPs in both the horizontal and vertical planes that tended to be less broad with respect to the level of response to stimulus angles adjacent to the best axis. This narrowing of the directional response area is similar to frequency tuning and has been called "sharpening" of the directional response (Edds-Walton and Fay 2005b). Quantification of this narrowing of the directional response was achieved by employing a sharpening ratio (SR):

$$
\mathrm{SR}=\left[\left(R_{1}+R_{2}\right) / 2\right] / R_{3}
$$


where $R_{3}$ is the maximum response at the best stimulus angle (or best axis, $\mathrm{BA}$ ); $R_{1}$ is the response at the adjacent stimulus axis that is $-30^{\circ}$ from the $\mathrm{BA}$; and $R_{2}$ is the response at the adjacent stimulus axis that is $+30^{\circ}$ from the BA (illustrated in Fig. $5 \mathrm{a}, \mathrm{b}$ ). This calculation was done separately for the horizontal plane (= azimuth) and for the vertical plane (or mid-sagittal plane=elevation). For a perfect cosine response function, the calculated SR is 0.866. The maximum SR possible is 1, which would be for a cell that has an equivalent response to three adjacent stimulus axes (and no distinct single best stimulus angle). An SR of 1 was never present in any of our data sets and would not be expected from saccular afferents unless the cell's ability to respond to a stimulus is "saturated" by stimulus levels well above threshold. An SR near "0" would indicate a very sharpened directional response wherein the cell responds well to only one axis. Due to the natural variations in spike counts for stimulus repetitions, particularly for cells with background activity, a minimum data set at two stimulus levels was required, and the critical value for considering a cell to be sharpened was an average SR $\leq 0.75$ (Fig. 5c). The median SR value for DON cells was 0.67 in azimuth and 0.62 in elevation (Edds-Walton and Fay 2005b).

In a subset of DON cells $(n=73), 64 \%$ exhibited sharpening $(\mathrm{SR}<0.76)$ in azimuth and $67 \%$ exhibited sharpening in elevation (Fig. 5c). Moreover, some of the DON cells were sharpened greatly ( $\mathrm{SR}<0.56$, Fig. $5 \mathrm{c}$ ) in both planes. An equally important observation was that there were cells for which sharpening occurred in one plane only (azimuth or elevation) or for which sharpening was unequal in the two planes. Taken together, the evidence indicates that sharpening is an important computation in DON, which occurs by various ways (likely the weighting of inputs) that result in different degrees of sharpening in different planes. In addition, directional sharpening and frequency tuning appear to be separate computational processes, as one is not predictive of the other (Edds-Walton and Fay 2003, 2008).

The best direction in three-dimensional space was calculated for afferents in DON and plotted on a flattened globe (northern hemisphere only) to compare the distribution around the fish with the best directions plotted for saccular afferents (Fig. 6). The globe's outer perimeter (equivalent to the equator of the flattened globe) represents $0^{\circ}$ in elevation, and directly above the fish (shown at the center of the globe) is $90^{\circ}$ elevation. Elevation rings (similar to latitude lines on a globe) are shown for 30 and $60^{\circ}$ in elevation around the fish. Azimuth is represented around the fish with $0^{\circ}$ in azimuth at the head of the fish; $30^{\circ}$ in azimuth is labeled on the left side of the fish for the saccular data to identify the angle around which most of the left saccular data were found. Note that the best direction is shown as the point on the globe at which the characteristic axis would pierce the northern hemisphere of a globe.

Comparing the best directions for afferents from the left saccule and cells in the left DON reveals very different distributions (Fig. 6). The directional plot for saccular afferents reflects the orientation of the saccule in the otic capsule of the fish. The large number of overlapping data points around $30^{\circ}$ left azimuth is consistent with the orientation of hair cells on the rostral saccule, where much of the physiological recording was done due to the accessibility of the rostral bundle of the saccular 
a $\mathrm{SR}=\frac{[(84+80) / 2]}{100}=0.82$, unsharpened cell

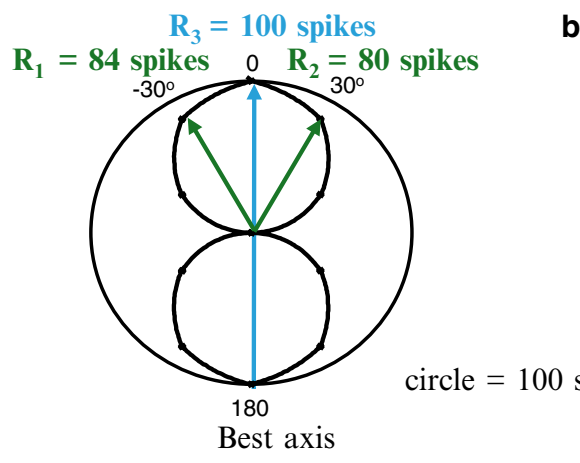

b $\mathrm{SR}=\frac{[(64+68) / 2]}{100}=0.66$, sharpened cell

$\mathbf{R}_{3}=100$ spikes

$\mathrm{R}_{1}=64$ spikes $0 \quad \mathrm{R}_{2}=68$ spikes

c Distribution of SR values in DON and TS

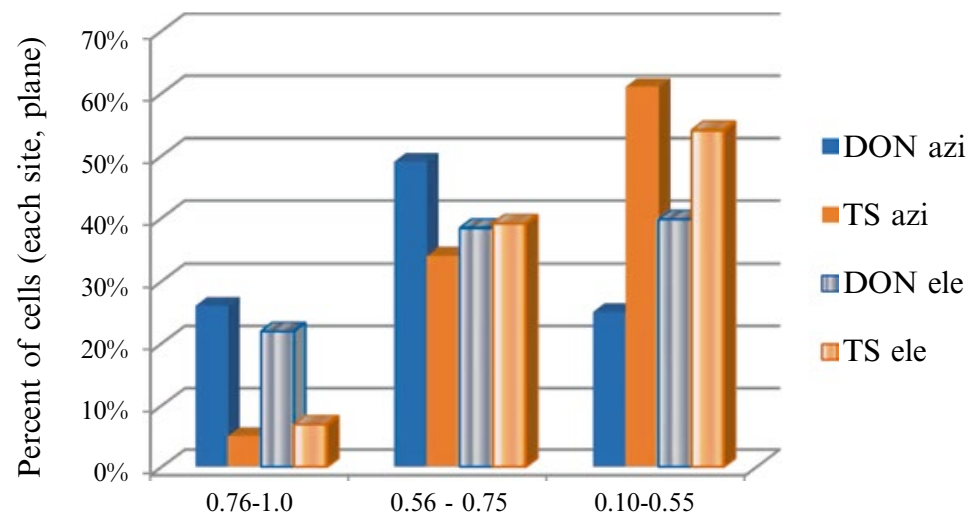

SR value -----increasingly narrow DRP--->

Fig. 5 Sharpening ratios $(S R)$ for cells in the dorsal division of the descending octaval nucleus $(D O N)$ and cells in the torus semicircularis $(T S)$. The SR calculation is illustrated and calculated from the relative spike rate at the best axis $\left(R_{3}\right.$, blue line $)$ and the spike rates for the two stimuli $\pm 30^{\circ}$ (green arrows) from the best axis, as revealed by the DRP for the directional stimulus set. SR was calculated separately for azimuth and elevation. SR for a perfect cosinusoidal response (shown in Fig. 1) is 0.866. (a) Calculation and illustration of the DRP of an unsharpened cell; the hypothetical values shown are average spikes per stimulus angle; blue line is the best axis in that plane, with only half of the adjacent stimulus axes shown for simplicity. The length of the axis line indicates relative spike rates at that angle, with the outer circle representing 100 spikes/s. The blue line touches the circle, thus the average spike rate at that stimulus direction was 100 spikes/s. (b) Calculation and illustration of the DRP of a sharpened cell; the values shown are realistic, but hypothetical. (c) Histogram illustrating the distribution of SR values for DON cells, in azimuth and elevation, to compare with the SR of TS cells in each plane. The distribution of SR in TS is shifted to the right as cells in TS were more sharpened than in the DON. The DRP is plotted with regard to the cell's response to each stimulus axis (modified from Edds-Walton and Fay 2005) 

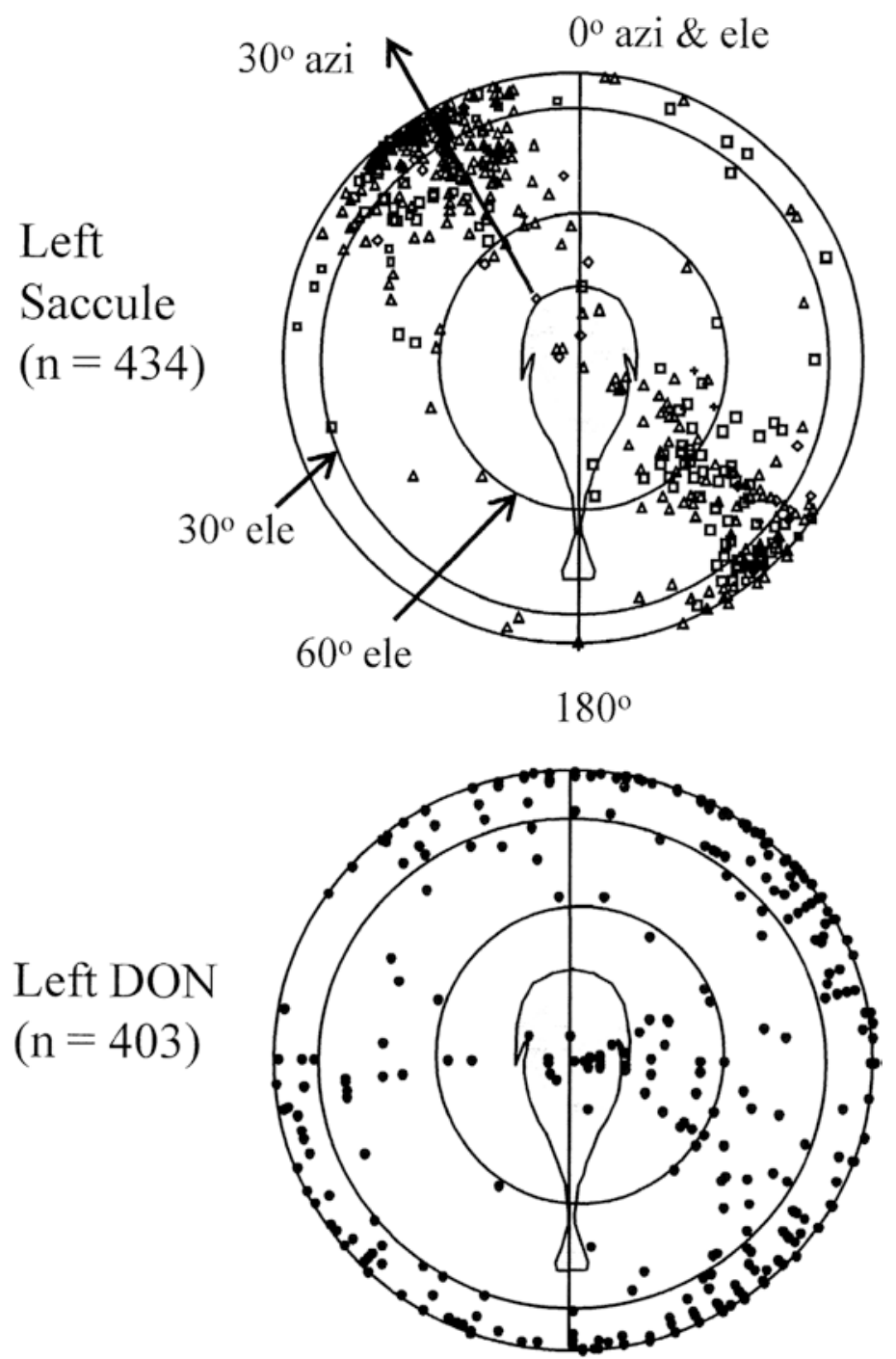

Fig. 6 Flattened globe illustrating the best directions for left saccular afferents (top) and for cells in the dorsal division of the left descending octaval nucleus (DON, below). Direction is represented by a point on the northern hemisphere of a globe at the appropriate azimuth and elevation where the vector for best direction would pierce the northern hemisphere. The outer circle is equivalent to the equator $\left(0^{\circ}\right.$ elevation) and directly above the fish is the equivalent of the North Pole ( $90^{\circ}$ elevation). Concentric circles indicate 30 and $60^{\circ}$ elevation. Azimuth is displayed with respect to the fish silhouette, $0^{\circ}$ at the head and $180^{\circ}$ at the tail. Each point is a different afferent or cell; different shapes indicate different data sets and data points overlap. The arrow at $30^{\circ}$ azimuth indicates the stimulus angle closest to the angle of the left saccule with respect to the midline of the fish. The distribution of best directions in the saccule reflects the orientation of the endorgan and the hair cell orientations on the sensory epithelium. The DON contains cells that represent the acoustic space all around the fish; the distribution is consistent with the convergence of inputs from the left and right saccules. Directional stimuli were presented at $30^{\circ}$ intervals in the horizontal and mid-sagittal planes, and the best directions shown here were interpolated based on the distribution of responses to the stimulus angles in both planes (modified from Edds-Walton and Fay 2005, 2008) 
nerve. Note also the relatively small number of cells with best directions directly above the fish, which is consistent with the relatively small and inaccessible area of the saccule, the middle, where purely vertical cells are located (Fig. 1b). The best directions for afferents from the caudal saccule overlap the locations of afferents from the rostral saccule (see Edds-Walton et al. 1999 for details on the caudal afferents). In contrast, the directional plot for DON cells reflects the acoustic space all around the fish. There are two potential ways to achieve this difference: convergence of inputs from the left and right saccules or convergence of input from other ipsilateral otolithic endorgans. At present, anatomical data can be used to support either circuit, but there are physiological data to support the convergence of left and right saccular data in the DON (and the TS, see Sect. 3.4.3).

Edds-Walton and Fay (2009) argued that the distribution of responses in DON could be the result of convergence of left and right saccular inputs based on the following data. Although saccular afferents do not cross the midline to the contralateral DON, there is a topographic tract that connects the dorsal divisions of the left and right DONs (Edds-Walton 1998b). In a unique study, Edds-Walton and Fay (2009) altered saccular inputs (by tipping one of the two saccular otoliths) while recording from directional auditory cells in DON. Data were difficult to obtain because three complete sets of frequency and directional data were needed: Pretipping, Tipping, and Post-tipping data (with results consistent with the pre-tipping data). Ipsilateral tipping confirmed that the method worked and was reversible. Often tipping eliminated spike activity in an ipsilateral or contralateral DON cell, which was consistent with removal of essential excitatory input from the saccule. Most importantly, Edds-Walton and Fay (2009) showed that altering contralateral inputs can alter the DRP (and sometimes frequency response) of a cell in DON. As was apparent in the sharpening analyses, there were a range of differences in the DRP during tipping, consistent with a variety of computations. The data clearly show that contralateral saccular input contributes to the computations that occur in DON (Edds-Walton and Fay 2009), and therefore, at least some of the computations in DON are binaural.

\subsubsection{Other Targets of the Saccule in the Octaval Column}

As noted earlier, MON and TON do not appear to be involved in the ascending auditory circuit in toadfish (consistent with other teleosts, McCormick 1999, 2011), but both receive input from the saccule as well as the utricle, lagena, and canal cristae. The saccular input to MON and TON is of interest because of the potential for dual function of the saccule as an auditory and vestibular (gravistatic) endorgan (Platt and Popper 1981). Highstein et al. (1992) suggested the MON as the origin of the ipsilateral descending vestibulospinal tract, which is consistent with a role in gravistatic orientation. Physiological recordings in MON confirmed that a subset of cells (in two of the three subdivisions designated by Highstein et al. 1992) respond well and phase-lock to auditory frequencies (Edds-Walton et al. 2013). The TON receives heavy input from all known vestibular structures and very little input from the 
saccule (Highstein et al. 1992; Edds-Walton 1998a). However, these data provide further evidence that some region of the saccule could contribute to circuits that modulate orientation with respect to gravity (yaw, pitch, roll) as well as circuits involved in behavioral responses to sound.

\subsubsection{Torus Semicircularis}

As in other teleosts, the midbrain of the oyster toadfish is a major integration site of sensory information. Visual input converges with other senses important for appropriate behavioral responses, as in other vertebrates (Tricus and Highstein 1990; Carr and Edds-Walton 2008; Straka and Baker 2013). Multimodal cells are to be expected, though sorting out the particular range of responses is a daunting task. The studies by Edds-Walton and Fay focused on auditory processing and the potential for integration of hearing and components of the lateral line sense (also known as Svenning; for a review, see Braun and Sand 2014).

The midbrain torus semicircularis of teleost fishes consists of two divisions: the more dorsal nucleus centralis (NC) and the more ventral nucleus ventrolateralis (NVL). Anterograde transport of neurobiotin from $\mathrm{dDON}$ revealed projections to the dorsal division of the secondary octaval population (SOdor) and to the auditory midbrain (NC). Retrograde transport of neurobiotin injected at characterized auditory sites in NC confirmed that a subset of dDON cells and SOdor cells projected to those sites (Edds-Walton and Fay 2003). Clearly, these inputs provide a multitude of possibilities for physiological computations in the midbrain. In addition, cells in NC and NVL have extensive processes, and interactions between the auditory input to NC and the lateral line input to NVL provide further opportunities for converging the inputs from those two sensory systems. Bimodal cells with a variety of response characteristics appear to be present in both nuclei (Fay and Edds-Walton 2001; Edds-Walton and Fay 2005a).

Auditory cells in the midbrain lack phase-locking, are broadly tuned as in DON, and exhibit sensitivity to temporal codes (interpulse intervals, Fay and Edds-Walton 2002). The bandwidth indicates that most cells that respond best to $100 \mathrm{~Hz}$ will also respond well to harmonics of $50 \mathrm{~Hz}$ (the lowest frequency tested) or $200 \mathrm{~Hz}$ if they are present at a similar level. Therefore, at least some of the cells in the NC respond very well to the pulses in conspecific vocalizations.

The auditory (and bimodal) cells also exhibit sharpened DRPs; however, the data indicated that the computations that produce sharpening continue along the ascending pathway (e.g., via SOdor) or occur in the TS. The distribution of SR values for cells in the TS is shifted toward lower values, indicating greater sharpening, particularly in the horizontal plane, in the TS (Fig. 5c). More than half of TS cells were in the highly sharpened category. The median SR value for azimuth among TS cells was 0.49 (DON median SR in azimuth $=0.67$ ) and the median SR value for elevation among TS cells was 0.54 (DON median SR in elevation=0.62). In addition, there was an even greater variety in the relative sharpening of the two planes in TS (coefficient of determination $=0.1$ ) compared to DON (coefficient of determination $=0.4$ ), 
which further indicates that the computations are the result of a variety of excitatory and inhibitory interactions among the various sources of input to the TS.

Edds-Walton and Fay (2009) demonstrated that binaural cells result from the convergence of excitatory (EE) and inhibitory (EI or IE) inputs to cells in both DON and NC (and see Edds-Walton et al. 2010). Therefore, there are potential sites in fishes for bilateral comparisons that may function similarly to binaural sites in the ascending auditory pathway of other vertebrates (e.g., nucleus laminaris in birds or nuclei of the superior olivary complex in mammals).

The otolith tipping experiments described for cells in the DON (Sect. 3.4.1) were also conducted with cells in the TS. The only otolithic input that was altered during these experiments was from the saccule. As in the DON, altering saccular input altered the DRPs and/or spiking activity of cells in the TS (Edds-Walton and Fay 2009). Unlike the DON, spike activity was rarely eliminated in a TS cell during tipping, consistent with complex interactions of converging inputs from various sources.

Lastly, plotting the characteristic axis for cells in the TS on the flattened globe (as in Fig. 6) provided confirmation that acoustic space around the fish is well represented in the midbrain as it is in DON (Edds-Walton and Fay 2003). Given that the directionality of auditory cells improves (becomes sharpened) along the ascending auditory pathway to the level of the midbrain, Edds-Walton and Fay (2005b) concluded that encoding the location of a sound source is an important component of auditory processing in the toadfish.

\section{Conclusions}

Studies in the oyster toadfish combined anatomical tract-tracing and physiological recordings from identified sites on the saccule, in the DON, and in the torus semicircularis to document auditory processing at each level of the ascending auditory pathway. The toadfish saccule encodes frequency, sound level, and sound source direction in phase-locked activity conveyed via auditory afferents ipsilaterally to nuclei of the octaval column. The large DON plays a major role in auditory processing and contributes bilaterally to the ascending auditory circuit. Binaural convergence of auditory information provides the fish with information about sound sources at locations all around the fish. Furthermore, a series of related physiological studies showed that the auditory system of the toadfish consistently encodes frequency, temporal pattern, sound level, and the axis of particle motion for sound sources. The response characteristics in the midbrain indicate that frequency tuning tends to be broad with little narrowing of the frequency response in the ascending auditory circuit. However, computations in the medulla and the midbrain narrow directional responses and should allow the fish to locate a vocalizing conspecific, to determine the locations of multiple sound sources around the fish based on direction and relative sound levels, and, in general, evaluate the soundscape. The toadfish ear tells the toadfish brain "what" and "where"- we are just beginning to understand "how." 


\section{Future Directions}

1. Do the sensory roles of the lagena and the saccule differ substantially for otophysines (fishes with otophysic connections that enhance detection of the pressure component of underwater sound) versus non-otophysines (like the oyster toadfish) that lack otophysic connections? This seems likely, but requires carefully conducted comparative studies. Fay (1984) provided the first data on the directional responses from the utricle, saccule, and lagena in the goldfish, using the same frequency stimulus for all three. Those data are a clear indication that all three endorgans can have overlapping frequency responses, and that each could contribute to directional sound analyses. However, there are distinct differences in the size and shape of the saccule and lagena in different fish species. The overall areas of the sensory epithelia for the lagena and the saccule in goldfish are nearly equivalent and the endorgans lie directly adjacent to each other (Platt 1977; Edds-Walton and Popper 2000). In most teleosts investigated thus far, the lagena is the smallest of the three otolithic endorgans and is located caudal to the saccule. In toadfish, the lagenar nerve joins VIII with the afferents from the posterior canal crista. Does the relative size and/or location of the lagena reliably reflect its role in audition versus gravistatic/postural functions?

2. What are the roles of the nuclei in the secondary octaval populations? Although they are clearly involved in the ascending auditory circuit, and maybe other sensory systems as well (McCormick 2011), the location and small size of these nuclei (though the individual cells can be large, particularly in the dorsal division) provide a huge technical challenge for electrophysiology. Answering this particular research question may best be approached by the use of a slice preparation centered at the entrance of VIII.

3. Can otophysine fishes determine the direction of a sound source, despite enhanced "unidirectional" input from the gas bladder? Zeddies et al. (2012) have shown that local particle motion is the key parameter used by the midshipman fish (a non-otophysine) to localize a sound source (conspecific vocalization from a speaker). A similar study (with a carefully quantified sound field) is needed, ideally using a vocal otophysine fish, but also using goldfish or carp. There are anecdotal stories of trained goldfishes or carp coming to a feeding site when a "dinner bell" attracts them. In that context, there are multiple cues for the fish, including visual observations of the feeder (human or mechanical) and chemical cues in the water. Will the goldfish localize a sound source without other cues to attract them in a natural setting?

4. Does input from the gas bladder facilitate sound source localization in fishes that lack a mechanical connection between the gas bladder and the ear? Coffin et al. (2014) have provided evidence that midshipman fish use the indirect input from the gas bladder to compute the direction of a sound source. In addition, a recent model of hearing in toadfish (Rozin et al. 2013) that incorporates the proximity of the gas bladder and the morphology of the otic capsule (Edds-Walton et al. 2015) provides mathematical evidence that indirect input from the gas bladder 
could be detected by the toadfish ear. Although the indirect input to the toadfish ear would not improve hearing sensitivity (nor extend the frequency range), the indirect input could provide phase information; therefore, the phase model of sound source localization first described for cod (Schuijf 1976) may apply to other teleost species as well. A better understanding of the potential role of the gas bladder in sound source localization in teleosts should be explored, ideally as a multi-species comparison of morphological variations in the gas bladder-ear association with the ability to localize a sound source under natural conditions.

Acknowledgements Arthur Popper gave a great gift to his graduate students - freedom to pursue what interested them about fish hearing. If components of the research were out of his area of expertise, he introduced the student to someone who could provide training and advice. Therefore, I thank him for his guidance and for introducing me to Catherine McCormick and Catherine Carr, both of whom provided critical instruction and feedback for the anatomical studies on $O$. tau completed in Arthur's lab. In addition, Arthur encouraged students to present their research and initiate interactions that might (and did) lead to post-doctoral collaborations, in my case, with Steve Highstein and Richard Fay. I gratefully acknowledge the instruction and guidance that Steve Highstein provided at the MBL, in particular, on surgical techniques and intracellular label injection using "Alfred."

All of the physiological work described here was conducted with Richard Fay, a close collaborator in every sense of the word. He was never one to direct research from afar-he was in the lab for nearly every experiment, "sweating the small stuff," as only the best scientists do. About 10 years ago, Dick Fay said "We know far less than we think we do about hearing in fish." No doubt there is much to learn. As many will state in this volume, his ideas and hypotheses have driven a diverse array of projects and stimulated many spirited discussions. There will be no end to his influence on research into the sense of hearing in fishes.

The work on the auditory pathway and hearing in toadfish was funded by an NIMH NRSA predoctoral fellowship to PL Edds-Walton; NIH NIDCD Program Project grants to SM Highstein and RR Fay, on which PL Edds-Walton was a post-doctoral scientist; and NIH NIDCD grants to RR Fay, on which PL Edds-Walton was a Research Associate or Co-principal Investigator. Lastly, I am grateful for the support of my husband and son over the past 20 years, for participating in my annual migrations to the MBL, cheering me up on difficult days, and understanding that some days the toadfish had to come first.

\section{References}

Braun CB, Sand O (2014) Functional overlap and nonoverlap between lateral line and auditory systems. In: Coombs S, Bleckman H, Fay RR, Popper AN (eds) The lateral line system, vol 48, Springer handbook of auditory research. Springer, New York, pp 281-312

Bregman A (1990) Auditory scene analysis: the perceptual organization of sound. MIT Press, Cambridge

Carr CE, Edds-Walton PL (2008) Vertebrate auditory pathways. In: Dallos P, Oertel D (eds) The senses: a comprehensive reference, vol 3, Audition. Elsevier, NY, pp 499-524

Coffin AB, Zeddies DG, Fay RR, Brown AD, Alderks PW, Bhandiwad AA, Mohr RA, Gray MD, Rogers PH, Sisneros JA (2014) Use of the swim bladder and lateral line in near-field sound source localization by fish. J Exp Biol 217:2078-2088. doi:10.1242/jeb.093831

Coombs S, Popper AN (1979) Hearing differences among Hawaiian squirrelfishes (Family Holocentridae) related to differences in the peripheral auditory system. J Comp Physiol 132:203-207 
Coombs S, Fay RR, Elepfandt A (2010) Dipole source encoding and tracking by the goldfish auditory system. J Exp Biol 213:3536-3547

Dailey DD, Braun CB (2011) Perception of frequency, amplitude, and azimuth of a vibratory dipole source by the octavolateralis system of goldfish (Carassius auratus). J Comp Psychol 125(3):286-295. doi:10.1037/a0023499

Dale T (1976) The labyrinthine mechanoreceptor organs of the cod, Gadus morhua L. (Teleostei: Gadidae). Norw J Zool 24:85-128

Edds-Walton PL (1998a) Projections of primary afferents from regions of the saccule in toadfish (Opsanus tau). Hear Res 115:45-60

Edds-Walton PL (1998b) Anatomical evidence for binaural processing in the descending octaval nucleus of the toadfish (Opsanus tau). Hear Res 123:41-54

Edds-Walton PL, Fay RR (2003) Directional selectivity and frequency tuning of midbrain cells in the oyster toadfish, Opsanus tau. J Comp Physiol A 189:527-543

Edds-Walton PL, Fay RR (2005a) Projections to bimodal sites in the torus semicircularis of the toadfish, Opsanus tau. Brain Behav Evol 66:73-87

Edds-Walton PL, Fay RR (2005b) Sharpening of directional responses along the auditory pathway of the oyster toadfish, Opsanus tau. J Comp Physiol A 19:1079-1086

Edds-Walton PL, Fay RR (2008) Directional and frequency response characteristics in the descending octaval nucleus of the toadfish (Opsanus tau). J Comp Physiol A 194:1013-1029

Edds-Walton PL, Fay RR (2009) Physiological evidence for binaural directional computations in the brainstem of the oyster toadfish, Opsanus tau (L.). J Exp Biol 212:1483-1493

Edds-Walton PL, Popper AN (1995) Hair cell orientation pattern on the saccule of juvenile and adult toadfish (Opsanus tau). Acta Zool 76(4):257-265

Edds-Walton PL, Popper AN (2000) Dendritic arbors on the saccule and lagena in the ear of the goldfish, Carassius auratus. Hear Res 141:229-242

Edds-Walton PL, Fay RR, Highstein SM (1999) Dendritic arbors and central projections of physiologically characterized auditory fibers from the saccule of the toadfish, Opsanus tau. J Comp Neurol 411(2):212-238

Edds-Walton PL, Mangiamele L, Rome L (2002) Variations of pulse repetition rate in boatwhistle sounds from oyster toadfish (Opsanus tau). Bioacoustics 13:153-173

Edds-Walton PL, Holstein G, Fay RR (2010) Gamma-aminobutyric acid is a neurotransmitter in the auditory pathway of oyster toadfish, Opsanus tau. Hear Res 262:45-55

Edds-Walton PL, Rivera-Matos S, Fay RR (2013) Does the magnocellular octaval nucleus process auditory information in the toadfish, Opsanus tau? J Comp Physiol A 199(5):353-363

Edds-Walton PL, Arruda, J, Fay RR, Ketten D (2015) Computerized tomography of the otic capsule and otoliths in the toadfish, Opsanus tau. J Morphol (in press). Published online Dec 2014, www.wileyonlinelibrary.com. doi:10.1002/jmor.20336

Enger PS, Hawkins AD, Sand O, Chapman CJ (1973) Directional sensitivity of saccular microphonic potentials in the haddock. J Exp Biol 59:425-433

Fay RR (1984) The goldfish ear codes the axis of particle motion in three dimensions. Science 225:951-953

Fay RR (1988) Hearing in vertebrates: a psychophysics databook. Hill-Fay Associates, Winnetka. ISBN 0-9618559-0-8

Fay RR (2005) Sound source localization by fishes. In: Popper AN, Fay RR (eds) Sound source localization, vol 25, Springer handbook of auditory research. Springer, NY, pp 36-66

Fay RR (2009) Soundscapes and the sense of hearing in fishes. Integr Zool 4:26-32

Fay RR (2014) The sense of hearing in fishes. In: Popper AN, Fay RR (eds) Perspectives on auditory research, vol 50, Springer handbook of auditory research. Springer Science+Business Media, New York, pp 107-123. doi:10.1007/978-1-4614-9102-6_7

Fay RR, Edds-Walton PL (1997a) Directional response properties of saccular afferents of the toadfish Opsanus tau. Hear Res 111:1-21

Fay RR, Edds-Walton PL (1997b) Diversity in frequency response properties of saccular afferents of the toadfish Opsanus tau. Hear Res 113:235-246 
Fay RR, Edds-Walton PL (2000) Directional encoding by fish auditory systems. Phil Trans R Soc Lond B 355:1281-1284

Fay RR, Edds-Walton PL (2001) Bimodal units in the torus semicircularis of the toadfish (Opsanus tau). Biol Bull 201:280-281

Fay RR, Edds-Walton PL (2002) Preliminary evidence for interpulse interval selectivity of cells in the torus semicircularis of the oyster toadfish (Opsanus tau). Biol Bull 203:195-196

Fay RR, Ream TJ (1986) Acoustic response and tuning in saccular nerve fibers of the goldfish (Carassius auratus). J Acoust Soc Am 79:1883-1895

Fine ML (1978) Seasonal and geographic variation in the mating call of the oyster toadfish Opsanus tau. Oecologia 36:45-57

Fish JF (1972) The effect of sound playback on the toadfish. In: Winn HE, Olla BL (eds) Behavior of marine animals: current perspectives in research, vol 2, Vertebrates. Plenum Press, New York, pp 386-434

Flock A (1971) Sensory transduction in hair cells. In: Lowenstein WR (ed) Handbook of sensory physiology, vol 2. Springer, Berlin, pp 396-441

Furukawa T, Ishii Y (1967) Neurophysiological studies on hearing in goldfish. J Neurophysiol 30:1377-1403

Gray GA, Winn HE (1961) Reproductive ecology and sound production of the toadfish, Opsanus tau. Ecology 42:274-282

Highstein SM, Kitch R, Carey J, Baker R (1992) Anatomical organization of the brainstem octavolateralis area of the oyster toadfish, Opsanus tau. J Comp Neurol 319:501-518

Hudspeth AJ, Corey DP (1977) Sensitivity, polarity, and conductance change in the response of vertebrate hair cells to controlled mechanical stimuli. Proc Natl Acad Sci U S A 74:2407-2411

$\mathrm{Lu}$ Z (2011) Physiology of the ear and brain: how fish hear. In: Farrell AP (ed) Encyclopedia of fish physiology. Elsevier Inc, Amsterdam, pp 292-297

Lu Z, Xu Z (2002) Effects of saccular otolith removal on hearing sensitivity of the sleeper goby (Dormitator latifrons). J Comp Physiol A 188(8):595-602

Lu Z, Song J, Popper AN (1998) Encoding of acoustic directional information by saccular afferents of the sleeper goby Dormitator latifrons. J Comp Physiol A 182:805-815

Lu Z, Xu Z, Buchser WJ (2003) Acoustic response properties of lagenar nerve fibers in the sleeper goby, Dormitator latifrons. J Comp Physiol A 189:889-905

Lu Z, Xu Z, Buchser WJ (2004) Coding of acoustic particle motion by utricular fibers in the sleeper goby, Dormitator latifrons. J Comp Physiol A 190:923-938

McCormick CA (1999) Anatomy of the central auditory pathways of fish and amphibians. In: Fay RR, Popper AN (eds) Comparative hearing: fish and amphibians. Springer-Verlag, New York, pp 155-217

McCormick CA (2011) Auditory/lateral line CNS: anatomy. In: Farrell AP (ed) Encyclopedia of fish physiology: from genome to environment, vol 1. Elsevier Inc, Amsterdam, pp 283-291

McCormick CA, Wallace AC (2012) Otolith end organ projections to auditory neurons in the descending octaval nucleus of the goldfish, Carassius auratus: a confocal analysis. Brain Behav Evol 80:41-63. doi:10.1159/000339746

Moulton JM, Dixon RH (1967) Directional hearing in fishes. In: Tavolga WN (ed) Marine bioacoustics, vol 2. Pergamon Press, New York, pp 187-232

Platt C (1977) Hair cell distribution and orientation in goldfish otolith organs. J Comp Neurol 172:283-298

Platt C, Popper AN (1981) Fine structure and function of the ear. In: Tavolga WN (ed) Hearing and sound communication in fishes. Springer-Verlag, New York, pp 3-38

Popper AN (1977) A scanning electron microscopic study of the sacculus and lagena in the ears of fifteen species of teleost fishes. J Morphol 153:397-417

Popper AN (1981) Comparative scanning electron microscopic investigations of the sensory epithelia in the teleost sacculus and lagena. J Comp Neurol 200:357-374 
Popper AN (2014) From cave fish to pile driving: a tail of fish bioacoustics. In: Popper AN, Fay RR (eds) Perspectives on auditory research, vol 50, Springer handbook of auditory research. Springer Science+Business Media, New York, pp 467-492. doi:10.1007/978-14614-9102-6_25

Popper AN, Coombs S (1982) The morphology and evolution of the ear in Actinopterygian fishes. Am Zool 22:311-328

Popper AN, Fay RR (1993) Sound detection and processing by fish: critical review and major research questions. Brain Behav Evol 41:14-38

Popper AN, Fay RR (1999) The auditory periphery in fishes. In: Fay RR, Popper AN (eds) Comparative hearing: fish and amphibians. Springer handbook of auditory research, vol 11. Springer, New York, pp 43-100 (chapter 3, p. 86, fig. 3.15 BAs goldfish saccule vs toadfish saccule)

Popper AN, Fay RR (2011) Rethinking sound detection by fishes. Hear Res 273:25-36

Radford CA, Montgomery JC, Caiger P, Higgs DM (2012) Pressure and particle motion detection thresholds in fish: a re-examination of salient auditory cues in teleosts. $\mathrm{J}$ Exp Biol 215:3429-3435

Rogers PH, Zeddies DG (2008) Multiple mechanisms for directional hearing in fish. In: Webb JF, Fay RR, Popper AN (eds) Fish bioacoustics. Springer-Verlag, New York, pp 233-252

Rozin R, Edds-Walton P, Hastings MC (2013) A model for peripheral auditory mechanics in the oyster toadfish, Opsanus tau. J Acoust Soc Am 134:4119. doi:dx.doi.org/10.1121/1.4831131

Sand O (1974) Directional sensitivity of microphonic potentials from the perch ear. J Exp Biol 60:881-899

Saidel WM, Popper AN (1983) The saccule may be the transducer for directional hearing of nonostariophysine teleosts. Exp Brain Res 50:149-152

Schellart NAM, Buwalda RJA (1990) Directional variant and invariant hearing thresholds in the rainbow trout (Salmo gairdneri). J Exp Biol 149:113-131

Schellart NAM, deMunck JC (1987) A model for directional and distance hearing in swimbladderbearing fish based on the displacement orbits of the hair cells. J Acoust Soc Am 82(3):822-829

Schuijf A (1975) Directional hearing of cod (Gadus morhua) under approximate free field conditions. J Comp Physiol 98:307-332

Schuijf A (1976) The phase mode of directional hearing in fish. In: Schuijf A, Hawkins AD (eds) Sound reception in fish. Elsevier Press, Amsterdam, pp 63-86

Schuijf A, Buwalda RJA (1975) On the mechanism of directional hearing in cod (Gadus morhua L.). J Comp Physiol 98:333-343

Straka H, Baker R (2011) Vestibular system anatomy and physiology. In: Farrell AP (ed) Encyclopedia of fish physiology: from genome to environment, vol 1. Elsevier Inc, Amsterdam, pp 244-252

Straka H, Baker R (2013) Vestibular blueprint in early vertebrates. Front Neural Circuits 7:82. doi:10.3389/fncir.2013.00182

Sugihara I, Furukawa T (1989) Morphological and functional aspects of two different types of hair cells on the goldfish sacculus. J Neurophysiol 62(6):1330-1343

Tavolga WN (1958) Underwater sounds produced by two species of toadfish, Opsanus tau and Opsanus beta. Bull Mar Sci Gulf Caribb 8:278-284

Tavolga WN (1960) Sound production and under-water communication in fishes. In: Lanyon WE, Tavolga WN (eds) Animal sounds and communication. AIBS, Washington, pp 93-136

Tavolga WN (1964) Sonic characteristics and mechanisms in marine fishes. In: Tavolga WN (ed) Marine bio-acoustics. Pergamon Press, Oxford, pp 195-211

Tomchik SM, Lu Z (2005) Octavolateral projections and organization in the medulla of a teleost fish, the sleeper goby (Dormitator latifrons). J Comp Neurol 481:96-117

Tricas TC, Highstein SM (1990) Visually mediated inhibition of lateral line primary afferent activity by the octavolateralis efferent system during predation in the free-swimming toadfish, Opsanus tau. Exp Brain Res 83:233-236 
Vasconcelos RO, Fay RR, Ramos A, Edds-Walton PL (2012) Differential roles of saccule and utricle for directional hearing and vestibular sense in a vocal benthic fish, Halobatrachus didactylus. Soc Neurosci Ann Mtg Abstr \#460.12/U15 (available at www.abstractsonline.com)

Vasconcelos RO, Simoes JM, Almada VC, Fonseca PJ, Amorim MCP (2010) Vocal behavior during territorial intrusions in the Lusitanian toadfish: boatwhistles also function as territorial 'keep-out' signals. Ethology 116:155-165. doi:10.1111/j.1439-0310.2009.01722.x

Watkins WA (1967) The harmonic interval: fact or artifact in spectral analysis of pulse trains. In: Tavolga WN (ed) Marine bio-acoustics, vol 2. Pergamon Press, Oxford, pp 15-43

Winn HE (1967) Vocal facilitation and the biological significance of toadfish sounds. In: Tavolga WN (ed) Marine bioacoustics, vol 2. Pergamon Press, Oxford, pp 15-43

Winn HE (1972) Acoustic discrimination by the toadfish with comments on signal systems. In: Winn HE, Olla BL (eds) Behavior of marine animals: current perspectives in research, vol 2, Vertebrates. Plenum Press, New York, pp 361-385

Zeddies DG, Fay RR, Gray MD, Alderks PW, Acob A, Sisneros JA (2012) Local acoustic particle motion guides sound-source localization behavior in the plainfin midshipman fish, Porichthys notatus. J Exp Biol 215:152-160 


\title{
Comparison of Electrophysiological Auditory Measures in Fishes
}

\author{
Karen P. Maruska and Joseph A. Sisneros
}

\begin{abstract}
Sounds provide fishes with important information used to mediate behaviors such as predator avoidance, prey detection, and social communication. How we measure auditory capabilities in fishes, therefore, has crucial implications for interpreting how individual species use acoustic information in their natural habitat. Recent analyses have highlighted differences between behavioral and electrophysiologically determined hearing thresholds, but less is known about how physiological measures at different auditory processing levels compare within a single species. Here we provide one of the first comparisons of auditory threshold curves determined by different recording methods in a single fish species, the soniferous Hawaiian sergeant fish Abudefduf abdominalis, and review past studies on representative fish species with tuning curves determined by different methods. The Hawaiian sergeant is a colonial benthic-spawning damselfish (Pomacentridae) that produces low-frequency, low-intensity sounds associated with reproductive and agonistic behaviors. We compared saccular potentials, auditory evoked potentials (AEP), and single neuron recordings from acoustic nuclei of the hindbrain and midbrain torus semicircularis. We found that hearing thresholds were lowest at low frequencies $(\sim 75-300 \mathrm{~Hz})$ for all methods, which matches the spectral components of sounds produced by this species. However, thresholds at best frequency determined via single cell recordings were $\sim 15-25 \mathrm{~dB}$ lower than those measured by AEP and saccular potential techniques. While none of these physiological techniques gives us a true measure of the auditory "perceptual" abilities of a naturally behaving fish, this study highlights that different methodologies can reveal similar detectable range of frequencies for a given species, but absolute hearing sensitivity may vary considerably.
\end{abstract}

Keywords Abudefduf $\bullet$ Acoustic $\bullet$ AEP $\bullet$ Hearing $\bullet$ Saccule $\bullet$ Torus semicircularis

\author{
K.P. Maruska ( $\square)$ \\ Department of Biological Sciences, Louisiana State University, \\ 202 Life Sciences Building, Baton Rouge, LA 70803, USA \\ e-mail:kmaruska@1su.edu \\ J.A. Sisneros \\ Department of Psychology, University of Washington, \\ 408 Guthrie Hall, Seattle, WA 98195, USA
}




\section{Introduction}

The ability to detect underwater sounds is of vital importance for fishes that use their auditory and mechanosensory lateral line systems to mediate behaviors such as prey detection, predator avoidance, and social communication, which are crucial for survival and species perseverance. How do fish hear? How well do fish hear, and how do we measure their hearing capabilities? These seemingly simple questions have spawned decades-worth of research on the mechanisms, morphologies, and behavioral functions of fish auditory systems, which have uncovered remarkable diversity in structure and function even though only a limited number of the $>30,000$ species of fishes have been examined thus far.

The methodologies researchers utilize to measure both spectral hearing range and auditory thresholds in fishes have undergone a historical progression from behavioral techniques, which are laborious and slow to generate entire audiograms, towards quicker electrophysiological techniques that allow audiograms to be completed within a few hours. How well do these different electrophysiological methods reflect the true auditory capabilities of a particular species? What pertinent information can we obtain from each method? Is one method better than another and are the various methods comparable? These questions are difficult to answer without substantial recording examples of different types performed under similar experimental paradigms in diverse representative species. Towards this goal, we present here a comparison of multiple electrophysiological recording methods in a single damselfish species and use it as a framework for discussing the relative utility of different physiological techniques for determining auditory capabilities in fishes.

\subsection{Methodologies Used to Measure Auditory Capabilities in Fishes}

Techniques used to determine various aspects of fish auditory abilities can be separated broadly into two main categories, behavioral and electrophysiological. Behavioral and psychophysical methods include assays such as avoidance (Tavolga and Wodinsky 1963), operant (Yan and Popper 1991) and classical (Fay and MacKinnon 1969) conditioning, startle response (Bang et al. 2000), and prepulse inhibition (Bhandiwad et al. 2013). These behavioral techniques are advantageous because they measure evoked responses resulting from the integration and perception of the entire auditory scene that is relayed to neural output circuits causing whole animal behaviors. Some disadvantages of these behavioral methods, however, include long training periods and testing trials, unknown relative contributions of lateral line and inner ear components to the response, and the fact that not all behavioral methods work for a particular fish species. In the early days, these behavioral techniques dominated the world of fish bioacoustic research and were perceived as the best way to measure hearing in all animals (Fay 1988). Electrophysiological methods, on the other hand, include both minimally invasive 
techniques such as auditory evoked potentials (AEP; formerly called auditory brainstem response, or ABR) (Kenyon et al. 1998; Ladich and Fay 2013), and more invasive approaches such as saccular potentials (Furukawa et al. 1972; Enger et al. 1973; Fay 1974; Sisneros 2007; Vasconcelos et al. 2011), single neuron recordings from auditory primary afferents (Fay 1978a, b; Fay and Ream 1986; Lu et al. 2003; Sisneros and Bass 2003) and single or multi-unit recordings from central auditory nuclei in the brain (Lu and Fay 1993, 1995; Bodnar and Bass 1997, 1999; EddsWalton and Fay 1998, 2003, 2008; Kozloski and Crawford 2000; Maruska and Tricas 2009b). These electrophysiological methods typically require animal anesthetization and restraint, and depending on the method, are often focused on only a specific subset of the auditory processing pathway, which will subsequently be integrated by the animal to display context-appropriate behaviors. Due to their quick and relatively easy setup, however, electrophysiological methods are particularly useful for testing auditory effects during ontogeny, before and after physiologically relevant (e.g., steroids), acoustical (e.g. noise), or accessory auditory structure (e.g., swim bladder) manipulations (Yan et al. 2000; Scholik and Yan 2001; Egner and Mann 2005; Smith et al. 2006), and for comparing among species, sexes, social status, and reproductive conditions (Kenyon et al. 1998; Maruska et al. 2007, 2012; Ladich and Fay 2013). Thus, while both behavioral and electrophysiological approaches have advantages and disadvantages, their utility for examining auditory abilities in fishes is valuable but will vary based on the research question, species used, and other experiment-dependent limitations. Recent advances in neural telemetry that permit simultaneous neural recordings in freely behaving fishes will also likely make important contributions towards fully understanding the relationships between behavioral and electrophysiological measures of fish auditory and mechanosensory capabilities (Palmer and Mensinger 2002; Maruska and Mensinger 2015; Radford and Mensinger 2014).

\subsection{Comparisons of Auditory Capabilities Using Different Methods within a Single Species}

To understand the efficacy of determining auditory capabilities in fishes via these diverse techniques, it is imperative to compare measures obtained via several methods within a single species under similar testing conditions. Unfortunately, the existing comparative data on this topic are scant. Auditory abilities using both behavioral and physiological AEP methods have been achieved for only a small representative number of the $>30,000$ species of fishes, and include the goldfish (Carassius auratus), oyster toadfish (Opsanus tau), Oscar cichlid (Astronotus ocellatus), little skate (Raja (Leucoraja) erinacea), perch (Perca fluviatilis), red sea bream (Pagrus major), and common carp (Cyprinus carpio) [reviewed in Ladich and Fay 2013]. From these comparisons it is clear that there is no universal conversion between behavioral auditory thresholds and AEP-determined thresholds. However, Ladich and Fay (2013) note the generalization that AEPs tend to produce 
higher thresholds at low frequencies $(<1000 \mathrm{~Hz})$, but lower thresholds at high frequencies $(>1000 \mathrm{~Hz})$ compared to behavioral thresholds. This suggests there may be a frequency-dependent effect between different assessment methods.

There are even fewer examples in which different electrophysiological-based recording methods have been determined in a single species. The goldfish (C. auratus), and batrachoidid oyster toadfish (O. tau) and midshipman fish (Porichthys notatus), are some of the most extensively studied species in terms of auditory capabilities. In addition to several behaviorally generated audiograms (Popper 1971; Enger 1966; Jacobs and Tavolga 1968; Offutt 1968), the goldfish has been examined physiologically by AEP (Kenyon et al. 1998; Smith et al. 2006; Cordova and Braun 2007; Ladich and Wysocki 2009), saccular potentials (Fay 1974; Fay and Popper 1975), single neuron recordings from saccular and lagenar primary afferents (Fay 1978a, b; Fay and Ream 1986) and recordings from various central auditory nuclei (Lu and Fay 1993, 1995; Kirsch et al. 2002; Ma and Fay 2002). The oyster toadfish has an AEP-generated audiogram (Yan et al. 2000), single neuron recordings from saccular primary afferents (Fine 1981; Edds-Walton and Fay 1995; Fay and EddsWalton 1997), and recordings from central auditory nuclei (Edds-Walton and Fay 1998, 2003, 2005; Fay and Edds-Walton 1999; Edds-Walton et al. 2013) using both speaker and shaker table stimulus delivery methods. The Lusitanian toadfish (Halobatrachus didactylus) also has AEP (Vasconcelos et al. 2007; Vasconcelos and Ladich 2008) and saccular potential recordings (Vasconcelos et al. 2011). In addition to behavioral measures (Alderks and Sisneros 2013), the midshipman fish has saccular potential recordings (Sisneros 2007, 2009; Alderks and Sisneros 2011) single neuron recordings from saccular primary afferents (McKibben and Bass 1999; Sisneros and Bass 2003, 2005; Sisneros et al. 2004), and central auditory recordings (Bodnar and Bass 2001a; Bodnar et al. 2001). Primary afferent and central auditory recordings have also been done in the sound-producing mormyrid fish Pollimyrus adspersus (Crawford 1993, 1997; Kozloski and Crawford 2000; Suzuki et al. 2002). These limited examples become even further reduced for comparative purposes, however, because (1) many of these studies were not focused on generating audiograms or determining thresholds, but rather, were testing for other specific temporal or spectral processing mechanisms (i.e., used iso-intensity stimuli), and (2) recording methods performed in different laboratories with different experimental setups, including stimulus delivery (e.g., underwater speaker vs. shaker table) and experimental analyses with different threshold criteria, can be variable and difficult to compare. Thus, our current understanding of the relative usefulness of different electrophysiological-based techniques for determining spectral range and auditory thresholds for a given species is still in its infancy. Further, the only species examined thus far with multiple methods are those with either specialized accessory hearing structures like the Weberian ossicles in goldfish, or those endowed with sonic muscles on their swim bladder that use acoustic signaling as a primary mode of communication like toadfish and midshipman. In contrast, nothing is known about the majority of fish species that do not possess these hearing or sonic adaptations. What is needed, therefore, is a comparison of different electrophysiological methods to generate audiograms under similar experimental conditions 
within the same species that will allow the assessment of these physiological measures at different auditory processing levels. These types of comparisons should provide insights into what information we can and cannot glean about auditory capabilities from singular recording methods within an individual species.

\subsection{Study Species: Hawaiian Sergeant Damselfish, Abudefduf abdominalis}

Damselfishes (family Pomacentridae) are a large group of reef fishes with approximately 360 species. Several damselfish genera are known to produce primarily broadband pulsed sounds during territorial and reproductive behavior, which conveys information about species, sex, body size, reproductive readiness, and aggression level (reviewed in Amorim 2006). Previous studies also demonstrate that both the frequency and temporal patterning of the pulsed sounds are critically important for acoustic communication in behaving pomacentrid fishes (Myrberg et al. 1993; Lobel and Mann 1995; Myrberg and Lugli 2006). The Hawaiian sergeant fish, Abudefduf abdominalis, is a colonial benthic-spawning damselfish that produces low-frequency, low-intensity pulsed sounds associated with reproductive and agonistic behaviors (Fig. 1). Further, the frequency hearing range matches the spectral content of sounds produced by naturally behaving wild fish (Maruska et al. 2007). During the protracted breeding season, males clean and prepare benthic substrates to attract females for courtship and spawning. After spawning, males remain to guard the nest, care for the developing young until they hatch, and continue to court and spawn with additional females over the course of the breeding season. Similar to other damselfishes examined thus far [see Zelick et al. 1999; Bass and McKibben 2003; Amorim 2006 for reviews], A. abdominalis does not appear to possess any special adaptations to enhance the detection of sound pressure, and the anterior edge of the swim bladder is typically several millimeters caudal to the otic capsule ( 1.5-3.0 \% of SL; Fig. 2a). This species is well suited for comparing different electrophysiological techniques that assess fish hearing because the behaviors associated with sound production including the temporal and spectral sound characteristics, central auditory nerve projections, and response properties of auditory neurons in the brain are already described (Maruska et al. 2007; Maruska and Tricas 2009a, b, 2011). This information facilitates interpretation of the auditory recording data in a biologically relevant context.

The goal of this study was to first characterize the AEP thresholds from the saccule (saccular potentials) in the Hawaiian sergeant fish, and then to compare them to the thresholds measured by the AEP and extracellular single unit recording techniques from the brain in this same species. These data are significant because no other study has directly compared auditory threshold measurements obtained by several different electrophysiological-based techniques from different auditory processing levels in a single soniferous fish under similar testing conditions. 

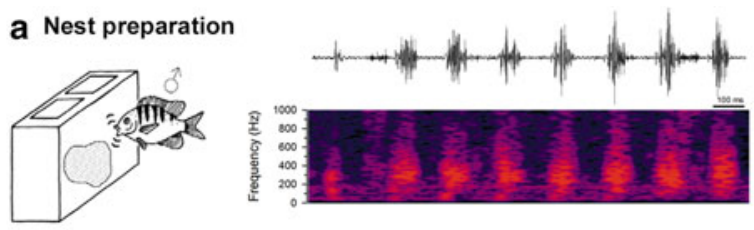

b Aggression / Nest defense
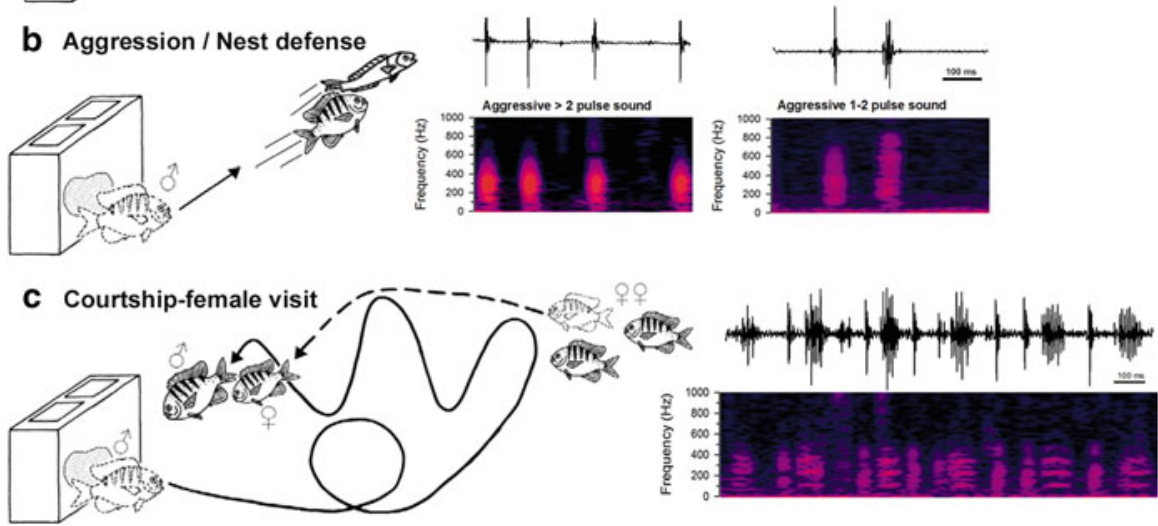

Fig. 1 Behaviors associated with sound production in the Hawaiian sergeant fish Abudefduf abdominalis. (a) Behavior and sound associated with nest preparation; males clean and prepare substrate adjacent to an existing nest (dotted circular area) and produce sounds when they scrape the substrate with their mouths, jaws and teeth. (b) Behavior and sound associated with aggression; males chase (arrow) both con and heterospecific (e.g., egg-predator wrasse) intruders away from the nest area while producing short-pulse aggressive sounds. (c) Behavior and sound associated with courtship-female-visit; males in blue nuptial coloration perform looping and zig-zag swims (solid arrow line) in the water column towards passing conspecific females. When a female follows the male back to the nest (broken arrow line), the courtship-female-visit sound is produced. Fish with a dotted outline in (b) and (c) represent the initial position, while fish with a solid outline represent the final position in the behavior sequence. Scale bars, $100 \mathrm{~ms}$. Sounds are depicted as waveforms (top) and sonograms (bottom). Modified in part from Maruska et al. (2007)

\section{Materials and Methods}

\subsection{Animals}

Adult Hawaiian sergeant fish, Abudefduf abdominalis, were caught with hook and line from Kane'ohe Bay, Oahu and used immediately in recording experiments, with the exception of individuals used for saccular potential recordings (see below). At the end of each experiment, fish were measured for standard length (SL) and total length to the nearest $0.5 \mathrm{~mm}$, body mass (BM) to the nearest $0.1 \mathrm{~g}$, and sex was determined by examination of sexually dimorphic genital papillae and gonads under a dissection microscope. Collection, maintenance, surgical, and recording procedures for all fish used in this study were approved by the University of Hawaii Institutional Animal Care and Use Committee. 


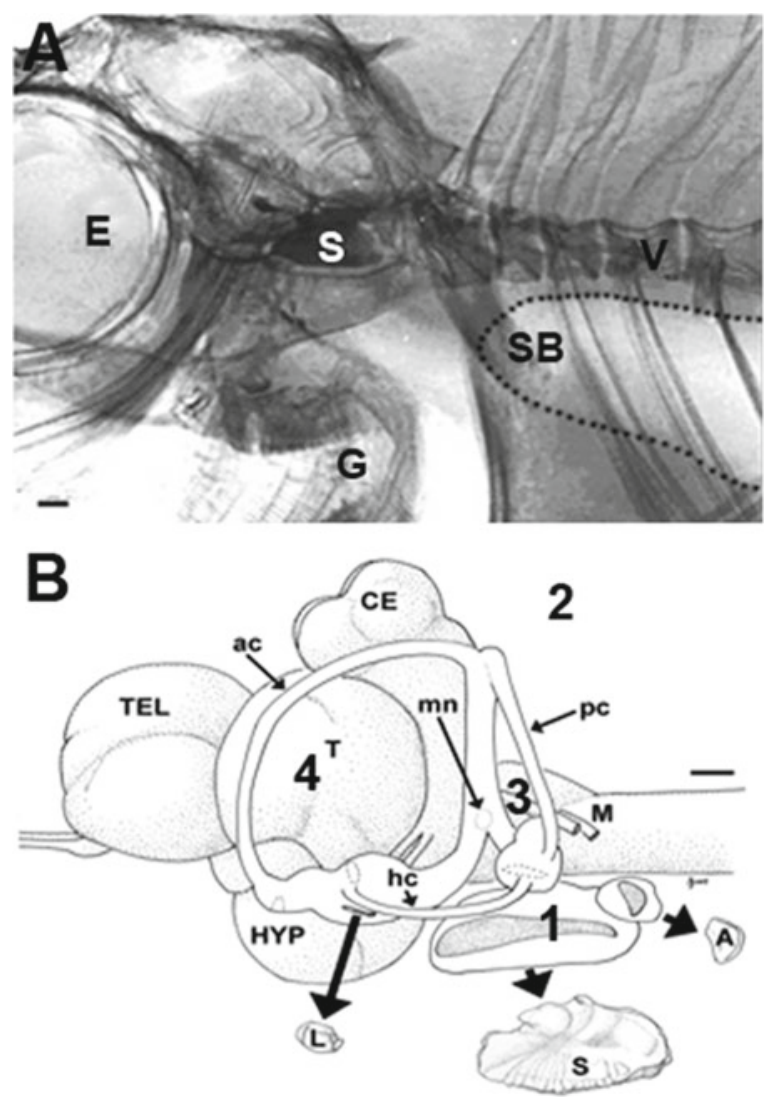

Fig. 2 Relative position of the inner ear to the swim bladder and location of auditory recording sites in the Hawaiian sergeant fish Abudefduf abdominalis. (a) Representative inverted X-ray to show the relative position of the swim bladder (dotted outline, SB) and saccule (S). Anterior edge of swim bladder is $\sim 2-4 \mathrm{~mm}(\sim 1.5-3.0 \%$ of SL) from caudal edge of the otic capsule. E, eye; G, gills; V, vertebral column. Scale bar, $1 \mathrm{~mm}$. (b) Lateral view of A. abdominalis brain is shown with otoliths removed (large arrows) to illustrate the four recording locations. 1, saccular potentials; 2, auditory evoked potentials (AEP) above the brain; 3, single neuron hindbrain; 4, single neuron midbrain torus semicircularis. A, asteriscus otolith of lagena; ac, anterior semicircular canal; CE, cerebellum; hc, horizontal semicircular canal; HYP, hypothalamus; L, lapillus otolith of utricle; M, medulla; mn, macula neglecta; pc, posterior semicircular canal; S, sagittal otolith of saccule; T, tectum; TEL, telencephalon. Scale bar, $1 \mathrm{~mm}$

\subsection{Saccular Potential Recordings}

Evoked saccular potentials from the Hawaiian sergeant fish were recorded at the University of Washington. Adult A. abdominalis were caught as described above, packaged individually in large bags filled with seawater and oxygen, and transported via overnight air-service to the Department of Psychology at the University 
of Washington. Fish were then transferred to holding tanks containing seawater at $20-22{ }^{\circ} \mathrm{C}$ and allowed to acclimate for at least $24 \mathrm{~h}$ prior to use in experiments. Fish were maintained on a $12 \mathrm{~h}$ light:dark cycle and fed daily with fish flakes or frozen squid/fish. Auditory threshold tuning curves were determined from 8 saccular potential recordings in 7 Hawaiian sergeant fish ( 3 males, 4 females; SL $=130.0 \pm 0.5$ SD mm; BM=93.2 \pm 12.4 SD g).

Methods for recording saccular potentials from the Hawaiian sergeant fish were adapted from those used on the plainfin midshipman fish (Sisneros 2007). Briefly, fish were anesthetized with benzocaine and immobilized by an intramuscular injection of pancuronium bromide. The saccule of the inner ear was exposed by dorsal craniotomy, and the cranial cavity was filled with teleost Ringer's solution to prevent drying and enhance clarity. Fish were positioned so that the saccule was $10 \mathrm{~cm}$ above the surface of an underwater loudspeaker (UW-30) that was embedded in sand on the bottom of a $30 \mathrm{~cm}$ diameter, $24 \mathrm{~cm}$ high Nalgene experimental tank. The tank was positioned on a vibration isolation table and housed within an acoustic isolation chamber (Industrial Acoustics Co.), while all recording and stimulus generation equipment was located outside the chamber. Fish were ventilated continuously with seawater $\left(22-24^{\circ} \mathrm{C}\right)$ pumped through the mouth and over the gills during the experiments.

Acoustic stimuli were generated by the reference output signal of a lock-in amplifier (Stanford Research Systems SR830) that was input to an audio amplifier and underwater speaker (UW-30). The frequency response of the underwater speaker was measured with a mini-hydrophone (Bruel and Kjaer 8103) in the position normally occupied by the fish head. Relative sound pressure measurements were then made with a spectrum analyzer (Stanford Research Systems SR780), calibrated by peak-to-peak voltage measurements on an oscilloscope, and then adjusted with Matlab software so that the sound pressures at all tested frequencies (75-385 $\mathrm{Hz}$ ) were of equal amplitude (within $\pm 2 \mathrm{~dB}$ ). Auditory stimuli consisted of 8-10 repetitions of single $500 \mathrm{~ms}$ duration tones with rise and fall times of $50 \mathrm{~ms}$. Each repetition was presented at a rate of 1 every $1.5 \mathrm{~s}$. Pure tone stimuli were presented at $10 \mathrm{~Hz}$ increments from 75 to $145 \mathrm{~Hz}$ and $20 \mathrm{~Hz}$ increments from 165 to $385 \mathrm{~Hz}$. To determine threshold tuning responses, pure tone stimuli were presented at sound pressures from 100 to $145 \mathrm{~dB}$ re: $1 \mu \mathrm{Pa}$ in incremental steps of $3 \mathrm{~dB}$.

Saccular potentials were recorded with glass microelectrodes (tip diameter, 1-2 $\mu \mathrm{m})$ filled with $3 \mathrm{M} \mathrm{KCl}(1-10 \mathrm{M} \Omega)$. Electrodes were visually guided and placed into the endolymph of the saccule close to the sensory macula. Analog saccular potentials were preamplified $(100 \times)$, input to a digital signal processing lock-in amplifier, and then stored on a PC computer running a custom data acquisition Matlab software control program. The lock-in amplifier yields a DC RMS voltage output signal that is proportional to the component of the signal whose frequency is exactly locked to the reference frequency. The reference frequency was set to the second harmonic of the stimulation frequency signal (i.e., twice the fundamental frequency) since the maximum evoked potential from the saccule of teleost fishes occurs at twice the stimulus sound frequency due to the presence of nonlinear and oppositely oriented hair cell populations within the saccule (Cohen and Winn 1967; 
Furukawa and Ishii 1967; Hama 1969; Fay 1974; Zotterman 1943). Noise signals at frequencies other than the reference frequency are rejected by the lock-in amplifier and do not affect the measurements.

Threshold tuning curves were constructed by characterizing the input-output measurements of the RMS amplitudes of the evoked saccular potentials over the range of stimulus intensities at the tested frequencies. Background noise measurements were also recorded for 8-10 repetitions of the stimulus interval at each of the test frequencies with no auditory stimulus present prior to the recording of each threshold tuning curve, and were then used to establish subthreshold saccular potential response levels. Auditory threshold at each stimulus frequency was designated as the lowest stimulus intensity that evoked a saccular potential that was at least 2 SD above the background noise measurement. The frequency that evoked the lowest saccular potential threshold was defined as the best frequency.

\subsection{Auditory Evoked Potential (AEP) Recordings}

AEP tuning curves were determined from 7 Hawaiian sergeant fish collected in late July (6 males, 1 female; SL=132.4 \pm 7.0 SD mm; BM=100.1 \pm 18.5 SD g). To ensure fish were in similar reproductive condition to those used for saccular potential recordings, these fish were collected and tested immediately prior to the fish that were collected and shipped to the University of Washington in early August. AEPs were performed identical to that described in Maruska et al. (2007), except that additional stimulus frequencies in $25 \mathrm{~Hz}$ increments were tested between 100 and $400 \mathrm{~Hz}$. This finer frequency resolution was performed to more closely match the frequencies used in saccular potential recordings, and because natural A. abdominalis sounds and best hearing sensitivity is within this low frequency spectral range. Briefly, immobilized fish were positioned in an experimental tank $(30 \mathrm{~cm}$ diameter, $36.5 \mathrm{~cm}$ high, water level $29.5 \mathrm{~cm}$ high; fish positioned $16.5 \mathrm{~cm}$ above speaker) above an underwater speaker (UW-30, Lubell Labs) and stainless steel sub-dermal electrodes (Rochester Electro-Medical, Inc.; 6-12 k 2 ) were placed beneath the skin in the head musculature above the hindbrain (recording electrode) and between the eyes (reference electrode). Fish were continuously ventilated with fresh seawater during all experiments. Acoustic stimuli were generated with a Cambridge Electronics Design (CED, Cambridge, UK) Micro 1401 controlled by Spike 2 software and delivered to the speaker via CED 3505 attenuator and amplifier (UMA 352, Peavey Electronics). Stimuli consisted of 2000 repetitions of $20 \mathrm{~ms}$ pulses (for $\geq 200 \mathrm{~Hz}: 10 \mathrm{~ms}$ plateau with rise and fall times of $5 \mathrm{~ms}$; for $100 \mathrm{~Hz}$ : $10 \mathrm{~ms}$ plateau, rise, and fall; for $80 \mathrm{~Hz}: 13 \mathrm{~ms}$ plateau, rise, and fall). Sequential alternation of stimulus phase during the 2000 repetitions was used to eliminate stimulus artifacts in the AEP recordings. Trials began at suprathreshold intensities and were decreased in $5 \mathrm{~dB}$ steps to a sound level below the presumed threshold before moving to the next test frequency. Sound levels produced by the speaker were calibrated with a B\&K hydrophone (model 8103; sensitivity $-211 \mathrm{~dB}$ re: $1 \mathrm{~V} / \mu \mathrm{Pa}$ ) 
placed in the experimental tank at the position the fish head normally occupies, amplified (Nexus amplifier) and signal averaged by the Spike 2 script to determine sound pressure levels in $\mathrm{dB}_{\mathrm{rms}}$ re: $1 \mu \mathrm{Pa}$.

AEPs recorded via the sub-dermal electrodes were differentially amplified and band-pass filtered (DP-301, Warner Instruments), and then digitized on a CED Micro 1401 analog to digital interface run by Spike 2 software. A total of 2000 repetitions were averaged for each sound intensity and frequency, and power spectra (FFT, 512 or 1024 points) of these averaged waveforms were calculated to examine peaks at twice the stimulus frequency that result from the opposed orientation of hair cells and non-linearities in the auditory system. Thresholds were defined as the lowest sound level to show a repeatable AEP waveform above background noise and an FFT peak at twice the stimulus frequency. AEP recordings obtained here were similar to those reported previously for this species using identical experimental setups (Maruska et al. 2007).

\subsection{Single Neuron Recordings in the Auditory Hindbrain and Midbrain}

Single cell extracellular auditory neuron recordings from the hindbrain and midbrain previously measured in A. abdominalis for a separate study (Maruska and Tricas 2009b) were used here for comparison with the newly generated saccular potential and AEP recording data. These recordings were performed in the auditory medulla and midbrain torus semicircularis, and full methodological details can be found in Maruska and Tricas (2009b). Briefly, immobilized fish were positioned in an acrylic head holder above an underwater speaker (UW-30) in an experimental tank (30 $\mathrm{cm}$ diameter; fish positioned $10 \mathrm{~cm}$ above speaker) on a vibration isolation table inside a sound isolation chamber (Industrial Acoustics). Fish were ventilated continuously with seawater $\left(23-25^{\circ} \mathrm{C}\right)$ pumped through the mouth and over the gills during the experiments. The brain was exposed by dorsal craniotomy and the cranial cavity filled with Fluorinert fluid (FC-75, 3M) to enhance clarity, prevent drying, and reduce bleeding.

Extracellular single neuron recordings were made with carbon fiber (Carbostar-1, Kation Scientific, Inc., 400-800 $\mathrm{k} \Omega$ ) or glass (15-35 M $\Omega$, filled with $4 \mathrm{M}$ sodium chloride) microelectrodes advanced through the midbrain torus semicircularis (TS) or octaval nuclei of the hindbrain (primarily descending octaval nucleus) as an auditory search stimulus was presented $\left(100-200 \mathrm{~Hz}\right.$ at $124-126 \mathrm{~dB}_{\text {rms }}$ re: $\left.1 \mu \mathrm{Pa}\right)$. Neural action potentials were amplified $(500 \times-10,000 \times)$ and band-pass filtered $(100-5000 \mathrm{~Hz})$ with a Neurolog system (Digitimer, Inc.) and then converted to digital files with a CED power 1401 system run by Spike 2 software. Acoustic stimuli were generated by the CED digital to analog interface controlled by Spike 2 software, attenuated, and amplified before being sent to the underwater speaker. Stimulus characteristics were similar to those described above for AEP experiments except that 100 repetitions of $40 \mathrm{~ms}$ (10 ms rise and fall, $20 \mathrm{~ms}$ plateau) were used 
for each test intensity and frequency to facilitate quicker generation of the entire audiogram data while the single neural recording was stable. Sound pressure levels were calibrated with a B\&K hydrophone as described above for AEPs.

Thresholds were determined for each test frequency by beginning with a suprathreshold intensity followed by decreasing intensities in $5 \mathrm{~dB}$ increments until the neuron no longer responded to the stimulus. Threshold was defined as the lowest intensity to produce a Rayleigh statistic, or $Z$ value, of $\geq 4.5$ (Lu and Fay 1993; Batschelet 1981). The $Z$ value measures the significance of phase-locking and is defined as $R^{2} \times N$, where $N$ is the total number of action potentials sampled, and $R$ is the synchronization coefficient, or vector strength calculated according to (Goldberg and Brown 1969). The degree of phase-locking is generally a good predictor of auditory frequency encoding among vertebrates for low frequency systems $(\leq 1$ kHz) (Fay 1978b; Javel and Mott 1988; Sisneros and Bass 2003).

The four different recording locations compared in this study are depicted in Fig. 2b (saccular potential, AEP, hindbrain and midbrain single neurons), and all experiments used the same underwater speaker positioned beneath the fish as a stimulus. While the Hawaiian sergeant fish is likely most sensitive to particle motion rather than sound pressure, due to technical limitations and for comparisons to other studies, we only characterized the stimulus for all recordings in terms of sound pressure levels $(\mathrm{dB}$ re: $1 \mu \mathrm{Pa})$ measured and calibrated in the experimental tanks with a hydrophone. We agree, however, that future studies on fish hearing should attempt to measure both sound pressure and particle motion in their experimental setups whenever possible as recently suggested by Popper and Fay (2011). This information would allow for better interpretation of auditory capabilities in biologically relevant contexts, as recent work shows differences in threshold curves expressed in terms of pressure versus particle motion primarily for species with special adaptations to transfer pressure fluctuations from the swim bladder to the inner ear (Horodysky et al. 2008; Wysocki et al. 2009; Radford et al. 2012).

\section{Results}

\subsection{Saccular Potential Recordings}

Similar to previous studies (Fay 1974; Fay and Popper 1974; Sisneros 2007), saccular potentials from the Hawaiian sergeant fish were evoked maximally at twice the stimulus frequency rather than at the same stimulus frequency (Fig. 3). This double frequency effect is due to hair cell populations with opposite orientations and is also dependent on the nonlinearity of the saccular potential such that the cancellation of two sinusoidal waveforms $180^{\circ}$ out of phase with each other is avoided (Fay 1974). Best frequency was defined as the frequency that evoked the saccular potential with the lowest threshold and ranged from 109 to $124 \mathrm{~dB}$ re: 1 $\mu \mathrm{Pa}$ at $75 \mathrm{~Hz}$ (the lowest frequency tested) for all individuals tested. The majority of saccular potential tuning curves showed lowest thresholds at this best frequency of 

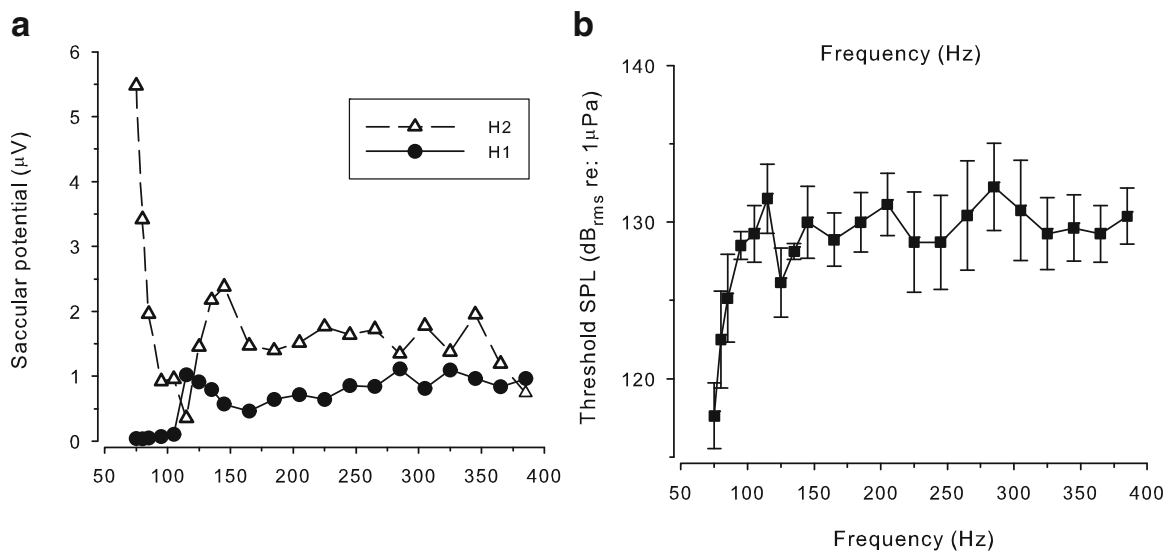

Fig. 3 Saccular potential recordings from the Hawaiian sergeant fish Abudefduf abdominalis show best sensitivity to low frequencies. (a) Representative example of iso-intensity curves of saccular potentials evoked at the same stimulus frequency $(\mathrm{H} 1$, the first harmonic or fundamental frequency) and at twice the stimulus frequency ( $\mathrm{H} 2$, second harmonic) from the saccule in response to single tones at $130 \mathrm{~dB}$ re: $1 \mu \mathrm{Pa}$. Both recordings were taken from the same position within the saccule. (b) Threshold tuning curve based on evoked potentials from the saccule. Threshold at each stimulus frequency was determined as the lowest stimulus intensity in $\mathrm{dB}$ re: $1 \mu \mathrm{Pa}$ that evoked a saccular potential that was at least 2 SD above the background noise measurement. Data are plotted as mean \pm SD. $N=7$ fish, 8 recordings

$75 \mathrm{~Hz}$, with an increase in threshold from 80 to $115 \mathrm{~Hz}$ and then a plateau in response from 115 to $385 \mathrm{~Hz}$ (Fig. 3). When thresholds were compared with a repeated measures one-way ANOVA, $75 \mathrm{~Hz}$ differed from all other test frequencies except 80 and $85 \mathrm{~Hz}\left(\mathrm{RM}\right.$ ANOVA; $F_{(7,136)}=4.32 ; p<0.001$; Holm-Sidak posthoc comparisons, $p<0.05)$. There were no other differences in threshold among test frequencies.

\subsection{Auditory Evoked Potential Recordings}

AEPs were obtained from all test fish and showed similar averaged response waveforms for a given frequency across all individuals (Fig. 4). FFT analyses of averaged AEP waveforms also showed peaks at twice the stimulus frequency for intensities at and above threshold. Best frequencies ranged from 80 to $125 \mathrm{~Hz}$ for all individuals tested (120-121 $\mathrm{dB}_{\text {rms }}$ re: $\left.1 \mu \mathrm{Pa}\right)$. Auditory thresholds determined by AEP showed

Fig. 4 (continued) determine threshold (1024 points). Five different stimulus intensities at $100 \mathrm{~Hz}$ are shown. Bottom trace (green) shows the stimulus waveform. FFT analyses illustrate peaks at approximately twice the stimulus frequency from 130 to $115 \mathrm{~dB}$. Threshold for this individual fish at this test frequency was $115 \mathrm{~dB}_{\text {rms }}$ re: $1 \mu \mathrm{Pa}$. (b) Threshold tuning curve for AEPs (left y-axis) with overlay of spectral content (right $y$-axis) of different natural sounds produced by the Hawaiian sergeant fish. AEP data (triangles) are plotted as mean $\pm \mathrm{SE}, N=7$ fish 


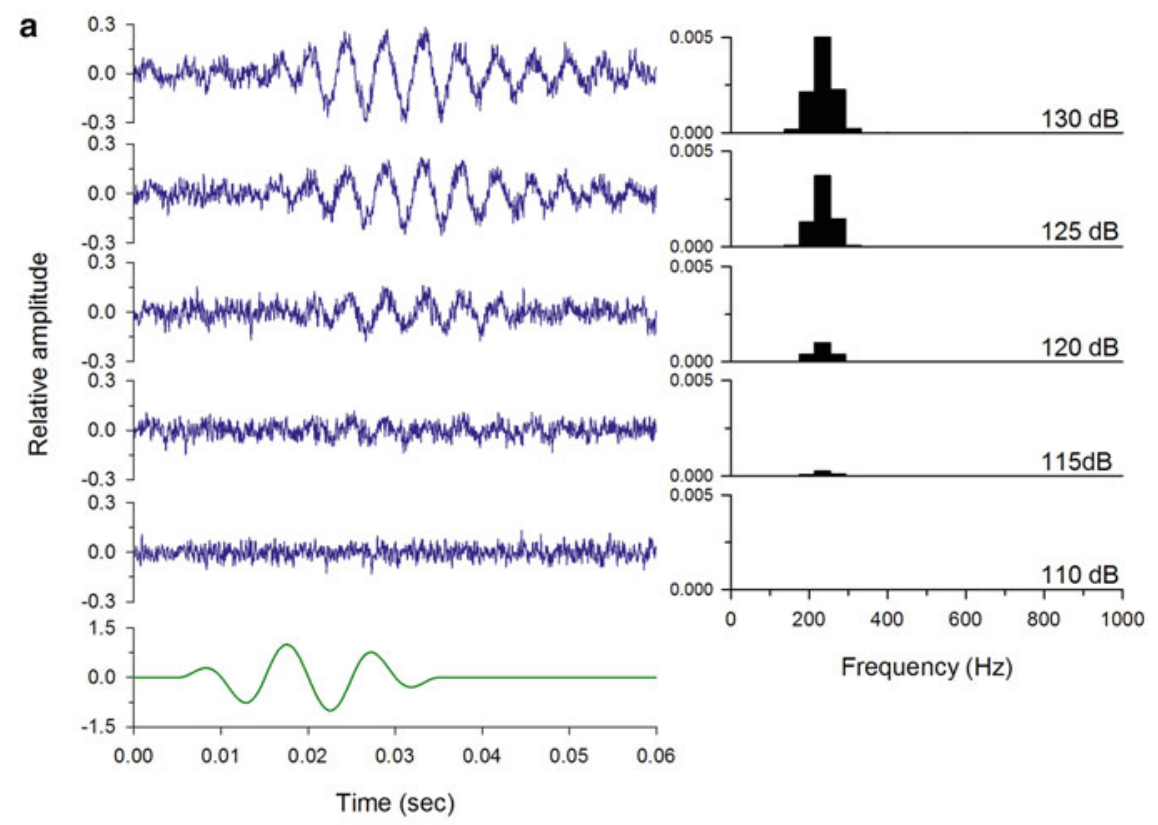

b

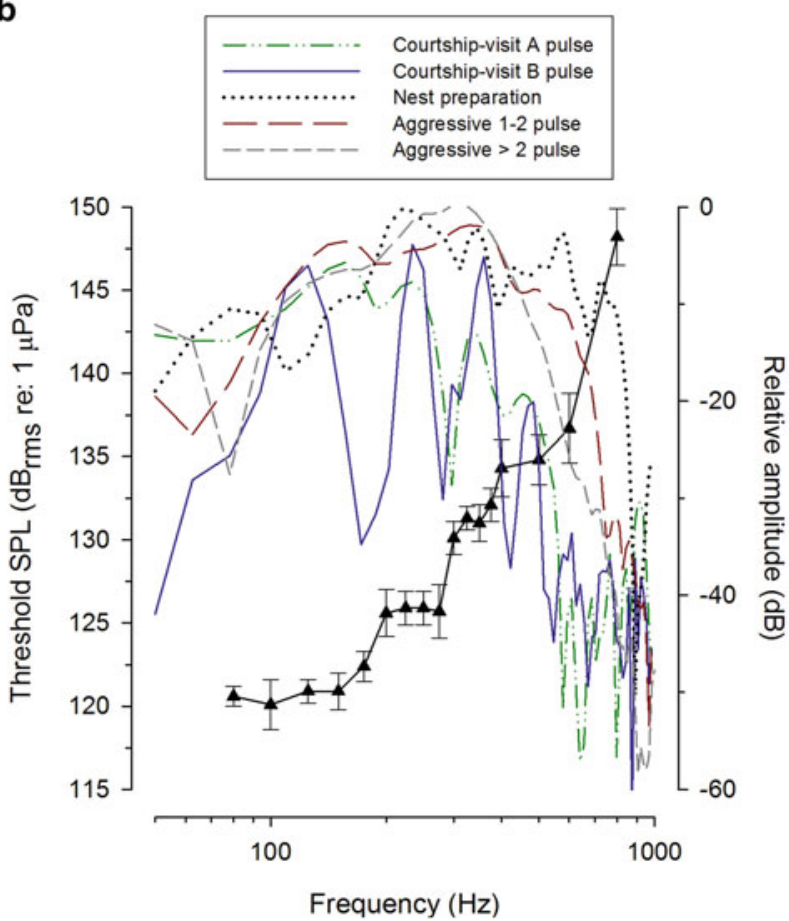

Fig. 4 Auditory evoked potential (AEP) recordings from the Hawaiian sergeant fish Abudefduf abdominalis show low-frequency sensitivity that matches the spectral content of sound production. (a) Representative example of averaged AEP waveforms (left) and FFT analyses (right) used to 
best sensitivity at low frequencies $(\leq 300 \mathrm{~Hz})$ for all tested fish, and there was a 30 $\mathrm{dB}$ difference in threshold values between the frequency of best sensitivity (80-125 $\mathrm{Hz})$ and worst sensitivity $(800 \mathrm{~Hz})$. AEP thresholds did not differ between 80 and $275 \mathrm{~Hz}$, but these lower frequencies differed from those at 300-600 Hz, and threshold at the highest test frequency $(800 \mathrm{~Hz})$ differed from all other frequencies (RM ANOVA, $p<0.001 ; F_{(6,96)}=56.29$; Holm-Sidak posthoc comparisons, $\left.p<0.05\right)$.

\subsection{Comparison of Saccular Potentials, AEPs, and Single Neuron Recordings in A. abdominalis}

The tuning curves determined by saccular potential, AEP, and single unit auditory hindbrain and midbrain recordings are plotted together in Fig. 5 and represent four different threshold measurements at levels from auditory hair cells to midbrain neurons. There are several important points to note from this figure. First, the lowest thresholds are at the low frequencies for all curves from 75 to $85 \mathrm{~Hz}$ for saccular

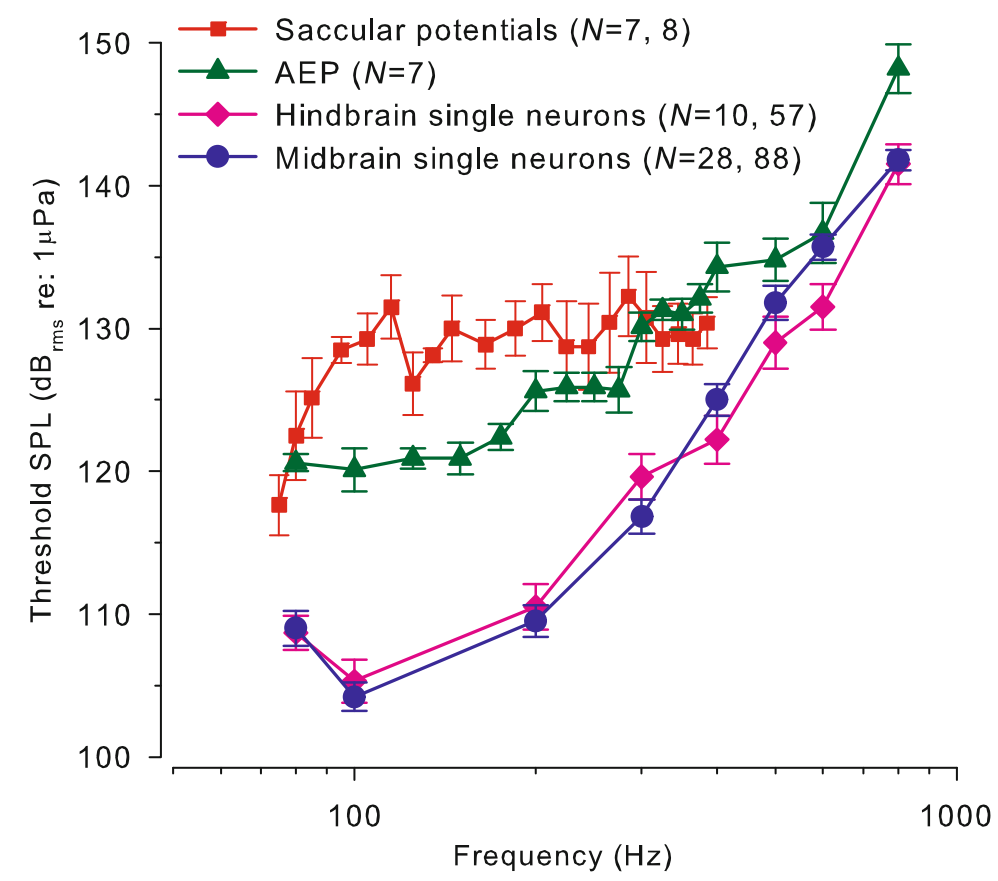

Fig. 5 Comparison of auditory threshold tuning curves in the Hawaiian sergeant fish Abudefduf abdominalis determined by different electrophysiological recording methods. Data are plotted as mean \pm SE. $N=$ number of animals, number of recordings for saccular potentials; number of animals for AEP recordings; and number of animals, number of neurons for hindbrain and midbrain single unit recordings 
potentials, and 80 to $300 \mathrm{~Hz}$ for AEP and single cell recordings in the brain. Second, the highest thresholds were observed in the saccular potential recordings. This is likely because the potentials are recorded from a small region of the hair-cell based sensory macula from the saccule on one side of the fish head. Thus, there is little neural convergence and no summation of the response from both inner ears, as would be present in the AEP and single unit recordings from the brain. A similar difference in thresholds $(\sim 10-20 \mathrm{~dB})$ was seen between saccular potentials and AEP thresholds in the Lusitanian toadfish (see Fig. 6). Third, the hindbrain single unit curve shows similar sensitivity to the midbrain units at the low frequencies (80-200 $\mathrm{Hz})$, but broader tuning at the higher frequencies $(300-800 \mathrm{~Hz})$. Thus there is possibly a low pass filtering mechanism between the hindbrain and midbrain in the
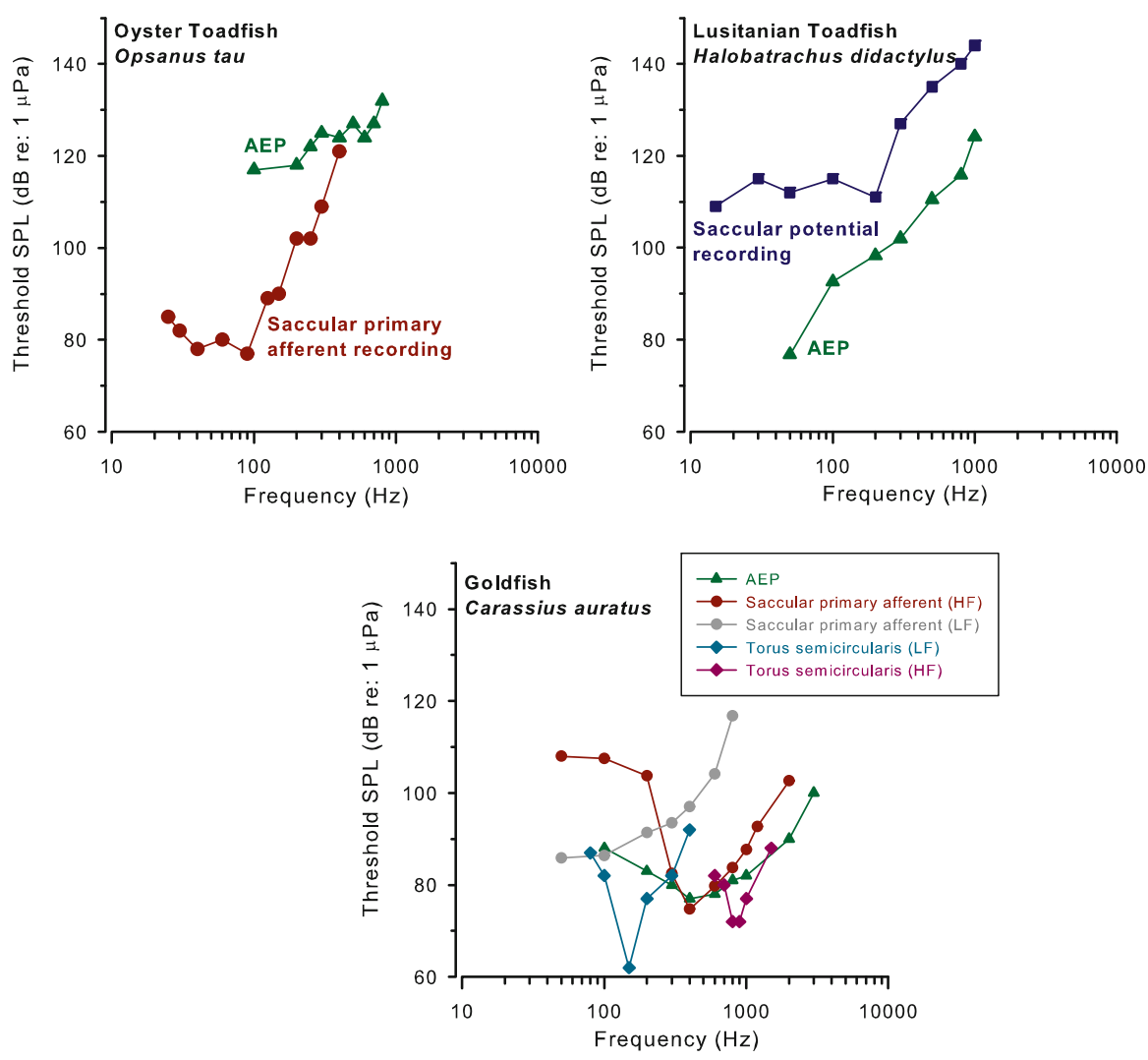

Fig. 6 Representative examples of auditory tuning curves obtained by different electrophysiological recording methods in several fish species. Values were estimated from previously published figures and data from the following papers: Oyster toadfish (Yan et al. 2000; Fine 1981); Lusitanian toadfish (Vasconcelos et al. 2007, 2011); Goldfish (Lu and Fay 1993; Fay 1978a; Ladich and Fay 2013; Fay and Ream 1986). Threshold sound pressure levels (SPL) reported for neural recordings in the goldfish were converted from $\mathrm{dB}$ re: 1 dyne/sq.cm to $\mathrm{dB}$ re: $1 \mu \mathrm{Pa}$ for comparisons. HF, high frequency neurons; LF, low frequency neurons 
Hawaiian sergeant fish, as shown for several other species (Feng and Schellart 1999). Fourth, the dynamic range of threshold values from lowest to highest sensitivity across similar ranges of frequencies is greatest for the midbrain single unit recordings $(37.6 \mathrm{~dB})$, followed by hindbrain units $(33.7 \mathrm{~dB})$, AEPs $(28.1 \mathrm{~dB})$, and saccular potentials $(12.8 \mathrm{~dB})$. Fifth, there is an approximately 15-20 dB difference in sensitivity at the best frequency of $100 \mathrm{~Hz}$ between the single unit recordings and the AEP recordings, and a $25 \mathrm{~dB}$ difference between the single units and the saccular potential recordings at this frequency. The reason for these differences in sensitivity is not known, but may be related to recording locations (e.g., peripheral vs. central auditory system) and methodology, or properties inherent to different portions of the auditory processing pathway.

\section{Discussion}

The goal of this study was to generate auditory threshold tuning curves in the Hawaiian sergeant fish using saccular potentials and AEP recordings, and then compare them to previously determined single neuron recordings from different auditory brain nuclei to determine how threshold measures at different processing levels compare in a single teleost species. Our results show that the Hawaiian sergeant fish is most sensitive to low frequency tone stimuli $(\leq 300 \mathrm{~Hz})$, regardless of recording technique, which matches the spectral content of their sound production during agonistic and reproductive behaviors. Relative hearing thresholds, however, differed by as much as $5-25 \mathrm{~dB}$ between the different recording methods, with largest differences occurring at these same low frequencies $(\leq 300 \mathrm{~Hz})$. Our results are interpreted below with the aim of discussing the utility of different electrophysiological methods in fish hearing and bioacoustics research, as well as their biological implications for the study species.

\subsection{Saccular Potentials and AEP Recordings in the Hawaiian Sergeant Damselfish}

Saccular potential recordings in A. abdominalis revealed best hearing sensitivities at low frequencies $(<125 \mathrm{~Hz})$. Several previous studies used evoked potentials to determine the sensitivity and response dynamics of saccular inner ear hair cells in teleost fishes (Adrian et al. 1938; Furukawa et al. 1972; Fay 1974; Sisneros 2007; Alderks and Sisneros 2011), and they are easily identified because they are evoked at twice the stimulus frequency due to the presence of nonlinearities and oppositely oriented hair cell populations in the fish saccule (Furukawa and Ishii 1967; Hama 1969; Fay 1974; Fay and Popper 1974). This frequency doubling effect is also evident in FFT analyses of AEP recordings and is present in the lateral line system (Flock 1965) for similar reasons, but is absent in the cochlea and vestibular system 
because the hair cells are oriented in only one direction and the evoked potential occurs at the stimulus frequency (de Vries and Bleeker 1949; Tasaki et al. 1954). The magnitude of the saccular potentials in the Hawaiian sergeant fish were generally lower than and did not have the dynamic range of those observed in the midshipman and Lusitanian toadfish measured with the identical experimental setup (Sisneros 2007; Alderks and Sisneros 2011; Vasconcelos et al. 2011). This difference could be due to several factors including electrode placement in the saccule (either distance between recording electrode and hair cells, or position of electrode in regions with hair cells oriented off the vertical stimulation axis), especially since the saccule in A. abdominalis is located deep within the otic capsule beneath the medulla. This location makes it difficult to position electrodes in this area compared to the more easily accessible and laterally positioned saccule in batrachoidid fishes. Alternatively, the Hawaiian sergeant fish saccule may just be less sensitive than the midshipman to stimuli along the dorso-ventral axis. Nevertheless, the tuning curves obtained by saccular potential recordings in the Hawaiian sergeant fish are within the range of thresholds obtained by the AEP technique in this species and in the congener A. saxatilis (Egner and Mann 2005). Recordings from individual endorgans like the saccule in fishes provide important information about the response properties of hair cells, which are the first processing level of the auditory system. These types of recordings are also valuable for comparisons to recordings done at subsequent processing levels. For example, saccular (and lagenar and utricular) recordings can be used to evaluate whether changes in auditory sensitivity due to circulating hormones or noise exposure occur at the level of the macula and hair cells, or elsewhere along the auditory pathway.

Our finer low-frequency resolution tuning curve generated for the Hawaiian sergeant fish by AEP is similar to that previously determined using fewer test frequencies (Maruska et al. 2007). The additional frequencies, however, further highlight that this species is most sensitive to tonal stimuli of $\leq 200 \mathrm{~Hz}$, with slightly lower sensitivity but with similar thresholds across the range of $200-285 \mathrm{~Hz}$, and then with a steady drop in auditory sensitivity from 300 to $800 \mathrm{~Hz}$. The low thresholds measured across this frequency range overlaps the dominant spectral energy found in all of the natural agonistic and courtship sounds produced by this species $(<80-400 \mathrm{~Hz})$ (Maruska et al. 2007), illustrating a match between hearing ability and sound production for communication. Low frequency acoustic information is also likely important for all fishes to survey complex "soundscapes" for mediating other non-communicative behaviors such as prey detection, predator avoidance, and assessment of ambient noise and environmental disturbances (Fay 2009). This low-pass frequency hearing is similar to most other fishes that do not have accessory auditory specializations (e.g., midshipman and toadfish) but instead rely on the otolithic endorgans that detect acoustic particle motion by acting as inertial accelerometers (Fay and Edds-Walton 1997; Sisneros 2007). Fishes that do possess adaptations to detect the pressure component of sound stimuli, on the other hand, typically have enhanced high-frequency hearing abilities (e.g., goldfish, mormyrids, clupeids, labyrinth fishes). However, even these species that detect high frequencies $(\geq 800 \mathrm{~Hz}$ ) have some saccular primary afferent and central neurons tuned to low 
frequencies $(\leq 200 \mathrm{~Hz})$ in addition to those tuned to higher frequencies (Lu and Fay 1993; Fay and Ream 1986; Suzuki et al. 2002). This suggests that the maintenance of low frequency encoding may be a general characteristic found in all fish auditory systems. This low frequency hearing may be driven by environmental constraints of the underwater environment that favor the detection of low frequency sounds that propagate farther distances than high frequency sounds, as well as facilitate the localization of sound sources using directional particle motion cues (Zeddies et al. 2012).

\subsection{Comparison of Different Auditory Physiology Recording Techniques}

Our comparison of different electrophysiological recording techniques illustrates the limitation of comparing data sets among studies that use different methods, and the value of using multiple techniques to examine auditory encoding in a single species. In the Hawaiian sergeant fish, different recording techniques revealed a similar detectable range of frequencies, but the thresholds or sensitivity measures varied considerably among methods. For example, auditory thresholds varied by as much as 10-25 dB among techniques, with the greatest differences occurring at low frequencies $(75-400 \mathrm{~Hz})$. Since the spectral content of the sounds produced by the Hawaiian sergeant fish is also at these same low frequencies to which their auditory system is most sensitive, the threshold differences have important biological implications. This generalization of comparable frequency range but varying thresholds appears to hold true for other species such as batracoidids, but not for goldfish, which shows more overlap in thresholds obtained by different recording techniques (Fig. 6). The oyster toadfish, for example, also shows differences in thresholds between AEP and primary afferent recordings from the saccular nerve, with a $40 \mathrm{~dB}$ difference between the techniques at $100 \mathrm{~Hz}$. In the Lusitanian toadfish, differences of 10-25 dB are also evident between AEP and saccular potential recordings across the low frequency range tested. These observed differences in auditory sensitivity among recordings in the same species could be due to methodology differences (e.g., electrode placement, threshold criteria, tank acoustics), or inherent biological characteristics of each recording location (e.g., summation, convergence, relative inputs from inner ear and lateral line) that are important for the animals perception of its auditory world.

While our study attempted to keep as many experimental conditions constant across recording methods as possible, there were several unavoidable variations that cannot be ruled out as contributors to the observed threshold differences. For example, the experimental tank, as well as the position of the entire fish and saccule beneath the water surface in AEP experiments differed from that of the other three techniques in which the saccule was closer to the water surface due to the surgical intervention required for electrode placement. Since the acoustics in small tanks and near the air-water interface can be complex (Parvulescu 1967; Akamatsu et al. 2002), 
it is possible that variations in tank dimensions and position of the saccule relative to the water surface has important consequences for threshold determination. However, tank dimensions and fish position were essentially identical between saccular potential recordings and single neuron recordings in the brain, suggesting that the differences in threshold between these techniques are due to biological rather than methodological variations. Nevertheless, future studies should carefully consider and characterize particle motion and sound pressure levels throughout their experimental tank, as well as any other subtle procedural variations.

One important auditory sensitivity measurement missing from our data set in the Hawaiian sergeant fish is a behavioral audiogram determined by classical conditioning or psychophysical methods. Behavioral auditory thresholds are often, but not always, lower than any electrophysiologically determined thresholds and may be the best indicator of true hearing abilities in a species. However, they are extremely time-consuming and difficult to generate in some fish species, especially those that do not respond to the training paradigms. Physiologically determined audiograms are valuable because they provide a good estimate of the frequency hearing abilities of a species (i.e., spectral range), including a measure of best frequency, in a comparatively shorter amount of time, even though they may underestimate hearing sensitivity at certain frequencies in some species. However, this underestimation is not a universal relationship among all fishes. For example, behavioral thresholds are lower than (Fay 1974; Kojima et al. 2005), greater than (Kenyon et al. 1998), or similar to (Fay 1978a, b; Kenyon et al. 1998; Ladich 1999, 2000) physiologically determined thresholds in different species [see also Ladich and Fay 2013 for a review], suggesting that differences may be species-specific and dependent on experimental factors that vary among labs. Based on their extensive comparison of AEP and behavioral tuning curves in many fishes, Ladich and Fay (2013) note that AEPs tend to produce higher thresholds at low frequencies $(<1000 \mathrm{~Hz})$ and lower thresholds at high frequencies $(>1000 \mathrm{~Hz}$ ) compared to behaviorally generated audiograms, suggesting there is also a frequency dependent effect between these two methods.

The type of auditory recording method employed in a study will depend largely on the research question addressed, species used, and the available resources. For example, AEPs have become popular in recent years because they are relatively quick to perform, easy to learn, inexpensive to setup, applicable to almost any species, and are minimally invasive allowing repeated measurements in the same individuals. AEPs are therefore valuable for obtaining rapid information on the frequency range and threshold tuning for a particular species, as well as doing before and after comparisons following manipulation or "intervention" to test some aspect of hearing (e.g., exploring temporary hearing changes that result from noise exposure). Single neuron recordings, on the other hand, require more expensive equipment, invasive surgical approaches, complex analysis tools, and expertise to perform and interpret. Neural recordings that examine auditory responses at different points along the ascending pathway, however, are quite valuable for providing important information on specific auditory processing and filtering mechanisms that occur at different levels within the central auditory system. This type of information cannot be obtained 
from recordings such as AEPs that likely average the response across multiple levels of the auditory processing pathway. In most AEP studies, what appear to be recorded are the evoked double frequency responses of the hair cells and their afferents along with some auditory brainstem and midbrain activity (Corwin et al. 1982). In contrast, single neuron recordings can reveal specific filtering and response properties of auditory neurons. These properties include the low pass filtering system observed between the hindbrain and midbrain in the Hawaiian sergeant fish (Maruska and Tricas 2009b), the sharpening of directional response properties that occurs along the auditory pathway in the toadfish (Edds-Walton and Fay 2005), and as a generalization, the decrease in spontaneous activity, increased latency, and sharpened tuning in the ascending auditory pathway from primary afferent to hindbrain to midbrain neurons that exists in several fish species (Feng and Schellart 1999). Thus, peripheral and central neural recordings have uncovered many important aspects of fish auditory processing capabilities such as temporal encoding (Fay 1977; Fay and Coombs 1983; Carr 1986; Bodnar and Bass 1997; Kozloski and Crawford 2000; Bodnar et al. 2001), frequency selectivity, role of inhibition in shaping frequency responses, filtering properties, and phase-locking ability (Fay 1978a, b; Lu and Fay 1996; Kawasaki and Guo 1998; Sisneros and Bass 2003; Maruska and Tricas 2009b), directional sensitivity (Fay 1979; Lu et al. 1998; Edds-Walton and Fay 2003, 2005), integration with other senses (Schellart 1983; Prechtl et al. 1998; Fay and Edds-Walton 2001), and effects of hormones and neuromodulators on the auditory system (Sisneros et al. 2004; Maruska and Tricas 2011).

Tuning curves from single neuron recordings, however, are difficult to compare directly to techniques such as AEP and saccular potentials because the auditory system contains neurons of many different types and response dynamics, particularly in the auditory nuclei of the brain. Thus, some individual neurons in the same fish can show differences in threshold of 20-40 dB to the same frequency, be untuned, broadly tuned, or sharply tuned, be tuned to only low, mid, or high frequency stimuli, and vary in their degree of phase-locking (Fay 1978a; Fay and Ream 1986; Lu and Fay 1993; Feng and Schellart 1999; Edds-Walton and Fay 2003; Maruska and Tricas 2009b). This individual variation may also contribute to the often lower thresholds detected with peripheral or central single neuron recordings compared to AEP and saccular potentials in the Hawaiian sergeant, toadfish, and goldfish (Fig. 6). Further, there are also differences in temporal processing features (e.g., overall envelope encoding, waveform structure detection) among individual neurons in the same brain area (Fay and Coombs 1983; Crawford 1997; Bodnar and Bass 1999, 2001b). These neural response characteristics are important for understanding how fishes encode the auditory scene and their perceptual world or "umwelt," which cannot be detected from behavioral, AEP, or saccular potential recordings. In fact, single auditory neurons in the midbrain and hindbrain of the Hawaiian sergeant fish are more sensitive to playbacks of natural courtship and aggressive sounds than to single frequency tonal stimuli (Maruska and Tricas 2009b). This indicates that thresholds to the tonal stimuli typically used in electrophysiology recording studies may be higher than that measured if more natural sounds which contain complex spectral and temporal characteristics were used. Thus, single neuron recordings are 
extremely useful for studying how salient information from sounds received at the inner ear is transformed along the auditory pathway and ultimately integrated with other senses and internal physiology to allow context-appropriate behavioral decisions.

Other important factors to consider when comparing different electrophysiological techniques are the relative contributions of the different endorgans (saccule, lagena, and utricle) and the mechanosensory lateral line system to the recorded "auditory" response, which may account for some of the observed differences in thresholds across techniques (Table 1). The majority of fish auditory research has concentrated on the largest endorgan, the saccule, but most species will also have significant inputs from the lagena and utricle that are likely species-specific but not yet completely understood. A recent study conducted in the goldfish also demonstrated that the lateral line system contributes to AEPs at low frequencies (Higgs and Radford 2013), and this is likely true for many species. In contrast, potentials recorded directly from the sensory macula or primary afferents of the saccule, utricle, or lagena would not contain input from the mechanosensory system, and the segregation of auditory and lateral line inputs to the hindbrain nuclei in fishes suggests most recordings from these medullary areas only contain inner ear information (McCormick 1999). Recordings from auditory-responsive regions of the midbrain torus semicircularis, diencephalic, and telencephalic nuclei, however, may contain bimodal or multimodal neurons that receive both lateral line and inner ear information, and in some cases visual and somatosensory cues as well (Schellart 1983; Lu and Fay 1995; Prechtl et al. 1998; Kirsch et al. 2002). Since most electrophysiological recording experiments use small experimental tanks with often

Table 1 Summary of potential sensory system contributions to hearing thresholds determined by different techniques

\begin{tabular}{l|l|l}
\hline & Auditory system (inner ear) & $\begin{array}{l}\text { Mechanosensory lateral } \\
\text { line system }\end{array}$ \\
\hline $\begin{array}{l}\text { Behavioral or psychophysical } \\
\text { methods }\end{array}$ & Saccule, lagena, utricle (both sides) & $\begin{array}{l}\text { Canal and superficial } \\
\text { neuromasts (whole body) }\end{array}$ \\
\hline Auditory evoked potentials & Saccule, lagena, utricle (both sides) & $\begin{array}{l}\text { Canal and superficial } \\
\text { neuromasts (whole body) }\end{array}$ \\
\hline Otolithic endorgan potentials & $\begin{array}{l}\text { Single otolithic endorgan only } \\
\text { (saccule, utricle, or lagena) }\end{array}$ & None \\
\hline $\begin{array}{l}\text { Primary afferent recordings } \\
\text { single neuron recordings }\end{array}$ & $\begin{array}{l}\text { Single otolithic endorgan only } \\
\text { (saccule, utricle, or lagena) }\end{array}$ & $\begin{array}{l}\text { None } \\
\text { ipsilateral) }\end{array}$ \\
\hline $\begin{array}{l}\text { Midbrain auditory torus } \\
\text { semicircularis single neuron } \\
\text { recordings }\end{array}$ & $\begin{array}{l}\text { Saccule, lagena, utricle } \\
\text { (contralateral and ipsilateral) }\end{array}$ & $\begin{array}{l}\text { Canal and superficial } \\
\text { neuromasts (whole } \\
\text { body) }\end{array}$ \\
\hline
\end{tabular}

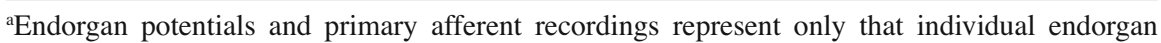
being recorded from

${ }^{b}$ Endorgan contribution is dependent on which hindbrain nucleus recordings are made from 'There is evidence for bimodal neurons that respond to both mechanosensory and auditory stimuli in the torus semicircularis of some fish species 
complex and unknown particle displacement fields (Parvulescu 1964, 1967; Akamatsu et al. 2002), it is important to recognize the relative contribution of otolithic endorgan versus lateral line system input to "hearing thresholds" across species. While in most cases it may not matter to the fish whether a biologically relevant stimulus is detected by the inner ear, lateral line, or both, it does become important when characterizing the response dynamics of individual sensory systems [see Braun and Sand 2014 for discussion of overlap between lateral line and auditory systems in fishes, and also Higgs and Radford, in this volume].

\section{Conclusions and Future Directions}

Our study comparing auditory threshold tuning curves measured by different electrophysiological methods in a single species highlights the great variability in thresholds within an animal's spectral range of best sensitivity among the different techniques, suggesting that single curves generated for a particular species should be interpreted with caution. Despite our current knowledge, there are still many remaining questions and important areas of future work, several of which are briefly mentioned below.

1. More studies should be performed using multiple recording methods within a single species, as well as in representatives of diverse species with different anatomical specializations. These studies should help clarify the methodological and biological reasons for the different thresholds measured across multiple levels of the auditory pathway from peripheral endorgan hair cells to central processing levels in the brain. Ideally these studies should be conducted in the same lab with identical experimental setups using similar stimulus delivery (i.e., speaker or shaker system) and threshold criteria, as well as characterization of the stimulus in terms of both sound pressure and particle motion.

2. To truly understand the auditory capabilities of a particular species, multiple electrophysiological recording techniques should also be combined and compared with behavioral audiograms within a single species. These data could then be used in combination with an assessment of the ambient noise and sound propagation properties of the fish's natural habitat to gain a better understanding of the ecology and evolution of a species' auditory system. Electrophysiology recordings using playbacks of natural sounds in addition to tonal stimuli will also be informative. The enormous diversity of fish auditory sensitivities, inner ear morphologies, and accessory hearing structures should provide fruitful future comparisons for the selective pressures that have shaped the evolution of the auditory system.

3. More electrophysiological recordings are also needed from the other putative auditory endorgans, the utricle and lagena. In comparison with the numerous studies on the saccule, there are few physiological recordings from these other endorgans in fishes (Fay and Olsho 1979; Lu et al. 2003, 2004; Maruska and 
Mensinger 2015; Meyer et al. 2010, 2012), and therefore limited understanding of how they contribute to auditory sensitivity and directional hearing abilities that should be further explored. Similarly, the relative contribution of the mechanosensory lateral line system to "hearing" thresholds and its overlap in acoustic sensitivity with the inner ear should be carefully considered when reporting auditory capabilities of different species (see Higgs and Radford, in this volume).

4. Lastly, moving forward, there is a need for studies that examine the relative role of the auditory system as only one sensory component of a fish's entire perceptual world, or umwelt. Fishes must constantly assess simultaneous incoming information from multiple sensory channels (auditory, mechanosensory, visual, chemosensory, somatosensory, vestibular, and in some cases electrosensory) and integrate it to make context-appropriate behavioral decisions about crucial tasks related to their survival and reproduction such as when to eat, when to flee from predators, and when to reproduce. Perception of the complex underwater "soundscape," therefore, represents just one aspect of the multimodal input used for neural computations, and future work is needed to determine the relative importance of auditory information in mediating different behaviors in all fishes, the most diverse and speciose group of vertebrates.

Acknowledgements The authors would like to thank Drs. Richard Fay and Arthur Popper for their continued inspiration, ideas, mentorship, and encouragement that they have given us as scientists. Our existing knowledge of fish bioacoustics and comparative hearing in vertebrates would be extremely limited without their career-long research progress and leadership. Their valuable research contributions to the field of fish hearing and bioacoustics will continue to inspire both new research directions and the next generation of scientists. Art Popper's work has stimulated an appreciation of the variety and specializations in inner ear morphology and accessory hearing structures responsible for diverse hearing capabilities among fishes, with many more discoveries to be made as the remaining $>30,000$ species of fishes are examined. Dick Fay's work has significantly improved our understanding of the neural mechanisms governing auditory perception, temporal and frequency domain processing, effective stimulus for the fish auditory system (e.g., use of shaker table stimulus), directional hearing abilities, and how information is transformed along the auditory pathway from the endorgan to higher processing centers in the brain. Together, Art and Dick have also provided invaluable data on auditory capabilities in fishes for comparison with those of other vertebrates, and have brought us closer to understanding how fish hear, what fish hear, and how they perceive the underwater soundscape they inhabit.

We also thank Tim Tricas for his guidance and insights during different stages of this research. Funding was provided in part by an NSF Doctoral Dissertation Improvement Grant (IBN 04-08197 to KPM). We also thank University of Hawaii at Manoa, Hawaii Institute of Marine Biology, University of Washington, and Louisiana State University for support during different phases of this work.

\section{References}

Adrian ED, Craik KJW, Strudy RS (1938) The electrical response of the auditory mechanism in cold-blooded vertebrates. Proc R Soc Lond B 125:435-455

Akamatsu T, Okumura T, Novarini N, Yan HY (2002) Empirical refinements applicable to the recording of fish sounds in small tanks. J Acoust Soc Am 112:3073-3082 
Alderks PW, Sisneros JA (2011) Ontogeny of auditory saccular sensitivity in the plainfin midshipman fish, Porichthys notatus. J Comp Physiol A Neuroethol Sens Neural Behav Physiol 197(4):387-398. doi:10.1007/s00359-010-0623-4

Alderks PW, Sisneros JA (2013) Development of the acoustically evoked behavioral response in larval plainfin midshipman fish, Porichthys notatus. PLoS One 8(12), e82182. doi:10.1371/ journal.pone. 0082182

Amorim M (2006) Diversity of sound production. In: Ladich F, Collin SP, Moller P, Kapoor BG (eds) Communication in fishes. Science Publishers, Enfield, pp 71-105

Bang PI, Sewell WF, Malicki JJ (2000) Behavioral screen for dominant mutations affecting zebrafish auditory system. Assoc Res Otolaryngol Abs 23:177-187

Bass AH, McKibben JR (2003) Neural mechanisms and behaviors for acoustic communication in teleost fish. Prog Neurobiol 69(1):1-26

Batschelet E (1981) Circular statistics in biology. Academic, New York

Bhandiwad AA, Zeddies DG, Raible DW, Rubel EW, Sisneros JA (2013) Auditory sensitivity of larval zebrafish (Danio rerio) measured using a behavioral prepulse inhibition assay. J Exp Biol 216(Pt 18):3504-3513. doi:10.1242/jeb.087635

Bodnar DA, Bass AH (1997) Temporal coding of concurrent acoustic signals in auditory midbrain. J Neurosci 17:7553-7564

Bodnar DA, Bass AH (1999) Midbrain combinatorial code for temporal and spectral information in concurrent acoustic signals. J Neurophysiol 81(2):552-563

Bodnar DA, Bass AH (2001a) Coding of concurrent vocal signals by the auditory midbrain: effects of duration. J Comp Physiol A Sens Neural Behav Physiol 187(5):381-391

Bodnar DA, Bass AH (2001b) Coding of concurrent vocal signals by the auditory midbrain: effects of stimulus level and depth of modulation. J Acoust Soc Am 109(2):809-825

Bodnar DA, Holub AD, Land BR, Skovira J, Bass AH (2001) Temporal population code of concurrent vocal signals in the auditory midbrain. J Comp Physiol A Neuroethol Sens Neural Behav Physiol 187(11):865-873

Braun CB, Sand O (2014) Functional overlap and nonoverlap between lateral line and auditory systems. In: Coombs S, Bleckmann H, Fay RR, Popper AN (eds) The lateral line system, Springer handbook of auditory research, vol 48. Springer, New York, pp 281-312

Carr CE (1986) Time coding in electric fish and barn owls. Brain Behav Evol 28(1-3):122-133

Cohen MJ, Winn HE (1967) Electrophysiological observations on hearing and sound production in the fish, Porichthys notatus. J Exp Zool 165(3):355-369. doi:10.1002/jez.1401650305

Cordova MS, Braun CB (2007) The use of anesthesia during evoked potential audiometry in goldfish (Carassius auratus). Brain Res 1153:78-83. doi:10.1016/j.brainres.2007.03.055

Corwin JA, Bullock TH, Scheitzer J (1982) The auditory brainstem response in five vertebrate classes. Electroencephalogr Clin Neurophysiol 54:629-641

Crawford JD (1993) Central auditory neurophysiology of a sound-producing fish: the mesencephalon of Pollimyrus isidori (Mormyridae). J Comp Physiol A 172(2):139-152

Crawford JD (1997) Feature-detecting auditory neurons in the brain of a sound producing fish. J Comp Physiol A 180:439-450

de Vries H, Bleeker JDJW (1949) The microphonic activity of the labyrinth of the pigeon. Part II: the response of the cristae in the semicircular canals. Acta Otolaryngol 37:298-306

Edds-Walton PL, Fay RR (1995) Regional differences in directional response properties of afferents along the saccule of the toadfish, Opsanus tau. Biol Bull 189(2):211-212

Edds-Walton PL, Fay RR (1998) Directional auditory responses in the descending octaval nucleus of the toadfish (Opsanus tau). Biol Bull 195(2):191-192

Edds-Walton PL, Fay RR (2003) Directional selectivity and frequency tuning of midbrain cells in the oyster toadfish, Opsanus tau. J Comp Physiol A Neuroethol Sens Neural Behav Physiol 189(7):527-543

Edds-Walton PL, Fay RR (2005) Sharpening of directional responses along the auditory pathway of the oyster toadfish, Opsanus tau. J Comp Physiol A Neuroethol Sens Neural Behav Physiol 191:1079-1086 
Edds-Walton PL, Fay RR (2008) Directional and frequency response characteristics in the descending octaval nucleus of the toadfish (Opsanus tau). J Comp Physiol A Neuroethol Sens Neural Behav Physiol 194(12):1013-1029. doi:10.1007/s00359-008-0373-8

Edds-Walton PL, Matos SR, Fay RR (2013) Does the magnocellular octaval nucleus process auditory information in the toadfish, Opsanus tau? J Comp Physiol A Neuroethol Sens Neural Behav Physiol 199(5):353-363. doi:10.1007/s00359-013-0799-5

Egner S, Mann D (2005) Auditory sensitivity of sergeant major damselfish Abudefduf saxatilis from post-settlement juvenile to adult. Mar Ecol Prog Ser 285:213-222

Enger PS (1966) Acoustic thresholds in goldfish and its relation to the sound source distance. Comp Biochem Physiol 18:859-868

Enger PS, Hawkins AD, Sand O, Chapman CJ (1973) Directional sensitivity of saccular microphonic potentials in the haddock. J Exp Biol 59:425-433

Fay RR (1974) Sound reception and processing in the carp: saccular potentials. Comp Biochem Physiol 46:29-42

Fay RR (1977) Auditory temporal modulation transfer function for the goldfish. J Acoust Soc Am 62:588

Fay RR (1978a) Coding of information in single auditory-nerve fibers of the goldfish. J Acoust Soc Am 63(1):136-146

Fay RR (1978b) Phase-locking in goldfish saccular nerve fibers accounts for frequency discrimination capacities. Nature 275:320-322

Fay RR (1979) Discharge patterns of lagenar and saccular neurones of the goldfish eight nerve: displacement sensitivity and directional characteristics. Comp Biochem Physiol A 62(2):377-386

Fay RR (1988) Hearing in vertebrates: a psychophysics databook. Hill-Fay Associates, Winnetka

Fay R (2009) Soundscapes and the sense of hearing of fishes. Integr Zool 4(1):26-32. doi:10.1111/j.1749-4877.2008.00132.x

Fay RR, Coombs S (1983) Neural mechanisms in sound detection and temporal summation. Hear Res 10(1):69-92

Fay RR, Edds-Walton PL (1997) Diversity in frequency response properties of saccular afferents of the toadfish, Opsanus tau. Hear Res 113(1-2):235-246

Fay RR, Edds-Walton PL (1999) Sharpening of directional auditory input in the descending octaval nucleus of the toadfish, Opsanus tau. Biol Bull 197(2):240-241

Fay RR, Edds-Walton PL (2001) Bimodal units in the torus semicircularis of the toadfish (Opsanus tau). Biol Bull 201(2):280-281

Fay RR, MacKinnon JR (1969) A simplified technique for conditioning respiratory mouth movements in fish. Behav Res Methods Instrum 1:123-124

Fay RR, Olsho LW (1979) Discharge patterns of lagenar and saccular neurones of the goldfish eighth nerve: displacement sensitivity and directional characteristics. Comp Biochem Physiol A 62:377-386

Fay RR, Popper AN (1974) Acoustic stimulation of the ear of the goldfish (Carassuis auratus). J Exp Biol 61:243-260

Fay RR, Popper AN (1975) Modes of stimulation of the teleost ear. J Exp Biol 62:370-387

Fay RR, Ream TJ (1986) Acoustic response and tuning in saccular nerve fibers of the Goldfish (Carassius auratus). J Acoust Soc Am 79(6):1883-1895

Feng AS, Schellart NA (1999) Central auditory processing in fish and amphibians. In: Fay RR, Popper AN (eds) Comparative hearing: fish and amphibians. Springer, New York, pp 218-268

Fine ML (1981) Mismatch between sound production and hearing in the oyster toadfish. In: Tavolga WA, Popper AN, Fay RR (eds) Hearing and sound communication in fishes, vol 1. 1st edn. Springer, New York, pp 257-263

Flock A (1965) Electron microscopic and electrophysiological studies on the lateral line canal organ. Acta Otolaryngol Suppl 199:7-90

Furukawa T, Ishii Y (1967) Effects of static bending of sensory hairs on sound receptors in the goldfish. Jpn J Physiol 17:572-588 
Furukawa T, Ishii Y, Matsura S (1972) An analysis of microphonic potentials of the sacculus of goldfish. Jpn J Physiol 22:603-616

Goldberg JM, Brown PB (1969) Response of binaural neurons of dog superior olivary complex to dichotic tonal stimuli: some physiological mechanisms of sound localization. J Neurophysiol 32(4):613-636

Hama K (1969) A study on the fine structure of the saccular macula of the gold fish. Z Zellforsch 94:155-171

Higgs DM, Radford CA (2013) The contribution of the lateral line to 'hearing' in fish. J Exp Biol 216(Pt 8):1484-1490. doi:10.1242/jeb.078816

Horodysky AZ, Brill RW, Fine ML, Musick JA, Latour RJ (2008) Acoustic pressure and particle motion thresholds in six sciaenid fishes. J Exp Biol 211(Pt 9):1504-1511. doi:10.1242/ jeb.016196

Jacobs DW, Tavolga WN (1968) Acoustic frequency discrimination in the goldfish. Anim Behav 16(67-71)

Javel E, Mott JB (1988) Physiological and psychophysical correlates of temporal processes in hearing. Hear Res 34:275-294

Kawasaki M, Guo YX (1998) Parallel projection of amplitude and phase information from the hindbrain to the midbrain of the African electric fish Gymnarchus niloticus. J Neurosci 18(18):7599-7611

Kenyon TN, Ladich F, Yan HY (1998) A comparative study of hearing ability in fishes: the auditory brainstem response approach. J Comp Physiol A 182(3):307-318

Kirsch JA, Hofmann MH, Mogdans J, Bleckmann H (2002) Response properties of diencephalic neurons to visual, acoustic and hydrodynamic stimulation in the goldfish, Carassius auratus. Zoology 105(1):61-70

Kozloski J, Crawford JD (2000) Transformations of an auditory temporal code in the medulla of a sound-producing fish. J Neurosci 20(6):2400-2408

Kojima T, Ito H, Komada T, Taniuchi T, Akamatsu T (2005) Measurements of auditory sensitivity in common carp Cyprinus carpio by the auditory brainstem response technique and cardiac conditioning method. Fisher Sci 71:95-100

Ladich F (1999) Did auditory sensitivity and vocalization evolve independently in otophysan fishes? Brain Behav Evol 53(5-6):288-304

Ladich F (2000) Acoustic communication and the evolution of hearing in fishes. Philosophical Transactions of the Royal Society of London Series B-Biological Sciences 355(1401): $1285-1288$

Ladich F, Fay RR (2013) Auditory evoked potential audiometry in fish. Rev Fish Biol Fish 23:317-364

Ladich F, Wysocki LE (2009) Does speaker presentation affect auditory evoked potential thresholds in goldfish? Comp Biochem Physiol A Mol Integr Physiol 154(3):341-346. doi:10.1016/j. cbpa.2009.07.004

Lobel PS, Mann DA (1995) Spawning sounds of the damselfish, Dascyllus albisella (pomacentridae), and relationship to male size. International Journal of Animal Sound and its Recording 6:187-198

Lu Z, Fay RR (1993) Acoustic response properties of single units in the torus semicircularis of the goldfish, Carassius auratus. J Comp Physiol A 173:33-48

Lu Z, Fay RR (1995) Acoustic response properties of single neurons in the central posterior nucleus of the thalamus of the goldfish, Carassius auratus. J Comp Physiol A 176(6):747-760

Lu Z, Fay RR (1996) Two-tone interaction in primary afferents and midbrain neurons of the goldfish, Carassius auratus. Audit Neurosci 2:257-273

Lu Z, Song J, Popper AN (1998) Encoding of acoustic directional information by saccular afferents of the sleeping goby, Dormitator latifrons. J Comp Physiol A 182:805-815

Lu Z, Xu Z, Buchser WJ (2003) Acoustic response properties of lagenar nerve fibers in the sleeper goby, Dormitator latifrons. J Comp Physiol A Neuroethol Sens Neural Behav Physiol 189(12):889-905 
Lu Z, Xu Z, Buchser WJ (2004) Coding of acoustic particle motion by utricular fibers in the sleeper goby, Dormitator latifrons. J Comp Physiol A Neuroethol Sens Neural Behav Physiol 190(11):923-938

Ma WL, Fay RR (2002) Neural representations of the axis of acoustic particle motion in nucleus centralis of the torus semicircularis of the goldfish, Carassius auratus. J Comp Physiol A Neuroethol Sens Neural Behav Physiol 188(4):301-313

Maruska KP, Mensinger AF (2015) Directional sound sensitivity in utricular afferents in the toadfish, Opsanus tau. J Exp Biol 218:1759-1766. doi:10.1242/jeb.115345

Maruska KP, Tricas TC (2009a) Central projections of octavolateralis nerves in the brain of a soniferous damselfish (Abudefduf abdominalis). J Comp Neurol 512(5):628-650. doi:10.1002/ cne. 21923

Maruska KP, Tricas TC (2009b) Encoding properties of auditory neurons in the brain of a soniferous damselfish: response to simple tones and complex conspecific signals. J Comp Physiol A Neuroethol Sens Neural Behav Physiol. doi:10.1007/s00359-009-0480-1

Maruska KP, Tricas TC (2011) Gonadotropin-releasing hormone (GnRH) modulates auditory processing in the fish brain. Horm Behav 59(4):451-464. doi:10.1016/j.yhbeh.2011.01.003

Maruska KP, Boyle KS, Dewan LR, Tricas TC (2007) Sound production and spectral hearing sensitivity in the Hawaiian sergeant damselfish, Abudefduf abdominalis. J Exp Biol 210(22):3990-4004

Maruska KP, Ung US, Fernald RD (2012) The African cichlid fish Astatotilapia burtoni uses acoustic communication for reproduction: sound production, hearing, and behavioral significance. PLoS One 7(5), e37612. doi:10.1371/journal.pone.0037612

McCormick C (1999) Anatomy of the central auditory pathways of fish and amphibians. In: Fay RR, Popper AN (eds) Comparative hearing: fish and amphibians. Springer, New York, pp 155-217

McKibben JR, Bass AH (1999) Peripheral encoding of behaviorally relevant acoustic signals in a vocal fish: single tones. J Comp Physiol A Sens Neural Behav Physiol 184(6):563-576

Meyer M, Fay RR, Popper AN (2010) Frequency tuning and intensity coding of sound in the auditory periphery of the lake sturgeon, Acipenser fulvescens. J Exp Biol 213(Pt 9):1567-1578. doi:10.1242/jeb.031757

Meyer M, Popper AN, Fay RR (2012) Coding of sound direction in the auditory periphery of the lake sturgeon, Acipenser fulvescens. J Neurophysiol 107(2):658-665. doi:10.1152/ jn.00390.2011

Myrberg AA, Jr., Lugli M (2006) Reproductive behavior and acoustical interactions. In: Ladich F, Collin SP, Moller P, Kapoor BG, eds. Communication in Fishes, Volume 1. Enfield, N.H.: Science Publishers. p 149-176

Myrberg AAJ, Ha SJ, Shamblott MJ (1993) The sounds of bicolor damselfish (Pomacentrus partitus): Predictors of body size and a spectral basis for individual recognition and assessment. Journal of the Acoustical Society of America 94 No. 6:3067-3070

Offutt GC (1968) Auditory response in the goldfish. J Aud Res 8:391-400

Palmer LM, Mensinger AF (2002) Sensitivity of the anterior lateral line to complex stimuli in free swimming oyster toadfish, Opsanus tau. Integr Comp Biol 42(6):1290

Parvulescu A (1964) Problems of propagation and processing. In: Tavolga WN (ed) Marine bioacoustics. Pergamon Press, Oxford, pp 87-100

Parvulescu A (1967) The acoustics of small tanks. In: Tavolga WN (ed) Marine bioacoustics. Pergamon Press, Oxford, pp 7-14

Popper AN (1971) The effects of size on auditory capacities of the goldfish. J Aud Res XI:239-247

Popper AN, Fay RR (2011) Rethinking sound detection by fishes. Hear Res 273(1-2):25-36. doi:10.1016/j.heares.2009.12.023

Prechtl JC, von der Emde G, Wolfart J, Karamursel S, Akoev GN, Andrianov YN, Bullock TH (1998) Sensory processing in the pallium of a mormyrid fish. J Neurosci 18(18):7381-7393

Radford CA, Mensinger AF (2014) Anterior lateral line nerve encoding to tones and play-back vocalisations in free-swimming oyster toadfish, Opsanus tau. J Exp Biol 217(Pt 9):1570-1579. doi:10.1242/jeb.092510 
Radford CA, Montgomery JC, Caiger P, Higgs DM (2012) Pressure and particle motion detection thresholds in fish: a re-examination of salient auditory cues in teleosts. J Exp Biol 215(Pt 19):3429-3435. doi:10.1242/jeb.073320

Schellart NA (1983) Acousticolateral and visual processing and their interaction in the torus semicircularis of the trout, Salmo gairdneri. Neurosci Lett 42(1):39-44

Scholik AR, Yan HY (2001) Effects of underwater noise on auditory sensitivity of a cyprinid fish. Hear Res 152(1-2):17-24

Sisneros JA (2007) Saccular potentials of the vocal plainfin midshipman fish, Porichthys notatus. J Comp Physiol A Neuroethol Sens Neural Behav Physiol 193(4):413-424. doi:10.1007/ s00359-006-0195-5

Sisneros JA (2009) Seasonal plasticity of auditory saccular sensitivity in the vocal plainfin midshipman fish, Porichthys notatus. J Neurophysiol 102(2):1121-1131. doi:10.1152/ jn.00236.2009

Sisneros JA, Bass AH (2003) Seasonal plasticity of peripheral auditory frequency sensitivity. J Neurosci 23(3):1049-1058

Sisneros JA, Bass AH (2005) Ontogenetic changes in the response properties of individual, primary auditory afferents in the vocal plainfin midshipman fish Porichthys notatus Girard. J Exp Biol 208(Pt 16):3121-3131. doi:10.1242/jeb.01742

Sisneros JA, Forlano PM, Deitcher DL, Bass AH (2004) Steroid-dependent auditory plasticity leads to adaptive coupling of sender and receiver. Science 305(5682):404-407

Smith ME, Coffin AB, Miller DL, Popper AN (2006) Anatomical and functional recovery of the goldfish (Carassius auratus) ear following noise exposure. J Exp Biol 209(Pt 21):4193-4202

Suzuki A, Kozloski J, Crawford JD (2002) Temporal encoding for auditory computation: physiology of primary afferent neurons in sound-producing fish. J Neurosci 22(14):6290-6301

Tasaki I, Davis H, Eldredge DH (1954) Exploration of cochlear potentials in the guinea pig with a microelectrode. J Acoust Soc Am 26:765-773

Tavolga WN, Wodinsky J (1963) Auditory capacities in fishes. Bull Am Mus Nat Hist 126:177-240

Vasconcelos RO, Ladich F (2008) Development of vocalization, auditory sensitivity and acoustic communication in the Lusitanian toadfish Halobatrachus didactylus. J Exp Biol 211(Pt 4):502-509. doi:10.1242/jeb.008474

Vasconcelos RO, Amorim MC, Ladich F (2007) Effects of ship noise on the detectability of communication signals in the Lusitanian toadfish. J Exp Biol 210(Pt 12):2104-2112. doi:10.1242/ jeb.004317

Vasconcelos RO, Sisneros JA, Amorim MC, Fonseca PJ (2011) Auditory saccular sensitivity of the vocal Lusitanian toadfish: low frequency tuning allows acoustic communication throughout the year. J Comp Physiol A Neuroethol Sens Neural Behav Physiol 197(9):903-913. doi:10.1007/ s00359-011-0651-8

Wysocki LE, Codarin A, Ladich F, Picciulin M (2009) Sound pressure and particle acceleration audiograms in three marine fish species from the Adriatic Sea. J Acoust Soc Am 126(4):21002107. doi: $10.1121 / 1.3203562$

Yan HY, Popper AN (1991) An automated positive reward method for measuring acoustic sensitivity in fish. Behav Res Methods Instrum Comput 23(3):351-356

Yan HY, Fine ML, Horn NS, Colon WE (2000) Variability in the role of the gasbladder in fish audition. J Comp Physiol A 186:435-445

Zeddies DG, Fay RR, Gray MD, Alderks PW, Acob A, Sisneros JA (2012) Local acoustic particle motion guides sound-source localization behavior in the plainfin midshipman fish, Porichthys notatus. J Exp Biol 215(Pt 1):152-160. doi:10.1242/jeb.064998

Zelick R, Mann DA, Popper AN (1999) Acoustic communication in fishes and frogs. In: Fay RR, Popper AN (eds) Comparative hearing: fishes and amphibians. Springer, New York, pp 363-412

Zotterman Y (1943) The microphonic effect of teleost labyrinths and its biological significance. J Physiol 102(3):313-318 


\title{
The Potential Overlapping Roles of the Ear and Lateral Line in Driving "Acoustic" Responses
}

\author{
Dennis M. Higgs and Craig A. Radford
}

\begin{abstract}
Examination of fish responses to sound stimuli has a rich and varied history but it is not always clear when responses are true measures of hearing or the lateral-line. The central innervation of auditory and lateral-line sensory afferents lie in close proximity in the brainstem and both sets of receptors are, at heart, hair cellbased particle motion detectors. While it is possible to separately measure physiological activity of these two receptor subtypes, many studies of fish "hearing" use whole brain potentials or behavioural assays in complex sound fields where it is not possible to distinguish inputs. We argue here that, as often measured, what is thought of as fish "hearing" is often a multisensory response of both auditory and lateral line receptors. We also argue that in many situations where fish use sound stimuli, the behaviour is also an integrative response of both systems, due to the often close proximity of fish during sound communication. We end with a set of recommendations for better understanding the separate and combined roles of ear and lateral-line hair cells as well as an acknowledgment of the seminal and continuing contributions of Arthur N. Popper and Richard R. Fay to this field.
\end{abstract}

Keywords Fish hearing • Mechanosensory • Auditory • Lateral line • Acoustic communication $\bullet$ Multisensory integration

\section{Introduction}

As generally reported, the response of fish to a sound source is typically considered "hearing" and structural correlates to this response have focused on ears and other auditory structures, such as Weberian ossicles and laterophysic connections (e.g.

\author{
D.M. Higgs $(\square)$ \\ Department of Biological Sciences, University of Windsor, Windsor, ON, Canada \\ e-mail: dhiggs@uwindsor.ca \\ C.A. Radford \\ Leigh Marine Laboratory, Institute of Marine Science, University of Auckland, \\ Auckland, New Zealand \\ e-mail: c.radford@auckland.ac.nz
}


Popper and Fay 1973, 1993, 1999; Fay and Popper 2012). While this might be a reasonable approach to take for terrestrial animals, we feel it is unjustified for studying responses of fish to sound due to the complexities of sound transmission underwater (Parvulescu 1967; Akamatsu et al. 2002; Zeddies et al. 2010) as well as the short distances over which fish "acoustic" communication typically occurs (reviewed in Zelick et al. 1999; Ladich 2004). As early as 1967 Parvulescu argued that, especially in laboratory experiments, "animal behavior may be due to lateral-line response rather than to auditory system response" (Parvulescu 1967) and yet many researchers focus largely on the "auditory response" when examining responses of fish after sound presentation in tanks. By focusing on hearing as the main mechanism of sound source detection in fish, not only are we missing valuable insights into how fish respond to sound stimuli but we also may have difficulty interpreting evolutionary trends in sound detection. We argue here that detection of many sound sources, although by no means all, is best examined as a multimodal response in which fish use both the ear and lateral line, and associated structures (e.g. Weberian ossicles and laterophysic connections), to form a full picture of sound stimuli, likely incorporating all inputs into a sensory gestalt after integration by central neural structures. While we of course do not advocate going back to the views of van Bergeijk (1964) that the ear plays little role in localization or even detection, we do argue that the pendulum has swung too far toward focus on the ear as the primary detector of sound stimuli, especially in the highly artificial laboratory or nearfield environment. The ear and lateral line are complementary, but not redundant, systems and only by fully understanding their central integration will we have a true appreciation for the importance of sound to the sensory ecology of fish and how this may have evolved across the Osteichthyes particularly and across the broader grouping of animals considered "fish".

\section{Basic Concepts}

An underwater acoustic stimulus has two components, the nearfield and farfield, both of which provide important information to fish. The "nearfield" is dominated by hydrodynamic flow and the "farfield" is dominated by a propagating pressure wave (Fig. 1). Hydrodynamic flow is generated by the movement of water near the acoustic stimulus source, while sound pressure waves propagate from the acoustic source as a cyclic compression and rarefaction of the water (Rogers and Cox 1988; Higgs et al. 2006). The fish mechanosensory lateral line is sensitive to hydrodynamic flow within one to two body lengths from the source (nearfield), and is not generally sensitive to pressure (Montgomery et al. 1995; Sand and Bleckmann 2008). The lateral line has two types of receptors: superficial neuromasts (particle velocity sensitive), which lie on the surface of the skin; and canal neuromasts (particle acceleration sensitive), which are found in subdermal canals that open to the external environment via a series of pores. The inner ear is also sensitive to the particle movement of an acoustic field as a result of whole-body accelerations (Rogers and 


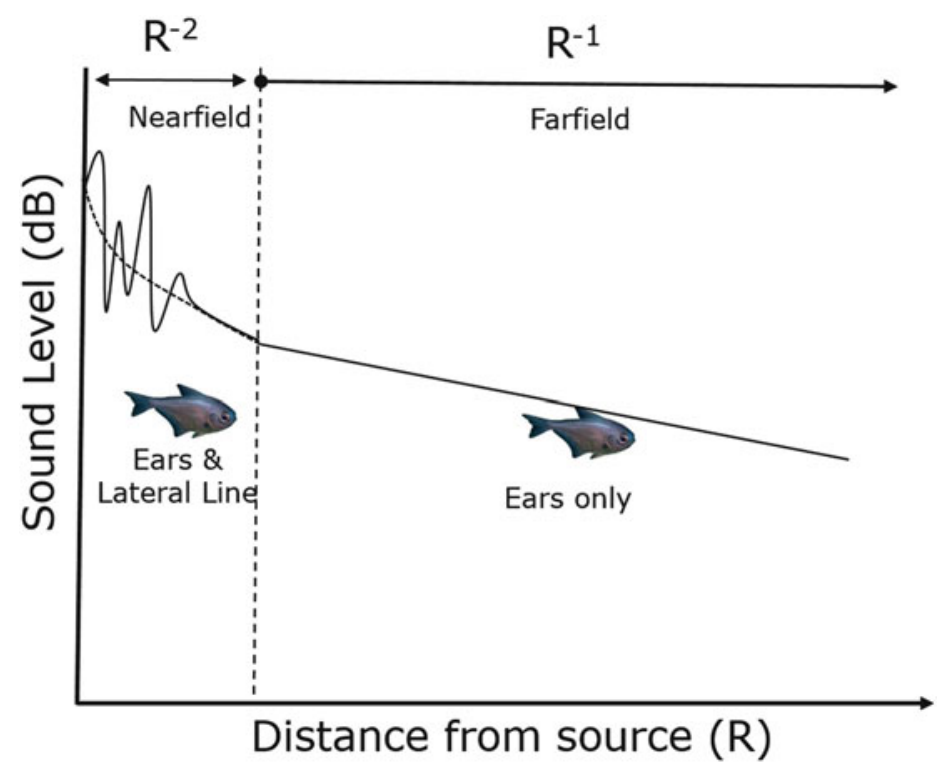

Fig. 1 Sound level as a function of distance for a representative source. Fluctuations near the source are due to source structure and would depend on direction. Dotted line shows sound level for an ideal point source

Cox 1988; Montgomery et al. 2006), through the differential movement of the denser otolith with the body motions of the fish. Sound pressure can be detected by fish from pressure-induced oscillations of the walls of an air pocket, such as the swim bladder, that then are transduced into mechanical stimuli appropriate to sensors (Higgs et al. 2006), such as the hair cells of the inner ear (Montgomery et al. 2006) or possibly the hair cells of the neuromasts that overlie laterophysic or otolaterophysic connections (Webb 1998; Webb and Smith 2000; Radford et al. 2013). The inner ear often lies just medial to the confluence of several cephalic lateral line canals (Fig. 2), so mechanical transduction to inner ear hair cells is also likely to be passed on to at least those neuromasts in the cephalic lateral line.

\section{Underwater Sound Propagation}

The behaviour of sound underwater is well characterized for ideal situations so will not be extensively reviewed here (see Rogers and Cox 1988; Montgomery et al. 2006). Sound consists of two components, particle motion and pressure, that, in theory, propagate in well-defined ways in unbounded media with the nearfield/farfield boundary dependent on wavelength. The problem with these physical descriptions of sound propagation for understanding the sensory ecology of fish is that the vast 


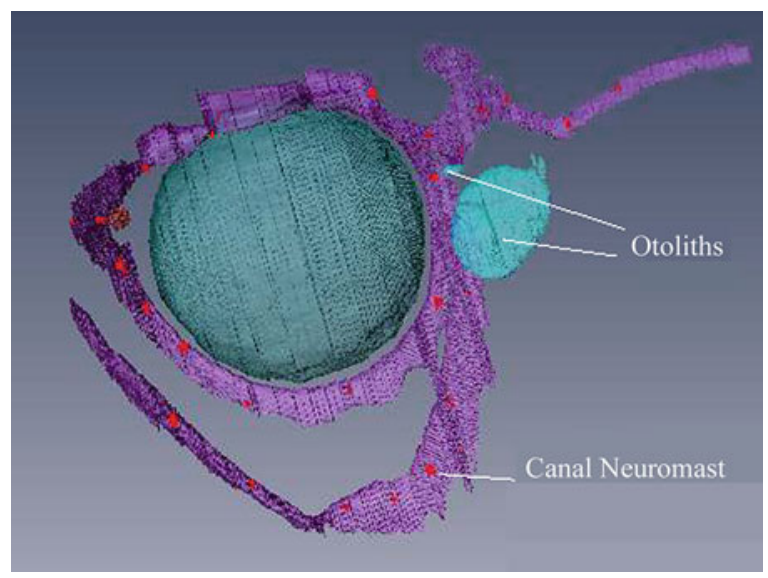

Fig. 2 MicroCT scan of a New Zealand Bigeye showing in vivo location of the otoliths and the canal neuromasts. Images were acquired on a Skyscan 1172 scanner and axial images were reconstructed as $17-35 \mathrm{~mm}$ slices. Anatomical structures were reconstructed from microCT slices, with Amira 5.2.1 (Visage Imaging, Inc.). Diagrams were prepared with Corel Graphics Suite X4. Green $=$ eye; blue $=$ otoliths; purple $=$ cephalic lateral line; red $=$ canal neuromasts

majority of fish species live in shallow and/or highly structured habitats (Lévêque et al. 2008) that disrupt sound propagation in highly unpredictable ways (Lugli and Fine 2007; Wilson et al. 2013). In the case of complex sound sources such as a coral reef, sound propagates much further than would be predicted from simple spreading models and it is likely that much of this propagation would be in the form of pressure waves (Fig. 3). Radford et al. (2011) described propagation of ambient reef sound from a temperate reef and observed a zone around the reef where sound loses little energy, what they termed the "reef effect" (Fig. 3c). Beyond the range of the reef effect (when the receiver is approximately $90^{\circ}$ to the reef) sound propagation can be described by cylindrical spreading with some bottom attenuation. The reef effect essentially extends the range at which reef sound can propagate away from the reef. Even when examining the propagation of single species calls, propagation dynamics do not follow theoretical predictions (Fig. 3a, b). Courtship calls of oyster toadfish (Opsanus tau) propagate less than $5 \mathrm{~m}$ from the source (Fig. 3b), with transmission loss much higher than predicted due to interaction with the substrate on which they are calling, although low frequency pure tones can propagate further than predicted due to boundary interactions (Fine and Lehnardt 1983). Damselfish (Pomacentridae) that enter the water column to signal (Fig. 3a) likely cannot detect their own calls over approximately $10 \mathrm{~m}$ away due to rapid propagation loss (Mann and Lobel 1997) and freshwater goby (Padogobius spp.) calls attenuate up to $30 \mathrm{~dB} 30 \mathrm{~cm}$ from the source (Lugli and Fine 2003) due to the shallow nature of their habitat. While simple spreading models would predict greater sound propagation of many of these low frequency calls, it is clear that-in the structured world in which many vocalizing fish live-habitat structure and depth put additional constraints on the effective 
a

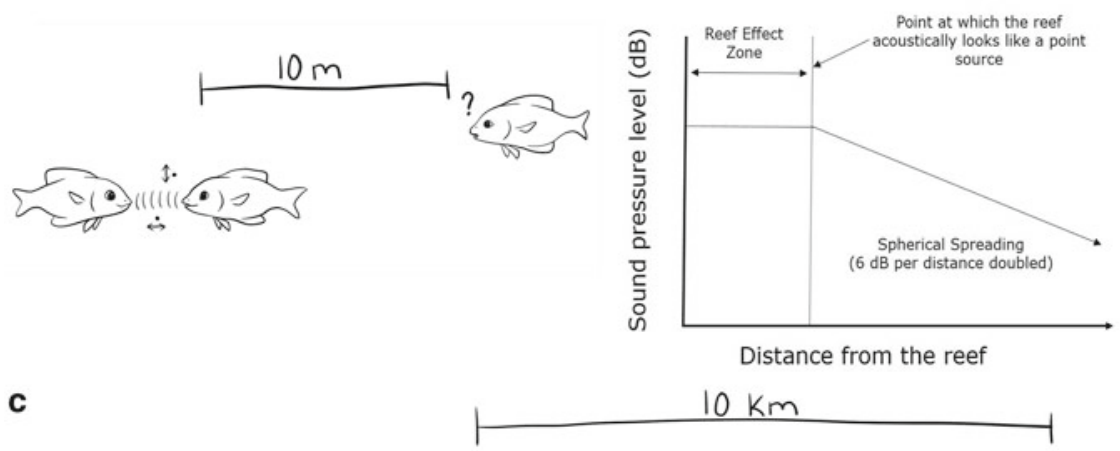

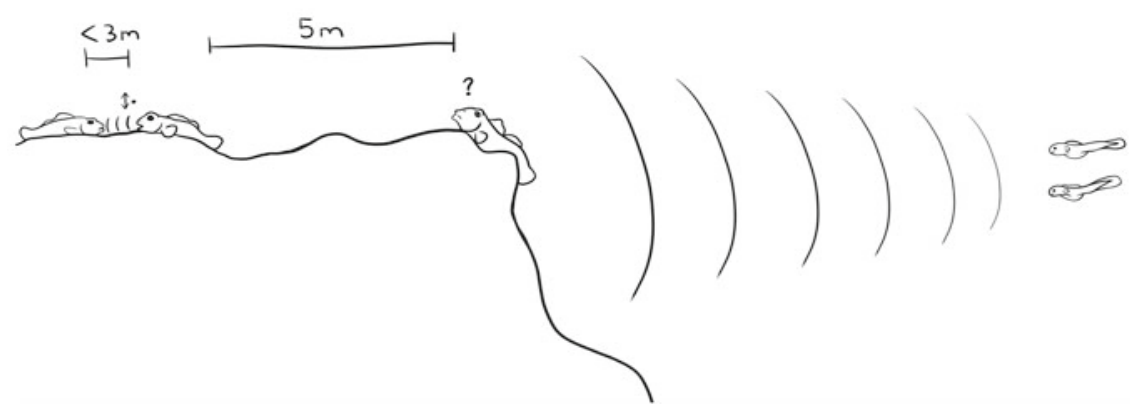

Fig. 3 Diagrammatic representation of relevant sound propagation in natural settings. (a) In pelagic spawning fish, communication sounds would be expected to stimulate both particle motion (double arrows in figure) and pressure sensors (arcs in figure) when fish are close together but likely are completely undetectable by either sensor at $10 \mathrm{~m}$ and beyond. (b) For benthic spawning fish, communication sounds likely are completely lost by $3 \mathrm{~m}$ from the source. (c) For reef communities there is little propagation loss even $1 \mathrm{~km}$ from the reef and then sound decays following idealized spherical spreading

distance of these calls and would put the effective range well within the detection range at which both ears and lateral lines would likely be stimulated (Fig. 3a, b).

\section{Sound Propagation in Tanks}

In experimental tanks, the propagation problem may be even harder to model due to relatively small tank sizes and variations in tank construction that have frequencydependent disruptions to sound travel. Sounds do not travel in standard plane waves in small tanks, causing inaccurate pressure recordings (Parvulescu 1967), and significant distortions can occur due to tank resonance, water depth and the complexity of sounds presented (Akamatsu et al. 2002). If carefully measured, the direct 
contributions of sound pressure and particle motion can be used to the experimenters' advantage by examining behavioural responses of freely swimming fish in different components of the sound field. Using this approach Zeddies et al. (2012) were able to definitively demonstrate that plainfin midshipman (Porichthys notatus) can localize to tonal signals by following particle motion gradients in a tank but this approach is rare. It is much more common to only characterize the sound pressure level at a release site and assume a constant gradient from the sound source to the animal of interest. Until more careful sound characterizations are done in the model of Zeddies et al. (2012) it will be difficult, if not impossible, to ascertain exactly what component of the sound is being used to drive "acoustic" responses in the laboratory environment (Coffin et al. 2014).

\section{Acoustic Ecology}

Despite the supposed importance of acoustic signalling in fish, there still remain very few studies that have actually measured the propagation of fish acoustic communication in natural environments but, where these studies do exist, it appears that acoustic communication is very limited in effective range (Egner and Mann 2005; Lugli and Fine 2003; Fine and Lehnardt 1983). Many of the vocalizing species that have been studied live in association with the bottom or in shallow, structured environments and in these situations there is poor sound propagation (Forrest et al. 1993). Even damselfish (Dascyllus albisella) that leave the bottom during acoustic "signal jumps" have propagation of acoustic signals lasting only 11-12 m from the source (Mann and Lobel 1997). Bottom-associated species such as gobies (Padogobius martensii) have an even greater transmission loss, calls are likely indistinguishable from noise approximately $50-60 \mathrm{~cm}$ away from the source (Lugli and Fine 2003). Even fishes in the family Batrachoididae ("toadfishes" such as $O$. tau and Halobatrachus didactylus) that are known to have quite loud calls (Fine and Perini 1994) likely cannot detect conspecifics above background noise within $5 \mathrm{~m}$ of the sources (Fine and Lehnardt 1983; Amorim and Vasconcelos 2008). Thus, the vast majority of fish acoustic communication likely occurs in the nearfield, where particle motion should dominate (Rogers and Cox 1988; Au and Hastings 2008), and is likely to use lateral line receptors in conjunction with auditory receptors. Lateral line receptivity has been characterized to explain the behavioural orientations to sound stimuli for at least one fish species, the squirrelfish, (Myripristis spp.) and physiological responses of lateral line afferents show directional-dependent responses that are consistent with, and possibly sufficient for, orientation behaviours to these sounds (Horch and Salmon 1973), although it remains possible that auditory responses could also aid in orientation. When investigating the interplay of sound and behaviour it is also important to consider the distance (farfield or nearfield) at which the behaviour is occurring and the acoustic modality used. Here we review the role sound plays in fish communication (short range) and orientation (long range). 
While fish may use sound as a long-distance attraction in some cases (see below), for conspecific communication - using Myrberg's (1981) definition of purposeful transfer of information to benefit the sender-both the signaller and the receiver are generally quite close together. In aggressive interactions involving sound cues, fish are typically within centimetres of each other (reviewed in Ladich 2004) and frequently produce high energy but low frequency $(<600 \mathrm{~Hz})$ sounds as aggressive displays (e.g. Tavolga 1958; Torricelli and Romani 1986; Torricelli et al. 1990; Amorim and Vasconcelos 2008; Johnston et al. 2008). In such cases, particle motion would predominate and both auditory and lateral line hair cells would likely be stimulated (Fig. 4a). For mating displays it is possible for fish to be further separated from one another, at least when calls might be used for mate attraction, and in these cases the predominant modality may change with distance from the source (Fig. 4b). In species such as midshipman (Brantley and Bass 1994), toadfish (Gray and Winn 1961), and many gobiids (Tavolga 1958; Torricelli and Romani 1986) males will vocalize without visual contact from a female. It is generally argued that directionalization is made possible by auditory processing (reviewed in Fay and Megela Simmons 1999), but lateral line inputs are known to be important in nearfield localization (Fay and Feng 1987) and have recently been hypothesized to work in conjunction with auditory processing at least for the midshipman response (Zeddies et al. 2012). For courtship sounds, the vocalization behaviour typically happens when a male and female are in close contact (Ladich 2004) and it is here that both hearing and lateral line hair cells are especially likely to be stimulated (Braun 2002; Sand and Bleckmann 2008). While it may be likely that longer-distance attractive calls are first detected and analysed by the auditory system, sounds used in final mating decisions are almost certainly analysed by both auditory and lateral-line peripheral and central mechanisms and both these systems must be considered when making functional correlates to behavioural responses.

a

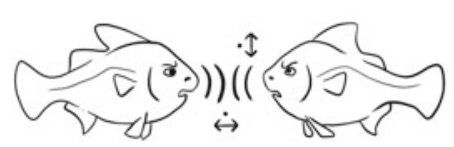

b

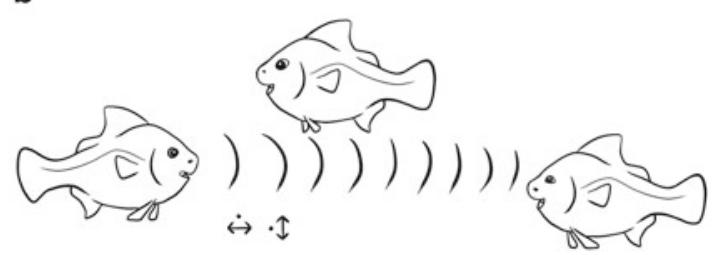

Fig. 4 In aggressive contexts (a), sound emission typically happens when fish are less than one body length apart and likely stimulate both particle motion (double arrows in figure) and pressure sensors (arcs in figure). Mating displays (b) may happen at a greater range of distances so sensory systems used will likely differ with distance, with pressure sensors needed further from the source but both ear and lateral line particle motion sensors stimulated as conspecifics come close for mating 


\section{Acoustic Attraction}

Long range (farfield) orientation studies began in the 1960s with Nelson and Myrberg's pioneering work on sharks, investigating the frequencies which attracted distant sharks the best. Nelson and Gruber (1963) found that different species of Carcharhinidae and Sphyrnidae were mostly attracted to low frequency $(20-60 \mathrm{~Hz})$ pulsed sounds compared to higher frequency $(400-600 \mathrm{~Hz})$ pulsed sounds or low frequency continuous sounds. Myrberg et al. $(1969,1972)$ took this work a step further and observed that sharks showed sensitivity to low amplitude irregular pulsed sounds up to a frequency of $1000 \mathrm{~Hz}$. The sharks also exhibited directional responses beyond the visual range of the camera $(>25 \mathrm{~m})$, which highlights that they were orienting to the sound stimulus well into what is typically thought of as the farfield (Myrberg et al. 1969). The actual nature of the attraction remains to be determined however, as sharks likely have little to no pressure sensitivity because they lack any pressure sensitive ancillary hearing structures, such as a swim bladder. Therefore, the particle motion component could be stimulating both the ear and external mechanoreceptors.

More recently, ambient underwater sound has been shown to play a major role in a key life history stage of many reef fish species - the transition from the larval pelagic stage to the benthic juvenile/adult stage (see Montgomery et al. 2001, 2006 for review). The first studies (Tolimieri et al. 2000; Simpson et al. 2004) employed the use of light traps and showed that traps with a sound source (recordings of ambient reef noise collected at night when most larvae settle) consistently caught more fish than silent traps. In free-swimming pelagic larvae followed by divers, it was also demonstrated that pre-settlement larvae will orient to a reef at night and that broadcast sounds can change their orientation behaviour, indicating that they can use sound to orient to reef habitats up to $1000 \mathrm{~m}$ from the reef source (Leis et al. 2002; Leis and Carson-Ewart 2003). The next step was using binary choice experiments which showed that all reef fish tested could directionally orient themselves to the sound source (Tolimieri et al. 2002, 2004; Leis and Lockett 2005). This was followed by patch reef experiments where reef fish settled onto the patch reefs associated with a sound source in greater numbers than silent patch reefs (Simpson et al. 2005). Not only do reef fish show a behavioural response towards sound, they also have the hearing capability to be able to detect these sounds (Wright et al. 2005, 2008, 2011). Combining the different hearing thresholds determined by Wright et al. (2011) with the reef sound propagation model developed by Radford et al. (2011), larval reef fish have the capability to detect a reef from between 8-15 km offshore. All these experiments highlight that sound plays a critical role as a long distance orientation and settlement cue for reef fish and at these distances it is likely that responses to sound are indeed likely dominated by true hearing responses because of the steep attenuation of particle motion sources likely to stimulate the lateral line at these distances (Figs. 1 and 3). 


\section{7 “Hearing” as a Physiological Response}

While some field studies have assessed hearing in free-field situations (e.g. Chapman 1973; Chapman and Hawkins 1973; Chapman and Sand 1974), the vast majority of especially physiological work has tested "hearing" in the lab environment. Sound travel in laboratory tanks is notoriously complex (Akamatsu et al. 2002) and likely contains particle motion information well beyond what is typically thought of as the nearfield limit. A common physiological measure of fish "hearing" is the use of auditory evoked potentials (AEP, previously called auditory brainstem response or $\mathrm{ABR})$. In this technique a fish is restrained under or at the surface of the water and a recording electrode implanted somewhere over the brainstem (Corwin et al. 1982; Kenyon 1996; Kenyon et al. 1998). In response to "sound" the waveform of brain activity will change in definable ways and the disappearance of this change as sound level decreases is taken to represent some sort of "auditory threshold". This technique is attractive to researchers because it is a fairly simple way to determine what sounds fish can detect and AEP can be quite useful in a comparative context to test how sound detection changes ontogenetically (e.g. Kenyon 1996; Higgs et al. 2002, 2003; Caiger et al. 2013), how experimental manipulations can affect detection (e.g. Yan et al. 2000; Radford et al. 2012, 2013; Higgs and Radford 2013), and to examine the bandwidth of detection between different species of interest (e.g. Corwin et al. 1982; Kenyon et al. 1998; Niemiller et al. 2013). While we have both used this technique extensively (e.g. Higgs et al. 2002; Radford et al. 2012, 2013; Higgs and Radford 2013) and recognize its utility in examination of sound detection, we no longer feel it can be used as an accurate test of hearing sensu strictu. The purpose of the present synopsis is not to review all the AEP/ABR papers that have been published, as that has been effectively done elsewhere (Ladich and Fay 2013), but rather to review the limited available evidence for the dual roles of the ear and lateral line in physiological responses to "acoustic" stimulation. The primary innervation sites for both auditory and lateral line nerves lie in close proximity in the brainstem (McCormick 1999; Higgs et al. 2006) and the same AEP recording setup that is commonly used in "hearing" studies has recently been used to measure direct lateral line stimulation (Brack and Ramcharitar 2012), therefore it seems likely that past AEP/ABR studies have been detecting responses of both systems. While there exists behavioural evidence that the lateral line can play a role in "acoustic" responses (see below), to our knowledge the only examination of the role of the lateral line in AEP responses is Higgs and Radford (2013). In that paper we showed that canal neuromasts play a role in "acoustic" thresholds previously attributed solely to the ear and that detection of sound stimuli in experimental tanks is likely an integrative response of both the ear and the lateral line, at least at low frequencies $(<400 \mathrm{~Hz})$. Direct recording from lateral line afferents in response to "acoustic" stimulation also shows that neuromasts can directly detect conspecific calls (Weeg and Bass 2002; Radford and Mensinger 2014) and can aid in localization of these calls in free-swimming fish (Radford and Mensinger 2014). The highlighted evidence clearly demonstrates that what was typically considered "hearing" may often 
be an integrative response between these two acoustic modalities. Unless the role of each system can be explicitly identified, we would recommend that future wholebrain physiological work be identified as acousticolateralis evoked potentials rather than the current ABR/AEP terminology.

\section{8 "Hearing” as a Behavioural Response}

In a more behavioural setup, there is also good evidence that lateral line afferents can also drive "hearing" responses, although the effect seems to vary with species. The Mauthner-mediated (M-cell) escape response is a reliable behavioural measure of reaction to aversive stimuli in fish that is driven by M-cell innervation of trunk musculature (Eaton et al. 1977). This M-cell escape response has been frequently used to test directional orientation to acoustic stimuli (reviewed in Eaton et al. 2001) and has been said to form a defined linkage between the ear and the trunk musculature (Moulton and Dixon 1967; Eaton and Popper 1995; Canfield and Rose 1996). While it is clear that the ear is involved in this behavioural response, the lateral line can also play an integrative role. Chemical ablation of the lateral line improves the ability of goldfish (Carassius auratus) to respond to sound stimuli while blocking the response of cichlids (Astatotilapia burtoni) (Canfield and Rose 1996) so both systems play a role in the M-cell response. The lateral line has been further implicated in both the directionality of this response and its interaction with environmental obstructions (i.e. tank walls) (Mirjany et al. 2011), showing that at least lower frequency sound stimuli are detected and processed by both auditory and lateral line systems.

\section{Particle and Pressure Detection}

To date there is only one published paper that has directly compared the contribution of particle motion and pressure sensitivity in fish (Radford et al. 2012). This paper compared the hearing thresholds of three species of fish (C. auratus, Pempheris adspersa, and Forstergyian lappilum) using a shaker table stimulus and an in-tank speaker stimulus. The results showed that all fish have the same basal hearing ability to particle motion and it is the fish's ability to detect the pressure stimulus that differentiates hearing ability between different groups, and likely drove evolutionary diversification in this modality. In a behavioural assay, female plainfin midshipman fish (Porichthys notatus) use particle velocity paths to directly guide their movement toward a vocalizing male with the response likely due to both hearing and lateral-line inputs (Zeddies et al. 2012). Radford and Mensinger (2014) have also shown that the toadfish $(O$. tau $)$ can use their anterior lateral line to respond to a speaker stimulus using chronic recordings. Thus both the lateral line and inner ear may play in sound source localisation and, depending how the stimulus is presented, 
behavioural and physiological techniques may actually measure an integrated response from the lateral line and ears.

Fish of course can be using their auditory systems for much more than just conspecific communication and it has been cogently argued elsewhere (Popper and Fay 1993, 1997; Fay 2009) that "hearing" in fish may have evolved to function for auditory scene analysis rather than just conspecific communication. Under this model, the fish auditory system works to extract a range of relevant signals out of the background noise, forming a sensory gestalt of the entire acoustic landscape. While there is little direct evidence for this hypothesis, it does make intuitive sense and it is in analysis of the broader range of sounds that auditory and lateral line inputs may be separated. For nearfield communication sounds however, and especially for sound fields in laboratory tanks, it is likely that central processing of both auditory and lateral line inputs is combined in integration centres to form an integrative picture of sound stimuli. Until this central integration is better understood it will not be clear exactly what roles the ear and lateral line play in sound detection, although for a fish it may not matter what system predominates as long as the appropriate response is elicited.

\section{Conclusions and Recommendations}

Popper and Fay have had an outsized influence on the general field of vertebrate hearing through their superb compendium of Springer-Verlag volumes, their strong individual scientific work, and their training and mentoring of numerous students, postdoctoral fellows and visiting researchers and, for fish hearing in particular, in their excellent series of review papers (Popper and Fay 1973, 1993, 1999; Fay and Popper 2012) laying out the state of the field and major research questions still to be addressed. While we are far from their status as 'senior bioacousticians' (Fay and Popper 2012), we wish to end this review by emulating their model and offer three suggestions where we feel the research community could helpfully progress. As we hope we outlined above, we are not the first to suggest these research foci but by laying them out explicitly below we urge the field to consider new approaches that will better elucidate how the ear and lateral line work together to form a central image in response to sound stimuli.

1. In other vertebrates, especially mammals, the study of multisensory integration has become well established but researchers studying fish sensory function have predominantly studied sensory systems in isolation. We feel an enhanced emphasis on truly integrative physiology has the potential to advance the field in significant ways. Both single- and multi-unit recordings from integrative centres such as the torus semicircularis in response to sound stimuli as well as more natural stimuli (e.g. conspecifics or prey stimuli presented in the recording chamber, e.g. Wysocki and Ladich 2003; Maruska et al. 2007) would better inform us as to how fish encode and process sensory stimuli at the central level and turn that processing into behavioural responses. This physiological work would ideally be 
coupled with anterograde and retrograde tracing to better understand how and where ear and lateral line afferents are integrated at a central level.

2. While there have been some attempts to isolate ear and lateral line inputs by selective ablation, especially of lateral line inputs (see above), more could be done in this regard. We echo Zeddies et al. (2012) suggestion that selective ablation of each input in freely behaving fish would be highly instructive in determining the role of each system. While selective ablation is not without controversy (Janssen 2000; Brown et al. 2011), if done carefully this technique can add insights into how fish perceive stimuli and how this perception drives responses.

3. While challenging, more effort must be put into physiological and behavioural responses in animals in their natural environment. At least for larger fish it is now possible to accurately track movements of free-swimming fish with either implanted passive integrated transponder (PIT) tags (e.g. www.Biomark.com) or acoustic tags (e.g. www.vemco.com) and these technologies could be effectively used to record responses of fish to a variety of sound stimuli. There has also been rapid progress in side-scan sonar applications from many companies that provide impressive details on fish movements and behaviours. Physiologically, it is now possible to record from neurons of free-swimming fish (e.g. Radford and Mensinger 2014) so more effort in this regard would be highly instructive as to how fish process sensory stimuli at both peripheral and central levels, although current technology would limit this to larger, more robust fish.

Acknowledgements Drs. Arthur Popper and Richard Fay have been the guiding influence for much of the field of fish bioacoustics throughout their careers and have advanced the field by their own primary research work as well as by the numerous commentary papers and compendia they have put together over the years. Art was a valued mentor for DH during a critical phase of his scientific career and acted as a true mentor as a scientist and as an academic. The time spent in Popper's lab continues to influence DH and contribute to his approach to science and mentoring. Dr. Fay was also an important sounding board for DH during his time as a postdoctoral fellow and, while DH never had the opportunity to work directly in Fay's lab he always appreciated the feedback and assistance when their paths crossed. While CR has not had the opportunity to work directly with either of Dr. Popper or Fay, they have really provided the foundation behind his work in understanding how larval marine fish use underwater sound as an orientation cue. In saying that, Dr. Popper has always supported CR's work through invitations and support to attend conferences.

The authors also gratefully appreciate the work of Ms. Meghan Donovan for drawing images for Figs. 3 and 4, Mr. Peter Johnston (MD) for the work on the CT-Scan images and two anonymous reviewers for many constructive comments on an earlier draft of this manuscript.

\section{References}

Akamatsu T, Okumura T, Novarini N, Yan HY (2002) Empirical refinements applicable to the recording of fish sounds in small tanks. J Acoust Soc Am 112:3073-3082

Amorim MCP, Vasconcelos RO (2008) Variability in the mating calls of the Lusitanian toadfish Halobatrachus didactlyus: cues for potential individual recognition. J Fish Biol 73:1267-1283 
Au WWL, Hastings MC (2008) Principles of marine bioacoustics. Springer, New York

Brack CL, Ramcharitar J (2012) Assessment of lateral line function: a potential technique for studies in ototoxicity. J Clin Neurosci 19:333-335

Brantley RK, Bass AH (1994) Alternative male spawning tactics and acoustic signals in the plainfin midshipman fish Porichthys notatus Girard (Teleostei, Batrachoididae). Ethology 96:213-232

Braun CB (2002) What is the nature of multisensory interaction between octavolateralis subsystems. Brain Behav Evol 59:162-176

Brown AD, Mussen TD, Sisneros JA, Coffin AB (2011) Reevaluating the use of aminoglycoside antibiotics in behavioral studies of the lateral line. Hear Res 272:1-2

Caiger PE, Montgomery JC, Bruce M, Lu J, Radford CA (2013) A proposed mechanism for the observed ontogenetic improvement in the hearing ability of hapuka (Polyprion oxygeneios). J Comp Phys A 199:653-661

Canfield JG, Rose GJ (1996) Hierarchical sensory guidance of Mauthner-mediated escape responses in goldfish (Carassius auratus) and cichlids (Haplochromis burtoni). Brain Behav Evol 48:137-156

Chapman CJ (1973) Field studies of hearing in teleost fish. Helgolander wiss Meeresunters 24:371-390

Chapman CJ, Hawkins AD (1973) A field study of hearing in the cod, Gadus morhua. J Comp Physiol 85:147-167

Chapman CJ, Sand O (1974) Field studies of hearing in two species of flatfish Pleuronectes platessa (L.) and Limnada limnada (L.) (Family Pleuronectidae). Comp Biochem Physiol 47A:371-385

Coffin AB, Zeddies DG, Fay RR, Brown AD, Alderks PW, Bhandiwad AA, Mohr RA, Gray MD, Rogers PH, Sisneros JA (2014) Use of the swim bladder and lateral line in near-field sound source localization by fish. J Exp Biol 217:2078-2088

Corwin JT, Bullock TH, Schweitzer J (1982) The auditory brain stem response in five vertebrate classes. Electroencephalogr Clin Neurophysiol 54:629-641

Eaton RC, Popper AN (1995) The octavolateralis system and Mauthner cell: interactions and questions. Brain Behav Evol 46:124-130

Eaton RC, Bombardier RA, Meyer DL (1977) The Mauthner-initiated startle response in teleost fish. J Exp Biol 66:65-81

Eaton RC, Lee RKK, Foreman MB (2001) The Mauthner cell and other identified neurons of the brainstem escape network of fish. Prog Neurobiol 63:467-485

Egner SA, Mann DA (2005) Auditory sensitivity of sergeant major damselfish Abudefduf saxatilis from post-settlement juvenile to adult. Mar Ecol Prog Ser 285:213-222

Fay R (2009) Soundscapes and the sense of hearing of fishes. Integr Zool 4:26-32

Fay RR, Feng AS (1987) Mechanisms for directional hearing among nonmammalian vertebrates. In: Yost WA, Gourevitch G (eds) Directional hearing. Springer, New York, pp 179-211

Fay RR, Megela Simmons A (1999) The sense of hearing in fishes and amphibians. In: Fay RR, Popper AN (eds) Comparative hearing: fish and amphibians. Springer, New York, pp 269-318

Fay RR, Popper AN (2012) Fish hearing: new perspectives from two "senior" bioacousticians. Brain Behav Evol 792:215-217

Fine ML, Lehnardt ML (1983) Shallow-water propagation of the toadfish mating call. Comp Biochem Physiol 76A:225-231

Fine ML, Perini MA (1994) Sound production evoked by electrical stimulation of the forebrain in the oyster toadfish. J Comp Physiol A 174:173-185

Forrest TG, Miller GL, Zagar JR (1993) Sound propagation in shallow water: implications for acoustic communication by aquatic animals. Bioacoustics 4:259-270

Gray GA, Winn HE (1961) Reproductive ecology and sound production of the toadfish, Opsanus tau. Ecology 42:274-282

Higgs DM, Lui, Z, Mann DA (2006) Hearing and mechanoreception. In: Evans DH (ed) The physiology of fishes, 3rd edn. CRC Press, pp 391-429 
Higgs DM, Radford CA (2013) The contribution of the lateral line to "hearing" in fish. J Exp Biol 216:1484-1490

Higgs DM, Souza MJ, Wilkins HR, Presson JC, Popper AN (2002) Age related changes in the inner ear and hearing ability of the adult zebrafish (Danio rerio). J Assoc Res Otolaryngol 3:174-184

Higgs DM, Rollo AK, Souza MJ, Popper AN (2003) Development of form and function in peripheral auditory structures of the zebrafish (Danio rerio). J Acoust Soc Am 113:1145-1154

Horch K, Salmon M (1973) Adaptations to the acoustic environment by the squirrelfishes Myripristis violaceus and M. pralinius. Mar Behav Physiol 2:121-139

Janssen J (2000) Toxicity of Co2+: implications for lateral line studies. J Comp Physiol A 186:957-960

Johnston CE, Bolling MK, Holt DE, Phillips CT (2008) Production of acoustic signals during aggression in Coosa bass, Micropterus coosae. Environ Biol Fish 82:17-20

Kenyon TN (1996) Ontogenetic changes in the auditory sensitivity of damselfishes (Pomacentridae). J Comp Physiol A 179:553-561

Kenyon TN, Ladich F, Yan HY (1998) A comparative study of hearing ability in fishes: the auditory brainstem response approach. J Comp Physiol A 182:307-318

Ladich F (2004) Sound production and acoustic communication. In: von der Emde G, Mogdans J, Kapoor BG (eds) The senses of fish: adaptations for the reception of natural stimuli. Narosa Publishing, New Delhi, pp 210-230

Ladich F, Fay RR (2013) Auditory evoked potential audiometry in fish. Rev Fish Biol Fish 23:317-364

Leis JM, Carson-Ewart BM (2003) Orientation of pelagic larvae of coral-reef fishes in the ocean. Mar Ecol Prog Ser 252:239-253

Leis JM, Lockett MM (2005) Localization of reef sounds by settlement stage larvae of coral-reef fishes (Pomacentridae). Bull Mar Sci 76:715-724

Leis JM, Carson-Ewart BM, Cato DH (2002) Sound detection in situ by the larvae of a coral-reef damselfish (Pomacentridae). Mar Ecol Prog Ser 232:259-268

Lévêque C, Oberdoff T, Paugy D, Stiassny MLJ, Tedesco PA (2008) Global diversity of fish (Pisces) in freshwater. Hydrobiologia 595:545-567

Lugli M, Fine ML (2003) Acoustic communication in two freshwater gobies: ambient noise and short-range propagation in shallow streams. J Acoust Soc Am 114:512

Lugli M, Fine ML (2007) Stream ambient noise, spectrum and propagation of sounds in the goby Padogobius martensii: sound pressure and particle velocity. J Acoust Soc Am 122:2881-2892

Mann DA, Lobel PS (1997) Propagation of damselfish (Pomacentridae) courtships sounds. J Acoust Soc Am 101:3783

Maruska KP, Boyle KS, Dewan LR, Tricas TC (2007) Sound production and spectral hearing sensitivity in the Hawaiian sergeant damselfish, Abudefduf abdominalis. J Exp Biol 210:3990-4004

Mccormick CA (1999) Anatomy of the central auditory pathways of fish and amphibians. In: Comparative hearing: fish and amphibians. Springer, New York, pp 155-217

Mirjany M, Preuss T, Faber DS (2011) Role of the lateral line mechanosensory system in directionality of goldfish auditory evoked escape response. J Exp Biol 214:3358-3367

Montgomery J, Coombs SL, Halstead M (1995) Biology of the mechanosensory lateral line in fishes. Rev Fish Biol Fish 5:399-416

Montgomery JC, Tolimieri N, Haine OS (2001) Active habitat selection by pre-settlement reef fishes. Fish Fish 2:261-277

Montgomery JC, Jeffs A, Simpson SD, Meekan M, Tindle C (2006) Sound as an orientation cue for the pelagic larvae of reef fishes and decapod crustaceans. Adv Mar Biol 51:143-196

Moulton JM, Dixon RH (1967) Directional hearing in fishes. Mar Bioacoust 2:187-228

Myrber AA, Spires JY (1972) Sound discrimination by the bicolor damselfish, Eupomacentrus partitus. J Exp Biol 57:727-735

Myrberg AA (1981) Sound communication and interception in fishes. In: Popper AN, Fay RR (eds) Hearing and sound communication in fishes. Springer, New York, pp 395-426 
Myrberg AA, Banner A, Richard JD (1969) Shark attraction using a video-acoustic system. Mar Biol 2:264-276

Nelson EM, Gruber SH (1963) Sharks: attraction by low-frequency sounds. Science 142:975-977

Niemiller ML, Higgs DM, Soares D (2013) Evidence for hearing loss in amblyopsid cavefishes. Biol Lett 9. doi:10.1098/rsbl.2013.0104

Parvulescu A (1967) The acoustics of small tanks. Mar Bioacoust 2:7-13

Popper AN, Fay RR (1973) Sound production and processing by teleost fishes: a critical review. J Acoust Soc Am 53:1515-1529

Popper AN, Fay RR (1993) Sound detection and processing by fish: critical review and major research questions. Brain Behav Evol 41:14-38

Popper AN, Fay RR (1997) Evolution of the ear and hearing: issues and questions. Brain Behav Evol 50:213-221

Popper AN, Fay RR (1999) Comparative hearing: fish and amphibians. Springer, New York

Radford CA, Mensinger AF (2014) Anterior lateral line nerve encoding to tones and play-back vocalisations in free-swimming oyster toadfish, Opsanus tau. J Exp Biol 217:1570-1579

Radford CA, Tindle CT, Montgomery JC, Jeffs AG (2011) Modelling a reef as an extended sound source increases the predicted range at which reef noise may be heard by fish larvae. Mar Ecol Prog Ser 438:167-174

Radford CA, Montgomery JC, Caiger P, Higgs DM (2012) Pressure and particle motion detection thresholds in fish: a re-examination of salient auditory cues in teleosts. J Exp Biol 215:3429-3435

Radford CA, Montgomery JC, Caiger P, Johnston P, Lu J, Higgs DM (2013) A novel hearing specialization in the New Zealand bigeye, Pempheris adspersa. Biol Lett 9:21020163

Rogers PH, Cox M (1988) Underwater sound as a biological stimulus. In: Atema J, Fay RR, Popper AN, Tavolga WN (eds) Sensory biology of aquatic animals. Springer, New York, pp 131-149

Sand O, Bleckmann H (2008) Orientation to auditory and lateral line stimuli. In: Webb JF, Popper AN, Fay RR (eds) Fish bioacoustics. Springer, New York, pp 183-231

Simpson SD, Meekan MG, McCauley RD, Jeffs A (2004) Attraction of settlement-stage coral reef fishes to reef noise. Mar Ecol Prog Ser 276:263-268

Simpson SD, Meekan MG, Montgomery JC, McCauley RD, Jeffs A (2005) Homeward sound. Science 308:221

Tavolga WN (1958) Underwater sounds produced by two species of toadfish, Opsanus tau and Opsanus beta. Bull Mar Sci 8:278-284

Tolimieri N, Jeffs A, Montgomery JC (2000) Ambient sound as a cue for navigation by the pelagic larvae of reef fishes. Mar Ecol Prog Ser 207:219-224

Tolimieri N, Haine O, Montgomery JC, Jeffs A (2002) Ambient sound as a navigational cue for larval reef fish. Bioacoustics 12:214-217

Tolimieri N, Haine O, Jeffs A, McCauley R, Montgomery JC (2004) Directional orientation of pomacentrid larvae to ambient reef sound. Coral Reefs 23:184-191

Torricelli P, Romani R (1986) Sound production in the Italian freshwater goby, Padogobius martensi. Copeia 1986:213-216

Torricelli P, Lugli M, Pavan G (1990) Analysis of sounds produced by male Padogobius martensi (Pisces, Gobiidae) and factors affecting their structural properties. Bioacoustics 2:261-275

van Bergeijk WA (1964) Directional and nondirectional hearing in fish. Mar Bioacoust 1:281-299

Webb JF (1998) Laterophysic connection: a unique link between the swimbladder and the lateral line system in Chaetodon (Perciformes: Chaetodontidae). Copeia 1998:1032-1036

Webb JF, Smith WL (2000) The laterophysic connection in chaetodontid butterflyfish: morphological variation and speculations on sensory function. Philos Trans R Soc B 355:1125-1129

Weeg MS, Bass AH (2002) Frequency response properties of lateral line superficial neuromasts in a vocal fish, with evidence for acoustic sensitivity. J Neurophysiol 88:1252-1262 
Wilson CJ, Wilson PS, Greene CA, Dunton KH (2013) Seagrass meadows provide an acoustic refuge for estuarine fish. Mar Ecol Prog Ser 472:117-127

Wright K, Higgs DM, Belanger AJ, Leis J (2005) Auditory and olfactory abilities of pre-settlement larvae and post-settlement juveniles of a coral reef damselfish (Pisces: Pomacentridae). Mar Biol 147:1425-1434

Wright K, Higgs DM, Leis J (2008) Auditory and olfactory abilities of larvae of the Indo-Pacific Coral Trout Plectropomus leopardus (Pisces: Serranidae) at settlement. J Fish Biol 72:2543-2556

Wright K, Higgs DM, Leis J (2011) Ontogenetic and interspecific variation in hearing ability in marine fish larvae. Mar Ecol Prog Ser 424:1-13

Wysocki LE, Ladich F (2003) The representation of conspecific sounds in the auditory brainstem of teleost fishes. J Exp Biol 206:2229-2240

Yan HY, Fine ML, Horn NS, Colón WE (2000) Variability in the role of the gasbladder in fish audition. J Comp Physiol 186:435-445

Zeddies DG, Fay RR, Alderks PW, Shaub KS, Sisneros JA (2010) Sound source localization by the plainfin midshipman fish, Porichthys notatus. J Acoust Soc Am 127:3104-3113

Zeddies DG, Fay RR, Gray MD, Alderks PW, Acob A, Sisneros JA (2012) Local acoustic particle motion guides sound-source localization behavior in the plainfin midshipman fish, Porichthyes notatus. J Exp Biol 215:152-160

Zelick R, Mann DA, Popper AN (1999) Acoustic communication in fishes and frogs. In: Fay RR, Popper AN (eds) Comparative hearing: fish and amphibians. Springer, New York, pp 363-411 


\title{
Multimodal Sensory Input in the Utricle and Lateral Line of the Toadfish, Opsanus tau
}

\author{
Allen F. Mensinger
}

\begin{abstract}
The utricular otolith and the mechanosensory lateral line of the toadfish, Opsanus tau, were investigated for sensitivity to multimodal sensory input by recording neural activity from free swimming fish. The utricle was sensitive to horizontal body movement, and displayed broad sensitivity to low frequency (80-200 $\mathrm{Hz}$ ) sound. The lateral line was sensitive to water currents, swimming, prey movements, and sound with maximal sensitivity at $100 \mathrm{~Hz}$. Both systems showed directional sensitivity to pure tones and toadfish vocalizations, indicating potential for sound localization. Thus, toadfish possess two hair cell based sensory systems that integrate information from disparate sources. However, swimming movements or predation strikes can saturate each system and it is unclear the effect that selfgenerated movement has on sensitivity. It is hypothesized that the toadfish's strategy of short distance swim movements allows it to sample the acoustical environment while static. Further study is needed to determine the integration of the two systems and if they are able to segregate and/or integrate multimodal sensory input.
\end{abstract}

Keywords Auditory $\bullet$ Vestibular $\bullet$ Sound localization $\bullet$ Behavior

\section{Introduction}

The inner ear of teleosts developed over 400 million years ago and consists of three otolith organs, the saccule, utricle, and lagena and three semicircular canals, all of which contain sensory hair cells. The colonization of the terrestrial environment by vertebrates led to the development of the outer ear to detect airborne sound and segregation of the inner ear components into vestibular (otoliths and semicircular canals) and auditory (cochlea or cochlea duct) organs (Fritzsch 1999). However, the dual auditory/vestibular function of the otoliths persists in extant teleosts, and it

\footnotetext{
A.F. Mensinger $(\square)$

Biology Department, University of Minnesota Duluth, Duluth, MN 55812, USA

Marine Biological Laboratory, Woods Hole, MA 02543, USA

e-mail: amensing@d.umn.edu
} 
remains unclear how these organs simultaneously integrate bimodal sensory input such as sound and self-generated movement.

Fish also possess a hair cell based mechanosensory lateral line which functions in schooling behavior (Partridge and Pitcher 1980), rheotaxis (Montgomery et al. 1997), localization of underwater objects (Weissert and von Campenhausen 1981), and predator/prey interactions (Montgomery et al. 1995). Unlike the inner ear, the lateral line was not retained throughout vertebrate evolution and is limited to fish and aquatic amphibians. Although the role of the lateral line in sound detection has long been debated (see Braun et al. 2002 for review), several studies have suggested that the fish's mechanosensory lateral line may play a role in sound localization (Higgs and Radford 2013; Mirjany and Faber 2011; Mirjany et al. 2011; Radford and Mensinger 2014; Weeg and Bass 2002). Thus, similar to the otoliths, the mechanosensory lateral line receives multimodal (i.e., vibration and sound) input.

A long-standing question in neuroethology is how fish localize sound underwater. Although the saccule is considered the primary auditory endorgan in fish (Popper and Fay 1993, 2011), both the saccule and utricle are sensitive to linear acceleration and acoustic particle motion, and display directional sensitivity, functioning predominantly as low frequency $(60-1000$ Hz) detectors (Boyle et al. 2001; Fay 1984; Fay and Edds-Walton 2000; Lu et al. 2004; Mensinger 2006). However, the mechanism by which otoliths contribute to sound localization remains unclear. While terrestrial vertebrates use interaural time delays to localize sound in the azimuth (Schnupp and Carr 2009), the small distances between otolith pairs, the low density of the cerebral spinal fluid and/or brain tissue in the intervening space and the relatively rapid underwater speed of sound, makes using time disparities challenging for teleosts. Further complicating matters is the otoliths' vestibular role as any selfgenerated movement may impact auditory sensitivity.

The traditional neurophysiological method of recording from restrained, anesthetized fish complicates investigating bimodal sensory input, especially associated with self-movement (i.e., respiration, swimming). Semi-submerged preparations make it difficult to deliver and/or quantify the sound impacting the otoliths, while submerged preparations often are complicated by echoes produced during sound presentation in small tanks (Mensinger and Deffenbaugh 2000). Furthermore, animal care regulations mandate the use of anesthesia with restrained and/or paralyzed fish, which may depress neural sensitivity (Palmer and Mensinger 2004). The development of the shaker table by the Fay laboratory (Fay 1984) allowed for very accurate measurement of acoustic sensitivity that partially offset previous testing problems, however it remained limited to restrained fish which makes it difficult to test bimodal stimuli.

It has long been the goal of neuroethologists to record from freely moving animals in their natural state. While significant advances have been made with terrestrial animals using radio telemetry for monitoring physiological processes (Kramer and Kinter 2003), the use of these techniques in the aquatic medium has been tempered by its opacity to radio waves and viscosity that produces drag on external devices. Tethered preparations using swivels have been successful with animals exhibiting two dimensional movement (i.e., mice in the horizontal plane) (Young 
and Davisson 2011), but less amenable for actively swimming fish that can quickly entangle themselves in the wire. The development of chronically implanted microwire electrodes and telemetry tag (Mensinger and Deffenbaugh 1998, 2000) or tether provided the ability for stable, long-term recording (up to a week) in freely moving fish. This chapter summarizes the use of this system for exploring the sensory physiology of the inner ear and lateral line. The eventual goal is to determine the relative contribution and the possible integration of each system during multimodal stimulation. For example, fish swimming will stimulate both otoliths and the lateral line, and it is unclear how these organs will process auditory input during movement.

\subsection{The Toadfish}

Batrachoid fish (Opsanus sp. and Porichthys sp.) have been developed into important biological models for investigating muscle physiology (Elemans et al. 2014; Harwood et al. 2011), excretory function (Walsh et al. 2008), and vestibular physiology (Rabbitt et al. 1995). However, as sound generation and reception is an integral part of their natural history, they also have become subjects for neuroethology and bioacoustic studies. The Fay laboratory has detailed the neuroanatomy and the auditory physiology of the saccular endorgan of the toadfish, Opsanus tau (EddsWalton et al. 1999, 2013; Edds-Walton and Fay 2003, 2005a, b, 2008, 2009) demonstrating its ability to encode pure tones in the range of fish vocalizations. Both male and female fish produce broadband grunts by means of rapid contraction of sonic muscles surrounding the swim bladder. However, only sexually mature male toadfish produce a bimodal vocalization, termed a boatwhistle, which is used to acoustically attract females to nesting sites (Fine et al. 1977; Gray and Winn 1961). The boatwhistle consists of a brief, irregular initial grunt (broadband) followed by an extended period of regular pulsing (fundamental frequency $<200 \mathrm{~Hz}$ ) (EddsWalton et al. 2002). Although the production and reception of the sound has resulted in many investigations on sonic muscle and auditory physiology (Harwood et al. 2011; Mensinger 2014; Walsh et al. 2008), the mechanism by which female fish locate the males, and which characteristics (i.e., amplitude, frequency, duration) of the call influence mate choice remain largely unknown.

\section{Materials and Methods}

\subsection{Telemetry Tag}

An inductive telemetry system was developed for recording neural activity from free swimming fish. The system consisted of three channel microwire electrodes, a cylindrical $(38 \times 15 \mathrm{~mm}$ dia) transmitting telemetry tag and receiver coils. The 
tritrodes (impedance $0.5-1.5 \mathrm{M} \Omega$ ) were fabricated with three strands of insulated 20 $\mu \mathrm{m}$-diameter $10 \%$ platinum/iridium wire that terminated into a multipin underwater connector which joined to the telemetry tag. Two miniature capacitors, a differential amplifier, low $(400 \mathrm{~Hz})$ and high $(4 \mathrm{kHz})$ filters, and a circular inductive coil were contained in the tag (Fig. 1a). The neural signals were transmitted as a frequency-modulated magnetic field ( $90 \mathrm{kHz}$ carrier, $20 \mathrm{kHz}$ bandwidth), to the receiver coils embedded in a recharging habitat and stage (RECHABS) (Fig. 1b).

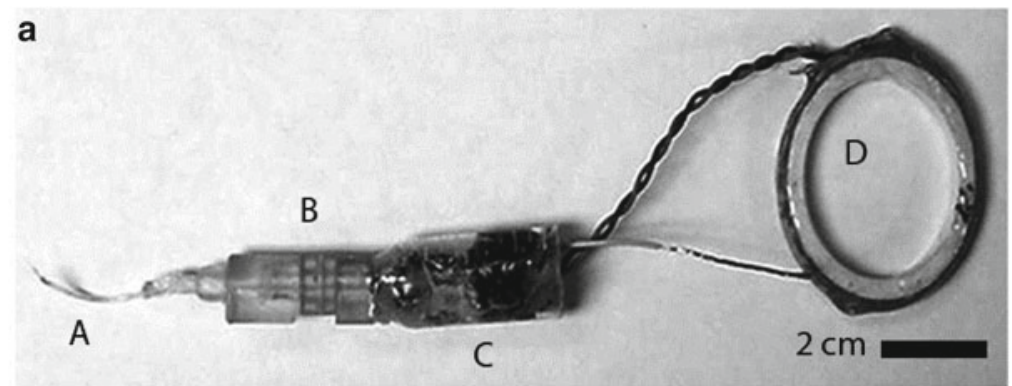

b

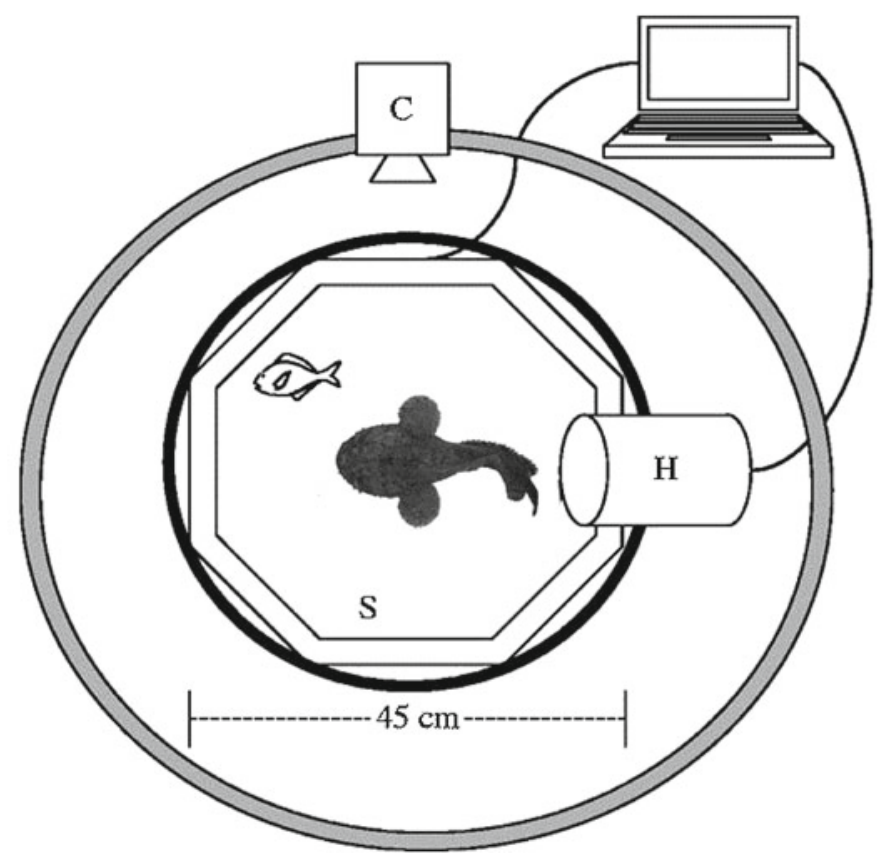

Fig. 1 (a) Photograph of the neural telemetry tag. (A) Electrode lead; $(B)$ waterproof connector; $(C)$ tag body with amplifier, capacitors, and filters: $(D)$ Inductive coil. (b) Dorsal view of the experimental arena. The recharging habitat and stage (RECHABS) consists of the cylindrical habitat $(H)$ and the octagonal stage $(S)$. Neural telemetry and tag recharging could transpire when the fish was in the habitat or over the stage. Fish movements were recorded with an overhead video camera $(C)$. Drawing is not to scale. Modified from Palmer et al. (2005) 
The RECHABS consisted of a cylindrical habitat $(12 \mathrm{~cm}$ internal diameter $\times 30 \mathrm{~cm})$ that opened onto an octagonal stage $(16 \mathrm{~cm}$ per side), and served to receive the telemetry signal and recharge the tag. Telemetry and recharging was possible whenever the fish was within the footprint of the RECHABS up to an elevation of approximately $15 \mathrm{~cm}$ above the stage. Magnetic induction fully powered the tag in less than $30 \mathrm{~s}$ and provided telemetry for up to $20 \mathrm{~min}$ between charging. Alternatively, the microwire electrodes were connected via a transdermal lead to a long, thin tether $(\sim 2.0 \mathrm{~m})$ that terminated into the head stage of the amplifier outside of the tank. Sufficient slack remained in the cable to allow the toadfish to freely move around the aquarium.

The electrodes were implanted chronically into the utricular or anterior lateral line nerves. All implants were performed on anesthetized (MS-222) and paralyzed (pancuronium bromide) toadfish. Extracellular potentials were differentially amplified and monitored on a portable computer. The two recording channels that provided the highest fidelity signal were chosen for the experiments. Cyanoacrylate gel was used to affix the electrode to the skull and seal the craniotomy with the overlying tissue sutured to provide a watertight seal over the implant and around the transdermal electrode lead.

Immediately after surgery, the toadfish was placed in an opaque round fiberglass tank ( $\sim 1 \mathrm{~m} \mathrm{dia})$ with a water depth of $30 \mathrm{~cm}$ and left undisturbed for a minimum of $90 \mathrm{~min}$, a time previously shown to eliminate any effects of anesthesia on neural recordings (Palmer and Mensinger 2004). A University Sound UW-30 speaker (frequency response $80 \mathrm{~Hz}-10 \mathrm{kHz}$ ) was suspended vertically in the water column approximately $80 \mathrm{~cm}$ from the fish, and a hydrophone was placed directly above the toadfish head.

Pure tones and previously recorded male toadfish vocalizations were used as auditory stimuli. The front of the RECHABS cylinder habitat was maintained $80 \mathrm{~cm}$ from the speaker, and fish were only presented with sounds while in the habitat with their head facing out near the opening. As the fish were free to move, small displacements inside the RECHABS of $\pm 5 \mathrm{~cm}$ from the opening and $/ \mathrm{or} \pm 5^{\circ}$ left or right were possible and allowed. However, if fish exited the habitat or retreated further than $5 \mathrm{~cm}$ into the habitat, the experiment was suspended and the fish repositioned in the cylinder. The habitats were rotated in $45^{\circ}$ increments relative to the speaker to test for directional sensitivity with the distance from the front of the habitat to the speaker kept constant (i.e., the endorgans remained the same distance from the speaker). For sound presentation to the lateral line, the habitat was removed to streamline sound presentation and only the tether was used for recording.

Thresholds were determined for each test frequency along the axis of best directional sensitivity by starting with a supra-threshold intensity followed by decreasing intensities until the afferent no longer responded to the stimulus. For the utricle experiments, a calibrated hydrophone (Brüel and Kjær 8103 or High Tech HTI-94) recorded the sound stimulus reaching the toadfish. Relative sound pressure levels (SPL) were calculated for each frequency and intensity by measuring the root mean square (rms) voltage at the position of the fish head and converted to SPL in $\mathrm{dB}_{\mathrm{rms}}$ re: $1 \mu \mathrm{Pa}$. For the lateral line experiments, the frequency response of the underwater 
loudspeaker was measured using a calibrated HTI-96-MIN hydrophone (High Tech Inc.) and a B\&K 4524 triaxial accelerometer (Brüel and Kjær) positioned at the location of the fish's head during the experiments. Relative sound pressure and particle motion were calculated using an oscilloscope and adjusted with the attenuator to ensure that the sound pressure and particle motion at all frequencies were of equal amplitude ( $\pm 2 \mathrm{~dB}$ ) (Radford and Mensinger 2014).

Single and multiunit recordings were amplified (x1000; Dagan Ex-1), filtered ( $300 \mathrm{~Hz}-3 \mathrm{kHz}$ ), recorded for up to 7 days after implant, stored on a portable computer using Chart5 software and analyzed offline with CED Spike2 software. Although microwires often yielded multiunit activity, neuron discrimination was usually limited to one or two units that yielded the greatest amplitude and had clearly distinguishable waveforms above the noise level. To verify that the same afferent(s) was consistently recorded during an experiment, individual fibers were distinguished using waveform analysis in addition to spike amplitude. All statistical analysis was performed using GraphPad Software (San Diego, CA, USA) or SigmaStat for Windows version 3.10 (Systat Software, Inc., Richmond, CA, USA). All data represent mean values \pm 1 S.E.M. unless otherwise indicated.

\subsection{Data Analysis}

Neural responses to tones were quantified for vector strength (VS or synchronization coefficient, $R$ ) and evoked spikes rates across the entire stimulus cycle. Spike rates for directional responses were expressed as the maximum evoked spike rate minus the mean resting rate for each neuron (e.g., peak-DC) (Goldberg and Brown 1969). VS varies from zero (random distribution; no phase locking) to one (all spikes in the same bin; strong phase locking) and has been determined to be a better predictor for auditory frequency encoding among vertebrates than maximum evoked spike rates for frequencies $\leq 1 \mathrm{kHz}$ (Fay 1978, 1982, 1994; Javel and Mott 1988; Sisneros and Bass 2003). The significance of phase locking was determined by the calculation of the Rayleigh statistic, $Z$, which is defined as $R^{2} \times N$, where $R$ is the coefficient of synchronization (or vector strength) and $N$ is the total number of spikes sampled. Responses with $Z \geq 4.5$ ( $P=0.01$, utricle) or $Z \geq 6.9$ ( $P=0.001$, lateral line) were considered significantly phase locked (Batschelet 1981). Threshold was defined at the lowest intensity to evoke an increase in spike rate above spontaneous activity, or a significant $Z$ value as described in other studies ( $\mathrm{Lu}$ and Fay 1993; Maruska and Tricas 2009) and determined from 80 to $400 \mathrm{~Hz}$. Directional responses for each individual neuron were calculated at the same supra-threshold stimulus strength ( $\sim 5-10 \mathrm{~dB}$ above threshold) at each of the eight different stimulus orientations and examined as both spike rate (spikes/sec) and vector strength. 


\section{Results}

\subsection{Initial Experiments with the Telemetry Tag}

The effectiveness of the telemetry tag was first demonstrated in the toadfish mechanosensory lateral line. Since ethical constraints make it difficult to justify removing anesthesia from restrained or paralyzed animals, it has been problematic to assess the effect of anesthesia on the fish nervous system, as it would entail removing the drug from immobilized animals. The telemetry tag proved effective in assessing the common fish anesthetic MS-222 on neural sensitivity. The electrodes were implanted under anesthesia, and the fish allowed to recover and resume normal activity. Subsequent challenges with anesthesia showed depression of neural activity correlated with increasing concentrations of MS-222 (Fig. 2). The results suggested that care should be taken when using the anesthetic and that once the surgical plane of anesthesia is achieved, the minimal dose that maintains the animal in this state should be used throughout the experiments (Palmer and Mensinger 2004).

The tag was next used to monitor neural activity from the anterior lateral line nerve in response to water movements generated by natural prey. Previous studies using vibrating dipoles had determined that the lateral line can detect water

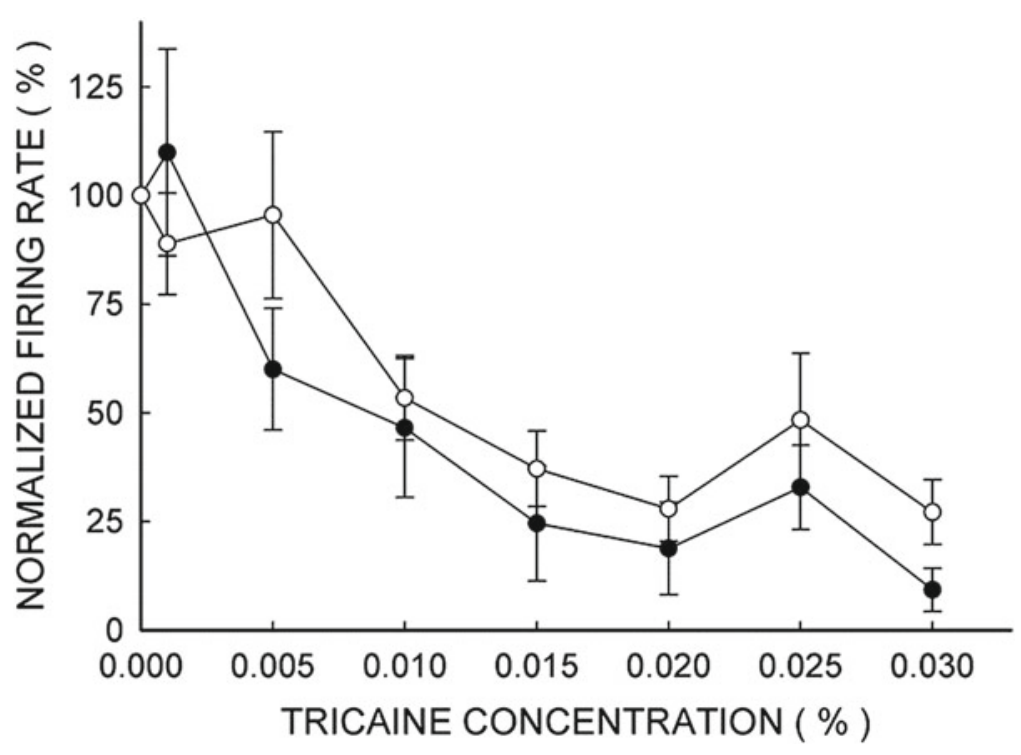

Fig. 2 MS-222 Dose response curve. Normalized firing rate of lateral line fibers ( $n=17: 11$ spontaneous and 6 silent) is plotted vs. increasing MS-222 concentrations. Firing rate is normalized as a percent of the preanesthetized firing activity. Spontaneous activity (black circle) represents the resting discharge rate from spontaneously active lateral line fibers. Evoked activity (white circle) is the firing rate from both spontaneous and silent fibers in response to water current. Error bars $=1$ SE. Modified from Palmer and Mensinger (2004) 
displacements, and that is a relatively short range sensory system (one to two body lengths) (Coombs and Janssen 1990). Nocturnal studies determined that juvenile toadfish only attacked prey within approximately one half of toadfish body length (Price and Mensinger 1999), however it was uncertain if this was the range at which the prey were detected or w hen the attack commenced. Subsequent studies, using the telemetry tag, with large $(30 \mathrm{~cm} \mathrm{sl})$ adult toadfish, indicated that small baitfish were only detectable by the lateral line at approximately $10 \mathrm{~cm}$ or a $1 / 3$ of a body length suggesting that, at least in toadfish, the lateral line mediates predator prey interactions at relatively short distances (Palmer et al. 2005) (Fig. 3).

\subsection{The Utricle}

The otolithic endorgans in teleost fishes (saccule, utricle, and lagena) have dual vestibular and auditory roles and function to encode linear particle motion. The saccule is the largest otolith and considered the primary auditory endorgan in most fish species (Popper and Fay 1993). The response characteristics of saccular afferents have been studied across a wide variety of fishes including goldfish (Fay 1978), midshipman (Sisneros and Bass 2005), sleeper goby (Lu et al. 1998), and toadfish (Fay and EddsWalton 1997), and are sensitive to linear acceleration and directionally sensitive to acoustic particle motion functioning predominantly as a low frequency detector $(60-1000 \mathrm{~Hz})$. The toadfish saccule is well adapted to detect the fundamental frequency of the male boatwhistle sound ( 150 to $200 \mathrm{~Hz})$ and grunt vocalizations ( $\sim 50$ to $250 \mathrm{~Hz}$ ) (Edds-Walton et al. 1999, 2002; Maruska and Mensinger 2009).

Unlike its congener Poricththys, the saccular nerve in Opsanus sp. was difficult to access, thin and variably branched and not amenable to implants. In contrast, the utricular nerve was easily accessible and of sufficient size for microwire insertion. The smaller utricular otolith has received less attention than the saccule and there is limited information on its physiology, having been examined in only a few species of fishes. Its vestibular role as a linear accelerometer had been established in normal (Rabbitt et al. 1995) and post space flight toadfish (Boyle et al. 2001). Utricular afferents also were determined to be sound sensitive and showed directional responses to $140 \mathrm{~Hz}$ in the goldfish (Fay 1984) and 50-400 Hz in the sleeper goby Dormitater latifrons (Lu et al. 2004). Therefore, the utricle provided a good candidate to investigate multimodal sensory input.

Wild and captive toadfish normally spend long periods of time motionless inside sheltered habitats with occasional brief forays limited mainly to foraging. Pre- and post-operative fish displayed similar behavior, and the tag or tether did not restrict movement, inhibit respiration or precipitate behavior to dislodge the devices. Recording fidelity was similar between direct recording nerve recording and using the telemetry tag or tether. The toadfish showed full recovery from the anesthesia within $2 \mathrm{~h}$ and resumed feeding within $24 \mathrm{~h}$ indicating that the fish quickly recovered and was displaying normal behavior during the testing. 

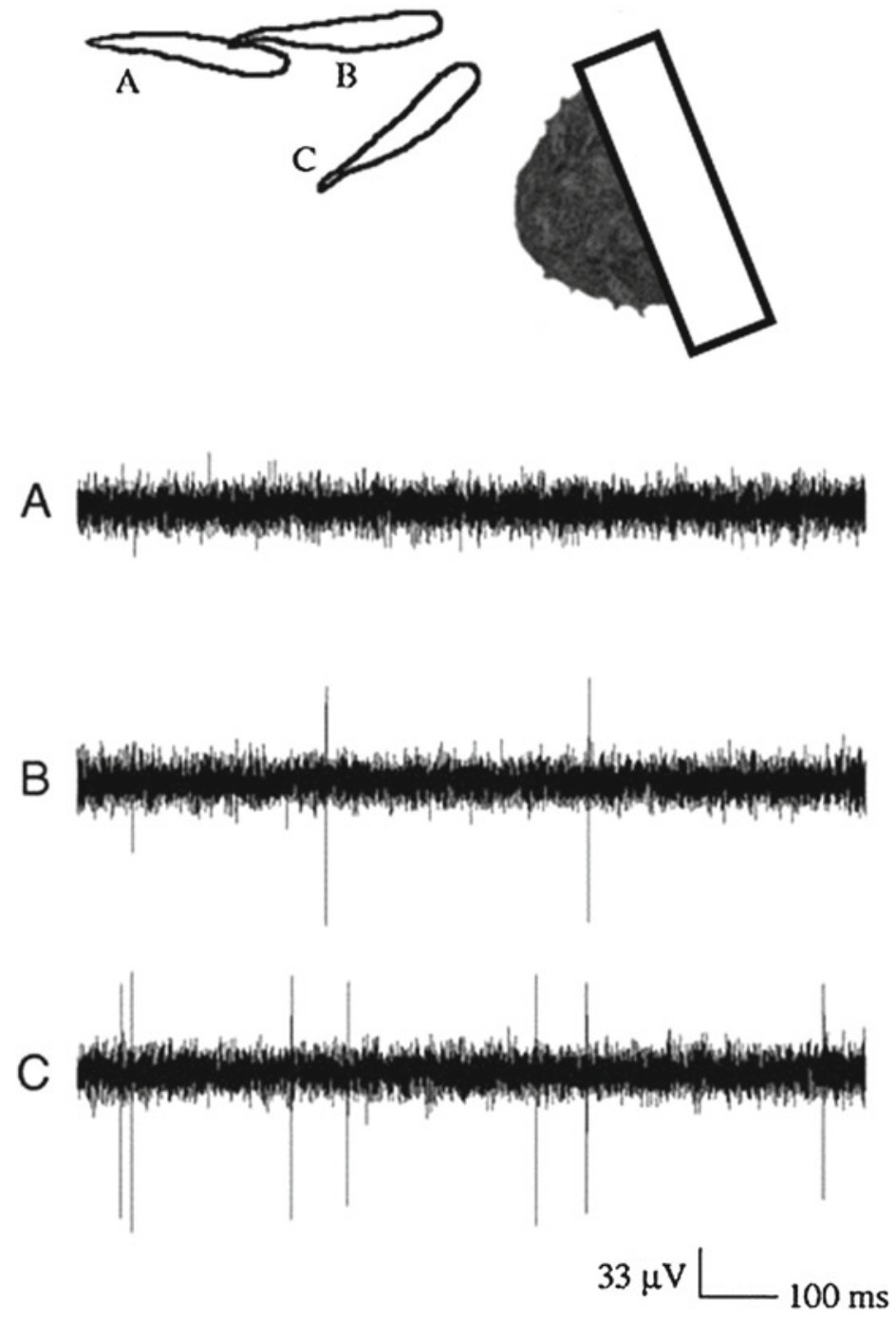

Fig. 3 Lateral line detection of prey. The diagram depicts the head of the toadfish projecting out of its habitat and the sequential positions of the approaching prey: (A) $10 \mathrm{~cm} ;(B) 3.5 \mathrm{~cm}$; (C) $1.0 \mathrm{~cm}$. Images were reconstructed from single video frames. The letter next to the prey fish corresponds to neural activity from a superficial neuromast on the suborbital portion of the infraorbital lateral line. Although multiunit activity is visible in the trace, data analysis was restricted to the fiber with the greatest amplitude. Modified from Palmer et al (2005)

Utricular neurons were quite sensitive to horizontal but not vertical movements of the toadfish. Sustained body movements of several seconds during either natural or evoked swimming led to continuous, elevated, and often maximal discharge rates in utricular afferents. Small $(1-3 \mathrm{~cm})$ lateral movements also evoked robust 
responses. The units also were modulated by ventilation and in large fish $(>25 \mathrm{~cm}$ $\mathrm{sl}$ ), breathing movements rarely displaced the quiescent toadfish more than $\pm 2 \mathrm{~mm}$ and in many cases, there was no discernable body movement demonstrating the high sensitivity of these fibers to small displacements (Boyle et al. 2001). Therefore, the ability to integrate of environmental stimuli must also take into account the input from breathing movements.

The underwater speaker precluded testing frequencies less than $80 \mathrm{~Hz}$, however the toadfish utricular neurons were most sensitive from 80 to $200 \mathrm{~Hz}$ with decreasing sensitivity at higher frequencies (Fig. 4). Most afferents consistently fired during sound presentation, and increased stimulus intensity resulted in greater firing rates. The sensitivity corresponded with the fundamental frequency of toadfish grunts $(80-120 \mathrm{~Hz}$ ) and male boatwhistles (100-200 Hz), and the utricle was responsive to playbacks of toadfish boatwhistles (Fig. 5). Thus not only was the utricle sensitive to low frequency sound, it is also well designed for detecting the frequencies of toadfish vocalizations used for intraspecific communication and therefore has the potential to assist in sound localization (Maruska and Mensinger 2009).

\subsection{Sound Localization}

One requirement for sound localization is that the endorgan exhibits directional sensitivity to sound. The majority $(75 \%)$ of utricular neurons $(n=12)$ displayed directional sensitivity, suggesting the utricle may be involved in sound localization, particularly in the azimuth (Fig. 6). Non-directional (or omnidirectional) neurons

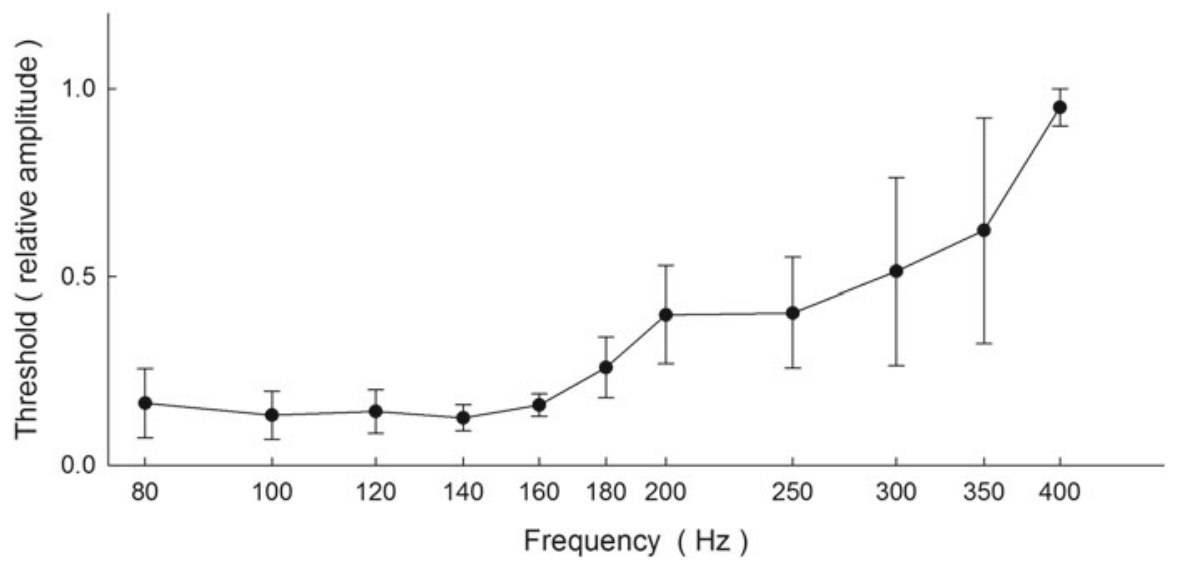

Fig. 4 Utricular afferent tuning curve. The sound threshold (relative amplitude) needed to invoke the criterion response is plotted versus sound frequency $(\mathrm{Hz})$ in toadfish $(N=15)$. Error bars $=1$ SE. Modified from Maruska and Mensinger (2009) 
Fig. 5 Response of a single utricular afferent to playback of toadfish boatwhistle vocalizations. Top trace is the playback of three toadfish boatwhistles presented via the underwater speaker and recorded by the hydrophone at the toadfish head, while the bottom trace is the waveform of the utricular neural activity recorded from a tethered toadfish. Modified from Maruska and Mensinger (2009)
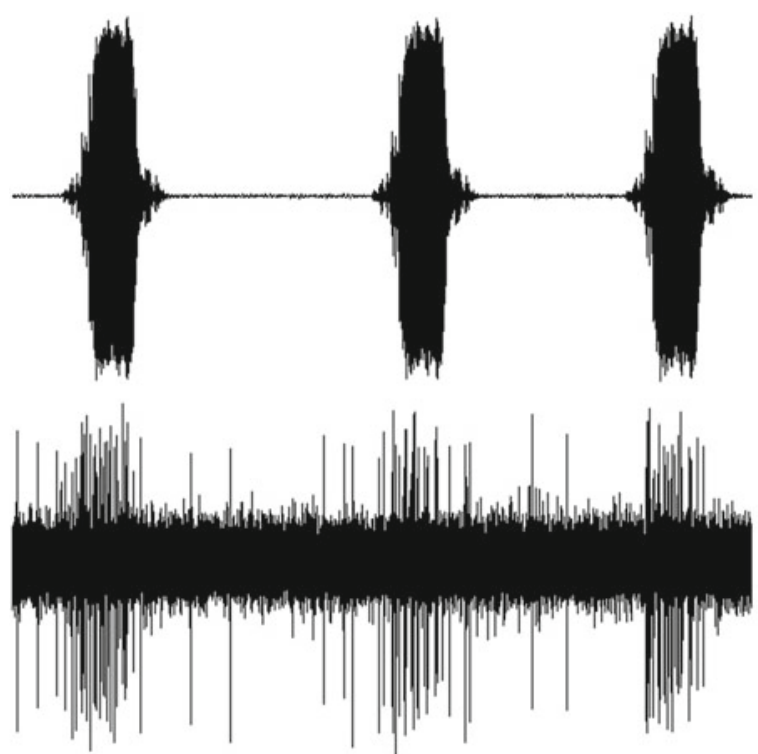

$1 \mathrm{sec}$ a

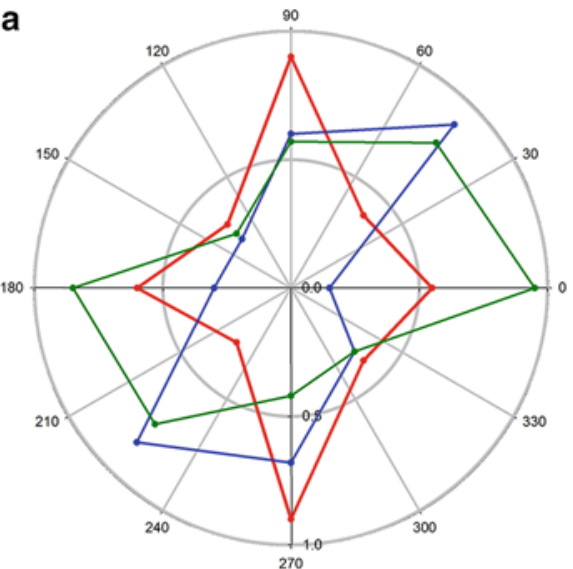

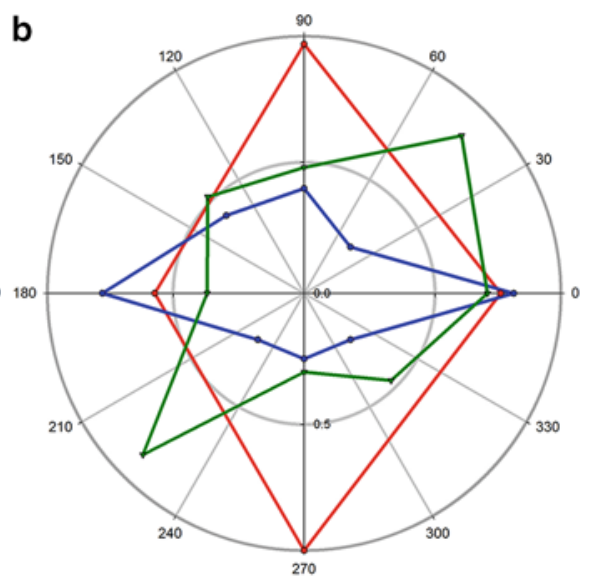

b

Fig. 6 Diversity of directional responses of utricular (a) and lateral line primary afferents (b) in the toadfish. Polar plots of neural responses using vector strength analysis from three representative primary afferents are shown to demonstrate directional responses (a: green $0-180^{\circ}$; red 90-270 ; blue $45-225^{\circ}$; b: green $45-225^{\circ}$; red $90-270^{\circ}$; blue $0-180^{\circ}$ ). Plots were constructed from recordings at the best frequency of each afferent at $5 \mathrm{~dB}$ above threshold. The distance from the central origin to each data point represents the vector strength, or coefficient of synchronization (ranges from 1.0 representing strong phase locking, to 0.0 representing no phase-locking or random firing), at each angle $0-180^{\circ}$ represents the rostro-caudal fish axis with fish's head point towards $0^{\circ}$. Modified from (a) Maruska and Mensinger (2015) and (b) Radford and Mensinger (2014) 
still responded robustly to acoustic stimuli, however, did not display clear directionality. Several additional neurons were acceleration sensitive and responded to fish movement, but were relatively insensitive to sound frequencies tested suggesting dichotomy in utricular hair cells with some hair cells functioning primarily as low frequency vestibular and not auditory sensors. Whether the converse is true is unknown, as only candidate fibers that responded to horizontal movement of the vibration isolation table during the implant were selected for sound tests. Alternatively, as these cells were not tested for sound sensitivity between 5 and 80 $\mathrm{Hz}$, these may be representative of the lower frequency fibers found in the sleeper goby (Lu et al. 2004).

The ability of fish to localize sound sources is complicated by small interaural distances and the high speed of sound underwater. The saccule has been implicated as the main endorgan of hearing and is certainly the largest otolith in toadfish. However, the caudal ends of the bilaterally positioned saccules are in close proximity, and even in adult fish, sound arrives at the posterior of each endorgan virtually simultaneously. The smaller utricles, on the other hand, are rostral to the saccules and in large, adult toadfish, are separated by distances of $1-3 \mathrm{~cm}$. Whether this spacing provides a sufficient delay to localize sounds based on interaural time differences remains to be determined.

What is clear, however, is that body movements and normal ventilation can also stimulate the utricle, and while these latter cyclic movements may be filtered in higher order processing centers (Montgomery and Bodznick 1994), the ability to hear and/or find the sound source may be compromised by self-generated movement. While male toadfish remain relatively stationary during advertisement calling, female fish must swim to find suitable males. Swimming movements can cause maximal excitation of utricle afferents and the ability to pin point sound sources during these forays may be compromised. Observations of female fish movement in the field are complicated by poor water visibility, cryptic coloration, and/or nocturnal movements. However, if the utricle is important in localizing sound, the female may need to alternate swimming with stationary pauses. Spontaneous toadfish movements in outdoor ponds and large tanks suggests that a typical toadfish "swim" consist of short legs, typically less than $1 \mathrm{~m}$ interspersed with pauses rather than long distance sustained bursts. While this behavior is more likely to have evolved to minimize alerting prey or predators outside of their protective habitats, it may also allow the fish to sample its acoustic environment without the added complications of self-generated movement.

The sensitivity of the utricle in the horizontal plane suggests it may function in detecting particle motion in azimuth, while the more vertically oriented saccule and lagena better detect particle motion in elevation. For the benthic-dwelling toadfish, sound detection in the horizontal plane is likely extremely important for detecting sounds generated by conspecifics, predators, and prey. Further studies are needed, however, to determine the relative role of each of the different otolithic endorgans and how they contribute to sound localization in fishes. 


\subsection{The Lateral Line}

The toadfish anterior lateral line responds to water flow, opercular displacement, prey movements, and swimming (Palmer et al. 2005; Palmer and Mensinger 2004). Although otoliths organs may be too close to use interaural time differences, the mechanosensory lateral has widely spaced neuromasts that may encode sufficient time delays for sound localization. The location, innervation, and morphological type of the neuromasts in the toadfish anterior lateral line has been established (Clapp 1891; Pankratz 1930). In comparison with other teleosts, the anterior lateral canals are reduced, with only 20 external canal pores on each side of the head. The superficial neuromasts ( $N=\sim 40$ per side) are surrounded by paired finger like projections with the hair cells aligned perpendicular to the appendages, consequently the directional sensitivity of the neuromasts can be predicted by external morphology (Marranzino et al. 2013).

Neural activity was monitored from the anterior lateral line during the presentation of pure tones $(80-400 \mathrm{~Hz})$ and toadfish vocalizations. All units showed greatest sensitivity to $100 \mathrm{~Hz}$ (Fig. 7). While overall sensitivity was independent of stimulus source location, the nerves' phase-locking ability was directly related to fish orientation (Fig. 7). Two types of units were classified, Type 1 (tonic), Type 2 (phasic) with Type 1 fibers further divided into sub-types based on their frequency response, which was hypothesized to be related to canal (Type 1-1) and superficial (Type 1-2)

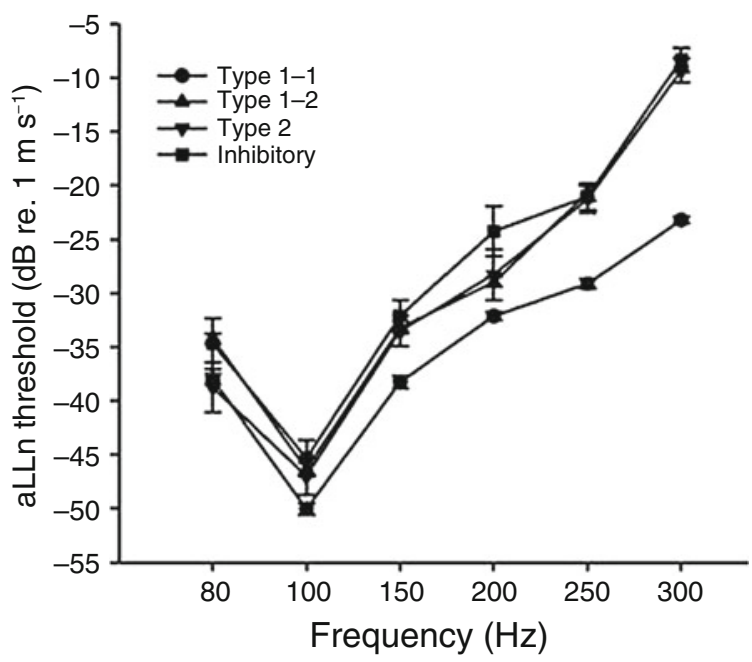

Fig. 7 Lateral line turning curves. Toadfish anterior lateral line thresholds ( $\mathrm{dB}$ re $1 \mathrm{~ms}^{-1}$ ) are plotted versus frequency. Each point represents the mean threshold for each fiber. The Type 1 response is split into 2 responses Type $1-1$ (black circle) responded to the entire frequency range $(n=25)$ and Type 1-2 (triangle) responded to a maximum frequency of $250 \mathrm{~Hz}(n=8)$. Phasic (inverted triangle Type 2, $n=4$ ), inhibitory (square, Type 3,n=1). Modified from Radford and Mensinger (2014) 
neuromast innervation. Lateral line units also exhibited phase locking to boatwhistle vocalizations, with greatest spike rates exhibited at the onset of the call. These results provide the first direct evidence that oyster toadfish can use their lateral line to detect behaviorally relevant sound stimuli, and potentially function in sound localization (Radford and Mensinger 2014).

The lateral line responds to the near field component of sound (particle motion) and has the potential to contribute to hearing sensitivity and sound localization (Mirjany et al. 2011). While delay lines such as found in the owl (Carr and Konishi 1988) have not been discovered, interneuromast distance, combined with afferent nerve length and conduction velocities may be sufficient to use sound delays to locate the source. Anterior lateral line neuromasts can be separated by over $10 \mathrm{~cm}$ with distances between anterior and posterior lateral line neuromasts capable of exceeding $25 \mathrm{~cm}$. For example, underwater sound $\left(35 \mathrm{ppt}, 20^{\circ} \mathrm{C}\right)$ directly in front of a $25 \mathrm{~cm}$ sl fish will impact the foremost anterior lateral neuromasts $16 \mu$ s prior to arriving at neuromasts located at the base of the caudal fin. However, factoring in toadfish cranial nerve diameters [1-12 $\mu \mathrm{m}$ (Mensinger and Highstein 1999)], conduction speeds associated with myelinated nerves of these diameters (10 or $50 \mathrm{~m} / \mathrm{s}$ ), and afferent lengths to second order neurons (up to $5 \mathrm{~cm}$ length for anterior and $20 \mathrm{~cm}$ for posterior; Mensinger unpublished), delays to the central nervous system would range from approximately $400 \mu \mathrm{s}$ to $2 \mathrm{~ms}$, which is within the time frame used for interaural delays found in other vertebrates.

\section{Discussion}

\subsection{Detection Distance}

The experiments demonstrate that the utricle and lateral line are well designed to detect toadfish vocalizations and they may play a role in sound localization. However, it remains unclear what is the functional range of each system, how acoustic input to both systems is integrated, and the effect of self-generated movement on hearing sensitivity. Male toadfish often nest in high densities (up to 10-12 $\mathrm{m}^{2}$ ) in estuaries near Woods Hole, MA, and produce loud $[\sim 140 \mathrm{~dB}$ re $1 \mu \mathrm{Pa}$ (Tavolga 1971)] boatwhistles with fundamental frequencies ranging between 90 and $250 \mathrm{~Hz}$ depending on season and geographical location (Fine 1978), which is within the sensitivity and range for the utricle and lateral line. Calls can propagate several meters underwater with distance influenced by toadfish size, water depth, and substrate composition (Fine and Lenhardt 1983) with hydrophones able to detect calls at least $5 \mathrm{~m}$ from toadfish nests (Mensinger 2014), although it remains to be determined at what range the females can detect the signal or what aspect of the boatwhistle influences mate choice.

Underwater acoustic stimulus consists of two components, the "nearfield," which is dominated by hydrodynamic flow and the "farfield," which is modulated by the 
propagating pressure wave (Popper and Fay 1993). The lateral line is sensitive to hydrodynamic flow within short distances from the source (nearfield), but is relatively insensitive to pressure (farfield) (Montgomery et al. 1995; Webb et al. 2008). Therefore, it is likely that the acoustic stimulation of the lateral line of teleosts will transpire in close proximity to the source. The near field dominates the acoustic field up to a distance of $\lambda / 2 \pi$ from the source (Bass and Clarke 2002), and should extend at least 1-3 $\mathrm{m}$ from the nests based on the fundamental frequencies of the boatwhistle, which would place the female fish well within the range of the acoustic field that would provide lateral line stimulation. The utricle may be able to detect vocalizations outside of the near field, providing the toadfish with both a long and short range acoustic detection system.

\subsection{Self-generated Movement}

Body movements, including normal ventilation, stimulate both the utricle and the anterior lateral line, and it is unclear the effects this has on sound sensitivity. While rhythmic movements may be filtered in higher order processing centers (Montgomery and Bodznick 1994), the ability to hear and/or find the sound source may be compromised by nonrhythmic or spontaneous movement. During predation strikes, the anterior lateral line was saturated in toadfish and unlikely to be able to integrate additional prey information (Palmer et al. 2005). However, the toadfish is an ambush predator that launches ballistic strikes, and its large mouth provides sufficient margin for error that sensory feedback during the strike is probably unnecessary.

Male toadfish also remain relatively stationary during advertisement calling and alternate calls to avoid overlap. However, they remain sensitive to conspecific signals which allows them to generate disruptive grunts during competitors' boatwhistles (Mensinger 2014). However, there is no evidence that they can detect these grunts, as the caller's auditory system is either saturated by boatwhistle generation or efferently modulated to avoid potentially damaging sound production. Thus, their quiescent nature during acoustical advertisement generates little movement and allows toadfish to maintain hearing sensitivity during inter call intervals.

The situation is more complicated for mobile females as they need to localize the males and swim to the nest. Swimming can cause maximal excitation of utricle and lateral line afferents and degrade the ability to pin point sound sources during these forays. Although in situ observations of female fish approaching males from a distance are complicated by the poor environmental visibility, one would predict that if the utricle is important in localizing sound, that the females may need to alternate swimming with stationary pauses to assist in locating the sound. This intermittent swimming strategy which has been observed in captivity may allow the fish to sample the acoustic field during stops using both the saccule and utricle and help localize the sound source.

However, not all movement may degrade acoustic sensitivity. The superficial neuromasts in the toadfish are surrounded by paired finger like projections and 
arrayed in different orientations. As the projections may act to restrict water flow along the neuromast, swimming fish would have a proportional of their neuromasts not impacted by movement/water flow and remain sensitive to acoustic stimulus. Additionally, the utricular organs act as linear accelerometers, and once the fish achieve constant velocity they could regain full sensitivity to acoustic input. Although in toadfish, the short, intermittent swimming motions make achieving constant velocity problematic, other species that display constant, steady swimming could maintain auditory sensitivity. Additionally, as both the lateral line and utricle are innervated by first order neurons, central nervous system filtering may also factor in modulating sensitivity.

\subsection{Future Directions}

It is equally important to investigate the effects of simultaneous bimodal sensory input into two systems. Preliminary experiments have proven the efficacy of implanting bilateral electrodes in the lateral line (Radford and Mensinger, unpublished). Future experiments aim to implant electrodes in both the lateral line and utricle to determine how these systems encode and integrate similar stimuli, and determine how the utricle and lateral line function during free swimming and sound localization behavior.

\section{Summary}

The neural telemetry tag has allowed exploration of multiple sensory input such as self-generated movement and sound in both the utricle and lateral line. It has allowed neural sensitivity to be explored in freely moving fish without the complications of anesthesia. Both systems were sensitive to sounds consistent with toadfish vocalizations and showed directional sensitivity, indicating a role in sound localization.

Acknowledgements I am grateful to Karen Maruska (utricle) and Craig Radford (lateral line) for performing the bulk of the experiments and data analysis reported in this chapter and to the Grass foundation for providing their support. Thanks to Lucy Palmer and Max Deffenbaugh for initial help in developing the tag. Funding was provided by NSF grants IOS 0316130, 0843735, and 1354745.

I would also thank Dick Fay and Art Popper for their contributions to fish bioacoustics. I first met Dick Fay while I was a post-doc in the Highstein lab during our summer toadfish research at the Marine Biological Laboratory in Woods Hole, Massachusetts. While our study sites in the toadfish brain were just mm apart, our interests at the time were quite divergent as Dick was investigating the saccule and I was concentrating on nerve regeneration and developing the telemetry tag. Dick was always quite supportive and encouraging of my research, and I appreciated his input and guidance. Although his shaker table and experiments were cutting edge, his patience for neurophysiology was certainly old school. There was never any need to ask Dick how the experiments were going, because the frequency of his outdoor "breaks" were inversely correlated with 
experimental success. Although I interacted with Art Popper less frequently, I always looked forward to our interactions at the MBL or scientific meetings. Art was also quite supportive of my career and always took the time to ask about my current research.

I cannot think of another scientific pair that so defined a field and yet were so generous with their time and support for students and colleagues. Thank you Dick and Art for your support, generosity and "sound" advice

\section{References}

Bass AH, Clarke CW (2002) The physical acoustics of underwater sound communication. Acoust Commun 16:15-64

Batschelet E (1981) The Rayleigh test. In: Batschelet E (ed) Circular statistics in biology. Academic, New York, pp 54-58

Boyle R, Mensinger AF, Yoshida K, Usui S, Intravaia A, Tricas T, Highstein SM (2001) Neural readaptation to earth's gravity following return from space. J Neurophysiol 86:2118-2122

Braun CB, Coombs S, Fay RR (2002) What is the nature of multisensory interaction between octavolateralis sub-systems? Brain Behav Evol 59:162-176

Carr CE, Konishi M (1988) Axonal delay-lines for time measurement in the owls brain-stem. Proc Natl Acad Sci U S A 85:8311-8315

Clapp CM (1891) Some points in the development of the Toad-fish (Batachus tau). J Morphol 5:494-501

Coombs S, Janssen J (1990) Behavioral and neurophysiological assessment of lateral line sensitivity in the mottled sculpin Cottus bairdi. J Comp Physiol A 167:557-567

Edds-Walton PL, Fay RR (2003) Directional selectivity and frequency tuning of midbrain cells in the oyster toadfish, Opsanus tau. J Comp Physiol A 189:527-543

Edds-Walton PL, Fay RR (2005a) Projections to bimodal sites in the torus semicircularis of the toadfish, Opsanus tau. Brain Behav Evol 66:73-87

Edds-Walton PL, Fay RR (2005b) Sharpening of directional responses along the auditory pathway of the oyster toadfish, Opsanus tau. J Comp Physiol A 191:1079-1086

Edds-Walton PL, Fay RR (2008) Directional and frequency response characteristics in the descending octaval nucleus of the toadfish (Opsanus tau). J Comp Physiol A 194:1013-1029

Edds-Walton PL, Fay RR (2009) Physiological evidence for binaural directional computations in the brainstem of the oyster toadfish, Opsanus tau (L.). J Exp Biol 212:1483-1493

Edds-Walton PL, Fay RR, Highstein SM (1999) Dendritic arbors and central projections of physiologically characterized auditory fibers from the saccule of the toadfish, Opsanus tau. J Comp Neurol 411:212-238

Edds-Walton PL, Mangiamele LA, Rome LC (2002) Variations of pulse repetition rate in boatwhistle sounds. Bioacoustics 13:153-173

Edds-Walton P, Matos S, Fay R (2013) Does the magnocellular octaval nucleus process auditory information in the toadfish, Opsanus tau? J Comp Physiol A 199:353-363

Elemans CPH, Mensinger AF, Rome LC (2014) Vocal production complexity correlates with neural instructions in the oyster toadfish (Opsanus tau). J Exp Biol 217:1887-1893

Fay RR (1978) Phase-locking in goldfish saccular nerve fibers accounts for frequency discrimination capacities. Nature 275:320-322

Fay RR (1982) Neural mechanisms of an auditory temporal discrimination by goldfish. J Comp Physiol 147:201-216

Fay RR (1984) The goldfish ear codes the axis of acoustic particle motion in 3 dimensions. Science 225:951-954

Fay RR (1994) Perception of temporal acoustic patterns by the goldfish (Carassius auratus). Hear Res 76:158-172 
Fay RR, EddsWalton PL (1997) Directional response properties of saccular afferents of the toadfish, Opsanus tau. Hear Res 111:1-21

Fay RR, Edds-Walton PL (2000) Directional encoding by fish auditory systems. Philos Trans R Soc Lond B Biol Sci 355:1281-1284

Fine ML (1978) Seasonal and geographic variation of mating call of oyster toadfish, Opsanus tau L. Oecologia 36:45-57

Fine ML, Winn HE, Joest L, Perkins PJ (1977) Temporal aspects of calling behavior in the oyster toadfish, Opsanus tau. Fish Bull 75:871-874

Fine M, Lenhardt M (1983) Shallow-water propagation of the toadfish mating call. Comp Biochem Physiol a-Physiol 76:225-231

Fritzsch B (1999) Hearing in two worlds: theoretical and actual adaptive changes for the aquatic and terrestrial ear for sound reception. In: Fay R, Popper A (eds) Comparative hearing: fish and amphibians. Springer, New York, pp 15-42

Goldberg J, Brown P (1969) Response of binaural neurons of dog superior olivary complex to dichotic tonal stimuli - some physiological mechanisms of sound localization. J Neurophysiol 32:613-636

Gray GA, Winn HE (1961) Reproductive ecology and sound production of the toadfish Opsanus tau. Ecology 28:9

Harwood C, Young I, Tikunov B, Hollingworth S, Baylor S, Rome L (2011) Paying the piper: the cost of Ca2+ pumping during the mating call of toadfish. J Physiol 589:5467-5484

Higgs D, Radford C (2013) The contribution of the lateral line to 'hearing' in fish. J Exp Biol 216:1484-1490

Javel E, Mott J (1988) Physiological and psychophysical correlates of temporal processes in hearing. Hear Res 34:275-294

Kramer K, Kinter LB (2003) Evaluation and applications of radiotelemetry in small laboratory animals. Physiol Genomics 13:197-205

Lu Z, Fay RR (1993) Acoustic response properties of single units in the torus semicircularis of the goldfish, Carassius auratus. J Comp Physiol A 173:33-48

Lu Z, Song J, Popper A (1998) Encoding of acoustic directional information by saccular afferents of the sleeper goby, Dormitator latifrons. J Comp Physiol A 182:805-815

Lu Z, Xu Z, Buchser W (2004) Coding of acoustic particle motion by utricular fibers in the sleeper goby, Dormitator latifrons. J Comp Physiol A 190:923-938

Marranzino A, Frank M, Lindemann S, Guiffrida B, Sipper K, Webb J, Mensinger A (2013) Functional morphology of cephalic protuberances in the oyster toadfish, Opsanus tau. Integr Comp Biol 53:E325

Maruska KP, Mensinger AF (2009) Acoustic characteristics and variations in grunt vocalizations in the oyster toadfish Opsanus tau. Environ Biol Fishes 84:325-337

Maruska K, Tricas T (2009) Encoding properties of auditory neurons in the brain of a soniferous damselfish: response to simple tones and complex conspecific signals. J Comp Physiol A 195:1071-1088

Maruska KP, Mensinger AF (2015) Directional sound sensitivity in utricular afferents in the toadfish Opsanus tau. J Exp Biol 218:1759-1766

Mensinger AF (2006) Sensitivity of utricular afferent fibers to intraspecific calling via inductive neural telemetry in free ranging oyster toadfish, Opsanus tau. Integr Comp Biol 46:E97

Mensinger AF (2014) Disruptive communication: stealth signaling in the toadfish. J Exp Biol 217:344-350

Mensinger AF, Deffenbaugh M (1998) Prototype rechargeable tag for acoustical neural telemetry. Biol Bull 195:194-195

Mensinger AF, Deffenbaugh M (2000) Anechoic aquarium for ultrasonic neural telemetry. Philos Trans R Soc Lond B Biol Sci 355:1305-1308

Mensinger AF, Highstein SM (1999) Characteristics of regenerating horizontal semicircular canal afferent and efferent fibers in the toadfish, Opsanus tau. J Comp Neurol 410:653-676

Mirjany M, Faber D (2011) Characteristics of the anterior lateral line nerve input to the Mauthner cell. J Exp Biol 214:3368-3377 
Mirjany M, Preuss T, Faber D (2011) Role of the lateral line mechanosensory system in directionality of goldfish auditory evoked escape response. J Exp Biol 214:3358-3367

Montgomery JC, Bodznick D (1994) An adaptive filter that cancels self-induced noise in the electrosensory and lateral-line mechanosensory systems of fish. Neurosci Lett 174:145-148

Montgomery J, Coombs S, Halstead M (1995) Biology of the mechanosensory lateral-line in fishes. Rev Fish Biol Fish 5:399-416

Montgomery J, Baker C, Carton A (1997) The lateral line can mediate rheotaxis in fish. Nature 389:960-963

Palmer LM, Mensinger AF (2004) Effect of the anesthetic tricaine (MS-222) on nerve activity in the anterior lateral line of the oyster toadfish, Opsanus tau. J Neurophysiol 92:1034-1041

Palmer LM, Deffenbaugh M, Mensinger AF (2005) Sensitivity of the anterior lateral line to natural stimuli in the oyster toadfish, Opsanus tau (Linnaeus). J Exp Biol 208:3441-3450

Pankratz DS (1930) The cranial-nerve components in the toadfish (Opsanus tau). J Comp Neurol 50:247-286

Partridge B, Pitcher T (1980) The sensory basis of fish schools: relative roles of lateral line and vision. J Comp Physiol A 130:315-325

Popper AN, Fay RR (1993) Sound detection and processing by fish - critical-review and major research questions. Brain Behav Evol 41:14-38

Popper AN, Fay RR (2011) Rethinking sound detection by fishes. Hear Res 273:25-36

Price NN, Mensinger AF (1999) Predator-prey interactions of juvenile toadfish, Opsanus tau. Biol Bull 197:246-247

Rabbitt RD, Boyle R, Highstein SM (1995) Mechanical indentation of the vestibular labyrinth and its relationship to head rotation in the toadfish, Opsanus tau. J Neurophysiol 73:2237-2260

Radford CA, Mensinger AF (2014) Anterior lateral line nerve encoding to tones and play-back vocalisations in free-swimming oyster toadfish, Opsanus tau. J Exp Biol 217:1570-1579

Schnupp JWH, Carr CE (2009) On hearing with more than one ear: lessons from evolution. Nat Neurosci 12:692-697

Sisneros JA, Bass AH (2003) Seasonal plasticity of peripheral auditory frequency sensitivity. J Neurosci 23:1049-1058

Sisneros JA, Bass AH (2005) Ontogenetic changes in the response properties of individual, primary auditory afferents in the vocal plainfin midshipman fish Porichthys notatus Girard. J Exp Biol 208:3121-3131

Tavolga WN (1971) Sound production and detection. In: Hoar WS, Randall DJ (eds) Fish physiology, vol 5. Academic, New York, pp 135-205

Walsh P, Mensinger A, Highstein S (2008) Toadfish as biomedical models. In: Walsh P, Smith S, Fleming L, Solo-Gabriele H, Gerwick WH (eds) Oceans and human health: risks and remedies from the seas. Academic, Burlington, VT, pp 547-558

Webb J, Montgomery J, Mogdans J (2008) Bioacoustics and the lateral line system of fishes. In: Webb J, Popper A, Fay R (eds) Fish bioacoustics. Springer, New York

Weeg M, Bass A (2002) Frequency response properties of lateral line superficial neuromasts in a vocal fish, with evidence for acoustic sensitivity. J Neurophysiol 88:1252-1262

Weissert R, von Campenhausen C (1981) Discrimination between stationary objects by the blind cavefish Anoptichthys jordani (Characidae). J Comp Physiol A 143:375-381

Young CN, Davisson RL (2011) In vivo assessment of neurocardiovascular regulation in the mouse: principles, progress, and prospects. Am J Physiol 301:H654-H662 


\title{
Development of Structure and Sensitivity of the Fish Inner Ear
}

\author{
Raquel O. Vasconcelos, Peter W. Alderks, and Joseph A. Sisneros
}

\begin{abstract}
Fish represent the largest group of vertebrates and display the greatest diversity of auditory structures. However, studies addressing how the form and function of the auditory system change during development to enhance perception of the acoustic environment are rather sparse in this taxon compared to other vertebrate groups. An ontogenetic perspective of the auditory system in fishes provides a readily testable framework for understanding structure-function relationships. Additionally, studying ancestral models such as fish can convey valuable comparable information across vertebrates, as early developmental events are often evolutionary conserved. This chapter reviews the literature on the morphological development of the fish auditory system, with particular focus on the inner ear structures that evolve from an otic placode during early embryonic development and then continue to undergo differentiation and maturation in the postembryonic phase. Moreover, the chapter provides a systematic overview of how auditory sensitivity develops during ontogeny. Although most studies indicate a developmental improvement in auditory sensitivity, there is considerably species-specific variation. Lastly, the paucity of information and literature concerning the development of auditory capabilities for social communication in fishes is also discussed. Further investigation on the development of structure and function of the fish auditory system is recommended in order to obtain a deeper understanding of how ontogenetic morphological changes in the auditory pathway relate to modifications in acoustic reception, auditory processing, and the capacity to communicate acoustically.
\end{abstract}

Keywords Fish ontogeny $\bullet$ Auditory development • Auditory physiology • Ear morphology

\footnotetext{
R.O. Vasconcelos $(\bowtie)$

Institute of Science and Environment, University of Saint Joseph, Macau, S.A.R., China

e-mail: raquel.vasconcelos@usj.edu.mo
}

P.W. Alderks

Department of Psychology, University of Washington, Seattle, WA 98195, USA

J.A. Sisneros

Department of Psychology, University of Washington, Seattle, WA 98195, USA

Department of Biology, University of Washington, Seattle, WA 98195, USA 


\section{Introduction}

Studies on the auditory system have provided an unmatched wealth of information related to the evolution and function of sensory systems in vertebrates. The comparative data obtained from different levels of the auditory system, from the peripheral to the central auditory system, is by far the richest among all sensory systems. However, despite our growing knowledge in auditory system neuroscience, there are a number of fundamental questions related to the development and function of auditory structures that remain poorly understood across vertebrate taxa. For example, how does auditory reception and its neural processing change during ontogeny? Which morphological changes occur in the inner ear versus the central auditory system that may account for developmental improvements in hearing? What is the relationship between auditory development and vocal differentiation? Although some effort has been made to answer these questions in comparative studies from birds and mammals, the available information is scarce and in need of further investigation that includes also lower vertebrates such as fish. Such a research perspective will be needed in order to gain fundamental comparative insights into the evolution and ecology of the vertebrate auditory system.

The diversity of structure and function of fish sensory systems is exceptional, suggesting that through evolution species have found ways to become more adapted to their highly diverse aquatic environments. This diversity is particularly evident in the octavolateralis system of fishes that includes the lateral line and the inner ear (Braun and Grande 2008).

Fishes rely on their auditory system to extract biologically relevant information from the auditory scene, such as the presence of conspecifics, predators, prey, and to detect abiotic elements for orientation. The capacity to detect acoustic signals in the soundscape seems to start early in life in most species. Besides being important for the detection of food or danger, the auditory sense in juvenile fish is also important for intraspecific acoustic communication during agonistic interactions in the context of competition over food or space (Schneider 1964; Henglmüller and Ladich 1999; Amorim and Hawkins 2005; Kéver et al. 2012).

Studies that examine the ontogeny of hearing in fishes can ultimately provide an evolutionary perspective and deeper understanding of the mechanisms underlying the development of the auditory sense in all vertebrates. Many of the early developmental events in fishes appear to be evolutionarily conserved across all vertebrate groups in spite of the large diversity in auditory structure found in adult animals (Retzius 1884; Baird 1974; Henson 1974).

In this chapter we review the available information on the ontogenetic development of the inner ear morphology and sensitivity in fish. In addition, we briefly describe the available information on the development of auditory capabilities for social acoustic communication in this taxon, another area of research where information is still fairly limited. 


\section{Morphological Development of the Fish Auditory System}

During ontogeny a number of important morphological changes occur in the otolithic end organs and peripheral auditory system of fishes. This section is meant as an overview of these structural changes that occur and likely influence auditory sensitivity, hearing perception, and communication and should not be considered a comprehensive review of the literature on this topic. The following sections briefly discuss the structure of the teleost inner ear, embryology, and early development of the auditory end organs, postembryonic development and changes to the peripheral auditory system.

\subsection{The Teleost Inner Ear}

Like other vertebrates, fish have ears that detect acoustic stimuli (Weber 1820; Parker 1903; von Frisch and Stetter 1932). The teleost inner ear is composed of three otolithic endorgans, the lagena, utricle, and saccule, which include otoliths and sensory epithelia, as well as three semicircular canals (see Fig. 1). All three otolithic end organs are thought to be capable of detecting both inertial stimuli and acoustic stimuli; however, it is likely that the three end organs differ in their relative contribution to motion detection and audition (Popper and Fay 1993; Popper et al. 2003). The saccule is the primary auditory end organ in most teleost fishes (Popper and Schilt 2008; Webb et al. 2008), whereas the other otolithic end organs seem to have either a vestibular role (von Frisch 1938; Platt 1983) or mixed auditory-vestibular functions (Popper et al. 1982; Schellart and Popper 1992).

The otolithic end organs respond to acoustic particle motion much like an accelerometer (Platt and Popper 1981; Popper and Tavolga 1981; Fay 1984). Here we describe how the otolithic end organs transduce vibrational energy using the saccule as our example. The saccule contains a dense otolith known as the sagitta, which is about three times more dense than the fish's body (de Vries 1950; Popper and Lu 2000). When sound passes through the fish, the sagitta moves at a different phase and amplitude than the saccular epithelium, which is attached to the sagitta by means of an otolith membrane (Dijkgraaf 1960; Fay and Popper 1975). A shearing motion results as the otolith and sensory epithelium move relative to one another during sound stimulation, causing the ciliary hair bundles to bend (Fay and Popper 1974; Popper and Fay 1993). Signal transduction occurs as the hair bundles bend toward the kinocilium and generate a receptor potential that can depolarize the hair cell and produce an action potential (Popper 1983; Fay and Popper 2000). Otolithic organs are most effective at responding to low frequencies below $1000 \mathrm{~Hz}$ (Fay 1988; Popper and Fay 1999).

Although we have described the most common features of the teleost inner ear, it is important to note that there is a great deal of variation and diversity of inner ear structures used for hearing in teleost fishes (Platt and Popper 1981). It is likely that 

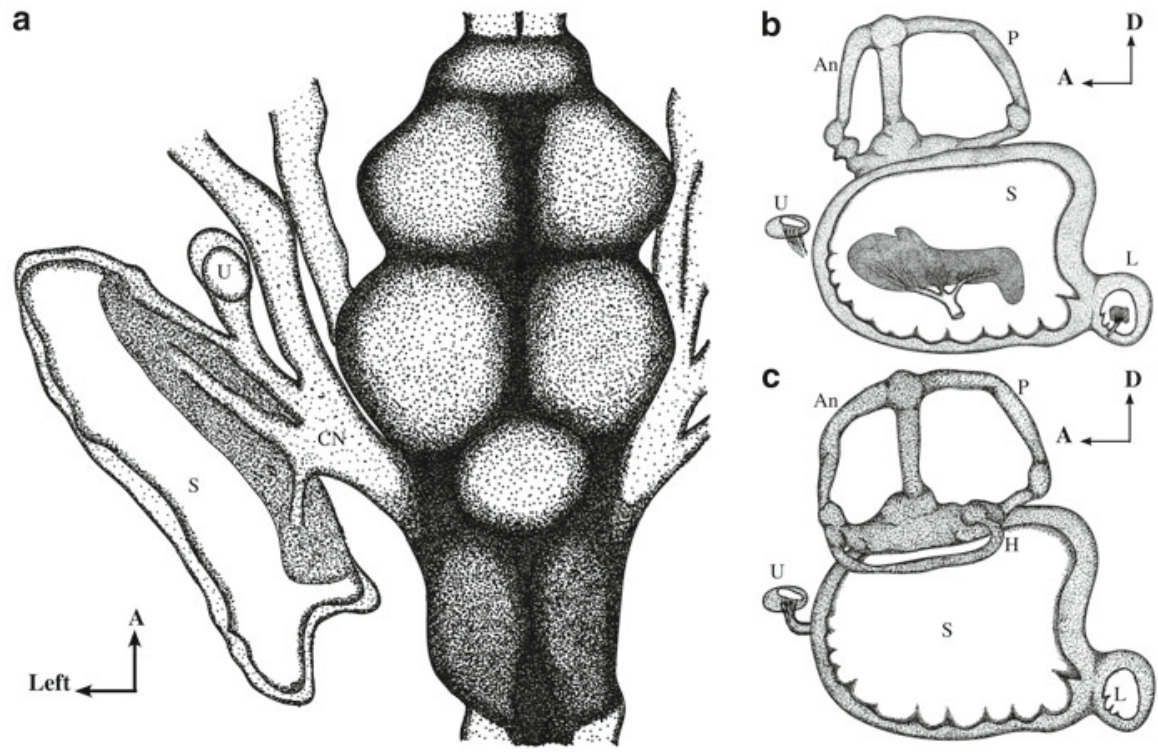

Fig. 1 The inner ear in the adult plainfin midshipman. Porichthys notatus (Batrachoididae) (a) depicts a dorsal view of the brain, auditory nerve ( $\mathrm{CN}$-VIIIth cranial nerve) and the inner ear ( $\mathrm{S}$ - saccule, $\mathrm{U}$-utricle). Notice the size of the saccule in relation to the brain. (b) and (c) show drawings of the right and left inner ears, respectively, in the plainfin midshipman. The three otolithic end organs ( $\mathrm{S}$-saccule, $\mathrm{L}$-lagena, and $\mathrm{U}$ - utricle) as well as the three semi-circular canals (An-anterior, $\mathrm{H}$ - horizontal, $\mathrm{P}$ - posterior) are visible

with inner ear otoliths acting as accelerometers all teleost fishes are able to detect the particle motion component of sound as discussed above, however several teleost groups have independently evolved specialized auditory structures that likely enhance hearing and/or make it possible for the additional detection of sound pressure (Fay and Popper 1975, 1980; Coombs and Popper 1979). For example, several groups have developed unique mechanisms that involve inner ear placement near a gas bladder, or by directly coupling the inner ear to a gas bladder that changes in volume in response to changes in sound pressure (Platt and Popper 1981). Additionally, there is a great deal of diversity in regard to the structure and morphology of teleost peripheral auditory system, such as the position of the inner ear within the braincase, the size and shape of each otolithic end organ and otoliths, as well as the size, shape, and ultrastructure of the sensory macula (Fay and Popper 1975; Platt and Popper 1981). All of these differences in auditory structure between various fish species likely reflect their high adaptation to specific environments that has been shaping the function of the auditory system. An ontogenetic perspective provides a readily testable framework for understanding the structure-function relationships within the auditory system. 


\subsection{Embryology and Early Development of the Auditory System}

Auditory structures, like other sensory systems, arise early during development through a process closely linked with and influenced by the forming of the central nervous system and mesoderm of the embryo (Fig. 2). The first major event in the development of the inner ear is the induction of the otic placode in the ectoderm of the developing embryo. The otic placode then invaginates to form the otic pit and the subsequent closing of the otic pit forms the otocyst, which separates from the ectoderm. The otocyst polarizes and differentiates into the various end organs of the auditory and vestibular systems. Here we provide a brief review of these events in greater detail.
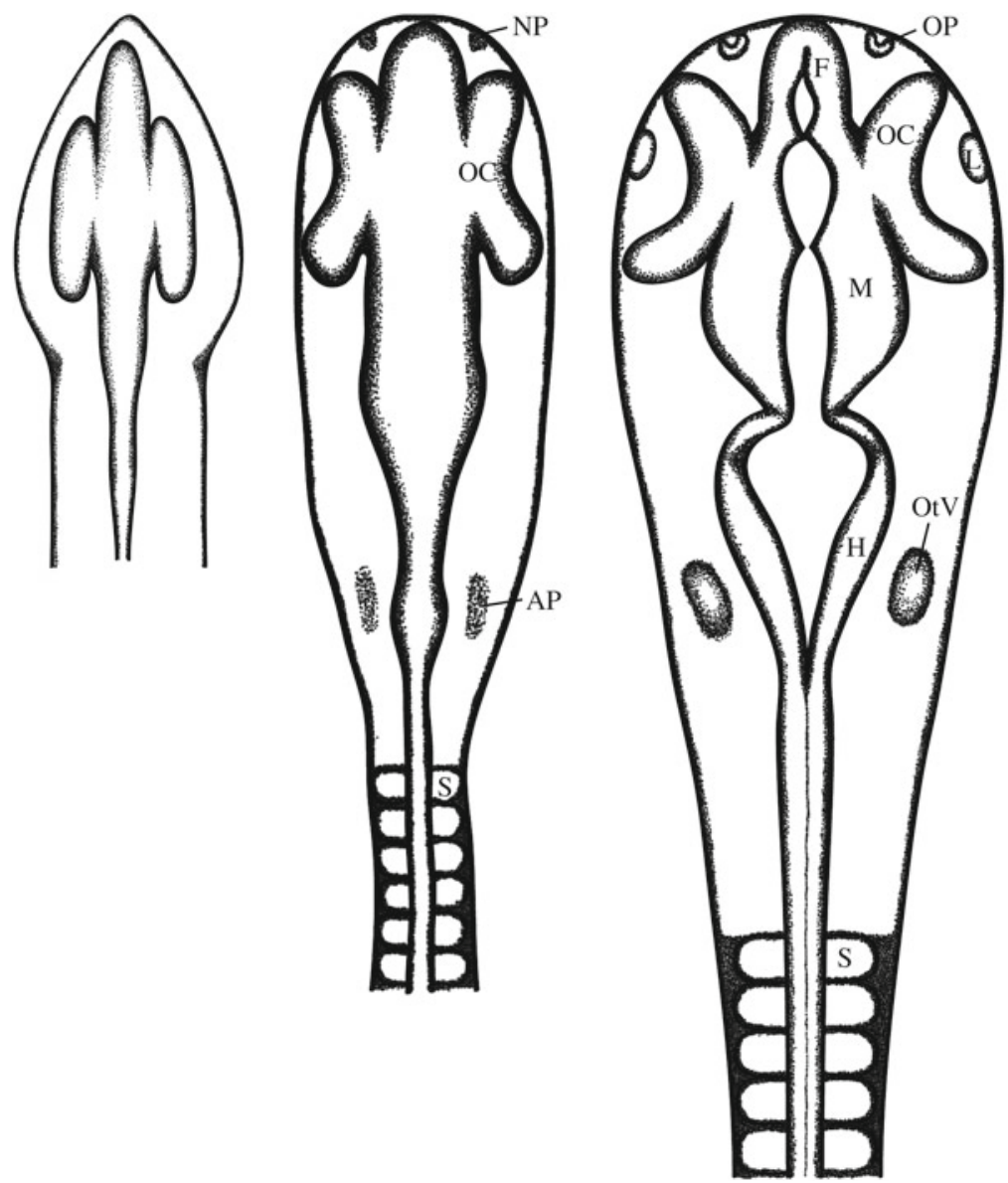

Fig. 2 Development of the brain and sensory organs in a fish embryo. NP - nasal placode, APauditory (otic) placode, $\mathrm{OC}$ - optic cup, S-somites, OP-olfactory pit, F-forebrain, M-midbrain, H-hindbrain, L-lens, OtV - otic vesicle (redrawn from Berrill and Karp 1976) 
The otic placode, one of several dorsolateral placodes, is an epithelial thickening of the ectoderm near the middle of the developing hindbrain (Nelsen 1953; Kelly and Corwin 1992). The hindbrain develops from the neural tube and has a complex series of rhombomeres or bulges that have differential gene expression, particularly Hox gene expression, allowing for rhombomere specific differentiation, which in turn forms the basis of nerve patterning in the hindbrain (Keynes and Krumlauf 1994; Gilland and Baker 1993). The otic placode and later developing otocyst is located in close proximity to this rhombencephalon and the influence of the rhombencephalon is necessary and sufficient to induce the ectoderm to develop the otic placode (Model et al. 1981; Van De Water 1983; see Fig. 3). It is likely that molecular cues from the developing hindbrain are responsible for inducing the development of fish inner ear (Ekker et al. 1992). In addition to rhombencephalilization, the notochordal mesoderm, paraxial mesoderm and neural crest play a role in otic placode induction (Yntema 1955; Van De Water 1983; Jacobson and Sater 1988).

As the brain develops, the telencephalon and diencephalon begin to differentiate. Just after cephalic flexure increases, the otic pit forms as the otic placode invaginates. It has been demonstrated in amphibians that the axis polarity is fixed during early otic pit formation (Harrison 1945). This is likely true for all vertebrates including fish. Fixation of the anteroposterior axis occurs first, followed by the dorsoventral axis during otic pit formation (Yntema 1955). Once polarized, the locations for inner ear structures become fixed within the otic pit and disruptions in the orientation of the otic pit or later the otocyst will cause deformities in the inner ear (Harrison 1945; Detwiler and van Dyke 1950; Mansour et al. 1993).

The otic pit next separates from the ectoderm and closes to form the otocyst. As the otocyst forms, cells in the anteroventral portion of the otocyst give rise to the otic ganglia, which migrates away and breaks contact from the otocyst (Von Kupffer 1895; Webb and Noden 1993; Haddon and Lewis 1996). Populations of embryonic stem cells that make up part of the neural crest give rise to the support and glial cells found in the otic ganglion (Ayer-Le Liver and Le Douarin 1982; D'Amico-Martel and Noden 1983). Shortly after the otocyst separates from the ectoderm, there is a proliferation of undifferentiated epithelial cells along the ventro-medial surface of the otocyst. This proliferation of undifferentiated epithelial cells precedes segregation and differentiation of the otocyst into the various vestibular and auditory sensory epithelia. These undifferentiated epithelial cells later develop into hair and support cells within the otic endorgans. In amphibians transplantation and grafting experiments have demonstrated that the otocyst must be in close proximity to both the hindbrain and cephalic mesenchyme, at least during a critical period in an early stage otocyst, in order for differentiation to occur (Kaan 1930; Detwiler and van Dyke 1950). Although the length of this critical period varies among other vertebrate groups, it is likely that fish undergo a similar critical period where proximity to the hindbrain and cephalic mesenchyme is necessary for segregation and differentiation of the sensory epithelia.

As the otocyst develops and differentiates, the otic ganglia must grow distal processes to innervate the sensory epithelia of the auditory end organs. Studies in other vertebrate groups have demonstrated that the otocyst releases trophic factors to 

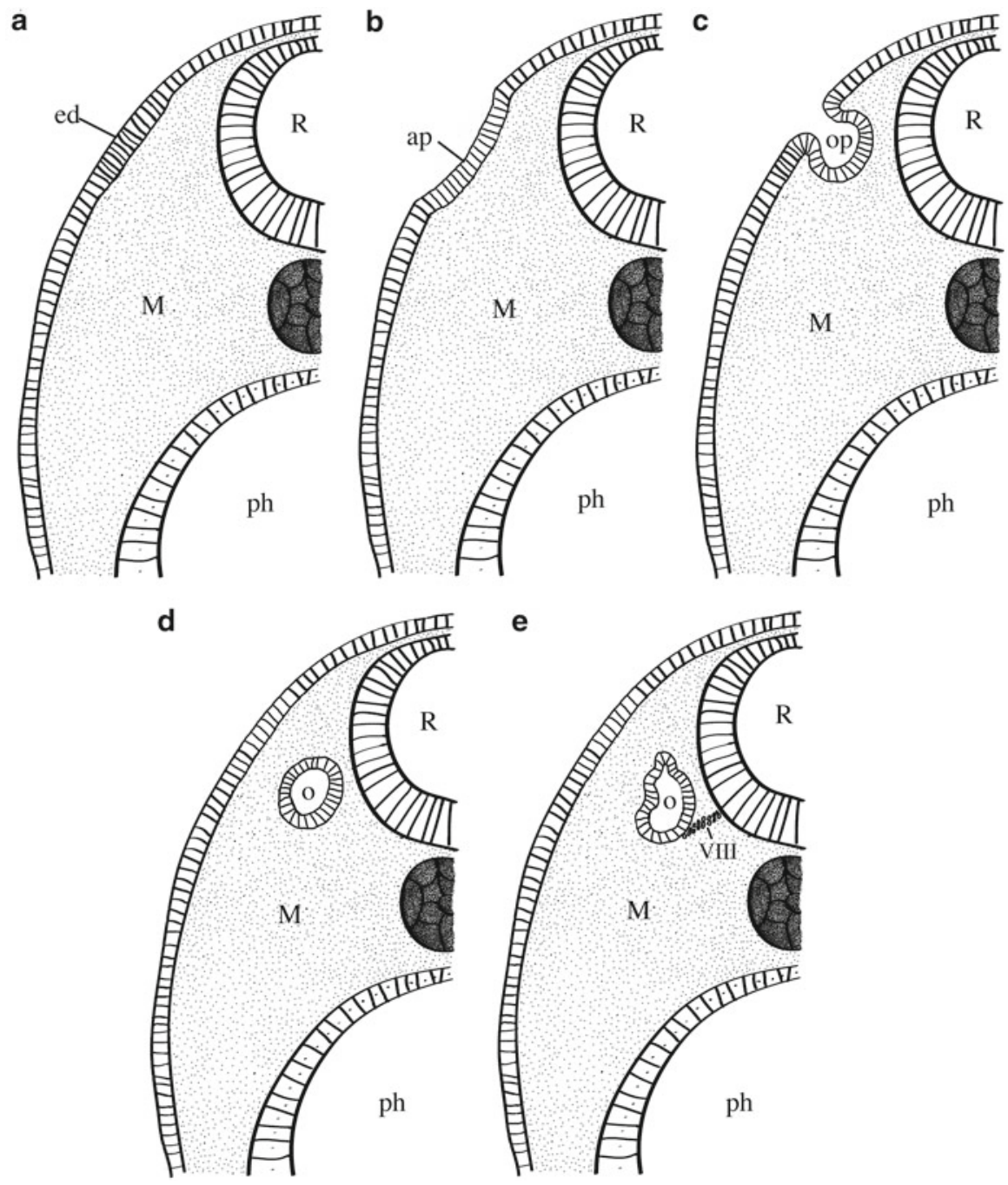

Fig. 3 Embryonic development of the auditory system in fishes. (a) Shows epithelial thickening in the ectoderm (ed) which is induced in (b) to form the auditory placode (ap) in the ectoderm of the developing embryo. In (c) the auditory placode invaginates to form the otic pit (op) and the subsequent closing of the otic pit in (d) forms the otocyst (o), which separates from the ectoderm. In (e) the otocyst polarizes and begins to differentiate into the various endorgans of the auditory and vestibular systems. $\mathrm{R}$-rhombencephalon, $\mathrm{M}$ - head mesenchyme, $\mathrm{ph}$ - pharynx, ed-ectoderm, ap-auditory placode, op-otic pit, o-otocyst, VIII - cranial nerve VIII

attract the growing ganglia toward the otocyst causing the neurons to enter at the appropriate sites (Hemond and Morest 1992; Bianchi and Cohan 1993). Although the exact timing of innervation by auditory afferents and efferents is not well studied in fishes, nerve innervation appears to take place before functional maturation of 
the hair cells in the sensory epithelium (Tanimoto et al. 2009). Afferent innervation does not appear to be necessary for hair cell differentiation, but it likely plays a role for long-term maintenance of individual hair cells (Sokolowski et al. 1993; Fritzsch et al. 2004). In the toadfish, Opsanus tau, cells located within the developing sensory epithelium that differentiate into hair cells have a layer of microvilli along the luminal surfaces, which elongate to form the stereocilia as the kinocilia begin to elongate (Lewis and Li 1973; Sokolowski and Popper 1988). Also, embryonic differentiation and hair cell addition in $O$. tau occurs throughout the saccule simultaneously and not only on the edges of the growing saccular macula (Sokolowski and Popper 1988). Once the processes of innervation, differentiation, and hair cell maturation have taken place in the auditory end organs, all of the structural components necessary for auditory perception are in place and transduction of acoustic stimuli can begin, however the auditory system continues to develop after fish hatch.

\subsection{Postembryonic Development of the Peripheral Auditory System}

Postembryonic sensory hair cell addition has been demonstrated in elasmobranch (Corwin 1981, 1983) and teleost fishes (Platt 1977; Popper and Hoxter 1984; Coffin et al. 2012). The size and shape of the sensory epithelia also change during ontogeny (Corwin 1983; Popper and Hoxter 1984; Lombarte and Popper 1994). Additional ontogenetic changes may include the density of sensory hair cells (Popper and Hoxter 1984; Lombarte and Popper 1994; Lu and DeSmidt 2013), and number of auditory nerve ganglion cells as well as the innervation patterns of the eighth nerve (Corwin 1983; Popper and Hoxter 1984), but at least in the European hake, Merluccius merluccius, it does not include orientation of the hair cells (Lombarte and Popper 1994).

Because the saccule is the main end organ of hearing in most teleost fishes, it has been the most extensively studied auditory end organ, however some data exists which suggests that the macula neglecta in elasmobranchs and other otolithic end organs such as the lagena and utricle in teleosts may also serve an auditory function. Popper and Hoxter (1990) found that sensory hair cells are added throughout the sensory macula of the saccule during normal development and not in a pattern similar to the annular growth rings of the sagitta found in Astronotus ocellatus. Hair cell addition was also observed throughout the lagenar and utricular sensory epithelia in M. merluccius (Lombarte and Popper 1994). This is in contrast to elasmobranchs, which have been shown to primarily add proliferating sensory hair cells to the margins of the sensory epithelium (Corwin 1981, 1983). Although hair cell proliferation appears to occur throughout the saccule in teleost fishes, in the European hake, M. merluccius, the caudal region of the saccule undergoes more hair cell proliferation than the rostral region of the saccule (Lombarte and Popper 
1994), so there appears to be variation among fishes in where hair cells are added within the sensory epithelia.

Additionally, there is a large variation in the rate of hair cells addition during ontogeny in the auditory maculae of sexually immature juvenile fishes: 302 cells per day in the European Hake, M. merluccius (Lombarte and Popper 1994), 167 cells per day in the saccule of cichlid Astronotus ocellatus (Popper and Hoxter 1984), 13 hair cells per day in the zebrafish Danio rerio (Lu and DeSmidt 2013), and the elasmobranch Raja calvata adds 1-3 sensory hair cells per day to the macula neglecta (Corwin 1983). Lombarte and Popper (1994) also found significant postembryonic proliferation of hair bundles in the lagenar and utricular epithelia in M. merluccius, although at a much-reduced rate, 47 hair cells per day in the utricle, and 37 hair cells per day in the lagena. The only study to examine hair bundle orientation found no changes in orientation patterns or percentage of area occupied by different orientation groups in all three otolithic epithelia during ontogeny in the European hake (Lombarte and Popper 1994).

As fish grow, so do the inner ears and the sensory maculae. In the zebrafish, D. rerio, the area of the otic vesicle as well as the area of saccular and utricular otoliths grow linearly, although the area of the saccular otolith grows at a greater rate than that of the utricular otolith (Lu and DeSmidt 2013). Lombarte and Popper (1994) found in M. merluccius that the utricular and lagenar epithelial areas grow at a slower rate than that of the saccular epithelial area, which grows isometrically with total length (TL). The shape of the sensory macula may or may not change as fish grow. In the ray, $R$. clavata, the macula neglecta elongates in the direction of the long axis of the posterior canal duct as the elasmobranch grows (Corwin 1983). This is in contrast to the zebrafish, which does not change shape during growth and development (Lu and DeSmidt 2013).

Another area where there seems to be variation in developmental patterns of the fish inner ear is hair bundle density. In the saccule of both A. ocellatus and M. merluccius hair bundle density decreased with age/size even though the total number of hair cells increased dramatically (Popper and Hoxter 1984; Lombarte and Popper 1994). In M. merluccius, the hair bundle density in the lagenar and utricular epithelia also decreased with size (Lombarte and Popper 1994). In D. rerio, hair bundle density in the saccule did not change in juvenile fish aged 3-18 months posthatch (Higgs et al. 2001), however during the first week of posthatched growth the density of hair cells increased linearly (Lu and DeSmidt 2013). It is possible during early postembryonic development that hair bundles rapidly increase in numbers relative to the growth of the sensory maculae causing an increase in density, which slows and reverses later during development due to a decrease in hair cell density as the area of the auditory macula grows and expands. More work is needed in other fishes over a broader range of developmental time periods to determine if this is the case.

Another area of the peripheral auditory system of fishes where ontogenetic plasticity has been demonstrated is the eighth cranial nerve. Relatively few data exists examining ontogenetic changes in the auditory nerve morphology, however Corwin (1983) found that the number of nerves that innervate the macula neglecta do not change in the skate, Raja clavata. In contrast, Barber et al. (1985) found that axon 
number, total axon area, and hair cell number of the macula neglecta increased linearly with size/age of the skate, $R$. ocellata, and that there were significant differences in hair cell numbers of the macula neglecta in females and males for any given size of skate with females having a greater number of total hair cells. In the teleost A. ocellatus, the number of ganglion cells innervating the saccule increase 4.8-fold (Popper and Hoxter 1984). The rate of hair cell addition drastically outpaces nerve growth in Astronotus ocellatus and in both studies the disproportionate addition of hair cells results in an increase in neural convergence ratio of hair cells to auditory afferents (Corwin 1983; Popper and Hoxter 1984). By retrograde filling of the nerve axons using cobalt, Corwin (1983) found that each nerve innervates several hair cells with terminals that branch over a small area, with the greatest arborization in the center of the macula and lesser arborization at the periphery. These hair cells appeared to innervate by only one auditory afferent neuron (Corwin 1983). Corwin (1983) also found that as the ray grows, the axons increase in diameter and terminal field size.

\subsection{Ontogenetic Structure-Function Relationships in the Fish Auditory System}

The functional significance of many of the observed morphological changes in the fish auditory system during development is not known because relatively few studies have related quantified morphological changes to some measure of auditory sensitivity. It is likely, as shown in other vertebrate groups, that changes in some aspect of sensory morphology will be correlated with functional and/or sensitivity changes of the auditory system (Weiss et al. 1976; Lewis et al. 1985). In the elasmobranch Raja clavata, Corwin (1983) found a 500-fold increase in auditory nerve sensitivity that is likely due to the addition of sensory hair cells. This increase in sensory hair cells was not accompanied by a corresponding increase in auditory nerve innervation thus leading Corwin (1983) to postulate that the observed increase in auditory sensitivity resulted from the increased convergence ratio of sensory hair cells to auditory afferent neurons. In teleost fishes, Lu and DeSmidt (2013) found an increase in the microphonic response and sensitivity of the saccule in the zebrafish, Danio rerio, which correlated with increases in the number and density of saccular hair cells. In contrast, Higgs et al. (2001) found no changes in hearing sensitivity or bandwidth in $D$. rerio that correlated with hair cell addition. It is important to note that Lu and DeSmidt (2013) measured hearing sensitivity of the hair cells in the saccule, the end organ where the morphological changes were observed, whereas Higgs et al. (2001) measured hearing sensitivity using the auditory evoked potential (AEP) recording technique, which measures overall neural responses potentially including higher-order brain regions of the central auditory system (see next section). Lu and DeSmidt (2013) also used fish during an earlier stage of zebrafish development than Higgs et al. (2001), which may have allowed them to capture a period of 
greater ontogenetic change. Additional studies looking at how other morphological changes relate to ontogenetic changes in auditory sensitivity would greatly improve our understanding of the structure function relationships between auditory structures and hearing sensitivity in fishes.

\section{Development of Hearing in Fishes}

In contrast to other vertebrate groups, there are only a few studies that have examined the development of hearing capabilities in fish. Most ontogenetic studies of fish hearing have focused on changes in auditory sensitivity in regard to thresholds of auditory evoked potentials (AEPs) across different-sized animals, although a few studies measured other functions such as changes in temporal encoding with age/ size (e.g., Sisneros and Bass 2005).

Depending on the specific research question and species of fish examined, there has been a large degree of variability in the developmental stages investigated. While some studies tried to understand the functional role of specific morphological structures for hearing enhancement (e.g. Lechner et al. 2011; Webb et al. 2012; Caiger et al. 2013) or even the relationship between auditory sensitivity and the onset of vocal communication (e.g. Wysocki and Ladich 2001; Vasconcelos and Ladich 2008) over a wide range of fish sizes, others have only focused on larval stages to determine whether the auditory system is developmentally functional to enable fish larvae to find specific habitats for settlement using environmental acoustic cues (Wright et al. 2011).

This section provides a systematic overview of the studies concerning the development of fish hearing during ontogeny organized by taxa. Moreover, a final part will focus on how the hearing sense in fishes has evolved for the enhancement of social acoustic communication.

\subsection{Diversity of Auditory Sensitivity}

In order to study the development of auditory sensitivity in juvenile fish, investigators have employed different methods for the assessment of hearing ranging from behavioral to electrophysiological approaches. Likely due to the long training periods and difficulty of training small juvenile fish, only one study has used a behavioral conditioning method to investigate the ontogenetic development of auditory sensitivity (Kenyon 1996). One behavioral technique that has proved useful in determining whether or not the auditory system is functional during development is the acoustic startle or startle-like escape responses that consist of a stereotyped "tail-flip" response evoked by relatively loud sound stimuli (Blaxtey and Batty 1985; Fuiman et al. 1999; Zeddies and Fay 2005; Alderks and Sisneros 2013). 
Alternatively, electrophysiology techniques have also been used, namely multiunit recordings from the auditory cranial nerve (Corwin 1983; Sisneros and Bass 2005) or measurement of evoked responses from populations of saccular hair cells (Alderks and Sisneros 2011), to characterize auditory sensitivity during ontogeny.

However, the most common electrophysiology technique used to determine hearing sensitivity in fish during ontogeny is the AEP recording technique, which was introduced and adapted for fish by Kenyon et al. (1998). This technique is used to measure the overall neural auditory responses evoked by auditory stimuli and consists of the summation of evoked field potentials from central brain regions, auditory nerve, and otolithic end organs over many presentations (for an extensive review of the use of the AEP technique in fish hearing, see Ladich and Fay 2013). The AEP technique has become a useful tool to assess the ontogenetic development of hearing in various marine and freshwater fishes.

In general, auditory thresholds of fishes have largely been characterized in terms of sound pressure, but it is now generally accepted that all fish species are capable of sensing particle motion via their otolithic end organs and only some fish species possess accessory hearing specializations that allow them to detect sound pressure. Most of the previous studies presented auditory threshold data in terms of sound pressure largely due to technical constraints, namely due to the difficulty of measuring particle motion directly and the commercial unavailability of neutrally buoyant underwater accelerometers. In addition, the reporting of auditory sensitivity in terms of sound pressure was a convenient mean of comparison with the sound spectra of conspecific vocalizations, which is typically characterized in terms of sound pressure.

Table 1 provides a systematic overview of the various fish species in which auditory sensitivity has been examined during ontogeny as well as the recordings techniques used in each study. The data in Table 1 reveals taxon-specific results, with most fish species exhibiting auditory sensitivity improvements with age/size during ontogeny. In addition to increased auditory sensitivity, some studies also report changes in peak frequency sensitivity and in the detectable frequency range or detection bandwidth.

\subsubsection{Chondrichthyes (Cartilaginous Fishes)}

\section{Rajiformes}

The first study to report changes in auditory sensitivity during development in fish was conducted by Corwin (1983) in the thornback skate Raja clavata (Chondrichthyes, Rajidae). By means of multiunit in vitro recordings of the macula neglecta (nonotolithic auditory end organ of the inner ear), the author showed a 500fold increase in auditory sensitivity with age/size in skates from 21 to $91 \mathrm{~cm}$ total length (TL). This increase in auditory sensitivity was observed across the range of tested frequencies such that the filter shape of the audiogram remained similar but 


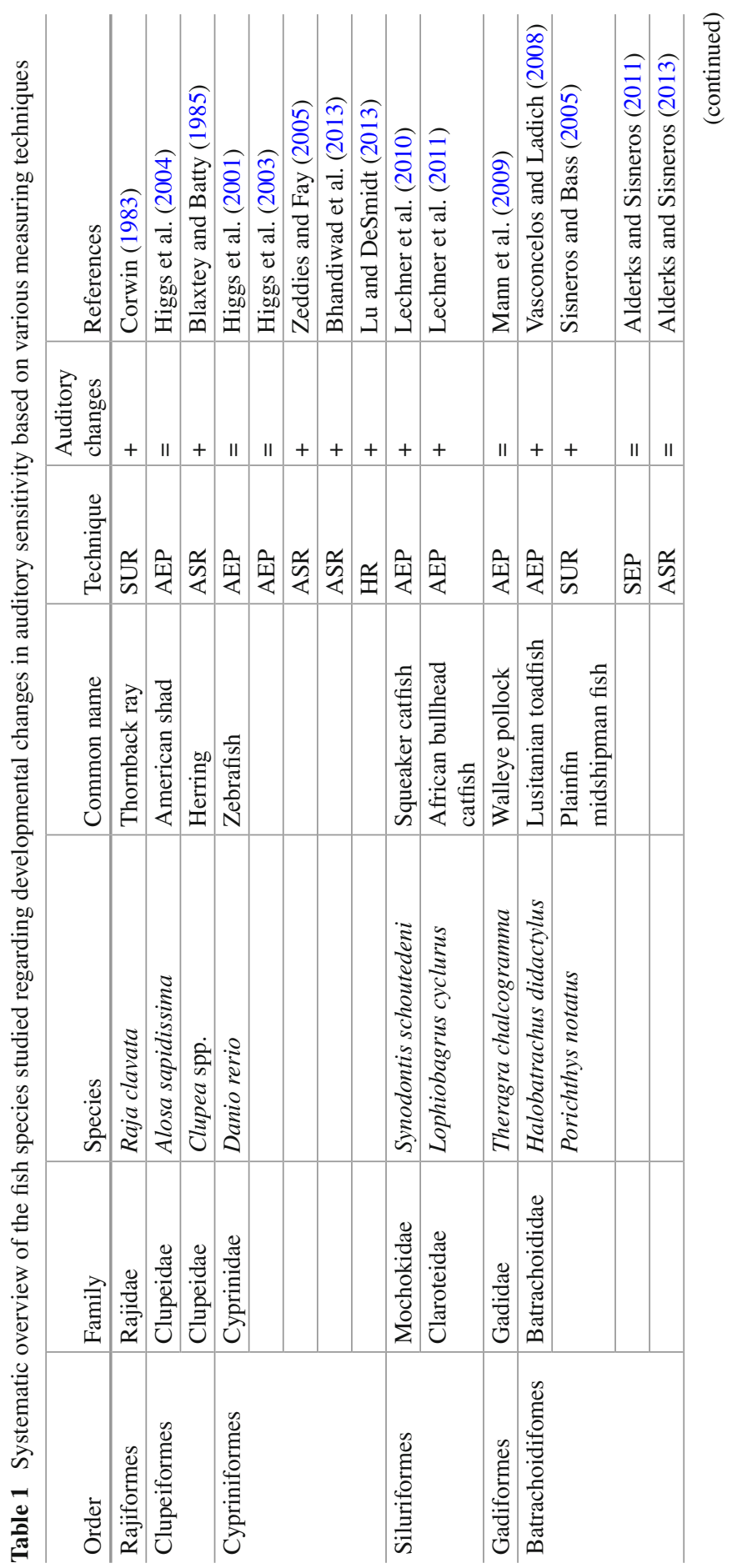




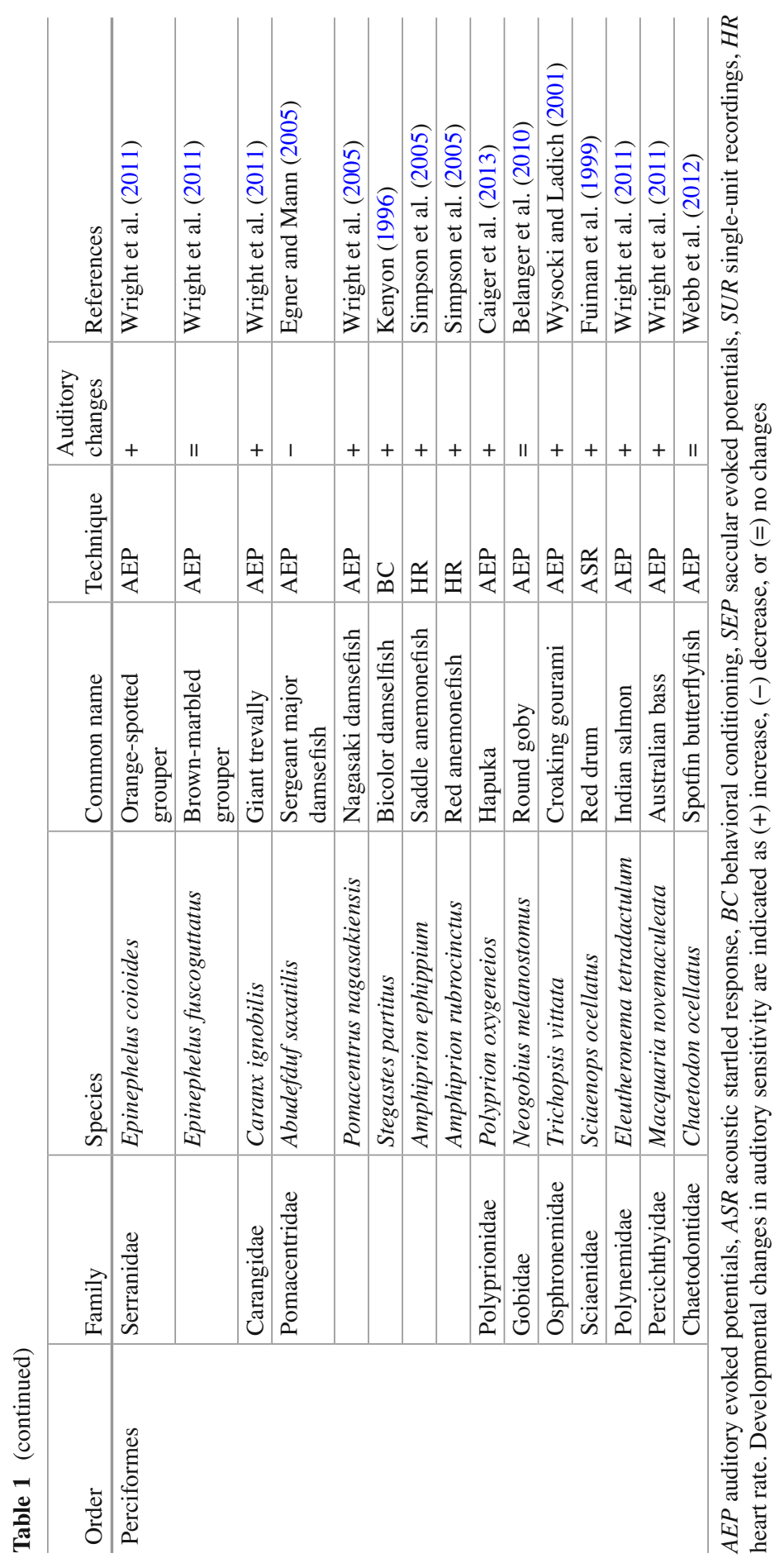


the thresholds decrease during ontogeny. Further studies need to be performed on other cartilaginous fish to determine whether these results are representative of hearing changes during development within this group of fishes.

\subsubsection{Teleostomi/Osteichthyes (Bony Fishes)}

\section{Clupeiformes}

Within this order that includes several species with high commercial value, such as herrings (Clupea sp.), sardines (Dussumieria sp., Escualosa sp. Sardina sp., Sardinella sp., and Sardinops sp.), shads (Alosa sp.), and anchovies (over 15 species with the most common being Anchoa sp., Thryssa sp., Stolephorus sp. and Coilia sp.), very little is known on development of their hearing capabilities. Many species that belong to this order are capable of ultra sound detection and understanding how their auditory sense is adapted throughout ontogeny would certainly provide valuable information for the fisheries industry and conservation.

In one of only two studies that have examined the development of hearing in fishes from this order, Blaxtey and Batty (1985) used a behavioral technique that examined the development of startle responses evoked by auditory stimuli in the larvae herring (Clupea harengus). These researchers found that the acoustic startle response (i.e., the Mauthner mediated C-start escape response) to auditory stimuli in herring larvae appeared after hatching. Herring larvae were observed to respond to sound at $22-36 \mathrm{~mm} \mathrm{TL}$, while only responding to touch stimuli during earlier stages of development at $10-12 \mathrm{~mm}$ TL.

In a second study, Higgs et al. (2004) conducted an ontogenetic physiological study to evaluate the onset of ultrasound detection in the American shad, Alosa sapidissima. According to the authors, once the developing shad was capable of detecting sounds, the auditory sensitivity as measured using the AEP technique was not observed to change with age/size. No improvements in sensitivity were registered with age/size, namely from larvae of 30-34 mm TL to adults greater than $100 \mathrm{~mm}$ TL over a frequency range of $0.1-90 \mathrm{kHz}$ (Fig. 4). According to the authors, the onset of ultrasound detection was coincident with the early development and specialization of the utricle.

\section{Cypriniformes}

This order contains the Ostariophysian fishes that possess accessory morphological hearing structures (i.e., Weberian ossicles), which couple the inner ear to the anterior part of the swim bladder that enable the fish to detect sound pressure stimuli.

The zebrafish (Danio rerio), a well-studied model, belongs to this taxon. This species has become a significant biomedical research model for investigating human hearing and vestibular disorders as it combines genetics, embryology, and excellent in vivo visualization all in a single organism (Whitfield et al. 2002; Lu and 

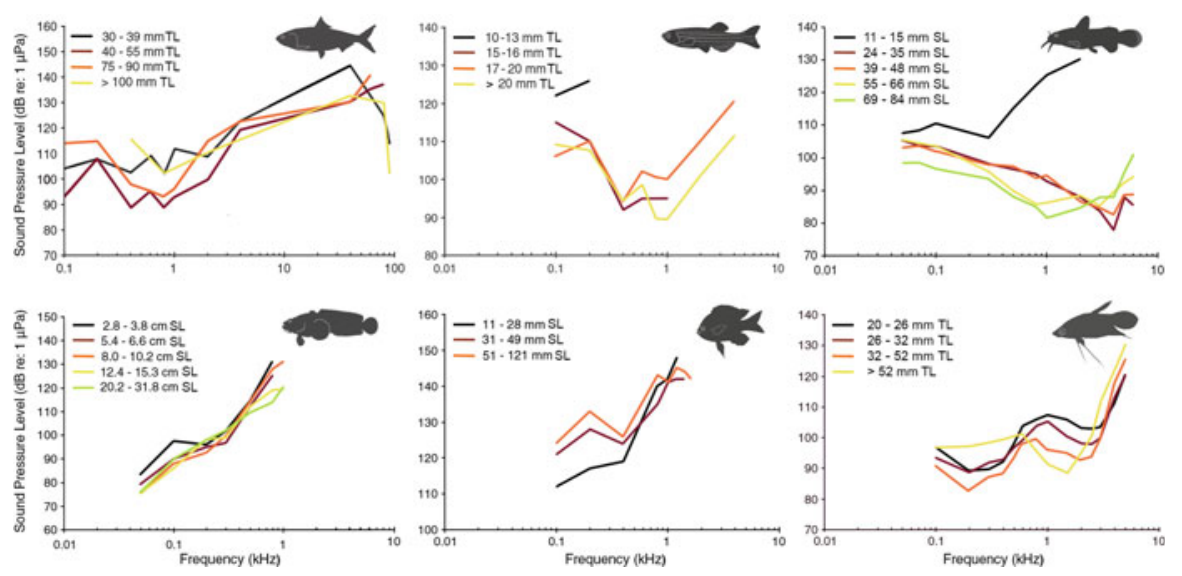

Fig. 4 Development of auditory sensitivity in various teleost fish species, namely: upper row, from left to right-American shad (Alosa sapidissima), zebrafish (Danio rerio), African bullhead catfish (Lophiobagrus cyclurus); lower row, from left to right-Lusitanian toadfish (Halobatrachus didactylus), sergeant major damselfish (Adudefduf saxatilis), croaking gourami (Trichopsis vittata). After Higgs et al. (2004), Higgs et al. (2003), Lechner et al. (2011), Vasconcelos and Ladich (2008), Egner and Mann (2005) and Wysocki and Ladich (2001), respectively

DeSmidt 2013). The first study to investigate the ontogeny of hearing in zebrafish was conducted by Higgs et al. (2001) using AEP recordings, and reported an absence of improvements in auditory sensitivity or bandwidth with growth and development, despite continuous hair cell production with age/size (body length tested: 25-34 mm up to 45-50 mm TL) (Fig. 4). According to this study, hearing sensitivity is not necessarily related to the number of sensory cells in the ear in juvenile or adult fish. Subsequently, Higgs et al. (2003) focused on zebrafish during earlier developmental stages (10-45 mm TL) and reported an increase in the maximum detectable frequency from $200 \mathrm{~Hz}$ (at $10 \mathrm{~mm}$ TL) to $4000 \mathrm{~Hz}$ (at $45 \mathrm{~mm} \mathrm{TL}$ ), which coincided with the development of the Weberian ossicles and sensitivity to sound pressure. Again, no differences were found regarding auditory sensitivity, response latency, or response amplitude with age/size for zebrafish across the size range tested.

Using a different technique based on observation of acoustic startle responses evoked by auditory/vibratory stimuli, Zeddies and Fay (2005) found that the stimulus thresholds and frequency bandwidth to which zebrafish responded was similar from $5 \mathrm{dpf}$ (days post fertilization) to the adult stage. However, the authors also found that deflating the swim bladder in adults decreased their startle-like responses, while the same procedure in larval fish did not affect hearing, indicating that acoustic startle response thresholds are adjusted as the fish develop in order to maintain appropriate reactions to relevant stimuli. According to this study, zebrafish seem to switch from particle motion sensitivity, at the larvae stage, to sound pressure sensitivity during the juvenile and adult stages, which possess a fully developed ear containing Weberian ossicles. 
Recently, Lu and DeSmidt (2013) recorded evoked potentials from saccular hair cells (microphonic responses) from zebrafish larvae at 2-7 dpf using particle motion stimulation delivered by a displacement-driven piezoelectric probe placed adjacent to the inner ear. Saccular potentials increased with stimulus intensity and frequency while auditory thresholds (at $200 \mathrm{~Hz}$ ) decreased gradually during fish growth with age/size. Such developmental changes were correlated with the increases in the number and density of saccular hair cells. The results reported in this study are in contrast with the previously published data on the same species (Higgs et al. 2001, 2003), however the latter investigation by Lu and DeSmidt (2013) used zebrafish larvae during the first week of development, a period of rapid anatomical and physiological changes in the inner ear, which could explain the changes in ontogenetic auditory sensitivity.

\section{Siluriformes}

Within this taxon (also otophysines), two catfish species have been investigated, namely the squeaker catfish (Synodontis schoutedeni) (Mockokidae) and the African bullhead catfish (Lophiobagrus cyclurus) (Bagridae) (Lechner et al. 2010, 2011). Based on AEP recordings, both species exhibited considerable improvement in auditory sensitivity and changes in best frequency sensitivity range with increases in size/age (Lechner et al. 2010). According to Lechner et al. (2010), the smallest juveniles $S$. schoutedeni with 22-37 mm standard length (SL) had relatively poor hearing ability in comparison with larger juveniles and adults that range up to $127 \mathrm{~mm}$ SL (tested over a frequency range of $0.5-1 \mathrm{kHz}$ ). The authors reported an ontogenetic increase in auditory sensitivity of $26 \mathrm{~dB}$ re $1 \mu \mathrm{Pa}$ and a change in the range of lowest thresholds from $2-3 \mathrm{kHz}$ in juveniles of $22-37 \mathrm{~mm}$ SL to $0.3-1 \mathrm{kHz}$ in larger fish of 62-127 $\mathrm{mm}$ SL.

In the bullhead catfish (L. cyclurues), auditory sensitivity was reported to increase up to $40 \mathrm{~dB}$ re $1 \mu \mathrm{Pa}$ during ontogeny (Lechner et al. 2011) (Fig. 4). The smallest juveniles (11-15 mm SL) were unable to detect frequencies higher than $2-3 \mathrm{kHz}$ while being most sensitive to frequencies of $0.05-2 \mathrm{kHz}$, whereas larger individuals ( $>24 \mathrm{~mm} \mathrm{SL}$ ) showed best sensitivity to higher frequencies of 4-6 kHz. According to the authors, the increase in auditory sensitivity and maximum detectable frequency was posited to be due to the development of interossicular ligaments between the Weberian ossicles.

\section{Gadiformes}

The single representative species of this order studied so far is the walleye pollock (Theragra chalcogramma) (Gadidae). Mann et al. (2009) showed that there were no significant differences in AEP sensitivity between three different size groups tested that ranged from 14 to $26 \mathrm{~cm}$ TL. The three size groups of walleye pollock had best hearing sensitivity from 100 to $200 \mathrm{~Hz}$ with thresholds of approximately $75 \mathrm{~dB}$ re 1 $\mu \mathrm{Pa}$. Although there were no significant differences in thresholds among the three 
size groups, the authors did find a significant interaction between frequency and age/size, as well as, a trend (but not significant) which indicated that older fish may have slightly lower thresholds. The same study also described a substantial increase in the size of the saccular otolith and associated saccular epithelia of the inner ear during development, suggesting that a large increase in the size of the inner ear size does not necessarily lead to a significant change in auditory sensitivity.

\section{Batrachoidiformes}

This order includes the midshipman fish and toadfishes, which rely on acoustic communication for social behaviors and, therefore, their auditory system has been focus of attention in many studies including ontogeny.

According to Vasconcelos and Ladich (2008), the Lusitanian toadfish Halobatrachus didactylus (Batrachoididae) exhibits slight developmental increases in auditory sensitivity and maximum detectable frequency with age/size. Using the AEP recording technique, the authors found that the smallest group analyzed (3-4 cm SL) was circa $11 \mathrm{~dB}$ less sensitive at $100 \mathrm{~Hz}$ compared to larger size groups and had a lower maximum detectable frequency $(800 \mathrm{~Hz})$. The remaining size groups, which ranged from 5-7 to 20-32 cm SL, responded at all frequencies tested (50-1000 Hz) with similar thresholds (Fig. 4).

Another member of Batrachoididae, the plainfin midshipman (Porichthys notatus), has also been investigated regarding ontogenetic changes in auditory capabilities using electrophysiology and behavioral methods. Sisneros and Bass (2005) conducted extracellular single unit recordings from saccular afferents in different-sized midshipman fish, from small juveniles $(3-5 \mathrm{~cm} \mathrm{SL})$ to the adults $(>10 \mathrm{~cm} \mathrm{SL})$. Both resting discharge rate and auditory sensitivity increased with fish size, while the temporal encoding of the tested frequencies at an iso-intensity of $130 \mathrm{~dB}$ re $1 \mu \mathrm{Pa}$ did not show any significant developmental shifts.

Also using the midshipman fish model, Alderks and Sisneros (2011) recorded evoked saccular potentials to investigate potential ontogenetic changes in saccular sensitivity across a wider range of animals from small juveniles (1.9-3.1 cm SL) to adults (9-22.6 cm SL). The authors showed an ontogenetic retention of saccular sensitivity with size (see Fig. 5). They also reported an increase in the maximum detectable frequency with age/size such that larger fish were more likely to detect frequencies greater than $385 \mathrm{~Hz}$. Subsequently, Alderks and Sisneros (2013) reported the development of the acoustic startle-like response in different-sized groups of midshipman fish larvae that ranged in size from 1.5 to $3.2 \mathrm{~cm}$ TL. The acoustic startle response was first observed in larvae at a size of $1.4 \mathrm{~cm}$ TL; above $1.8 \mathrm{~cm}$ TL, all larvae responded to a broadband stimulus of $154 \mathrm{~dB}$ re $1 \mu \mathrm{Pa}$. Larval fish from the medium size group (1.9-2.4 cm TL) had significantly lower acoustic startle-like thresholds at $75-145 \mathrm{~Hz}$ than the other size groups, which may be related to differential growth and development of the saccule during different time points during early larval development (Fig. 5). Future work will be needed to determine the mechanisms responsible for the observed differences in acoustic startle-like response among the size groups tested for this species. 


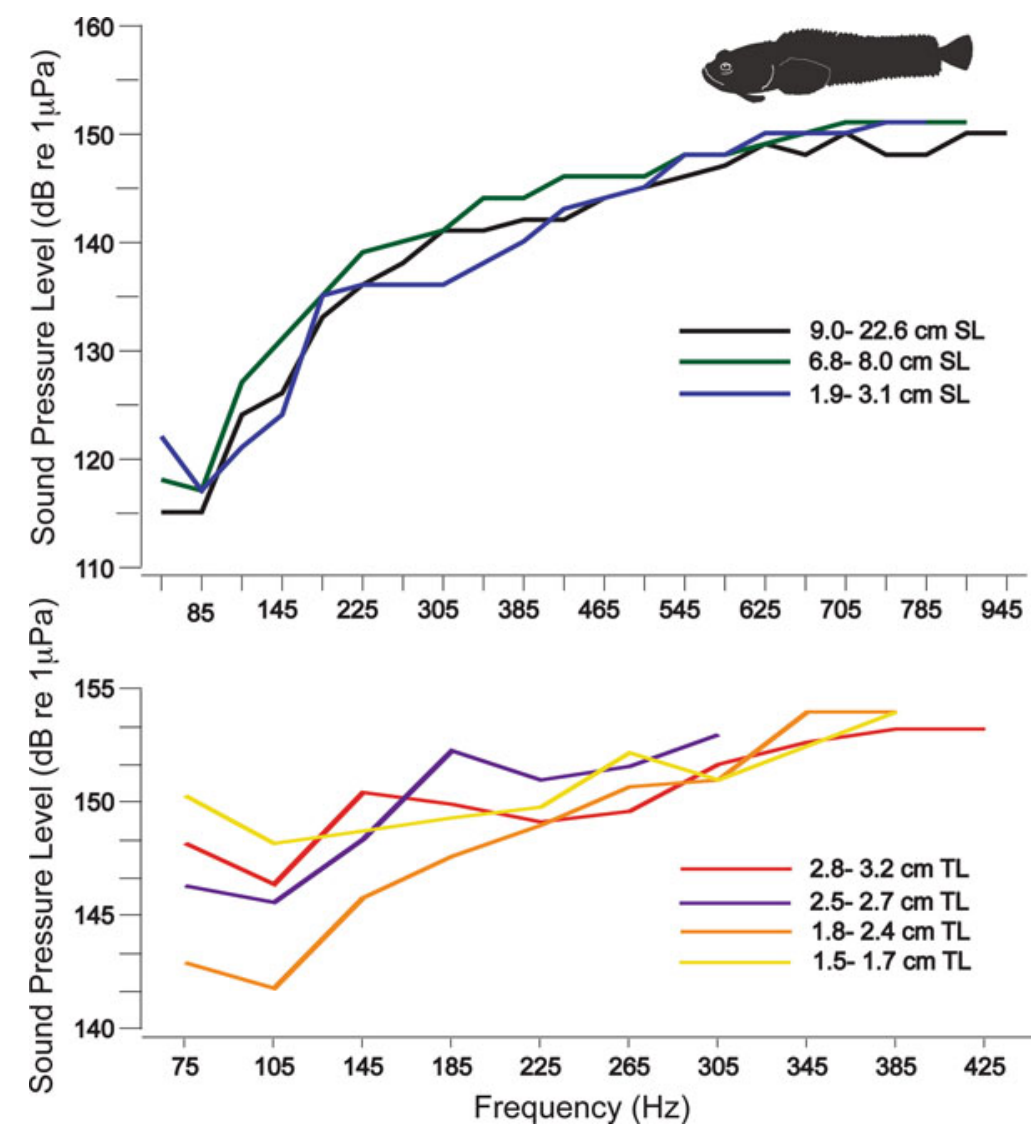

Fig. 5 Auditory sensitivity in the plainfin midshipman (Poricithys notatus) throughout development: top, tuning curves derived from saccular potential recordings in three size classes of fish. Notice the similar tuning profile from all three size groups, however larger fish are able to detect higher frequencies; bottom, tuning curves derived from auditory evoked behavioral responses in four different size groups of fish. Again notice the similar shape in the tuning curves from all four size groups. However larval fish in the 1.9-2.4 cm TL size group had significantly lower acoustic startle-like thresholds at $75-145 \mathrm{~Hz}$ than the other size groups, which may be related to differential growth and development of the saccule during different time points during early larval development

\section{Perciformes}

Within this highly diverse order, representatives of several families have been investigated. One research question that has received recent interest is whether the biotic sounds of reef habitats serve as important sound orientation cues for pelagic larvae and facilitate the localization and recruitment to appropriate settlement habitats. 
Although it is clear that settlement-stage fish larvae can detect reef sound at distances of a few $100 \mathrm{~m}$ (Wright et al. 2010), it is less understood how such auditory sensitivity develops throughout the larval phase and how the auditory abilities vary between species.

The early hearing capabilities in several pelagic reef Pomacentrid species have been examined during larval stages with mixed results. Using AEP recordings, Egner and Mann (2005) reported an ontogenetic change in the auditory sensitivity of the sergeant major damselfish (Abudefauf saxatilis, Pomacentridae) (Fig. 4). Curiously, at 100 and $200 \mathrm{~Hz}$ there was a significant effect of size on hearing thresholds with auditory sensitivity decreasing with standard fish length. In addition, maximum detectable frequency increased with SL with the larger fish ( $>50 \mathrm{~mm} \mathrm{SL}$ ) being more responsive at higher frequencies $(1000-1600 \mathrm{~Hz})$. This study suggests that sound may play a role in short-range orientation $(<1 \mathrm{~km})$ of pelagic larvae to reefs.

In contrast, both hearing improvement and absence of developmental changes have been described among other species within the Pomacentridae family. Kenyon (1996), through classical conditioning experiments conducted in a standing wave tube to control sound pressure and particle motion cues, showed that the bicolor damselfish (Stegastes partitus) exhibit an ontogenetic increase in auditory sensitivity, up to $45 \mathrm{~dB}$ re $1 \mu \mathrm{Pa}$ at their most sensitive frequency of $300 \mathrm{~Hz}$. Likewise, Wright et al. (2005) also reported increases in AEP responses of roughly $8 \mathrm{~dB}$ re 1 $\mu \mathrm{Pa}$ at 100 and $600 \mathrm{~Hz}$ between pre-settlement (12-15 mm SL) and post-settlement (15-17 mm SL) in juvenile damselfish (Stegastes nagasakiensis).

Simpson et al. (2005) investigated sound detection in early embryonic stages of two clownfish species, the saddle anemone fish (Amphiprion ephippium) and the red anemone fish (A. rubrocinctus, Pomacentridae), by measuring the heart rate of embryos while exposed to sounds in the range of $100-1200 \mathrm{~Hz}$ at $80-150 \mathrm{~dB}$ (re 1 $\mu \mathrm{Pa}$ at $1 \mathrm{~m}$ ). The authors found that after $3 \mathrm{dpf}$ the heart rate of larvae increased significantly in response to sound. Throughout development, larvae responded to sound via changes in heart rate to large range of frequencies from $400-700 \mathrm{~Hz}$ at 3 dpf and 100-1200 Hz at $9 \mathrm{dpf}$. Larval auditory sensitivity was also shown to increase during development approximately $51 \mathrm{~dB}$ re $1 \mu \mathrm{Pa}$ at $700 \mathrm{~Hz}$.

More recently, Wright et al. (2011) described using AEP recordings ontogenetic increases in auditory sensitivity ranging up to $25 \mathrm{~dB}$ re $1 \mu \mathrm{Pa}$ in three pelagic coralreef fish species. Ontogenetic increases in auditory sensitivity were demonstrated for larval stages of carangid (Caranx ignobilis), serranid (Epinephalus coioides), and polynemid (Eleutheronema tetradactulum) fishes ranging from 9 to $28 \mathrm{~mm}$ TL. However, fish larvae from two other species examined, Epinephelus fuscoguttatus (Serranidae) and Macquaria novemaculeata (Percichthyidae), did not show any ontogenetic changes in auditory sensitivity across different-sized groups. Such species-specific variation in auditory sensitivity during ontogeny suggests that both the developmental stage and species are important factors to consider when investigating whether sound may be a salient cue used by pelagic larvae for navigation and orientation to reef habitats. 
Fuiman et al. (1999) used acoustic startle responses to investigate hearing in the sciaenid Sciaenops ocellatus (red drum) and observed an increase in sensitivity to acoustic stimuli, as well as to visual stimuli, throughout ontogeny (mostly in early larval stages with less than $8 \mathrm{~mm}$ TL). Several variables, such as response magnitude, frequency, duration, speed, and distance (to the auditory stimulus source) increased considerably during early development.

Among the family Osphronemidae, the croaking gourami (Trichopsis vittata) has been investigated by Wysocki and Ladich (2001), which revealed an increase in auditory sensitivity with size/age (from $20 \mathrm{~mm}$ to greater than $52 \mathrm{~mm}$ TL) for a frequency range of $0.8-3 \mathrm{kHz}$. The authors also reported a shift in the most sensitive frequency during development from 2.5 to $1.5 \mathrm{kHz}$ (Fig. 4). According to Wysocki and Ladich (2001), such developmental changes in hearing sensitivity are most likely related to morphological changes in the air-breathing apparatus of the suprabranchial chamber that functions as an accessory hearing organ.

In contrast, the round goby (Neogobius melanostomus) belonging to the family Gobidae has been investigated by Belanger et al. (2010) and showed similar AEP thresholds with no changes in sensitivity during development across different size stages ranging from $40 \mathrm{~mm}$ TL to greater than $120 \mathrm{~mm}$ TL. The authors of this study suggest that the lack of size effects on auditory sensitivity is likely due to the concurrent growth of both otolith (sulcus) area and auditory epithelium, which results in maintaining hair cell density in the auditory macula during development.

In the spotfin butterflyfish (Chaetodon ocellatus, family Chaetodontidae), Webb et al. (2012) also reported the absence of ontogenetic changes in auditory sensitivity to sound pressure in fish of 21-31 mm SL. However, the authors did report a significantly higher sensitivity of larvae from this species compared to other similar-sized larvae of other coral reef species that lack the swim bladder horns found in C. ocellatus. The absence of developmental hearing improvements in $C$. ocellatus may be due to the fact that the swim bladder horns (accessory morphological hearing structures) are established earlier in development prior to a size of $21 \mathrm{~mm}$ SL.

More recently, Caiger et al. (2013) investigated the hearing abilities of hapuka (Polyprion oxygeneios, family Polyprionidae) using AEP recordings and described increases in both ontogenetic auditory sensitivity (up to $27 \mathrm{~dB}$ re $1 \mu \mathrm{Pa}$ ) and in auditory bandwidth (from maximum of 800 up to $1000 \mathrm{~Hz}$ ) within the first year of development (from 10 to $262 \mathrm{~mm}$ fork length). The authors suggested that the development of rostral extensions of the swim bladder to the otic capsule may explain the increased auditory sensitivity of this species during development.

\subsection{Development of Auditory Capabilities for Social Communication}

Communication requires both a sender and receiver, thus one must analyze both the development of auditory sensitivity and sound production when investigating how acoustic communication develops in fishes. Only three non-related species have 
been investigated regarding the development of auditory capabilities and sound production in the context of acoustic communication, namely the croaking gourami (T. vittata, Osphronemidae) (Wysocki and Ladich 2001), the Lusitanian toadfish (Halobatrachus didactylus, Batrachoididae) (Vasconcelos and Ladich 2008), and the squeaker catfish (Synodontis schoutedeni, Mochokidae) (Lechner et al. 2010). In each of these species, ontogenetic improvements in auditory sensitivity were coincident with changes in the spectral features of sound production, such as dominant frequency and amplitude.

More specifically, as mentioned before, in the croaking gourami (Trichopsis vittata), auditory sensitivity increased up to $14 \mathrm{~dB}$ re $1 \mu \mathrm{Pa}$ between 0.8 and $3.0 \mathrm{kHz}$ and the most sensitive frequency within this range shifting from 2.5 to $1.5 \mathrm{kHz}$ (Wysocki and Ladich 2001). The authors of this study also reported that sound production in $T$. vittata began early in development (at $17.5 \mathrm{~mm} \mathrm{SL}$ ) and the dominant frequency of vocalizations shifted from 3 to $1.5 \mathrm{kHz}$ accompanied by an increase in amplitude of $43 \mathrm{~dB}$ re $1 \mu \mathrm{Pa}$. Such results suggested the onset of acoustic communication occurs only after improvements in both auditory sensitivity and vocal amplitude around the same frequencies (circa $1.5 \mathrm{kHz}$ ).

In the Lusitanian toadfish (H. didactylus), the best hearing sensitivity was found at $50 \mathrm{~Hz}$ for all sizes analyzed (from 3 to $32 \mathrm{~cm} \mathrm{SL}$ ) and auditory sensitivity improved at $100 \mathrm{~Hz}$, as well as, at higher frequencies such as 800 and $1000 \mathrm{~Hz}$ with age/size (Vasconcelos and Ladich 2008). Comparing auditory thresholds with sound spectra within each size group revealed that smaller juveniles were potentially barely able to detect agonistic vocalizations of similar-sized fish, contrary to larger fish. The authors suggested that the onset of acoustic communication occurs when juveniles were able to generate grunts of higher sound amplitude and lower dominant frequency.

Finally, in the squeaker catfish (S. schoutedeni), auditory sensitivity increased at higher frequencies during ontogeny, namely at 5 and $6 \mathrm{kHz}$, and comparisons between audiograms and sound spectra revealed a match between that the most sensitive hearing frequencies and the dominant frequencies of agonistic sounds for all sizes analyzed (Lechner et al. 2010). This study showed that S. schoutedeni could detect conspecific vocalizations at all developmental stages examined, most likely due to the presence of the Weberian apparatus.

In these studies, all juvenile fishes vocalized in agonistic context, showing similar changes in sound features despite possessing different sound production mechanisms. In all three studies the dominant frequency decreased with fish development, whereas sound pressure levels and pulse periods increased throughout ontogeny. In both the croaking gourami and the squeaker catfish sound duration also increased throughout ontogeny. Future studies should analyze how the vocal repertoire changes during development, especially in highly vocal species such as the toadfishes, and whether vocal differentiation parallels auditory improvements. 


\section{Conclusions and Future Directions}

Fish represent the largest extant group of vertebrates and display the greatest diversity of structures of the vertebrate auditory system. Thus, this taxon has the potential to provide valuable insights into the ecology and evolution of the vertebrate auditory system. However, despite the greater than 30,000 known fish species only a relatively small number has been examined in terms of ontogenetic development of structure and sensitivity of the auditory system. Thus, more studies should be performed on representatives of diverse species and families with different anatomical hearing specializations. The remarkable diversity of inner ear morphologies and accessory hearing structures in fishes should provide a rich source for future comparisons to gain insights on the selective pressures that have shaped the evolution of fish auditory systems.

There remain many important questions and areas of research that should be addressed in future work, several of which are briefly detailed below:

1. Although the saccule is the main auditory end organ in most teleost species, more physiology studies are needed for the other putative auditory end organs, the lagena and utricle, and their characterization in terms of ontogenetic changes in morphology, sensitivity, and contribution to the development of hearing in fishes. Compared to the numerous studies for the fish saccule, there are only a limited number of studies for the lagena and utricle regarding their potential contribution to hearing during ontogeny (Higgs et al. 2004; Webb et al. 2012; Inoue et al. 2013).

2. Another topic that needs further study concerns the ontogenetic morphological changes in hair cell addition and bundle density in the three putative auditory end organs (saccule, lagena, and utricle). Questions that should be addressed include: (1) Are there differences in hair cell addition and bundle density in the saccule, lagena, and utricle during different stages of development? (2) How do changes in hair cell bundle density relate to the auditory sensitivity of the end organ? (3) In addition to ontogenetic changes, are there seasonal differences in the proliferation and density of hair cells in these auditory end organs across different stages of the reproductive cycle? Recently a study by Coffin et al. (2012) reported seasonal changes in hair cell density in the saccules of female plainfin midshipman fish (Porichthys notatus) that did not occur in the other two end organs (lagena or utricle). The saccular-specific changes in hair cell density were correlated with reproductive state-dependent changes in auditory saccular sensitivity of female midshipman. Additional studies should be performed in other vocal and non-vocal species to determine how widespread this phenomenon is among fishes.

3. Very few studies have examined the concurrent development of the auditory system and sound production in fishes in the context of social acoustic communication. In order to better understand how the vocal motor system develops together 
with the auditory system for acoustic communication, future studies should analyze the ontogenetic development of the vocal-auditory pathways. In these studies, a particular focus should be given to highly vocal species exhibiting vocal differentiation, which might be influenced by developmental changes in the central auditory circuitry.

4. Finally, the effects of the acoustic environment, including sounds from conspecifics and self-generated vocalizations, on early development of the fish auditory system remain to be investigated.

Acknowledgements The authors would like to thank Drs. Richard Fay and Arthur Popper for their guidance, mentorship and for being role models for young scientists in the field of fish hearing and bioacoustics. All three authors (ROV, PWA, and JAS) had the privileged opportunity to work with Dick Fay. They are very grateful for his patience and thoughtfulness as a mentor, and for his guidance and kindness over the years. ROV thanks Dick Fay for the opportunity to work in his laboratory at the Marine Biological Laboratory (MBL), for his guidance during her Grass Fellowship working on directional and frequency sensitivity in the Lusitanian toadfish. ROV is grateful to both Dick Fay and Peggy Edds-Walton for being such an amazing team, for their inspirational work, constant support, and friendship. PWA has also been privileged to work with Dick Fay at the UC Bodega Marine Lab and has benefited greatly from the opportunity to discuss science and learning directly from him. PWA thanks Dick Fay for being such a benevolent teacher and masterful researcher, and for his availability to sit down and share his knowledge. JAS also had the privilege of working with Dick on a number of physiology and behavioral experiments since they first met at the MBL, during the Grass Fellowship of JAS.

All three of the authors would like to thank Art Popper for playing a major role in training virtually everyone active in the fish hearing research community. The extensive network of Popper's Laboratory of Aquatic Bioacoustics alums has provided a great wealth of knowledge and personal assistance as we all have "learned the ropes" in the fish world.

Research conducted by ROV has been supported by FDCT, Macao (grant FDCT 019/2012/A1), and MCTES, Portugal (SFRH/BD/30491/2006). Research in the Sisneros Lab was supported by an NSF grant (IOS 0642214) and a Royal Research Fund grant to JAS and an NIH Auditory Neuroscience Training Fellowship (NIH NIDCD 2T32DC005361-06) to PWA.

\section{References}

Alderks PW, Sisneros JA (2011) Ontogeny of auditory saccular sensitivity in the plainfin midshipman fish (Poricithys notatus). J Comp Physiol A 197:387-398

Alderks PW, Sisneros JA (2013) Development of the acoustically evoked behavioral response in larval plainfin midshipman fish, Porichthys notatus. PLoS One 8, e82182

Amorim MCP, Hawkins AD (2005) Ontogeny of acoustic and feeding behaviour in the grey gurnard, Eutrigla gurnardus. Ethology 111:255-269

Ayer-Le Liver CS, Le Douarin NM (1982) The early development of cranial sensory ganglia and the potentialities of their component cells studied in quail-chick chimeras. Dev Biol 94:291-310

Baird IL (1974) Anatomical features of the inner ear in submammalian vertebrates. In: Keidel WD, Neff WD (eds) Handbook of sensory physiology: auditory system. Springer, Berlin, pp 159-212

Barber VC, Yake KI, Clark VF, Pungur J (1985) Quantitative analyses of sex and size differences in the macula neglecta and ramus neglectus in the inner ear of the skate, Raja ocellata. Cell Tissue Res 241:597-605 
Belanger AJ, Bobeica I, Higgs DM (2010) The effect of stimulus type and background noise on hearing abilities of the round goby Neogobius melanostomus. J Fish Biol 77:1488-1504

Berrill NJ, Karp G (1976) Development. McGraw-Hill Book Co, NY, p 324

Bhandiwad AA, Zeddies DG, Raible DW, Rubel EW, Sisneros JA (2013) Auditory sensitivity of larval zebrafish (Danio rerio) measured using a behavioral prepulse inhibition assay. J Exp Biol 15:3504-3513

Bianchi LM, Cohan CS (1993) Effects of the neurotrophins and CNTF on developing statoacoustic neurons: comparison with an otocyst-derived factor. Dev Biol 159:353-365

Blaxtey JHS, Batty RS (1985) The development of startle responses in herring larvae. J Mar Biol Assoc UK 65:737-750

Braun CB, Grande T (2008) Evolution of peripheral mechanisms for the enhancement of sound reception. In: Popper AN, Fay RR, Webb JL (eds) Handbook of auditory research: fish bioacoustics. Springer, NY, pp 99-144

Caiger PE, Montgomery JC, Bruce M, Lu J, Radford CA (2013) A proposed mechanism for the observed ontogenetic improvement in the hearing ability of hapuka (Polyprion oxygeneios). J Comp Physiol A 199:653-661

Coffin AB, Mohr RA, Sisneros JA (2012) Saccular-specific hair cell addition correlates with reproductive state-dependent changes in the auditory saccular sensitivity of a vocal fish. J Neurosci 32:1366-1376

Coombs S, Popper AN (1979) Hearing differences among Hawaiian squirrelfish (family Holocentridae) related to differences in the peripheral auditory system. J Comp Physiol A 132:203-207

Corwin JT (1981) Postembryonic production and aging in inner ear hair cells in sharks. J Comp Neurol 201:541-553

Corwin JT (1983) Postembryonic growth of the macula neglecta auditory detector in the ray, Raja clavata: continual increases in hair cell number, neural convergence, and physiological sensitivity. J Comp Neurol 217:315-356

D'Amico-Martel A, Noden DM (1983) Contribution of placode and neural crest cells to avian cranial peripheral ganglia. Am J Anat 166:445-468

de Vries HL (1950) The mechanics of the labyrinth otoliths. Acta Otolaryngol 38:262-273

Detwiler SR, van Dyke RH (1950) The role of the medulla in the differentiation of the otic vesicle. J Exp Zool 113:179-199

Dijkgraaf S (1960) Hearing in bony fishes. Proc R Soc Lond B 152:51-54

Egner SA, Mann DA (2005) Auditory sensitivity of sergeant major damselfish Abudefduf saxatilis from post-settlement juvenile to adult. Mar Ecol Prog Ser 285:213-222

Ekker M, Wegner J, Akimenko MA et al (1992) Coordinate embryonic expression of three zebrafish engrailed genes. Development 116:1001-1010

Fay RR (1984) The goldfish ear codes the axis of acoustic particle motion in three dimensions. Science 225:951-954

Fay RR (1988) Hearing in vertebrates: a psychophysics databook. Hill-Fay Associates, Winnetka

Fay RR, Popper AN (1974) Acoustic stimulation of the ear of the goldfish (Carassius auratus). J Exp Biol 61:243-260

Fay RR, Popper AN (1975) Modes of stimulation of the teleost ear. J Exp Biol 62:379-387

Fay RR, Popper AN (1980) Structure and function in teleost auditory systems. In: Popper AN, Fay RR (eds) Comparative studies of hearing in vertebrates. Springer, New York, pp 3-42

Fay RR, Popper AN (2000) Evolution of hearing in vertebrates: the inner ears and processing. Hear Res 149:1-10

Fritzsch B, Tessarollo L, Coppola E et al (2004) Neurotrophins in the ear: their roles in sensory neuron survival and fiber guidance. Prog Brain Res 146:265-278

Fuiman LA, Smith ME, Malley VN (1999) Ontogeny of routine swimming speed and startle responses in red drum, with a comparison of responses to acoustic and visual stimuli. J Fish Biol 55:215-226

Gilland E, Baker R (1993) Conservation of neuroepithelial and mesodermal segments in the embryonic vertebrate head. Acta Anat 148:110-123 
Haddon CM, Lewis J (1996) Early ear development in the embryo of the zebrafish, Danio rerio. J Comp Neurol 365:113-128

Harrison RG (1945) Relations of symmetry in the developing embryo. Trans Connecticut Acad Arts Sci 36:277-330

Hemond SG, Morest DK (1992) Trophic effects of otic epithelium on cochleovestibular ganglion fiber growth in vitro. Anat Rec 232:273-284

Henglmüller SM, Ladich F (1999) Development of agonistic behavior and vocalization in croaking gouramis. J Fish Biol 54:380-395

Henson OW Jr (1974) Comparative anatomy of the middle ear. In: Keidel WD, Neff WD (eds) Handbook of sensory physiology: auditory system. Springer, Berlin, pp 39-110

Higgs DM, Souza MJ, Wilkins HR et al (2001) Age- and size-related changes in the inner ear and hearing ability of the adult zebrafish (Danio rerio). J Assoc Res Otolaryngol 03:174-184

Higgs DM, Rollo AK, Souza MJ, Popper AN (2003) Development of form and function in peripheral auditory structures of the zebrafish (Danio rerio). J Acoust Soc Am 113:1145-1154

Higgs DM, Plachta DTT, Rollo AK, Singheiser M, Hastings MC, Popper AN (2004) Development of ultrasound detection in American shad (Alosa sapidissima). J Exp Biol 207:155-163

Inoue M, Tanimoto M, Oda Y (2013) The role of ear stone in hair cell acoustic sensory transduction. Sci Rep 3:2114

Jacobson AG, Sater AK (1988) Features of embryonic induction. Development 104:341-359

Kaan H (1930) The relation of the developing auditory vesicle to the formation of the cartilage capsule in Amblystoma punctatum. J Exp Zool 55:263-291

Kelly MW, Corwin JT (1992) Development of hair cell structure and function in fish and amphibians. In: Romand R (ed) Development of auditory and vestibular systems 2. Elsevier, Amsterdam, pp 139-159

Kenyon TN (1996) Ontogenetic changes in the auditory sensitivity of the bicolor damselfish, Pomacentrus partitus (Poey). J Comp Physiol A 179:553-561

Kenyon TN, Ladich F, Yan HY (1998) A comparative study of hearing ability in fishes: the auditory brainstem response approach. J Comp Physiol A 182:307-318

Kéver L, Boyle KS, Dragičević B, Dulčić J, Casadevall M, Parmentier E (2012) Sexual dimorphism of sonic apparatus and extreme intersexual variation of sounds in Ophidion rochei (Ophidiidae): first evidence of a tight relationship between morphology and sound characteristics in Ophidiidae. Front Zool 2012:9-34

Keynes R, Krumlauf R (1994) Hox genes and regionalization of the nervous system. Annu Rev Neurosci 17:109-132

Ladich F, Fay RR (2013) Auditory evoked potential audiometry in fish. Rev Fish Biol Fish 23:317-364

Lechner W, Wysocki LE, Ladich F (2010) Ontogenetic development of auditory sensitivity and sound production in the squeaker catfish Synodontis schoutedeni. BMC Biol 8:10

Lechner W, Heiss E, Schwaha T, Glösmann M, Ladich F (2011) Ontogenetic development of Weberian ossicles and hearing abilities in the African bullhead catfish. PLoS One 6, e18511

Lewis ER, Li CW (1973) Evidence concerning the morphogenesis of saccular receptors in the bullfrog (Rana catesbeiana). J Morphol 139:351-361

Lewis ER, Leverenz EL, Bialek WS (1985) The vertebrate ear. CRC Press, Boca Raton

Lombarte A, Popper AN (1994) Quantitative analyses of postembryonic hair cell addition in the otolithic endorgans of the inner ear of the European hake, Merluccius merluccius (Gadiformes, Teleostei). J Comp Neurol 345:419-428

Lu Z, DeSmidt AA (2013) Early development of hearing in zebrafish. J Assoc Res Otolaryngol 14:509-521

Mann DA, Wilson CD, Song J, Popper AN (2009) Hearing sensitivity of the walleye pollock. Trans Am Fish Soc 138:1000-1008

Mansour SL, Goddard JM, Capecchi MR (1993) Mice homozygous for a targeted disruption of the proto-oncogene int-2 have developmental defects in the tail and inner ear. Development 117:13-28 
Model PG, Jarret LS, Bonazzoli R (1981) Cellular contacts between hindbrain and prospective ear during inductive interaction in the axolotl embryo. J Embryol Exp Morphol 66:27-41

Nelsen OE (1953) Comparative embryology of the vertebrates. McGraw-Hill Book Company, New York

Parker GH (1903) The sense of hearing in fishes. Am Nat 37:185-203

Platt C (1977) Hair cell distribution and orientation in goldfish otolith organs. J Comp Neurol 172:283-297

Platt C (1983) The peripheral vestibular system in fishes. In: Northcutt RG, Davis RE (eds) Fish neurobiology, vol 1. University of Michigan Press, Ann Arbor, pp 89-124

Platt C, Popper AN (1981) Structure and function in the ear. In: Tavolga WN, Popper AN, Fay RR (eds) Hearing and sound communication in fishes. Springer, New York, pp 3-38

Popper AN (1983) Organization of the inner ear and processing of acoustic information. In: Northcutt RG, Davis RE (eds) Fish neurobiology and behavior. University of Michigan Press, Ann Arbor, pp 125-178

Popper AN, Fay RR (1993) Sound detection and processing by fish: critical review and major research questions. Brain Behav Evol 41:14-38

Popper AN, Fay RR (1999) The auditory periphery in fishes. In: Fay RR, Popper AN (eds) Comparative hearing: fish and amphibians. Springer, New York, pp 43-100

Popper AN, Hoxter B (1984) Growth of a fish ear. I. Quantitative analysis of sensory hair cell and ganglion cell proliferation. Hear Res 15:133-142

Popper AN, Hoxter B (1990) Growth of a fish ear: II. Locations of newly proliferated sensory hair cells in the saccular epithelium of Astronotus ocellatus. Hear Res 45:33-40

Popper AN, Lu Z (2000) Structure-function relationships in fish otolith organs. Fish Res 46:15-25

Popper AN, Schilt CR (2008) Hearing and acoustic behavior (basic and applied). In: Webb JF, Fay RR, Popper AN (eds) Fish bioacoustics. Springer Science+Business Media, New York, pp 17-48

Popper AN, Tavolga WN (1981) Structure and function of the ear of the marine catfish, Arius felis. J Comp Physiol A 144:27-34

Popper AN, Platt C, Saidel WM (1982) Acoustic function in the fish ear. Trends Neurosci 5:276-280

Popper AN, Fay RR, Platt C et al (2003) Sound detection mechanisms and capabilities of teleost fishes. In: Collin SP, Marshall NJ (eds) Sensory processing in aquatic environments. Springer, New York, pp 3-38

Retzius G (1884) Gehörorgan des Wirbeltiere. II Das Gehörgan der, Reptilien, der Vögel, und der Säugetiere. Samson and Wallin, Stockholm

Schellart NAM, Popper AN (1992) Functional aspects of the evolution of the auditory system of actinopterygian fish. In: Webster DB, Fay RR, Popper AN (eds) Comparative evolutionary biology of hearing. Springer, New York, pp 295-322

Schneider H (1964) Physiologische und morphologische Untersuchungen zur Bioakustik der Tigerfische (Pisces, Therapoidae). Z Vergl Physiol 47:493-558

Simpson SD, Yan HY, Wittenrich ML, Meekan MG (2005) Response of embryonic coral reef fishes (Pomacentridae: Amphiprion spp.) to noise. Mar Ecol Prog Ser 287:201-208

Sisneros JA, Bass AH (2005) Ontogenetic changes in the response properties of individual, primary auditory afferents in the vocal plainfin midshipman fish Porichthys notatus Girard. J Exp Biol 208:3121-3131

Sokolowski BHA, Popper AN (1988) Transmission electron microscopic study or the saccule in the embryonic, larval, and adult toadfish Opsanus tau. J Morphol 198:49-69

Sokolowski BHA, Stahl LM, Fuchs PA (1993) Morphological and physiological development of vestibular hair cells in the organ-cultured otocyst of the chick. Dev Biol 155:134-146

Tanimoto M, Ota Y, Horikawa K et al (2009) Auditory input to CNS is acquired coincidentally with development of inner ear after formation of functional afferent pathway in zebrafish. J Neurosci 29:2762-2767 
Van De Water TR (1983) Embryogenesis of the inner ear: "in vitro studies". In: Romand R (ed) Development of auditory and vestibular systems. Academic, New York, pp 337-374

Vasconcelos RO, Ladich F (2008) Development of vocalization, auditory sensitivity and acoustic communication in the Lusitanian toadfish Halobatrachus didactylus. J Exp Biol 11:502-509

von Frisch K (1938) Über die Bedeutung des Sacculus und der Lagena für den Gehörsinn der Fische. Z Vergl Physiol 25:703-747

von Frisch K, Stetter H (1932) Untersuchungen über den Sitz des Gohörsinnes bei der Elritze. Z Vergl Physiol 17:686-801

Von Kupffer C (1895) Studien zur vergleichenden Entvicklungsgeschichte des Lopfes der Kranioten, vol 3. Die Entvicklung der Kopfnerven von Ammocoetes planeri. Lehmann, Munich

Webb JF, Noden DM (1993) Ectodermal placodes: contributions to the development of the vertebrate head. Am Zool 33:434-447

Webb JF, Fay RR, Popper AN (eds) (2008) Fish bioacoustics. Springer Science+Business Media, New York

Webb JF, Walsh RM, Casper BM, Mann DA, Kelly N, Cicchino N (2012) Development of the ear, hearing capabilities and laterophysic connection in the spotfin butterflyfish (Chaetodon ocellatus). Environ Biol Fish 95:275-290

Weber EH (1820) De Aure et Auditu Hominis et Animalium. Pars I. De Aure Animalium Aquatilium. Gerhard Fleischer, Leipzig

Weiss T, Mulroya MJ, Turnera RG et al (1976) Tuning of single fibers in the cochlear nerve of the alligator lizard: relation to receptor morphology. Brain Res 115:71-90

Whitfield TT, Riley BB, Chiang M, Phillips B (2002) Development of the zebrafish inner ear. Dev Dyn 233:427-458

Wright KJ, Higgs DM, Belanger AJ, Leis JM (2005) Auditory and olfactory abilities of presettlement larvae and post-settlement juveniles of a coral reef damselfish (Pisces: Pomacentridae). Mar Biol 147:1425-1434

Wright KJ, Higgs DM, Cato DH, Leis JM (2010) Auditory sensitivity in settlement-stage larvae of coral reef fishes. Coral Reefs 29:235-243

Wright KJ, Higgs DM, Leis JM (2011) Ontogenetic and interspecific variation in hearing ability in marine fish larvae. Mar Ecol Prog Ser 424:1-13

Wysocki LE, Ladich F (2001) The ontogenetic development of auditory sensitivity, vocalization and acoustic communication in the labyrinth fish Trichopsis vittata. J Comp Physiol A 187:177-187

Yntema CL (1955) Ear and nose. In: Willier BH, Weiss PA, Amburger V (eds) Analysis of development. Saunders, Philadelphia, pp 415-428

Zeddies DG, Fay RR (2005) Development of the acoustically evoked behavioral response in zebrafish to pure tones. J Exp Biol 208:1363-1372 


\section{Part IV \\ Morphology and Neuroanatomy}




\title{
Peripheral Hearing Structures in Fishes: Diversity and Sensitivity of Catfishes and Cichlids
}

\author{
Friedrich Ladich
}

\begin{abstract}
Fishes have evolved an astonishing diversity of peripheral (accessory/ ancillary) auditory structures to improve hearing based on their ability to transmit oscillations of gas bladder walls to the inner ears. So far it is unclear to what degree the size of the bladder and the linkage to the ear affect hearing in fishes. An interfamilial study in catfishes revealed that families which possess large, single swim bladders and one to four Weberian ossicles were more sensitive at higher frequencies $(\geq 1 \mathrm{kHz})$ than families which have small, paired, and encapsulated bladders and one to two ossicles. An intrafamilial investigation in thorny catfishes (family Doradidae) revealed that small differences in bladder morphology did not affect hearing similarly. Members of the cichlid family possess an even larger variation in peripheral auditory structures than catfishes. The linkage between the swim bladder and ear can either be present via anterior extensions of the bladder or be completely absent (in contrast to catfishes). Representatives having large bladders with extensions had the best sensitivities. Cichlids lacking extensions had lower sensitivities above $0.3 \mathrm{kHz}$. Species with a vestigial swim bladder exhibited a smaller hearing bandwidth than those with larger swim bladder (maximum frequency: $0.7 \mathrm{kHz}$ vs. 3 $\mathrm{kHz}$ ). Catfishes and cichlids reveal that larger gas bladders and more pronounced connections between the swim bladder and the inner ear result in improved hearing at higher frequencies. The lack of a connection between a large bladder and the inner ear does not necessarily result in a smaller detectable frequency range.
\end{abstract}

Keywords Swim bladder morphology $\bullet$ Auditory ossicles $\bullet$ Audiograms $\bullet$ Auditory sensitivity $\bullet$ AEP

F. Ladich $(\bowtie)$

Department of Behavioural Biology, University of Vienna,

Althanstrasse 14, 1090 Vienna, Austria

e-mail: friedrich.ladich@univie.ac.at 


\section{Introduction}

All fishes (except lampreys and hagfishes) possess inner ears consisting of three semicircular canals and three otolithic endorgans (utricle, saccule, lagena) (Retzius 1881; Platt and Popper 1981; Popper 2011). These otolithic endorgans enable fish to detect particle motion in a sound field at low frequencies (up to a few hundred hertz) (Hawkins 1986; Ladich and Popper 2004). Interestingly, ray-finned bony fishes (class Actinopterygii) evolved numerous ways to connect the inner ears with air-filled cavities within the body which are primarily used for other purposes such as buoyancy and air-breathing (Braun and Grande 2008). The general notion is that these connections improve hearing due to the ability of fish to detect pressure fluctuations in a sound field by transmitting volume changes in their gas-filled cavities in various ways to the inner ears (Hawkins 1986). The ability to detect sound pressure changes in the far field, besides particle motion detection in the near field, enables numerous taxa to extend their hearing range up to several kilohertz and their hearing sensitivities down to low sound levels. In numerous species where such connections have been described, the auditory function of these structures has not been determined (Braun and Grande 2008; Ladich 2014).

Evidence for the notion that a particular peripheral (accessory or ancillary) structure improves hearing came from numerous elimination experiments starting in the early twentieth century by Karl von Frisch and his collaborators (von Frisch and Stetter 1932; von Frisch 1936, 1938; Schneider 1941). In most cases peripheral structures for hearing were eliminated either completely or by removing air from the bladder and/or by filling the bladder with fluids (Kleerekoper and Roggenkamp 1959; Fay and Popper 1974, 1975; Yan and Curtsinger 2000; Yan et al. 2000). In two investigations, only the connections to the inner ear were interrupted and the swim bladders were left intact. Poggendorf (1952) and Ladich and Wysocki (2003) extirpated the tripus, the largest auditory ossicles in otophysines. Results from elimination experiments typically showed a decrease in auditory sensitivities but were very contradictory with regard to the amount of the decline in sensitivity at different frequencies. Poggendorf (1952) observed a rather similar decrease in hearing of about 30 and 40 $\mathrm{dB}$ between $60 \mathrm{~Hz}$ and $6 \mathrm{kHz}$ in the brown bullhead Ictalurus nebulosus, whereas Ladich and Wysocki (2003) found a frequency-dependent hearing loss in the goldfish ranging from $7 \mathrm{~dB}$ at $100 \mathrm{~Hz}$ to $33 \mathrm{~dB}$ at $2 \mathrm{kHz}$.

Three major types (each with numerous subtypes) of peripheral structures for improved hearing can be distinguished in bony fishes (Fig. 1). Numerous groups such as sciaenids or holocentrids possess swim bladder extensions that protrude anteriorly to contact the occipital bones or even the inner ears in different ways (Coombs and Popper 1979, 1982; Ramcharitar et al. 2004, 2006; Schulz-Mirbach et al. 2013) (Fig. 1a). In holocentrids in general there is no relationship between the swim bladder and the auditory bullae, an enlarge portion of the otic region of the skull. Some representatives, however, possess a direct relationship between anterior end of the bladder and the membranous areas of the auditory bullae. Finally, in the subfamily Myripristinae there exists an intimate contact between the anterior extensions of the bladder and the membranous areas of the enlarged auditory bullae (Nelson 1955). 

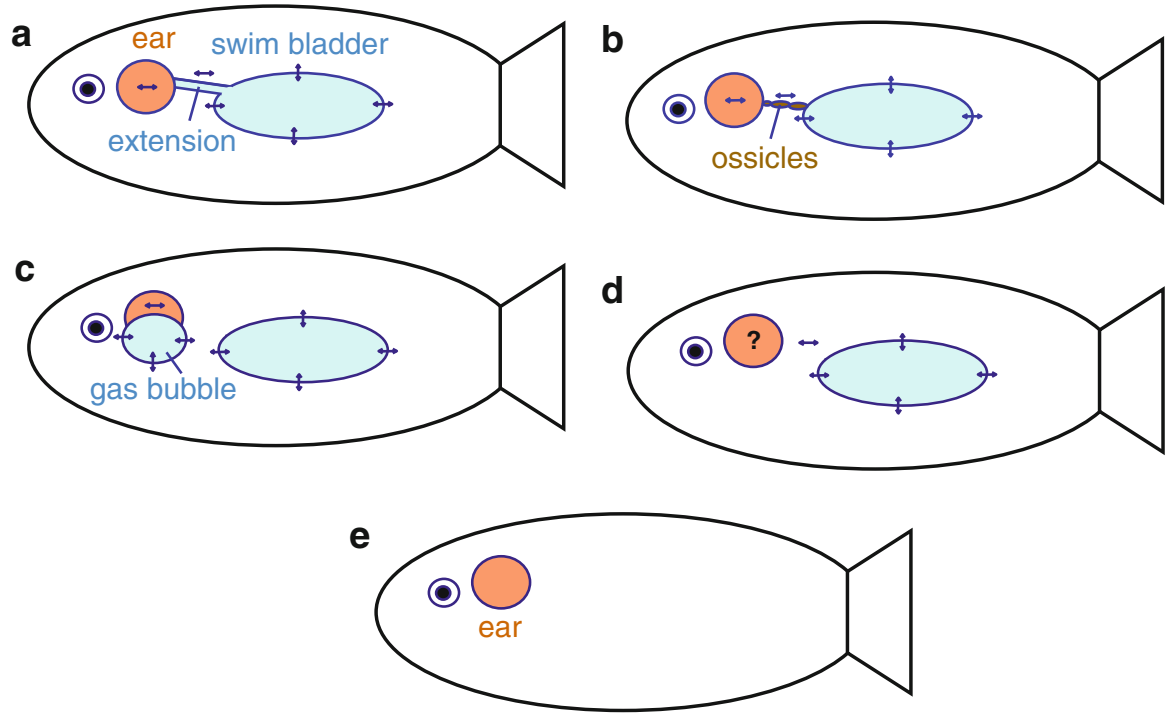

Fig. 1 Schematic relationship between the inner ear and peripheral (accessory or ancillary) structures that enhance hearing in fishes. (a) Direct connection between the swim bladder and inner ear via an anterior swim bladder extension such as in the cichlid Etroplus maculatus. (b) Otophysines in which a chain of auditory (Weberian) ossicles transmits swim bladder vibrations to the ear. (c) Air-filled cavities directly attached to the inner ear such as in mormyrids and labyrinth fishes. (d) No connection between swim bladder and inner ear. In the latter, the bladder may (damselfish) or may not (toadfish) have an auditory function (see question mark). (e) No gas-filled cavity (swim bladder) and subsequently no peripheral structure to improve hearing (flatfishes). Double-headed arrows indicate oscillations of gas bladder walls (due to sound pressure fluctuations in a sound field), of auditory ossicles, of tissue outside the bladder, and of inner ear fluids. Modified from Ladich and Popper (2004)

The second and probably most sophisticated strategy is found in otophysines, a huge group of bony fishes comprising four different orders and more than 8000 species: Gymnotiformes (knife fishes), Cypriniformes (carps and minnows), Siluriformes (catfishes), and Characiformes (e.g. piranhas and tetras). Otophysines possess a bony connection between the inner ear (Greek: otos) and the swim bladder (Greek: physa) consisting of up to four Weberian ossicles and interossicular ligaments that transmit swim bladder vibrations to an unpaired perilymphatic canal connecting both inner ears (Weber 1819, 1820; Chranilov 1927, 1929; von Frisch and Stetter 1932; von Frisch 1936, 1938; Chardon 1968; Ladich and Wysocki 2003) (Fig. 1b). In otophysines the anterior wall of the swim bladder functions similar to a tympanum (ear drum) in tetrapods, and Weberian ossicles transmit oscillations of this "tympanum" to the inner ear similar to the middle ear ossicles in mammals.

The third major type of peripheral auditory structures comprises gas-filled cavities directly attached to the inner ear without any connection to the swim bladder (Fig. 1c). Weakly electric mormyrids possess an otic gas bladder within the inner ear; it constitutes an anterior extension of the swim bladder, which became completely separated. Elimination experiments showed that the otic bladder improves 
hearing in mormyrids (Stipetić 1939; Yan and Curtsinger 2000). The non-related perciform suborder Anabantoidei (labyrinth fishes) possesses a suprabranchial cavity (organ) dorsally of the gills for air-breathing. This labyrinth is anatomically in direct contact with the saccule and enhances hearing, as has been shown experimentally (Schneider 1941; Yan 1998).

In fishes lacking a direct connection between a gas bladder and inner ear, it is assumed that the bladder has no auditory function and thus does not serve as a peripheral structure for hearing (Fig. 1d). This, however, cannot be concluded based solely on anatomical considerations. In all species without a connection, the auditory function needs to be assessed experimentally in order to be certain that this is not the case (Popper and Fay 2011). It is experimentally difficult to prove that a fish with a swim bladder does not respond to sound pressure changes in a sound field. This can either be demonstrated by decoupling sound pressure from particle motion in an experimental tank (such as in standing wave tubes) or by eliminating the gas bladder (e.g. removing the gas and/or filling it with fluids) and then recording whether this procedure decreases hearing sensitivities. Elimination experiments have shown that swim bladders not connected to inner ears have no auditory function in toadfish and labyrinth fish (Yan et al. 2000) but that they do have such a function in cods and damselfish (Sand and Enger 1973; Myrberg and Spires 1980). In the latter species the assumption is that the tissue between the bladder and the inner ear transmits bladder vibrations and enables detection of sound pressure changes.

Finally, based on the above, peripheral auditory structures can be ruled out only in species that completely lack any gas-filled cavities (swim bladders) such as flatfishes or sculpins (cottids) (Fig. 1e). In all other species lacking a connection, it needs to be shown experimentally that gas bladders play no role in hearing. Accessory hearing structures may also differ in size within species either due to ontogenetic development (see review Ladich 2015) or experimental manipulation (Sand and Enger 1973).

The aim of the review is to go beyond our current knowledge, which is mainly based on the observation that shorter distances between the bladder and inner ears improve hearing. Comparative morphological and physiological studies show that the size of the accessory gas bladders and the structure of the connection to the inner ears affect hearing in fishes as well. This is analyzed based on recent inter- and intrafamilial findings in catfishes and cichlids.

\section{Interfamilial Comparison in Catfishes}

All otophysines possess swim bladders and Weberian ossicles. Neither bladders nor ossicles have been completely lost in any of the more than 8000 species known. Otophysines inhabit freshwaters (except for 2 out of 36 families of catfishes), comprising about two-thirds of all freshwater fish species. Peripheral structures for hearing improvement vary considerably among otophysines (Chranilov 1927, 1929; Alexander 1962, 1964; Chardon 1968). This is particularly the case in the orders Siluriformes and Cyriniformes. 

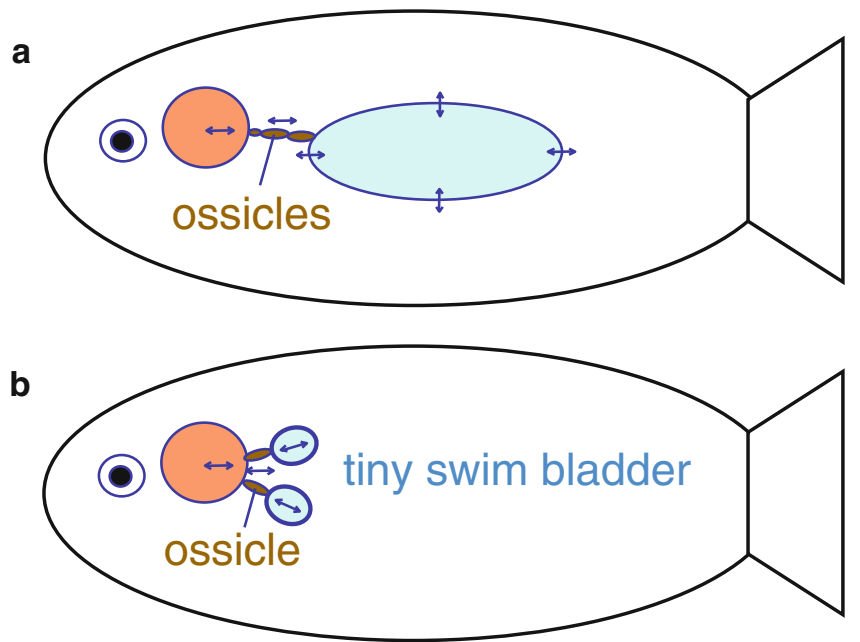

Fig. 2 Schematic relationship between swim bladders and inner ears in catfishes. (a) Species possessing large, free, and unpaired swim bladders and a series of up to four Weberian ossicles transmitting bladder oscillations to the inner ear, such as members of the families Ariidae and Pimelodidae. (b) Two tiny bladders to the left and right of the vertebral column, encapsulated in bone; members of the respective families (Loricariidae and Callichthyidae) have only one to two Weberian ossicles. Note that all otophysine species have two chains of ossicles and two inner ears that are directly connected to each other, but only members of type (b) possess a pair of completely separated swim bladders

Catfishes vary considerably in the size of their swim bladders, their bony encapsulation, and in the number of auditory ossicles. Numerous catfish families have large unpaired and not encapsulated (free) swim bladders and up to four Weberian ossicles (tripus, intercalarium, scaphium, claustrum) (Fig. 2). In contrast, several groups have tiny and paired swim bladders located directly behind the cranium (Fig. 2a, b) (Chranilov 1929; Alexander 1964; Chardon 1968; Bleckmann et al. 1991; Lechner and Ladich 2008). These tiny bladders are surrounded by bony capsules formed by the skull and anterior vertebrae (Fig. 2b). Such divergent gas bladders prompted Bridge and Haddon (Bridge and Haddon 1889, 1892, 1893) to split catfish into two groups, namely "siluridae normales" with normally developed bladders and the "siluridae abnormales" with reduced bladders. Due to the small size of these bladders, it is safe to assume that they do not function as swimming or buoyancy organs. Surprisingly, they are not completely absent such as in flatfishes or sculpins but were kept, most likely, for hearing purposes.

Ladich (1999) observed that members of pimelodid and doradid catfishes are more sensitive to sound than Corydoras paleatus, a member of the family Callichthyidae with reduced bladders. In order to determine whether this is a common difference between "normal" and "abnormal" catfishes, Lechner and Ladich (2008) investigated swim bladders, Weberian ossicles, and hearing sensitivities in 11 species from 8 different catfish families. Representatives of the families Ariidae, Pseudopimelodidae, Malapteruridae, Heptapteridae, Mochokidae, and Auchenipteridae possess large, 
unpaired, and not encapsulated swim bladders with a relative swim bladder length (calculated according to the formula: bladder length + height + width/3) of 8.4-15.2\% of the fishes' standard length (Fig. 3a). Members of these families typically have four Weberian ossicles (with exceptions) and an ossicular chain length comprising 3.5-5 $\%$ of their standard length (Fig. 4a) (Lechner and Ladich 2008). In contrast, representatives of the families Loricariidae and Callichthyidae have significantly smaller swim bladders (relative bladder length: 1.6-5.7 \% of standard length), just one to two auditory ossicles, and thus a significantly shorter ossicular chain (relative chain length: 1.1-1.9\%) (Figs. 3a and 4a).

How do differences in swim bladder and ossicle structure affect hearing in catfishes? Measurements of auditory sensitivities using the auditory evoked potential (AEP) recording technique revealed that all 11 species investigated detect tone bursts between $50 \mathrm{~Hz}$ and $5 \mathrm{kHz}$ (Fig. 5a). The lowest absolute auditory threshold was found in the ariid catfish (67 $\mathrm{dB}$ re $1 \mu \mathrm{Pa})$, and the highest in a callichthyid (121 $\mathrm{dB}$ re $1 \mu \mathrm{Pa}$ ). Mean auditory thresholds of all six species having large bladders and of all five species having tiny paired bladders revealed significant differences in hearing sensitivity between both groups between 1 and $5 \mathrm{kHz}$ but not at lower frequencies (Fig. 5b).

Furthermore, the relative swim bladder length was negatively correlated to the hearing threshold at frequencies above $1 \mathrm{kHz}$ ( $r$-values between -0.71 and -0.80 ). Species with larger bladders were more sensitive than others. Similarly, a longer ossicular chain and a higher number of ossicles resulted in better hearing at $3-5 \mathrm{kHz}$ ( $r$-values between -0.61 and -0.67) (Lechner and Ladich 2008). These data indicate that larger, free swim bladders, and longer ossicular chains affect hearing in catfishes positively by increasing the hearing sensitivities at higher frequencies.

\section{Thorny Catfishes}

The large Amazonian catfish family Doradidae or thorny catfishes ( 150 species) exhibit a large intrafamilial variation in swim bladder morphology. This organ is always unpaired, of different size, and may bear a caudal sac (secondary bladder) and numerous partly branched diverticula (Birindelli and Sousa 2009; Kaatz and Stewart 2012). Doradids are a potential model to investigate the role of the diversity in swim bladder morphology on hearing within one family because, in contrast to non-otophysines such as holocentrids, sciaenids, or cichlids, the factor distance between the swim bladder and the ear is negligible. Their bladders are always directly connected to the inner ears via a chain of ossicles. Morphological measurements of the swim bladders revealed that species can be grouped according to relative swim bladder size into two groups, namely those species having smaller and those having larger bladders (Zebedin and Ladich 2013) (Fig. 6).

The intrafamilial differences in relative swim bladder length in thorny catfishes are, however, much smaller than the interfamilial difference among catfishes described above. Zebedin and Ladich (2013) found that relative bladder length in 
a

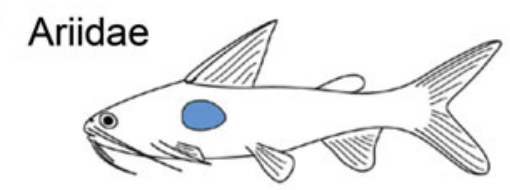

Pseudopimelodidae

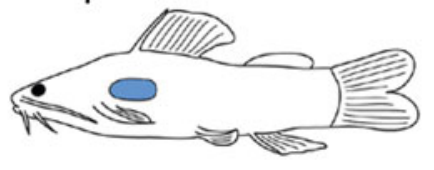

\section{Malapteruridae}

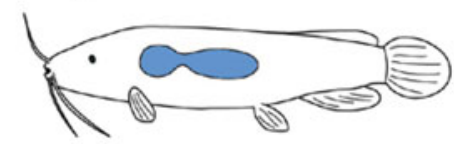

\section{Heptapteridae}

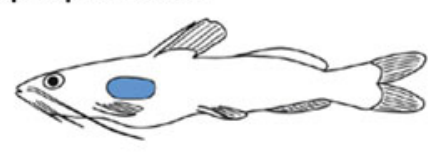

b

Loricariidae
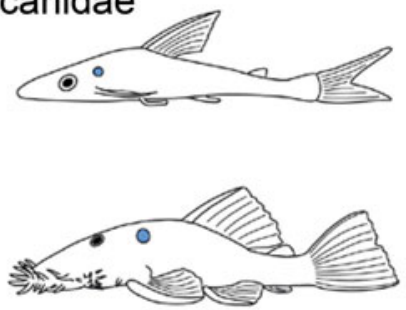

\section{Callichthyidae}
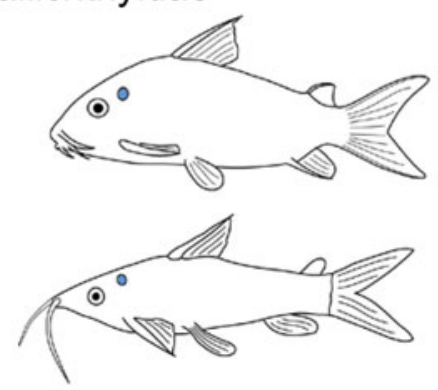
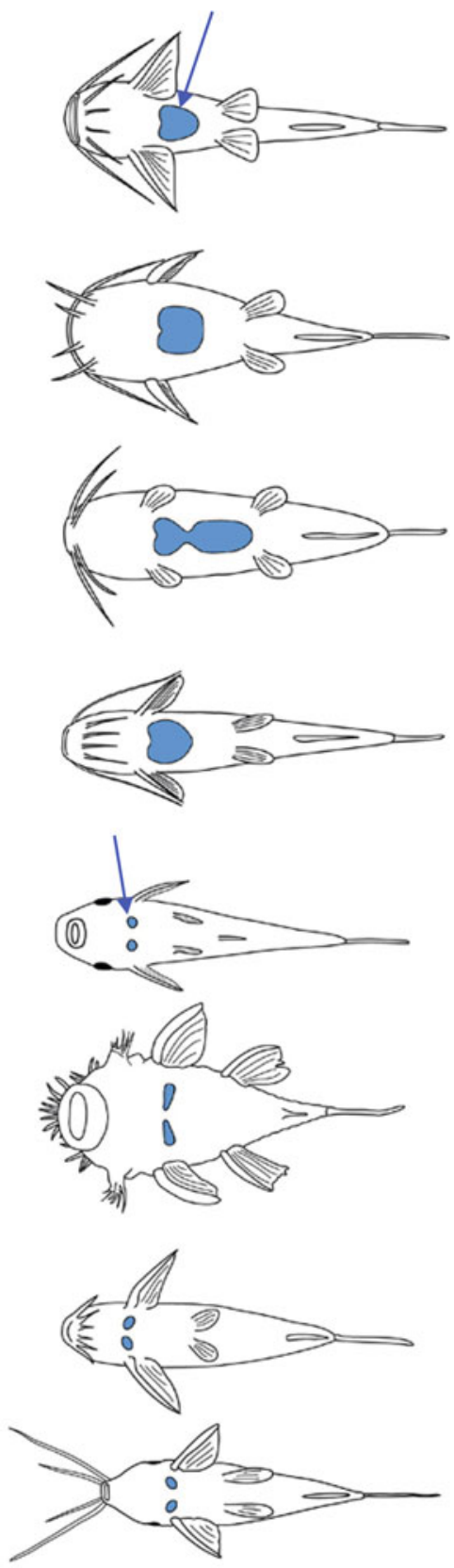

Fig. 3 Lateral and ventral view of catfish species possessing either large unpaired (a) or tiny paired (b) swim bladders. Swim bladders indicated by arrows. (a) Representatives of the families Ariidae (Ariops seemanni), Pseudopimelodidae (Batrochoglanis raninus), Malapteruridae (Malapterurus beninensis), and Heptapteridae (Pimelodella sp.); (b) Members of the families Loricariidae (Hypoptopoma thoracatum, Ancistrus ranunculus) and Callichthyidae (Corydoras sodalis, Dianema urostriata). Modified after Lechner and Ladich (2008) 
a

Ariidae

4

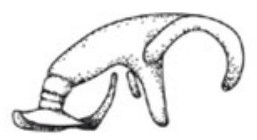

Pseudopimelodidae

4

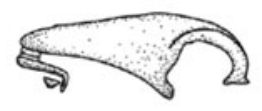

b

Loricariidae

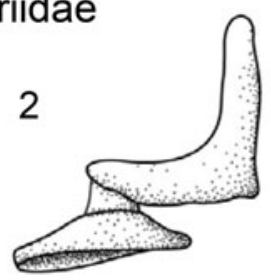

Callichthyidae
Malapteruridae

4

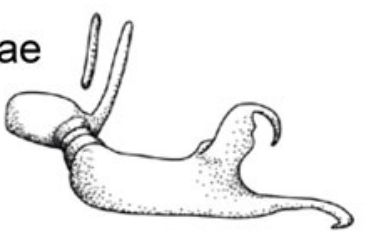

Heptapteridae

4

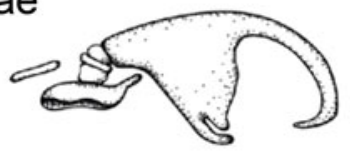

1

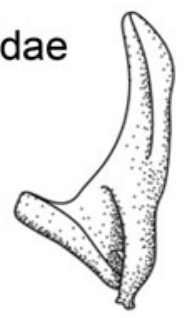

1

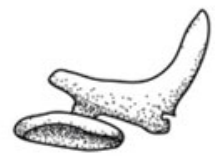

Fig. 4 Views of the Weberian ossicles in representatives of the catfish families illustrated in Fig. 3 except for A. ranunculus. (a) Ossicles in families with large unpaired swim bladders and (b) ossicles in families with tiny paired bladders. Numbers: number of ossicles in each species. Rostral is always to the left and caudal to the right. Modified after Lechner and Ladich (2008)

Acanthodoras spinosissimus (talking catfish), Agamyxis pectinifrons (whitebarred catfish), and Megalodoras uranoscopus varied from 0.174 to 0.201 and that it varied in a second group including Amblydoras affinis, Hemidoras morrisi, and Oxydoras niger (ripsaw catfish) between 0.129 and 0.158 (Fig. 7).

Besides bladder size, these six species show a large variation in bladder morphology. Acanthodoras spinosissimus and A. affinis have apple-shaped bladders without any diverticula (Fig. 7). Agamyxis pectinifrons possesses small simpleformed diverticula at the caudal end. Bladders are cordiform (heart-shaped) in $M$. uranoscopus, O. niger, and $H$. morrisi. In M. uranoscopus and $H$. morrisi they have many long, branched diverticula cranially, laterally, and caudally. Two species, $M$. uranoscopus und $O$. niger, have a small secondary bladder.

All species detect tone bursts between $70 \mathrm{~Hz}$ and $6 \mathrm{kHz}$. Audiograms were typically U-shaped with best hearing located between 0.5 and $1 \mathrm{kHz}$ except for one species (Zebedin and Ladich 2013) (Fig. 8a). Averaged hearing sensitivities of the three species with smaller swim bladders were significantly higher (= thresholds were lower) than in the three species with larger swim bladders (maximum differ- 
Fig. 5 (a) Mean AEP thresholds of six catfish species with free, large unpaired swim bladders (solid lines) and of five species with encapsulated, tiny, and paired swim bladders (dashed lines). (b) Mean hearing thresholds of all species with free swim bladders and paired encapsulated bladders.

Asterisks indicate statistically significant differences between these two groups at particular frequencies. Modified from Lechner and Ladich (2008)

Fig. 6 Schematic relationship between swim bladders within thorny catfishes. (a) Species with larger swim bladders and (b) species with smaller swim bladders. Note that bladders are always unpaired and unencapsulated, in contrast to those in Fig. $2 b$ a

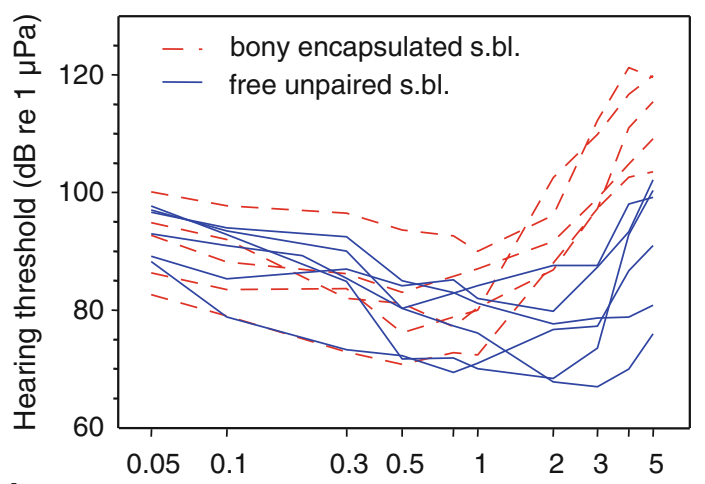

b

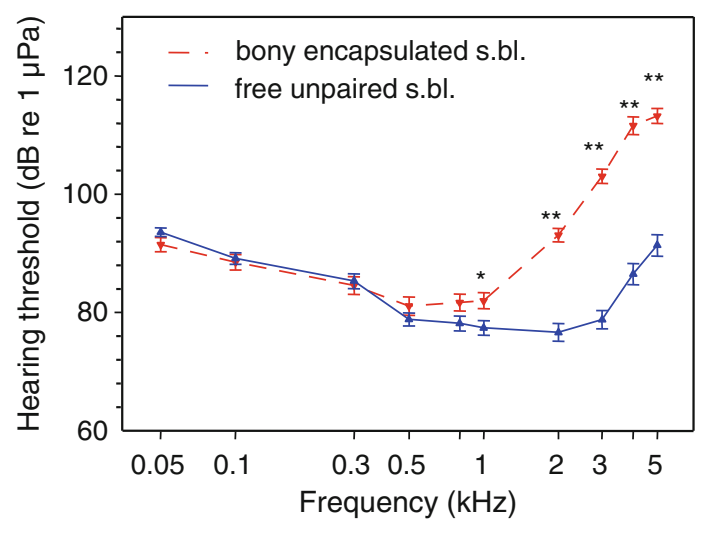

a

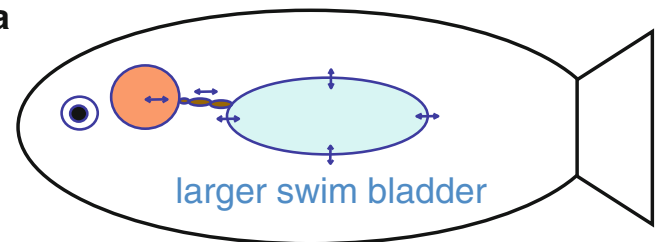

b

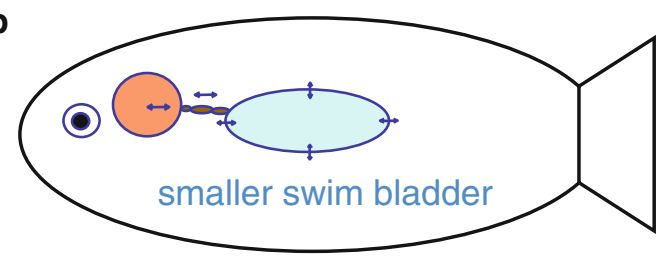


a

Acanthodoras spinosissimus

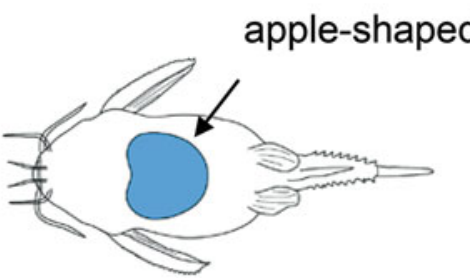

Agamyxis pectinifrons

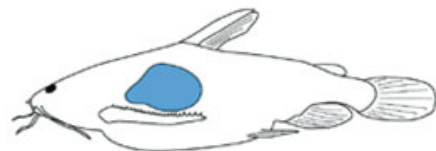

abbreviated

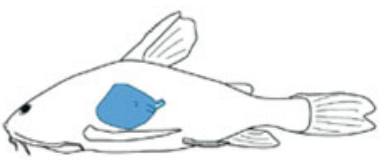

heart-shaped

Megalodoras uranoscopus
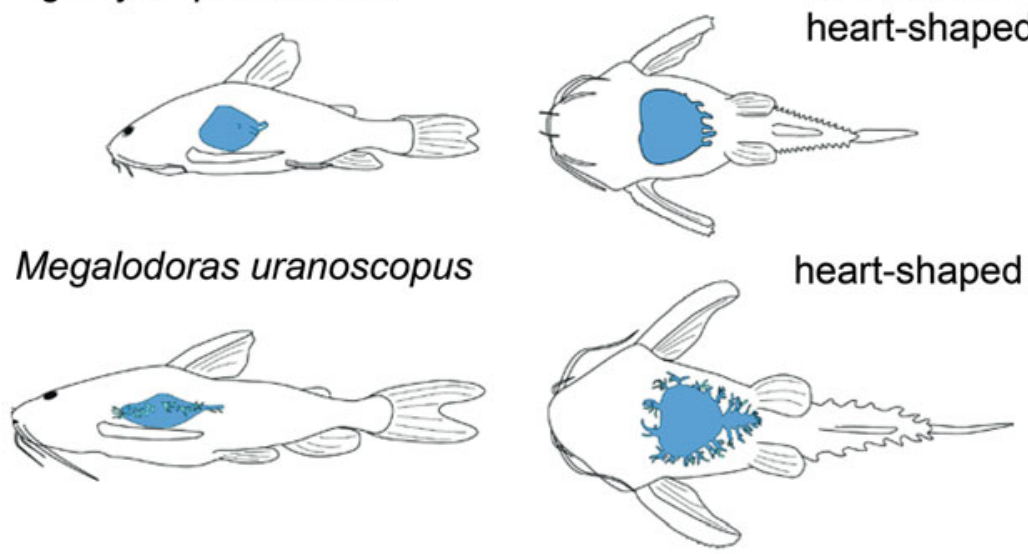

b

Amblydoras affinis
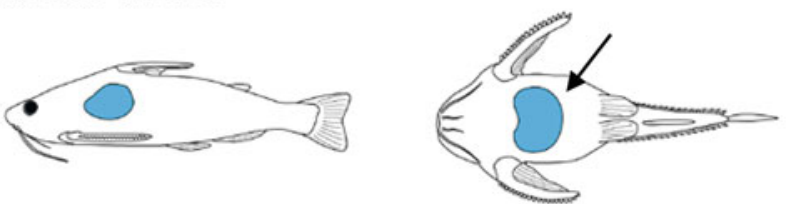

\section{Hemidoras morrisi}

heart-shaped
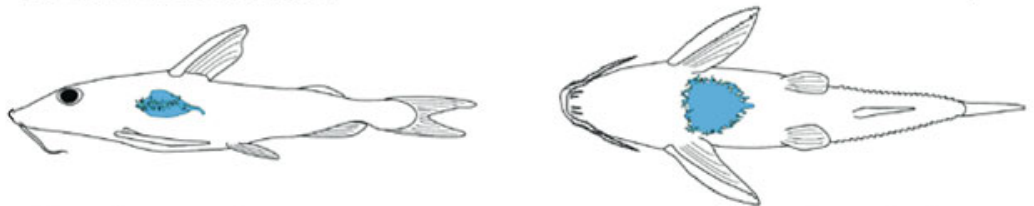

Oxydoras niger

heart-shaped
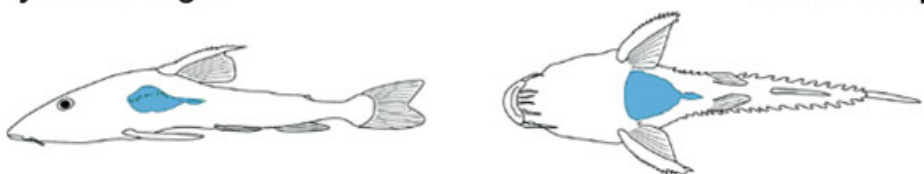

Fig. 7 Lateral (left) and ventral view (right) of the six thorny catfish species including their swim bladders (arrows). (a) Species having relatively larger swim bladders and (b) species having relatively smaller bladders. Modified from Zebedin and Ladich (2013) 
ence: $8.5 \mathrm{~dB}$ ). The variability between species having smaller swim bladders was much larger than between species possessing larger swim bladders (Fig. 8b). Differences between both groups were not frequency-dependent, as was the case of the intrafamilial comparison, indicating a similar trend at all frequencies (with a smaller difference at the most sensitive frequencies).

The findings by Zebedin and Ladich (2013) show a relationship between swim bladder form and its function in thorny catfishes. The results are, however, surprising with regard to the interfamilial comparison conducted by Lechner and Ladich (2008), which showed that fish become more sensitive at higher frequencies when bladder size increases. This comparison in catfishes shows that the relationship between swim bladder morphology and hearing abilities is (similar to sciaenids: Horodysky et al. 2008) not always straightforward because other factors such as the surrounding tissue or the fine structure of the bladder wall may affect its vibration patterns and subsequently the hearing sensitivity.

Fig. 8 Audiograms of the (a) thorny catfish Acanthodoras spinosissimus, Agamyxis pectinifrons, and Megalodoras uranoscopus having larger swim bladders (dashed lines) and of Amblydoras affinis, Hemidoras morrisi, and Oxydoras niger with smaller bladders (solid lines). (b) Averaged hearing thresholds of thorny catfish species having larger and smaller bladders. Standard errors drawn only in one direction to avoid overlap. Modified from Zebedin and Ladich (2013)

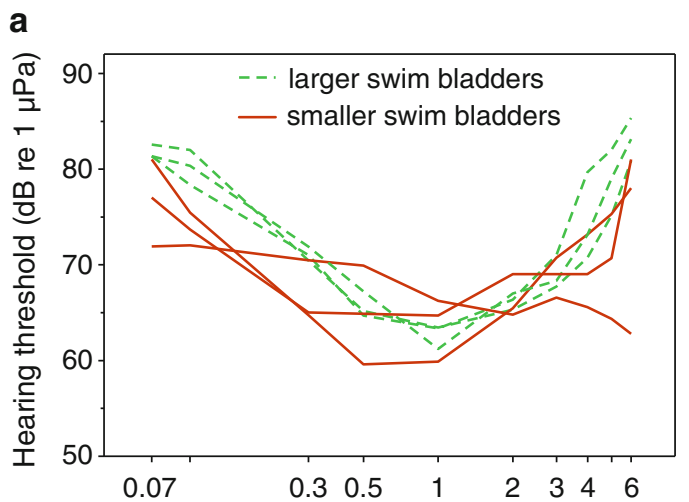

b

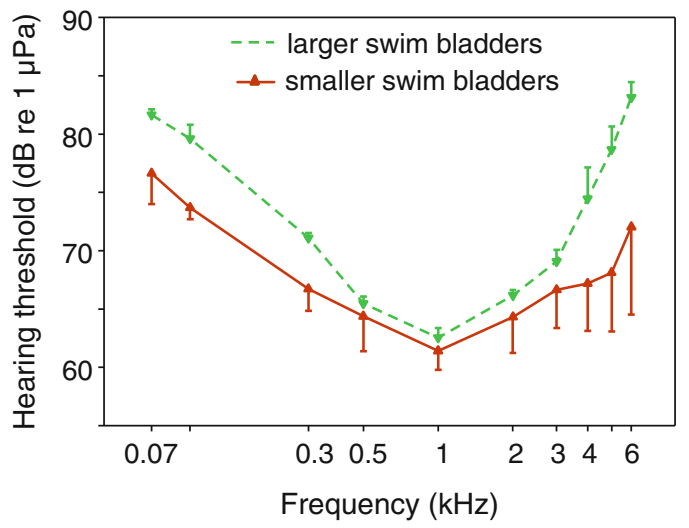




\section{Cichlids}

Cichlids represent a huge family of freshwater fishes (more than 1000 species) and are an interesting group of bony fishes for studying the relationship between swim bladder form and its effect on hearing sensitivity. This is because they exhibit a large diversity in swim bladder size and in the swim bladder-inner ear linkage. In contrast to catfishes (and otophysines in general) they do not always possess a mechanical linkage between the swim bladder and the inner ear, and in contrast to other families such as sciaenids (Ramcharitar et al. 2006) their swim bladder varies considerably in size (Fig. 9). Thus both the effect of swim bladder size and its link to the inner ear can be investigated.

Cichlid swim bladders can be directly connected to the inner ears via an anterior extension such as in the orange chromid Etroplus maculatus from India or the Malagassy species Paratilapia polleni (Figs. 9a and 10a) (Schulz-Mirbach et al. 2012, 2013). In most cichlids the swim bladder is normal sized and not connected to the inner ears, for example, in the jewel cichlid Hemichromis guttatus (Figs. 9b and 10b). Finally, some representatives within the cichlid family have small vestigial swim bladders that are distinctly apart from the inner ears (Figs. 9c and 10c).

Three out of four cichlid species investigated by Schulz-Mirbach et al. (2012), namely $H$. guttatus, $P$. polleni, and E. maculatus, responded to tone bursts from 0.1 to $3 \mathrm{kHz}$, whereas in $S$. tinanti no response was detectable above $0.7 \mathrm{kHz}$ (Fig. 11). Hearing thresholds differed significantly between species. S. tinanti and H. guttatus showed best hearing sensitivity at $0.2 \mathrm{kHz}$, whereas E. maculatus and P. polleni had best sensitivity at $0.5 \mathrm{kHz}$ in terms of sound pressure level (SPL) and particle acceleration level (PAL). Above $0.3 \mathrm{kHz}$, auditory sensitivity increased slightly in $E$. maculatus and P. polleni but decreased steeply in S. tinanti and H. guttatus (Fig. 11).

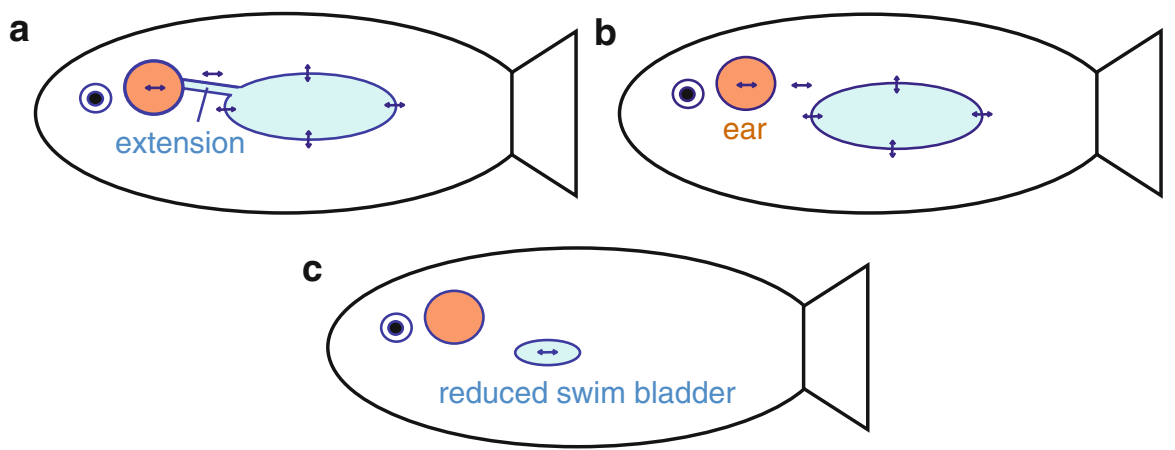

Fig. 9 Schematic relationship between swim bladders and inner ears within the cichlid family. (a) Species possessing large swim bladders and a direct connection to the inner ear via an anterior swim bladder extension. (b) Species with swim bladders lacking any connection to the inner ear. It is assumed and indicated by double-headed arrows that bladder vibrations are transmitted to the inner ear. (c) Species with vestigial swim bladders and no connection to the inner ear 

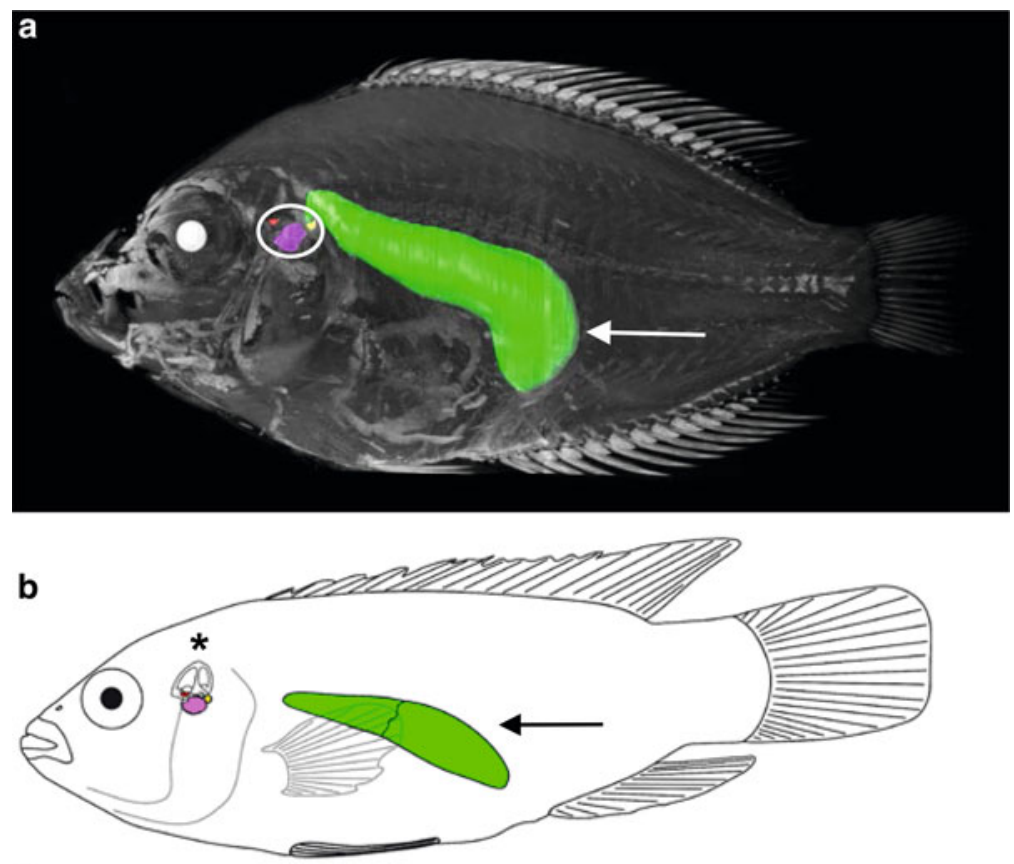

C

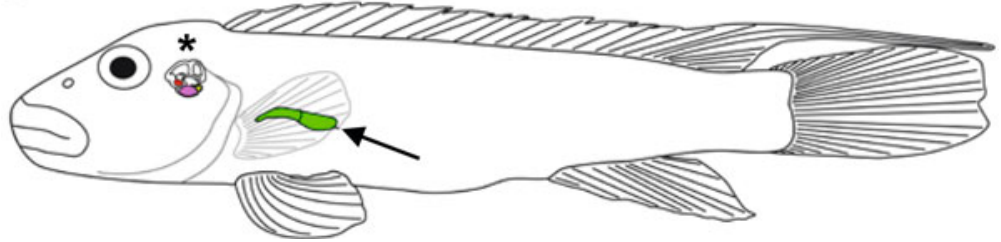

Fig. 10 Lateral view of three cichlid species including their swim bladders (arrows) and inner ears (circle in a and asterisks in $\mathbf{b}$ and $\mathbf{c}$ ). (a) microCT scan and 3D reconstruction of Etroplus maculatus, which possesses anterior swim bladder horns directly contacting the inner ears (circle encloses otoliths). (b) and (c) line drawings of (b) Hemichromis guttatus and (c) Steatocranus tinanti, which both lack anterior swim bladder extensions but differ widely in swim bladder size. Modified from Schulz-Mirbach et al. (2012)

This results in sensitivity differences between species of approximately 20-40 dB (SPL and PAL) (Schulz-Mirbach et al. 2012).

The relationship between swim bladder morphology and auditory sensitivity in cichlids is straightforward in E. maculatus (P. polleni) and S. tinanti. Species having swim bladder extensions directly contacting the inner ear show distinctly higher auditory sensitivities and a broader hearing bandwidth than $S$. tinanti, which has a vestigial swim bladder without a direct connection to the inner ear. Interestingly, $H$. guttatus, which has a large bladder not connected to the inner ear, displays an intermediate sensitivity. This species can detect frequencies up to $3 \mathrm{kHz}$, similar to $E$. maculatus, but thresholds increase steeply above $0.3 \mathrm{kHz}$, similar to $S$. tinanti. This indicates that the large swim bladder contributes to their high-frequency sensitivity 


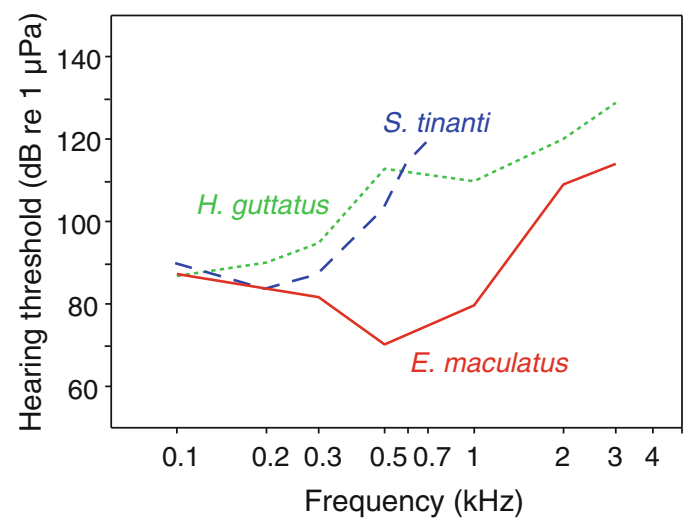

Fig. 11 Audiograms of the cichlids Etroplus maculatus (solid line), Hemichromis guttatus (dotted line), and Steatocranus tinanti (dashed line). Note that only sound pressure thresholds are given due to the similarity of sound pressure and particle acceleration thresholds in this study. Modified from Schulz-Mirbach et al. (2012)

despite the lack of a bladder-inner ear connection and that the sensitivity above $0.3 \mathrm{kHz}$ is low when such a connection is missing (Schulz-Mirbach et al. 2012).

\section{Comparison of Catfishes and Cichlids with Other Bony Fishes}

Besides catfishes and cichlids, sufficient anatomical and physiological data are available only in two more (out of 500) fish families, namely squirrelfishes (family Holocentridae) and drums or croakers (family Sciaenidae), for studying the relationship between swim bladder morphology and hearing sensitivity in detail.

Hearing thresholds of four species of the family Holocentridae reveal major differences in sensitivity that clearly reflect differences in swim bladder-inner ear morphology. Coombs and Popper (1979) measured hearing in the shoulderbar soldierfish Myripristis kuntee and the Hawaiian squirrelfish Sargocentron xantherythrum (formerly Adioryx xantherythrus) and found major differences in hearing thresholds and frequency range (Fig. 12). Myripristis kuntee detected sound up to 3 $\mathrm{kHz}$, whereas $S$. xantherythrum detected frequencies only up to $800 \mathrm{~Hz}$ at much higher sound levels. This difference is paralleled by differences between genera in swim bladder morphology (note that the swim bladder morphology of M. kuntee and $S$. xantherythrum is unknown). Nelson (1955) showed that the brick soldierfish Myripristis amaena has an anterior swim bladder extension that extends forward and covers the auditory bullae (Fig. 12b). In contrast, the swim bladder of the tinsel soldierfish Sargocentron suborbitalis (formerly Holocentrus suborbitalis) is not connected to the skull. In the squirrelfish Holocentrus adscensionis the swim bladder approaches the posterior end of the auditory bullae, and this species seems to 
a

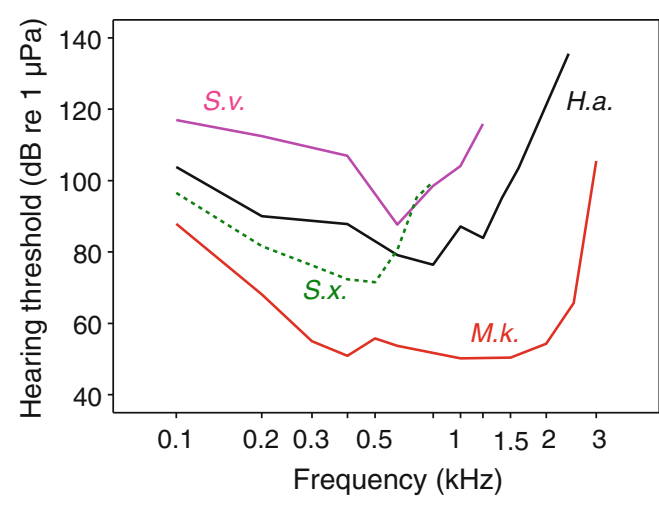

b

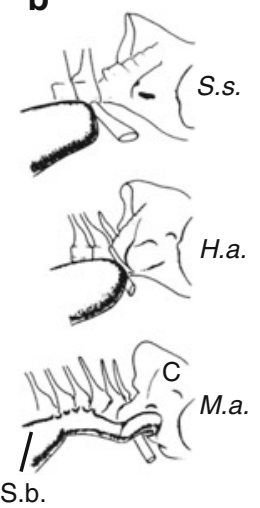

Fig. 12 Comparison of hearing thresholds in four species and of the anterior swim bladder (S.b.) and posterior cranium (C) situation in three species of the family Holocentridae (soldierfishes). (a) Thresholds of Myripristis kuntee (M.k.) and Sargocentron xantherythrum (S.x.) are from Coombs and Popper (1979), those of Sargocentron vexillarium (S.v.) and of Holocentrus adscensionis (H.a.) from Tavolga and Wodinsky (1963). (b) Anatomical drawings from Hawkins (1986) based on Nelson (1955). Upper drawing Sargocentron suborbitalis (S.s.), lower drawing Myripristis amaena (M.a). Hearing thresholds from different studies need to be compared with caution because of possible differences in threshold determination between different labs (see Hawkins 1981)

have an intermediate hearing ability in terms of frequency bandwidth but not in absolute thresholds between 0.1 and $5 \mathrm{kHz}$ (Tavolga and Wodinsky 1963) (Fig. 12a, b). Surprisingly, members of the genus Sargocentron differ considerably (up to 30 $\mathrm{dB}$ ) in sensitivity, potentially reflecting swim bladder morphology differences (note that only physiological but no morphological data are available for $S$. vexillarius and $S$. xantherythrus) or differences in threshold determination between labs (for methodological differences see Hawkins 1981; Ladich and Wysocki 2009; Ladich and Fay 2013). Nevertheless, holocentrids show a relationship between the distance of the swim bladder to the inner ear and the hearing sensitivity. Members of the subfamily Myripristinae (Myripristis) have an anterior swim bladder extension and sensitivities similar to otophysines, and members of the subfamily Holocentrinae (Holocentrus, Sargocentron) lack a direct connection and have reduced hearing sensitivities. The size of the gas bladder and its possible effect on hearing have not been investigated in this family.

The situation is much more complex, less straightforward, and partly contradictory within the family Sciaenidae. Ramcharitar et al. (2006) showed that two species of western Atlantic sciaenids-the weakfish Cynoscion regalis and the spot Leiostomus xanthurus - differ in swim bladder morphology and hearing sensitivity. The swim bladder in $C$. regalis has a pair of anterior horns that terminate close to the ear, while there are no extensions in L. xanthurus. Cynoscion regalis detects frequencies up to $2 \mathrm{kHz}$, whereas L. xanthurus only up to $700 \mathrm{~Hz}$. Both species do not differ in absolute sensitivity. The low sensitivity in $C$. regalis is surprising (lowest threshold at $90 \mathrm{~dB}$ ) because its peripheral hearing structures touch the swim 
bladder. In the silver perch Bairdiella chrysoura the anterior chamber of the swim bladder surrounds the otic capsule and terminates lateral to the saccules (Ramcharitar et al. 2004). B. chrysoura detects sound up to $4 \mathrm{kHz}$ and has thresholds almost as low as goldfish (74 dB at $600 \mathrm{~Hz}$ ). In contrast, Horodysky et al. (2008) found no significant difference in hearing thresholds in species with (Cynoscion regalis, Cynoscion nebulosus, Micropogonias undulatus) and without swim bladder specializations (Sciaenops ocellatus, Leiostomus xanthurus). Surprisingly, the authors found that sensitivities in the Northern kingfish Menticirrhus saxatilis, a species which has a reduced swim bladder in adults, were among the highest above $0.6 \mathrm{kHz}$. Furthermore the Mediterranean brown meagre Sciaena umbra, which lacks specialization, has a broader hearing bandwidth $(3 \mathrm{kHz})$ than all other species except $B$. chrysoura (Wysocki et al. 2009) (for a comparison of all sciaenid audiograms see figures 21 and 22 in Ladich and Fay 2013). Again, swim bladder size has not been investigated in sciaenids except for the above report on M. saxatilis. In summary, the form-function relationship in the Sciaenidae is not as consistent as in catfishes, holocentrids, and cichlids. Ramcharitar et al. (2006) found a relationship between maximum frequency detected and minimum swim bladder-otic capsule distance (in millimeters). This correlation cannot be confirmed by the data from Horodysky et al. (2008) because the latter did not measure frequencies beyond $1.2 \mathrm{kHz}$. The swim bladder-inner ear distance does not seem to affect the absolute auditory sensitivity in this family, particularly at higher frequencies, as expected from numerous other studies.

\section{Conclusions}

One of the most interesting aspects in fish audition is the tendency in numerous taxa (genera, families, orders) to exploit vibrations of gas-filled cavities or bladders in a sound field for improvement of hearing. Sound pressure fluctuations in a sound field create volume changes and subsequently oscillations of the walls of gas cavities (swim bladders, air-breathing organs) which can be transmitted to the inner ear. These oscillating walls may then function as tympana (ear drums), similar to tympana in tetrapods (anurans, reptiles, birds, mammals) (Ladich 2010). While sound pressure hearing via tympana has become the standard pattern of sound detection in tetrapods (with a few exceptions such as whales), this was not the case in fishes. Among fishes, "tympana" and connections to the inner ears evolved in all otophysines, anabantoids (labyrinth fishes), and mormyrids. Several other families such as cichlids, holocentrids, and sciaenids exhibit diversity in peripheral structures for hearing and subsequently in hearing sensitivities. Interestingly, diversity in swim bladders and auditory sensitivities is also found in otophysines, particularly in catfishes.

Earlier intrafamilial studies investigating the effects of swim bladder morphology on hearing concentrated on the distance to the inner ears but did not study swim 
bladder size. Holocentrids show an improved auditory sensitivity and extended frequency range with decreasing distance to the inner ears. Sciaenids revealed a similar trend, but an improvement of hearing sensitivity due to shorter distances could not be demonstrated unequivocally.

Catfishes are ideal candidates for studying the influence of swim bladder morphology, especially regarding organ size on hearing, because their bladders are always connected to the inner ear. The interfamilial study by Lechner and Ladich (2008) showed that swim bladder size and distance affect hearing in catfishes. A larger swim bladder increases sensitivity from 1 to $6 \mathrm{kHz}$, but a shorter distance between the bladder and the inner ear (based on a shorter ossicular chain) decreases sensitivity. This is in contrast to our expectations that shorter distances improve hearing but agrees with the observation in all other vertebrate classes that a higher number of ossicles improves high-frequency hearing. Mammals possess three auditory ossicles and are on average able to detect much higher frequencies than anurans, reptiles, or birds, which have only one middle ear ossicle (Ladich 2010). The intrafamilial study in thorny catfishes by Zebedin and Ladich (2013) showed that the influence of bladder size on hearing cannot be generalized. The hearing abilities cannot be predicted when differences in swim bladder size are rather small.

Cichlids, in contrast, are the ideal fish family for studying both the effects of size and distance because members of this family have large or vestigial swim bladders and some species have connections between the swim bladder and inner ears. Schulz-Mirbach et al. (2013) demonstrated that size and the presence of connections affect hearing in cichlids, but in different ways. Size affects the detectable frequency range and a direct connection improves hearing sensitivity.

Finally, it needs to be mentioned that differences in auditory sensitivity between closely related species may also reflect factors other than peripheral hearing structures. Results from different studies need to be compared with caution due to potential differences in techniques applied in measuring hearing. Moreover, studies show that the inner ear structure may be linked to peripheral hearing structures and that differences in otolith size, size and form of sensory fields (maculae), as well as orientation patterns of sensory hair cells may affect hearing in parallel to peripheral hearing structures (Ramcharitar et al. 2006; Popper and Schilt 2008; SchulzMirbach et al. 2014). An interesting task for future studies will be to show if and to what degree particular inner ear structures help improve hearing in fishes.

Acknowledgements This review is dedicated to Arthur N. Popper and Richard R. Fay to celebrate more than 45 years of work in fish bioacoustics. I am grateful to have the opportunity to work and publish with both of them. Art invited me to his lab in 1998 and 1999 and introduced me to the field of inner ear structure in fishes, which resulted in a common paper on labyrinth fish ears in 2001. Subsequently we wrote a review on the parallel evolution of fish hearing organs. This cooperation with Art on ears resulted years later in several studies of mine with colleagues in Germany. Dick invited me to Fallmouth and Woods Hole in 1999. He impressed me by his knowledge in vertebrate hearing (see his 1988 book) and his interests in all fields and techniques including the auditory evoked potential (AEP) technique (which he never used). Our common "AEP" interest resulted in 2013 in a review on the auditory evoked potential audiometry in fishes in which we compared behavioral to AEP data and summarized all studies published within the last 15 years. 


\section{References}

Alexander RM (1962) The structure of the Weberian apparatus in the Cyprini. Proc Zool Soc Lond 139:451-473

Alexander RM (1964) The structure of the Weberian apparatus in the Siluri. Proc Zool Soc Lond 142:419-440

Birindelli JLO, Sousa LM (2009) Morphology of the gasbladder in thorny catfishes (Siluriformes: Doradidae). Proc Acad Natl Sci Philadelphia 158:261-296

Bleckmann H, Niemann U, Fritzsch B (1991) Peripheral and central aspects of the acoustic and lateral line system of the bottom dwelling catfish, Ancistrus sp. J Comp Neurol 314:452-466

Braun CB, Grande T (2008) Evolution of peripheral mechanisms for the enhancement of sound reception. In: Webb JF, Popper AN, Fay RR (eds) Fish bioacoustics. Springer, New York, pp 99-144

Bridge TW, Haddon AC (1889) Contribution to the anatomy of fishes. I. The airbladder and Weberian ossicles in the Siluridae. Proc R Soc Lond 46:209-227

Bridge TW, Haddon AC (1892) Contribution to the anatomy of fishes: II. The air-bladder and Weberian ossicles in the siluroid fishes. Proc R Soc Lond 52:139-157

Bridge TW, Haddon AC (1893) Contribution to the anatomy of fishes II. The air-bladder and Weberian ossicles in the siluroid fishes. Philos Trans R Soc B Biol Sci 184:65-333

Chardon M (1968) Anatomie comparee de l'appareil de Weber et des structures connexes chez les Siluriformes. Musee Royal de l'Afrique Centrale - Tervuren, Belgique Annales, Serie in 8. Sci Zool 169:1-273

Chranilov NS (1927) Beiträge zur Kenntnis des Weber'schen Apparates der Ostariophysi 1. Vergleichend-anatomische Übersicht der Knochenelemente des Weber'schen Apparates bei Cypriniformes. Zool Jahrb (Anatomie) 49:501-597

Chranilov NS (1929) Beiträge zur Kenntnis des Weber'schen Apparates der Ostariophysi: 2. Der Weber'sche Apparat bei Siluroidea. Zool Jahrb (Anatomie) 51:323-462

Coombs S, Popper AN (1979) Hearing differences among Hawaiian squirrelfish (family Holocentridae) related to differences in the peripheral auditory system. J Comp Physiol 132:203-207

Coombs S, Popper AN (1982) Structure and function of the auditory system in the clown knifefish, Notopterus chitala. J Exp Biol 97:225-239

Fay RR, Popper AN (1974) Acoustic stimulation of the ear of the goldfish (Carassius auratus). J Exp Biol 61:243-260

Fay RR, Popper AN (1975) Modes of stimulation of the teleost ear. J Exp Biol 62:379-387

Hawkins AD (1981) The hearing abilities of fish. In: Tavolga WN, Popper AN, Fay RR (eds) Hearing and sound communication in fishes. Springer, New York, pp 109-133

Hawkins AD (1986) Underwater sound and fish behaviour. In: Pitcher TJ (ed) The behaviour of teleost fishes. Croom Helm, London \& Sydney, pp 114-151

Horodysky AZ, Brill RW, Fine ML, Musick JA, Latour RJ (2008) Acoustic pressure and particle thresholds in six sciaenid fishes. J Exp Biol 211:1504-1511

Kaatz IM, Stewart DJ (2012) Bioacoustic variation of swimbladder disturbance sounds in neotropical doradoid catfishes (Siluriformes: Doradidae, Auchenipteridae): Potential morphological correlates. Curr Zool 58:171-188

Kleerekoper H, Roggenkamp PA (1959) An experimental study on the effect of the swimbladder on hearing sensitivity in Ameiurus nebulosus (Lesueur). Can J Zool 37:1-8

Ladich F (1999) Did auditory sensitivity and vocalization evolve independently in otophysan fishes? Brain Behav Evol 53:288-304

Ladich F (2010) Hearing: vertebrates. In: Breed MD, Moore J (eds) Encyclopedia of animal behaviour. Academic, Oxford, pp 54-60

Ladich F (2014) Diversity in hearing in fishes: ecoacoustical, communicative, and developmental constraints. In: Koeppl C, Manley GA, Popper AN, Fay RR (eds) Insights from comparative hearing. Springer Science+Business Media, New York, pp 289-321 
Ladich F (2015) Ontogenetic development of sound communication in fishes. In: Ladich F (ed) Sound Communication in Fishes. Springer-Verlag, Wien, pp 127-148

Ladich F, Fay RR (2013) Auditory evoked potential audiometry in fish. Rev Fish Biol Fisheries 23:317-364

Ladich F, Popper AN (2004) Parallel evolution in fish hearing organs. In: Manley G, Fay RR, Popper AN (eds) Evolution of the vertebrate auditory system. Springer, New York, pp 95-127

Ladich F, Wysocki LE (2003) How does tripus extirpation affect auditory sensitivity in goldfish? Hear Res 182:119-129

Ladich F, Wysocki LE (2009) Does speaker presentation effect auditory evoked potential threshold in goldfish? Comp Biochem Physiol A 154:341-346

Lechner W, Ladich F (2008) Size matters: diversity in swimbladders and Weberian ossicles affects hearing in catfishes. J Exp Biol 211:1681-1689

Myrberg AA, Spires JY (1980) Hearing in damselfishes: an analysis of signal detection among closely related species. J Comp Physiol 140:135-144

Nelson EM (1955) The morphology of the swim bladder and auditory bulla in the Holocentridae. Fieldiana: Zoology 37:121-130

Platt C, Popper A (1981) Fine structure and function of the ear. In: Tavolga W, Popper A, Fay R (eds) Hearing and sound communication in fishes. Springer, New York, pp 3-36

Poggendorf D (1952) Die absolute Hörschwelle des Zwergwelses (Amiurus nebulosus) und Beiträge zur Physik des Weberschen Apparates der Ostariophysen. Z Vergl Physiol 34:222-257

Popper AN (2011) Auditory system morphology. In: Farrel AP (ed) Encyclopedia of fish physiology: from genome to environment. Academic Press, San Diego, pp 252-261

Popper AN, Fay RR (2011) Rethinking sound detection by fishes. Hear Res 273:25-36

Popper AN, Schilt CR (2008) Hearing and acoustic behavior: basic and applied considerations. In: Webb JF, Fay RR, Popper AN (eds) Fish bioacoustics. Springer, New York, pp 17-48

Ramcharitar JU, Deng X, Ketten D, Popper AN (2004) Form and function in the unique inner ear of the teleost: the silver perch (Bairdiella chrysoura). J Comp Neurol 475:531-539

Ramcharitar JU, Higgs DM, Popper AN (2006) Audition in sciaenid fishes with different swim bladder-inner ear configurations. J Acoust Soc Am 119:439-443

Retzius G (1881) Das Gehörorgan der Wirbelthiere. I. Das Gehörorgan der Fische und Amphibien. Samson \& Wallin, Stockholm

Sand O, Enger PS (1973) Evidence for an auditory function of the swimbladder in the cod. J Exp Biol 59:405-414

Schneider H (1941) Die Bedeutung der Atemhöhle der Labyrinthfische für ihr Hörvermögen. Z Vergl Physiol 29:172-194

Schulz-Mirbach T, Metscher B, Ladich F (2012) Relationship between swim bladder morphology and hearing abilities - a case study on Asian and African cichlids. PLoS One 7, e42292

Schulz-Mirbach T, Heß M, Metscher B, Ladich F (2013) A unique swim bladder-inner ear connection in a teleost fish revealed by a combined high-resolution microCT and 3D histological study. BMC Biol 11:75

Schulz-Mirbach T, Ladich F, Plath M, Metscher BD, Heß M (2014) Are accessory hearing structures linked to inner ear morphology? Insights from $3 \mathrm{D}$ orientation patterns of ciliary bundles in three cichlid species. Front Zool 11:25

Stipetić E (1939) Über das Gehörorgan der Mormyriden. Z Vergl Physiol 26:740-752

Tavolga WN, Wodinsky J (1963) Auditory capacities in fishes. Pure tone thresholds in nine species of marine teleosts. Bull Am Mus Nat Hist 126:177-240

von Frisch K (1936) Über den Gehörsinn der Fische. Biol Rev 11:210-246

von Frisch K (1938) The sense of hearing in fish. Nature 141:8-11

von Frisch K, Stetter H (1932) Untersuchungen über den Sitz des Gehörsinnes bei der Elritze. Z Vergl Physiol 17:687-801

Weber EH (1819) Vergleichende Anatomie der Gehörwerkzeuge. Deut Arch Physiol 5:323-332

Weber EH (1820) De aure et auditu hominis et animalium. Part I. De aure animalium aquatilium. Apud Gerhardum Fleischerum, Lipsiae 
Wysocki LE, Codarin A, Ladich F, Picciulin M (2009) Sound pressure and particle acceleration audiograms in three marine fish species from the Adriatic Sea. J Acoust Soc Am 126:2100-2107

Yan HY (1998) Auditory role of the suprabranchial chamber in gourami fish. J Comp Physiol A 183:325-333

Yan HY, Curtsinger WS (2000) The otic gasbladder as an ancillary structure in a mormyrid fish. J Comp Physiol A 186:595-602

Yan HY, Fine ML, Horn NS, Colon WE (2000) Variability in the role of the gasbladder in fish audition. J Comp Physiol A 186:435-445

Zebedin A, Ladich F (2013) Does the hearing sensitivity in thorny catfishes depend on swim bladder morphology? PLoS One 8(6), e67049 


\title{
Diversity of Inner Ears in Fishes: Possible Contribution Towards Hearing Improvements and Evolutionary Considerations
}

\author{
Tanja Schulz-Mirbach and Friedrich Ladich
}

\begin{abstract}
Fishes have evolved the largest diversity of inner ears among vertebrates. While G. Retzius introduced us to the diversity of the gross morphology of fish ears in the late nineteenth century, it was A. N. Popper who unraveled the large variety of the fine structure during the last four decades. Modifications of the basic inner ear structure-consisting of three semicircular canals and their sensory epithelia, the cristae and three otolithic end organs (utricle, saccule, lagena) including the maculaemainly relate to the saccule and lagena and the respective sensory epithelia, the macula sacculi and macula lagenae. Despite the profound morphological knowledge of inner ears and the morphological variability, the functional significance of this diversity is still largely unknown. The aims of this review are therefore twofold. First it provides an update of the state of the art of inner ear diversity in bony fishes. Second it summarizes and discusses hypotheses on the evolution of this diversity as well as formulates open questions and promising approaches to tackle these issues.
\end{abstract}

Keywords Osteichthyes • Teleostei • Sensory epithelium • Orientation pattern of ciliary bundles $\bullet$ Ancillary auditory structures $\bullet$ Otolith

\section{Introduction}

Retzius (1881) was the first to give a detailed description and illustration of inner ear diversity in fishes, followed by Bierbaum (1914), Yamamoto (1929), and Froese (1938). These studies revealed a large diversity of the morphology of the inner ear. This diversity is reflected in the size and position of the end organs relative to each other, in their sensory epithelia (termed cristae or maculae) and the hard parts,

\footnotetext{
T. Schulz-Mirbach ( $\square)$

Department Biology II, Ludwig-Maximilians-University, Großhaderner Strasse 2, 82152 Planegg-Martinsried, Germany

e-mail: schulz-mirbach@biologie.uni-muenchen.de

F. Ladich

Department of Behavioural Biology, University of Vienna,

Althanstrasse 14, 1090 Vienna, Austria

e-mail: friedrich.ladich@univie.ac.at
} 
namely the otoliths or otoconia (Platt and Popper 1981a). Despite the partly extensive (gross) morphological studies, details about the arrangement of sensory hair cells expressed in the ciliary bundle orientation patterns remained uninvestigated until Popper's discovery that particularly oriented ciliary bundles are arranged in groups on the maculae of the lake whitefish Coregonus clupeaformis (Popper 1976). Follow-up studies revealed that teleost fishes exhibit a considerable variety of orientation patterns on the macula of the saccule and partly on the macula of the lagena, but less so on the macula of the utricle and almost none on the cristae.

Since Retzius' study (Retzius 1881), detailed documentation of the inner ear morphology tremendously increased over the past 40 years. The result is solid knowledge about the range of inner ear diversity within bony fishes. In contrast, our understanding of fish hearing abilities other than hearing bandwidth and auditory thresholds is still fragmentary. This is in part due to methodological shortcomings that, at present, hinder an unambiguous differentiation of the amount of inner ear stimulation through particle motion and pressure at different frequencies (Popper and Fay 2011; Ladich and Fay 2013). This makes it difficult to assign certain modifications of the inner ear or different inner ear morphology in closely related taxa to specific physiological functions. Moreover, even less is known about the potential selective pressures and constraints acting on inner ear evolution of bony fishes. This leaves unanswered the central question of why this exceptional diversity of ears in bony fishes, especially in teleosts, exists.

Many aspects of inner ear diversity could be discussed. In this review, however, we concentrate on the sensory epithelia because they are the sensory "unit" of the inner ear that is probably most intimately tied to auditory tasks. The purpose of our review is therefore twofold. The first is a recent overview of inner ear diversity in bony fishes with a focus on sensory epithelia, especially on maculae (macula sacculi and macula lagenae); the latter display most of the variability among the inner ear's sensory epithelia (e.g., Platt and Popper 1981a; Popper and Schilt 2008). Second, we discuss the assumption that inner ear diversity is linked to the presence of ancillary auditory structures and examine which underlying factors may have affected inner ear evolution. We ask whether the orientation pattern diversity reveals differences in auditory tasks in bony fishes, and we discuss how this diversity may have evolved in bony fishes (Platt and Popper 1981a; Popper and Coombs 1982; Ladich and Popper 2004).

\section{Diversity in Inner Ears}

Though there is no "one" ear among bony fishes, a basic ear structure can be identified: an upper inner ear consisting of three semicircular canals and the utricle, and a lower inner ear comprising the saccule and the lagena (Fig. 1) (Popper 2011; Popper

Fig. 1 (continued) especially in the saccule and lagena. Some species, however, like Eutrigla gurnardus (e) are characterized by distinctly large semicircular canals. All ears are shown in medial view. Illustrations were modified from Ladich and Popper (2001, 2004), Lu and Popper (1998), Retzius (1881), and Schulz-Mirbach et al. (2011). $a$ anterior, $c c$ common canal, $d$ dorsal, $s c$ semicircular canal. Copyright 1998 (1C) and 2001 (1D), with kind permission from Elsevier 
a Otophysa, Siluriformes

(Silurus glanis)

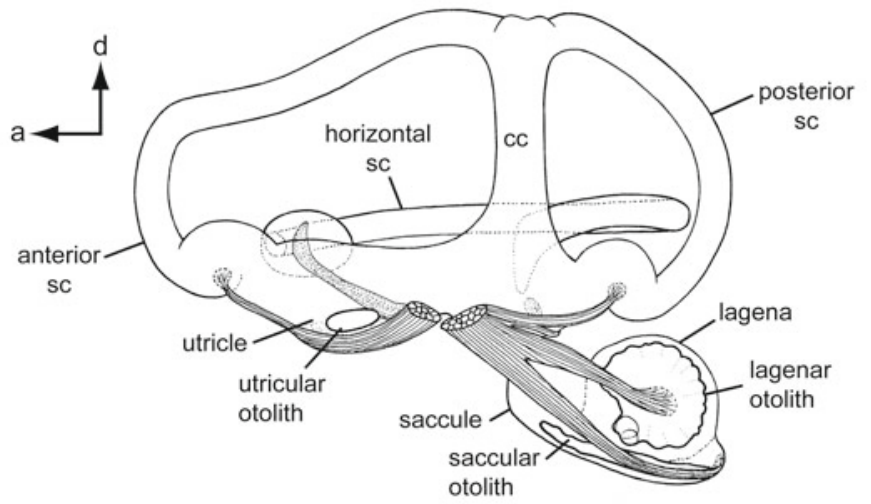

b Cyprinodontiformes

c Gobiiformes

(Poecilia mexicana)

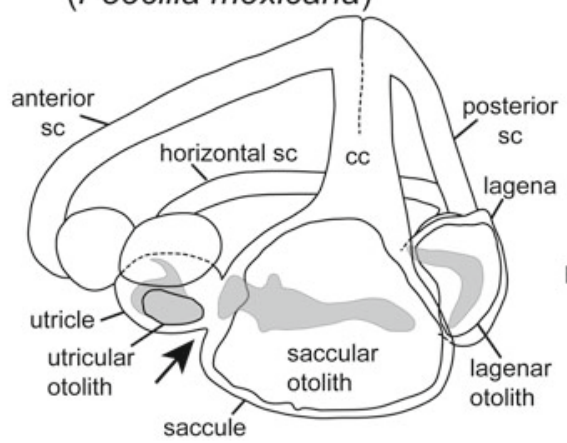

\section{(Dormitator latifrons)}

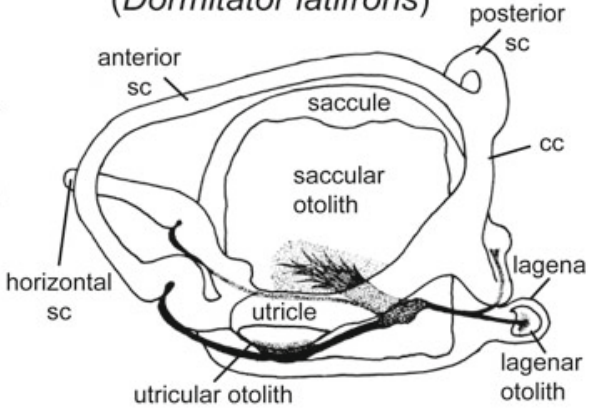

d Anabantiformes

(Trichopsis vittata)

e Perciformes

(Eutrigla gurnardus)
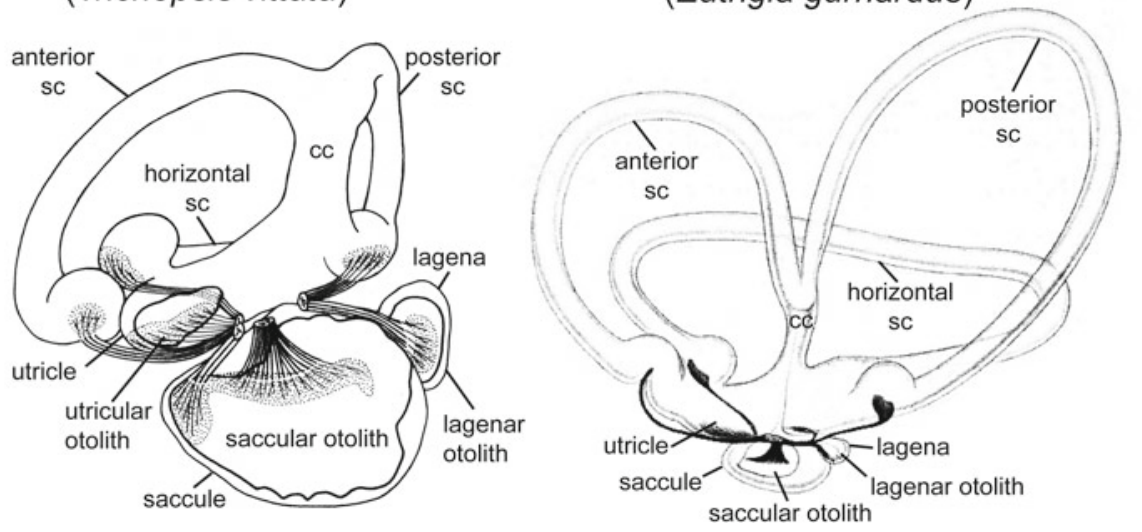

Fig. 1 Overview of inner ear diversity in bony fishes illustrated by means of several teleost groups. Otophysan ears have a large round lagenae with an asterisk-like otolith and an elongate saccule and saccular otolith (a). Non-otophysans generally possess a saccule larger than the utricle and lagena (b-e). Cyprinodonotiforms (b) show a utricle connected anteriorly to the saccule (indicated by black arrow). In gobiiform fishes (c) the saccule is distinctly large and semicircular canals runFig. 1 (continued) around this end organ rather than having an anterodorsal position. The ear of the anabantiform Trichopsis vittata (d) represents a gross morphology found in many non-otophysans. Variation regarding the semicircular canals are rare compared to the diversity found in the otolithic end organs, 
Table 1 The following modifications of the basic ear structure relate to inner ear diversity of fishes (see Platt and Popper 1981a and Fig. 1)

\begin{tabular}{l|l}
\hline Gross morphology & $\begin{array}{l}\text { Position of upper to lower parts of the inner ear, i.e. position of } \\
\text { utricle relative to saccule and lagena }\end{array}$ \\
\cline { 2 - 2 } Distance between left and right ears \\
\hline Presence/absence of a connection between left and right ears \\
\hline Size and diameter of semicircular canals \\
\hline Size ratios of end organs: utricle:saccule:lagena \\
\hline $\begin{array}{l}\text { Amount of surrounding skull bone; potential attachment of } \\
\text { membranous labyrinth to skull bone }\end{array}$ \\
\hline Presence/absence of a macula neglecta \\
\hline Shape and orientation of maculae \\
\hline Orientation patterns of ciliary bundles on the maculae \\
\hline & $\begin{array}{l}\text { Ciliary bundle types (bundle length; ratio kinocilium length to } \\
\text { longest stereovillus) }\end{array}$ \\
\hline Surface morphology of supporting cells \\
\hline & Presence of special areas of supporting cells \\
\hline & Innervation pattern of sensory epithelia \\
\hline Otoliths/otoconia & Otolith (otoconia) morphology \\
\hline & Area, mass, density of otoliths (otoconia) \\
\hline Size ratio of otoliths: utricular:saccular:lagenar otoliths \\
\hline & Percent of macula covered by the respective otolith \\
\hline
\end{tabular}

and Fay 2011). The orientation pattern of the sensory epithelia of the semicircular canals (=cristae) is similar in all studied vertebrates, and the cristae are thus the most conservative of all sensory epithelia of the inner ear (Mathiesen 1984). The utricle also shows minimal variation (Platt and Popper 1981a), indicating that the vestibular part of the inner ear functions similarly in all vertebrates (except perhaps for jawless fishes having just one or two canals) (see Ladich and Popper 2004). Modification of this basic type can relate to (1) gross morphology, e.g. proportions of the end organs, (2) sensory epithelia, e.g. orientation patterns of ciliary bundles on the maculae, and (3) otolith (and to a lesser degree otoconia) morphology (Table 1).

The maculae of the otolithic end organs typically consist of several groups of similarly oriented hair cells resulting in a certain orientation pattern. The orientation of ciliary bundles and thus the morphological and physiological polarization of hair cells is determined according to the eccentrically positioned kinocilium of the ciliary bundle. The largest diversity in orientation patterns occurs on the macula sacculi (Platt and Popper 1981a; Popper and Coombs 1982) for which five different patterns have been described by Popper and Coombs (1982) (Fig. 2). Four of them show horizontal and vertical orientation groups and are called standard, dual, opposing, or alternating patterns; the fifth pattern type is characterized by vertical orientation groups only (Popper and Coombs 1982). As available data on different taxa increased, Popper and colleagues started to interpret their results from a phylogenetic perspective. An important outcome was that inner ear morphological fea- 


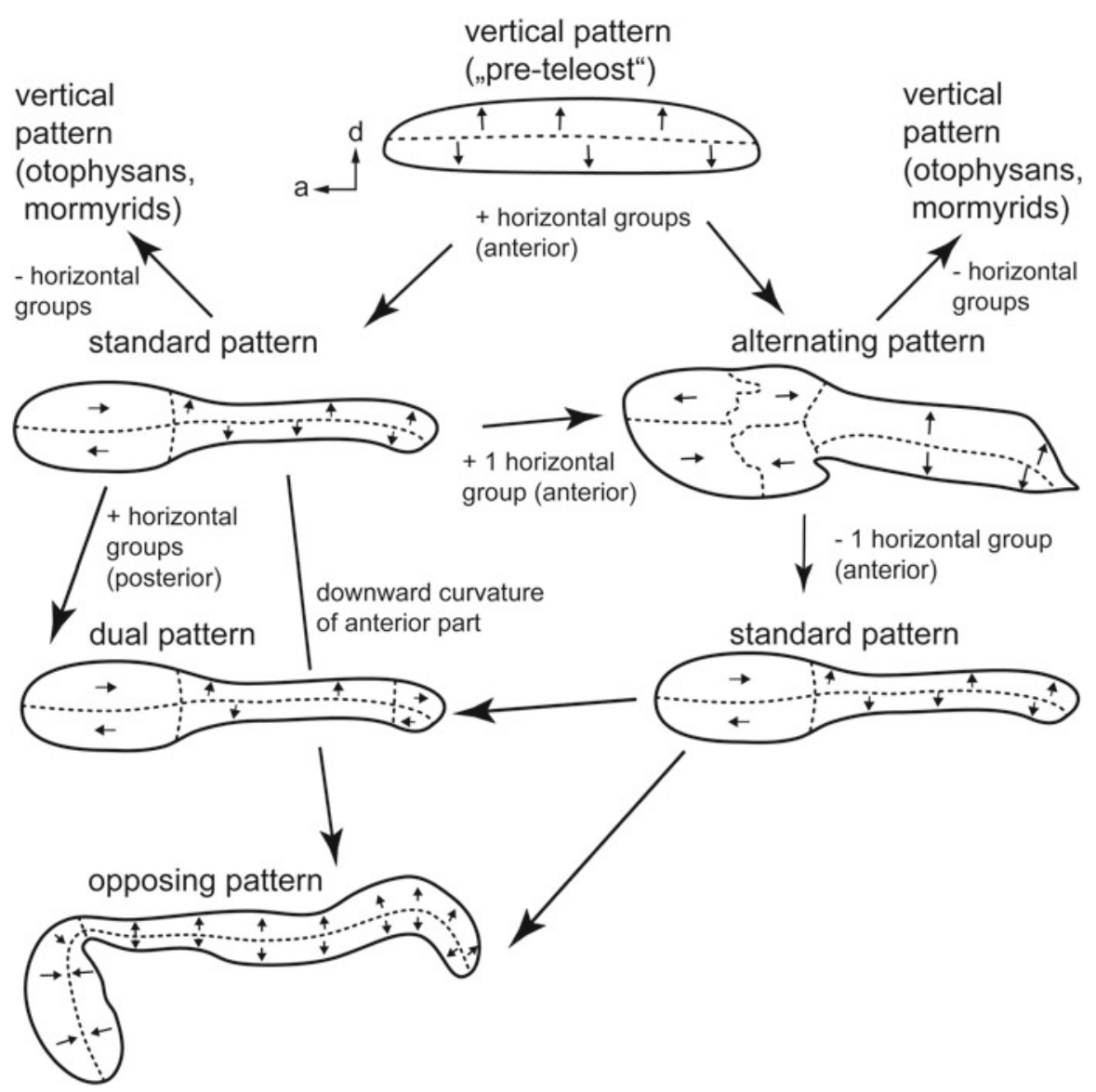

Fig. 2 The main ciliary bundle orientation patterns in teleosts and how the patterns may be derived from one another. Arrow tips point in the direction of the kinocilia, indicating the orientation of the ciliary bundles in the respective area; the dashed lines separate different orientation groups. Addition of two or three horizontally oriented groups of ciliary to the vertical pattern results in the standard or alternating patterns, respectively. From the standard pattern the dual pattern can be derived by adding horizontal groups in the posterior region; in the opposing pattern, the anterior macula portion is ventrally bent while the orientation of the horizontal groups is retained. The standard pattern may also be obtained by removing one horizontal group from the alternating pattern. The vertical patterns in otophysans and mormyrids may be derived by removing the horizontal groups from the standard of the alternating patterns. The five patterns are modified from Popper and Coombs (1982) and Popper and Schilt (2008). $a$ anterior, $d$ dorsal

represents the appropriate stimulus for the otolithic end organs but this particle motion emanates from the oscillating swim bladder walls and not directly from the sound source itself (e.g., Rogers et al. 1988). Fishes that can also make use of the second stimulation pathway tend to have a wider hearing bandwidth and better auditory sensitivity than taxa without ancillary auditory structures (Fay 1988; Braun and Grande 2008; Ladich and Fay 2013). The maculae, especially the macula sacculi, of 
the otolithic end organs of teleosts with ancillary auditory structures often have orientation patterns of the ciliary bundles that deviate from the patterns found in fish lacking these structures (Platt and Popper 1981a; Popper and Coombs 1982; Popper and Schilt 2008; Popper and Fay 2011).

The following overview of inner ear diversity in the major groups of bony fishes follows the systematics presented by Betancur-R. et al. (2013), Broughton et al. (2013) and updated outcomes of the DeepFin project (Project 2003-2009). The main focus of the descriptions is on sensory epithelia, the presence of ancillary auditory structures and hearing abilities (summarized in Table 2). Hard parts of the inner ear, especially the otoliths in teleosts, also show considerable diversity. Otolith mineralization is a separate, complex field depending on a number of factors such as endolymph chemistry and fish metabolism. As this is beyond the scope of our review we will not discuss variation of otolith morphology in detail.

\subsection{Sarcopterygii}

In the coelacanth Latimeria (Actinistia), saccule and lagena are two interconnected pouches (Fritzsch 1987, 2003). A saccular otolith is reported, but no other otoliths or otoconia were described (Carlström 1963; Millot and Anthony 1965; Bernstein 2003). In addition to the maculae of the end organs and the macula neglecta, Latimeria possesses a (sensory) epithelium that has been hypothesized to be homologous to the tetrapod basilar papilla and thus indicating a close relationship to the tetrapods (Fritzsch 1987, 2003). The orientation pattern of the macula lagenae, however, is similar to that in other bony fishes, i.e. it consists of two opposing groups of ciliary bundles and therefore differs from that found in amphibians, in which the ciliary bundles point away from the dividing line (Platt 1994; Platt et al. 2004). This finding contradicts the assumption that one similarity between Latimeria and tetrapods is expressed through a similar lagenar orientation pattern (Fritzsch 1987; Fritzsch et al. 2013). As no hearing data are available, one can only speculate whether Latimeria is sound pressure sensitive and if its hearing abilities are comparable to terrestrial vertebrates.

In lungfishes (Dipnomorpha), saccule and lagenae form a single pouch (Retzius 1881). Within this pouch, the macula sacculi and the macula lagenae represent a continuum, a sacculolagenar macula in which two regions of high hair cell densities (striolas) are separated by areas of lower densities of sensory hair cells (Platt et al. 2004). Such a sacculolagenar macula is unique among bony fishes. The sacculolagenar macula is overlain by two "otoliths" apparently made up of numerous single otoconia rather than being massive biomineralisates (Gauldie et al. 1986a; Platt et al. 2004). In Protopterus a tetrapod-like feature was identified for the crista of the horizontal semicircular canal, which resembles a hemicrista (Platt et al. 2004). Although inner ear diversity does not necessarily reflect phylogenetic relationships, this similarity is in accordance with recent molecular analyses indicating that lung- 


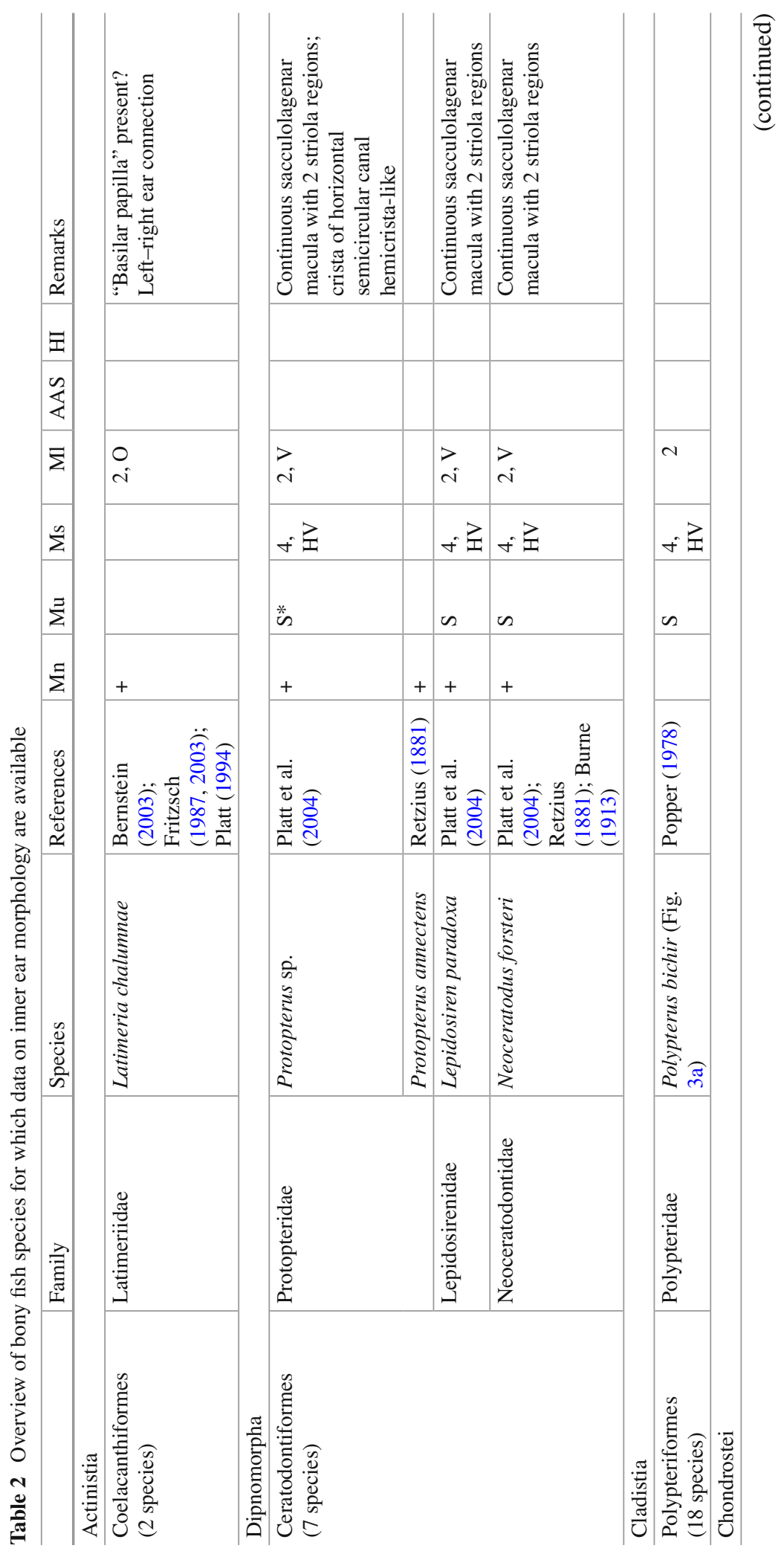




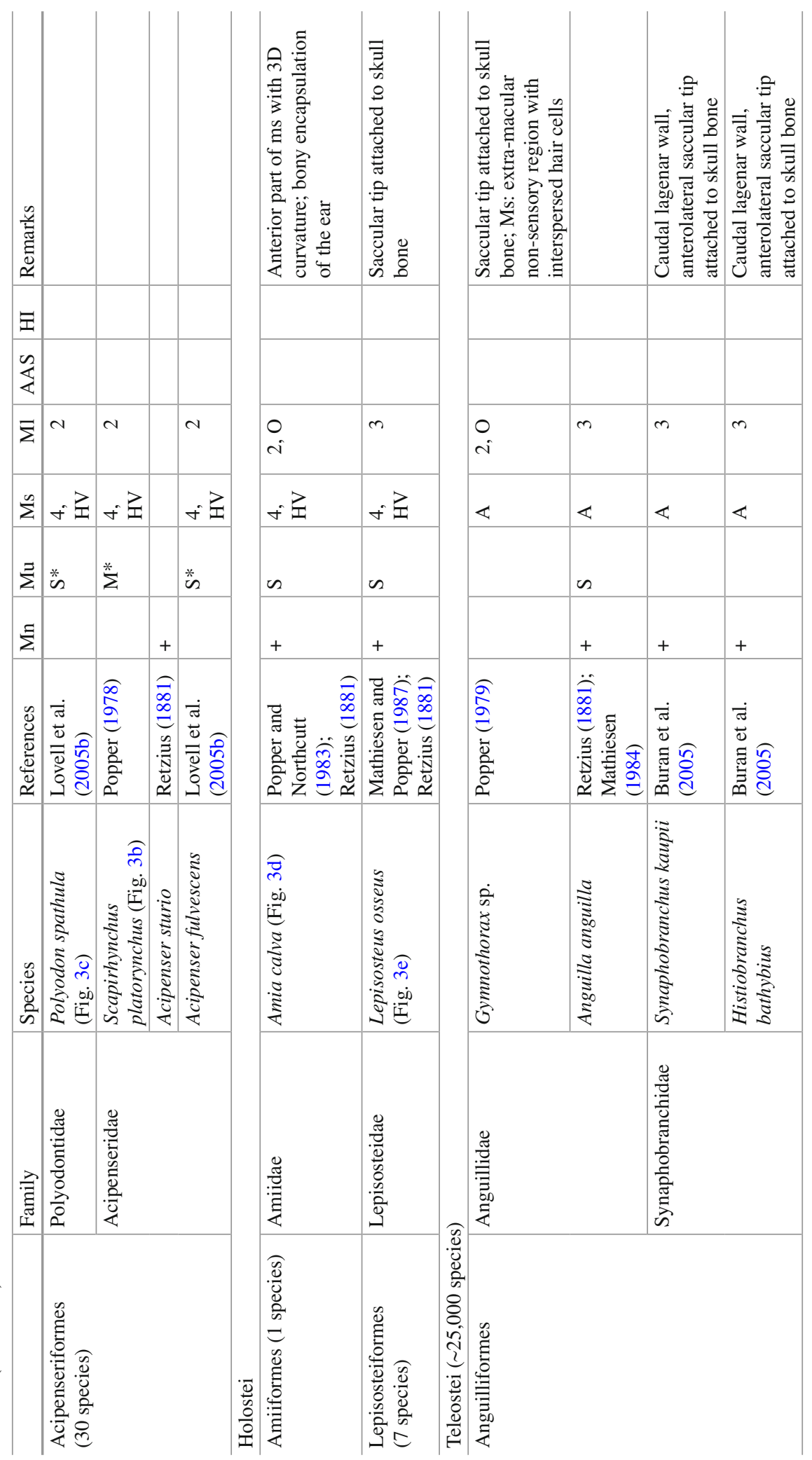




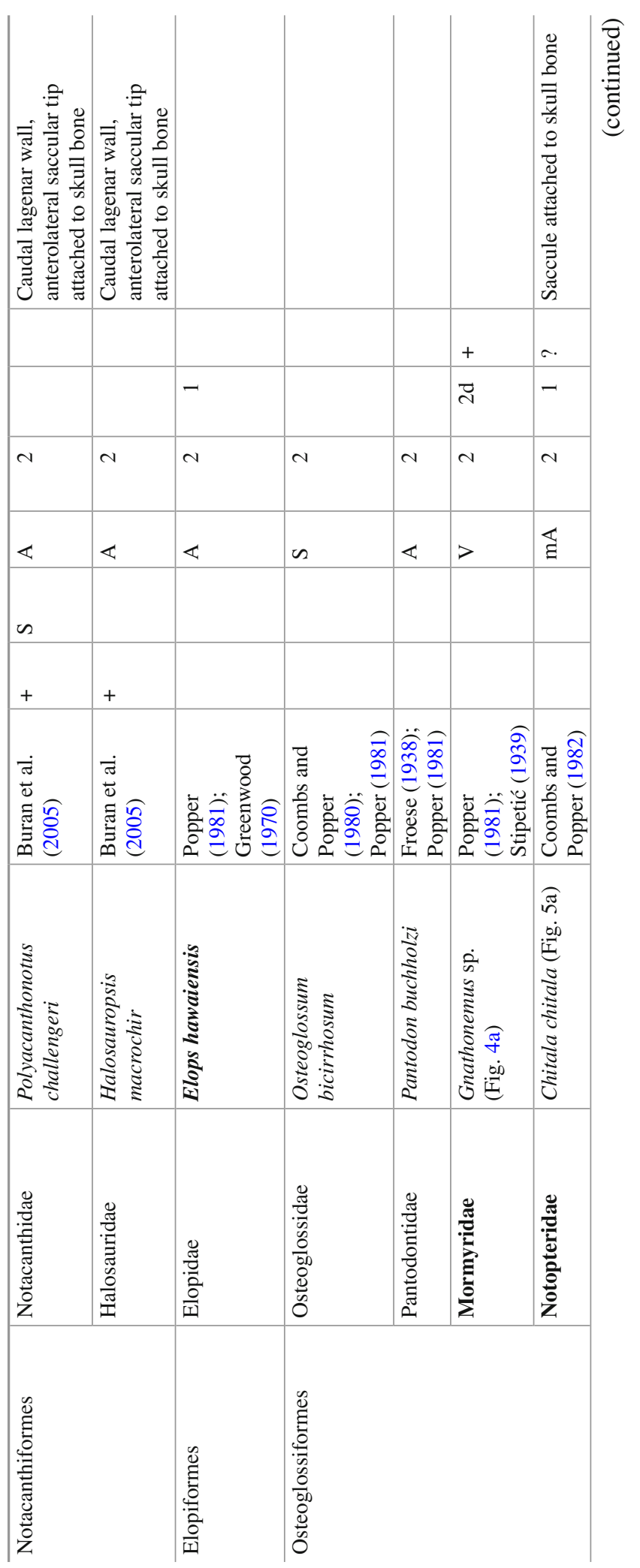




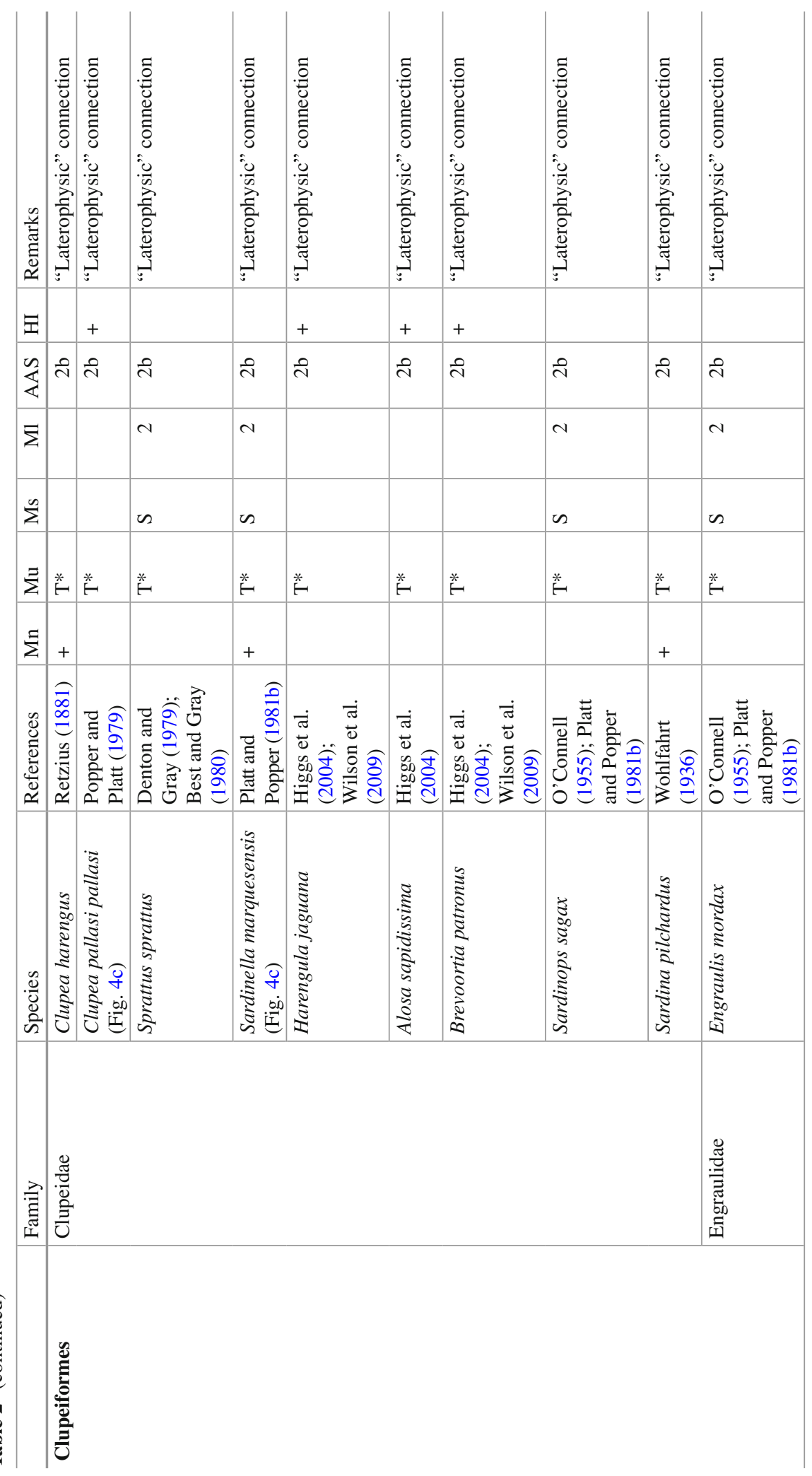




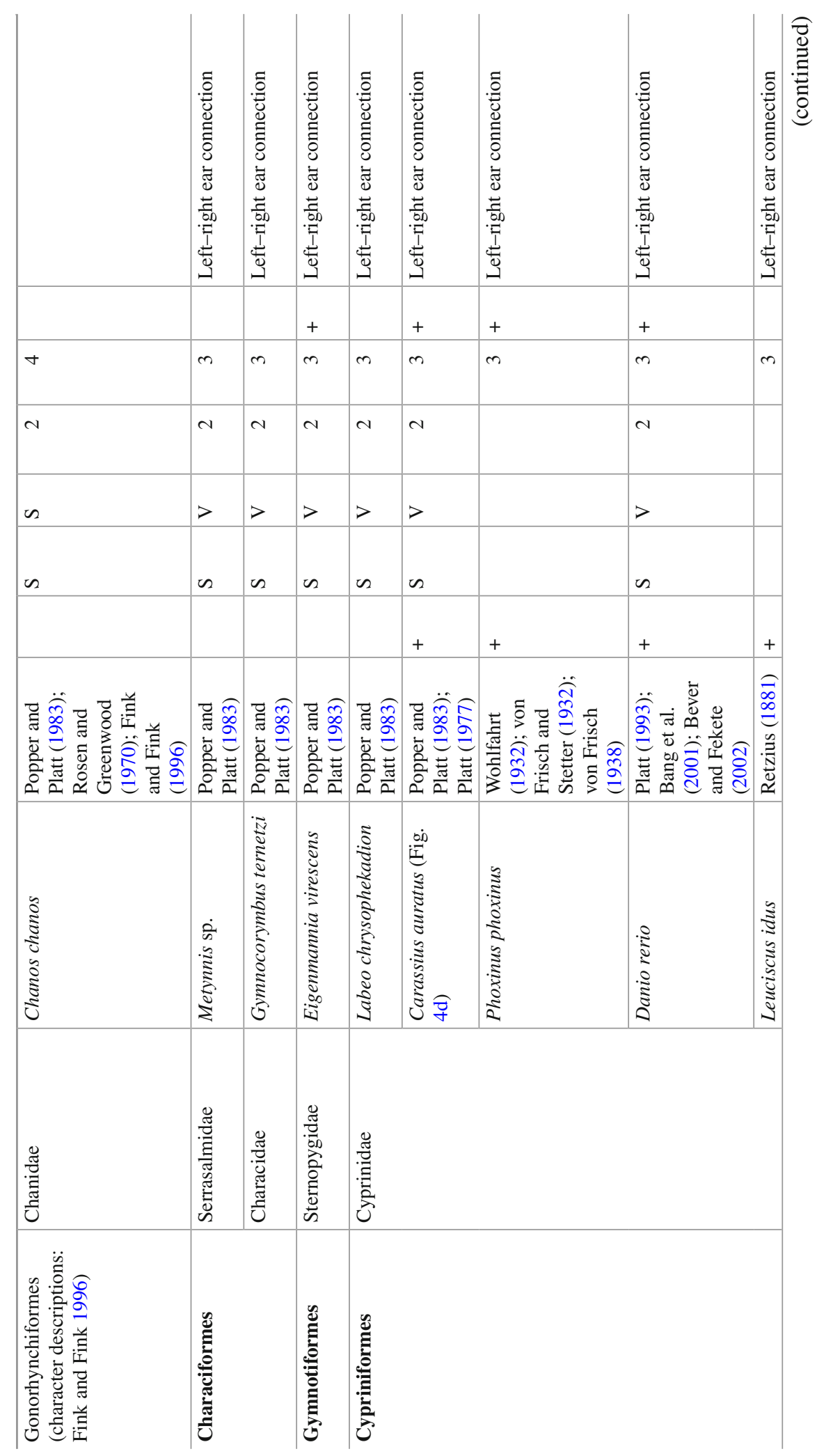




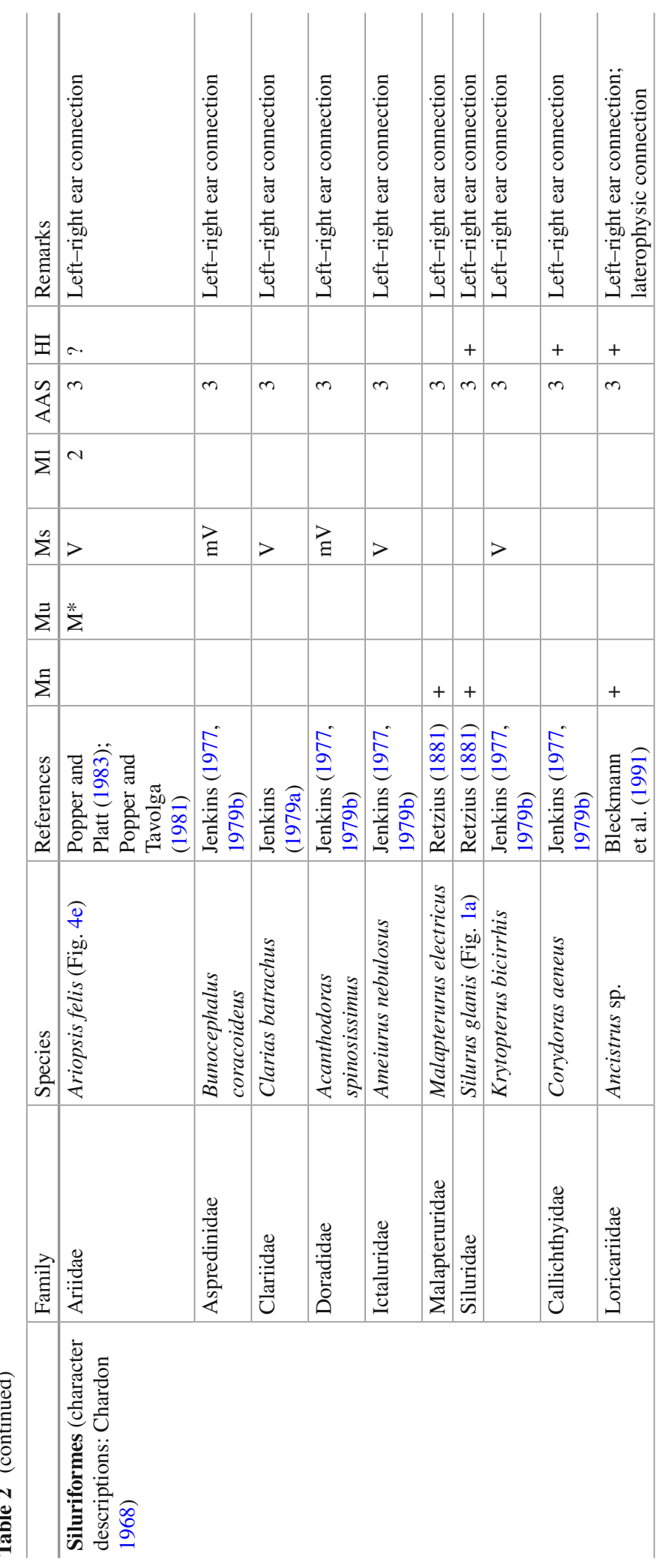




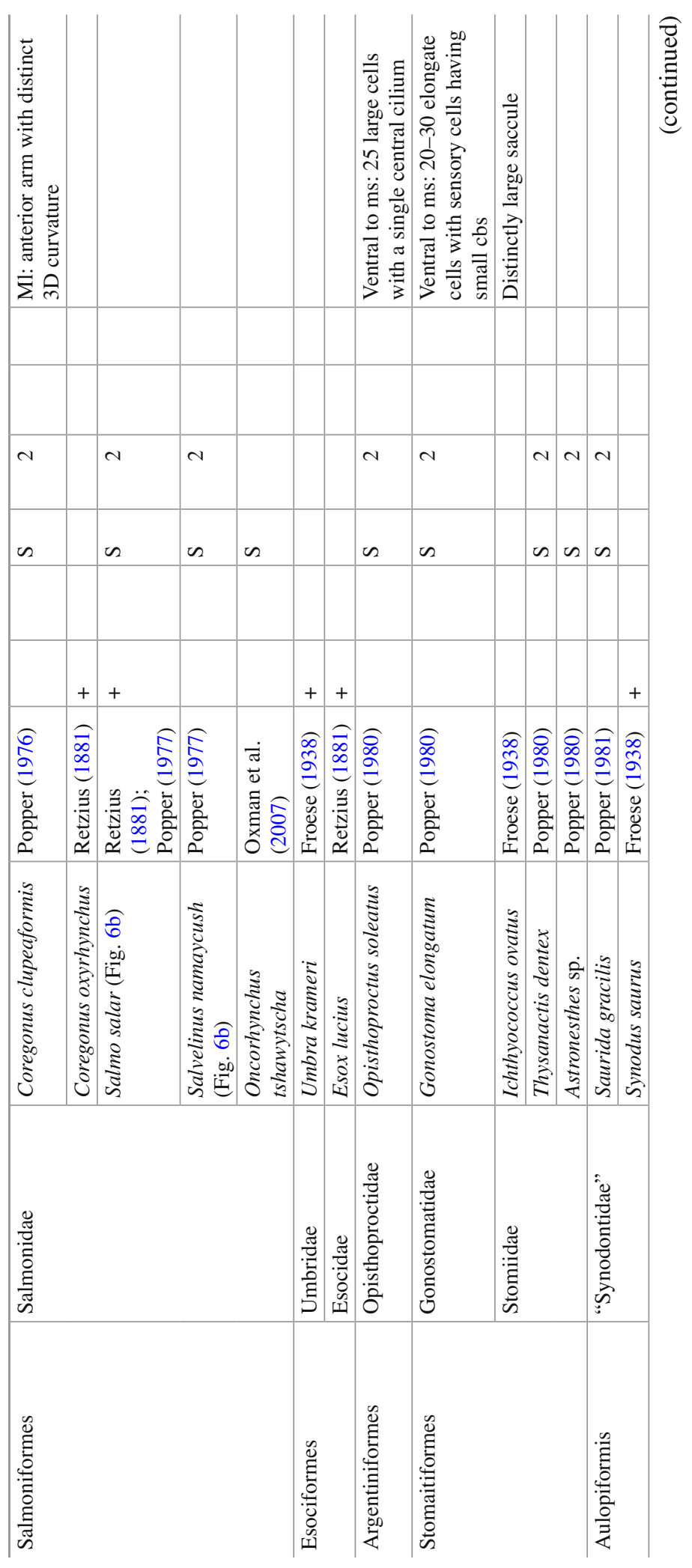




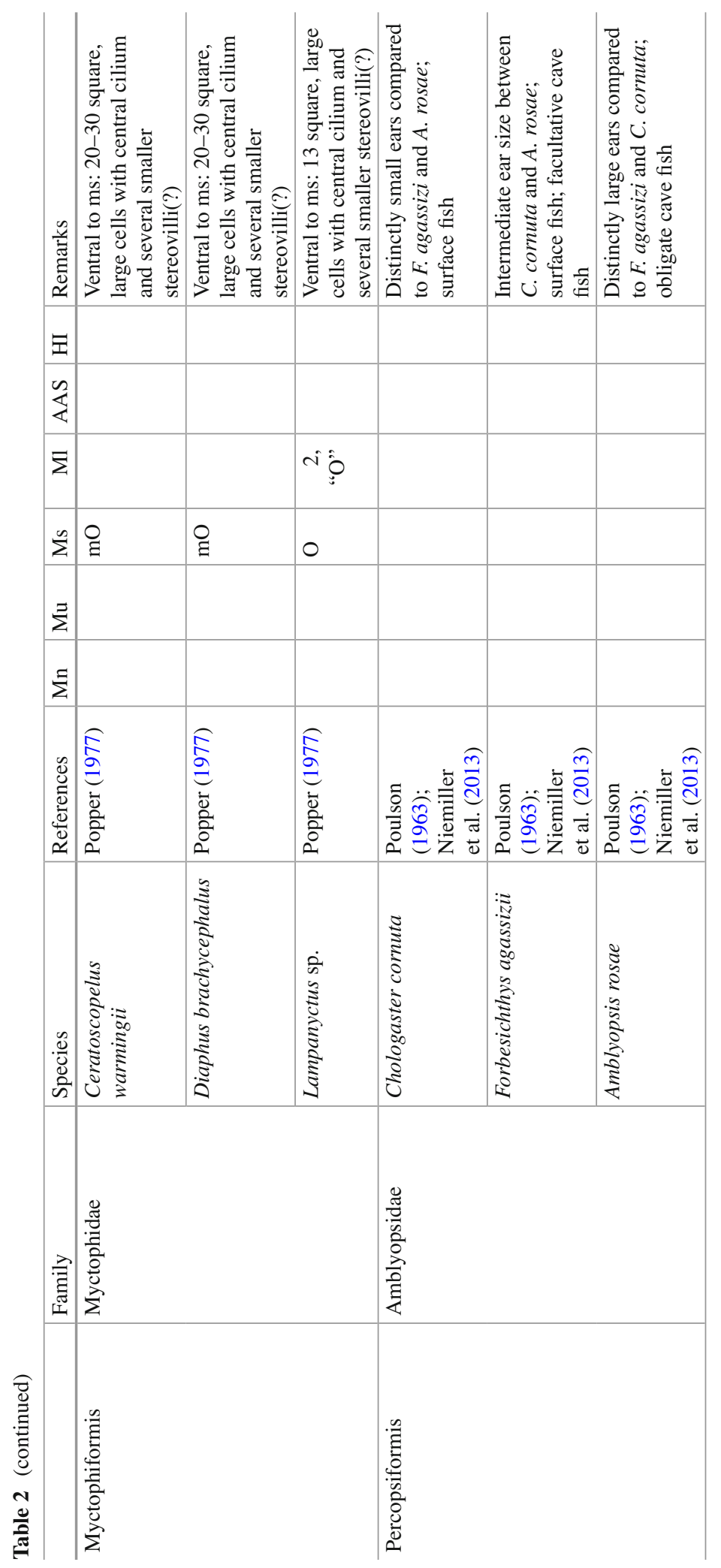




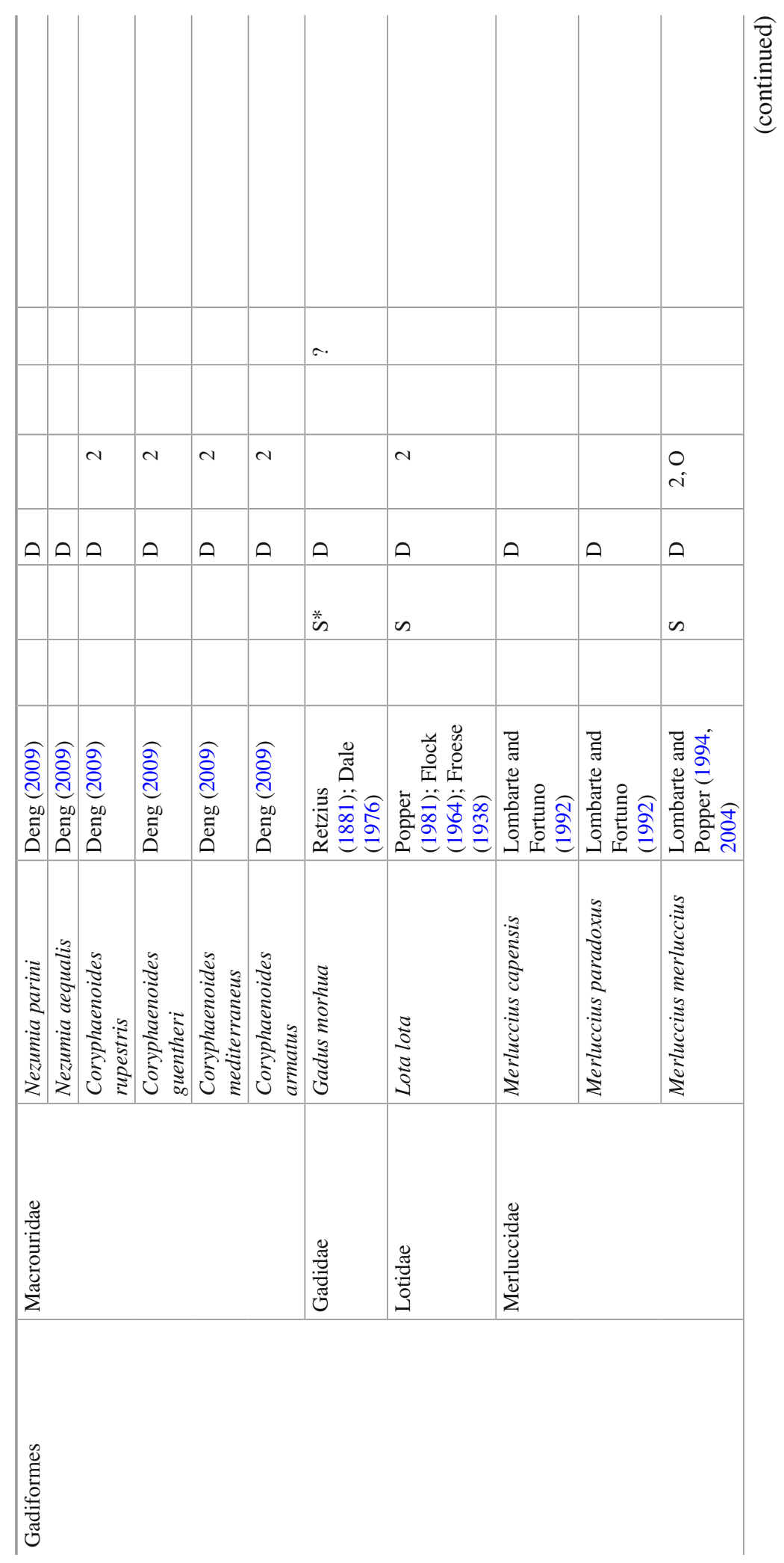




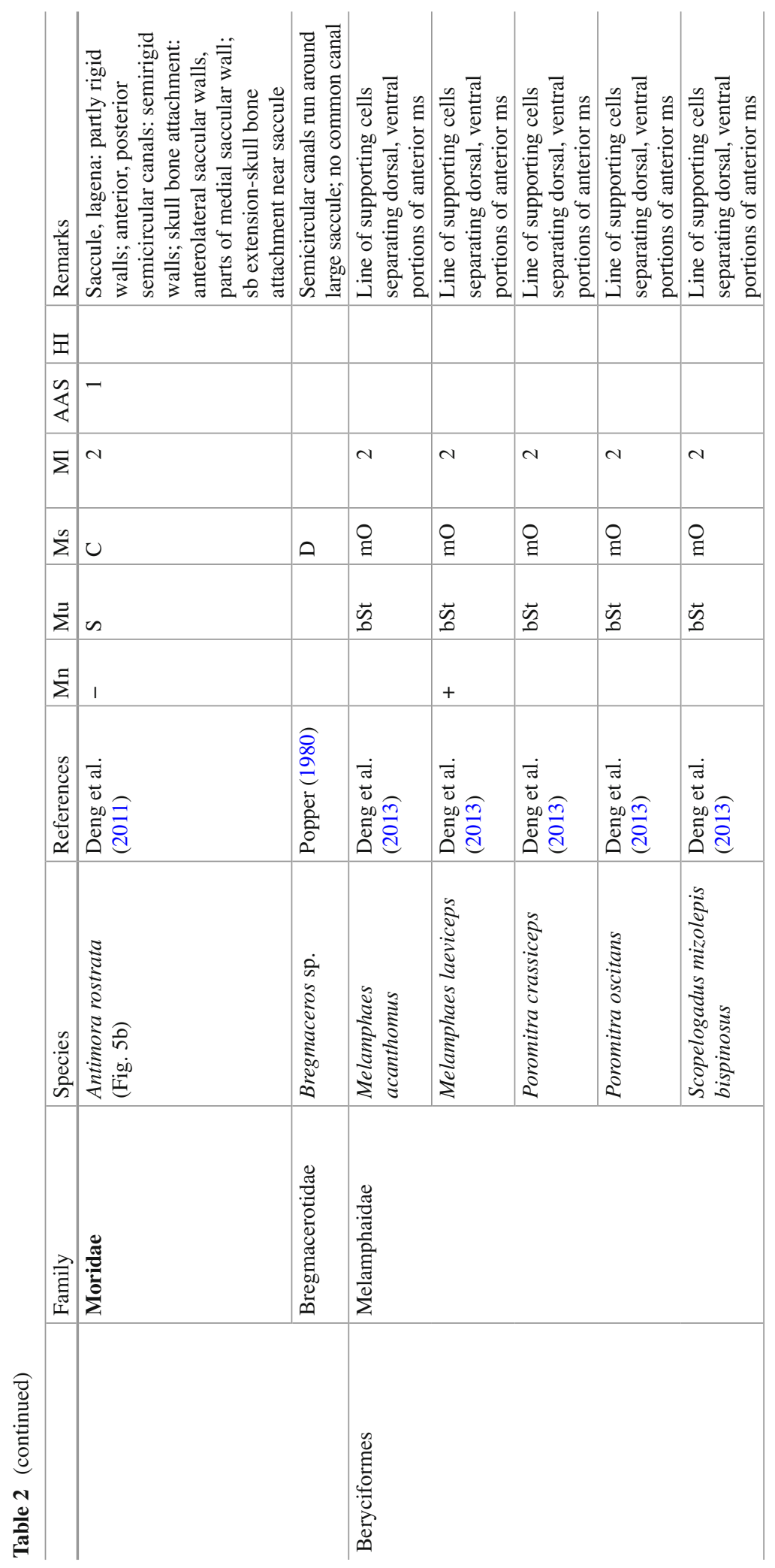




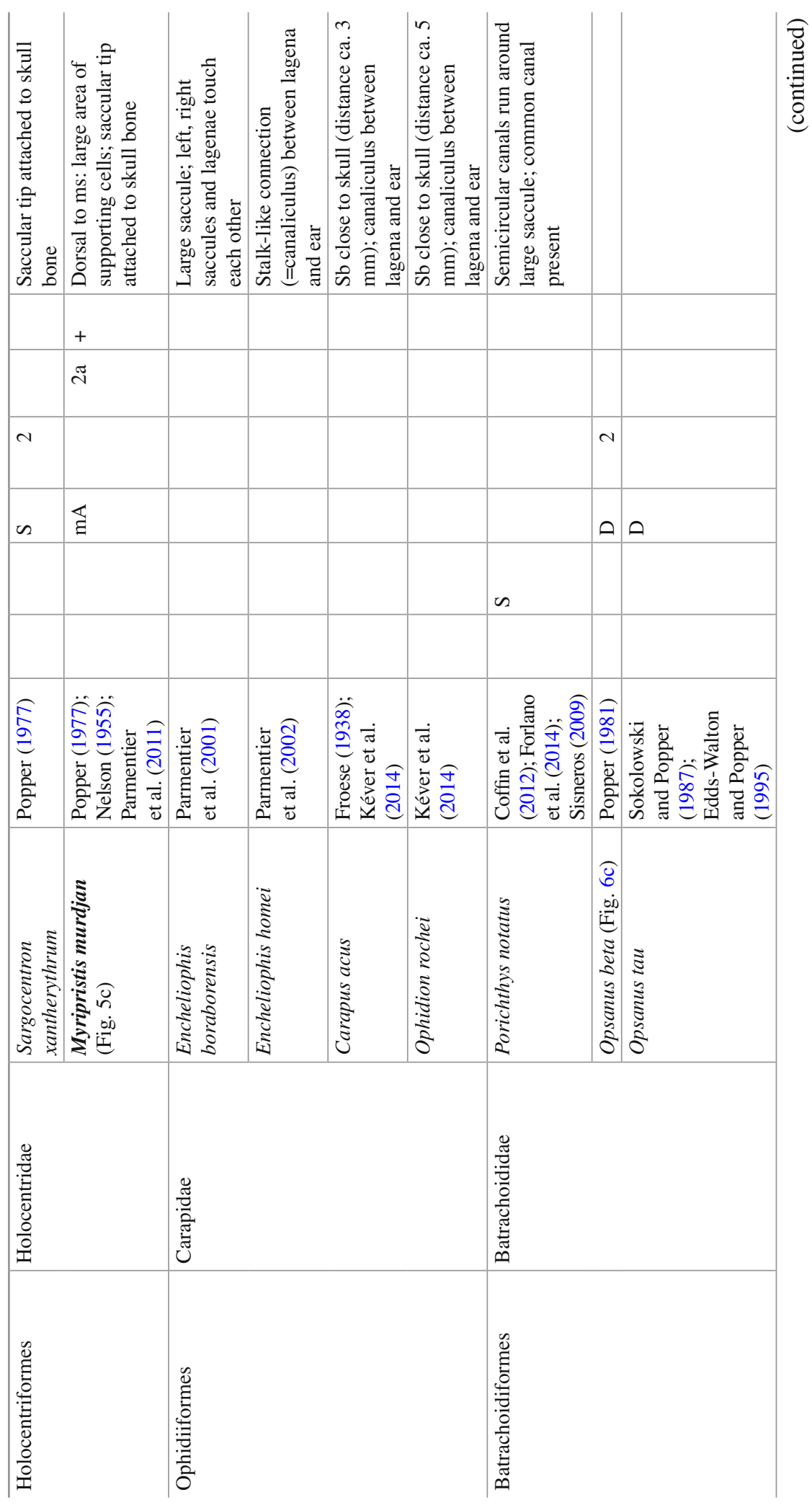




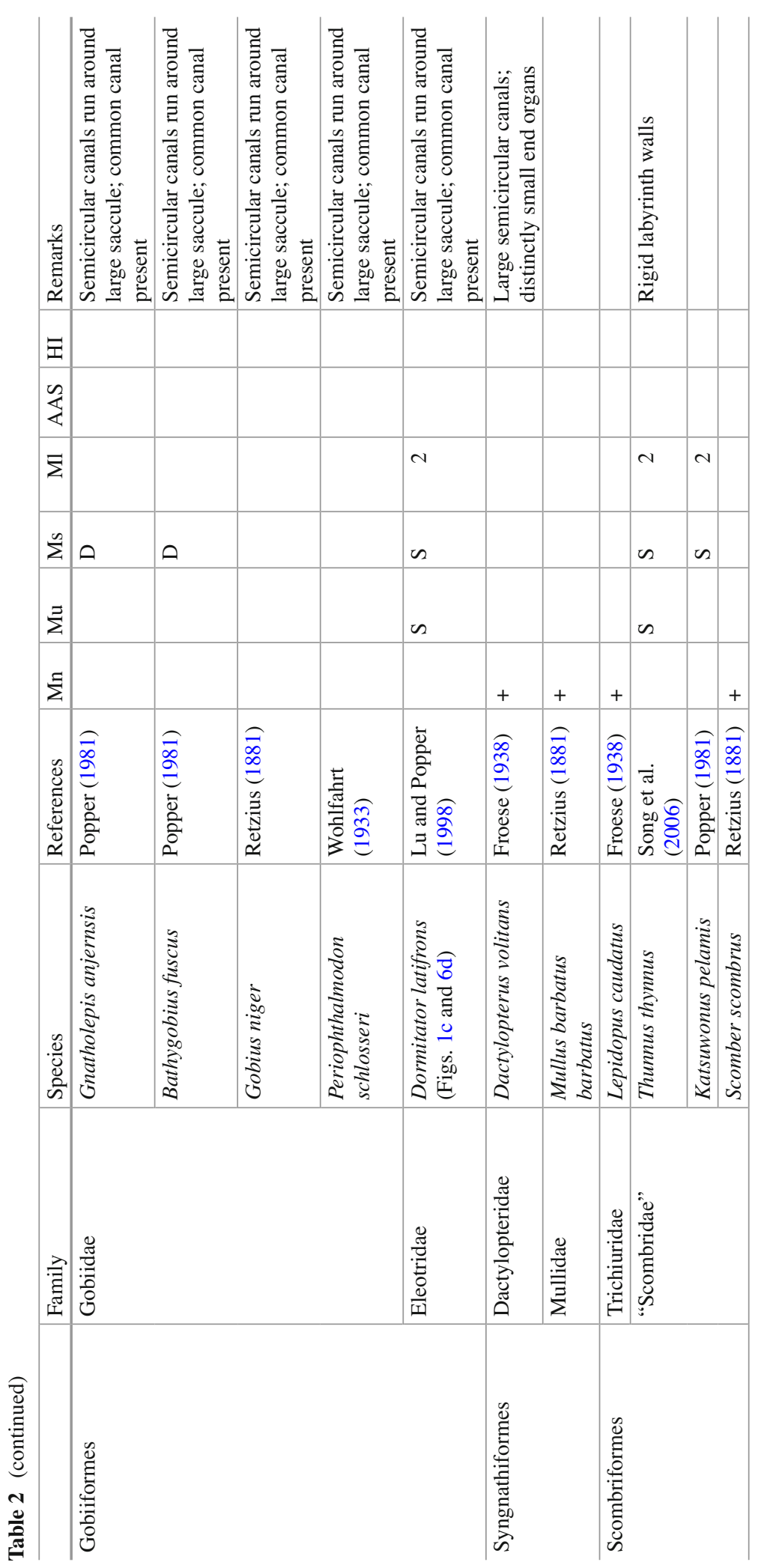




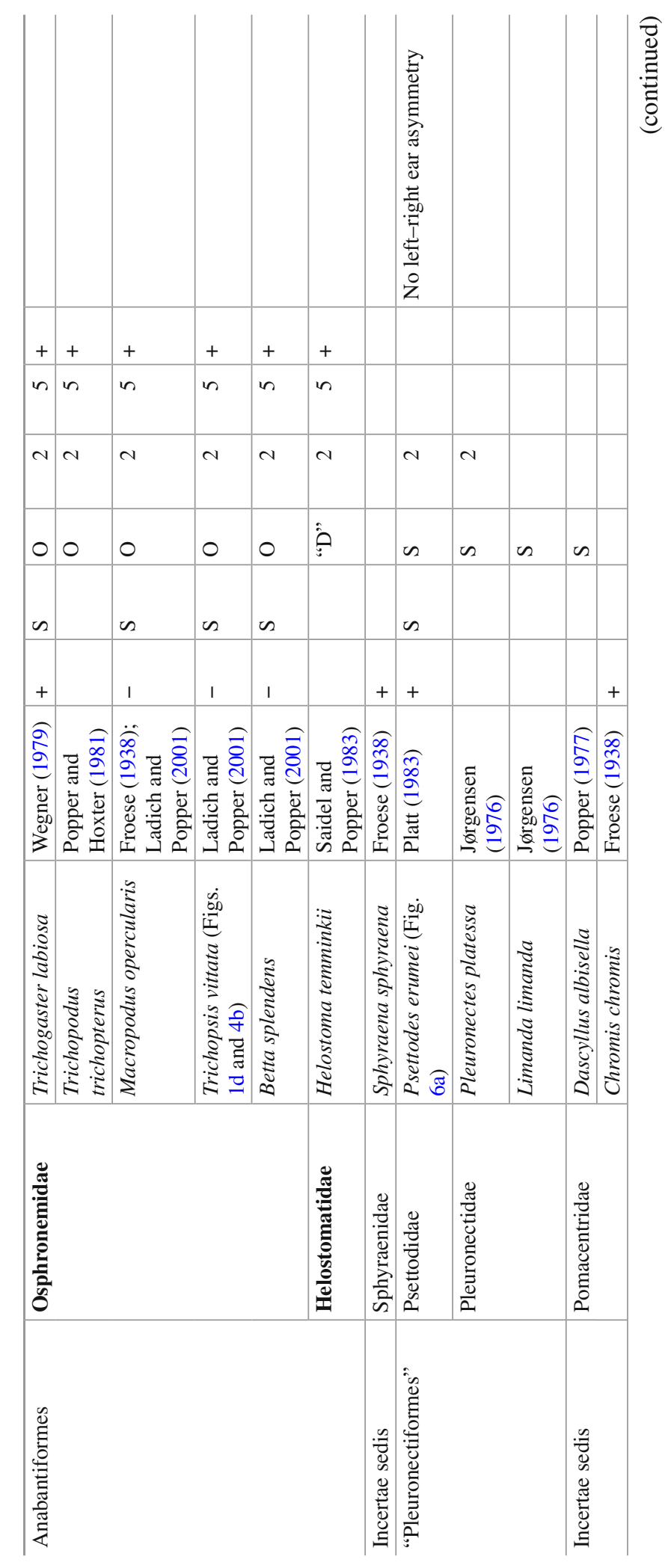




\begin{tabular}{|c|c|c|c|c|c|c|c|c|c|c|c|c|}
\hline & 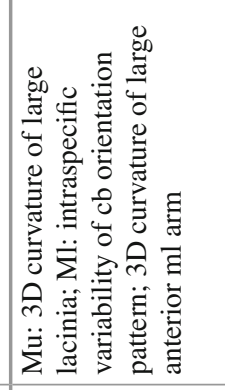 & & & & & & & 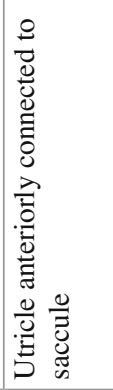 & 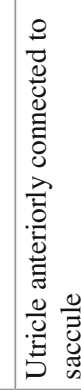 & 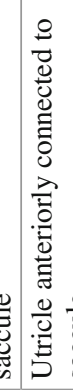 & 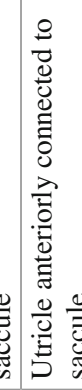 & \\
\hline- & + & + & $£$ & & & & & & & & & \\
\hline 4 & $\ddot{\sim}$ & - & & & & & & & & & & \\
\hline $\bar{\Sigma}$ & 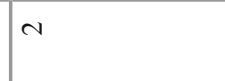 & & $\sim$ & N & & & $\sim$ & N & & & & $\sim$ \\
\hline$\sum^{n}$ & o & & 0 & 0 & $\bar{y}^{2}$ & $\infty 0$ & is & is & & & & is \\
\hline $\bar{\Sigma}$ & 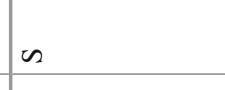 & & n & n & & & & n & & & & \\
\hline$\Sigma$ & & & 1 & 1 & & & & 1 & & & & \\
\hline & 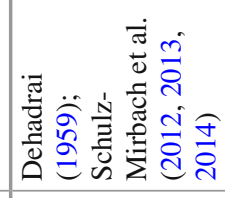 & 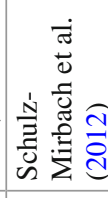 & 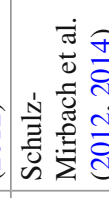 & 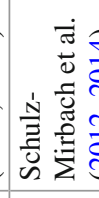 & 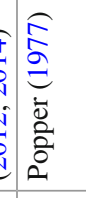 & 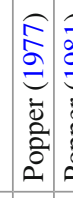 & & 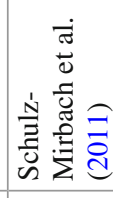 & 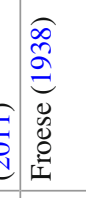 & 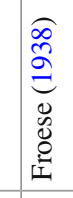 & 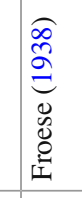 & 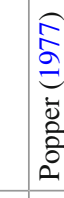 \\
\hline & 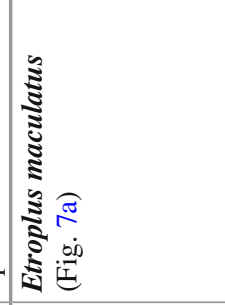 & 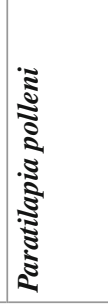 & 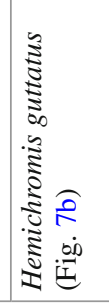 & 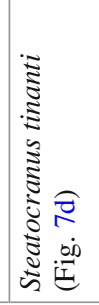 & 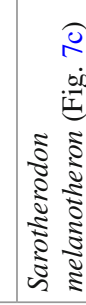 & $\frac{\sqrt{3}}{3}$ & & 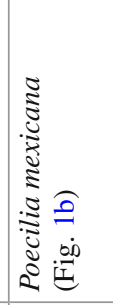 & 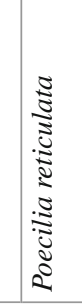 & 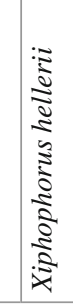 & 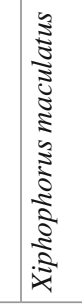 & \\
\hline
\end{tabular}

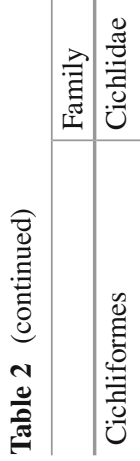

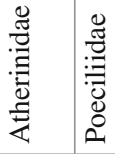

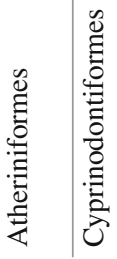




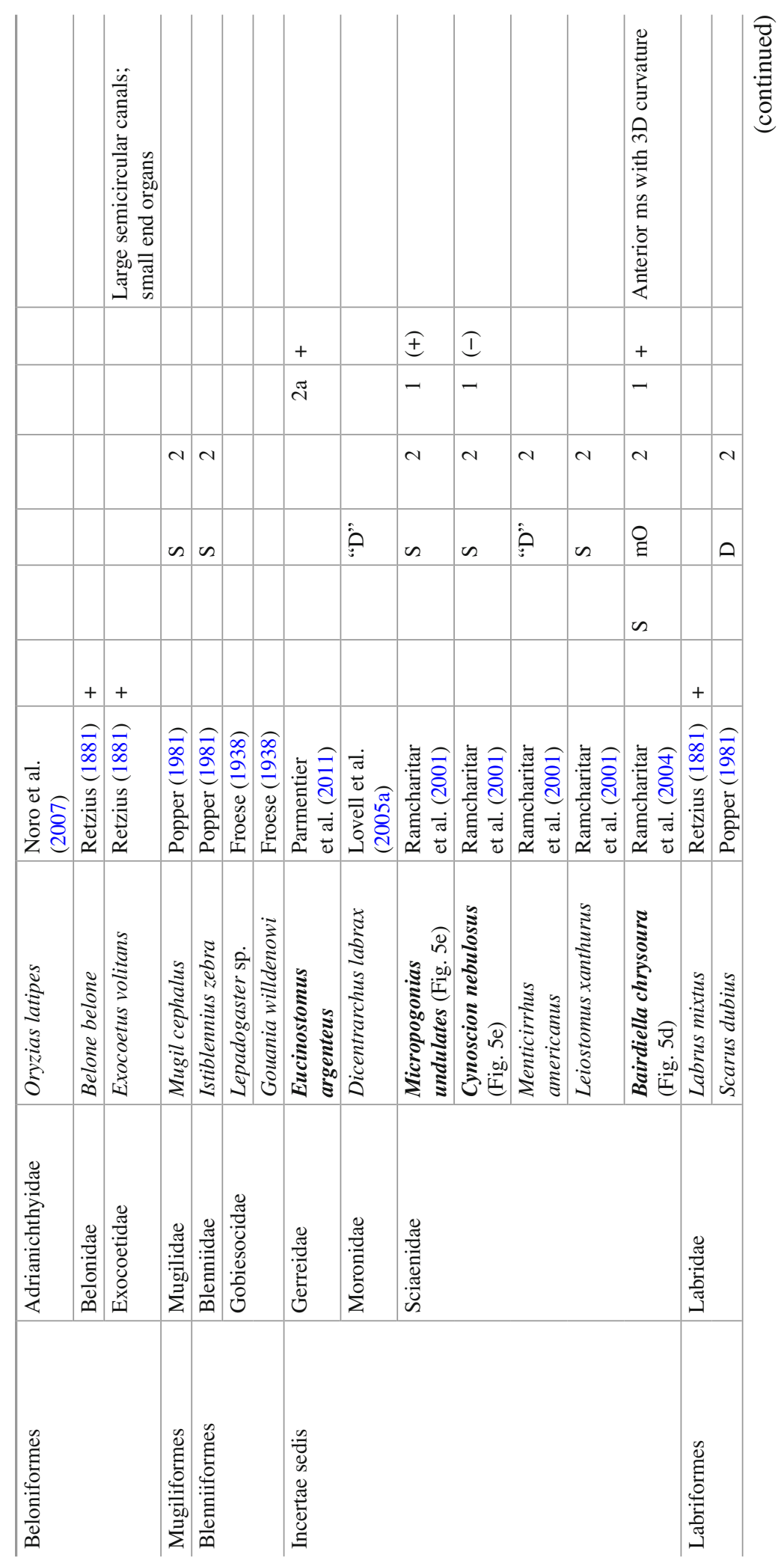




\begin{tabular}{|c|c|c|c|c|c|c|c|c|c|c|c|c|c|}
\hline 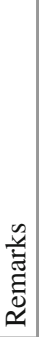 & & & 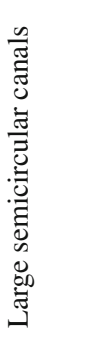 & 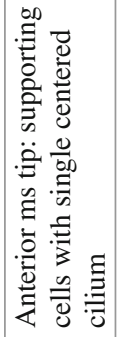 & & & & 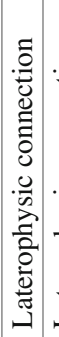 & 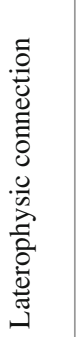 & 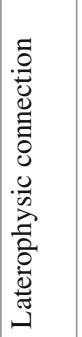 & 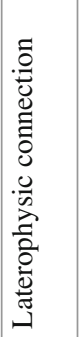 & & \\
\hline 玨 & & & & & & & & & & & & & \\
\hline$\sum_{4}^{\infty}$ & - & & & & & & & - & - & - & - & & \\
\hline $\bar{\Sigma}$ & $N$ & & & $N$ & $\mathrm{~N}$ & $N$ & $N$ & $N$ & $N$ & & & & $N$ \\
\hline$\sum^{\infty}$ & is & & & $\sim s$ & ఓֶ. & $\sim \sim s$ & $n$ & $\approx 0$ & 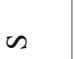 & $\Omega$ & is & is & $n$ \\
\hline$\sum_{\Sigma}^{\Xi}$ & & & & & & & & $\Leftrightarrow 0$ & $\Omega$ & $n$ & is & is & \\
\hline$\Sigma$ & & + & & & & & & & & & & & \\
\hline 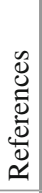 & 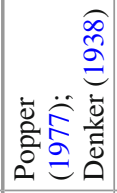 & 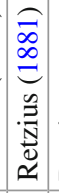 & 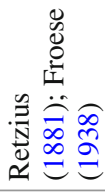 & 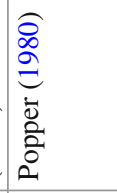 & 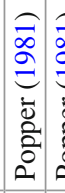 & 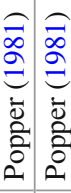 & 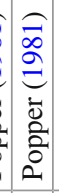 & 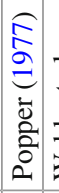 & 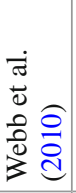 & 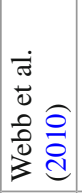 & 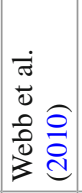 & 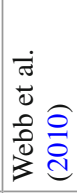 & 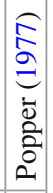 \\
\hline 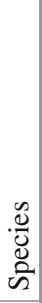 & 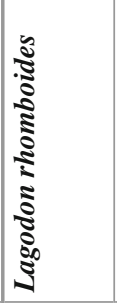 & $\mid \begin{array}{c}0 \\
8 \\
0 \\
0 \\
0 \\
0 \\
0 \\
0 \\
0 \\
\vdots \\
0 \\
0 \\
0 \\
0 \\
0\end{array}$ & 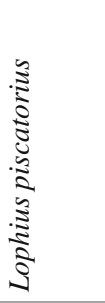 & 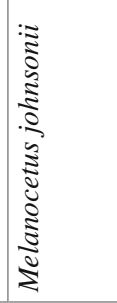 & 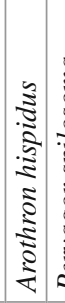 & 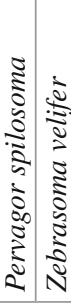 & 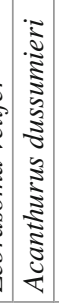 & 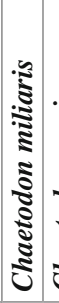 & 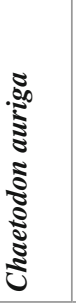 & 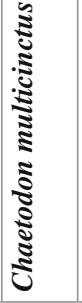 & 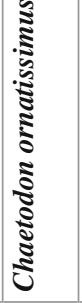 & 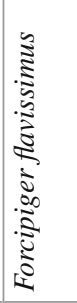 & 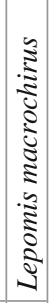 \\
\hline 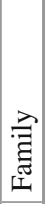 & 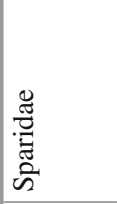 & & 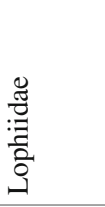 & 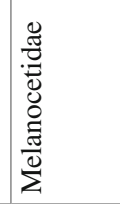 & 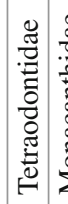 & 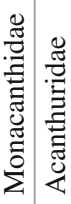 & & 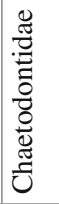 & & & & & 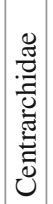 \\
\hline & 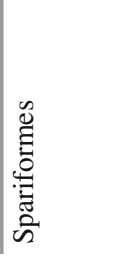 & & 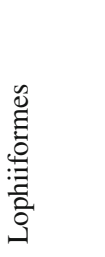 & & 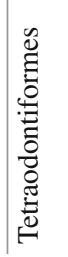 & 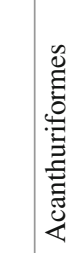 & & 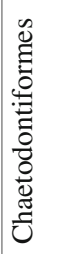 & & & & & 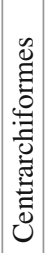 \\
\hline
\end{tabular}




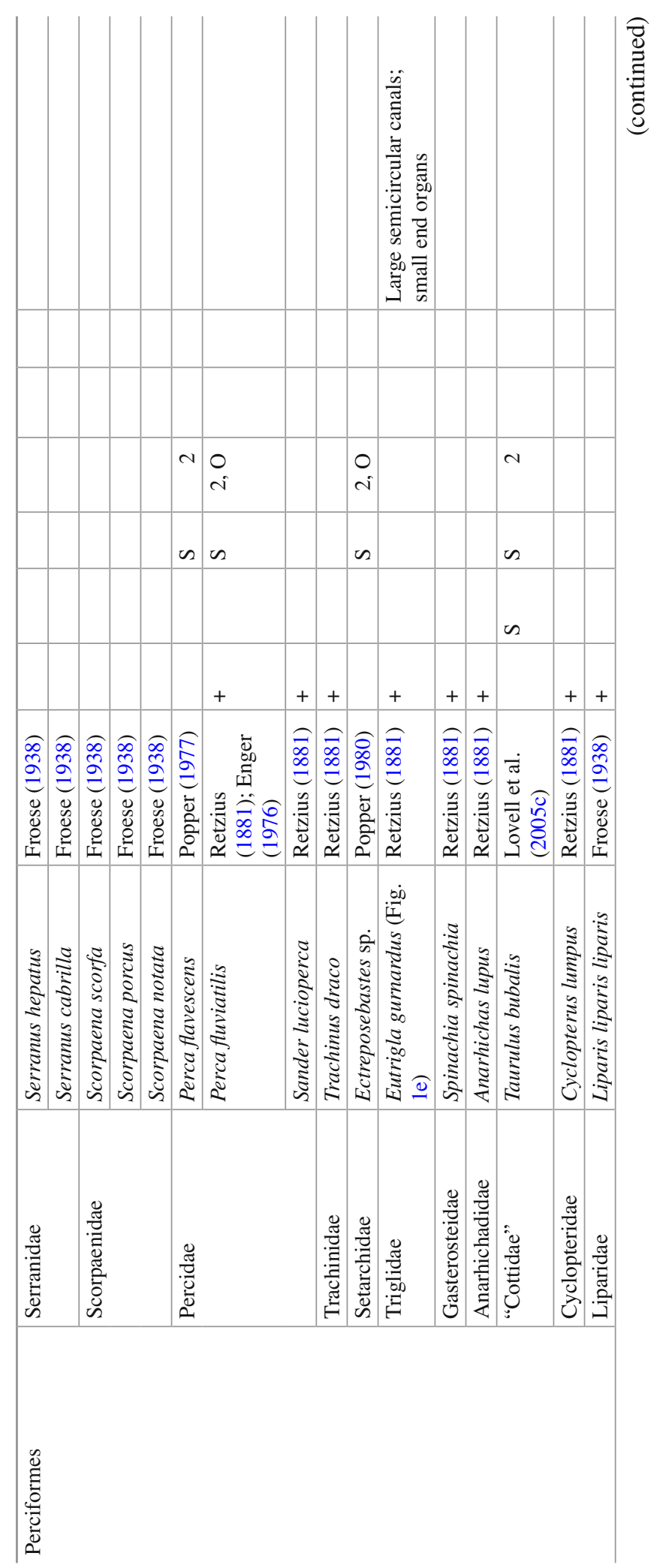



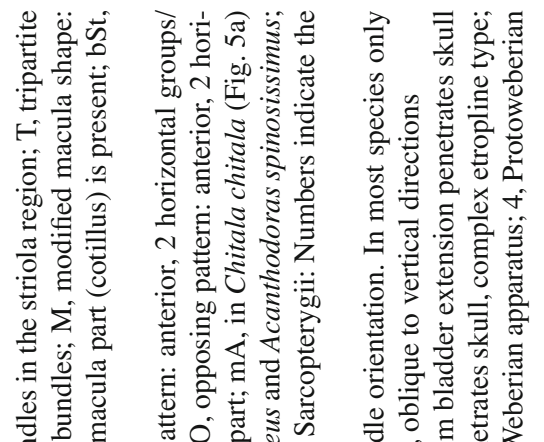

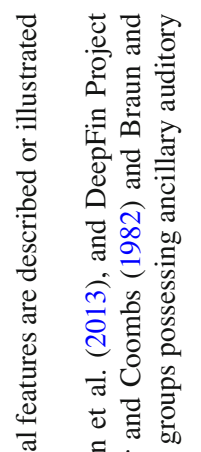

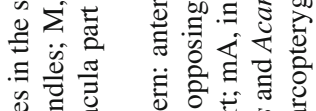

ڤैछ

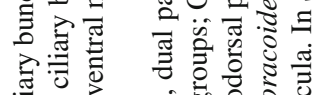

䎡苍苍

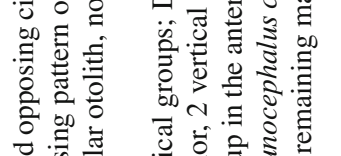

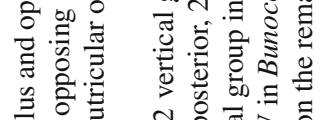

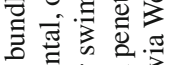

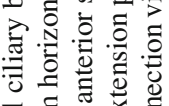

สูป

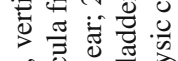

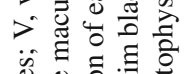

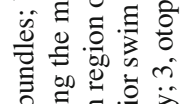
륧

ㅋํㅇำ

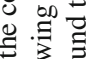

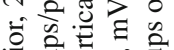

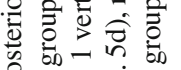

겨을

б。

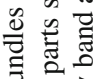

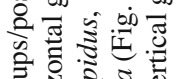

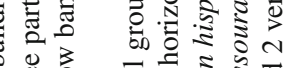

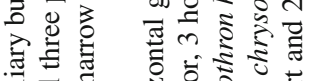

需壱

氖言

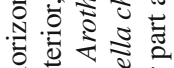

ज割

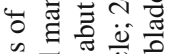

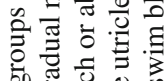

क力

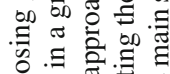

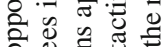

范苛

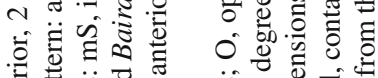

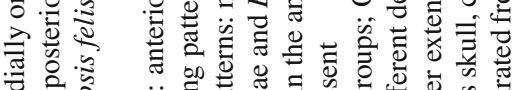

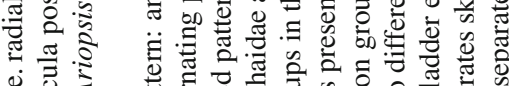

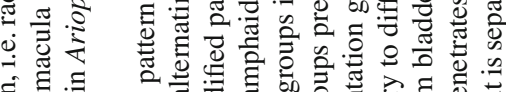

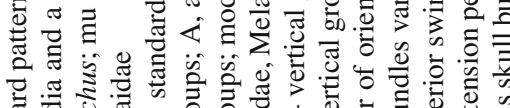

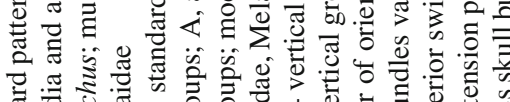

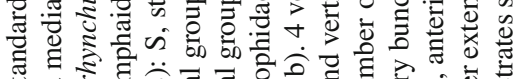

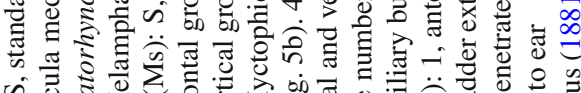

iि

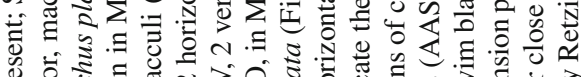

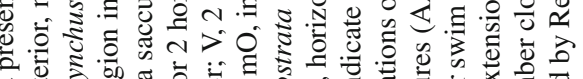

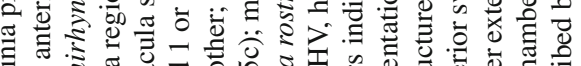

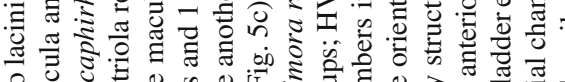

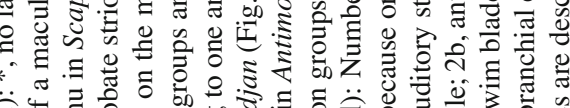

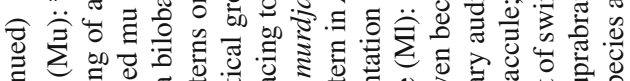

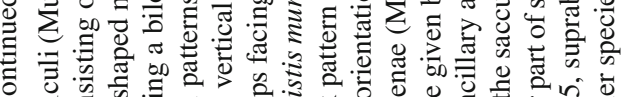

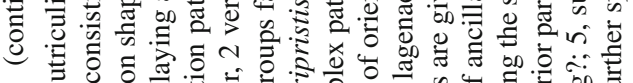

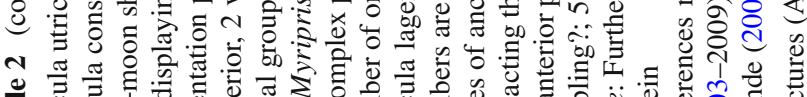

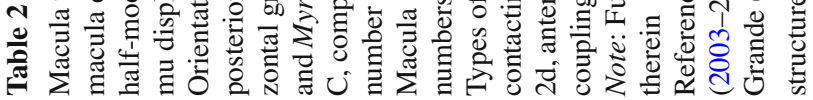


fishes and not actinistians represent the sister group to the tetrapods (Betancur-R. et al. 2013; Broughton et al. 2013).

The African lungfish Protopterus annectens was shown to detect both particle motion and pressure at frequencies ranging from 80 up to $640 \mathrm{~Hz}$ (Christensen et al. 2015). The air-filled lungs in these fish seem to function as pressure-to-particle motion transducer, though the lungs are not directly linked to the inner ears (Christensen et al. 2015). This recent study used a standing wave tube setup to disentangle the particle and pressure component of underwater sound which enabled the authors to revise the outcomes of an earlier study which had indicated a lack of sound pressure detection in lungfish (Christensen-Dalsgaard et al. 2011). Moreover, Christensen et al. (2015) demonstrated that lungfish are also sensitive to airborne sound which these fish detect via sound induced vibrations of the head.

\subsection{Non-teleost Actinopterygii (Cladistia, Chondrostei, Holostei)}

In all studied non-teleost actinopterygians, the saccule and lagena form one sac. The macula sacculi and the macula lagenae are, however, separated. The bowfin Amia, the gar Lepisosteus and sturgeon Acipenser possess otoliths and otoconia that overlie the maculae of the end organs (Popper and Northcutt 1983; Mathiesen and Popper 1987; Lychakov 1995).

In contrast to teleosts, these fishes show considerable diversity of the macula lagenae, mainly with regard to its overall shape (Popper 1978; Popper and Northcutt 1983; Mathiesen and Popper 1987; Lovell et al. 2005b) (Fig. 3). The macula lagenae is almost as large as or even larger than the macula sacculi (except in Amia), which contrasts the condition found in many teleost species (Platt and Popper 1981a; Ladich and Popper 2004). The two main orientation groups on the macula lagenae are similar to those seen in teleosts with the exceptions of Amia, which exhibits a striola-like region that resembles that of utricular maculae (Popper and Northcutt 1983), and Lepisosteus osseus displaying a tripartite orientation pattern (Mathiesen and Popper 1987). Three orientation groups are also present in some teleosts such as the elopomorph Anguilla anguilla (Mathiesen 1984) or the chaetodontid Chaetodon miliaris (Popper 1977); but in these teleosts the third orientation group is restricted to a very narrow band at the posterior margin of the macula lagenae (Mathiesen and Popper 1987).

The macula sacculi is hook-shaped (Polypterus bichir) (Fig. 3a) or has a hookshaped anterior part (Fig. 3b-e). In the anterior portion, ciliary bundle orientation follows the curvature of the closest macula margin, creating horizontal groups. In Amia, the anterior portion of the macula sacculi has a distinct 3D curvature bringing the ciliary bundles in a new spatial orientation (Popper and Northcutt 1983). The macula utriculi has the typical bowl-shape and orientation pattern described in many vertebrates. The studied chondrostean species lack a lacinia, and in Acipenser the macula is half-moon shaped (Popper 1978; Popper and Northcutt 1983; Mathiesen and Popper 1987; Lovell et al. 2005b). 
a Cladistia (Polypterus bichir)
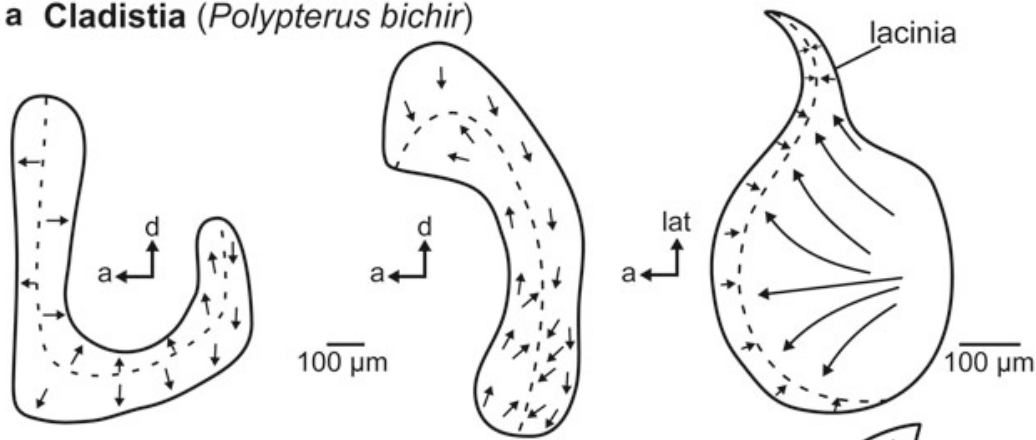

b Chondrostei (Scaphirhynchus platorynchus)

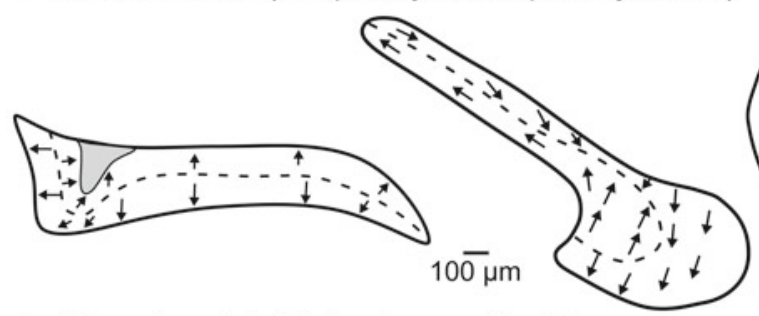

c Chondrostei (Polyodon spathula)
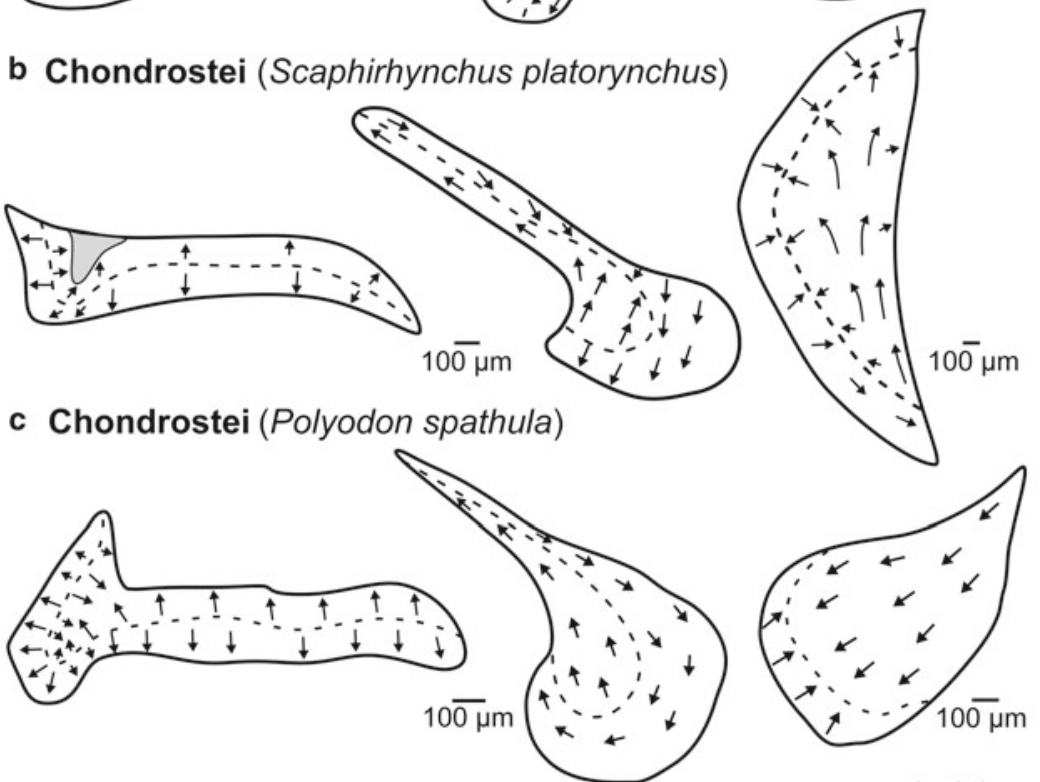

d Holostei (Amia calva)

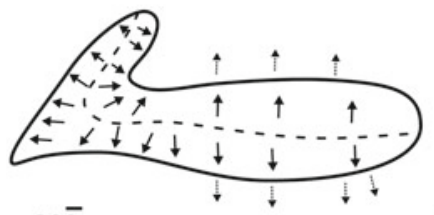

$$
20 \overline{0} \mu \mathrm{m}
$$
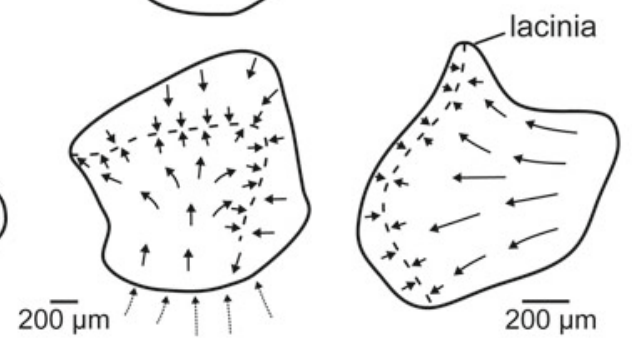

e Holostei (Lepisosteus osseus)
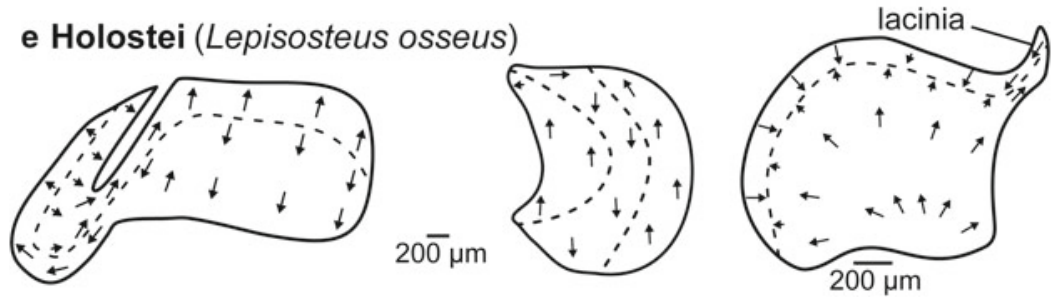
It is noteworthy that the inner ears in Amia and Lepisosteus are very similar (Mathiesen and Popper 1987) and that the taxon "Holostei," comprising bowfins and gars, has recently been re-erected and confirmed by molecular analyses (Betancur-R. et al. 2013; Broughton et al. 2013).

So far, hearing abilities were evaluated for two chondrostean species, the paddlefish Polyodon spathula and the lake sturgeon Acipenser fulvescens (Lovell et al. 2005b). Both species detected sounds between 100 and $500 \mathrm{~Hz}$. Audiograms indicate - although given in sound pressure units - that these fishes are most likely only particle motion sensitive (Ladich and Fay 2013) and that they lack ancillary auditory structures.

\subsection{Teleostei}

In most teleosts, saccule and lagena are located in two pouches that communicate via a more or less wide opening. A macula neglecta is present in some species (for details and references see Table 2). The macula of the end organs are overlain by massive calcium carbonate biomineralisates, the otoliths that appose material according to a daily rhythm (Pannella 1971). The simultaneous presence of otoconia has been reported in only a few species (Gauldie et al. 1986b).

\subsubsection{Basal Teleosts: Elopomorpha and Osteoglossomorpha}

Within elopomorph fishes (Anguillliformes, Notacanthiformes, Elopiformes), ciliary bundle orientation patterns on the macula sacculi are rather uniform, displaying the alternating pattern that is characterized by three horizontal groups in the anterior macula portion (Popper 1979, 1981; Mathiesen 1984; Buran et al. 2005). More variability of orientation patterns is found on the macula lagenae, especially in deep-sea species (Buran et al. 2005). In some members such as species of the genus Elops, anterior swim bladder extensions approach the ears; despite the swim bladder modification, the macula sacculi in E. hawaiensis did not show any deviations from the alternating pattern (Popper 1981).

Fig. 3 Macula sacculi (left column), macula lagenae (middle column), and macula utriculi (right column) in non-teleost actinopterygians. These fish show a considerable diversity in shape and ciliary bundle orientation patterns of the macula lagenae. The macula sacculi is completely curved (Polypterus bichir) or at least the anterior part is hook-shaped; in the anterior portion of the macula sacculi, ciliary bundle orientation follows the closest macula margin. The macula utriculi is similar to that found in teleosts; however, the macula utriculi of Scaphirhynchus platorynchus displays a half-moon shape and a slightly deviating ciliary bundle orientation pattern. The shaded grey area in (b) indicates a special area of supporting cells. Note that the orientation of the macula utriculi in (c) does not necessarily correspond to that of the other maculae utriculi in this figure because the orientation was not clearly indicated in the original publication (Lovell et al. 2005b). Arrows around the maculae in (d) indicate the orientation of ciliary bundles in regions with low densities of sensory hair cells. All illustrations were redrawn from Lovell et al. (2005b), Mathiesen and Popper (1987), Popper (1978), and Popper and Northcutt (1983). $a$ anterior, $d$ dorsal, lat lateral 
In contrast to Elopomorpha, osteoglossiform fishes display a considerable variability in inner ear morphology and hearing abilities. Mormyridae and Notopteridae possess ancillary auditory structures. Mormyrids have intracranial gas bladders - parts of the swim bladder that become isolated from the main swim bladder during ontogenetic development - that contact the saccule (Stipetic 1939; Braun and Grande 2008). In Notopteridae, anterior projections of the swim bladder abut the skull in the region of the saccule (Coombs and Popper 1982). Both groups have highly modified ears, i.e. the vertical pattern of the macula sacculi in mormyrids (Fig. 4a) and a complex trilobate macula sacculi with a modified alternating pattern in the Clown knifefish Chitala chitala (Notopteridae; Fig. 5a). Nonetheless, the hearing improvement is more distinct in mormyrids than in $C$. chitala. Mormyrids are sound pressure sensitive and detect sounds up to several kilohertz (Brienomyrus brachyistius: 100-4000 Hz, Yan and Curtsinger 2000; Gnathonemus petersii: 100$2500 \mathrm{~Hz}$, McCormick and Popper 1984), whereas C. chitala detects sounds only up to $1000 \mathrm{~Hz}$ (Coombs and Popper 1982).

Osteoglossiforms without ancillary auditory structures have either a standard (Osteoglossum bicirrhosum, Osteoglossidae) or an alternating pattern (Pantodon buchholzi, Pantodontidae) on the macula sacculi (Coombs and Popper 1980; Popper 1981); they have limited hearing abilities, detecting frequencies up to $500 \mathrm{~Hz}(O$. bicirrhosum) (Coombs and Popper 1980)

\subsubsection{Otomorpha (Clupeiformes; Anotophysa + Otophysa)}

All clupeiform fishes are characterized by swim bladder extensions that form two intracranial parts enveloped by bone, namely the pterotic and prootic bullae. The membrane of the gas-filled part of the prootic bulla is connected to the middle part of the macula utriculi (=macula media) via a thread-like suspension (Wohlfahrt 1936; O'Connell 1955; Blaxter et al. 1981; Higgs et al. 2004; Wilson et al. 2009). The unique tripartite macula utriculi (Fig. 4c) (Popper and Platt 1979; Platt and Popper 1981b; Higgs et al. 2004) is in part (middle and posterior macula) overlain by a highly modified utricular otolith (Wohlfahrt 1936; O'Connell 1955). This otolith has a tetrahedral shape and thin extensions in anterolateral and ventral directions instead of the "stone-like" appearance present in most teleosts (Wohlfahrt

Fig. 4 (continued) Within otophysans the maculae and their orientation patterns show low variability; ariid catfishes, however, are characterized by a unique elongate instead of bowl-shaped macula utriculi, forming an equatorial band curving around the large utricular otolith. Note that the macula utriculi is figured below the macula sacculi and macula lagenae. No ventral part of the macula utriculi is found in this group. All clupeiform fishes possess a highly modified tripartite macula utriculi, whereas macula sacculi and macula lagenae are similar to those in teleosts without ancillary auditory structures. From left to right: macula sacculi, macula lagenae, macula utriculi. Note that in (a) only the macula sacculi and macula lagenae are shown. All illustrations are redrawn from Ladich and Popper (2001), Platt (1977), Platt and Popper (1981b), Popper (1981), Popper and Platt (1979), and Popper and Tavolga (1981). The schematic fish illustrations are modified from Ladich, this volume. $a$ anterior, $d$ dorsal, lat lateral 


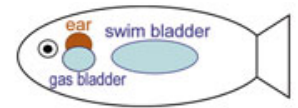

a Osteoglossiformes, Mormyridae (Gnathonemus sp.)

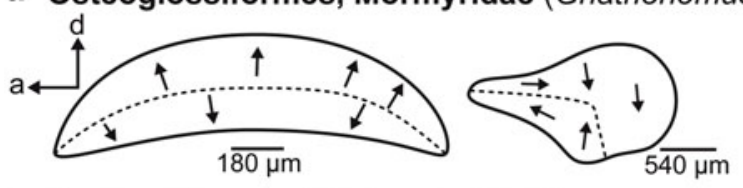

b Anabantiformes (Trichopsis vittata)

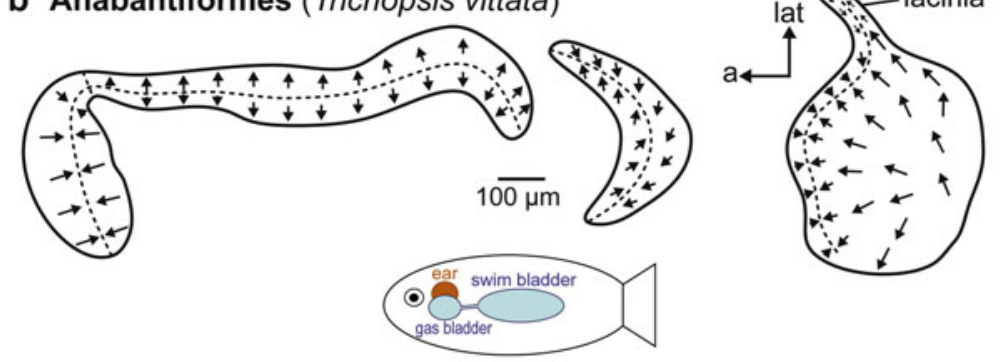

c Clupeiformes (Sardinella marquensis, Clupea pallasi pallasi)
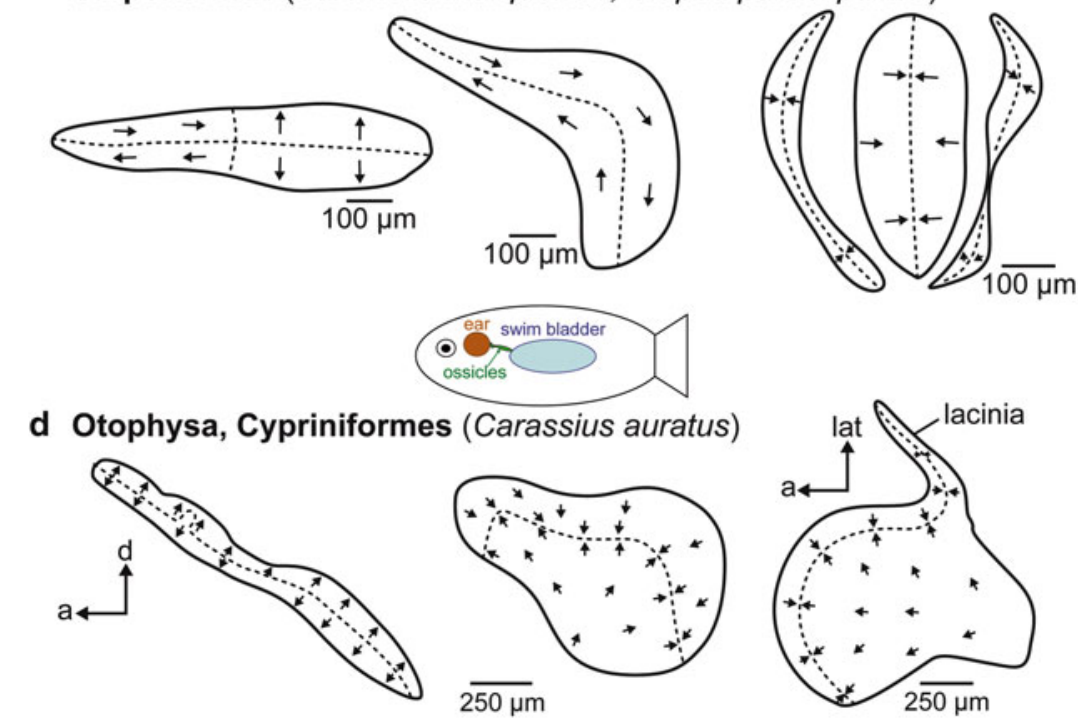

e Otophysa, Siluriformes, Ariidae (Ariopsis felis)

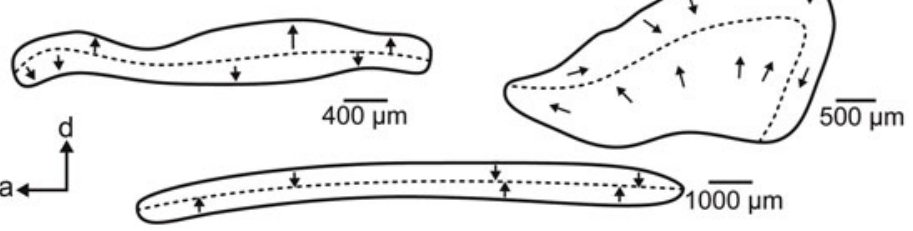

Fig. 4 Ciliary bundle orientation patterns on maculae in teleosts with ancillary auditory structures. (a, b) Gas bladders close to the ears. (c) Ears are contacted by intracranial gas bladders that in turn are connected to the swim bladder. (d, e) fishes with a Weberian apparatus (otophysans). 
1936; Assis 2005). In addition, clupeiforms possess a laterophysic connection (Wohlfahrt 1936; Wilson et al. 2009). The macula sacculi shows the standard orientation pattern of ciliary bundles consisting of two horizontal groups in the anterior part and two vertical groups in the posterior portion (Fig. 4c); the macula lagenae has a crescent shape and two orientation groups (Fig. 4c) (Platt and Popper 1981b).

All clupeiforms are sound pressure sensitive, detecting sounds up to at least $4000 \mathrm{~Hz}$ (Mann et al. 2001). Members of the subfamily Alosinae (Alosa sapidissima, Brevoortia patronus) were shown to detect ultrasound with frequencies up to $180 \mathrm{kHz}$ (Mann et al. 1997, 1998, 2001). It was hypothesized that the differently developed suspension of the middle part of the macula utriculi to the acoustic bulla (Higgs et al. 2004) and/or differences in the laterophysic connection in species with and without ultrasound detection (Wilson et al. 2009) account for ultrasound hearing. Avoidance of echolocating predators (dolphins, toothed whales) might have triggered the evolution of ultrasound detection (see Popper et al. 2004).

Otophysans are all characterized by the otophysic connection mediated via the Weberian apparatus (one up to four Weberian ossicles and interossicular ligaments) (Weber 1819, 1820). The Weberian apparatus connects the swim bladder with a special perilymphatic space, the sinus impar itself contacting the transverse canal; the transverse canal connects left and right saccules (Wohlfahrt 1932; von Frisch 1936). The lagena in otophysans is round and larger than the elongate saccule (Fig. 1a). The macula sacculi shows the vertical pattern of ciliary bundle orientation (Fig. 4d, e) (Popper and Platt 1983). The saccular otolith in otophysans is needlelike, generally carrying several thin flutes; the lagenar otolith is large and round (Adams 1940; Assis 2003). Otophysans have highly improved hearing abilities with a wide hearing bandwidth up to several $\mathrm{kHz}$ and high auditory sensitivities (for an overview of acoustical studies on otophysans see Fay 1988; Ladich and Fay 2013; Ladich 2014a; Ladich, this volume).

Although inner ears including ciliary bundle orientation patterns are rather uniform and hardly variable throughout the otophysans, some catfishes show deviations from the vertical pattern on the macula sacculi. Jenkins described four vertical groups in the anterior portion of the macula sacculi in aspredinid and doradid species (Jenkins 1974, 1979b). Moreover, ariid catfishes possess a highly modified utricle with a large utricular otolith and a macula utriculi curving around the otolith like an equatorial band whereas the ventral part of the maculi utriculi-typical of most vertebrate utricles-is absent (Fig. 4e). This modification was discussed in light of high auditory sensitivities in the low frequency range (Popper and Tavolga 1981), but could not be confirmed in another study comparing hearing abilities of catfishes (Lechner and Ladich 2008).

Anotophysa - the sister group of the otophysans within Ostariophysi-lack a Weberian apparatus, but have a Weberian-like (protoweberian) structure that consists of a special arrangement of ribs, muscles, and connective tissue (Rosen and Greenwood 1970; Fink and Fink 1996). The ear of the milkfish Chanos chanos resembles that of non-otophysans, with a saccule larger than the lagena, a large and robust saccular otolith, and a standard pattern of ciliary bundles on the macula sacculi. The round form of the lagena and the rather large macula lagenae have affini- 
ties to the lagena in otophysans (Popper and Platt 1983). So far, no data about the hearing abilities of anotophysans are available (Fay 1988; Ladich and Fay 2013).

\subsubsection{Euteleostomorpha}

Euteleostomorpha comprise numerous teleost orders that show considerable diversity in gross inner ear morphology. In Gobiiformes (Fig. 1c; Fig. 6d) and Batrachoidiformes the saccule is much larger than the other two otolithic end organs and the semicircular canals run around the saccule rather than being located dorsally to it. Cyprinodontiform fishes (e.g., poeciliids) (Fig. 1b) and Oryzias latipes (Beloniformes) possess a utricle that is directly connected to the anterior portion of the saccule (Froese 1938; Noro et al. 2007; Schulz-Mirbach et al. 2011), whereas in most other bony fishes the utricle is located anterodorsally to the saccule. Further gross morphological variation is found in sea horses (Syngnathidae, Syngnathiformes). They have "compact" ears with almost rectangular instead of rounded semicircular canals (Retzius 1881). Moreover, several unrelated species of flying fishes (Dactylopterus volitans, Dactylopteridae, Syngnathiformes; Exocoetus volitans, Beloniformes) show distinctly large semicircular canals and extremely small otolithic end organs (Retzius 1881; Froese 1938). Large semicircular canals are also present in Lophius piscatorius (Lophiiformes) and Eutrigla gurnardus (Perciformes; Fig. 1e) (Retzius 1881). The functional meaning of these enlarged semicircular canals remains to be studied.

Among the euteleostomorph fishes, several groups include deep-sea fishes like the Myctophidae (Myctophiformes), Bregmacerotidae, Macrouridae, Moridae, and Gadidae (all four families belong to the Gadiformes), Melamphaidae (Beryciformes), Opisthoproctidae (Argentiniformes), Gonostomatidae (Stomaitiformes), Melanocetidae (Lophiiformes), or Holocentridae (Holocentriformes). Ears of deepsea fishes show some of the most remarkable modifications, especially with respect to the maculae (Popper 1977, 1980; Deng 2009; Deng et al. 2011, 2013). Several species are marked by distinctly long ciliary bundles (Melamphaidae; Antimora rostrata, Moridae) (Deng et al. 2011, 2013), special fields of supporting cells (Melamphaidae; Myctophidae; Opistoproctus soleatus; Gonostomus elongatum; Melanocetus johnsonii; Myripristis, Holocentridae) (Popper 1977, 1980; Deng et al. 2011, 2013) (Fig. 5c) and complex orientation patterns on the macula sacculi (e.g., Antimora rostrata; Myripristis) (Fig. 5b, c). Some species also possess anterior swim bladder extensions, for example Antimora rostrata and species of the genus Myripristis (Nelson 1955; Deng et al. 2011). Except for the improved hearing in several reef-associated holocentrids such as Sargocentron xantherythrum (formerly Adioryx xantherythrus) and Myripristis kuntee (Coombs and Popper 1979; see overviews in Hawkins 1993 and Ladich, this volume), the effects of these inner ear modifications are unknown because auditory abilities of deep-sea fishes cannot be measured under lab conditions. It is assumed that long ciliary bundles enhance the ability to detect the low frequencies that probably play a certain role in the deepsea; improvements of the vestibular sense and adaptations to the high water pres- 


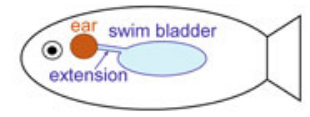

a Osteoglossiformes, Notopteridae (Chitala chitala)

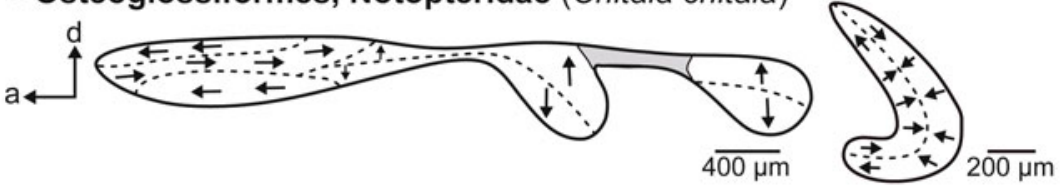

b Gadiformes, Moridae (Antimora rostrata)

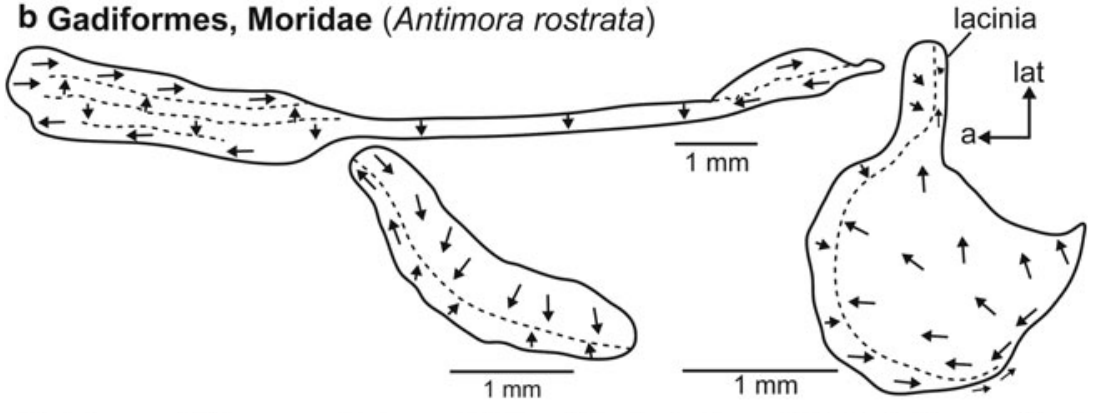

c Holocentriformes, Holocentridae, Myripristinae (Myripristis murdjan)

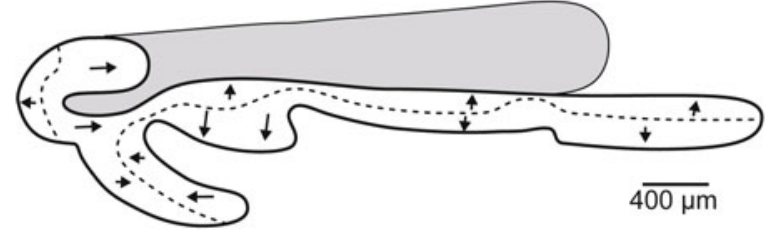

d Incertae sedis, Sciaenidae (Bairdiella chrysoura)
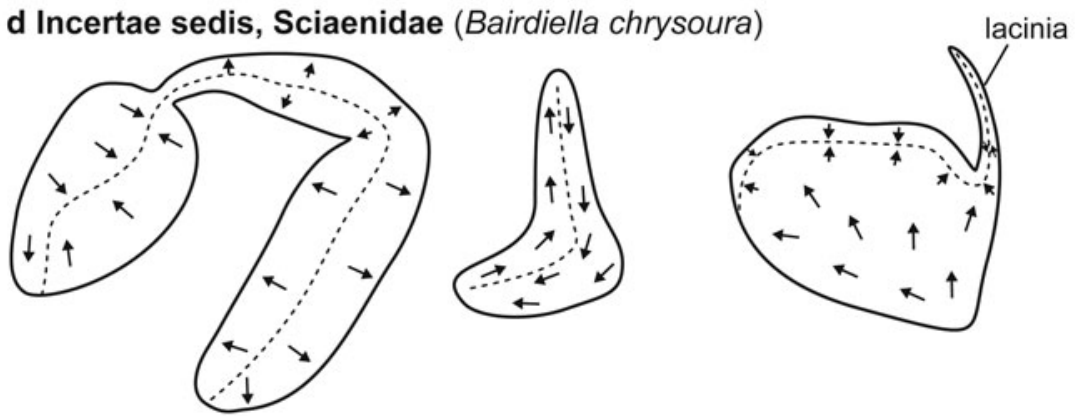

\section{e Incertae sedis, Sciaenidae} Micropogonias undulates
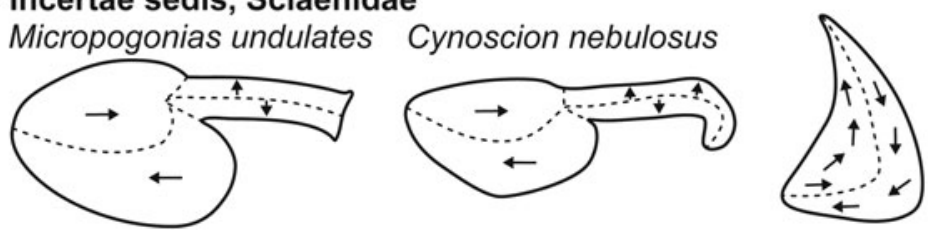
sure have also been discussed in this context (for a comprehensive overview of the potential interpretation, see the discussions in Deng et al. 2011, 2013).

In several additional groups of euteleostomorph fishes, ancillary auditory structures evolved. Anabantiformes (labyrinth fishes) possess suprabranchial airbreathing organs that are located close to the saccules. The macula sacculi shows the opposing pattern of ciliary bundle orientation, while the maculae utriculi and lagenae have "standard" patterns (Fig. 4b). These fishes have improved auditory abilities, detecting frequencies up to $4 \mathrm{kHz}$ (Schneider 1942; Ladich and Yan 1998). In this group, it is assumed that the ancillary auditory structures primarily evolved for air-breathing, enabling the fish to inhabit freshwaters with low oxygen concentrations, and that improved hearing was a by-product of this development (Ladich and Popper 2001).

Members of the Etroplinae (Cichliformes, Cichlidae) and some members of the Sciaenidae (Micropogonias undulates, Cynoscion nebulosus, Bairdiella chrysoura; order incertae sedis) and Chaetodontidae (genus Chaetodon; Chaetodontiformes) display anterior swim bladder extensions approaching or contacting the ears (Ramcharitar et al. 2001; Webb et al. 2001; Ramcharitar et al. 2004; Webb et al. 2006; Braun et al. 2012; Schulz-Mirbach et al. 2013). In sciaenids these modifications are either associated with changed inner ear morphology as in B. chrysoura (large otoliths, opposing instead of standard pattern on the macula sacculi, 3D curvature of the macula sacculi) (Fig. 5d) or do not reveal significant deviations (see $M$. undulates and C. nebulosus) (Fig. 5e) from ears in species without ancillary auditory structures (Ramcharitar et al. 2001, 2004). In the genus Chaetodon, ears do not display distinct modifications; the maculae sacculi, utriculi, and lagenae show "standard" patterns (like those shown in Fig. 6) (Webb et al. 2010). In contrast, ears in the cichlid Etroplus maculatus display a modified shape, orientation, and 3D curvature of the macula lagenae and a large lacinia of the macula utriculi with a pronounced 3D curvature (Schulz-Mirbach et al. 2014). The orientation patterns on artificially flattened maculae (all three macula types) were similar (Schulz-Mirbach et al. 2014) to those in other cichlids such as Sarotherodon melanotheron and Andinoacara pulcher (Popper 1977) without anterior swim bladder extensions (Fig. 7a vs. b-d). Distinctly improved hearing in terms of a broader hearing

Fig. 5 Ciliary bundle orientation patterns on maculae in teleosts with anterior swim bladder extensions. While all members of Notopteridae and Moridae apparently possess swim bladder extensions, only Myripristinae within Holocentridae and some sciaenid species have these ancillary auditory structures (Braun and Grande 2008; Deng et al. 2011). In (b) and (d) all three macula types are shown. (a) Macula sacculi and macula lagenae; (c) macula sacculi; (e) maculae sacculi from Micropogonias undulates and Cynoscion nebulosus, respectively, and macula lagenae with similar morphology in both species. Shaded grey areas in (a) and (c) indicate special fields of supporting cells. For the maculae in (d) and (e) no scale bars were indicated in the original publications (Ramcharitar et al. 2001, 2004). All illustration are redrawn from Coombs and Popper (1982), Deng et al. (2011), Popper (1977), and Ramcharitar et al. (2001, 2004). The schematic fish illustration is modified from Ladich, this volume. $a$ anterior, $d$, dorsal lat lateral 


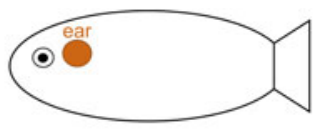

a „Pleuronectiformes“ (Psettodes erumi)
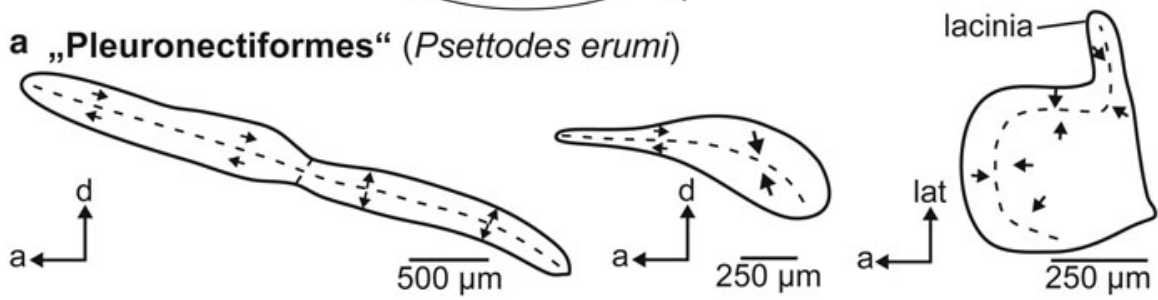

b Salmoniformes

(Salmo salar, Salvelinus namaycush)
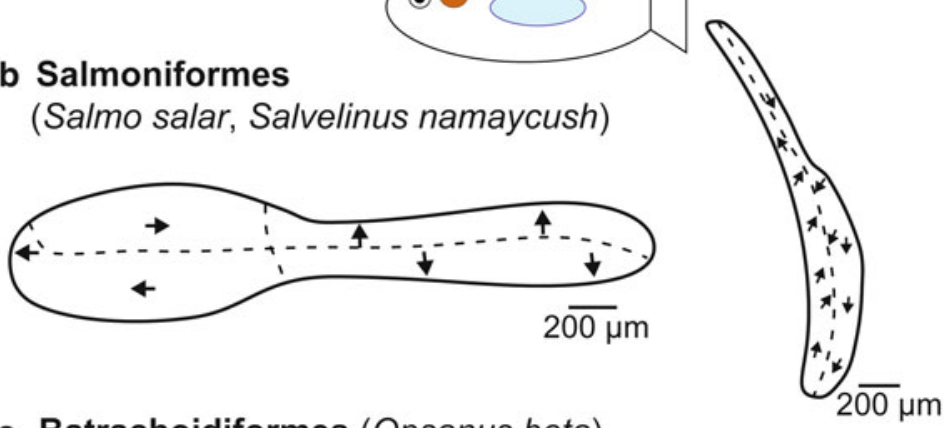

c Batrachoidiformes (Opsanus beta)
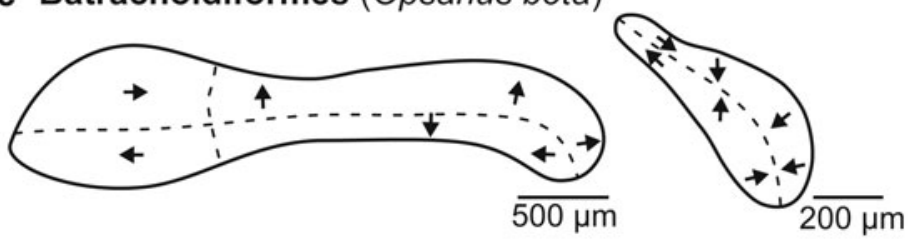

d Gobiiformes (Dormitator latifrons)
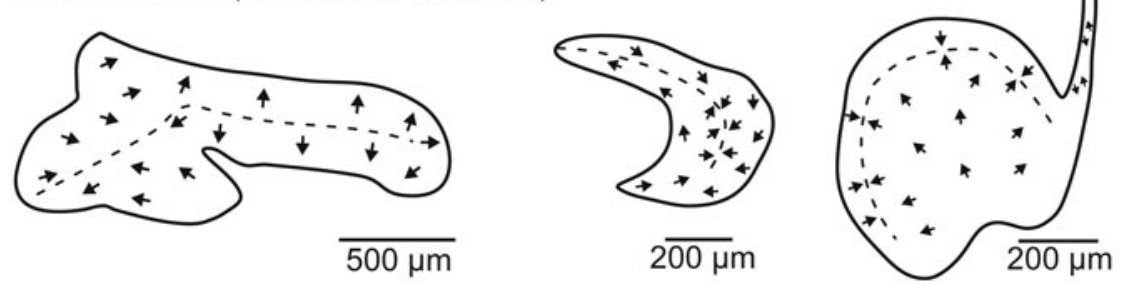

Fig. 6 Ciliary bundle orientation patterns on maculae in teleosts without swim bladder (a) or ancillary auditory structures (b-d). In (a) and (d) all three macula types are shown (from left to right: macula sacculi, macula lagenae, macula utriculi), whereas in $(\mathbf{b}, \mathbf{c})$ only the macula sacculi and macula lagenae are illustrated. Species lacking ancillary auditory structures or even swim bladders either display the standard $(\mathbf{a}, \mathbf{b})$ or the dual pattern $(\mathbf{c}, \mathbf{d})$ on the macula sacculi. All illustrations are redrawn from Lu and Popper (1998), Platt (1983) and Popper (1977, 1981). The schematic fish illustrations are modified from Ladich, this volume. $a$ anterior, $d$ dorsal, lat lateral 


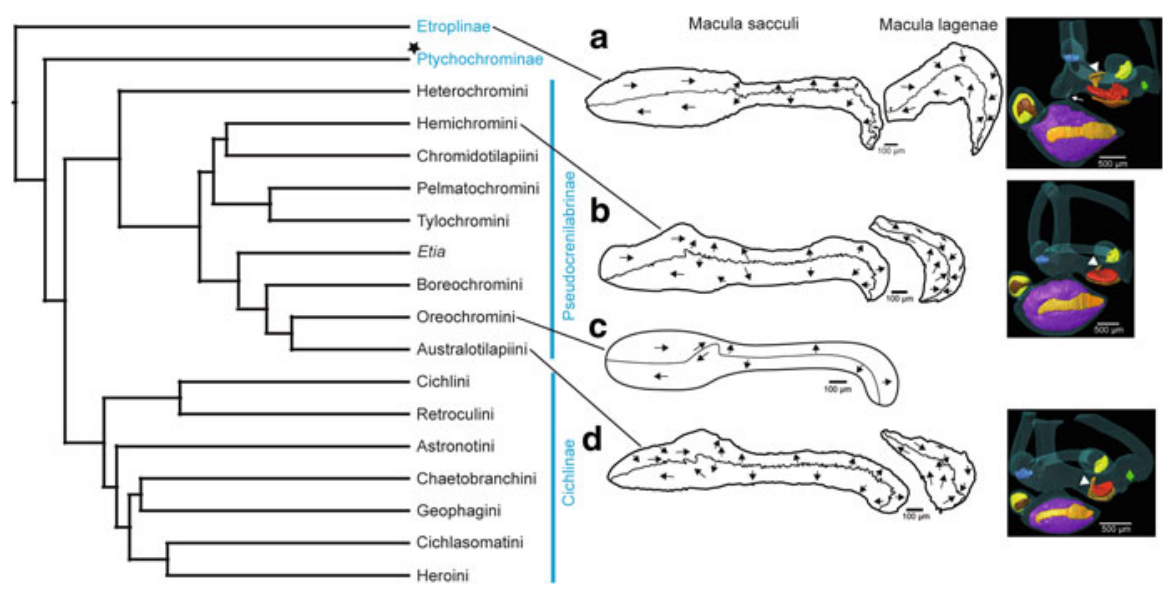

Fig. 7 Inner ear morphology and maculae in cichlids related to their phylogenetic position (according to McMahan et al. 2013). Despite great diversity of swim bladder morphology in cichlids (see Schulz-Mirbach et al. 2012), orientation patterns of ciliary bundles on the macula sacculi are similar in Etroplinae (possessing ancillary auditory structures), Pseudocrenilabrinae and Cichlinae (maculae of Andinoacara pulcher were described by Popper 1977). In contrast, the macula lagenae is distinctly different in Etroplinae compared to that in members of Pseudocrenilabrinae and Cichlinae; in Etroplinae, the anterior arm of the macula lagenae is oriented anteriorly instead of anterodorsally and shows a distinct 3D curvature. Differences between Etroplinae and Pseudocrenilabrinae and Cichlinae were also observed for the lacinia of the macula utriculi (white arrowheads) and gross inner ear morphology. No data on maculae are yet available for any member of the subfamily Ptychochrominae (black asterisk). (a) Etroplus maculatus; (b) Hemichromis guttatus; (c) Sarotherodon melanotheron; (d) Steatocranus tinanti. The white arrow highlights the extremely thin connection between saccule and upper inner ear in Etroplus. Illustrations of maculae and 3D images of inner ears originate from Popper (1977) and SchulzMirbach et al. (2014). Drawings of maculae and 3D reconstructions of inner ears are shown from medial view with anterior to the left. 3D ears, color code: yellow, lagenar otolith; brown, macula lagenae; purple, saccular otolith; light orange, macula sacculi; red, utricular otolith; light brown, macula utriculi; cristae are shown in blue, light yellow, and green (from posterior to anterior)

bandwidth and higher auditory sensitivities was shown for the sciaenid B. chrysoura and the cichlids E. maculatus and Paratilapia polleni (Ramcharitar et al. 2004; Schulz-Mirbach et al. 2012).

\section{Evolution of Ciliary Bundle Orientation Patterns}

What was the ancestral state in the teleostean macula sacculi: the vertical pattern or a pattern with vertical and horizontal groups? Tetrapods have only two "vertical" groups on the macula sacculi and this may also hold true for non-teleost actinopterygians as well as lungfishes: the horizontal groups in these fishes are 
classified to be no "true" horizontal groups because originally vertically oriented ciliary bundles simply follow the curvature of the closest macula margin, gradually leading to an increased horizontal-like orientation (Popper and Platt 1983) (Fig. 3). Popper and Platt then discussed two alternative hypotheses. First, the vertical pattern is an ancestral pattern that was retained in otophysans and mormyrids, whereas in the remaining teleosts true horizontal groups evolved at least seven times independently. The second scenario assumes that the ancestral teleost condition is the pattern including vertical and horizontal groups and that horizontal groups were lost twice, in otophysans and mormyrids. If the second hypothesis applies - which is the more parsimonious one-the vertical pattern in otophysans and mormyrids may have convergently evolved due to similar selection pressures (Popper and Platt 1983).

The vertical pattern is the constant element in each of the five different orientation patterns on the macula sacculi in teleosts (Popper 1981) (Fig. 2), and the vertical pattern is also found in Dipnotetrapodomorpha, non-teleost actinopterygians (see above), and Chondrichthyes (Popper and Fay 1977). Accordingly, it may further be assumed that the vertical pattern on the macula sacculi is the basic vertebrate pattern on this sensory epithelium (Mathiesen and Popper 1987), which did not experience diversification before the emergence and diversification of the teleosts.

The five orientation groups can be derived from one another if one either adds two or three horizontal groups to the vertical pattern (resulting in the standard or the alternating pattern) or removing the horizontal groups, leading to the vertical pattern (Fig. 2). From the standard pattern (1) the dual pattern can be obtained by adding two horizontal groups in the posterior portion and (2) the opposing pattern can be created by bending the anterior macula downwards in ventral direction while ciliary bundles retain their horizontal orientation in this area. Alternatively, the standard pattern can emerge from an alternating pattern when one (the most anterodorsal) horizontal group is lost. Only genetic studies could unravel how orientation groups form during ontogeny, leading to different orientation patterns.

Knowledge about underlying genetic processes of pattern formation is increasing (Duncan and Fritzsch 2012; Sienknecht et al. 2014) and is likely to shed new light on the evolution of different orientation patterns in different lineages. Comparative studies of transcription patterns of candidate genes during ontogenetic development of maculae in related species with and without ancillary auditory structures and in non-teleost actinopterygians and teleosts could enlighten whether and to what extent genetic pathways of ciliary bundle orientation pattern formation differ. This approach would also provide information on how genes involved in pattern formation evolved in different species and more generally in actinopterygians. Such studies could use two model organisms as starting points, making use of the profound knowledge of the genetic background in Danio rerio (Whitfield et al. 1996, 2002; Nicolson 2005), an otophysan with a vertical pattern on the macula sacculi, and Oryzias latipes (Hochmann et al. 2007), a non-otophysan that very likely displays the standard pattern. 


\section{Do Modifications of Inner Ear Morphology Relate to Hearing Improvements?}

From a functional perspective, one might ask for the physiological meaning of the "invention" of horizontal orientation groups of ciliary bundles on the macula sacculi. The combination of vertical and horizontal groups was explained as an adaptation for localizing sound sources, independently achieved by ciliary bundles that follow the curvature of the macula in non-teleost actinopterygians and lungfishes or the "invention" of true horizontal groups in teleosts (Platt and Popper 1981a; Popper and Northcutt 1983). Experimental data indicate that differently oriented ciliary bundles are stimulated to different degrees depending on the location of the sound source, i.e. the angle between ciliary bundle orientation and the direction of the acoustic stimuli (Lu et al. 1998).

But how do otophysans and mormyrids that possess only vertical groups on the macula sacculi infer directional clues? A study on the goldfish indicated that also the macula lagenae and the macula utriculi detect directional information (Fay 1984). This was confirmed by detailed investigations of the non-otophysan Dormitator latifrons (Gobiiformes) which revealed a strong relationship between the orientation patterns of ciliary bundles on the macula lagenae and macula utriculi with the preferred best response axes of the afferent fibers of the lagena and the utricle (Lu et al. 2003, 2004). Large lagenae in otophysans (and possibly also in mormyrids) may thus have evolved for sound source localization, whereas the saccule is specialized to detect low-pressure sounds indicating a division of labor between these two end organs (Popper and Platt 1983). Several non-otophysans with ancillary auditory structures show a remarkable complex structuring of the macula into several distinct regions which are completely separated (see the tripartite macula utriculi in clupeiform fish, Fig. 4c) or interconnected by thin epithelial bridges (e.g., the trilobate macula sacculi in Chitala chitala, Fig. 5a or the bilobate macula sacculi in Antimora rostrata, Fig. 5b) in 2D or through a distinct 3D shape in which certain regions are out-of plane compared to the remaining macula (e.g., macula sacculi in Bairdiella chrysoura, Fig. 5d). It is tempting to speculate whether this structuring might reflect division of labor within the macula which accounts for stimulation via particle motion originating directly from the sound source vs. reradiated particle motion from the swim bladder. Future studies may tackle the questions of how and when these "separated" macula regions develop during ontogeny and whether these maculae show specialized innervation patterns. Modeling of the stimulation of the different macula regions may shed light on this distinct macula structuring.

Certain modified orientation patterns - mainly on the macula sacculi-may have evolved to enhance hearing together with ancillary auditory structures. Apparently, species with ancillary auditory structures, which mostly correlate with improved hearing (Ladich and Popper 2004; Braun and Grande 2008; Ladich and Fay 2013; Ladich 2014a), often display modified orientation patterns on the maculae, mainly on the macula sacculi (Platt and Popper 1981a). This is evident in the vertical pattern 
of otophysans and mormyrids (Fig. 4a, d, e), the opposing pattern of anabantiform fishes (Fig. 4b) or "unique" patterns (see Antimora; Fig. 5b) that cannot be assigned to one of the five patterns (Table 2). It is conceivable that the inner ear in such species and ancillary auditory structures coevolved to some degree to guarantee finetuning between these two units to improve audition.

In some cases, however, ancillary structures and modified orientation patternsdeviating from the standard or dual patterns - are present but without distinctly improved hearing compared to species that lack these accessory structures. The Clown knifefish Chitala chitala, for example, does not show an expanded hearing bandwidth or higher auditory sensitivities (Coombs and Popper 1982), and the sciaenid species Micropogonias undulates and Cynoscion nebulosus show a slightly expanded bandwidth but similar auditory sensitivities as species without anterior swim bladder extensions (Horodysky et al. 2008). Moreover, ancillary auditory structures and improved auditory abilities do not necessarily correlate with modified (more complex) orientation patterns on the maculae, as demonstrated for the Hawaiian ladyfish Elops hawaiensis (Elopidae) (Popper 1981) and the cichlid Etroplus maculatus: they have "standard" patterns on all three macula types (when analyzing artificially flattened maculae; compare Fig. 7a to Fig. 6a) (SchulzMirbach et al. 2014). A distinct 3D curvature bringing the ciliary bundles in new spatial orientation without modifications of the orientation patterns in $2 \mathrm{D}$ is present in E. maculatus. The anterior arm of its macula lagenae and the lacinia of the macula utriculi are strongly curved. The wider range of directions of ciliary bundles based on the 3D curvature-a condition also found in the macula sacculi of the silver perch Bairdiella chrysoura (Sciaenidae) - might translate into a wider range of directional stimuli being detectible, and thus may play a role in localizing sound sources (Schulz-Mirbach et al. 2014). Finally, species such as the cod Gadus morhua were shown to be pressure sensitive without any obvious morphological modifications of the auditory periphery (see Hawkins 1993); cod lacks swim bladder extensions and possesses a dual pattern on the macula sacculi. The cichlid Hemichromis guttatus seems to be another example of a species lacking morphological specializations while displaying an expanded hearing bandwidth comparable to that of E. maculatus.

Generally, more experimental data about hearing in fishes will be necessary before definitively answering questions of how inner ear morphology is linked to physiology (see Popper and Fay 2011). So far, most knowledge refers to auditory thresholds and hearing bandwidth in a variety of species (see Fay 1988; Ladich and Fay 2013). Data on frequency discrimination, tuning, and detection of directional stimuli are limited to only a few species such as Porichthys notatus, goldfish and Opsanus tau. They hardly cover the full range of inner ear diversity (Fay and EddsWalton 1997; Edds-Walton et al. 1999; Sisneros 2007; Smith et al. 2011; Zeddies et al. 2012) and thus do not allow drawing conclusions about the correlation between orientation pattern diversity and these auditory parameters. Hence, more sophisticated comparative physiological measurements are needed for a deeper understand- 
ing of modified orientation patterns, of different arrangements of maculae in 2D and 3D and of changed otolith morphology. Methodological innovations are especially important to improve auditory measurements to better disentangle the proportion of particle motion and pressure information detected by the fish at certain frequencies (Popper and Fay 2011; Ladich and Fay 2013). Despite the application of particle motion sensors or a set of hydrophones to evaluate particle motion of the sound field "during" measurements (for an overview see Fay 1988; Ladich and Fay 2013), a simple way for directly measuring particle motion and/or pressure detection in fishes is still lacking and is the main reason why clear evidence for the detection of both acoustical components is restricted to just a few species (e.g., Gadus morhua, see Hawkins 1993 and Carribean Stegastes species, Pomacentridae, Myrberg and Spires 1980).

Another aspect of inner ear diversity that is related to sensory epithelia is the morphology of the apical surface of the supporting cells and ciliary bundle morphology, i.e. bundle length and width as well as the ratio of kinocilium length to the longest stereovillus. Especially deep-sea fishes display a great variability of ciliary bundle morphology and supporting cells, with several species possessing exceptionally long ciliary bundles on certain portions of the maculae and/or special regions of supporting cells interspersed into the macula or adjacent to dorsal or ventral macula portions (see Table 2 and Fig. 5c) (Popper 1980; Deng et al. 2011, 2013). Soundexposure experiments on goldfish are suggestive of long bundles (formerly classified as F3-type, see Popper and Platt 1983) primarily detecting low frequencies (100 $\mathrm{Hz}$ ), whereas shorter bundles (formerly classified as F1-type, see Popper and Platt 1983 ) in the anterior and middle portion of the macula seem to be sensitive to higher frequencies $(\geq 800 \mathrm{~Hz}$ ) (Smith et al. 2011). Based on these studies it was assumed that deep-sea fishes are particularly sensitive to low frequencies or that long ciliary bundles also represent an adaptation to high water pressures (e.g., Deng et al. 2011). Studies in tetrapods on the relationship between ciliary bundle length and frequency (e.g., Manley 2000; Arch et al. 2012) are in accordance with those in fishes, i.e. shorter bundles are more sensitive to higher frequencies. However, further studies similar to the experiments with goldfish (Smith et al. 2011) are needed for other fish species that lack ancillary auditory structures or any gas-filled bladders. Modeling of the micromechanical behavior of different ciliary bundle types from the macula utriculi of a red-eared turtle (Trachemys (Pseudemys) scripta) indicates that the length ratio of the kinocilium $(\mathrm{K})$ compared to the tallest stereovillus $(\mathrm{S})$ influences bundle stiffness and the magnitude of tensions of the tip links (=links connecting the tips of stereovilli to each other) (Silber et al. 2004). Bundles in which the kinocilium is only slightly longer than the tallest stereovillus are stiffer and tensions of tip links are lower when the same force of deflection is exerted than in bundles with a distinctly longer kinocilium compared to the tallest stereovillus. Ciliary bundles with a large KS ratio were assumed to possess a wider operational range with respect to bundle displacement but that they have lower sensitivities to bundle displacement (Baird 1994). 


\section{Inner Ear Diversity in the Light of Phylogeny}

Modifications of inner ears and/or ancillary auditory structures might be to some extent linked to phylogenetic constraints or may represent a phylogenetic "legacy." Including a phylogenetic perspective is thus an important prerequisite to test any evolutionary hypothesis regarding the evolution of the auditory periphery and audition (e.g., Braun et al. 2012; Deng et al. 2013). A recent study by Deng et al. (2013) on the inner ear morphology of melamphaid fishes demonstrated the importance of such an approach. The melamphaid Scopelogadus mizolepis bispinosus has a simple-shaped round saccular otolith lacking the spur-like structure characterizing Melamphaes and Poromitra. Without phylogenetic background, it is tempting to speculate that the round saccular otolith in Scopelogadus represents the plesiomorphic condition. When saccular morphology is plotted on a phylogeny (based on the mitochondrial COI gene) that identifies Melamphaes and Scopelogadus to be more closely related to each other than to Poromitra, the round otolith without spur could equally be interpreted as a derived character, i.e. the spur was secondarily lost in Scopelogadus (Deng et al. 2013).

A promising model to study inner ear evolution based on a phylogenetic hypothesis is the speciose family Cichlidae, whose phylogenetic relationships have been intensively studied (Sparks and Smith 2004; Azuma et al. 2008; Sparks 2008; McMahan et al. 2013). Future studies on inner ear morphology with focus on the macula shape and ciliary bundle orientations within the cichlid genus Paretroplus, but also of the whole cichlid subfamily Ptychochrominae, would be highly interesting (Fig. 7) because a rather robust phylogeny exists for them (Sparks 2004; Sparks and Smith 2004; McMahan et al. 2013). The Ptychochrominae display different swim bladder morphologies ranging from bladders without anterior extensions (Katria) via short extensions to extensions that abut the posterior skull (Paratilapia) (Sparks 2008; Schulz-Mirbach et al. 2012). In combination with extensive ecoacoustical data from the habitats of these species (see Braun et al. 2012), this may help enlighten the evolution of the maculae and orientation patterns in this subfamily and the amount of coevolution between inner ear morphology, ancillary auditory structures and hearing abilities.

\section{What Factors May Have Influenced the Evolution of the Auditory Periphery?}

Driving factors in the evolution of the auditory periphery (here: inner ears and ancillary auditory structures) in fishes are clearly those linked to audition. Fishes may gain information from the auditory scene in their habitat that is crucial for survival (e.g., avoidance of predators) or their reproductive success (e.g., detection of vocalizing mates). Abiotic (waves, water turbulences, etc.) and biotic (predators, prey, conspecifics) sound sources, i.e. the acoustical environment, should thus play an 
important role in shaping hearing abilities and the corresponding morphological structures (ear, ancillary auditory structures) (Fay 2011; Ladich 2014a, b). Ecoacoustical hypotheses have been extensively presented and discussed elsewhere (Rogers and Cox 1988; Schellart and Popper 1992; Ladich 2014a, b) and, as this is not the focus of our review, we refer the reader to those articles. Notwithstanding the fundamental influence of the acoustical environment on inner ear and hearing evolution, other factors must also be taken into account to get a more complete picture of how the auditory periphery evolved. In the following, we briefly discuss the role of constraints other than ecological/ecoacoustical ones that potentially acted on the evolution of the inner ear.

Spatial constraints within the ear might, for example, account for modified macula shapes or 3D curvature of maculae, as seen, for example, in melamphaids and cichlids. Melamphaids are characterized by a bilobate striola region (Table 2) that was assumed to be a consequence of hampered macula growth of the striola in the region where the ampulla of the anterior semicircular canal opens into the utricle (Deng et al. 2013). A similar reason can be envisioned for the strong 3D curvatures in the macula lagenae and macula utriculi in the cichlid Etroplus maculatus. Maculae are significantly enlarged in this species when compared to other cichlid members without anterior swim bladder extensions such as Hemichromis guttatus and Steatocranus tinanti (Schulz-Mirbach et al. 2014). Enlargement of the anterior arm of the macula lagenae in 2D is limited in anterodorsal direction by the opening of the lagena into the saccule. Accordingly, the macula expansion may thus give way in anterior direction following the curvature of the anterior lagenar wall, which in turn results in a 3D curved anterior macula portion (Schulz-Mirbach et al. 2014).

An interesting topic to tackle in future research would be the question of how much phenotypic integration and modularity (inner ears and swim bladder are then seen as separate modules) (see, e.g., Wainwright 2007; Klingenberg 2008) affect the evolution of inner ear diversity and ancillary auditory structures. A study on the interactions between the modules brain, skull, jaw region, and feeding strategy in cichlids revealed a strong correlation between brain size and morphology with head morphology; the conclusion was that either spatial constraints of the skull act on brain size and morphology or that evolution of larger brains demands coevolution of brain and head (Tsuboi et al. 2014). Accordingly, trait coupling in terms of earswim bladder/gas bladder connection of initially separated modules such as the ear and the swim bladder should lead to coevolution of these structures. Coevolution, however, may restrict the diversity of possible ear and/or swim bladder modifications (see, e.g., Frédérich et al. 2014). This would potentially explain why only a limited number of different "modified" orientation patterns on the macula sacculi evolved in taxonomically unrelated species that possess ancillary auditory structures (Popper and Coombs 1982).

Developmental and genetic constraints may also influence inner ear evolution. Some of the genes responsible of inner ear development are also involved in fundamental processes during ontogenetic development. Several mutants in the zebrafish display mutations in the inner ear that are associated with the absence of the swim bladder, brain and heart defects or skull deformations (Malicki et al. 1996; Schibler 
and Malicki 2007). Certain mutations that would result in new, modified and possibly "more optimized" ear morphologies may negatively affect other structures for survival and thus could not be realized in a living animal. This, in turn, would mean that again only a limited number of ear modifications are possible.

Finally, sensory trade-offs may be important when fishes inhabit extreme habitats such as the deep-sea, characterized by perpetual darkness and food scarcity. Depending on the mode of life, i.e. as scavenger, predator on large (e.g., other fishes) or small prey (e.g., plankton), different senses like olfaction and gustation in a scavenger, enlarged eyes, or improved audition may compensate for the lack of visual input. In macrourid species, Deng (2009) found smaller maculae in the species still primarily relying on vision, whereas the only vocal species studied showed a large macula sacculi and saccular otolith. These findings could be interpreted as sensory trade-offs in which one sense is improved at the cost of another due to energy limitation (Deng 2009).

\section{Conclusions and Outlook}

Inner ear diversity of bony fishes may partly be linked to the presence of ancillary auditory structures; but phylogenetic relationships or adaptation to extreme ecological conditions as found in deep-sea habitats or the ecoacoustical environment may also have contributed to this diversity. Selective forces or constraints acting on inner ear evolution are still poorly understood. This paucity of knowledge is evident when trying to explain the potential functional role and evolution of the different orientation patterns on the macula sacculi. Although it is very likely that this diversity of orientation patterns serves in audition, we have insufficient data to infer which auditory functions (e.g., sound localization) are facilitated by which pattern type. It is also possible that the same or similar auditory tasks are enabled by different pattern types. Certain pattern types or variation in ciliary bundle morphology may also be linked to (1) different ecological conditions such as high water pressures in the deep sea or the ability to detect faint noise in a quiet water body or (2) to solve different tasks in sound communication (short-range vs. long-range communication or sound detection). Despite the diversity of the auditory periphery, the currently available data point to only a limited number of morphological modifications that result in hearing enhancement; this is reflected in the "only" five orientation patterns on the macula sacculi, of which the vertical, the opposing and modifications of the alternating patterns can be assigned to improved audition. Different selective pressures may have favored either the "vertical pattern" or certain patterns combining horizontal and vertical orientation groups.

Future research should focus on:

1. Evaluating the differences in ear morphology of (closely related) species with and without ancillary auditory structures, especially with regard to shape, curva- 
ture of the macula and the orientation patterns of ciliary bundles (Ramcharitar et al. 2001; Schulz-Mirbach et al. 2014). The ontogenetic development of the ear, ancillary auditory structures and audition of such (closely related) species is an additional promising field of study.

2. Development and application of physiological/experimental measurements with respect to hearing abilities other than bandwidth and sensitivity and of inner ear physiology in general. Moreover, more studies on closely related species (differing in ancillary auditory structures) are needed to relate inner ear morphology to (1) directional responses of different hair cell orientations (e.g., Lu and Popper 2001), (2) the ability of sound source localization, and (3) potential tonotopic frequency selectivity (e.g., Smith et al. 2011). It is important that these comparative studies also incorporate a phylogenetic approach to disentangle which inner ear characters and certain auditory abilities are plesiomorphic and which are more apomorphic.

3. The genetic background especially regarding the formation of differently oriented ciliary bundle groups on the maculae (Sienknecht 2013; Sienknecht et al. 2014) and the genetic control of the development of inner ears and ancillary auditory structures which may exert constraints on inner ear variability.

4. Evaluating the amount of coevolution of sound production and inner ear morphology in vocal species as indicated by seasonal plasticity in the number of sensory hair cells in females of the plainfin midshipman or large saccular otoliths in some ophidiiform species or Nezumia aequalis (Parmentier et al. 2001; Deng 2009; Sisneros 2009; Coffin et al. 2012; Kéver et al. 2014).

5. The role of natural ambient noise on the evolution of hearing abilities and inner ear morphology by (1) measuring ambient noise levels in the field and testing whether hearing abilities of species living in the respective habitats can be correlated with these ambient noise levels (Amoser and Ladich 2005; Ladich 2014a) and (2) evaluating the contribution of inner ears/inner ear components to auditory tasks like auditory scene analysis or short range vs. long range sound detection.

6. "Comparative" modeling (Finneran and Hastings 2000; Rodgers and Rogers 2011; Krysl et al. 2012) of the movement of inner ear components and accessory structures based on 3D models of species with and without ancillary auditory structures. Cichlids may provide a suitable model for such investigations. A better understanding of the mechanical interactions of inner ear components and ancillary auditory structures may provide the basis for testing adaptive vs. nonadaptive evolutionary hypotheses.

7. In vivo measurements of the movement of the different parts of the auditory periphery, i.e. of the otolith relative to the macula, the transmission of oscillation of gas-filled bladders to the surrounding tissue, skull bone, perilymphatic spaces, or the endolymph. This would be indispensable for a better functional morphological understanding (Sand and Michelsen 1978; Finneran and Hastings 2000; Chen et al. 2011). 
Acknowledgements This review is dedicated to Arthur N. Popper and Richard R. Fay to celebrate more than 40 years of their influential work in fish bioacoustics. The second author is grateful for having had the opportunity to work with Art in his lab in the late 1990s on inner ears of labyrinth fishes and in this way became introduced into the field of inner ear structure in fishes. The first author was fundamentally inspired by Art's early studies on cave-dwelling forms of the Mexican tetra Astyanax mexicanus and his numerous works on inner ear structures and his evolutionary hypotheses. Moreover, the first author worked in the second author's lab on inner ears, ancillary auditory structures and auditory sensitivities and thus became in some way Art's scientific "granddaughter." Art's lifelong interest in the diversity and evolution of fish inner ears and hearing is continued by us and by others. Our current review, largely based on Art's work of almost 50 years, summarizes this diversity and highlights open questions and inspiring approaches that might lead to novel and deeper insights into this challenging and highly interesting field of research.

We are also grateful to Michael Stachowitsch for scientific English proof-reading and two anonymous reviewers for their constructive comments on an earlier version of this chapter.

\section{References}

Adams LA (1940) Some characteristics otoliths of American Ostariophysi. J Morphol 66:497-527

Amoser S, Ladich F (2005) Are hearing sensitivities of freshwater fish adapted to the ambient noise in their habitats? J Exp Biol 208(18):3533-3542

Arch VS, Simmons DD, Quiñones PM, Feng AS, Jiang J, Stuart BL, Shen J-X, Blair C, Narins PM (2012) Inner ear morphological correlates of ultrasonic hearing in frogs. Hear Res 283:70-79

Assis CA (2003) The lagenar otoliths of teleosts: their morphology and its application in species identification, phylogeny and systematics. J Fish Biol 62:1268-1295

Assis CA (2005) The utricular otoliths, lapilli, of teleosts: their morphology and relevance for species identification and systematics studies. Scientia Marina 69(2):259-273

Azuma Y, Kumazawa Y, Miya M, Mabuchi K, Nishida M (2008) Mitogenomic evaluation of the historical biogeography of cichlids toward reliable dating of teleostean divergences. BMC Evol Biol 8(215):1-13

Baird RA (1994) Comparative transduction mechanisms of hair cells in the bullfrog utriculus. II. Sensitivity and response dynamics to hair bundle displacement. J Neurophysiol 71(2):685-705

Bang PI, Sewell WF, Malicki JJ (2001) Morphology and cell type heterogeneities of the inner ear epithelia in adult and juvenile zebrafish (Danio rerio). J Comp Neurol 438(2):173-190

Bernstein P (2003) The ear region of Latimeria chalumnae: functional and evolutionary implications. Zoology 106:233-242

Best ACG, Gray JAB (1980) Morphology of the utricular recess in the sprat. J Mar Biol Assoc UK 60(3):703-715

Betancur-R. R, Broughton R, Wiley EO, Carpenter K, López JA, Li C, Holcroft NI, Arcila NI, Sanciangco M, Cureton II JC, Zhang F, Buser T, Campbell MA, Ballesteros JA, Roa-Varon A, Willis S, Borden WC, Rowley T, Reneau PC, Hough DJ, Lu G, Grande T, Arratia G, Ortí G (2013) The tree of life and a new classification of bony fishes. PLoS Currents Tree of Life

Bever MM, Fekete DM (2002) Atlas of the developing inner ear in zebrafish. Dev Dyn 223(4):536-543

Bierbaum G (1914) Untersuchungen über den Bau der Gehörorgane von Tiefseefischen. Zeitschrift für wissenschaftliche Zoologie 111(3):281-380

Blaxter JHS, Denton EJ, Gray JAB (1981) Acousticolateralis system in clupeid fishes. In: Tavolga WN, Popper AN, Fay RR (eds) Hearing and sound communication in fishes. Proceedings in life sciences. Springer, New York, pp 39-59 
Bleckmann H, Niemann U, Fritzsch B (1991) Peripheral and central aspects of the acoustic and lateral line system of a bottom dwelling catfish, Ancistrus sp. J Comp Neurol 314(3):452-466

Braun CB, Grande T (2008) Evolution of peripheral mechanisms for the enhancement of sound reception. In: Webb JF, Fay RR, Popper AN (eds) Fish bioacoustics. Springer handbook of auditory research, vol 32. Springer, New York, pp 99-144

Braun CB, Baldwin ZH, Sparks JS (2012) Diversity of auditory abilities and hearing-enhancing morphologies in Malagasy-South Asian cichlids. Paper presented at the tenth international congress of neuroethology, College Park, MD, USA, 5-10 August 2012

Broughton RE, Betancur-R. R, Li C, Arratia G, Ortí G (2013) Multi-locus phylogenetic analysis reveals the pattern and tempo of bony fish evolution. PLoS Currents Tree of Life

Buran BN, Deng XH, Popper AN (2005) Structural variation in the inner ears of four deep-sea elopomorph fishes. J Morphol 265:215-225

Burne RH (1913) Note on the membranous labyrinth of Neoceratodus forsteri. Anat Anz 43:396-400

Carlström D (1963) A crystallographic study of vertebrate otoliths. Biol Bull 125(3):441-463

Chardon M (1968) Anatomie comparée de l'appareil de Weber et des structures connexes chez les siluriformes. Annales - Musee Royal de l'Afrique centrale, Sciences Zoologiques 169:1-277

Chen F, Zha D, Fridberger A, Zheng J, Choudhury N, Jacques SL, Wang RK, Shi X, Nuttall AL (2011) A differentially amplified motion in the ear for near-threshold sound detection. Nat Neurosci 14(6):770-774

Christensen CB, Christensen-Dalsgaard J, Madsen PT (2015) Hearing of the African lungfish (Protopterus annectens) suggests underwater pressure detection and rudimentary aerial hearing in early tetrapods. J Exp Biol 218:381-387

Christensen-Dalsgaard J, Brandt C, Wilson M, Wahlberg M, Madsen PT (2011) Hearing in the African lungfish (Protopterus annectens): pre-adaptation to pressure hearing in tetrapods? Biol Lett 7(1):139-141

Coffin AB, Mohr RA, Sisneros JA (2012) Saccular-specific hair cell addition correlates with reproductive state-dependent changes in the auditory saccular sensitivity of a vocal fish. J Neurosci 32(4):1366-1376

Coombs S, Popper AN (1979) Hearing differences among Hawaiian squirrelfish (family Holocentridae) related to differences in the peripheral auditory system. J Comp Physiol A 132:203-207

Coombs S, Popper AN (1980) Auditory sensitivity and inner ear ultrastructure in Osteoglossum bicirrhosum. Am Zool 20(4):785

Coombs S, Popper AN (1982) Structure and function of the auditory system in the Clown knifefish, Notopterus chitala. J Exp Biol 97:225-239

Dale T (1976) The labyrinthine mechanoreceptor organs of the cod Gadus morhua L. (Teleostei: Gadidae). Norw J Zool 24:85-128

Dehadrai PV (1959) On the swimbladder and its connection with the internal ear in family Cichlidae. Proc Natl Inst Sci India B 25(5):254-261

Deng XH (2009) Comparative studies on the structure of the ears of deep-sea fishes. Dissertation, University of Maryland, College Park, MD, USA

Deng XH, Wagner H-J, Popper AN (2011) The inner ear and its coupling to the swim bladder in the deep-sea fish Antimora rostrata (Teleostei: Moridae). Deep-Sea Res I 58:27-37

Deng XH, Wagner H-J, Popper AN (2013) Interspecific variations of inner ear structure in the deep-sea fish family Melamphaidae. Anat Rec 296:1064-1082

Denker A (1938) Zur Anatomie und Funktion des Labyrinths der Meerbrassen (Sparidae). Archiv für Ohren-, Hals- und Kehlkopfheilkunde 144:417-424

Denton EJ, Gray JAB (1979) The analysis of sound by the sprat ear. Nature 282:406-407

Duncan JS, Fritzsch B (2012) Evolution of sound and balance perception: innovations that aggregate single hair cells into the ear and transform a gravistatic sensor into the organ of Corti. Anat Rec 295:1760-1774 
Edds-Walton PL, Popper AN (1995) Hair cell orientation patterns on the saccules of juvenile and adult Toadfish, Opsanus tau. Acta Zool 76(4):257-265

Edds-Walton PL, Fay RR, Highstein SM (1999) Dendritic arbors and central projections of physiologically characterized auditory fibers from the saccule of the Toadfish, Opsanus tau. J Comp Neurol 411:212-238

Enger PS (1976) On the orientation of haircells in the labyrinth of perch (Perca fluviatilis). In: Schuijf A, Hawkins AD (eds) Sound reception in fish. Elsevier, Amsterdam, pp 49-62

Fay RR (1984) The goldfish ear codes the axis of acoustic particle motion in three dimensions. Science 225:951-954

Fay RR (1988) Peripheral adaptations for spatial hearing in fish. In: Atema J, Fay RR, Popper AN, Tavolga WN (eds) Sensory biology of aquatic animals. Springer, New York, pp 711-731

Fay RR (2011) Psychoacoustics: what fish hear. In: Farrell AP (ed) Encyclopedia of fish physiology: from genome to environment. Academic, San Diego, pp 276-282

Fay RR, Edds-Walton PL (1997) Directional response properties of saccular afferents of the toadfish, Opsanus tau. Hear Res 111:1-21

Fink SV, Fink WL (1996) Interrelationships of ostariophysan fishes (Teleostei). In: Stiassny MLJ, Parenti LR, Johnson GD (eds) Interrelationships of fishes. Academic, San Diego, pp 209-249

Finneran JJ, Hastings MC (2000) A mathematical analysis of the peripheral auditory system mechanics in the goldfish (Carassius auratus). J Acoust Soc Am 108(3):1308-1321

Flock $\AA$ (1964) Structure of the macula utriculi with special reference to directional interplay of sensory responses as revealed by morphological polarization. J Cell Biol 22:413-431

Forlano PM, Kim SD, Krzyminska ZM, Sisneros JA (2014) Catecholaminergic connectivity to the inner ear, central auditory and vocal motor circuitry in the plainfin midshipman fish, Porichthys notatus. J Comp Neurol 522(13):2887-2927

Frédérich B, Olivier D, Litsios G, Alfaro ME, Parmentier E (2014) Trait decoupling promotes evolutionary diversification of the trophic and acoustic system of damselfishes. Proc R Soc B Biol Sci 281:20141047

Fritzsch B (1987) Inner ear of the coelacanth fish Latimeria has tetrapod affinities. Nature 327:153-154

Fritzsch B (2003) The ear of Latimeria chalumnae revisited. Zoology 106:243-248

Fritzsch B, Pan N, Jahan I, Duncan JS, Kopecky BJ, Elliott KL, Kersigo J, Yang T (2013) Evolution and development of the tetrapod auditory system: an organ of Corti-centric perspective. Evol Dev 15(1):63-79

Froese H (1938) Vergleichend-anatomische Studien über das Knochenfischlabyrinth. Z Vgl Physiol 34(4):610-646

Gauldie RW, Dunlop D, Tse J (1986a) The remarkable lungfish otolith. N Z J Mar Freshw Res 20(1):81-92

Gauldie RW, Dunlop D, Tse J (1986b) The simultaneous occurrence of otoconia and otoliths in four teleost fish species. N Z J Mar Freshw Res 20(1):93-99

Greenwood PH (1970) Skull and swimbladder connections in fishes of the family Megalopidae. Bull Br Mus (Nat Hist) Zool 19(3):121-135

Hawkins AD (1993) Underwater sound and fish behaviour. In: Pitcher TJ (ed) Behaviour of teleost fishes. Chapman and Hall, London, pp 129-169

Higgs DM, Plachta DTT, Rollo AK, Singheiser M, Hastings MC, Popper AN (2004) Development of ultrasound detection in American shad (Alosa sapidissima). J Exp Biol 207:155-163

Hochmann S, Aghaallaei N, Bajoghli B, Soroldoni D, Carl M, Czerny T (2007) Expression of marker genes during early ear developmental in medaka. Gene Expr Patterns 7:355-362

Horodysky AZ, Brill RW, Fine ML, Musick JA, Latour RJ (2008) Acoustic pressure and particle motion thresholds in six sciaenid fishes. J Exp Biol 211(9):1504-1511

Jenkins DB (1974) Preliminary report on anatomical studies of inner ear in catfishes (Siluriformes). Anat Rec 178(2):382

Jenkins DB (1977) A light microscopic study of the saccule and lagena in certain catfishes. Am J Anat 150:605-630 
Jenkins DB (1979a) Anatomical investigation of the saccule in Clarius batrachus. Scan Electron Microsc 1979:949-954

Jenkins DB (1979b) A transmission and scanning electron microscopic study of the saccule in five species of catfishes. Am J Anat 154:81-102

Jørgensen JM (1976) Hair cell polarization in the flatfish inner ear. Acta Zool 57:37-39

Kéver L, Colleye O, Herrel A, Romans P, Parmentier E (2014) Hearing capacities and otolith size in two ophidiiform species (Ophidion rochei and Carapus acus). J Exp Biol 217:2517-2525

Klingenberg CP (2008) Morphological integration and developmental modularity. Annu Rev Ecol Evol Syst 39:115-132

Krysl P, Hawkins AD, Schilt C, Cranford TW (2012) Angular oscillation of solid scatterers in response to progressive planar acoustic waves: do fish otoliths rock? PLoS One 7(8), e42591

Ladich F (2014a) Diversity in hearing in fishes: ecoacoustical, communicative, and developmental constraints. In: Köppl C, Manley GA, Popper AN, Fay RR (eds) Insights from comparative hearing research. Springer handbook of auditory research, vol 49. Springer, New York, pp 238-321

Ladich F (2014b) Fish bioacoustics. Curr Opin Neurobiol 28:121-127

Ladich F, Fay RR (2013) Auditory evoked potential audiometry in fish. Rev Fish Biol Fish 23:317-364

Ladich F, Popper AN (2001) Comparison of the inner ear ultrastructure between teleost fishes using different channels for communication. Hear Res 154(1-2):62-72

Ladich F, Popper AN (2004) Parallel evolution in fish hearing organs. In: Manley G, Fay RR, Popper AN (eds) Evolution of the vertebrate auditory system. Springer handbook of auditory research, vol 22. Springer, New York, pp 95-127

Ladich F, Yan HY (1998) Correlation between auditory sensitivity and vocalization in anabantoid fishes. J Comp Physiol A Sens Neural Behav Physiol 182(6):737-746

Lechner W, Ladich F (2008) Size matters: diversity in swimbladders and Weberian ossicles affects hearing in catfishes. J Exp Biol 211(10):1681-1689

Lombarte A, Fortuno JM (1992) Differences in morphological features of the sacculus of the inner ear of two hakes (Merluccius capensis and M. paradoxus, Gadiformes) inhabits from different depth of sea. J Morphol 214(1):97-107

Lombarte A, Popper AN (1994) Quantitative analyses of postembryonic hair cell addition in the otolithic endorgans of the inner ear of the Europan hake, Merluccius merluccius (Gadiformes, Teleostei). J Comp Neurol 345(3):419-428

Lombarte A, Popper AN (2004) Quantitative changes in the otolithic organs of the inner ear during the settlement period in European hake Merluccius merluccius. Mar Ecol Prog Ser 267:233-240

Lovell JM, Findlay MM, Harper G, Moate RM, Pilgrim DA (2005a) The polarisation of hair cells from the ear of the European bass (Dicentrarchus labrax). Comp Biochem Physiol A 141:116-121

Lovell JM, Findlay MM, Moate RM, Nedwell JR, Pegg MA (2005b) The inner ear morphology and hearing abilities of the Paddlefish (Polyodon spathula) and the Lake Sturgeon (Acipenser fulvescens). Comp Biochem Physiol A 142:286-296

Lovell JM, Findlay MM, Moate RM, Pilgrim DA (2005c) The polarization of inner ear ciliary bundles from a scorpaeniform fish. J Fish Biol 66:836-846

Lu Z, Popper AN (1998) Morphological polarizations of sensory hair cells in the three otolithic organs of a teleost fish: fluorescent imaging of ciliary bundles. Hear Res 126(1-2):47-57

Lu Z, Popper AN (2001) Neural response directionality correlates of hair cell orientation in a teleost fish. J Comp Physiol A Sens Neural Behav Physiol 187(6):453-465

Lu Z, Song J, Popper AN (1998) Encoding of acoustic directional information by saccular afferents of the sleeper goby, Dormitator latifrons. J Comp Physiol A Sens Neural Behav Physiol 182(6):805-815

Lu Z, Xu Z, Buchser WJ (2003) Acoustic response properties of lagenar nerve fibers in the sleeper goby, Dormitator latifrons. J Comp Physiol A Neuroethol Sens Neural Behav Physiol 189(12):889-905 
Lu Z, Xu Z, Buchser WJ (2004) Coding of acoustic particle motion by utricular fibers in the sleeper goby, Dormitator latifrons. J Comp Physiol A Neuroethol Sens Neural Behav Physiol 190(11):923-938

Lychakov DV (1995) Investigation of the otolithic apparatus in the Acipenser fry. J Evol Biochem Physiol 31(3):333-341

Malicki J, Schier AF, Solnica-Krezel L, Stemple DL, Neuhauss SCF, Stainier DYR, Abdelilah S, Rangini Z, Zwartkruis F, Driever W (1996) Mutations affecting development of the zebrafish ear. Development 123:275-283

Manley GA (2000) Cochlear mechanisms from a phylogenetic viewpoint. Proc Natl Acad Sci 97(22):11736-11743

Mann DA, Lu ZM, Popper AN (1997) A clupeid fish can detect ultrasound. Nature 389(6649):341

Mann DA, Lu ZM, Hastings MC, Popper AN (1998) Detection of ultrasonic tones and simulated dolphin echolocation clicks by a teleost fish, the American shad (Alosa sapidissima). J Acoust Soc Am 104(1):562-568

Mann DA, Higgs DM, Tavolga WN, Souza MJ, Popper AN (2001) Ultrasound detection by clupeiform fishes. J Acoust Soc Am 109(6):3048-3054

Mathiesen C (1984) Structure and innervation of inner ear sensory epithelia in the European eel (Anguilla anguilla L.). Acta Zool 65(4):189-207

Mathiesen C, Popper AN (1987) The ultrastructure and innervation of the ear of the gar, Lepisosteus osseus. J Morphol 194(2):129-142

McCormick CA, Popper AN (1984) Auditory sensitivity and psychophysical tuning curves in the elephant nose fish, Gnathonemus petersii. Journal of Comparative Physiology A 155(6): 753-761

McMahan CD, Prosanta C, Sparks JS, Smith LW, Davis MP (2013) Temporal patterns of diversification across global cichlid biodiversity (Acanthomorpha: Cichlidae). PLoS One 8(8), e71162

Millot J, Anthony J (1965) Anatomie de Latimeria chalumnae II. Système nerveux et organes des sens. Centre National de la Recherche Scientifique, Paris

Myrberg AA Jr, Spires JY (1980) Hearing in damselfishes: an analysis of signal detection among closely related species. J Comp Physiol A 140:135-144

Nelson EM (1955) The morphology of the swim bladder and auditory bulla in the Holocentridae. Fieldiana: Zoology 37:121-130

Nicolson T (2005) The genetics of hearing and balance in zebrafish. Annu Rev Genet 39:9-22

Niemiller ML, Higgs DM, Soares D (2013) Evidence for hearing loss in amblyopsid cavefishes. Biol Lett 9(3):20130104

Noro S-i, Yamamoto N, Ishikawa Y, Ito H, Ijiri K (2007) Studies on the morphology of the inner ear and semicircular canal endorgan projections of $h a$, a medaka behavior mutant. Fish Biol J Medaka 11:31-41

O'Connell CP (1955) The gas bladder and its relation to the inner ear in Sardinops caerulea and Engraulis mordax. Fish Bull 56(505-533)

Oxman DS, Barnett-Johnson R, Smith ME, Coffin A, Miller DL, Josephson R, Popper AN (2007) The effect of vaterite deposition on sound reception, otolith morphology, and inner ear sensory epithelia in hatchery-reared Chinook salmon (Oncorhynchus tshawytscha). Can J Fish Aquat Sci 64(11):1469-1478

Pannella G (1971) Fish otoliths: daily growth layers and periodical patterns. Science 173(4002):1124-1127

Parmentier E, Vandewalle P, Lagardere F (2001) Morpho-anatomy of the otic region in carapid fishes: eco-morphological study of their otoliths. J Fish Biol 58(4):1046-1061

Parmentier E, Lagardere F, Vandewalle P (2002) Relationships between inner ear and sagitta growth during ontogenesis of three Carapini species, and consequences of life-history events on the otolith microstructure. Mar Biol 141(3):491-501

Parmentier E, Mann K, Mann D (2011) Hearing and morphological specializations of the mojarra (Eucinostomus argenteus). J Exp Biol 214(16):2697-2701

Platt C (1977) Hair cell distribution and orientation in goldfish otolith organs. J Comp Neurol 172(2):283-297 
Platt C (1983) Retention of generalized hair cell patterns in the inner ear of the primitive flatfish Psettodes. Anat Rec 207(3):503-508

Platt C (1993) Zebrafish inner ear sensory surfaces are similar to those in goldfish. Hear Res 65(1-2):133-140

Platt C (1994) Hair cells in the lagenar otolith organ of the coelacanth are unlike those in amphibians. J Morphol 220:381

Platt C, Popper AN (1981a) Fine structure and function of the ear. In: Tavolga WN, Popper AN, Fay RR (eds) Hearing and sound communication in fishes. Springer, New York, pp 3-38

Platt C, Popper AN (1981b) Otolith organ receptor morphology in herring-like fishes. In: Gualtierotti T (ed) The vestibular system: function and morphology. Springer, New York, pp 64-76

Platt C, Jørgensen JM, Popper AN (2004) The inner ear of the lungfish Protopterus. J Comp Neurol 471(3):277-288

Popper AN (1976) Ultrastructure of auditory regions in inner ear of Lake whitefish. Science 192(4243):1020-1023

Popper AN (1977) Scanning electron microscopic study of sacculus and lagena in ears of fifteen species of teleost fishes. J Morphol 153(3):397-417

Popper AN (1978) Scanning electron microscopic study of the otolithic organs in the Bichir Polypterus bichir and Shovel-nose sturgeon Scaphirhynchus platorhynchus. J Comp Neurol 181(1):117-128

Popper AN (1979) Ultrastructure of the sacculus and lagena in a moray eel (Gymnothorax sp.). J Morphol 161(3):241-256

Popper AN (1980) Scanning electron microscopic study of the sacculus and lagena in several deep-sea fishes. Am J Anat 157(2):115-136

Popper AN (1981) Comparative scanning electron microscopic investigation of the sensory epithelia in the teleost sacculus and lagena. J Comp Neurol 200(3):357-374

Popper AN (2011) Auditory system morphology. In: Farrel AP (ed) Encyclopedia of fish physiology: from genome to environment. Academic Press, San Diego, pp 252-261

Popper AN, Coombs S (1982) The morphology and evolution of the ear in actinopterygian fishes. Am Zool 22(2):311-328

Popper AN, Fay RR (1977) Structure and function of elasmobranch auditory system. Am Zool 17(2):443-452

Popper AN, Fay RR (2011) Rethinking sound detection by fishes. Hear Res 273(1-2):25-36

Popper AN, Hoxter B (1981) The fine structure of the sacculus and lagena of a teleost fish. Hear Res 5(2-3):245-263

Popper AN, Lu ZM (2000) Structure-function relationships in fish otolith organs. Fish Res 46(1-3):15-25

Popper AN, Northcutt RG (1983) Structure and innervation of the inner ear of the bowfin, Amia calva. J Comp Neurol 213(3):279-286

Popper AN, Platt C (1979) Herring has a unique receptor pattern. Nature 280(5725):832-833

Popper AN, Platt C (1983) Sensory surface of the saccule and lagena in the ears of ostariophysan fishes. J Morphol 176(2):121-129

Popper AN, Schilt CR (2008) Hearing and acoustic behavior: basic and applied considerations. In: Webb JF, Fay RR, Popper AN (eds) Fish bioacoustics. Springer handbook of auditory research, vol 32. Springer, New York, pp 17-48

Popper AN, Tavolga WN (1981) Structure and function of the ear in the marine catfish, Arius felis. J Comp Physiol A 144(1):27-34

Popper AN, Plachta DTT, Mann DA, Higgs DM (2004) Response of clupeid fish to ultrasound: a review. ICES J Mar Sci 61(7):1057-1061

Popper AN, Ramcharitar J, Campana SE (2005) Why otoliths? Insights from inner ear physiology and fisheries biology. Mar Freshw Res 56(5):497-504

Poulson TL (1963) Cave adaptation in amblyopsid fishes. Am Midl Nat 70(2):257-290

Project TD (2003-2009) Phylogenetic classification of bony fishes - version 3. www.deepfin.org/ Classification_v3.htm. Accessed 19 Sept 2014 
Ramcharitar JU, Higgs DM, Popper AN (2001) Sciaenid inner ears: a study in diversity. Brain Behav Evol 58(3):152-162

Ramcharitar JU, Deng XH, Ketten DR, Popper AN (2004) Form and function in the unique inner ear of a teleost: the silver perch (Bairdiella chrysoura). J Comp Neurol 475(4):531-539

Retzius G (1881) Das Gehörorgan der Fische und Amphibien. In: Das Gehörorgan der Wirbelthiere, vol 1. Samson \& Wallin, Stockholm

Rodgers GV, Rogers PH (2011) Experimental investigation of the Krysl-Cranford-Schilt model for the otolith vibration of a teleost fish. J Acoust Soc Am 129(4):2473

Rogers PH, Cox M (1988) Underwater sound as a biological stimulus. In: Atema J, Fay RR, Popper AN, Tavolga WN (eds) Sensory biology of aquatic animals. Springer, New York, pp 131-149

Rogers PH, Popper AN, Hastings MC, Saidel WM (1988) Processing of acoustic signals in the auditory system of bony fish. J Acoust Soc Am 83(1):338-349

Rosen DE, Greenwood PH (1970) Origin of the Weberian apparatus and the relationships of the ostariophysan and gonorynchiform fishes. Am Mus Novit 2428:1-25

Saidel WM, Popper AN (1983) Spatial organization in the saccule and lagena of a teleost - hair cell pattern and innervation. J Morphol 177(3):301-317

Sand O, Michelsen A (1978) Vibration measurements of perch saccular otolith. J Comp Physiol A 123(1):85-89

Schellart NAM, Popper AN (1992) Functional aspects of the evolution of the auditory system of actinopterygian fish. In: Webster DE, Fay RR, Popper AN (eds) The evolutionary biology of hearing. Springer, New York, pp 295-322

Schibler A, Malicki J (2007) A screen for genetic defects of the zebrafish ear. Mech Dev 124(7-8):592-604

Schneider H (1942) Die Bedeutung der Atemhöhle der Labyrinthfische für ihr Hörvermögen. Z Vgl Physiol 29(1-2):172-194

Schulz-Mirbach T, Hess M, Plath M (2011) Inner ear morphology in the Atlantic molly Poecilia mexicana - first detailed microanatomical study of the inner ear of a cyprinodontiform species. PLoS One 6(11), e27734

Schulz-Mirbach T, Metscher BD, Ladich F (2012) Relationship between swim bladder morphology and hearing abilities - a case study on Asian and African cichlids. PLoS One 7(8), e42292

Schulz-Mirbach T, Heß M, Metscher BD, Ladich F (2013) A unique swim bladder-inner ear connection in a teleost fish revealed by a combined high-resolution microCT and $3 \mathrm{D}$ histological study. BMC Biol 11:75

Schulz-Mirbach T, Ladich F, Plath M, Metscher BD, Heß M (2014) Are accessory hearing structures linked to inner ear morphology? Insights from 3D orientation patterns of ciliary bundles in three cichlid species. Front Zool 11:25

Sienknecht UJ (2013) Origin and development of hair cell orientation in the inner ear. In: Köppl C, Manley GA, Popper AN, Fay RR (eds) Insights from comparative hearing research. Springer handbook of auditory research. Springer, New York, pp 1-41

Sienknecht UJ, Köppl C, Fritzsch B (2014) Evolution and development of hair cell polarity and efferent function in the inner ear. Brain Behav Evol 83:150-161

Silber J, Cotton J, Nam J-H, Peterson EH, Grant W (2004) Computational models of hair cell bundle mechanics: III. 3-D utricular bundles. Hear Res 197:112-130

Sisneros JA (2007) Saccular potentials of the vocal plainfin midshipman fish, Porichthys notatus. J Comp Physiol A 193(4):413-424

Sisneros JA (2009) Adaptive hearing in the vocal plainfin midshipman fish: getting in tune for the breeding season and implications for acoustic communication. Integr Zool 4:33-42

Smith M, Schuck J, Gilley R, Rogers B (2011) Structural and functional effects of acoustic exposure in goldfish: evidence for tonotopy in the teleost saccule. BMC Neurosci 12(1):19

Sokolowski BHA, Popper AN (1987) Gross and ultrastructural development of the saccule of the Toadfish Opsanus tau. J Morphol 194(3):323-348

Song J, Mathieu A, Soper RF, Popper AN (2006) Structure of the inner ear of bluefin tuna Thunnus thynnus. J Fish Biol 68(6):1767-1781 
Sparks JS (2004) Molecular phylogeny and biogeography of the Malagasy and South Asian cichlids (Teleostei: Perciformes: Cichlidae). Mol Phylogenet Evol 30(3):599-614

Sparks JS (2008) Phylogeny of the cichlid subfamily Etroplinae and taxonomic revision of the Malagasy cichlid genus Paretroplus (Teleostei: Cichlidae). Bull Am Mus Nat Hist 314:1-151

Sparks JS, Smith WL (2004) Phylogeny and biogeography of cichlid fishes (Teleostei: Perciformes: Cichlidae). Cladistics 20(6):501-517

Stipetić E (1939) Über das Gehörorgan der Mormyriden. Z Vgl Physiol 26(5):740-752

Tsuboi M, Gonzalez-Voyer A, Kolm N (2014) Phenotypic integration of brain size and head morphology in Lake Tanganyika cichlids. BMC Evol Biol 14:39

von Frisch K (1936) Über den Gehörsinn der Fische. Biol Rev 11(2):210-246

von Frisch K (1938) Über die Bedeutung des Sacculus und der Lagena für den Gehörsinn der Fische. Zeitschrift für vergleichende Physiologie 25:703-747

von Frisch K, Stetter H (1932) Untersuchungen über den Sitz des Gehörsinnes bei der Elritze. Z Vgl Physiol 17(4):686-801

Wainwright PC (2007) Functional versus morphological diversity in macroevolution. Annu Rev Ecol Evol Syst 38:381-401

Webb JF, Smith WL, Ketten DR (2001) The laterophysic connection, a unique swim bladderlateral line connection in butterflyfishes: an evolutionary novelty with implications for sensory function. J Morphol 248(3):298-299

Webb JF, Smith WL, Ketten DR (2006) The laterophysic connection and swim bladder of butterflyfishes in the genus Chaetodon (Perciformes: Chaetodontidae). J Morphol 267(11):1338-1355

Webb JF, Herman JL, Woods CF, Ketten DR (2010) The ears of butterflyfishes (Chaetodontidae): 'hearing generalists' on noisy coral reefs? J Fish Biol 77(6):1406-1423

Weber EH (1819) Vergleichende Anatomie der Gehörwerkzeuge. Deutsches Archiv für die Physiologie 5:323-332

Weber EH (1820) De aure et auditu hominis et animalium. Part I. De aure animalium aquatilium. Apud Gerhardum Fleischerum, Lipsiae

Wegner NT (1979) The orientation of hair cells in the otolithic organs and papilla neglecta in the inner ear of the anabantide fish Colisa labiosa (Day). Acta Zool 60(4):205-216

Whitfield TT, Granato M, vanEeden FJM, Schach U, Brand M, FurutaniSeiki M, Haffter P, Hammerschmidt M, Heisenberg CP, Jiang YJ, Kane DA, Kelsh RN, Mullins MC, Odenthal J, NussleinVolhard C (1996) Mutations affecting development of the zebrafish inner ear and lateral line. Development 123:241-254

Whitfield TT, Riley BB, Chiang M-Y, Phillips B (2002) Development of the zebrafish inner ear. Dev Dyn 223:427-458

Wilson M, Montie EW, Mann KA, Mann DA (2009) Ultrasound detection in the Gulf menhaden requires gas-filled bullae and an intact lateral line. J Exp Biol 212(21):3422-3427

Wohlfahrt TA (1932) Anatomische Untersuchungen über das Labyrinth der Elritze (Phoxinus laevis L.). Z Vgl Physiol 17(4):659-685

Wohlfahrt TA (1933) Das Ohrlabyrinth des Schlammspringers (Periophthalmus schlosseri Pall.) Ein Beitrag zur Kenntnis der Anatomie des Gobiidenlabyrinthes. Anat Embryol 102(2): 298-306

Wohlfahrt TA (1936) Das Ohrlabyrinth der Sardine (Clupea pilchardus Walb.) und seine Beziehungen zur Schwimmblase und Seitenlinie. Zoomorphology 31(3):371-410

Yan HY, Curtsinger WS (2000) The otic gasbladder as an ancillary auditory structure in a mormyrid fish. Journal of Comparative Physiology A 186(6):595-602

Yamamoto T (1929) Morphologische Untersuchungen der Gehörorgane von Süsswasserknochenfischen. Folia Anat Jpn 7(4):325-378

Zeddies DG, Fay RR, Gray MD, Alderks PW, Acob A, Sisneros JA (2012) Local acoustic particle motion guides sound-source localization behavior in the plainfin midshipman fish, Porichthys notatus. J Exp Biol 215(1):152-160 


\title{
Causes and Consequences of Sensory Hair Cell Damage and Recovery in Fishes
}

\author{
Michael E. Smith and J. David Monroe
}

\begin{abstract}
Sensory hair cells are the mechanotransductive receptors that detect gravity, sound, and vibration in all vertebrates. Damage to these sensitive receptors often results in deficits in vestibular function and hearing. There are currently two main reasons for studying the process of hair cell loss in fishes. First, fishes, like other non-mammalian vertebrates, have the ability to regenerate hair cells that have been damaged or lost via exposure to ototoxic chemicals or acoustic overstimulation. Thus, they are used as a biomedical model to understand the process of hair cell death and regeneration and find therapeutics that treat or prevent human hearing loss. Secondly, scientists and governmental natural resource managers are concerned about the potential effects of intense anthropogenic sounds on aquatic organisms, including fishes. Dr. Arthur N. Popper and his students, postdocs and research associates have performed pioneering experiments in both of these lines of fish hearing research. This review will discuss the current knowledge regarding the causes and consequences of both lateral line and inner ear hair cell damage in teleost fishes.
\end{abstract}

Keywords Acoustic trauma $\bullet$ Anthropogenic sound $\bullet$ Fish $\bullet$ Hair cell $\bullet$ Hearing loss - Inner ear $\bullet$ Lateral line $\bullet$ Ototoxicity $\bullet$ Regeneration

\section{Introduction}

Hearing and balance and their dysfunction are studied much more in mammals than in other vertebrate taxa. This is because hearing research has obvious implications for human health, and mammalian models present many structural and physiological similarities to the human auditory and vestibular systems. Recently, however, there has been considerable interest in studying sensory hair cell and hearing loss in fishes. Two foci of this research are: (1) the study of sensory hair cell development and regeneration in fishes to find therapeutics for human deafness, and (2) the investigation of how anthropogenic sound sources affect fishes. In the former, hair cell dysfunction is congenital or is induced via exposure to ototoxic chemicals or

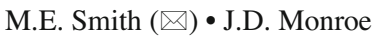

Department of Biology, Western Kentucky University, Bowling Green, KY 42101, USA

e-mail: michael.smith1@wku.edu; jerry.monroe@wku.edu 

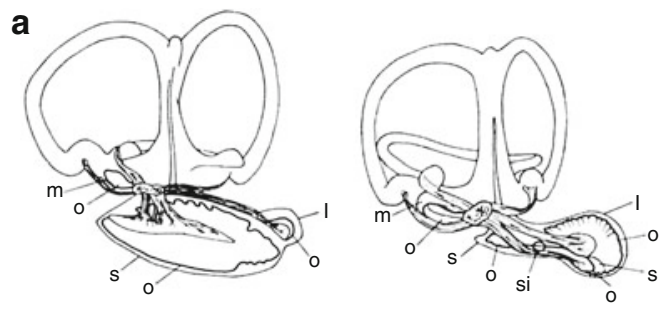

b

Fig. 1 (a) Drawing of the inner ear of a zander (left), Sander lucioperca, and ide (right), Leuciscus idus. While the ide has anatomical specializations for detecting sound pressure, the zander does not. The auditory portions of the ear are labeled and only the auditory portion of the eighth nerve is shown. $l$ lagena, $m$ utriculus, $o$ otolith of each endorgan, $s$ sacculus, si transverse canal (adapted with permission from Popper AN and Fay RR (1973) Sound detection and processing by teleost fishes: a critical review. JASA 53:1515-1528, Copyright 1973, Acoustical Society of America). (b) Spatial distribution of superficial (small dots) and canal (dots within shaded canal areas) neuromasts on the head and trunk of the Lake Michigan mottled sculpin (Cottus bairdi) (with kind permission from Springer Science+Business Media: Autonomous Robots 11 (2001) 255-261, Coombs S, Fig. 1)

acoustic overstimulation. In the latter, fishes are exposed to acoustical stimuli from man-made sources, such as seismic airguns, pile driving, sonars, and boat noise, or signals that mimic these sound sources.

Although fishes have no external or middle ears, their inner ears are similar to those of other vertebrates. In fact, it is hypothesized that hearing first evolved in fishes (Popper and Fay 1999). The fish ear consists of three semicircular canals (except in more primitive taxa, i.e., hagfishes and lampreys, which have fewer) and three otolithic end organs, the utricle, lagena, and saccule (Fig. 1a). Within each pouch-like end organ is a patch of sensory epithelium, the macula, which contains a layer of sensory hair cells and supporting cells, and an associated otolith composed of calcium carbonate in a protein matrix. Hair cells are specialized mechanoreceptors so named because the multiple actin-rich stereocilia and single microtubulebased kinocilium in their apical surfaces appear like tufts of hair. Hair cells are polarized, with the longest stereocilia being closest to the kinocilium and shorter stereocilia positioned farther from the kinocilium in a graded manner. Since the otoliths overlying the hair cell bundles are denser than the body of the fish, when sound passes through the fish, there is a lag in the transmission of the sound vibration in the otolith relative to the body. This asynchrony causes the underlying hair cell stereociliary bundles to be deflected, opens cation channels, and produces receptor potentials that are transmitted to the brain by the auditory afferent fibers of cranial nerve XIII (Popper and Fay 1999).

Fish also have hair cells located on their skin or in canals just below the skin's surface. Groups of these hair cells are found in sensory structures called neuromasts, which detect the relative motion of the surrounding water and the fish. These neuromasts comprise the lateral line system and are located either on the surface (superficial) or in a channel with pores connecting them to the external medium (canal) (Fig. 1b; Coombs 2001; Coombs et al. 2001; McHenry and van Netten 2007). Neuromasts are located in either the head (i.e., anterior lateral line) or along 

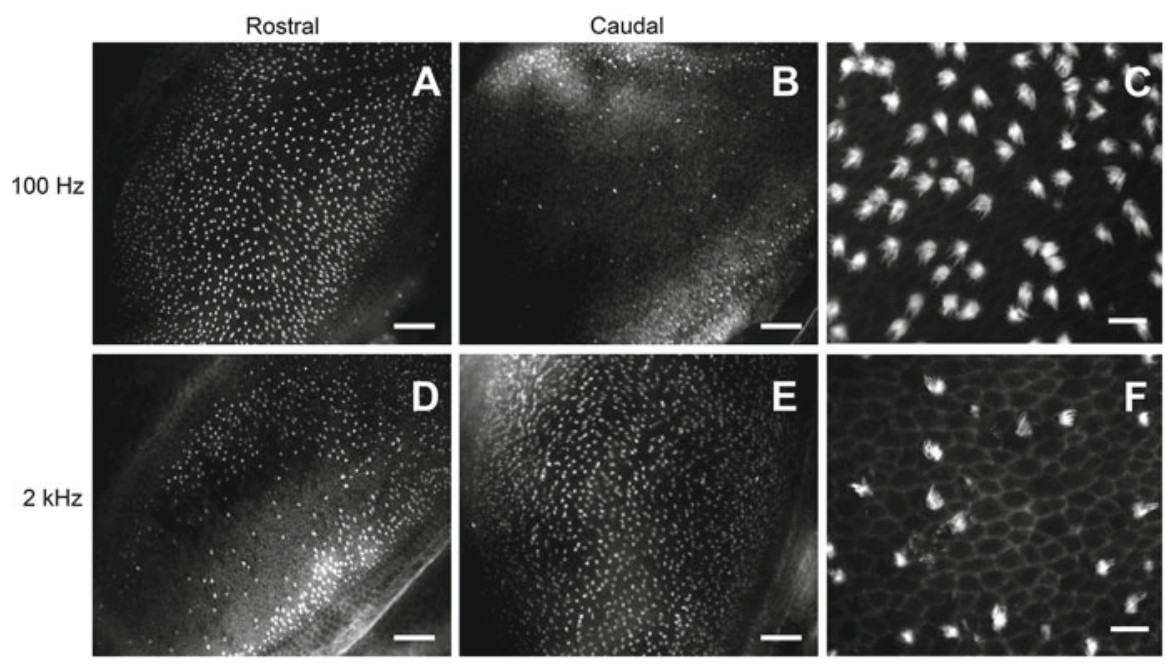

Fig. 2 Hair cell bundle loss as a function of tone frequency and saccule location in goldfish (Carassius auratus). Phalloidin-labeled saccular epithelia showing evidence of differential hair cell bundle loss between rostral $(\mathbf{a}, \mathbf{d})$ and caudal $(\mathbf{b}, \mathbf{e})$ regions in goldfish exposed to $100(\mathbf{a}, \mathbf{b})$ versus $2000(\mathbf{d}, \mathbf{e}) \mathrm{Hz}$ tones. Scale bars $=50 \mu \mathrm{m}$. Higher magnification comparison between control (c) and $4000 \mathrm{~Hz}$ tone-exposed (f) saccular epithelia show differential hair cell bundle loss. Scale bars $=5 \mu \mathrm{m}$ (modified from Smith et al. 2011)

the trunk and tail (i.e., posterior lateral line) (Ghysen and Dambly-Chaudière 2004). Adjacent to neuromasts are two types of accessory cells: support and mantle cells (Villegas et al. 2012). Following hair cell damage, interior support cells proliferate and differentiate into new hair cells (Ma et al. 2008). Neuromasts have cellular layers and nervous connections structurally similar to those found in the inner ear sensory maculae (Nicolson 2005; Haehnel et al. 2012). Unlike inner ear hair cells, lateral line stereociliary bundles project into a cupula, a gelatinous chamber, which allows them to transduce vibrational forces into a neural signal (Nicolson 2005; McHenry and van Netten 2007).

Sensory hair cells are prone to damage from intense and/or long-lasting acoustic exposure (Fig. 2; Schuck and Smith 2009; Smith et al. 2011; Casper et al. 2013a) and ototoxic chemicals such as aminoglycoside antibiotics (Song et al. 1995; Owens et al. 2008; Van Trump et al. 2010; Uribe et al. 2013b) and antineoplasmic agents (Ou et al. 2007; Coffin et al. 2013; Thomas et al. 2013). This review summarizes the effects of such experimental exposures, specifically examining the causes and consequences of hair cell damage and/or loss in the auditory, vestibular, and lateral line system in fishes.

\section{Causes of Hearing Loss}

Human hearing loss can be divided into two basic types, conductive and sensorineural. Conductive hearing loss involves damage to external or middle ear structures and not the cochlea of the inner ear, while sensorineural hearing loss is 
caused by damage to the cochlea, particularly its hair cells, or the auditory nerve (Pickles 1996).

Fishes do not have an external or middle ear, but some species possess anatomical specializations that are functionally similar to middle ear bones. For example, fishes of the Superorder Ostariophysi have a Weberian apparatus, which is composed of modified vertebral bones (i.e., ossicles) and associated ligaments that connect the swim bladder to the inner ear. These structures allow the transmission of sound-induced vibrations from the swim bladder to the inner ear (Weber 1820). Although the Weberian apparatus is associated with more sensitive hearing and broader frequency detection (Higgs et al. 2003; Ladich and Wysocki 2003; Lechner et al. 2011), conductive hearing loss in fishes has only been shown in a few studies. Bang et al. (2002) found that approximately $1 \%$ of the zebrafish (Danio rerio) that were exposed to a $400 \mathrm{~Hz}$ tone did not exhibit an escape reflex. Those that did not respond had abnormalities in conductive elements of the peripheral auditory system, e.g., either the swim bladder or Weberian ossicles. This shows that hearing loss can occur in fishes without inner ear hair cell damage, but it is unknown how common such conductive system deficits are in nature.

In an attempt to understand the roles of the swim bladder and Weberian apparatus on hearing in ostariophysan fishes, researchers have removed the tripus (one of the Weberian ossicles; Ladich and Wysocki 2003) or deflated the swim bladder (Yan et al. 2000). Both manipulations significantly reduced hearing sensitivity. Similarly, the removal of gas from gas-filled chambers near the ears of non-ostariophysan species, such as the suprabranchial chambers of gouramis or the otic gasbladder of mormyrids, also significantly decreased hearing sensitivity (Yan 1998; Yan and Curtsinger 2000). Thus, underwater sound impulses that could potentially rupture these gas-filled chambers may be able to cause conductive hearing loss in fishes.

Unlike conductive hearing loss, there are many examples of sensorineural hearing loss in fishes. To date, sensorineural research has focused primarily on damage to the sensory hair cells. This review will first discuss what is known about congenital and acquired causes of hearing and vestibular sensorineural loss in fishes before covering the consequences of and recovery from hair cell damage.

\section{Congenital Hearing Loss}

In humans, congenital hearing loss can result from non-genetic factors such as maternal physiological status, infections/diseases, and trauma during pregnancy such as toxemia or anoxia, and from genetic factors, e.g., Waardenburg, Usher, and Down syndromes (ASHA 2014). Congenital hearing loss from genetic factors in fishes has also been reported, although no research has yet been performed examining nongenetic, i.e., maternal factors. In large-scale genetic screens in zebrafish, many mutations affecting the development of the inner ear have been identified (Malicki et al. 1996; Nicolson et al. 1998; Whitfield et al. 2002, 2005; Nicolson 2005). For example, the mariner phenotype of the circler zebrafish mutant is defective in myosin 
VIIA. This mutant exhibits morphological and functional defects similar to those of mouse mutants with inner ear defects (Ernest et al. 2000) and to humans with nonsyndromic deafness caused by myosin VIIA mutations (Liu et al. 1997). Also, Foxil (aka FKh10) expressed in the otic precursor cells is necessary for normal inner ear development in both mice (Hulander et al. 2003) and zebrafish (Solomon et al. 2003). The fact that similar genes are important for auditory and vestibular function in both mammals and fishes support the hypothesis that vertebrate hair cells and the sense of hearing first evolved in early fishes (Popper and Fay 1999; Coffin et al. 2004). Since there is considerable conserved synteny between zebrafish and human genes, roles for human genes can potentially be understood from zebrafish mutations (Barbazuk et al. 2000). Thus, fishes may provide insight into human hereditary deafness and into the pathways of hair cell death and regeneration.

Many zebrafish mutations that affect the inner ear and lateral line also affect other critical physiological systems and are lethal during early development, thus standard psychophysical or physiological hearing tests have not been reported for fish with such mutations. Instead, loss of auditory and vestibular function in zebrafish is assumed when abnormal development of auditory or lateral line structures is evident, or crudely measured from behavioral acoustic startle response assays (Bang et al. 2000, 2002). As the startle response is mediated by Mauthner cells, large reticulospinal neurons that innervate contralateral spinal motor neurons and receive signals from ipsilateral sensory afferents (Weiss et al. 2006), excitatory post-synaptic currents (EPSCs) have been recorded from these cells as a correlate of auditory function (Han et al. 2011). More recently, assays have been developed to better quantify hearing sensitivities across different frequencies in zebrafish larvae (Zeddies and Fay 2005; Cervi et al. 2012; Bhandiwad et al. 2013). These novel techniques should allow for more detailed assessment of potential hearing deficits in fish mutants in the future.

\section{Acquired Hearing Loss}

Acquired hearing loss in humans can result from aging, ear infections, diseases, acoustic trauma, and ototoxic medications (ASHA 2014). No studies have examined the effect of aging or disease on hearing in fishes, although the zebrafish has been used as a model for aging research (Gerhard 2003). However, hearing loss in fishes following exposure to intense sound stimulation and ototoxins has been extensively documented.

\subsection{Sound-Induced Hearing Loss}

The first study to report hearing loss in a fish was done by Popper and Clarke (1976). They exposed goldfish (Carassius auratus) to intense pure tones of either 300, 500, 800 , or $1000 \mathrm{~Hz}$ at approximately $149 \mathrm{~dB}$ re $1 \mu \mathrm{Pa}$ for $4 \mathrm{~h}$ and then measured 
behavioral hearing thresholds at 500 and $800 \mathrm{~Hz}$. This caused temporary threshold shifts (TTS) that varied depending upon stimulation and test frequency, but hearing thresholds returned to normal within a day. Sensory hair cell loss in a fish was first reported by Enger (1981), who exposed Atlantic cod (Gadus morhua) to tones between 50 and $400 \mathrm{~Hz}$ that were $100-110 \mathrm{~dB}$ above the most sensitive hearing threshold of cod. Immediately following a 1-5 h exposure, saccules were prepared for scanning electron microscopy. Enger found that large patches of hair cells were damaged, with a complete or almost complete lack of stereocilia, and that lower frequency tones damaged the caudal portion of the saccule while higher frequencies damaged the rostral saccule. More recent studies have generally focused on the effects of anthropogenic sounds on fishes, an interest which began in the early 1990s when high intensity underwater sounds were first projected across oceans to assess global warming (Baggeroer and Munk 1992). Although initial concerns focused on the potentially negative impacts of these sounds on marine mammals (Richardson et al. 1995), this naturally led to studies on other aquatic organisms such as fishes.

In 1996, Hastings et al. exposed oscars (Astronotus ocellatus) to pure tones that varied in frequency $(60$ or $300 \mathrm{~Hz}$ ), duty cycle ( $20 \%$ or continuous), and intensity $(100,140$, or $180 \mathrm{~dB}$ re $1 \mu \mathrm{Pa})$ and examined the hair cells of the inner ear and lateral line. They found that fish exposed to a continuous $300 \mathrm{~Hz}$ tone exhibited limited damage in small regions of the utricle and lagena. The examination of hair cell damage was later coupled with the recording of auditory evoked potentials (AEP) to perform auditory testing on sound-exposed fish. This method allowed hearing tests on fishes to be performed relatively quickly and efficiently compared to standard behavioral methods (Corwin et al. 1982; Kenyon et al. 1998).

Sound-induced hearing loss has been reported in a number of fish species [e.g., goldfish, Carassius auratus (Amoser and Ladich 2003; Smith et al. 2004a, b); fathead minnows, Pimephales promelas (Scholik and Yan 2001, 2002a); northern pike, Esox Lucius; lake chub, Couesius plumbeus (Popper et al. 2005); Pimelodus pictus (Amoser and Ladich 2003); sailfin molly, Poecilia latipinna, and koi, Cyprinus carpio (Coffey 2014)], while other species exhibited no or minimal hearing threshold shifts following intense sound exposure [bluegill sunfish, Lepomis macrochirus (Scholik and Yan 2002b); Oreochromis niloticus (Smith et al. 2004b); rainbow trout, Oncorhynchus mykiss (Wysocki et al. 2007)].

Using goldfish as an experimental model, general patterns for sound-induced hearing loss have been found. First, hearing loss, as measured in decibels of TTS, increases with duration of noise exposure and decreases, i.e., recovers, with time post-exposure (Smith et al. 2004a, 2006; Popper et al. 2004). Second, TTS increases linearly with sound pressure level (SPL) of the stimulus (Fig. 3; Smith et al. 2004b). Third, fish tend to exhibit the greatest hearing loss at frequencies where they are the most sensitive such that the curve of TTS across frequency has a shape that is the inverse of the control audiogram of the fish (Smith et al. 2004b, 2006, 2011). As a result, it has been suggested that researchers should use the SPL difference between the intensity of sound stimuli and the baseline hearing threshold level as a means of predicting threshold shifts instead of the actual SPL of the noise (Smith 2012). Fourth, saccular hair cell loss is correlated with hearing loss, and hearing recovery 


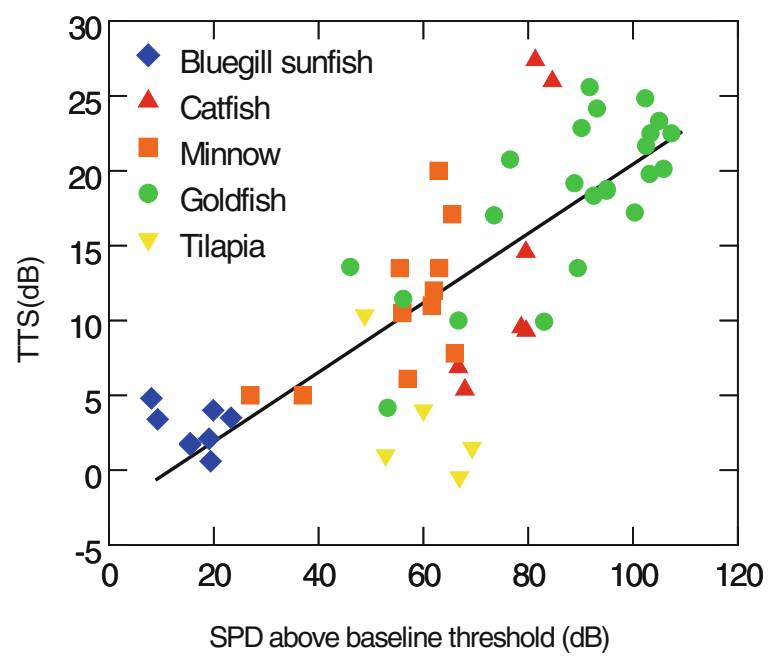

Fig. 3 Temporary threshold shift (TTS) as a function of noise sound pressure differences (SPD) between the noise exposure sound pressure level and the baseline hearing threshold of five species of teleost fishes (bluegill sunfish, Lepomis macrochirus; catfish Pimelodus pictus; fathead minnow, Promelas pimephales; goldfish, Carassius auratus; tilapia, Oreochromis niloticus). The line shows the linear regression relationship for all the species (TTS $=0.23 x-2.44, r^{2}=0.62$ ) (from Smith et al. 2004b)

is concomitant with hair cell regeneration (Smith et al. 2006, 2011; Smith 2016). Lastly, the teleost saccule is at least crudely tonotopically organized such that intense low and high frequency sounds produce sensory hair cell loss in the caudal and rostral regions, respectively (Fig. 4; Enger 1981; Smith et al. 2011). Thus, fish exposed to lower frequency tones exhibit greater TTS at lower frequencies, while high-tone exposure leads to hearing loss at higher frequencies (Smith et al. 2011).

There are some caveats to these generalizations. First, all fish hearing loss studies have reported TTS as dB relative to SPL for control animals, and sound stimuli were quantified in terms of SPL ( $\mathrm{dB}$ re $1 \mu \mathrm{Pa}$ ). However, not all fish can detect sound as pressure stimuli and fish can also detect sound stimuli in the form of particle displacement. There is a continuum of hearing in fishes, with fishes that have a high sensitivity to pressure on one end of the spectrum, and those that detect only particle motion on the other (Popper and Fay 2011). Fishes that detect the pressure component of sound do so because of anatomical specializations which couple gas-filled structures such as swim bladders, suprabranchial chambers, and otic bullae (which are compressible in response to pressure fluctuations) to the fluid-filled canals of the inner ear. Species with these specializations, e.g., goldfish, fathead minnows, lake chub, koi, have lower hearing thresholds and are more susceptible to sound-induced hearing loss than species lacking such specializations that only detect the particle motion component of sound, e.g., bluegill sunfish, tilapia, rainbow trout. Although particle motion thresholds are now being quantified (Radford et al. 2014), particle motion threshold shifts have not yet been measured. Thus, the general patterns of 

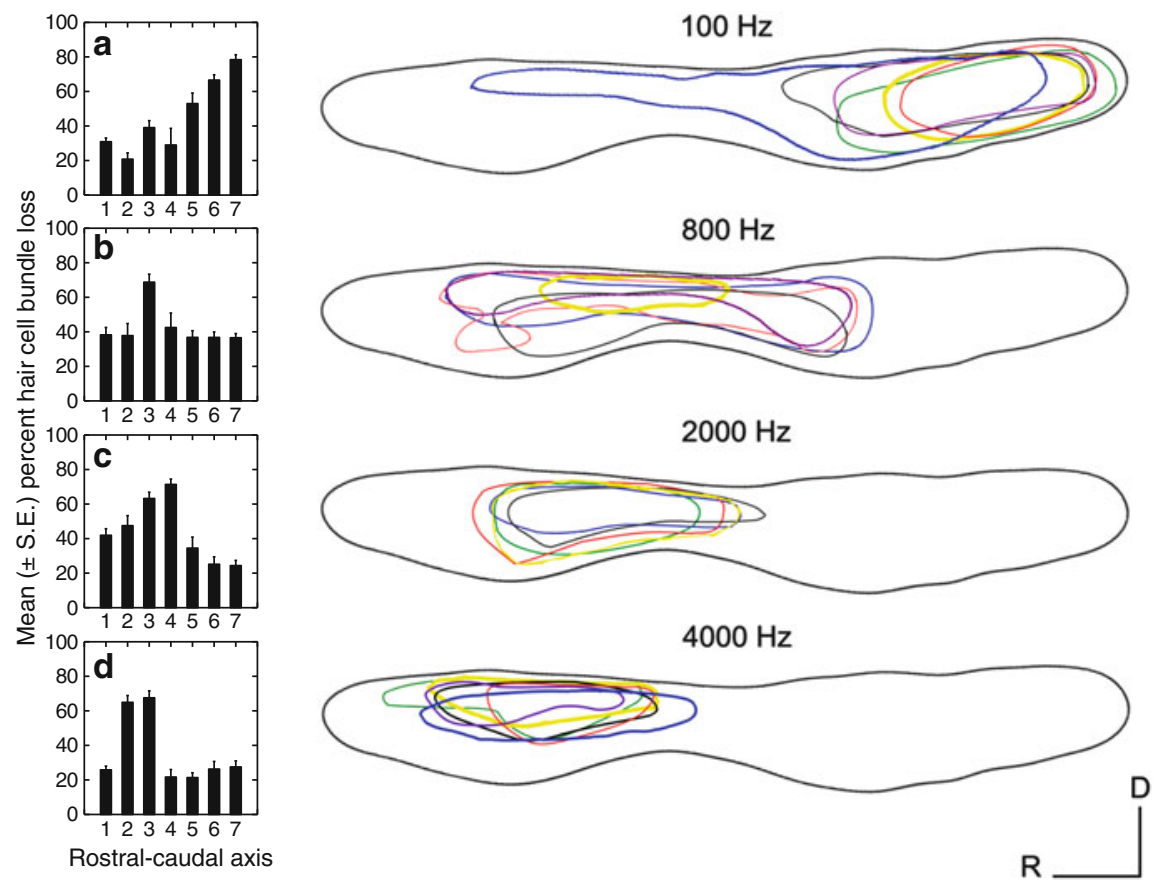

Fig. 4 Mean $( \pm \mathrm{SE})$ percent hair cell loss as a function of location along the rostral-caudal axis of the saccule for each of four tone exposures $(A, B, C, D=100,800,2000$, and $4000 \mathrm{~Hz}$, respectively). Region 1 represents the far rostral area of the saccule and region 7 represents the far caudal area, with $2-6$ being intermediate between these two extremes $(n=10-12)$. Drawings of the distribution of damaged areas on the left saccular macula at the exposure tones indicated are to the right of the appropriate graph. Areas were marked as damaged if they appeared to be missing significant numbers of hair cells when viewed at low magnification (20x objective). Each colored line represents areas of hair cell bundle loss for an individual left saccule $(n=5-6)$. Similar patterns were found in right saccules (from Smith et al. 2011)

hearing loss will most likely differ depending upon the species and its type of hearing, as well as the ratio of pressure and particle motion of the sound source.

Aspects of sound detection other than threshold sensitivity can be affected by noise exposure. For example, Wysocki and Ladich (2005) exposed goldfish to 158 $\mathrm{dB}$ re $1 \mu \mathrm{Pa}$ white noise for $24 \mathrm{~h}$ and found that this increased the minimum click period that could be resolved. As the ability to resolve temporal patterns is an important aspect of sound perception, deficits in temporal resolution ability could negatively impact fish. Background noise could also mask biologically relevant auditory or vibratory signals without necessarily damaging the auditory or lateral line system (Fay and Megela Simmons 1999). Although auditory masking is an important issue in understanding the effects of sound on fishes, as sensory hair cells are likely not damaged by background noise, this topic is out of the purview of this review.

Also, many anthropogenic sound sources, such as sonars, seismic air guns, and pile driving, are very different from most continuous laboratory sound sources, e.g., 
tones, white noise, band-passed noise. Air guns and pile driving pulses can produce rapid increases and decreases in pressure in a very short period of time and are usually characterized by peak pressure (Parkes and Hatton 1986; Popper and Hastings 2009). Sonars are transient signals (because they are from a moving ship) with frequency sweeps over time (Popper et al. 2007). Because of the different properties of these sound sources, measures other than the root-mean-square (RMS) of the SPL may be required to accurately predict hearing loss in fishes. Two potential alternative measures are cumulative sound energy or the sound exposure level (SEL) (see Hastings and Popper 2005 for a discussion of this topic).

\subsection{Effects of Anthropogenic Sound Sources}

Relatively few studies have examined the effect of anthropogenic sound sources on fish hearing. McCauley et al. (2003) were the first to show that anthropogenic sound can cause sensory hair cell damage in fish ears. They exposed caged pink snapper (Pagrus auratus) to signals from a towed airgun (simulating a passing seismic vessel). Their ears exhibited considerable hair cell loss at both $18 \mathrm{~h}$ and 58 days after exposure, but no hearing tests were performed to quantify hearing loss. Popper et al. (2005) reported hearing loss in fishes following exposure to a seismic airgun array, with threshold shifts varying between species. The fishes were exposed to a mean received SPL of 205-209 dB re $1 \mu \mathrm{Pa}$ (peak) and a mean SEL of 176-180 dB re 1 $\mu \mathrm{Pa}^{2}$ s per airgun shot. Lake chub (Couesius plumbeus) exhibited the greatest threshold shifts, while adult northern pike (Esox lucius) were intermediate, and broad whitefish (Coregonus nasus) showed no hearing loss. This pattern was related to baseline hearing thresholds, with the most sensitive species (C. plumbeus) exhibiting the greatest shift (Fig. 5). Hearing loss increased with the number of seismic blasts that the fish were exposed to, but in all cases hearing thresholds returned to normal within $24 \mathrm{~h}$. These same fish were examined for sensory hair cell damage and none was detected (Song et al. 2008). This suggests that any damage in the fishes may have occurred at an individual hair cell level as in mammals where seismic blasts can cause broken tip links between the hair cell stereocilia which disrupts mechanotransduction and leads to hearing deficits (Indzhykulian et al. 2013). Such subtle damage is not easily detectable and can only be visualized by high power scanning electron microscopy.

Popper et al. (2005) examined the effects of high intensity sonar on rainbow trout (Oncorhynchus mykiss). Fish were exposed to a U.S. Navy Surveillance Towed Array Sensor System (SURTASS) Low Frequency Active (LFA) sonar with a maximum received RMS SPL of $193 \mathrm{~dB}$ re $1 \mu \mathrm{Pa}^{2} \mathrm{~s}$ for 324 or $648 \mathrm{~s}$. The trout exhibited a $20 \mathrm{~dB}$ threshold shift at $400 \mathrm{~Hz}$, but, similar to Song et al. (2008), no obvious damage to the inner ear sensory epithelia or other non-auditory tissues was found. This work was extended by adding data for three additional species, largemouth bass (Micropterus salmoides), yellow perch (Perca flavescens), and channel catfish (Ictalurus punctatus) (Halvorsen et al. 2013). Threshold shifts were evident for the 

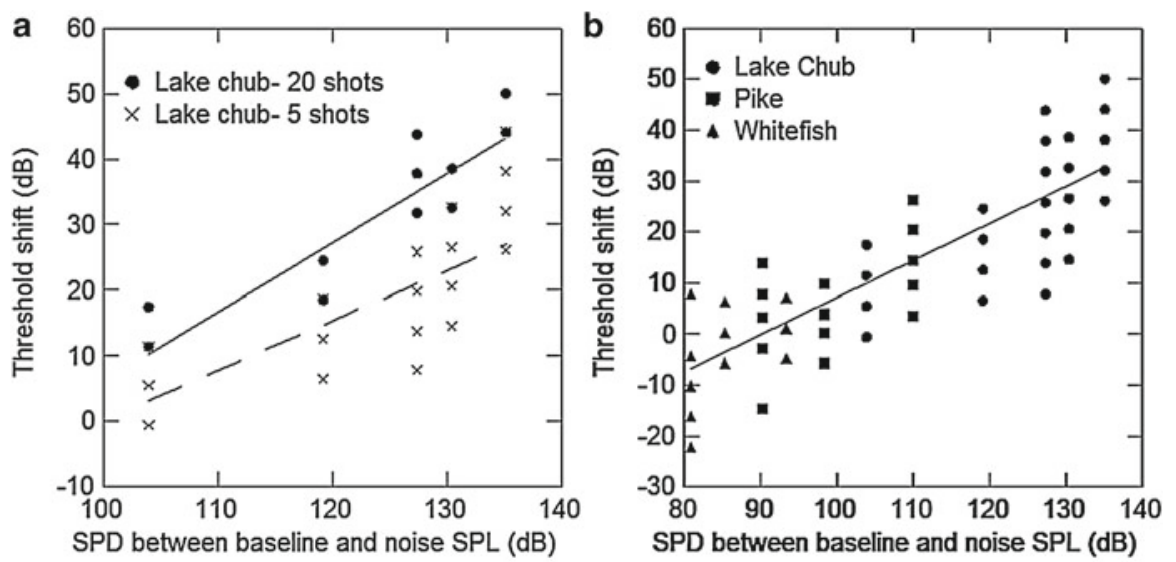

Fig. 5 Relationship between sound pressure difference (SPD) between the noise level and baseline hearing thresholds and temporary threshold shifts (TTS) for lake chub (C. plumbeus) exposed to 5 or 20 shots of a seismic airgun (a) and for lake chub, northern pike (Esox lucius), and broad whitefish (Coregonus nasus) exposed to the airgun (b). Each data point represents the TTS $(n=4-5)$ at each of the five frequencies tested and lines represent significant linear regression relationships (adapted with permission from Popper AN, Smith ME, Cott PA et al. (2005) Effects of exposure to seismic airgun use on hearing of three fish species. JASA 117:3958-3971, Copyright 2005, Acoustical Society of America)

channel catfish, but not for the bass or perch. Mid-frequency active (MFA) sonar, at a cumulative SEL of $220 \mathrm{~dB}$ re $1 \mu \mathrm{Pa}^{2} \mathrm{~s}$, did not cause a hearing threshold shift in rainbow trout, but channel catfish exhibited a 4-6 dB threshold shift at $2300 \mathrm{~Hz}$, which recovered within $24 \mathrm{~h}$ (Halvorsen et al. 2012c). In summary, the effects of sonar on fish hearing depend upon the sensitivity and bandwidth of the species and the frequency range of the sonar.

Recently, a number of studies have examined the effects of pile driving sounds on fishes (Halvorsen et al. 2011, 2012a, b; Casper et al. 2012, 2013a, b). Most of these studies focused on barotrauma and the effects of these impulsive sounds on non-sensory tissues such as swim bladder, liver, and blood vessels, but one study examined the effect of pile driving signals on the sensory epithelia of fish. Casper et al. (2013a) exposed hybrid striped bass (Morone chrysops X Morone saxatilis) and Mozambique tilapia (Oreochromis mossambicus) to 960 pile driving strikes at either 216, 213, or $210 \mathrm{~dB}$ re $1 \mu \mathrm{Pa}^{2}$ s cumulative SEL. Both sound-exposed species exhibited barotraumas. The bass also had significant saccular hair cell damage and loss, but only after being exposed to the highest sound level, while only one tilapia exhibited damage.

In conclusion, anthropogenic sound sources can produce sensory hair cell and hearing loss in fishes. However, most of these studies represent artificial scenarios in which the fishes are constrained relatively close to the sound source. Fishes in the wild would likely be frightened away by initial sounds, which would probably greatly mitigate their continued exposure to the sound source. Thus, there is a great need for behavioral studies of the responses of fishes to anthropogenic sound in their natural environments (see Popper and Hastings 2009). In addition, data is 
currently only available for a few species of fishes. As fish species differ considerably in the structure and functionality of their inner ear and lateral line, one cannot readily extrapolate the results from one species to another.

\subsection{Ototoxic Drug-Induced Hair Cell Loss}

In addition to noise, various ototoxic chemicals can damage lateral line and inner ear fish hair cells causing reduced auditory and vestibular sensory response. Ototoxin damage to fish hair cells has been demonstrated in Atlantic cod (Gadus morhua) (Faucher et al. 2009), goldfish (Carassius auratus) (Ramcharitar and Brack 2010; Ramcharitar and Selckmann 2010), Mexican blind cavefish (Astyanax mexicanus) (Van Trump et al. 2010), the oscar (Astronotus ocellatus) (Lombarte et al. 1993; Song et al. 1995), and the zebrafish (Danio rerio) (Hernández et al. 2006, 2007; Santos et al. 2006; Olivari et al. 2008; Uribe et al. 2013a, b). These chemicals include alkaloids (e.g., vinblastine and quinine), aminoglycosides (e.g., gentamicin, neomycin, and streptomycin), heavy metals and platinum based chemotherapy drugs (Yan et al. 1991; Lombarte et al. 1993; Song et al. 1995; Harris et al. 2003; Hernández et al. 2006, 2007; Ton and Parng 2005; Santos et al. 2006; Chiu et al. 2008; Ma et al. 2008; Olivari et al. 2008; Van Trump et al. 2010; Buck et al. 2012; Higgs and Radford 2013). Hair cell loss induced by ototoxins can cause hearing deficits. For example, zebrafish given an injection of gentamicin exhibited both hair cell loss and auditory threshold shifts (Fig. 6; Uribe et al. 2013b).

a

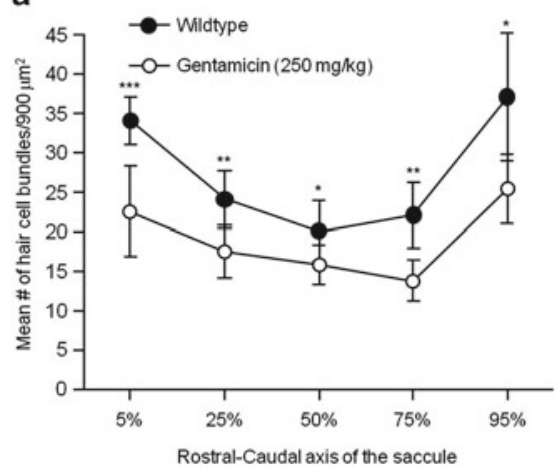

b

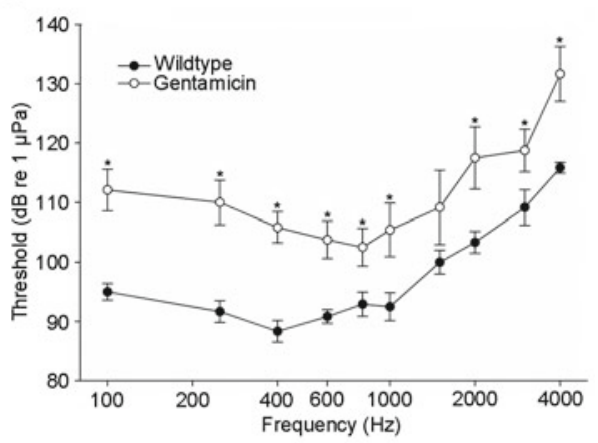

Fig. 6 (a) Mean $\left( \pm\right.$ SE) number of saccular hair cell bundles per $900 \mu \mathrm{m}^{2}$ of epithelia. Significantly fewer phalloidin-labeled hair bundles were counted at each area along the length of the saccule in gentamicin-treated animals compared to controls. ${ }^{*} p<0.05$, ** $p<0.01$, *** $<<0.001 ; n=6-13$ saccules per area per condition. (b) Auditory thresholds measured via electrophysiological recordings of auditory evoked potentials were used to construct audiograms to compare auditory function in treated and control fish. There was a significant auditory threshold shift $\left({ }^{*} p<0.05\right)$ at almost every frequency tested in gentamicin-treated fish when compared to untreated controls. $n=6$ animals per treatment (modified from Uribe et al. 2013b) 
The level of hair cell damage can depend on ototoxin concentration (Yan et al. 1991; Ton and Parng 2005; Hernández et al. 2006; Olivari et al. 2008) and exposure time (Song et al. 1995). Susceptibility of inner ear hair cells may also differ based on their location. For example, intramuscular gentamicin injections led to hair cell damage in the caudal portion of the saccule and the striolar region of the utricle in the goldfish ear (Ramcharitar and Selckmann 2010). In oscars, the striolar regions of both the utricles and lagenae were sensitive to gentamicin (Yan et al. 1991), while gentamicin can induce damage across the entire saccule and in both striolar and extrastriolar areas of the utricle in zebrafish (Uribe et al. 2013b). It is unclear if such differences are due to physiological differences between hair cell types or species, or due to experimental differences, e.g., gentamicin concentrations or injection methods. Differential susceptibility may also occur in the lateral line system of fishes. It was first reported that gentamicin produces damage in the canal but not the superficial neuromasts of the lateral line (Song et al. 1995). Recently, new data shows that gentamicin can kill hair cells in both canal and superficial neuromasts (Van Trump et al. 2010), suggesting that caution should be used when using aminoglycosides in behavioral studies of the lateral line (Brown et al. 2011). Another factor that should be taken into account is the ontogenic stage as ototoxic susceptibility in the zebrafish lateral line can increase as fish undergo development (Harris et al. 2003; Murakami et al. 2003; Santos et al. 2006).

Heavy metals and platinum containing chemotherapy drugs can also kill inner ear and lateral line hair cells. In larval zebrafish, lateral line hair cells and neuromast supporting cells are damaged by copper exposure in a concentration dependent manner (Hernández et al. 2006, 2007). In zebrafish, the platinum based chemotherapy agent cisplatin acts as an ototoxin (Ton and Parng 2005; Ou et al. 2007; Chiu et al. 2008; Owens et al. 2008; Giari et al. 2012). Cisplatin can cause greater damage to zebrafish inner ear hair cells than those in the lateral line (Giari et al. 2012). Ototoxicity increases when cisplatin is used in conjunction with other chemicals including the solvent DMSO and some anti-cancer drugs (Hirose et al. 2011; Uribe et al. 2013a).

Zebrafish lateral line studies are now used to discover otoprotectant chemicals that counteract ototoxins (Coffin et al. 2009, 2010, 2013; Ou et al. 2010; Esterberg et al. 2013). These studies have identified many promising compounds that can counteract cisplatin and aminoglycoside modulated ototoxicity (Kim et al. 2008; Owens et al. 2008; Ou et al. 2012; Shin et al. 2012; Vlasits et al. 2012). Thus, fish models are now not only successfully used for identifying ototoxins, but are rapidly becoming powerful new tools for identifying pharmaceutical leads that may prevent damage to hair cells.

\section{Consequences of Vestibular and Lateral Line Deficits}

Large-scale mutagenesis screens have discovered zebrafish mutants that are morphologically normal but exhibit balance deficits (Whitfield et al. 1996; Nicolson 2005). Loss of vestibular function in fishes can be identified via swimming behavior, the potentiated dorsal light reflex, the acoustic/vibrational startle reflex, monitoring neuronal activity in the mid- and hind-brain, and measuring microphonic potentials of 
lateral line neuromasts (Nicolson et al. 1998; Trapani and Nicolson 2011). For example, adult sputnik mutants exhibit circling behavior while swimming with forward somersaulting and random lateral looping and cosmonaut zebrafish spin in a pinwheel fashion around their head as an axis. Sputnik also lacks a startle response and has altered and non-functional stereociliary bundles in the crista of the semicircular canals (Nicolson et al. 1998). As different zebrafish vestibular mutants exhibit different deficits correlated with specific genes along the auditory-vestibular mechanoreception pathway, they are being used to understand the molecular basis of auditory-vestibular signal transduction. For example, sputnik mutants have mutations in cadherin 23 (cdh23), an important protein found in hair cell stereocilia tip links which are necessary for hair cell mechanotransduction (Söllner et al. 2004).

The lateral line system is implicated in a fish's ability to swim in schools (Pitcher et al. 1976), avoid predators (Blaxter and Fuiman 1989), orient in a current (Montgomery et al. 1997), and localize prey (Coombs et al. 2001). Thus, any dysfunction in this system could have serious fitness consequences. Differences in acoustically induced startle responses have been reported between wild and hatchery-reared fishes (Smith and Fuiman 2004). It is possible that behavioral deficits in hatchery-reared fishes are the result of differences in their inner ear and lateral line system compared to wild-type fish. For example, hatchery-reared juvenile steelhead (Oncorhynchus mykiss) exhibited smaller numbers of superficial neuromasts and greater numbers of abnormal otoliths compared to wild-collected individuals (Brown et al. 2013).

In order to better understand the role of the lateral line on fish behavior, experimenters have damaged the lateral line system and quantified the resulting behavioral deficits. For example, Blaxter and Fuiman (1989) found a reduction in startle responses after neuromast ablation in herring (Clupea harengus), cod (Gadus morhua), plaice (Pleuronectes platessa), flounder (Platichthys flesus), and halibut (Hippoglossus hippoglossus) larvae. Similarly, Montgomery et al. (1997) reported a significant reduction in rheotactic response in torrentfish (Cheimarrichthys fosteri), bald notothen (Pagothenia borchgrevinki), and blind cavefish (Astyanax fasciatus) following blockage or damage to the lateral line system by ototoxic treatments, i.e., cobalt, streptomycin, or gentamicin, or physical ablation of the superficial neuromasts by gentle scraping.

While these studies suggest that the behavioral deficits are the result of a loss of lateral line neuromast function, there may be comorbid non-sensory physiological effects from the pharmacological treatments that produce shifts in behavior (Janssen 2000). In fact, recent work using fluorescent dye stains shows that streptomycin or gentamicin treatments produce limited neuromast damage and suggests that even in the absence of damage, pharmacologic agents might be able to modulate physiology and produce behavioral deficits (Brown et al. 2011).

\section{Consequences of Anthropogenic Noise Exposure}

As discussed previously, hearing and vestibular loss in fishes can result from mutations, treatment with ototoxic chemicals, and exposure to acoustic trauma. Although the effects of mutations and ototoxins on fish hearing loss are of considerable 
interest, this section will focus on the consequences of acoustic trauma. Noise from anthropogenic sound sources can produce negative effects on fishes ranging from physical damage and death due to very intense sounds such as underwater explosions, sonar, pile driving, or seismic surveys (Popper et al. 2005, 2007; Casper et al. 2012, 2013a, b; Halvorsen et al. 2012a, b) to more subtle behavioral effects such as reduced foraging, shelter maintenance, and predator defense (Purser and Radford 2011; Bruintjes and Radford 2013). The extreme effects of physical damage and death have been recently reviewed elsewhere (Edds-Walton and Finneran 2006; Popper and Hastings 2009), as have behavioral effects with potential long-term population level consequences (Slabbekoorn et al. 2010; Radford et al. 2014). Therefore, we will focus here on the intermediate effect of anthropogenic sound, hearing loss.

In order to understand the effect of hearing loss on fishes, one must first assess which types of acoustic stimuli are biologically relevant to them. One thing that they listen to is other fishes (both conspecific and heterospecific), as well as other aquatic sound-producing organisms (Lagardère et al. 2005; Vasconcelos et al. 2011; McIver et al. 2014). Fishes produce sounds in a variety of ways including drumming of the swim bladder, stridulation of bones such as pectoral spines and pharyngeal teeth, and vibration of tendons (Ladich and Fine 2006). Approximately 800 species of fish from over 100 different families are known to produce sound (Ladich and Fine 2006; Ladich and Bass 2008). Although the behavioral significance of most of these sounds has not yet been examined, it is known that some species use sound for spatial orientation, defense from predators or competitors, reproductive behaviors including courtship, mate choice and synchronization of gamete release, and alarm/ stress calls (Winn 1964; Tavolga 1971, 1977; Hawkins 1993; Ladich 2000; Ladich and Fine 2003; Ladich and Bass 1998). As sounds produced by fishes can vary by species, populations, gender, size, and motivation, they can provide useful information that might be used to modify fish behavior and thus influence their reproductive fitness (Hawkins and Rasmussen 1978; Myrberg et al. 1993; Parmentier et al. 2005; Verzijden et al. 2010).

Intense sound exposure has been shown to elicit short-term physiological stress responses and startle behaviors in fishes (Skalski et al. 1992; Wardle et al. 2001; Smith et al. 2004a; Boeger et al. 2006; Wysocki et al. 2006, 2007). Unfortunately, there are few behavioral studies on the effects of anthropogenic sound on fishes and most of these studies have used test cages or tanks during the sound exposure (McCauley et al. 2003; Boeger et al. 2006; Popper et al. 2007). Thus the behavioral observations of these experiments may differ from how fish might react unrestrained in the wild. More recent experiments have shown that background noise can affect fish foraging and antipredator behavior (Purser and Radford 2011; Bruintjes and Radford 2013), but in no behavioral experiment performed to date has hearing loss been quantified such that the relationship between hearing loss and specific behavioral deficits can be elucidated. At this point, we can only speculate that hearing loss in fishes would produce similar disruptions in acoustic communication as in other vertebrates (reviewed in Radford et al. 2014). Increased hearing thresholds would mean that fish would have to be closer to sound-producing prey, mates, competitors, or predators before they could detect them. Hearing loss may also inhibit 
discrimination between conspecific or heterospecific sounds that might differ subtly in terms of temporal patterning or frequency.

Some fish species are not known to produce sound. It has been hypothesized that the evolution of hearing in fish may not have been for communication per se, but rather to gain acoustical information from the surrounding environment, i.e., the auditory scene (Fay and Popper 1999). These sounds could have a physical source, such as wave and tidal action, or be biological, such as the sounds produced by predators or prey. Although data is still very limited, it is possible that hearing loss could have negative consequences on a fish's ability to forage, reproduce, avoid predators, and orient in their environment, thus affecting their fitness.

\section{Regeneration of Sensory Hair Cells and Recovery from Auditory Deficits}

In the 1980s it was discovered that the number of inner ear hair cells of elasmobranch and teleost fishes increased for several years into adulthood (Corwin 1981, 1983; Popper and Hoxter 1984). This also suggested that fish may have the ability to regenerate sensory hair cells. Lombarte et al. (1993) were the first to document hair cell regeneration in a fish. They showed that treatment with gentamicin sulfate caused hair cell loss in the striolar regions of the utricle and lagena of the oscar. However hair cell ciliary bundles recovered to control level densities within approximately 10 days following maximal hair cell loss.

Similarly, after 21 days of exposure to $160-170 \mathrm{~dB}$ re $1 \mu \mathrm{Pa}$ white noise, goldfish which initially exhibited an average TTS of $18 \mathrm{~dB}$ recovered to control levels within 14 days (Smith et al. 2004a). Much of this recovery occurred within the first 7 days, as in goldfish exposed to the same stimulus for only 2 days (Smith et al. 2006). Although recovery of hearing was within $4 \mathrm{~dB}$ of control levels 7 days postexposure, caudal saccular hair cell densities had still not returned to normal after 8 days, suggesting that a full set of hair cells are not necessary for normal auditory responses, at least in terms of AEPs (Fig. 7; Smith et al. 2006). Fathead minnows (Pimephales promelas) exposed to $142 \mathrm{~dB}$ re $1 \mu \mathrm{Pa}$ white noise for $2 \mathrm{~h}$ had thresholds that returned to control levels within 6 days following sound exposure while those exposed for $24 \mathrm{~h}$ did not completely recover after 14 days (Scholik and Yan 2001). In another goldfish study, fish exposed for 12-24 h returned to control levels within 3 days (Amoser and Ladich 2003). Obviously, the time course for recovery from hearing loss will likely depend upon the species being examined and its normal hearing sensitivity, the sound exposure intensity and duration, and the amount of sensory epithelial damage and hearing loss that is induced by the acoustic trauma.

No permanent hearing loss has been reported for fishes as long-term acoustic studies are typically not performed and fish inner ear hair cells have the ability to regenerate (Smith et al. 2006; Schuck and Smith 2009; Schuck et al. 2011). The longest time following a noise exposure in which the inner ear sensory cells of a fish have been examined is 58 days. McCauley et al. (2003) exposed pink snapper 


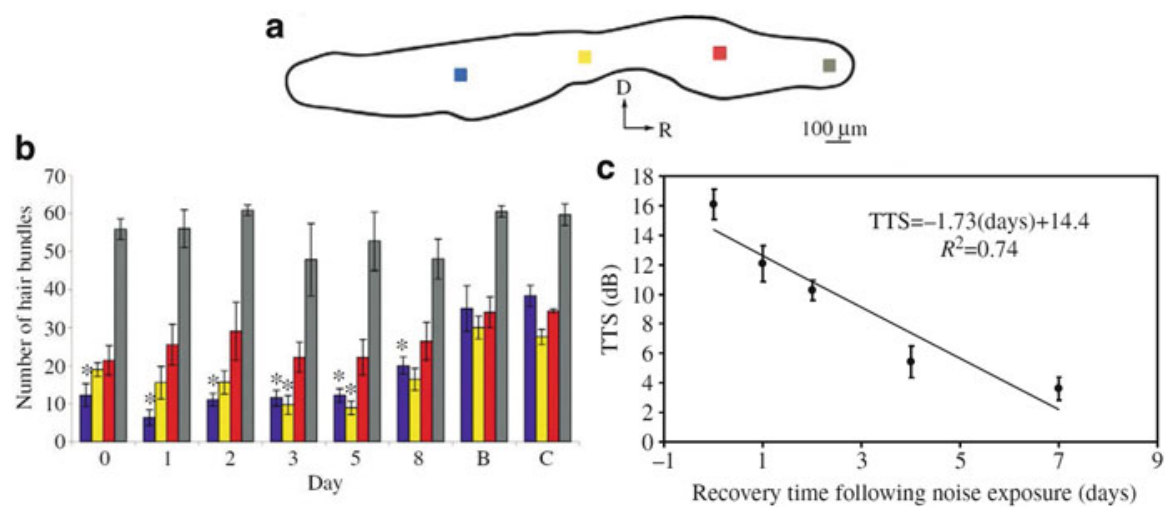

Fig. 7 (a) Drawing showing the four $2500 \mu \mathrm{m}^{2}$ regions of the saccular macula where hair bundles were quantified. (b) Mean $( \pm \mathrm{SE})$ numbers of hair bundles in each saccular region by day post-noise exposure, where " 0 " begins immediately following $48 \mathrm{~h}$ of noise exposure. " $\mathrm{B}$ " indicates baseline animals that were sacrificed prior to the experiment and " $\mathrm{C}$ " indicates control animals that were held in the experimental setup for $48 \mathrm{~h}$ without the sound stimulus. $n=6$ per data point for controls and Days $0-8 . n=2$ for baseline. Asterisks indicate significant differences from baselines and controls $(p<0.05)$. (c) Mean $( \pm$ SE) TTS of noise-exposed goldfish at various times following $48 \mathrm{~h}$ of white noise exposure. $n=6$ per data point (one mean value of six fish for each of six frequencies). The line represents the linear regression equation for the data shown (modified from Smith et al. 2006)

(Pagrus auratus) to an acoustic stimulus that mimicked a passing seismic vessel. They found considerably more holes in the saccular epithelia at 58 compared to 18 days post-exposure suggesting that the process of sensory hair cell death and regeneration is very slow in this species. As no hearing tests were done on these fish, it is impossible to say whether the hair cell loss caused hearing loss, but other studies have shown a strong relationship between saccular hair cell loss and hearing loss (Smith et al. 2011; Smith 2012). As other studies discussed previously show postacoustic trauma recovery of hair cells and hearing within approximately 2 weeks, it is unclear why the snapper still exhibited significant hair cell damage after 58 days, but it may have been the result of the intensity of the seismic stimulus.

The time course of recovery following ototoxic damage in fish ears has only been investigated in one study. Faucher et al. (2009) examined hair cell damage and functional recovery in Atlantic cod (Gadus morhua) given intrasaccular injections of gentamicin. They found that hair cell densities returned to control levels 14 days post-injection (dpi), although average hair cell kinocilia length was still shorter than normal at $21 \mathrm{dpi}$, suggesting that newly formed hair cells may still be growing. AEP hearing thresholds returned to normal at $17 \mathrm{dpi}$.

While lost auditory hair cells appear to take a few weeks to completely recover in the inner ear of fishes, neuromasts and their associated hair cells in the lateral line system recover much more quickly. For example, larval zebrafish briefly exposed to neomycin or dissolved copper recovered their hair cell numbers within 48-72 $\mathrm{h}$ as a result of supporting cell proliferation and then differentiation into hair cells 
(Harris et al. 2003; Ma et al. 2008; Mackenzie and Raible 2012). The rate of regeneration was delayed by one or more days when the larvae were treated with cisplatin or higher concentrations of copper, suggesting that the time course of regeneration is dependent upon the severity of the ototoxic insult (Mackenzie and Raible 2012). In fact, high concentrations of ototoxins can damage hair cells and supporting cells, which can proliferate and differentiate into new hair cells (Olivari et al. 2008). There may be a selective advantage for lateral line hair cells to regenerate more rapidly than inner ear hair cells because the external placement of lateral line hair cells exposes them more intensely to chemical and mechanical stressors.

As a major impetus for sensory hair cell research in fish is to find potential therapeutics for human hearing loss and its prevention, an understanding of hair cell death and regeneration signal-transduction pathways is necessary. Although a full discussion of this topic is beyond the scope of this review, several central points will be briefly mentioned. Microarray, microRNA, and next-generation sequencing (NGS) techniques enable the characterization of gene expression in fish auditory sensory tissues under various experimental conditions and facilitate identification of the molecular effectors of sensory hair cell regeneration (reviewed in Smith and Rajadinakaran 2013). Many of the molecules and pathways implicated in fish hair cell death and recovery are found in humans as well. For example, hair cell death in zebrafish is modulated by c-jun N-terminal kinase (JNK; Ou et al. 2006) and both caspase dependent (Cunningham et al. 2002; Cheng et al. 2003) and independent pathways (Jiang et al. 2006), which are also regulated in mammalian models (Cheng et al. 2005). Pathways regulated in zebrafish during hair cell regeneration include Wnt/ $\beta$-Catenin, Notch, Sox 2 and Rb (Ma et al. 2008; Millimaki et al. 2010; Aman et al. 2011; Lin et al. 2013). These and other pathways have recently been reviewed more thoroughly elsewhere (Smith and Rajadinakaran 2013; Lush and Piotrowski 2014).

\section{Future Research Directions}

Considerable progress has been made in the last two decades towards advancing our understanding of the causes and consequences of sensory hair cell loss in fishes. The use of zebrafish as a biomedical model of sensory hair cell death and regeneration has grown exponentially. Using zebrafish high-throughput methods, mutations affecting inner ear development have been found that are relevant to human hearing loss (Malicki et al. 1996; Whitfield et al. 2005), numerous pharmaceutical agents have been tested for ototoxicity (reviewed in Coffin and Ramcharitar 2015; Coffin and Ramcharitar 2015), and otoprotective compounds have been identified (Coffin et al. 2010, 2013). In addition, many pathways involved in sensory hair cell death and regeneration have been discovered (Smith and Rajadinakaran 2013). In the future, specific cellular mechanisms involved in hair cell death and regeneration will need to be elucidated further, and many of the ototoxic and otoprotective compounds discovered will need to be tested in mammalian models before use in human 
clinical trials. As genetic manipulations can produce disorganized placement of new hair cells in the mammalian organ of Corti without recovery of hearing (Löwenheim et al. 1999; Mansour et al. 2009), it is likely that functional hair cell regeneration in the cochlea will involve more than a single gene or cellular pathway. However, the utility of the zebrafish as an auditory model may make them very valuable in further characterizing the many genes and pathways involved in hair cell death and regeneration in humans. The usage of zebrafish screens to find effective pharmaceutical compounds with reduced ototoxicity should also continue to be an area of productive research effort.

Research on the effects of anthropogenic sounds on fishes is relatively new compared to biomedical studies of hair cells. Audiograms have only been recorded for a limited number of taxa out of the over 27,000 species of fishes, and sound-induced hearing loss has been tested in less than 20 species. Thus, data on how anthropogenic sound effects fishes is needed on more species. Models to predict soundinduced hearing loss have been developed using the SPL of the acoustic stimulus and the hearing sensitivity of the species (Smith et al. 2004b; Smith 2012), but future models should use particle motion sensitivity measures and account for species-specific pressure versus particle motion sensitivity. There are also a number of questions that are still unanswered: Can fish exhibit permanent hearing loss if the sensory epithelia is damaged sufficiently? What is the best measure of a sound stimulus to predict hearing loss in fishes, e.g., peak sound pressure, SEL, particle velocity, or intensity (i.e., acoustic energy flux)? What are the behavioral and survival effects for fishes affected by anthropogenic sound? As more researchers are investigating how anthropogenic sound affects animals, we believe that progress will be made within the next decade to answer these and other questions related to acoustic exposure of fishes.

Acknowledgements The authors express their gratitude to both Arthur N. Popper and Richard R. Fay for their many years of exceptional research on fish hearing and bioacoustics and their leadership and mentoring in this field. MES thanks Art Popper for his first postdoctoral job and for the wise advice, friendship, and consummate mentoring at the University of Maryland, where the author began his career in fish hearing research and started examining the effects of sound on fishes. Art provided numerous career development opportunities to present research at conferences, to receive specific training, e.g., a course on Acoustic Communication in Denmark, to team-teach courses, to collaborate on broader lab projects, and to network with other researchers in the field of fish hearing. Of course, Dick Fay was one of those colleagues that Art introduced MES to and he is grateful for Dick's advice on projects, particularly the work on the tonotopic organization of the goldfish saccule. MES thanks numerous undergraduate researchers, former graduate students Julie Schuck, Chia-Hui Lin, Yajie Wang, Gopinath Rajadinakaran, and Bethany Coffey, and former postdoctoral researchers Todd Penberthy and Huifang Sun, for their many hours of auditory evoked potential recordings and inner ear dissections to examine hair cell and hearing loss in fishes.

Research in the Smith lab was supported by the National Institute of General Medical Sciences of the NIH (P20 RR-16481, 8 P20 GM103436-12, 2 P20 GM103436-14), a Kentucky Science and Engineering Foundation Research \& Development Excellence Grant (KSEF-148-502-14-325), and an NSF SOMAS Award (DUE-0426266). We thank Drs. Allison Coffin and Joseph Sisneros for helpful comments on an earlier draft of this manuscript. 


\section{References}

Aman A, Nguyen M, Piotrowski T (2011) Wnt/Beta-catenin dependent cell proliferation underlies segmented lateral line morphogenesis. Dev Biol 249:470-482

Amoser S, Ladich F (2003) Diversity in noise-induced temporary hearing loss in otophysine fishes. J Acoust Soc Am 113:2170-2179

ASHA (2014) The American Speech-Language-Hearing Association (ASHA) register. http:// www.asha.org. Accessed 10 July 2014

Baggeroer A, Munk W (1992) The Heard Island feasibility test. Phys Today 45:22-30

Bang PI, Sewell WF, Malicki JJ (2000) Behavioral screen for dominant mutations affecting zebrafish auditory system. Assoc Res Otolaryngol Abs 23:177-187

Bang PI, Yelick PC, Malicki JJ et al (2002) High-throughput behavioral screening method for detection auditory response defects in zebrafish. J Neurosci Methods 118:177-187

Barbazuk WB, Korf I, Kadavi C et al (2000) The syntenic relationship of zebrafish and human genomes. Genome Res 10:1351-1358

Bhandiwad AA, Zeddies DG, Raible DW, Rubel EW, Sisneros JA (2013) Auditory sensitivity of larval zebrafish (Danio rerio) measured using a prepulse inhibition assay. J Exp Biol 216:3504-3513

Blaxter JA, Fuiman LA (1989) Function of the free neuromasts of marine teleost larvae. In: Coombs S, Gorner P, Munz H (eds) The mechanosensory lateral line. Springer, New York, pp 481-499

Boeger WA, Pie MR, Ostrensky A et al (2006) The effect of exposure to seismic prospecting on coral reef fishes. Braz J Oceanogr 54:235-239

Brown AD, Mussen TD, Sisneros JA et al (2011) Reevaluating the use of aminoglycoside antibiotics in behavioral studies of the lateral line. Hear Res 272:1-4

Brown AD, Sisneros JA, Jurasin T et al (2013) Differences in lateral line morphology between hatchery- and wild-origin steelhead. PLoS One 8(3), e59162

Bruintjes R, Radford AN (2013) Context-dependent impacts of anthropogenic noise on individual and social behavior in a cooperatively breeding fish. Anim Behav 85:1343-1349

Buck LM, Winter MJ, Redfern WS et al (2012) Ototoxin-induced cellular damage in neuromasts disrupts lateral line function in larval zebrafish. Hear Res 284:67-81

Casper BM, Popper AN, Matthews F et al (2012) Recovery of barotrauma injuries in Chinook salmon, Oncorhynchus tshawytscha from exposure to pile driving sound. PLoS One 7, e39593

Casper BM, Smith ME, Halvorsen MB et al (2013a) Effects of exposure to pile driving sounds on fish inner ear tissues. Comp Biochem Physiol A 166:352-360

Casper BM, Halvorsen MB, Mathews F et al (2013b) Recovery of barotrauma injuries resulting from exposure to pile driving sounds in two sizes of hybrid striped bass. PLoS One 8, e73844

Cervi AL, Poling KR, Higgs DM (2012) Behavioral measure of frequency detection and discrimination in the zebrafish, Danio rerio. Zebrafish 9:1-7

Cheng AG, Cunningham LL, Rubel EW (2003) Hair cell death in the avian basilar papilla: characterization of the in vivo model and caspase activation. J Assoc Res Otolaryngol 4:91-105

Cheng AG, Cunningham LL, Rubel EW (2005) Mechanisms of hair cell death and protection. Curr Opin Otolaryngol Head Neck Surg 13:343-348

Chiu LL, Cunningham LL, Raible DW et al (2008) Using the zebrafish lateral line to screen for ototoxicity. J Assoc Res Otolaryngol 9:178-190

Coffey B (2014) Melanin as an oto-protective pigment in two fish species: Poecilia latipinna and Cyprinus carpio. Western Kentucky University, Master's Thesis

Coffin AB, Ramcharitar J (2015) Chemical ototoxicity of the fish inner ear and lateral line. In: Sisneros J (ed) Fish hearing and bioacoustics: an anthology in honor of Arthur N. Popper and Richard R. Fay. Springer, New York (this volume)

Coffin AB, Kelley M, Manley GA et al (2004) Evolution of sensory hair cells. In: Manley GA, Popper AN, Fay RR (eds) Evolution of the vertebrate auditory system. Springer, New York, pp 55-94 
Coffin AB, Reinhart KE, Owens KN et al (2009) Extracellular divalent cations modulate aminoglycoside-induced hair cell death in the zebrafish lateral line. Hear Res 253:42-51

Coffin AB, Ou H, Owens KN et al (2010) Chemical screening for hair cell loss and protection in the zebrafish lateral line. Zebrafish 7:3-11

Coffin AB, Rubel EW, Raible DW (2013) Bax, Bcl2, and p53 differentially regulate neomycinand gentamicin-induced hair cell death in the zebrafish lateral line. J Assoc Res Otolaryngol 14:645-659

Coombs S (2001) Smart skins: information processing by lateral line flow sensors. Auton Robot 11:255-261

Coombs S, Braun CB, Donovan B (2001) The orienting response of Lake Michigan mottled sculpin is mediated by canal neuromasts. J Exp Biol 204:337-348

Corwin JT (1981) Postembryonic production and gaining in inner ear hair cells in sharks. J Comp Neurol 201:541-553

Corwin JT (1983) Postembryonic growth of the macula neglecta auditory detector in the ray, Raja clavata: continual increases in hair cell number, neural convergence, and physiological sensitivity. J Comp Neurol 217:345-356

Corwin JT, Bullock TH, Schweitzer J (1982) The auditory brainstem response in five vertebrate classes. Electroencephalogr Clin Neurophysiol 54:629-641

Cunningham LL, Cheng AG, Rubel EW (2002) Caspase activation in hair cells of the mouse utricle exposed to neomycin. J Neurosci 22:8532-8540

Edds-Walton PL, Finneran JJ (2006) Evaluation of evidence for altered behavior and auditory deficits in fishes due to human-generated noise sources. Technical Report 1939, SPAWAR, Department of the Navy, San Diego, CA

Enger PS (1981) Frequency discrimination in teleosts - central or peripheral? In: Tavolga WN, Popper AN, Fay RR (eds) Hearing and sound communication in fishes. Springer, New York

Ernest S, Rauch GJ, Haffter P et al (2000) Mariner is defective in myosin VIIA: a zebrafish model for human hereditary deafness. Hum Mol Genet 9:2189-2196

Esterberg R, Coffin AB, Ou H et al (2013) Fish in a dish: drug discovery for hearing habilitation. Drug Discov Today Dis Models 10(1). doi:10.1016/j.ddmod.2012.02.001

Faucher K, Aas-Hansen $\varnothing$, Damsgård B et al (2009) Damage and functional recovery of the Atlantic cod (Gadus morhua) inner ear hair cells following local injection of gentamicin. Int J Audiol 48:456-464

Fay RR, Megela Simmons A (1999) The sense of hearing in fish and amphibians. In: Fay RR, Popper AN (eds) Comparative hearing: fish and amphibians. Springer, New York, pp 269-318

Fay RR, Popper AN (1999) Hearing in fishes and amphibians: an introduction. In: Fay RR, Popper AN (eds) Comparative hearing: fish and amphibians. Springer, New York, pp 1-14

Gerhard GS (2003) Comparative aspects of zebrafish (Danio rerio) as a model for aging research. Exp Gerontol 38:1333-1341

Ghysen A, Dambly-Chaudière C (2004) Development of the zebrafish lateral line. Curr Opin Neurobiol 14:67-73

Giari L, Dezfuli BS, Astolfi L et al (2012) Ultrastructural effects of cisplatin on the inner ear and lateral line system of zebrafish (Danio rerio) larvae. J Appl Toxicol 32:293-299

Haehnel M, Taguchi M, Liao JC (2012) Heterogeneity and dynamics of lateral line afferent innervation. J Comp Neurol 520:1376-1386

Halvorsen MB, Casper BM, Woodley CM et al (2011) Predicting and mitigating hydroacoustic impacts on fish from pile installations. NCHRP Research Results Digest 363, Project 25-28, National Cooperative Highway Research Program, Transportation Research Board, National Academy of Sciences, Washington, DC

Halvorsen MB, Casper BM, Woodley CM et al (2012a) Threshold for onset of injury in Chinook salmon from exposure to impulsive pile driving sounds. PLoS One 7, e38968

Halvorsen MB, Casper BM, Matthews F et al (2012b) Effects of exposure to pile driving sounds on the lake sturgeon, Nile tilapia, and hogchoker. Proc R Soc B 279:4705-4714 
Halvorsen MB, Zeddies DG, Ellison WT, Chicoine DR, Popper AN (2012c) Effects of midfrequency active sonar on hearing in fish. J Acoust Soc Am 131:599-607

Halvorsen MB, Zeddies DG, Chicoine DR, Popper AN (2013) Effects of low-frequency naval sonar exposure on three species of fish. J Acoust Soc Am 134:EL205-EL210

Han Y, Mu Y, Li X et al (2011) Grhl2 deficiency impairs otic development and hearing ability in a zebrafish model of the progressive dominant hearing loss DFNA28. Hum Mol Genet 20:3213-3226

Harris JA, Cheng AG, Cunningham LL et al (2003) Neomycin-induced hair cell death and rapid regeneration in the lateral line of zebrafish (Danio rerio). J Assoc Res Otolaryngol 4:219-234

Hastings MC, Popper AN (2005) Effects of sound on fish. California Department of Transportation Contract 43A0139 Task Order, 1

Hastings MC, Popper AN, Finneran JJ et al (1996) Effect of low frequency underwater sound on hair cells of the inner ear and lateral line of the teleost fish Astronotus ocellatus. J Acoust Soc Am 99:1759-1766

Hawkins AD (1993) Underwater sound and fish behavior. In: Pitcher TJ (ed) Behaviour of teleost fishes. Chapman and Hall, London, pp 129-169

Hawkins AD, Rasmussen KJ (1978) The calls of gadoid fish. J Mar Biol Assoc UK 58:891-911

Hernández PP, Moreno V, Olivari FA et al (2006) Sub-lethal concentrations of waterborne copper are toxic to lateral line neuromasts in zebrafish (Danio rerio). Hear Res 213:1-10

Hernández PP, Olivari FA, Sarrazin AF et al (2007) Regeneration in zebrafish lateral line neuromasts: expression of the neural progenitor cell marker sox 2 and proliferation-dependent andindependent mechanisms of hair cell renewal. Dev Neurobiol 67:637-654

Higgs DM, Radford CA (2013) The contribution of the lateral line to 'hearing' in fish. J Exp Biol 216:1484-1490

Higgs DM, Rollo AK, Souza MJ et al (2003) Development of form and function in peripheral auditory structures of the zebrafish (Danio rerio). J Acoust Soc Am 113:1145-1154

Hirose Y, Simon JA, Ou HC (2011) Hair cell toxicity in anti-cancer drugs: evaluating an anticancer drug library for independent and synergistic toxic effects on hair cells using the zebrafish lateral line. J Assoc Res Otolaryngol 12:719-728

Hulander M, Kiernan AT, Blomqvuist SR et al (2003) Lack of pendrin expression leads to deafness and expansion of the endolymphatic compartment in the inner ears of Foxil null mutant mice. Development 130:2013-2025

Indzhykulian AA, Stepanyan R, Nelina A et al (2013) Molecular remodeling of tip links underlies mechanosensory regeneration in auditory hair cells. PLoS Biol 11(6), e1001583

Janssen J (2000) Toxicity of $\mathrm{Co}^{2+}$ : implications for lateral line studies. J Comp Physiol A 186:957-960

Jiang H, Sha S-H, Forge A et al (2006) Caspase-independent pathways of hair cell death induced by kanamycin in vivo. Cell Death Differ 13:20-30

Kenyon TN, Ladich F, Yan HY (1998) A comparative study of hearing ability in fishes: the auditory brainstem approach. J Comp Physiol A 182:307-318

Kim CH, Kang SU, Pyun J et al (2008) Epicatechin protects auditory cells against cisplatininduced death. Apoptosis 13:1184-1194

Ladich F (2000) Acoustic communication and the evolution of hearing in fishes. Philos Trans R Soc Lond 335:1285-1288

Ladich F, Bass A (1998) Sonic/vocal motor pathways in catfishes: comparisons with other teleosts. Brain Behav Evol 15:315-330

Ladich F, Bass A (2008) Vocal-acoustic communication: from behavior to neurons. In: Popper A, Fay R, Webb J (eds) Fish bioacoustics. Springer, New York, pp 253-278

Ladich F, Fine ML (2003) Sound production, spine locking, and related adaptations. In: Ladich F, Collin SP, Moller P et al (eds) Catfishes, vol 1, Science Publishers. Inc, Entfield, pp 249-290

Ladich F, Fine ML (2006) Sound-generating mechanisms in fishes: a unique diversity in vertebrates. In: Ladich F, Collin SP, Moller P et al (eds) Communication in fishes, vol 1, Science Publishers. Inc, Entfield, pp 3-43 
Ladich F, Wysocki LE (2003) How does tripus extirpation affect auditory sensitivity in goldfish? Hear Res 182:119-129

Lagardère JP, Millot S, Parmentier E (2005) Aspects of sound communication in the pearlfish Carapus boraborensis and Carapus homei (Carapidae). J Exp Zool A Comp Exp Biol 303:1066-1074

Lechner W, Heiss E, Schwaha T et al (2011) Ontogenetic development of Weberian ossicles and hearing abilities in the African bullhead catfish. PLoS One 6(4), e18511

Lin Q, Li W, Chen Y, Sun S, Li H (2013) Disrupting Rb-Raf-1 interaction inhibits hair cell regeneration in zebrafish lateral line neuromasts. Neuroreport 24:190-195

Liu X-Z, Walsh J, Mburu P et al (1997) Mutations in the myosin VIIA gene cause non-syndromic recessive deafness. Nat Genet 16:188-190

Lombarte A, Yan HY, Popper AN et al (1993) Damage and regeneration of hair cell ciliary bundles in a fish ear following treatment with gentamicin. Hear Res 64:1661-1674

Löwenheim H, Furness DN, Kil J et al (1999) Gene disruption of p27 $7^{\text {Kipl }}$ allows cell proliferation in the postnatal and adult organ of Corti. Proc Natl Acad Sci U S A 96:4084-4088

Lush ME, Piotrowski T (2014) Sensory hair cell regeneration in the zebrafish lateral line. Dev Dyn 243:1187-1202

Ma EY, Rubel EW, Raible DW (2008) Notch signaling regulates the extent of hair cell regeneration in the zebrafish lateral line. J Neurosci 28:2261-2273

Mackenzie SM, Raible DW (2012) Proliferative regeneration of zebrafish lateral line hair cells after different ototoxic insults. PLoS One 7, e47257

Malicki J, Schier AF, Solnica-Krezel L et al (1996) Mutations affecting development of the zebrafish ear. Development 123:275-283

Mansour SL, Twigg SRF, Freeland RM et al (2009) Hearing loss in a mouse model of Muenke syndrome. Hum Mol Genet 18:43-50

McCauley RD, Fewtrell J, Popper AN (2003) High intensity anthropogenic sound damages fish ears. J Acoust Soc Am 113:1-5

McHenry MJ, van Netten SM (2007) The flexural stiffness of superficial neuromasts in the zebrafish (Danio rerio) lateral line. J Exp Biol 210:4244-4253

McIver EL, Marchaterre MA, Rice AN, Bass AH (2014) Novel underwater soundscape: acoustic repertoire of plainfin midshipman fish. J Exp Biol 217:2377-2389

Millimaki BB, Sweet EM, Riley BB (2010) Sox2 is required for maintenance and regeneration, but not initial development, of hair cells in the zebrafish inner ear. Dev Biol 338:262-269

Montgomery JC, Baker CF, Carton AG (1997) The lateral line can mediate rheotaxis in fish. Nature 38:960-963

Murakami SL, Cunningham LL, Werner LA et al (2003) Developmental differences in susceptibility to neomycin-induced hair cell death in the lateral line neuromasts of zebrafish (Danio rerio). Hear Res 186:47-56

Myrberg AA, Ha SJ, Shamblott MJ (1993) The sounds of bicolor damselfish (Pomacentrus partitus): predictors of body size and a spectral basis for individual recognition and assessment. J Acoust Soc Am 94:3067-3070

Nicolson T (2005) The genetics of hearing and balance in zebrafish. Annu Rev Genet 39:9-22

Nicolson T, Rusch A, Friedrich RW et al (1998) Genetic analysis of vertebrate sensory hair cell mechanosensation: the zebrafish circler mutants. Neuron 20:271-283

Olivari FA, Hernández PP, Allende ML (2008) Acute copper exposure induces oxidative stress and cell death in lateral line hair cells of zebrafish larvae. Brain Res 1244:1-12

Ou HC, Santos F, Raible DW et al (2006) c-Jun N-terminal kinase inhibition blocks aminoglycoside but not cisplatin-induced hair cell death in the zebrafish lateral line. Midwinter Research Meeting of the Association for Research in Otolaryngology

Ou HC, Raible DW, Rubel EW (2007) Cisplatin-induced hair cell loss in zebrafish (Danio rerio) lateral line. Hear Res 233:46-53

Ou HC, Santos F, Raible DW et al (2010) Drug screening for hearing loss: using the zebrafish lateral line to screen for drugs that prevent and cause hearing loss. Drug Discov Today $15: 265-271$ 
Ou H, Simon JA, Rubel EW et al (2012) Screening for chemicals that affect hair cell death and survival in the zebrafish lateral line. Hear Res 288:58-66

Owens KN, Santos F, Roberts B et al (2008) Identification of genetic and chemical modulators of zebrafish mechanosensory hair cell death. PLoS Genet 4(2), e1000020

Parkes G, Hatton L (1986) The marine seismic source. D. Reidel Publishing Company, Dordrecht

Parmentier E, Lagardere JP, Vandewalle P, Fine ML (2005) Geographical variation in sound production in the anemonefish Amphiprion akkallopisos. Proc R Soc Lond B Biol Sci 272:1697-1703

Pickles JO (1996) An introduction to the physiology of hearing, 2nd edn. Academic, San Diego

Pitcher T, Partridge B, Wardle C (1976) A blind fish can school. Science 194:963-965

Popper AN, Clarke NL (1976) The auditory system of the goldfish (Carassius auratus): effects of intense acoustic stimulation. Comp Biochem Physiol A 53:11-18

Popper AN, Fay RR (1999) The auditory periphery in fishes. In: Fay RR, Popper AN (eds) Comparative hearing: fish and amphibians. Springer, New York, pp 43-100

Popper AN, Fay RR (2011) Rethinking sound detection by fishes. Hear Res 273:25-36

Popper AN, Hastings MC (2009) The effects of anthropogenic sources of sound on fishes. J Fish Biol 75:455-489

Popper AN, Hoxter B (1984) Growth of a fish ear: I. Quantitative analysis of sensory hair cell and ganglion cell proliferation. Hear Res 15:133-142

Popper AN, Fewtrell J, Smith ME et al (2004) Anthropogenic sound: effects on the behavior and physiology of fishes. Mar Technol Soc J 37:35-40

Popper AN, Smith ME, Cott PA et al (2005) Effects of exposure to seismic airgun use on hearing of three fish species. J Acoust Soc Am 117:3958-3971

Popper AN, Halvorsen MB, Kane A et al (2007) The effects of high-intensity, low-frequency active sonar on rainbow trout. J Acoust Soc Am 122:623-635

Purser J, Radford AN (2011) Acoustic noise induces attention shifts and reduces foraging performance in three-spined sticklebacks (Gasterosteus aculeatus). PLoS One 6, e17478

Radford AN, Kerridge E, Simpson SD (2014) Acoustic communication in a noisy world: can fish compete with anthropogenic sound? Behav Ecol 00:1-9. doi:10.109/beheco/aru029

Ramcharitar JU, Brack CL (2010) Physiological dimensions of ototoxic responses in a model fish species. J Clin Neurosci 17:103-106

Ramcharitar JU, Selckmann GM (2010) Differential ablation of sensory receptors underlies ototoxin-induced shifts in auditory thresholds of the goldfish (Carassius auratus). J Appl Toxicol 30:536-541

Richardson WJ, Green CR Jr, Malme CI et al (1995) Marine mammals and noise. Academic, New York

Santos F, MacDonald G, Rubel EW et al (2006) Lateral line hair cell maturation is a determinant of aminoglycoside susceptibility in zebrafish (Danio rerio). Hear Res 213:25-33

Scholik AR, Yan HY (2001) Effects of underwater noise on auditory sensitivity of a cyprinid fish. Hear Res 152:17-24

Scholik AR, Yan HY (2002a) Effects of boat engine noise on the auditory sensitivity of the fathead minnow, Pimephales promelas. Environ Biol Fish 63:203-209

Scholik AR, Yan HY (2002b) The effects of noise on the auditory sensitivity of the bluegill sunfish, Lepomis macrochirus. Comp Biochem Physiol A 133:43-52

Schuck JB, Smith ME (2009) Cell proliferation follows acoustically-induced hair cell bundle loss in the zebrafish saccule. Hear Res 253:67-76

Schuck JB, Sun H, Penberthy WT et al (2011) Transcriptomic analysis of the zebrafish inner ear points to growth hormone mediated regeneration following acoustic trauma. BMC Neurosci 12:88

Shin YS, Song SJ, Kang SU et al (2012) A novel synthetic compound, 3-amino-3-(4-fluorophenyl)-1H-quinoline-2,4-dione, inhibits cisplatin-induced hearing loss by the suppression of reactive oxygen species: in vitro and in vivo study. Neuroscience 14:1-12

Skalski JR, Pearson WH, Malme CI (1992) Effects of sounds from a geophysical survey device on catch-per-unit-effort in a hook-and-line fishery for rockfish (Sebastes spp.). Can J Fish Aquat Sci 49:1357-1365 
Slabbekoorn H, Bouton N, van Opzeeland I, Coers A et al (2010) A noisy spring: the impact of globally rising underwater sound levels on fish. Trends Ecol Evol 25:419-427

Smith ME (2012) Predicting hearing loss in fishes. Adv Exp Med Biol 730:259-262

Smith ME (2016) The relationship between hair cell loss and hearing loss in fishes. In: Popper AN, Hawkins A (eds) The Effects of Noise on Aquatic Life II. Advances in Experimental Medicine and Biology, Springer-Verlag, New York, pp. 1079-1086

Smith ME, Fuiman LA (2004) Behavioral performance of wild-caught and laboratory-reared red drum Sciaenops ocellatus (Linnaeus) larvae. J Exp Mar Biol Ecol 302:17-33

Smith ME, Rajadinakaran G (2013) The transcriptomics to proteomics of hair cell regeneration: looking for a hair cell in a haystack. Microarrays 2:186-207

Smith ME, Kane AS, Popper AN (2004a) Noise-induced stress response and hearing loss in goldfish (Carassius auratus). J Exp Biol 207:427-435

Smith ME, Kane AS, Popper AN (2004b) Acoustical stress and hearing sensitivity in fishes: does the linear threshold hypothesis hold water? J Exp Biol 207:3591-3602

Smith ME, Coffin AB, Miller DL et al (2006) Anatomical and functional recovery of the goldfish (Carassius auratus) ear following noise exposure. J Exp Biol 209:4193-4202

Smith ME, Schuck JB, Gilley RR et al (2011) Structural and functional effects of acoustic exposure in goldfish: evidence for tonotopy in the teleost saccule. BMC Neurosci 12:19

Söllner C, Rauch GJ, Siemens J et al (2004) Mutations in cadherin 23 affect tip links in zebrafish sensory hair cells. Nature 428:955-959

Solomon KS, Kudoh T, Dawid IB et al (2003) Zebrafish foxil mediated otic placode formation and jaw development. Development 130:929-940

Song J, Yan HY, Popper AN (1995) Damage and recovery of hair cells in fish canal (but not superficial) neuromasts after gentamicin exposure. Hear Res 91:63-71

Song J, Mann DA, Cott PA, Hanna BW, Popper AN (2008) The inner ears of Northern Canadian freshwater fishes following exposure to seismic air gun sounds. J Acoust Soc Am 124:1360-1366

Tavolga WN (1971) Sound production and detection. In: Hoar WS, Randall DJ (eds) Fish physiology, vol 5. Academic, New York, pp 135-205

Tavolga WN (1977) Mechanisms for directional hearing in the sea catfish (Arius felis). J Exp Biol 67:97-115

Thomas AJ, Hailey DW, Stawicki TM et al (2013) Functional mechanotransduction is required for cisplatin-induced hair cell death in the zebrafish lateral line. J Neurosci 33:4405-4414

Ton C, Parng C (2005) The use of zebrafish for assessing ototoxic and otoprotective agents. Hear Res 208:79-88

Trapani JG, Nicolson T (2011) Mechanism of spontaneous activity in afferent neurons of the zebrafish lateral-line organ. J Neurosci 31:1614-1623

Uribe PM, Mueller MA, Gleichman JS et al (2013a) Dimethyl sulfoxide (DMSO) exacerbates cisplatin-induced sensory hair cell death in zebrafish (Danio rerio). PLoS One 8(2), e55359

Uribe PM, Sun H, Wang K et al (2013b) Aminoglycoside-induced hair cell death of inner ear organs causes functional deficits in adult zebrafish (Danio rerio). PLoS One 8(3), e58755

Van Trump WJ, Coombs S, Duncan K et al (2010) Gentamicin is ototoxic to all hair cells in the fish lateral line system. Hear Res 261:42-50

Vasconcelos RO, Fonseca PJ, Amorim MCP et al (2011) Representation of complex vocalizations in the Lusitanian toadfish auditory system: evidence of fine temporal, frequency and amplitude discrimination. Proc R Soc B 278:826-834

Verzijden MN, van Heusden J, Bouton N et al (2010) Sounds of male Lake Victoria cichlids vary within and between species and affect female mate preferences. Behav Ecol 21:548-555

Villegas R, Martin SM, O'Donnell KC et al (2012) Dynamics of degeneration and regeneration in developing zebrafish peripheral axons reveals a requirement for extrinsic cell types. Neural Dev 7:19. doi:10.1186/1749-8104-7-19

Vlasits AL, Simon JA, Raible DW et al (2012) Screen of FDA-approved drug library reveals compounds that protect hair cells from aminoglycosides and cisplatin. Hear Res 294:153-165 
Wardle CS, Carter TJ, Urquhart GG (2001) Effects of seismic air guns on marine fish. Cont Shelf Res 21:1005-1027

Weber EH (1820) De Aure et Auditu Hominis et Animalium, Pars I. De Aure Animalium Aquatium, Leipzig

Weiss SA, Zottoli SJ, Do SC et al (2006) Correlation of C-start behaviors with neural activity recorded from the hindbrain in free-swimming goldfish (Carassius auratus). J Exp Biol 209:4788-4801

Whitfield TT, Granato M, van Eeden FJ et al (1996) Mutations affecting development of the zebrafish inner ear and lateral line. Development 123:241-254

Whitfield TT, Riley BB, Chiang MY et al (2002) Development of the zebrafish inner ear. Dev Dyn 223:427-458

Whitfield TT, Mburu P, Hardisty-Hughes RE et al (2005) Models of congenital deafness: mouse and zebrafish. Drug Discov Today Dis Models 2:85-92

Winn HE (1964) The biological significance of fish sounds. In: Tavolga WN (ed) Marine bioacoustics, vol 2. Pergamon Press, New York, pp 213-231

Wysocki LE, Ladich F (2005) Effects of noise exposure on click detection and the temporal resolution ability of the goldfish auditory system. Hear Res 201:27-36

Wysocki LE, Dittami JP, Ladich F (2006) Ship noise and cortisol secretion in European freshwater fishes. Biol Conserv 128:501-508

Wysocki LE, Davidson JW, Smith ME et al (2007) Effects of aquaculture production noise on hearing, growth, and disease resistance of rainbow trout Onchohrynchus mykiss. Aquaculture 272:687-697

Yan HY (1998) Auditory role of the suprabranchial chamber in gourami fish. J Comp Physiol A 183:325-333

Yan HY, Curtsinger WS (2000) The otic gasbladder as an ancillary structure in a mormyrid fish. J Comp Physiol A 186:595-600

Yan HY, Saidel WM, Chang JS et al (1991) Sensory hair cells of the fish ear: evidence of multiple types based on ototoxicity sensitivity. Proc R Soc Lond B 245:133-138

Yan HY, Fine ML, Horn NS et al (2000) Variability in the role of the gasbladder in fish audition. J Comp Physiol A 186:435-445

Zeddies DG, Fay RR (2005) Development of the acoustically evoked behavioral response in zebrafish to pure tones. J Exp Biol 208:1363-1372 


\title{
Chemical Ototoxicity of the Fish Inner Ear and Lateral Line
}

\author{
Allison B. Coffin and John Ramcharitar
}

\begin{abstract}
Hair cell-driven mechanosensory systems are crucial for successful execution of a number of behaviors in fishes, and have emerged as good models for exploring questions relevant to human hearing. This review focuses on ototoxic effects in the inner ear and lateral line system of fishes. We specifically examine studies where chemical ototoxins such as aminoglycoside antibiotics have been employed as tools to disable the lateral line. Lateral line ablation results in alterations to feeding behavior and orientation to water current in a variety of species. However, neither behavior is abolished in the presence of additional sensory cues, supporting the hypothesis that many fish behaviors are driven by multisensory integration. Within biomedical research, the larval zebrafish lateral line has become an important model system for understanding signaling mechanisms that contribute to hair cell death and for developing novel pharmacological therapies that protect hair cells from ototoxic damage. Furthermore, given that fishes robustly regenerate damaged hair cells, ototoxin studies in fishes have broadened our understanding of the molecular and genetic events in an innately regenerative system, offering potential targets for mammalian hair cell regeneration. Collectively, studies of fish mechanosensory systems have yielded insight into fish behavior and in mechanisms of hair cell death, protection, and regeneration.
\end{abstract}

Keywords Hair cell $\bullet$ Lateral line $\bullet$ Ear $\bullet$ Auditory $\bullet$ Fish

\footnotetext{
A.B. Coffin $(\bowtie)$

Department of Integrative Physiology and Neuroscience, Washington State University, Vancouver, WA, USA

e-mail: Allison.coffin@wsu.edu

J. Ramcharitar

Department of Biology, St. Mary's College of Maryland, St Marys City, MD, USA

College of Medicine, International American University, Vieux Fort, St. Lucia, West-Indies

e-mail: jramcharitar@iau.edu.lc
} 


\section{Introduction}

The sensory arsenal of fishes has likely contributed to their tremendous evolutionary success, allowing them to thrive in diverse habitats. Fishes are armed with chemical, visual, tactile, auditory, and vestibular sensory apparati that are morphologically and functionally comparable to those found in other vertebrate taxa. Sensory hair cells serve as receptors in both the auditory and vestibular systems, and in an additional hair cell-based system, the mechanosensory lateral line found in fishes and aquatic amphibians. Together, these sensory systems operate in concert to provide fishes with a comprehensive picture of the ambient environment. Multisensory integration is a critical feature for successful execution of a host of fish behaviors such as prey detection, predator avoidance, and escape responses (Collins et al. 2003; Mirjany et al. 2011; Van Trump and McHenry 2013).

Here, we review studies of fish hair cell systems, with a focus on how chemical ototoxins, substances that damage hair cells, have been employed as tools to enhance fish hair cell research. We first examine how ototoxins, combined with detailed morphological assessment, have informed our understanding of vertebrate hair cell heterogeneity and evolution. We then look at studies of mechanosensory-mediated behaviors in fishes, again relying on selective ablation with ototoxins to determine the relative contribution of these systems to fish behavior. In addition to understanding fish mechanosensation, the inner ear and lateral line have been deployed as valuable models for human auditory studies. Section 4 describes some of this biomedical research, both the cellular understanding of ototoxicity itself and the use of ototoxic tools for investigating hair cell regeneration. The bulk of both behavioral and biomedical studies use known ototoxins, such as aminoglycoside antibiotics, but several studies suggest that many other compounds are potentially ototoxic (Hirose et al. 2011). We conclude with a brief description of newly identified putative ototoxins, specifically those found in the aquatic environment, and with some of the unresolved questions that ototoxic research may help answer in the future.

The inner ears of fishes comprise three semicircular canals, each with associated sensory cristae and three otolithic end organs, the saccule, utricle, and lagena (Fig. 1; Popper 1977, 1978; Popper and Lu 2000). All end organs contain populations of sensory hair cells interdigitated with non-sensory supporting cells. The semicircular canals and the utricle primarily subserve vestibular functions, although the utricle plays an auditory role in some taxa. On the other hand, the saccule is the primary auditory end organ in most species, while the function of the lagena is poorly understood (Popper and Lu 2000). The vestibular organs provide positional information, while the auditory organ(s) allow the fish to detect both abiotic (e.g., rainfall or wave noise) and biotic (e.g., conspecific calls) acoustic stimuli of biological relevance. Psychophysical studies in the late 1990s demonstrated that fishes are capable of auditory scene analysis, and this finding supports the hypothesis that they are broadly sensitive to sound stimuli from diverse sources (Fay 1998; Fay and Popper 2012).

The second major hair cell-based system in fishes, the lateral line system, is responsive to mechanosensory stimulation in a relatively low and narrow frequency range of 50-200 Hz (Kalmijn 1988; reviewed in Coombs et al. 2014). In the lateral 


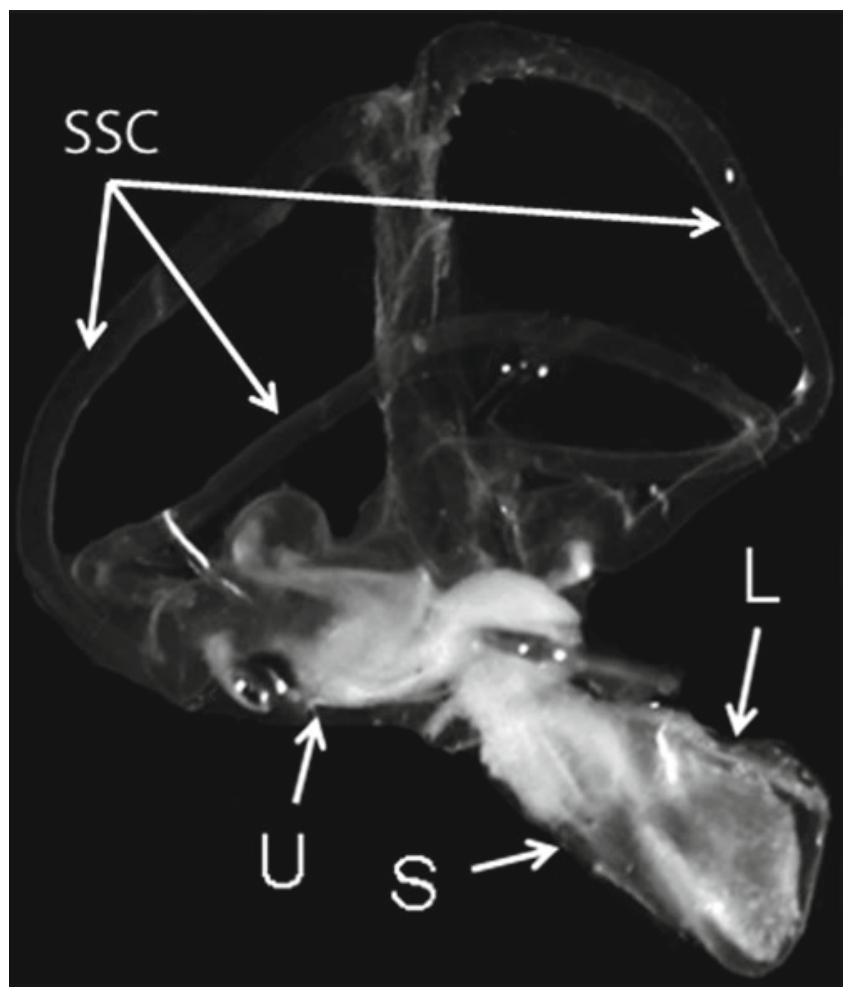

Fig. 1 Lateral view of the goldfish inner ear (from Ramcharitar and Selckmann 2010, used with permission). The saccule $(S)$, lagena $(L)$, and utricle $(U)$ are indicated. Each of these otolithic structures contains a sensory epithelium with an overlying dense calcareous otolith. Vestibular semicircular canals $(S C C)$ are also shown

line system, clusters of sensory hair cells and associated supporting cells are housed in sensory organs called neuromasts that populate the head and body of the fish (Fig. 2). Neuromasts are either contained within canals (canal neuromasts, CN) or are free-standing (superficial neuromasts, $\mathrm{SN}$ ). The lateral line system mediates schooling, prey capture, and predator avoidance, as well as navigation around inanimate obstacles (Gompel et al. 2001; Bleckmann and Zelick 2009; Coombs et al. 2014). Throughout this chapter we used the terms "lateral line" and "lateral line system" interchangeably to refer to the entire sensory system, with specific reference to subsystems (i.e., CN, canal neuromast; SN, superficial neuromast) where appropriate.

Fish mechanosensory systems are of particular interest in biomedical sciences because they contain hair cells that are structurally and functionally similar to the hair cells of the human inner ear (Chang et al. 1992; Popper 2000; Coffin et al. 2010). In addition, the sensory hair cells of fish have a propensity for regeneration a feature not observed in mammals (Matsuura et al. 1971; Lombarte et al. 1993; Lanford and Popper 1996; Corwin and Oberholtzer 1997). This is of clinical rele- 
Fig. 2 Schematic of neuromast structure illustrating sensory hair cells (green), support cells (orange), and cupula (yellow). From Chiu et al. (2008), reprinted with permission

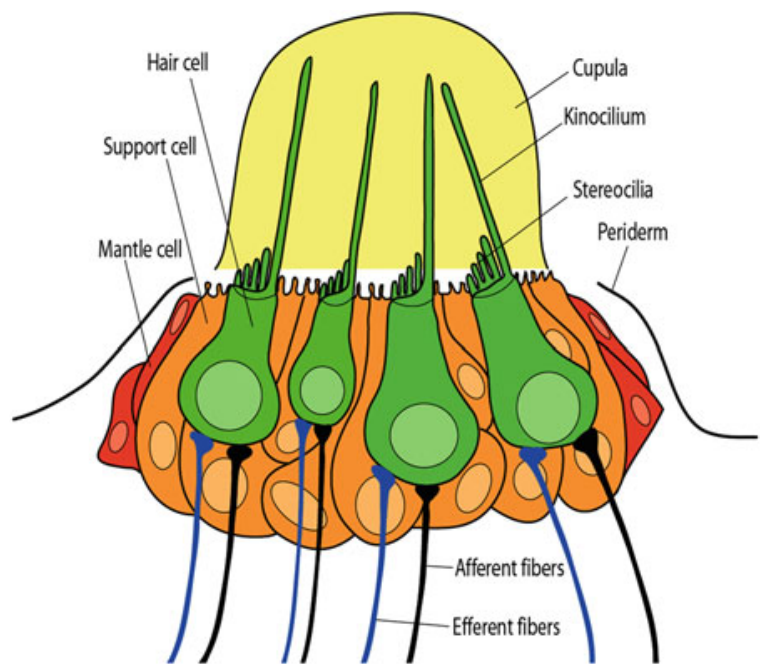

vance as loss of inner ear hair cells accounts for a large majority of acquired and congenital hearing disorders in humans (Behra et al. 2009; Brignull et al. 2009).

Much of our understanding of fish mechanosensory systems results from the use of chemical ototoxins. Ototoxin studies have yielded valuable insight into the relative contribution of different hair cell sub-populations to fish behaviors, as well as informing mechanistic understanding of hair cell death and regeneration. Aminoglycoside antibiotics were the first class of drugs reported to present the problem of ototoxicity, with the first incidence of human hearing loss noted in the 1940s (Schacht 1993). Gentamicin is currently the most widely used aminoglycoside in clinical settings, but may lead to a $30 \%$ incidence of hearing loss, necessitating the development of otoprotective drugs (Nakashima et al. 2000; Santucci and Krieger 2000). Many classes of drugs are now known to cause ototoxic effects, including cisplatin, a platinum-based compound that is widely used to treat various malignancies (Lynch et al. 2005; Guthrie 2008).

Gentamicin was the agent of choice for initial ototoxic investigations in fishes. These studies focused primarily on the auditory system of the goldfish (Carassius auratus) and oscar (Astronotus ocellatus) (Yan et al. 1991; Chang et al. 1992; Lombarte et al. 1993). While the majority of these early investigations focused on collection of histological data, several studies have demonstrated changes in auditory thresholds or lateral line evoked potentials elicited by administration of gentamicin (e.g., Ramcharitar and Brack 2010; Ramcharitar and Selckmann 2010; Brack and Ramcharitar 2012).

More recently, larval zebrafish (Danio rerio) have taken center stage in ototoxicity investigations. Zebrafish are small, highly fecund tropical fish that breed readily in captivity, allowing for quantitative studies using large numbers of larvae. Lateral line visualization is easily achieved in live larvae with vital dye labeling or by using one of the growing number of transgenic strains that express fluorescent proteins in 


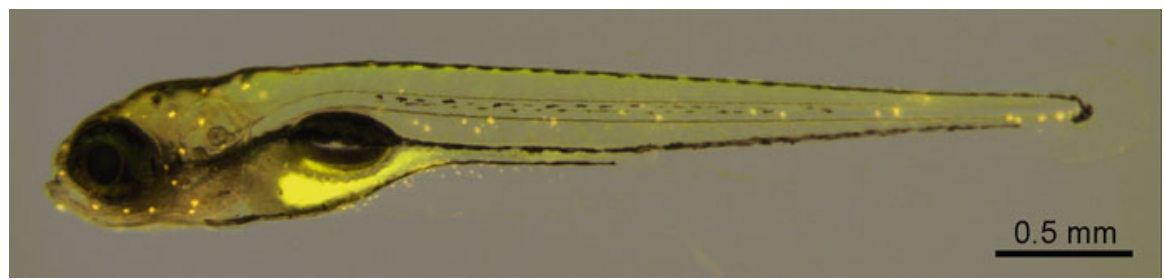

Fig. 3 Five-day-old zebrafish larvae labeled with the vital dye DASPEI. When viewed with fluorescence microscopy, neuromasts are clearly visible as bright dots on the head and body of the animal

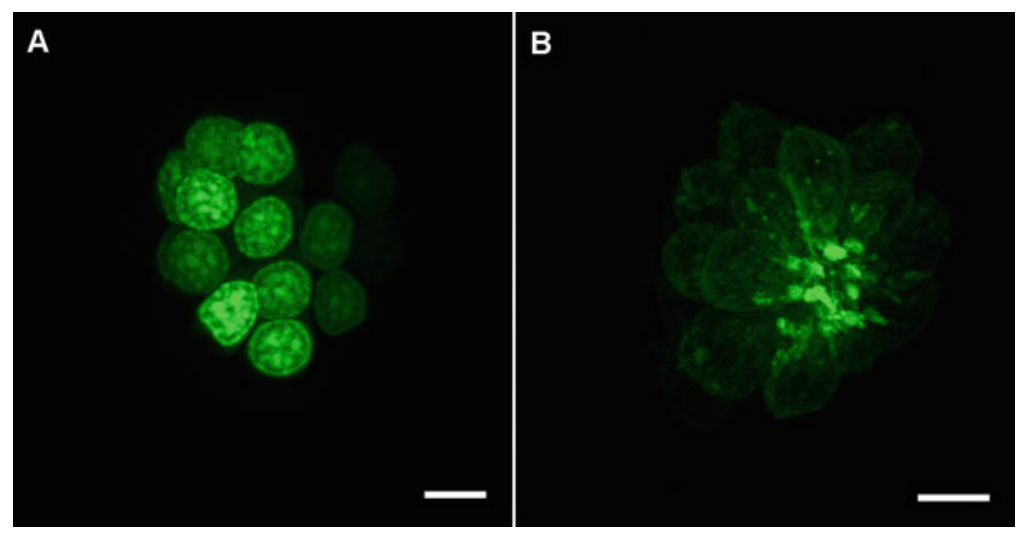

Fig. 4 Images of single neuromasts labeled with (a) the vital dye Yo-Pro-1, which labels hair cell nuclei, and (b) green fluorescent protein $(G F P)$. This image is from a Brn3c:mGFP transgenic fish, which expresses GFP in hair cell membranes. Scale bars $=5 \mu \mathrm{m}$

hair cells (Figs. 3 and 4, and see Coffin et al. 2014b). To date, thousands of compounds with established and potential ototoxic activity have been successfully explored in zebrafish (e.g., Ou et al. 2009; Hirose et al. 2011).

Here we review ototoxicity studies in fishes, examining both neuroethology research aimed at understanding fish sensory function and behavior, as well as biomedical studies that may influence clinical use of agents with demonstrated ototoxicity.

\section{Evolutionary Perspectives}

Do fishes have a homogenous population of hair cells? A combination of ultrastructural and ototoxicity studies suggest that fish hair cells are indeed heterogeneous, falling into characteristic sub-types similar to those found in mammals (Chang et al. 1992; Lanford et al. 2000; Popper 2000). Mammalian utricles have distinct striolar 
and extrastriolar regions, with flask-shaped type I hair cells present in the striolar region and cylindrical type II hair cells in extrastriolar areas (Wersäll 1956, 1960). Data from early transmission electron microscopy (TEM) studies suggested that the sensory hair cells of anamniotes were exclusively type II (Wersäll 1961). However, more recent TEM investigations have demonstrated that the sensory epithelia of the lagena and utricle have two distinct populations of hair cells, one within a striolar region, which contains larger hair cells and a distinct line of hair bundle polarity reversal, and the other in an extrastriolar zone (Saidel et al. 1990; Chang et al. 1992).

In the mammalian ear, striolar hair cells are particularly susceptible to aminoglycoside toxicity (Forge and Li 2000; see Wu et al. 2002; Salvi et al. 2008). Similarly, striolar hair cells in fishes are preferentially ablated by gentamicin, while extrastriolar hair cells remain relatively unaffected (Yan et al. 1991; Chang et al. 1992; Lanford et al. 2000). Regional differences in gentamicin-induced hair cell loss have also been demonstrated in the goldfish saccule along with shifts in auditory thresholds (Ramcharitar and Brack 2010; Ramcharitar and Selckmann 2010), suggesting that hair cell heterogeneity is present in all three otolith end organs. Collectively, these data demonstrate similarities in hair cell morphology and associated ototoxin sensitivity across vertebrates, suggesting that inner ear hair cell heterogeneity arose early in vertebrate evolution.

In contrast, there are conflicting data on the differential susceptibility of superficial versus canal neuromast hair cells to ototoxic damage. Initial studies using SEM to assess hair cell damage suggested that $\mathrm{CN}$ hair cells were preferentially damaged by ototoxic treatment, while SN remained intact, suggesting a possible parallel between CN hair cells and the type I hair cells of the inner ear (Song et al. 1995; Coombs et al. 2001). However, a recent study by Van Trump et al. (2010) used fluorescence-based assays to determine that gentamicin significantly reduced hair cell survival in both superficial and canal neuromasts in zebrafish and Mexican blind cavefish (Astyanax mexicanus). Future studies are needed to resolve these conflicting data and clarify the pharmacologic heterogeneity of lateral line hair cells. Nonetheless, as a whole, the data strongly suggest that hair cell heterogeneity arose very early in the evolution of vertebrates (Popper 2000).

\section{Perception and Behavior}

Ototoxic compounds, most often aminoglycoside antibiotics and cobalt chloride, have long been used to disable the lateral line system so as to study the effects of mechanosensory depravation on fish behavior. These studies have investigated behaviors such as rheotaxis (orientation to water current) and feeding, and the relative contribution of the lateral line to sound reception. This body of work underscores the dynamic use of the lateral line system for a variety of behaviors, depending on species, feeding modality, and availability of additional sensory information. Wersäll and Flock (1964) were the first to report aminoglycoside sensitivity in the 
fish lateral line system. Using the gadiform fish Lota lota, they demonstrated that local application of streptomycin to $\mathrm{CN}$ over several minutes transiently and reversibly suppressed lateral line microphonic potentials, opening up the possibility of using aminoglycoside treatment as a tool in functional studies (Wersäll and Flock 1964). Most recent studies use bath immersion for one or more hours, rather than short-term focal application, to deliver aminoglycosides to the entire lateral line system, resulting in ablation (death) of sensory hair cells rather than short-term functional suppression (e.g., Song et al. 1995; Buck et al. 2012; Suli et al. 2012; Sampson et al. 2013).

Chemical ototoxins are important tools for studying the role of the lateral line in feeding behavior. Both largemouth bass (Micropterus salmoides) and muskellunge (Esox masquinongy) altered their approach to a prey item when the lateral line was inactivated with cobalt chloride (New et al. 2001; Gardiner and Motta 2012). Under these conditions, bass increased pre-strike velocity and muskellunge changed their approach angle, suggesting that near-field vibratory stimuli contribute to a more nuanced approach to prey capture (New et al. 2001; Gardiner and Motta 2012). Similarly, lateral line ablation altered the orienting response of mottled sculpin (Cottus bairdi) to a vibrating (prey-like) stimulus (Coombs et al. 2001). In keeping with the importance of the lateral line for feeding, larval striped bass (Morone saxatilis) prey-capture rates decreased following neomycin exposure, particularly for fish tested in the dark (i.e., without visual cues) (Sampson et al. 2013). Furthermore, experimentally blinded muskellunge have similar prey capture rates as sighted ones, providing strong evidence that mechanosensory cues detected via the lateral line are sufficient for feeding (New et al. 2001). Selective physical ablation of superficial neuromasts vs. chemical ablation of canal neuromasts with gentamicin (which selectively damages CN in some species, although see Van Trump et al. 2010 and Brown et al. 2011 for evidence of damage to SN) suggests that orientation to a prey-like stimulus depends primarily on canal neuromasts, at least in sculpin (Coombs et al. 2001). As sculpin are bottom dwelling "lie and wait" predators, it remains to be determined if this finding applies to fishes that use different prey capture strategies or if species occupying similar ecological niches use the lateral line in similar ways.

Further evidence supporting the role of canal neuromasts in feeding comes from recent comparative studies in cichlid fishes, where canal morphology is correlated with lateral line-mediated feeding behavior. Aulonocara stuartgranti, which has wide canals and enlarged neuromasts, can feed successfully in both light and dark conditions, based on video analysis of prey capture behavior (Schwalbe et al. 2012). Inactivation of the lateral line with cobalt chloride inhibited the ability of these fish to feed in the dark, demonstrating that without visual cues, the lateral line is necessary for prey detection and/or strike behavior (Schwalbe et al. 2012). In contrast, cichlids from the genus Tramitichromis, which have narrow canals and smaller neuromasts, did not strike at prey in lightless conditions, and lateral line ablation did not substantially alter prey capture behavior in the light (Schwalbe and Webb 2014). Collectively, these data demonstrate that different fishes rely on different combinations of sensory modalities for feeding, and that the lateral line is important for prey detection and capture in some fishes. 
While canal neuromasts play a role in feeding in some species, superficial neuromasts appear to mediate rheotaxis behavior in a variety of fishes. In a classic study by Montgomery et al. (1997), chemical ablation of the entire lateral line system significantly decreased rheotaxis, such that significantly higher flow velocities were necessary to elicit orienting behavior. $\mathrm{CN}$ ablation with gentamicin did not alter rheotaxis, suggesting that only $\mathrm{SN}$ are necessary for responding to low velocity flow. Consistent with this finding, Buck et al. (2012) and Suli et al. (2012) demonstrated that in larval zebrafish, which only have SN, chemical ablation of the lateral line resulted in decreased rheotaxis (defined as an increase in the angle of the fish's head relative to current direction) and flow-mediated startle responses. These data are consistent with the presumed function of SN as low frequency, direct current detectors and $\mathrm{CN}$ as accelerometers that subserve flow sensing at higher velocities (Coombs et al. 1989, 2014).

One long-standing question is the relative contribution of the lateral line to sound reception. Higgs and Radford (2013) measured auditory evoked potentials (AEPs) in goldfish after streptomycin ablation of the lateral line and found increased thresholds (reduced sensitivity) to low frequency sound stimuli (100-200 Hz). Physical SN ablation had no effect on thresholds, suggesting that $\mathrm{CN}$ specifically contribute to the AEP response. Coffin et al. (2014a) examined the role for the lateral line in sound source localization in plainfin midshipman fish (Porichthys notatus), a soniferous species for which directional hearing and source localization is critical for reproductive success. Female midshipman showed no changes in the proportion of animals that localized the source after lateral line ablation, although changes in bearing angle during the final approach to the target speaker suggest that the lateral line may help fine-tune the approach, similar to what is seen in feeding studies. Collectively, these data support the hypothesis that many fish behaviors are driven by the multisensory integration of visual, mechanosensory, and other sensory information (Braun and Coombs 2000; Webb et al. 2008; Schwalbe and Webb 2014).

\section{Biomedical Applications}

Fish inner ear and lateral line hair cells are homologous to hair cells in the mammalian inner ear and share a number of properties, including susceptibility to ototoxic drugs (reviewed in Coffin et al. 2004, 2010). This latter feature makes fishes choice models for biomedical studies of drug-induced hair cell death and protection. Unlike mammals, however, fish can fully regenerate lost hair cells, opening up a range of studies exploring the cellular mechanisms underlying hair cell regeneration (Brignull et al. 2009). Chemical ototoxins are effective tools for regeneration studies, as they are usually employed to kill hair cells and trigger the regenerative process. In this section we briefly survey some of the cellular and molecular research on hair cell death, protection, and regeneration using the fish inner ear and lateral line as a model system. More comprehensive reviews are available in Brignull et al. (2009), Coffin et al. (2010, 2014b), and Esterberg et al. (2012). 


\subsection{Hair Cell Death and Protection}

Inner ear ototoxicity studies generally rely on daily systemic aminoglycoside injections spanning multiple days (e.g., Lombarte et al. 1993; Ramcharitar and Selckmann 2010). Intramuscular injection is simple to administer but often causes morbidity due to nephrotoxic side effects. One group has recently employed direct intrasaccular gentamicin injection using X-ray-assisted needle placement in Atlantic cod (Gadus morhua) (Faucher et al. 2008a, 2009), an elegant approach that bypasses systemic toxicity, although the systemic model more closely approximates human clinical use. Using either treatment paradigm, most fish inner ear aminoglycoside research is descriptive rather than mechanistic. Several studies in the oscar employed SEM imaging of dissected sensory epithelia to demonstrate selective loss of striolar hair cells in the utricle and lagena (Yan et al. 1991; Chang et al. 1992; Lombarte et al. 1993), consistent with findings of increased toxin sensitivity in mammalian striolar hair cells (reviewed in Salvi et al. 2008). While these earlier studies did not report evidence of saccular hair cell loss, Ramcharitar and Selckmann (2010) and Uribe et al. (2013) demonstrated hair cell loss in the caudal region of the saccule in goldfish and zebrafish, respectively, correlated with a significant hearing threshold shift in the low frequency range. These ototoxicity studies inform future biomedical work using the fish inner ear as a model system.

In contrast to inner ear research, many lateral line biomedical studies are mechanistic or translational. This body of work primarily relies on a tractable genetic model, the zebrafish. Over a decade ago, Williams and Holder (2000) and Harris et al. (2003) demonstrated that hair cells of 5-day-old zebrafish larvae respond to aminoglycoside damage similarly to mature mammalian hair cells, setting the stage for a myriad of studies aimed at understanding the intracellular death cascade initiated by chemical ototoxins and at identifying novel therapeutics that protect hair cells from drug damage.

Studies on zebrafish larvae demonstrate that mitochondrial swelling and a loss of mitochondrial membrane potential occur shortly after treatment with the ototoxin neomycin. These data are consistent with genetic and pharmacologic evidence for the importance of Bcl-2 family proteins that regulate mitochondrial-dependent cell death pathways (Owens et al. 2007; Coffin et al. 2013a, b). Mitochondria are a major calcium store in many cell types, and an elegant series of experiments with transgenic zebrafish expressing a genetically encoded calcium sensor clearly demonstrate that calcium dysregulation plays an important role in aminoglycosideinduced hair cell loss (Esterberg et al. 2013, 2014). Neomycin treatment first leads to a decrease in calcium in the endoplasmic reticulum, following by an increase in mitochondrial calcium and ending with a cytoplasmic calcium spike immediately preceding hair cell death (Esterberg et al. 2013, 2014). Nuclear condensation, a hallmark of classical apoptosis, occurs in aminoglycoside-damaged hair cells, although the role of caspases (cysteine-dependent proteases associated with apoptosis) has not been conclusively demonstrated (Williams and Holder 2000; Santos et al. 2006; Ou et al. 2009; Coffin et al. 2013a). Collectively, these studies are con- 
sistent with hair cell death research in the inner ears of amniotic vertebrates, particularly chickens and rodents, demonstrating conservation of hair cell death mechanisms across mechanosensory systems and taxa (Matsui et al. 2002, 2004; Cunningham et al. 2004). Even the lack of consensus on caspase activation parallels mammalianbased research, as some studies in the rodent inner ear suggest a requirement for caspases in aminoglycoside ototoxicity, while others demonstrate activation of caspase-independent mechanisms (Cunningham et al. 2002; Cheng et al. 2005; Jiang et al. 2006).

Larval zebrafish are particularly amenable for large-scale drug screening, an unbiased drug discovery process that probes a collection of chemical compounds for a phenotypic effect or behavioral response of interest (Peterson et al. 2000; reviewed in Kaufman et al. 2009). The lateral line also provides a tractable model system for identifying novel compounds that may protect hair cells from ototoxininduced damage. Ton and Parng (2005) first took advantage of this system in a small-scale drug screen, demonstrating that several antioxidants, including glutathione and D-methionine, attenuated hair cell death from the chemotherapy agent cisplatin. Screens of libraries of FDA-approved drugs and similar bioactive compounds have yielded several otoprotective molecules for potential translational development, including antidepressants such as paroxetine (Paxil) and anticholinergics (Tacrine) (Ou et al. 2009; Vlasits et al. 2012). Other otoprotection screens have cast a wider net, including a screen of 10,000+ small molecules with diverse chemical structures that discovered a novel benzothiophene carboxamide, now called PROTO-1, which robustly protects zebrafish hair cells from aminoglycoside toxicity (Owens et al. 2008). Together, these studies have identified new potential uses for several approved drugs and uncovered new drug candidates for future development. The majority of drug discovery studies have relied on morphological criteria for hair cell protection, but recent advances in physiology and behavior set the stage for functional studies of newly identified protective compounds (Zeddies and Fay 2005; Trapani and Nicolson 2010; Brack and Ramcharitar 2012; Buck et al. 2012; Suli et al. 2012; Bhandiwad et al. 2013).

\subsection{Regeneration}

All fishes examined to date robustly regenerate hair cells, although the time course of recovery depends on the sensory system in question (inner ear vs. lateral line), developmental stage of the test organism, and ototoxin administered (Lombarte et al. 1993; Ma et al. 2008; reviewed in Brignull et al. 2009; Lush and Piotrowski 2014). In the ear of adult oscars, structural regeneration post-gentamicin treatment is complete 10 days after observation of maximum damage (20 days from first gentamicin injection; Lombarte et al. 1993). A similar recovery time course is seen in Atlantic cod that received an intrasaccular gentamicin injection (Faucher et al. 2009), suggesting that 20 days post-trauma is a typical regeneration period for adult fishes. In contrast, larval zebrafish manifest complete lateral line 
regeneration 3-4 days after aminoglycoside insult (Harris et al. 2003; Ma et al. 2008; MacKenzie and Raible 2012; Fig. 5). Experiments with cell division markers and cell cycle inhibitors demonstrate that lateral line regeneration primarily results from a wave of supporting cell proliferation and differentiation of newly born progeny into hair cells (Ma et al. 2008; MacKenzie and Raible 2012), although non-proliferative regeneration has been observed following copper ototoxicity (Hernández et al. 2007). Interestingly, the time course of regeneration is delayed when some ototoxins (e.g., copper) are employed to ablate hair cells, suggesting that at high concentrations, copper (and perhaps cisplatin) damages supporting cells as well as hair cells (Hernández et al. 2006; Linbo et al. 2006; MacKenzie and Raible 2012).

Both mutagenesis and chemical screens have attempted to identify the underlying molecular factors responsible for hair cell regeneration in the lateral line. The novel gene Phoenix is one such factor, as Phoenix mutants demonstrate normal lateral line development but reduced supporting cell proliferation after ototoxic insult (Behra et al. 2009). The underlying cause of this proliferative defect is unknown, as the mutated gene in Phoenix encodes a novel protein. In contrast, chemical screens have provided tantalizing hints into innate regenerative mechanisms. The glucocorticoids dexamethasone and prednisolone enhance regeneration by increasing supporting cell proliferation, suggesting that the inflammatory response may modulate regenerative potential (Namdaran et al. 2012). Low molecular weight fucoidan, an extract from marine algae that also has anti-inflammatory properties, similarly enhances proliferative regeneration (Moon et al. 2011; Kim et al. 2012). Interestingly, caudal fin regeneration is not affected in Phoenix mutants and fin regeneration is reduced by glucocorticoid exposure, suggesting that hair cell regeneration proceeds by a mechanism distinct from other regenerative processes (Behra et al. 2009; Namdaran et al. 2012).

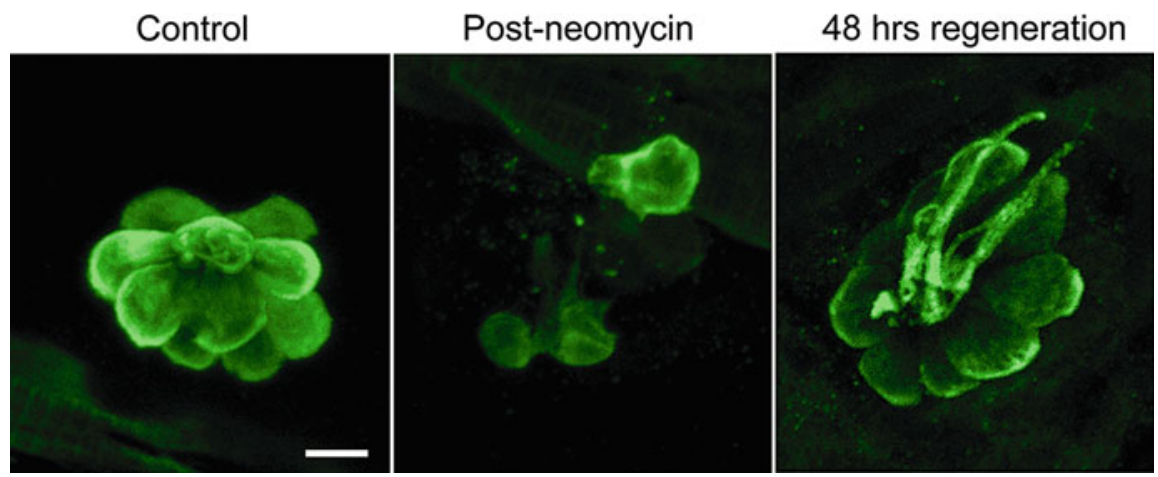

Fig. 5 Hair cells in the larval zebrafish lateral line quickly regenerate after ototoxic damage. (a) Intact neuromast, (b) neuromast following one hour of exposure to $300 \mu \mathrm{M}$ neomycin, and (c) neuromast $48 \mathrm{~h}$ after neomycin treatment. Hair cells were labeled with an antibody to parvalbumin. The scale bar in $\mathrm{A}=5 \mu \mathrm{m}$ and applies to all images 
In an experimental tour de force, two recent studies examined transcriptomelevel changes in isolated lateral line supporting cells from ototoxin-treated larval zebrafish as a major step towards identifying the complete set of molecular factors responsible for innate regenerative capacity (Jiang et al. 2014; Steiner et al. 2014). These studies saw changes in several signaling pathways important for hair cell development and regeneration, including Notch and Wnt signaling, consistent with previous pharmacologic and genetic manipulation studies demonstrating the importance of these pathways for hair cell regeneration (Ma et al. 2008; Head et al. 2013; Wada et al. 2013; Jacques et al. 2014). Genomics tools have also been applied to insightful regeneration studies in the adult zebrafish inner ear. These studies, which used intense noise exposure to ablate hair cells, found that activation of stat $3 /$ socs 3 and growth hormone signaling pathways were involved in proliferative regeneration in the adult zebrafish saccule (Schuck et al. 2011; Liang et al. 2012). It is unclear if these pathways are also important for lateral line regeneration, and conversely if pathways identified in the lateral line are required for regeneration of inner ear hair cells. Moreover, it is possible that different ototoxins activate different regenerative mechanisms, although this hypothesis has not been fully tested (but see Mackenzie and Raible 2012).

\section{Environmental Toxins}

While many in the auditory field think of "chemical ototoxicity" as it relates to aminoglycoside antibiotics and platinum-based chemotherapy agents, some environmental contaminants, particularly metals, have damaging effects on hair cells. Exposure to these contaminants may have long-term consequences for the fish by disrupting lateral line function and reducing lateral line-mediated behaviors. Environmentally relevant concentrations of cadmium $(0.5-2 \mu \mathrm{g} / \mathrm{ml})$ damage hair bundles and reduce rheotaxis and startle responses in banded kokopu (Galaxias fasciatus) and sea bass (Dicentrarchus labrax), respectively (Baker and Montgomery 2001; Faucher 2006, 2008b). Copper concentrations as low as $10 \mu \mathrm{M}$ rapidly kill hair cells in larval zebrafish, likely by inducing oxidative stress (Linbo et al. 2006; Olivari et al. 2008). Zinc may similarly damage hair cells, while other metals such as silver or manganese have no visible effect. Both cadmium and copper are also toxic to fish olfactory receptors (Hansen et al. 1999; Baker and Montgomery 2001; Blechinger et al. 2007), suggesting that direct contact with the aquatic environment plays an important role in sensory receptor susceptibility to toxins. Recent evidence suggests that the ubiquitous contaminant bisphenol-A, a component of many plastics, is also a hair cell toxin and may impede hair cell regeneration (Hayashi et al. 2015). Collectively, these findings underscore the vulnerability of the lateral line to aquatic pollutants. Furthermore, these studies inform human health, as environmental contaminants in food and water sources may exert similar effects on mammalian hair cells. 


\section{Looking Forward: Where Do These Studies Lead Us?}

The use of fish models in ototoxicity research has come a long way since the initial testing of gentamicin-mediated effects on auditory and vestibular sensory epithelia in the research laboratory of Dr. Arthur Popper (Yan et al. 1991; Chang et al. 1992). Notwithstanding the burgeoning larval zebrafish model in this arena of scientific investigation, several important questions remain unresolved, including:

1. What are the relative contributions of the different inner ear end organs and lateral line neuromasts to the detection and processing of auditory, vestibular, and current-mediated stimuli? Ablation studies demonstrate that the lateral line is not required for sound source localization in one fish species (the plainfin midshipman; Coffin et al. 2014a), but it is not known if this finding applies to other fishes, or if the lateral line and inner ear act in concert to perform nonlocalization tasks. Further, the role of the lagena remains a mystery.

2. What are the relative contributions of particle motion and pressure stimuli to the auditory, vestibular, and lateral line-mediated senses? Comprehensive assessment of mechanosensory stimuli remains elusive in the complex soundscape of aquatic media. Differential ototoxin-induced ablation of superficial versus canal neuromasts may yield insight into the role of particle versus pressure signals in mediating sensory hair cell transduction.

3. What accounts for variation in data concerning differential susceptibility of fish sensory hair cell sub-types to ototoxic damage? Differences in aminoglycoside sensitivity in the lateral line are still a puzzle - are these differences based on species, ototoxic treatment paradigm, or detection method? Future comparative studies are needed to differentiate between these possibilities.

4. How is neuromast size regulated during development and regeneration? Following chemical ablation of the lateral line in larval zebrafish, neuromasts regenerate to their original size, with larger neuromasts pre-neomycin damage also possessing more hair cells after regeneration (Ma et al. 2008). However, the molecular mechanisms that regulate neuromast size are unknown. Pharmacological or genetic manipulation of cell patterning pathways during the regeneration process can help answer these questions.

5. Could auditory- and lateral line-evoked potentials yield greater insight into neural correlates of ototoxic damage? Auditory- and lateral line-evoked potentials from fishes may be used to investigate response thresholds, although little is known about the specific neural activities that underlie the various waveforms that characterize these responses. Standardization of techniques (per species) may go a long way in establishing waveform criteria for investigating auditoryand lateral line-evoked potentials. This may lead to more powerful analysis of ototoxic effects.

6. How do we advance the use of initial screening of potential pharmaceutical agents for toxicity in larval zebrafish assays for later assessment of identified compounds in mammalian models, and then potentially to clinical trials? Chemical screens in zebrafish have yielded a wealth of novel protective com- 
pounds, but few have advanced to mammalian testing. Close collaboration between fish and mammalian researchers is necessary to facilitate this "bench to bedside" pipeline.

Thanks to decades of study in fish mechanosensory systems using chemical ototoxins, we are closer to understanding (1) hair cell evolution and the different subtypes found across vertebrate taxa, (2) the role(s) of the fish inner ear and lateral line to behavior, (3) how chemical ototoxins kill hair cells, and (4) how fish regenerate hair cells following ototoxic damage. We believe the next several decades will see continued progress in these areas, leading to answers to the questions above and to many others we do not yet foresee.

Acknowledgements The authors thank Drs. Richard R. Fay and Arthur N. Popper for their mentoring, scientific inspiration, and encouragement. Both ABC and JUR were Ph.D. students in the Popper Lab and we consider Art's guidance, advice, and example as central to the advancement of our own careers. Similarly, we both interacted with Dick Fay throughout our graduate education, with Dick serving on JUR's dissertation committee.

ABC thanks Art Popper for his continued mentoring, both in the lab and in her administrative pursuits. She credits both Art and Dick for teaching her to think like a comparative and evolutionary biologist, even when pursing biomedical questions. $\mathrm{ABC}$ is honored to serve as an associate editor (along with J. Sisneros) for the Springer Handbook in Auditory Research series, a series created (and still led) by Art and Dick. ABC also thanks Dick Fay for his ongoing career support, including attending one of her interview talks to provide moral support when she was searching for a faculty job. ABC thanks former Popper Lab undergraduate Payal Razdan for her early (unpublished) work on fish ototoxicity, and current and former Coffin Lab members Phillip Uribe, Matthew Kruger, Alex Young, Nicole Smith, Sarah Neveux, Lauren Hayashi, and Meghal Sheth for their contributions to our work on hair cell damage and regeneration.

JUR is sincerely thankful to Dr. Arthur Popper for being an outstanding mentor in graduate school, and through the various stages of his professional development and career-to this day. Dr. Arthur Popper inculcated in JUR a true appreciation and excitement for the process of science, from the very conception of experimental ideas, to publication and presentation at public scientific meetings. Tremendous credit is owed to both Art and Dick for the successes JUR enjoyed at the bench, especially at St. Mary's College of Maryland, where experimental tools acquired at the University of Maryland were used to investigate ototoxic effects in fish models, including goldfish and zebrafish. Much of the work conducted in the research lab of JUR at SMCM was driven by undergraduate effort. This was made possible by a mentoring style inherited, in large measure, from Dr. Arthur Popper.

A. Coffin is supported by NIH grants DC011344 and DC013900, and by start-up funds courtesy of Washington State University Vancouver. The ototoxicity research of J. Ramcharitar was supported by a SOMAS award (supported by NSF, HHMI, and Davison College) and by funding from the Capita Foundation. Thanks to Matthew Kruger for providing the image for Fig. 3 and to Alex Young for the images in Fig. 5.

\section{References}

Baker CF, Montgomery JC (2001) Sensory deficits induced by cadmium in banded kokopu, Galazias fasciatus, juveniles. Environ Biol Fish 62:455-464 
Behra M, Bradsher J, Sougrat R, Gallardo V, Allende ML, Burgess SM (2009) Phoenix is required for mechanosensory hair cell regeneration in the zebrafish lateral line. PLoS Genet 5(4), e1000455

Bhandiwad AA, Zeddies DG, Raible DW, Rubel EW, Sisneros JA (2013) Auditory sensitivity of larval zebrafish (Danio rerio) measured using a behavioral prepulse inhibition assay. J Exp Biol 216(18):3504-3513

Blechinger SR, Kusch RC, Haugo K, Matz C, Chivers DP, Krone PH (2007) Brief embryonic cadmium exposure induces a stress response and cell death in the developing olfactory system followed by long-term olfactory deficits in juvenile brafish. Toxicol Appl Pharmacol 224(1):72-80

Bleckmann H, Zelick R (2009) Lateral line system of fish. Integr Zool 4(1):13-25

Brack CL, Ramcharitar J (2012) Assessment of lateral line function: a potential technique for studies on ototoxicity. J Clin Neurosci 19:333-335

Braun CB, Coombs S (2000) The overlapping role of the inner ear and lateral line: the active space of dipole source detection. Philos Trans R Soc Lond 355:1115-1119

Brignull HR, Raible DW, Stone JS (2009) Feathers and fins: non-mammalian models for hair cell regeneration. Brain Res 1277:12-23

Brown AD, Mussen TD, Sisneros JA, Coffin AB (2011) Reevaluating the use of aminoglycoside antibiotics in behavioral studies of the lateral line. Hear Res 272(1-2):1-4

Buck LMJ, Winter MJ, Redfern WS, Whitfield TT (2012) Ototoxin-induced cellular damage in neuromasts disrupts lateral line function in larval zebrafish. Hear Res 284:67-81

Chang JSY, Popper AN, Saidel WM (1992) Heterogeneity of sensory hair cells in a fish ear. J Comp Neurol 324:621-640

Cheng AG, Cunningham LL, Rubel EW (2005) Mechanisms of hair cell death and protection. Curr Opin Otolaryngol Head Neck Surg 13(6):343-348

Chiu LL, Cunningham LL, Raible DW, Rubel EW, Ou HC (2008) Using the zebrafish lateral line to screen for ototoxicity. J Assoc Res Otolaryngol 9(2):178-190

Coffin AB, Kelley MW, Manley GA, Popper AN (2004) Evolution of sensory hair cells. In: Manley GA, Fay RR, Popper AN (eds) Evolution of the auditory system. Springer-Verlag, New York

Coffin AB, Ou H, Owens KN, Santos F, Simon JA, Rubel EW, Raible DW (2010) Chemical screening for hair cell loss and protection in the zebrafish lateral line. Zebrafish 7(1):3-11

Coffin AB, Rubel EW, Raible DW (2013a) Bax, Bc12, and p53 differentially regulate neomycinand gentamicin-induced hair cell death in the zebrafish lateral line. J Assoc Res Otolaryngol. doi:10.1007/s10162-013-0404-1

Coffin AB, Williamson KL, Mamiya A, Raible DW, Rubel EW (2013b) Profiling drug-induced cell death pathways in the zebrafish lateral line. Apoptosis. doi:10.1007/s10495-013-0816-8

Coffin AB, Zeddies DG, Fay RR, Brown AD, Alderks PW, Bhandiwad AA, Mohr RA, Gray MD, Rogers PH, Sisneros JA (2014a) Use of the swim bladder and lateral line in near-field sound source localization by fishes. J Exp Biol. doi:10.1242/jeb.093831

Coffin AB, Brignull H, Raible DW, Rubel EW (2014b) Hearing loss, protection, and regeneration in the larval zebrafish lateral line. In: Coombs S, Bleckmann H, Fay RR, Popper AN (eds) The lateral line system. Springer, New York

Collins SP, Marshall JN, Atema J, Fay RR (2003) Sensory processing aquatic environments. Springer, New York

Coombs S, Görner P, Münz H (1989) The mechanosensory lateral line: neurobiology and evolution. Springer-Verlag, New York

Coombs S, Braun CB, Donovan B (2001) The orienting response of Lake Michigan mottled sculpin is mediated by canal neuromasts. J Exp Biol 204:337-348

Coombs S, Bleckmann H, Fay RR, Popper AN (2014) The lateral line system. Springer, New York

Corwin JT, Oberholtzer JC (1997) Fish n' chicks: model recipes for hair-cell regeneration? Neuron 19(5):951-954

Cunningham LL, Cheng AG, Rubel EW (2002) Caspase activation in hair cells of the mouse utricle exposed to neomycin. J Neurosci 22(19):8532-8540 
Cunningham LL, Matsui JI, Warchol ME, Rubel EW (2004) Overexpression of Bcl-2 prevents neomycin-induced hair cell death and caspase- 9 activation in the adult mouse utricle in vitro. J Neurobiol 60(1):89-100

Esterberg R, Coffin AB, Ou H, Simon JA, Raible DW, Rubel EW (2012) Fish in a dish: drug discovery for hearing habilitation. Drug Discov Today Dis Models. doi:10.1016/j. ddmod.2012.02.001

Esterberg R, Hailey DW, Coffin AB, Raible DW, Rubel EW (2013) Disruption of intracellular calcium regulation is integral to aminoglycoside-induced hair cell death. J Neurosci 33(17):7513-7525

Esterberg R, Hailey DW, Rubel EW, Raible DW (2014) ER-mitochondrial calcium flow underlies vulnerability of mechanosensory hair cells to damage. J Neurosci 34(29):9703-9719

Faucher K, Fichet D, Miramand P, Lagardère J-P (2006) Impact of acute cadmium exposure on the trunk lateral line neuromasts and consequences on the "C-start" response behaviour of the sea bass (Dicentrarchus labrax L.; Teleostei, Moronidae). Aquat Toxicol 76:278-294

Faucher K, Aas-Hansen O, Damsgard B, Stenklev NC (2008a) Effects of systemic versus local gentamicin on the inner ear in the Atlantic cod, Gadus morhua (L.), relevance for fish hearing investigations. Hear Res 240:12-21

Faucher K, Fichet D, Miramand P, Lagardère J-P (2008b) Impact of chronic cadmium exposure at environmental dose on escape behaviour in sea bass (Dicentrarchus labrax L.; Teleostei, Moronidae). Environ Pollut 151:148-157

Faucher K, Aas-Hansen O, Damsgard B, Laukli E, Stenklev NC (2009) Damage and functional recovery of the Atlantic cod (Gadus morhua) inner ear hair cells following local injection of gentamicin. Int J Audiol 48(7):456-464

Fay RR (1998) Auditory stream segregation in goldfish (Carassius auratus). Hear Res 120:69-76

Fay RR, Popper AN (2012) Fish hearing: new perspectives from two 'senior' bioacousticians. Brain Behav Evol 79:215-217

Forge A, Li L (2000) Apoptotic death of hair cells in mammalian vestibular sensory epithelia. Hear Res 139:97-115

Gardiner JM, Motta PJ (2012) Largemouth bass (Micropterus salmoides) switch feeding modalities in response to sensory deprivation. Zoology 115:78-83

Gompel N, Dambly-Chaudière C, Ghysen A (2001) Neuronal differences prefigure somatotopy in the zebrafish lateral line. Development 128(3):387-393

Guthrie OW (2008) Aminoglycoside induced ototoxicity. Toxicology 249:91-96

Hansen JA, Rose JD, Jenkins RA, Gerow KG, Bergman HL (1999) Chinook salmon (Oncorhynchus tshawytscha) and rainbow trout (Oncorhynchus mykiss) exposed to copper: neurophysiological and histological effects on the olfactory system. Environ Toxicol Chem 18(9):1979-1991

Harris JA, Cheng AG, Cunningham LL, MacDonald G, Raible DW, Rubel EW (2003) Neomycininduced hair cell death and rapid regeneration in the lateral line of zebrafish (Danio rerio). J Assoc Res Otolaryngol 4(2):219-234

Hayashi L, Sheth M, Young A, Kruger M, Wayman GA, Coffin AB (2015) The effect of the aquatic contaminants bisphenol-A and PCB-95 on the zebrafish lateral line. Neurotoxicology 46:125-136

Head JR, Gocioch L, Pennisi M, Meyers JR (2013) Activation of canonical Wnt/ $\beta$-catenin signaling stimulations proliferation in neuromasts in the zebrafish posterior lateral line. Dev Dyn 242(7):832-846

Hernández PP, Moreno V, Olivari FA, Allende ML (2006) Sub-lethal concentrations of waterborne copper are toxic to lateral line neuromasts in zebrafish (Danio rerio). Hear Res 213(1-2):1-10

Hernández PP, Olivari FA, Sarrazin AF, Sandoval PC, Allenda ML (2007) Regeneration in zebrafish lateral line neuromasts: expression of the neural Progenitor cell marker sox 2 and proliferation-dependent and-independent mechanisms of hair cell renewal. Dev Neurobiol 67(5):637-654 
Higgs DM, Radford CA (2013) The contribution of the lateral line to 'hearing' in fish. J Exp Biol 216:1484-1490

Hirose Y, Simon JA, Ou HC (2011) Hair cell toxicity in anti-cancer drugs: evaluating an anticancer drug library for independent and synergistic toxic effects on hair cells using the zebrafish lateral line. J Assoc Res Otolaryngol. doi:10.1007/s10162-011-0278-z

Jacques BE, Montgomery WH 4th, Uribe PM, Yatteau A, Asuncion JD, Resendiz G, Matsui JI, Dabdoub A (2014) The role of Wnt/ $\beta$-catenin signaling in proliferation and regeneration of the developing basilar papilla and lateral line. Dev Neurobiol 74(4):438-456

Jiang H, Sha SH, Forge A, Schacht J (2006) Caspase-independent pathways of hair cell death induced by kanamycin in vivo. Cell Death Differ 13(1):20-30

Jiang L, Romero-Carvajal A, Haug JS, Seidel CW, Piotrowski T (2014) Gene-expression analysis of hair cell regeneration in the zebrafish lateral line. Proc Natl Acad Sci. doi:10.1073/ pnas. 1402898111

Kalmijn AJ (1988) Hydrodynamic and acoustic field detection. In: Fay RR, Popper AN, Tavolga WN (eds) Sensory biology of aquatic animals. Springer-Verlag, New York

Kaufman CK, White RM, Zon L (2009) Chemical genetic screening in the zebrafish embryo. Nat Protoc 4(10):1422-1432

Kim K-J, Yoon K-Y, Lee B-Y (2012) Low molecular weight fucoidan from the sporophyll of Undaria pinnatifida suppresses inflammation by promoting the inhibition of mitogen-activated protein kinases and oxidative stress in RAW264.7 cells. Fitoterapia 83(8):1628-1635

Lanford PJ, Popper AN (1996) A unique afferent structure in the crista ampullaris of the goldfish. J Comp Neurol 366:572-579

Lanford PJ, Platt C, Popper AN (2000) Structure and function in the saccule of the goldfish (Carassius auratus): a model of diversity in the non-amniote ear. Hear Res 143:1-13

Liang J, Wang D, Renaud G, Wolfberg TG, Wilson AF, Burgess SM (2012) The stat3/socs3a pathway is a key regulator of hair cell regeneration in zebrafish. J Neurosci 32(31):10662-10673

Linbo TL, Stehr CM, Incardona JP, Scholz NL (2006) Dissolved copper triggers cell death in the peripheral mechanosensory system of larval fish. Environ Toxicol Chem 25(2):597-603

Lombarte A, Yan HY, Popper AN, Chang JS, Platt C (1993) Damage and regeneration of hair cell ciliary bundles in a fish ear following treatment with gentamicin. Hear Res 64(2):166-174

Lush ME, Piotrowski T (2014) Sensory hair cell regeneration in the zebrafish lateral line. Dev Dyn 243:1187-1202

Lynch ED, Gu R, Pierce C, Kil J (2005) Reduction of acute cisplatin ototoxicity and nephrotoxicity in rats by oral administration of allopurinol and ebselen. Hear Res 201:81-89

Ma EY, Rubel EW, Raible DW (2008) Notch signaling regulates the extent of hair cell regeneration in the zebrafish lateral line. J Neurosci 28(9):2261-2273

Mackenzie SM, Raible DW (2012) Proliferative regeneration of zebrafish lateral line hair cells after different ototoxic insults. PLoS One 7(10), e47257

Matsui JI, Ogilvie JM, Warchol ME (2002) Inhibition of caspases prevents ototoxic and ongoing hair cell death. J Neurosci 22(4):1218-1227

Matsui JI, Gale JE, Warchol ME (2004) Critical signaling events during the aminoglycosideinduced death of sensory hair cells in vitro. J Neurobiol 61(2):250-266

Matsuura S, Ikeda K, Furukawa T (1971) Effects of streptomycin, kanamycin, quinine, and other drugs on the microphonic potentials of goldfish sacculus. Jpn J Physiol 21:579-590

Mirjany M, Preuss T, Faber DS (2011) Role of the lateral line mechanosensory system in directionality of goldfish auditory escape response. J Exp Biol 214(20):3358-3367

Montgomery JC, Baker CF, Carton AG (1997) The lateral line can mediate rheotaxis in fish. Nature 389:960-963

Moon IS, So JH, Jung YM, Lee WS, Kim EY, Choi JH, Kim CH, Choi JY (2011) Fucoidan promotes mechanosensory hair cell regeneration following amino glycoside-induced cell death. Hear Res 282(1-2):236-242

Nakashima T, Teranishi M, Hibi T, Kobayashi M, Umemura M (2000) Vestibular and cochlea toxicity of aminoglycosides. Acta Otolaryngol 120:904-911 
Namdaran P, Reinhart KE, Owens KN, Raible DW, Rubel EW (2012) Identification of modulators of hair cell regeneration in the zebrafish lateral line. J Neurosci 32(10):3516-3528

New JG, Fewkes LA, Khan AN (2001) Strike feeding behavior in the muskellunge, Esox masquinongy: contributions of the lateral line and visual sensory systems. J Exp Biol 204:1207-1221

Olivari FA, Hernández PP, Allende ML (2008) Acute copper exposure induces oxidative stress and cell death in lateral line hair cells of zebrafish larvae. Brain Res 1244:1-12

Ou HC, Cunningham LL, Francis SP, Brandon CS, Simon JA, Raible DW, Rubel EW (2009) Identification of FDA-approved drugs and bioactives that protect hair cells in the zebrafish (Danio rerio) lateral line and mouse (Mus musculus) utricle. J Assoc Res Otolaryngol 10(2):191-203

Owens KN, Cunningham DE, MacDonald G, Rubel EW, Raible DW, Pujol R (2007) Ultrastructural analysis of aminoglycoside-induced hair cell death in the zebrafish lateral line reveals an early mitochondrial response. J Comp Neurol 502(4):522-543

Owens KN, Santos F, Roberts B, Linbo T, Coffin AB, Knisely AJ, Simon JA, Rubel EW, Raible DW (2008) Identification of genetic and chemical modulators of zebrafish mechanosensory hair cell death. PLoS Genet 4(2), e1000020

Peterson RT, Link BA, Dowling JE, Schreiber SL (2000) Small molecule developmental screens reveal the logic and timing of vertebrate development. Proc Natl Acad Sci U S A 97(24):12965-12969

Popper AN (1977) A scanning electron microscope study of the sacculus and lagena in the ears of fifteen species of teleost fishes. J Morphol 153:397-418

Popper AN (1978) Scanning electron microscope study of the otolith organs in the birchir (Polypterus bichir) and shovel-nose sturgeon (Scaphirhynchus platorhynchus). J Comp Neurol 18:117-128

Popper AN (2000) Hair cell heterogeneity and ultrasonic hearing: recent advances in understanding fish hearing. Philos Trans R Soc Lond B 355:1277-1280

Popper AN, Lu Z (2000) Structure and function relationships in fish otolith organs. Fish Res 46:15-25

Ramcharitar JU, Brack CL (2010) Physiological dimensions of ototoxic responses in a model fish species. J Clin Neurosci 17:103-106

Ramcharitar J, Selckmann GM (2010) Differential ablation of sensory receptors underlies ototoxin-induced shifts in auditory thresholds of the goldfish (Carassius auratus). J Appl Toxicol 30(6):536-541

Saidel WM, Popper AN, Chang JS (1990) Spatial and morphological differentiation of trigger zones in afferent fibers to the teleost utricle. J Comp Neurol 302:629-642

Salvi RJ, Popper AN, Fay RR (2008) Hair cell regeneration, repair, and protection. Springer, New York

Sampson JA, Duston J, Croll RP (2013) Superficial neuromasts faciliate non-visual feeding by larval striped bass (Morone saxatilis). J Exp Biol 216:3522-3530

Santos F, MacDonald G, Rubel EW, Raible DW (2006) Lateral line hair cell maturation is a determinant of aminoglycoside susceptibility in zebrafish (Danio rerio). Hear Res 213(1-2):25-33

Santucci RA, Krieger JN (2000) Gentamicin for the practicing urologist: review of efficacy, single daily dosing and "switch" therapy. J Urol 163:1076-1084

Schacht J (1993) Biochemical basic of aminoglycoside ototoxicity. Otolaryngol Clin North Am 26:845-856

Schuck JB, Sun H, Penberthy WT, Cooper NG, Li X, Smith ME (2011) Transcriptomic analysis of the zebrafish inner ear points to growth hormone mediated regeneration following acoustic trauma. BMC Neurosci 12:88. doi:10.1186/1471-2202-12-188

Schwalbe MAB, Webb JF (2014) Sensory basis for detection of benthic prey in two Lake Malawi cichlids. Zoology 117:112-121

Schwalbe MAB, Bassett DK, Webb JF (2012) Feeding in the dark: lateral-line- mediated prey detection in the peacock cichlid Aulonocara stuartgranti. J Exp Biol 215:2060-2071 
Song J, Yan HY, Popper AN (1995) Damage and recovery of hair cells in fish canal (but not superficial) neuromasts after gentamicin exposure. Hear Res 91(1-2):63-71

Steiner AB, Kim T, Cabot V, Hudspeth AJ (2014) Dynamic gene expression by putative hair-cell progenitors during regeneration in the zebrafish lateral line. Proc Natl Acad Sci U S A 111:E1393-E1401. doi:10.1073/pnas.1318692111

Suli A, Watson GM, Rubel EW, Raible DW (2012) Rheotaxis in larval zebrafish is mediated by lateral line mechanosensory hair cells. PLoS One 7(2), e29727

Ton C, Parng C (2005) The use of zebrafish for assessing ototoxic and otoprotective agents. Hear Res 208(1-2):79-88

Trapani JG, Nicolson T (2010) Physiological recordings from zebrafish lateral-line hair cells and afferent neurons. Methods Cell Biol 100:219-231

Uribe PM, Sun H, Wang K, Asuncion JD, Wang Q, Chen CW, Steyger PS, Smoth ME, Matsui JI (2013) Aminoglycoside-induced hair cell death of inner ear organs causes functional deficits in adult zebrafish (Danio rerio). PLoS One 8(3):e58755

Van Trump WJ, McHenry MJ (2013) The lateral line system is not necessary for rheotaxis in the Mexican blind cavefish (Astyanax fasciatus). Integr Comp Biol 53(5):799-809

Van Trump WJ, Coombs S, Duncan K, McHenry MJ (2010) Gentamicin is ototoxic to all hair cells in the fish lateral line system. Hear Res 261(1-2):42-50

Vlasits AL, Simon JA, Raible DW, Rubel EW, Owens KN (2012) Screen of FDA-approved drug library reveals compounds that protect hair cells from aminoglycosides and cisplatin. Hear Res 294(1-2):153-165

Wada H, Ghysen A, Asakawa K, Abe G, Ishitani T, Kawakami K (2013) Wnt/Dkk negative feedback regulates sensory organ size in zebrafish. Curr Biol 23(16):1559-1565

Webb JF, Fay RR, Popper AN (2008) Fish bioacoustics. Springer, New York

Wersäll J (1956) Studies on the structure and innervation of the sensory epithelium of the cristae ampullaris in the guinea pig. Acta Otolaryngol Suppl 126

Wersäll J (1960) Electron micrographic studies of vestibular hair cell innervation. In: Rasmussen GL, Windle WF (eds) Handbook of sensory physiology. Springer, New York

Wersäll J (1961) Vestibular receptor cells in fish and mammals. Acta Otolaryngol Suppl $126: 1-85$

Wersäll J, Flock $\AA$ (1964) Suppression and restoration of the microphonic output from the lateral line organ after local application of streptomycin. Life Sci 3:1151-1155

Williams JA, Holder N (2000) Cell turnover in neuromasts of zebrafish larvae. Hear Res 143(1-2):171-181

Wu W-J, Sha S-H, Schacht J (2002) Recent advances in understanding aminoglycoside ototoxicity and its prevention. Audiol Neurootol 7:171-174

Yan HY, Saidel WM, Chang JS, Presson JC, Popper AN (1991) Sensory hair cells of a fish ear: evidence of multiple types based on ototoxicity sensitivity. Proc R Soc Lond B 245:133-138

Zeddies DG, Fay RR (2005) Development of the acoustically evoked behavioral response in zebrafish to pure tones. J Exp Biol 208(7):1363-1372 


\title{
Neuroanatomical Evidence for Catecholamines as Modulators of Audition and Acoustic Behavior in a Vocal Teleost
}

\author{
Paul M. Forlano and Joseph A. Sisneros
}

\begin{abstract}
The plainfin midshipman fish (Porichthys notatus) is a well-studied model to understand the neural and endocrine mechanisms underlying vocalacoustic communication across vertebrates. It is well established that steroid hormones such as estrogen drive seasonal peripheral auditory plasticity in female Porichthys in order to better encode the male's advertisement call. However, little is known of the neural substrates that underlie the motivation and coordinated behavioral response to auditory social signals. Catecholamines, which include dopamine and noradrenaline, are good candidates for this function, as they are thought to modulate the salience of and reinforce appropriate behavior to socially relevant stimuli. This chapter summarizes our recent studies which aimed to characterize catecholamine innervation in the central and peripheral auditory system of Porichthys as well as test the hypotheses that innervation of the auditory system is seasonally plastic and catecholaminergic neurons are activated in response to conspecific vocalizations. Of particular significance is the discovery of direct dopaminergic innervation of the saccule, the main hearing end organ, by neurons in the diencephalon, which also robustly innervate the cholinergic auditory efferent nucleus in the hindbrain. Seasonal changes in dopamine innervation in both these areas appear dependent on reproductive state in females and may ultimately function to modulate the sensitivity of the peripheral auditory system as an adaptation to
\end{abstract}

P.M. Forlano $(\square)$

Department of Biology, Brooklyn College, and The Graduate Center,

City University of New York, Brooklyn, NY, USA

Aquatic Research and Environmental Assessment Center,

Brooklyn College, Brooklyn, NY, USA

e-mail: pforlano@brooklyn.cuny.edu

J.A. Sisneros

Departments of Psychology and Biology, University of Washington, Seattle, WA, USA

(C) Springer International Publishing Switzerland 2016 
the seasonally changing soundscape. Diencephalic dopaminergic neurons are indeed active in response to exposure to midshipman vocalizations and are in a perfect position to integrate the detection and appropriate motor response to conspecific acoustic signals for successful reproduction.

Keywords Porichthys notatus $\bullet$ Dopamine $\bullet$ Saccule $\bullet$ Acoustic communication • Hair cell

\section{Introduction}

Although both the neural pathways and physiological response properties of the auditory system in teleost fishes have been investigated in numerous studies (e.g., Bass et al. 2005; Fay and Edds-Walton 2008; Lu 2011; Maruska and Sisneros, this volume; McCormick 1999, 2011; Edds-Walton, this volume), much less is known about neuromodulators that affect auditory circuitry and subsequent behaviors in response to biotic and abiotic sounds encountered by fishes over the course of their life history. Neuromodulators, including traditional neurotransmitters, neuropeptides, and steroid hormones may be dynamically or seasonally expressed in order to coordinate the internal state of the animal with changes in sensory physiology that underlie appropriate encoding and behavioral responses to auditory stimuli (Forlano and Bass 2011; Forlano et al. 2015a; Forlano et al. 2015b). The plainfin midshipman fish, Porichthys notatus (family Batrachoididae), is highly amenable for investigating these types of questions as its auditory circuitry has been well delineated throughout the CNS (Bass et al. 2000; Bass et al. 1994; Goodson and Bass 2002), its peripheral and central physiology is well characterized (Bodnar and Bass 1997, 1999; McKibben and Bass 1999, 2001b; Rohmann and Bass 2011; Sisneros and Bass 2003), and females exhibit an unconditioned positive phonotaxic response to the fundamental frequency of the male advertisement call (McKibben and Bass 1998; Zeddies et al. 2010).

In this chapter, we focus on recent studies that build on this large foundation of midshipman neuroanatomy, physiology, and behavior to investigate a role for catecholamines, which include dopamine (DA) and noradrenaline (NA), as potential neuromodulators of central and peripheral auditory circuitry and as substrates for the coordination of motivated behavioral responses to social acoustic signals in this species. It is anticipated that these neuroanatomical findings are not necessarily specific only to midshipman or other soniferous fishes, but are likely characteristic of all vertebrates that employ conspecific acoustic communication.

Until recently, catecholamines have not been investigated as potential neuromodulators of auditory physiology or for auditory-driven social behavior in fishes. Our recent findings offer new insights into the conserved nature and function of catecholamines, namely, DA, and how the midshipman model may in fact be the most appropriate vertebrate model for investigating the functional significance of DA modulation in the auditory periphery in a natural behavioral context. 


\subsection{Catecholamines as Good Candidates for Modulation of Audition and Auditory-Driven Behaviors}

Catecholamines are well documented as regulators of motivation, attention, arousal, and reward as well as modulators of motor and sensory systems across vertebrates (Berridge 2008; Berridge and Waterhouse 2003; Hurley et al. 2004; Joshua et al. 2009; Kelly and Goodson 2015; Riters 2012). Importantly, it has been proposed from multiple studies in songbirds that seasonal changes in steroid hormones may regulate brain catecholamines, which in turn increase incentive salience of conspecific vocalizations (Caras 2013; Maney 2013; Maney and Pinaud 2011). In particular, the ascending DA system, largely studied in the context of rewardseeking behavior, is thought to interact with the highly conserved vertebrate social behavior network $(\mathrm{SBN})$, a group of interconnected nuclei within the basal forebrain and midbrain of all vertebrate taxa, to reinforce and mediate appropriate behavioral responses to social acoustic signals (Goodson 2005; Goodson and Kabelik 2009; Goodson and Kingsbury 2013; O'Connell and Hofmann 2011). Furthermore, several studies spanning diverse vertebrate taxa have identified auditory nuclei in the central nervous system (CNS) as clear targets of catecholaminergic (CA) projections from both DA and NA cell populations (e.g., Appeltants et al. 2001; Endepols et al. 2000; Forlano et al. 2014; Klepper and Herbert 1991; Mello et al. 1998) and neurophysiological preparations have demonstrated catecholamines as potent modulators of auditory response properties in both the central (Edeline et al. 2011; Gittelman et al. 2013; Kossl and Vater 1989; Schall et al. 1999) and peripheral auditory system (Garrett et al. 2011; Maison et al. 2012; Niu and Canlon 2006; Ruel et al. 2001; Ruel et al. 2007), although the latter has only been investigated in rodents.

Studies which have investigated mechanisms of action of dopamine signaling on the inner ear have suggested a role for dopamine in protection from acoustic trauma damage, as dopamine appears to suppress the excitotoxic effects of acoustic overstimulation (Lendvai et al. 2011). One might argue that while informative, these studies (and conclusions) are unsatisfying for those researchers interested in the neural adaptations of natural behavior, as vertebrate auditory efferent systems did not evolve in the presence of equivalent noise levels in those studies (see Kirk and Smith 2003; Koppl 2011; Smith and Keil 2015 for similar discussion on mammalian cholinergic efferent system). Thus, to date, the natural biological function of dopamine in the inner ear and its role in normal auditory processing and behavior remains unknown. Surprisingly, the functional significance of the auditory efferent system as a whole remains unclear (Koppl 2011). Here, we will discuss the advantages and appropriateness of the midshipman model as an unparalleled opportunity to gain insight on the structure and function of catecholamines in auditory processing and behavior. 


\section{Midshipman Life History}

The plainfin midshipman fish is an excellent model to investigate the neural and endocrine mechanisms underlying vocal-acoustic communication across vertebrates because much of the animal's life history and social behavior is dependent on the production and detection of social acoustic signals (Bass and McKibben 2003; Forlano et al. 2015b). In the summer reproductive season, type I or "singing" males excavate and defend nests in the rocky intertidal zone of northern California and the Pacific Northwest, USA and court females at night by producing a long duration $(>1$ min) advertisement call, the "hum," generated by simultaneous contraction of vocal musculature along the sides of the swim bladder (Bass and McKibben 2003; Cohen and Winn 1967). The type I male's advertisement call is a multiharmonic signal with a fundamental frequency that ranges from 90 to $100 \mathrm{~Hz}$ at temperatures of 15-16 ${ }^{\circ} \mathrm{C}$ (Bass et al. 1999; Ibara et al. 1983) and the call's harmonics can extend up to $700 \mathrm{~Hz}$ (Brantley and Bass 1994; McIver et al. 2014). There also exists a second male morph known as a type II male that employs an alternative reproductive tactic that consists of satellite and/or "sneak" spawning to steal fertilizations from type I males spawning with females. Type II males do not produce advertisement calls or build nest sites but instead invest more energy in testes size to compete with type I males for spawning (Bass 1996). The testes of type II males can be as large as $15-20 \%$ of their body weight and presumably have more sperm than that of type I males (Bass 1996; Brantley and Bass 1994). Reproductive females are attracted to the advertisement call of males and localize potential mates by pinpointing the source of the humming male in his nest, spawn once by depositing eggs on the roof of the male's nest where fertilization occurs, and then return off shore after spawning is completed, while nesting type I males continue to court and spawn with other females and care for the young alone (Bass 1996; Bass and McKibben 2003; Forlano and Bass 2011).

Nesting type I males provide all the parental care of the developing offspring and will vigorously guard and defend their nest from egg predators. The developing nest larvae take approximately 50-60 days at a temperature of $15^{\circ} \mathrm{C}$ to absorb their yolk (Alderks and Sisneros 2013) before they detach from the nest, become free swimming, and then move into the shallow sea grass beds for food and safety.

\subsection{Seasonal Plasticity of the Midshipman Auditory Sense}

Behavioral studies of female midshipman to simulated advertisement calls show that gravid females (full of eggs) exhibit robust phonotaxis to natural and synthetic advertisement calls. This unconditioned phonotaxic response of gravid females is clearly unambiguous and results in the localization of the sound source, whereas recently spawned females (void of eggs) do not exhibit phonotaxis or sound source localization, nor show any interest in the advertisement call (McKibben and Bass 
1998, 2001a; Zeddies et al. 2010; Zeddies et al. 2012). Because nocturnally active reproductive females were known to rely on their auditory sense to locate mates, Sisneros and Bass (2003) posited that the animal's seasonal reproductive state influenced female auditory sensitivity and thus proceeded to test the hypothesis that female reproductive state (gravid vs. non-gravid) modulated the frequency response properties and sensitivity of the peripheral auditory system. Sisneros and Bass (2003) showed that summer reproductive females were more sensitive than winter non-reproductive females to higher frequencies within the species' hearing range. Specifically, the auditory saccular afferents of reproductive females had greater phase-locking accuracy than that of non-reproductive females to frequencies of 120-400 Hz, which corresponded to the dominant higher harmonic components of the male's advertisement call. Similarly, Sisneros (2009a) showed that the hair cells in the saccule, the main organ of hearing in midshipman, from reproductive females were $2.5-4.5 \times$ more sensitive than that of non-reproductive females to frequencies of $75-385 \mathrm{~Hz}$, which also corresponds to the frequencies of the advertisement call that contain the majority of the energy in the call.

Recently, Rohmann et al. (2013) showed that the pore-forming alpha-subunit slo 1 gene and its transcripts, slo $1 a$ and slo $1 b$, both of which are expressed in the saccular epithelium (Rohmann et al. 2009), are upregulated during the summer reproductive season, which is consistent with higher BK channel expression and enhanced higher frequency encoding in females (Rohmann et al. 2013). Higher BK channel expression in the saccule of reproductive females is significant because in nonmammalian vertebrates, hair cells with greater expression of calcium-activated potassium (BK) channels are capable of higher resonant frequencies, and thus are better at encoding higher frequency sounds (Fettiplace and Fuchs 1999). Together these studies provide evidence that the peripheral auditory sensitivity of female midshipman is modulated by the female's reproductive cycle such that reproductive females are better adapted than non-reproductive females to detect and encode the dominant harmonic frequencies in the male's advertisement call. This enhanced sensitivity may represent an adaptation of the teleost auditory system to increase the probability of mate localization and enable females to acquire acoustic information needed for mate choice decisions.

The seasonal enhancement of hearing in female midshipman for the detection of the higher frequency harmonics in the male social acoustic signals is likely adaptive for the shallow water acoustic environment where midshipman court and socially interact during the breeding season. Sound propagation of low frequency sounds in shallow water environments are greatly affected by water depth and substrate composition (Rogers and Cox 1988). The higher frequency harmonics of the male's advertisement call have been proposed to provide greater signal detection of the male's social acoustic signal for females because the advertisement call's dominant harmonics $(200-400 \mathrm{~Hz})$ will propagate farther than the lower fundamental frequency $(\sim 80-100 \mathrm{~Hz})$ in shallow water environments due to an inverse relationship between the cutoff frequency of sound transmission and water depth (Fine and Lenhardt 1983; Rogers and Cox 1988; Sisneros and Bass 2003). Substrate composition of the shallow water environment is also an important factor that affects 
sound propagation because the speed of sound varies with substrate type (e.g., the speed of sound is faster in rock versus sand or clay, etc.) which in turn will affect the cutoff frequency of sound propagation (Bass and Clark 2003; Rogers and Cox 1988). In terms of signal perception by the receiver, the harmonics of the mate call may also influence the detection of the signal when females are near the source of the advertisement call. McKibben and Bass (2001b) showed that encoding of a tone at or near the fundamental frequency of the mate call was improved, at the level of the saccular afferents, when tones similar to harmonics were added to the presentation stimuli.

Recently Coffin et al. (2012) showed that midshipman females also exhibit seasonal changes in saccular hair cell densities that were concurrent with changes in sensitivity of the saccule. This increase in hair cell density was only observed in the saccule of reproductive females and not in the other inner ear end organs (i.e., lagena and utricle) of reproductive females. Also, the seasonal change in saccular hair cell density was not dependent on body size because the observed increase in hair cell density was consistent across the size range of fish sampled. In addition, Coffin et al. (2012) also reported an increase in the number of small, potentially immature saccular hair cell bundles in summer reproductive females. In sum, the seasonal increase in saccular hair cell density coupled with an increase in smaller hair cell bundles in reproductive females was concurrent with a dramatic increase in the magnitude of the recorded evoked saccular potentials and corresponded with an increase in saccular sensitivity. Thus, the saccular-specific changes in hair cell density and morphology likely contribute to the seasonal enhancement of female midshipman hearing for the detection of male advertisement calls.

\subsection{Steroid-Dependent Plasticity of the Midshipman Auditory Sense}

The steroid hormones testosterone, 11-ketotestosterone and estrogen (17 $\beta$-estradiol) are known to fluctuate seasonally in male and female plainfin midshipman with their reproductive cycle (Sisneros et al. 2004b). The seasonal variation of these steroid hormone levels is consistent with changes in midshipman reproductive behavior and biology (Brantley et al. 1993; Knapp et al. 1999; Sisneros et al. 2004b). Sisneros et al. (2004b) defined four time periods that corresponded with the annual reproductive cycle of the plainfin midshipman that included pre-nesting, nesting, post-nesting, and non-reproductive periods. The pre-nesting period occurs in the spring months of March and April when type I males and females exhibit gonadal recrudescence of the testes and ovaries, respectively, with type I males exhibiting a gradual increase in plasma levels of testosterone $(\mathrm{T})$ and 11-ketotesosterone (11KT) while females exhibit a brief spike of $17 \beta$-estradiol $\left(E_{2}\right)$ and T plasma levels in April, which is approximately 1 month before to the start of summer breeding season. The nesting period occurs in late-spring and summer during the months of May through August when type I males with an intermediate gonadal somatic index 
(GSI, ratio of gonad to body mass) have T and 11-KT levels that peak at the beginning of the nesting season in May and June while reproductive females with a relatively high GSI have well-developed eggs ( $\sim 5 \mathrm{~mm}$ diameter) and low $\mathrm{T}$ and $\mathrm{E}_{2}$ levels. During the nesting period, "humming" type I males have significantly higher circulating plasma levels of 11-KT than non-humming males (Genova et al. 2013). The post-nesting period occurs during the fall months of September and October when type I males and females exhibit a marked decrease in their GSI and in $E_{2}, T$, and 11-KT plasma levels. The non-reproductive period occurs during the winter months from December to February when type I males have low GSI with no sperm present and low T and 11-KT plasma levels, whereas females have low GSI with ovaries that contain undeveloped oocytes and low $\mathrm{E}_{2}$ and $\mathrm{T}$ plasma levels.

The brief spike in $\mathrm{E}_{2}$ levels that female midshipman exhibit approximately 30 days before the start of the breeding season led Sisneros et al. (2004b) to hypothesize that $\mathrm{E}_{2}$ or $\mathrm{T}$ was responsible for inducing the observed seasonal changes in saccular afferent sensitivity (Sisneros and Bass 2003). Results from Sisneros et al. (2004a) showed that ovariectomized non-reproductive females implanted with either $\mathrm{E}_{2}$ or $\mathrm{T}$ capsules to mimic pre-nesting steroid levels resulted in increased saccular sensitivity. Specifically, $\mathrm{E}_{2}$ and $\mathrm{T}$ separately improved the phase-locking accuracy of saccular afferents and enhanced the encoding of the auditory afferents to frequencies that corresponded to the dominant harmonic components of the male advertisement call. The response profiles of the saccular afferents were shown to be similar to the female reproductive auditory phenotype previous reported by Sisneros and Bass (2003). Sisneros et al. (2004a) also confirmed the presence of estrogen receptor alpha $(\mathrm{ER} \alpha)$ in the sensory macula of the saccule, which provided further evidence for direct effects of steroid hormones on the peripheral auditory system.

\section{Context for Recent Studies on Catecholamines and the Midshipman Model}

While it is well established that steroid hormones such as estrogen drive seasonal peripheral auditory plasticity in female Porichthys in order to better encode the male's mate call, neuromodulators downstream of steroids as well as central mechanisms are unexplored and little is known of the neural substrates that underlie the motivation and coordinated behavioral response to auditory social signals. As discussed by Bhandiwad and Sisneros (this volume), how attention affects hearing and perception is unexplored in fishes, and the neurochemical components which underlie attention to sound may account for individual variability in behavioral assays. Our studies focused on establishing if catecholamines are potential substrates for modulation of auditory physiology and motivated auditory-driven behaviors (e.g., phonotaxis). Therefore, we first aimed to characterize CA innervation of the central and peripheral auditory system of midshipman. Secondly, we tested the hypotheses that (1) innervation of the auditory system is seasonally plastic and (2) CA neurons are activated in response to conspecific vocalizations. 


\subsection{Organization of the Midshipman Ascending Auditory System}

Like most other teleosts, the saccule is the largest inner ear end organ (Fig. 1) and thought to be the main peripheral sensory structure for hearing (Fay and EddsWalton 2008). The midshipman auditory system has been well delineated from multiple studies that have employed a variety of tract tracing techniques including bulk fills of the saccular branch of the eighth nerve as well as isolation and characterization of single unit recordings of midbrain neurons followed by injections of biotin compounds (Bass et al. 2000; Bass et al. 1994; Sisneros et al. 2002). In addition, tracer injection into vocally active circuitry has demonstrated auditory-vocal integration sites in forebrain, midbrain, and hindbrain (Goodson and Bass 2002; Kittelberger and Bass 2013). Due to their small molecular weight, biocytin and neurobiotin compounds have been shown to be actively transported transynaptically, which has allowed for identification of multiple levels of processing within the hindbrain alone (Bass et al. 2000; Bass et al. 1994; Sisneros et al. 2002). The most likely explanation for this degree of multi-synapse transport is via gap junctions (Bass et al. 1994). Primary afferents from the saccule synapse onto hindbrain neurons of the descending octaval nucleus (DO) which are connected to secondary octaval neurons (SO); both hindbrain groups project to the midbrain torus semicircularis (TS), which in turn projects to several diencephalic nuclei including the anterior tuberal hypothalamus (AT), lateral division of nucleus preglomerulosus (PGl) and central posterior thalamus (CP), as well as to ventral telencephalic nuclei. The auditory thalamus (CP) also receives input from AT and relays information to

Fig. 1 (continued) analyzed in Forlano et al. (2015a) (adapted from Forlano et al. 2014). Abbreviations: $a c$ anterior commissure, $A T$ anterior tuberal nucleus, $C$ cerebellum, $C A$ cerebral aqueduct, $c c$ cerebellar crest, $C m$ molecular layer of the corpus of the cerebellum, $C g$ granular layer of the corpus of the cerebellum, $C P$ central posterior nucleus of the thalamus, $D f$ diffuse nucleus of the hypothalamus, $d l$ dorsolateral division of the descending octaval nucleus, $D l$ lateral zone of area dorsalis of the telencephalon, $d m$ dorsomedial division of the descending octaval nucleus, $D m$ medial zone of area dorsalis of the telencephalon, $D O$ descending octaval nucleus, $G$ nucleus glomerulosus, $H a$ habenula, $H c$ central periventricular hypothalamus, $H d$ dorsal periventricular hypothalamus, $H v$ ventral periventricular hypothalamus, iaf internal arcuate fiber tract, $I V$ fourth ventricle, $L C$ locus coeruleus, $l l$ lateral lemniscus, $M$ midbrain, $M E D$ medial octavolateralis nucleus, $M F B$ medial forebrain bundle, $M L F$ medial longitudinal fasciculus, $O B$ olfactory bulb, $O E$ octavolateralis efferent nucleus, $O T$ optic tract, $P A G$ periaqueductal gray, $P e$ periventricular cell layer of the torus semicircularis, $P P a$ anterior parvocellular preoptic nucleus, $P G l$ lateral division of nucleus preglomerulosus, Pit pituitary, PTN posterior tuberal nucleus, $P T T$ paratoral tegmentum, $P V O$ paraventricular organ, $R F$ reticular formation, $S E$ saccular epithelium of the inner ear, $S O$ secondary octaval nucleus, $S R$ superior raphe, $S V$ saccus vasculosus, $T$ telencephalon, $T e$ midbrain tectum, $T P p$ periventricular nucleus of the posterior tuberculum, $T S$ torus semicircularis, $V c$ central nucleus of area ventralis of the telencephalon, $V d$ dorsal nucleus of area ventralis of the telencephalon, Vde descending tract of the trigeminal nerve, VIII eighth nerve, $V L$ ventrolateral nucleus of the thalamus, $V M$ ventromedial nucleus of the thalamus, $V p$ postcommissural nucleus of area ventralis of the telencephalon, $V s$ supracommissural nucleus of area ventralis of the telencephalon, $v T$ ventral tuberal hypothalamus. Scale bar $=1.5 \mathrm{~mm}$ (dorsal brain); $500 \mu \mathrm{m}$ (sections) 


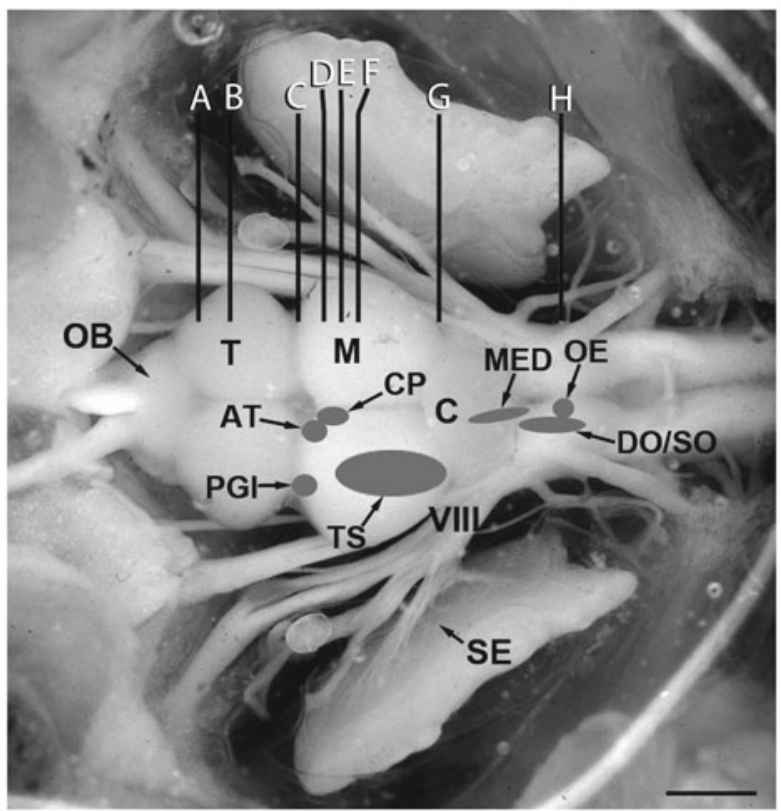

a

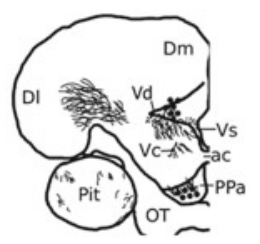

b

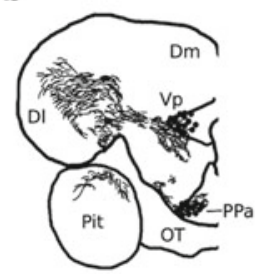

f

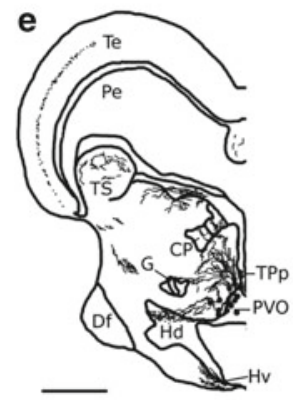

c

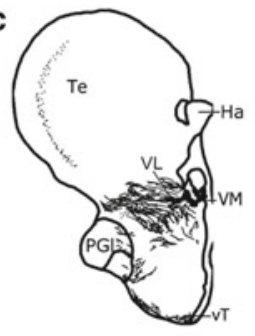

g

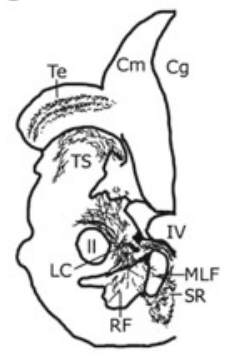

d

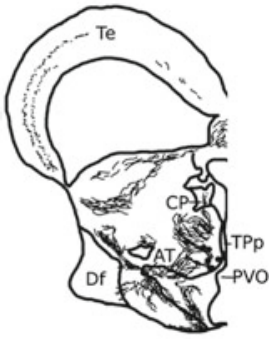

h

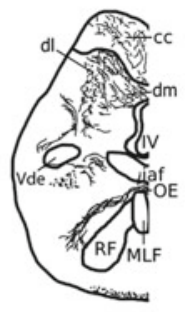

Fig. 1 Dorsal view of an exposed midshipman brain and inner ear. Shaded areas indicate location of auditory nuclei (adapted from Bass et al. 2000; Forlano et al. 2015a). Vertical lines $(A-H)$ indicate levels of transverse sections below. A representative series of line drawings illustrating rostrocaudal distribution of major tyrosine hydroxylase immunoreactive (TH-ir) cell populations (large dots), fibers (lines), and terminals (small dots) in the midshipman brain covering auditory areas 
both the ventral divisions [supracommissural (Vs), ventral (Vv) and postcommissural (Vp)] and dorsomedial telencephalon (Bass et al. 2000; Bass et al. 1994; Goodson and Bass 2002).

\subsection{Catecholaminergic Connectivity to Auditory Circuitry}

We mapped the distribution of tyrosine hydroxylase ( $\mathrm{TH}$; the rate limiting enzyme in catecholamine synthesis) immunoreactive (-ir) fibers and terminals throughout the midshipman brain with focus on nuclei within the central auditory system (Fig. 1). In addition, we utilized bulk neurobiotin labeling of the saccule combined with immunohistochemistry to show TH-ir innervation on and around neurons directly connected within nuclei of the ascending auditory system as delineated by this technique (Figs. 2, 3, and 4) (Forlano et al. 2014).

\subsubsection{Higher Auditory Nuclei}

With the exception of the dorsal medial telencephalon (Dm; Goodson and Bass 2002), all higher order auditory nuclei contain robust CA innervation (Fig. 1) (Forlano et al. 2014). The major recipient of ascending projections from hindbrain auditory nuclei is the nucleus centralis (NC) division of the midbrain TS (Bass et al. 2000; Bass et al. 2005; McCormick 1999). Interestingly, NC is more robustly innervated with TH-ir fibers and terminals compared to lateral and deeper cell layers that process lateral line stimuli (Figs. 1e-g and 2a, b; Bass et al. 2000; Weeg and Bass 2000). Major efferent targets of NC include AT, CP, and PGl, which are all heavily innervated by TH-ir fibers and terminals (Fig. 2c-f). After saccular backfill experiments, neurobiotinlabeled cells with putative TH-ir contacts are occasionally found in both AT and CP (Fig. 2d (inset), f; Forlano et al. 2014). Neurobiotin-labeled cells and terminals also intermixed with abundant $\mathrm{TH}$-ir varicosities were consistently found in the eminentia granularis, which contains input from the vocal hindbrain (Bass et al. 1994) (Fig. 2g). In addition, neurobiotin-filled cells were consistently found as far rostral as the posterior parvocellular preoptic nucleus (PPp), whose dendritic field is densely innervated by TH-ir varicose fibers. Although PPp and AT contain their own small population of TH-ir somata, backfilled cells in these areas were never found to be TH-ir (Forlano et al. 2014). Parvocellular preoptic nuclei ( $\mathrm{PPa} / \mathrm{p})$, AT as well as Vs and Vp all have reciprocal connections with CP (Goodson and Bass 2002). Vs and Vp also contain their own local population of TH-ir (DA) neurons (Fig. 1).

\subsubsection{Auditory Hindbrain}

Saccular backfills produced neurobiotin-labeled cells in hindbrain auditory nuclei including the dorsomedial $(\mathrm{dm})$ and rostrointermediate (ri) divisions of the descending octaval nucleus (DO), ventral secondary octaval nucleus (SOv), ventral 

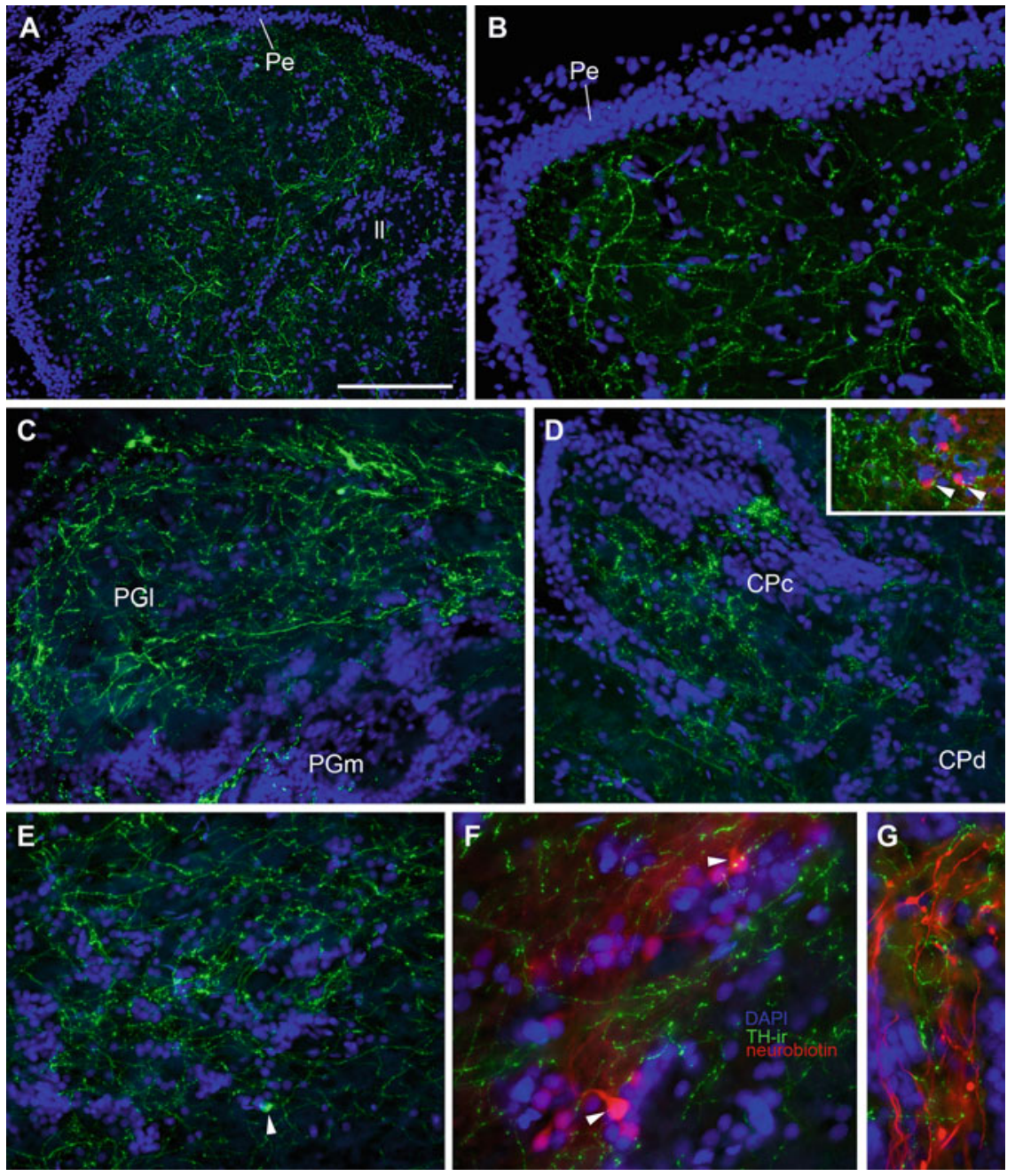

Fig. 2 TH-ir in higher order auditory nuclei; blue is DAPI nuclear stain. (a, b) TH-ir fibers and terminals are abundant in the midbrain torus semicircularis (TS). (a) Horizontal section through TS. Rostral is to the left, medial is top of the image. (b) Transverse section through auditory area centralis of TS. Compact band of nuclei is the periventricular cell layer (Pe) of TS. (c) TH-ir projections and varicosities in the lateral (PGl) and medial (PGm) division of nucleus preglomerulosus. Image taken from same section shown in 4c. (d) TH-ir terminals in the compact (CPc) and diffuse (CPd) divisions of the central posterior nucleus (auditory thalamus). Inset shows TH-ir terminals on neurobiotin-filled cells (red) in CPc following a bilateral backfill of the saccular branch of VIII. (e) A single TH-ir cell (arrowhead) together with dense TH-ir terminals in the hypothalamic anterior tuberal nucleus (AT). (f) TH-ir terminals on neurobiotin-filled cells (red, arrowheads) in AT following a bilateral backfill of the saccular branch of VIII. AT is also part of the descending vocal motor circuitry and contains reciprocal connections with CP. (g) TH-ir terminals are found intermixed with neurobiotin-filled afferents (red) from a saccular backfill in the eminentia granularis. Scale bar in $=200 \mu \mathrm{m}$ in $\mathbf{a}, 100 \mu \mathrm{m}$ in $\mathbf{b}-\mathbf{e}, 50 \mu \mathrm{m}$ in $\mathbf{f}$ and $\mathbf{g}$. From Forlano et al. (2014) 

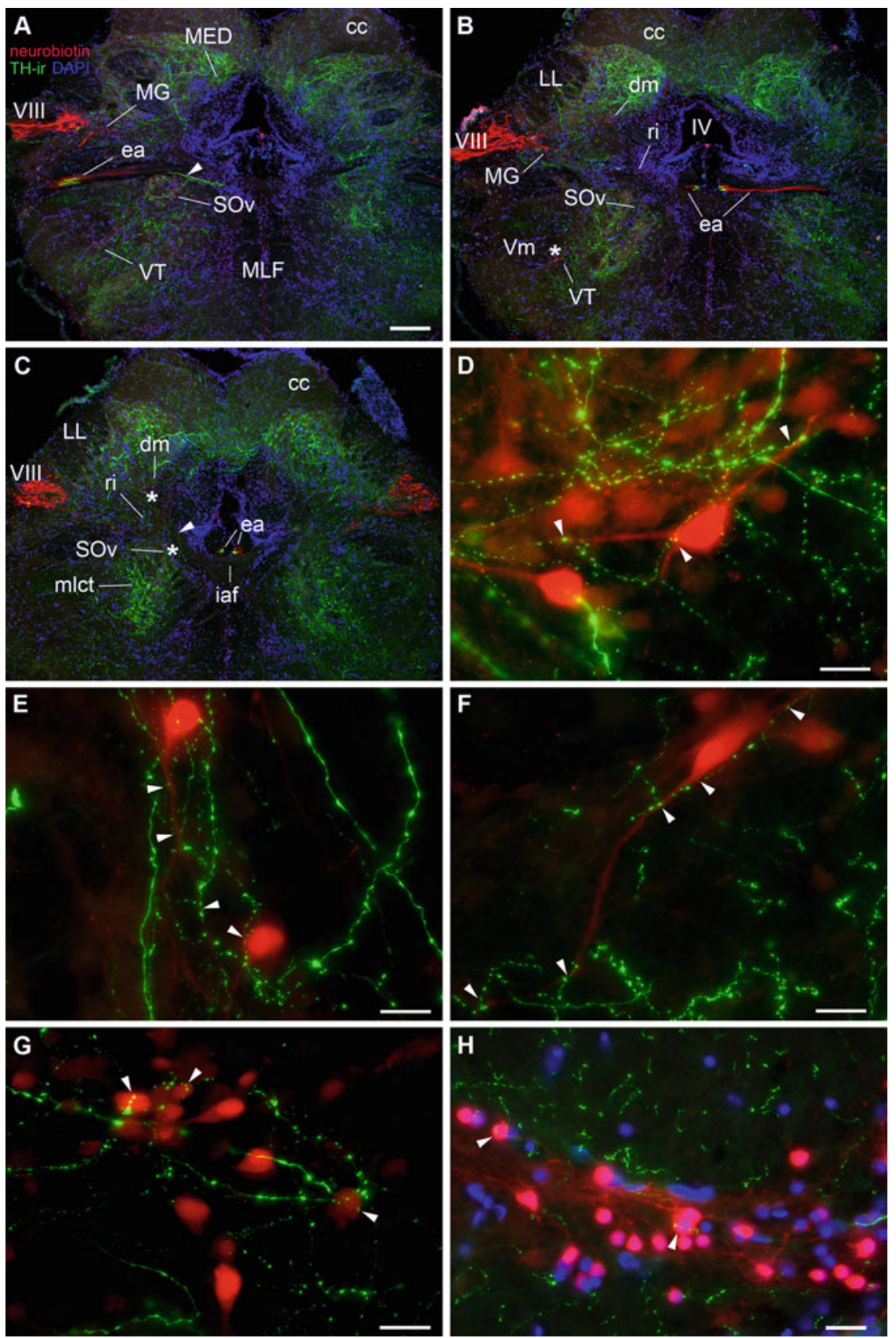

Fig. 3 TH-ir innervation of transneuronal-labeled hindbrain auditory nuclei following a bilateral application of neurobiotin on the saccular epithelium. (a-c) Low magnification rostral-caudal series of transverse sections showing location of neurobiotin-filled cells in the auditory system and prominent $\mathrm{TH}$-ir terminal fields in the dorsal and ventral hindbrain. Note both $\mathrm{TH}$-ir and 
tegmental (VT) cells, and inferior olive (IO), all of which were found to contain putative TH-ir terminals on both their somata and dendrites (Fig. 3d-h). All of these nuclei are consistent with previous studies that delineated hindbrain auditory circuitry by saccular backfills (Bass et al. 2000; Bass et al. 1994; Sisneros et al. 2002). $\mathrm{TH}$-ir fibers and terminals are heavily concentrated throughout the longitudinal column of the dorsal hindbrain that includes $\mathrm{dm}$ and dorsolateral (dl) divisions of DO and the lateral line recipient nucleus medialis (MED) as well as the magnocellular octaval nucleus (MG) which sits adjacent to the entry of nerve VIII (Figs. 3a-c and $4 \mathrm{a}-\mathrm{c})$. At rostral levels, TH-ir fibers are highly concentrated within bilateral tracts coursing through the ventral medial hindbrain which includes where SOv and VT are located. TH-ir fibers are also present but less dense within the cerebellar crest (cc), and within central tracts of the posterior and anterior lateral line nerves (LL), adjacent to dl (Fig. 3).

\subsubsection{Octavolateralis Efferent Nucleus}

A bulk saccular fill will also delineate the hindbrain octavolateralis efferent nucleus (OE) which projects to all inner ear end organs and the lateral line system (Bass et al. 2000; Bass et al. 1994; Chagnaud et al. 2011; Chagnaud and Bass 2013; Weeg et al. 2005). These neurons are known to be cholinergic as they are labeled by choline acetyltransferase (ChAT)-ir (Brantley and Bass 1988; Forlano et al. 2015a). Qualitatively, the $\mathrm{OE}$ contains the most striking pattern of TH-ir innervation in the brain (Figs. 4 and 5), and is also thus far the densest area of TH-ir terminals measured quantitatively (Forlano et al. 2015a). The large OE somata which lie at the midline of the hindbrain just below the fourth ventricle have prominent ventrolaterally projecting dendrites and the distribution of TH-ir fibers closely matches this dendritic field and forms terminals on both neurobiotin-filled somata and dendrites (Fig. 4e-h). The pattern is consistent in both the rostral and caudal divisions of $\mathrm{OE}$ which are also lightly labeled by backfill of a single vocal nerve (Fig. 4d; Bass et al. 1994;

Fig. 3 (continued) neurobiotin-labeled (red) octavolateralis efferent axons (ea) within the lateral efferent bundle just caudal to where they join VIII. Arrowhead in a indicates TH-ir axon bundle entering the lateral efferent tract just dorsal to the ventral secondary octaval nucleus (SOv). TH-ir axons are seen descending within the efferent tract (b) as it turns to run longitudinally along the midline (c) dorsal to internal arcuate fiber tract (iaf) rostral to the octavolateralis efferent nucleus (OE, see Fig. 4d). Arrowhead in c shows TH-ir fibers projecting dorsally into the rostral intermediate (ri) and dorsal medial $(\mathrm{dm})$ subdivisions of the descending octaval nucleus (compare with Fig. 5b). (d, e) High magnification of areas indicated by (*) in c showing TH-ir terminals and varicosities on somata and dendrites (arrowheads) of $\mathrm{dm}$ and SOv neurons in $\mathbf{d}$ and e, respectively. (f) High magnification of area indicated by $(*)$ in $\mathbf{b}$ showing TH-ir varicosities on dendrites of a ventral tegmental (VT) neuron which lies just medial to the trigeminal motor nucleus $(\mathrm{Vm}) .(\mathbf{g}, \mathbf{h}) \mathrm{TH}$-ir terminals and varicosities on filled cells in ri and inferior olive (IO), respectively. Images in $\mathbf{g}$ and $\mathbf{h}$ were selected from sections outside of $\mathbf{a}-\mathbf{c}$. IO lies along the ventrolateral border of the caudal hindbrain. Scale bar $=200$ $\mu \mathrm{m}$ in $\mathbf{a}-\mathbf{c}, 16 \mu \mathrm{m}$ in $\mathbf{d}-\mathbf{g}$, and $20 \mu \mathrm{m}$ in $\mathbf{h}$. From Forlano et al. (2014) 

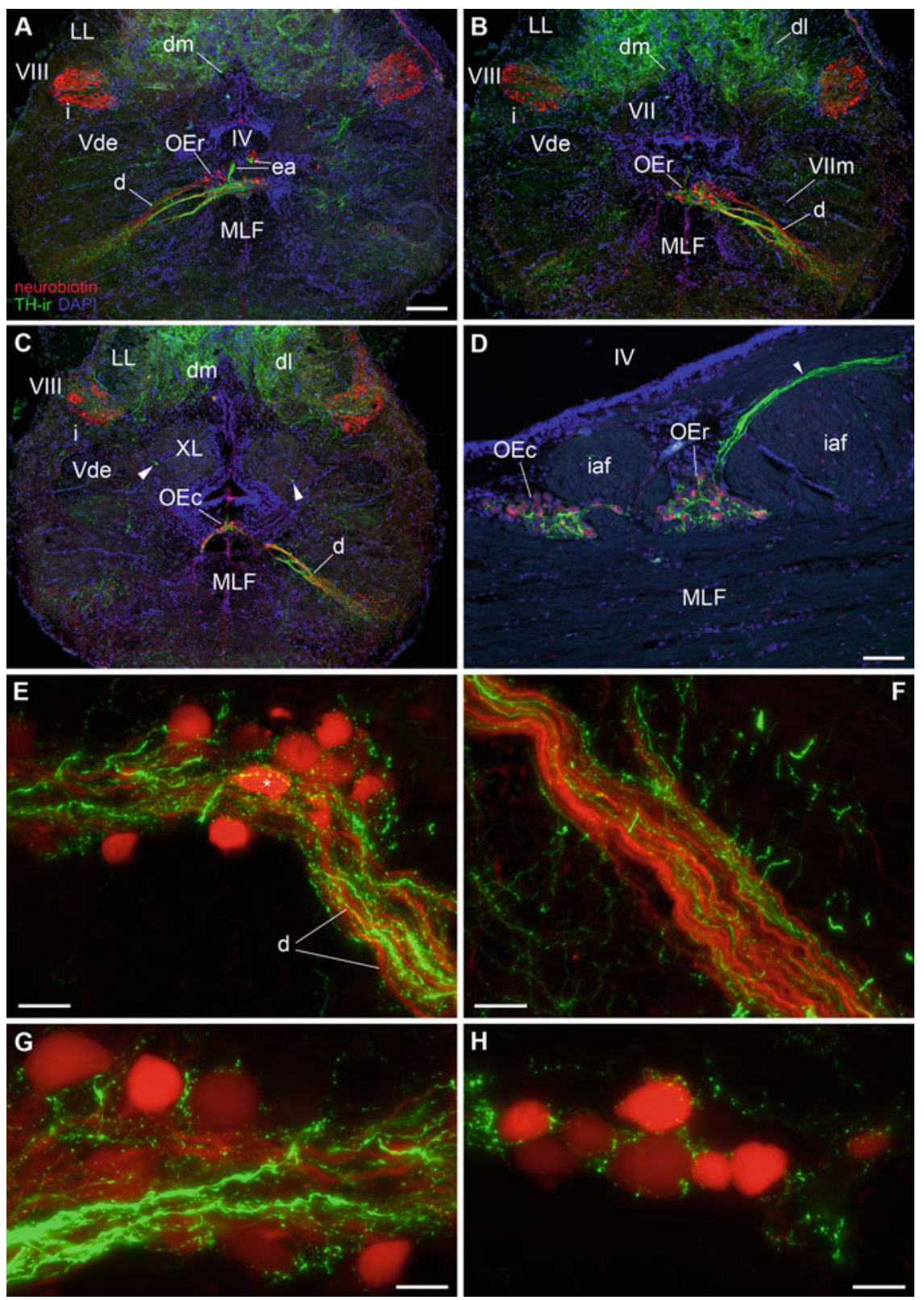

Fig. 4 Massive TH-ir innervation on somata and dendrites of the octavolateralis efferent nucleus (OE). $(\mathbf{a}-\mathbf{c})$ Low magnification series of transverse sections that show backfilled neurons of the rostral (OEr) and caudal $(\mathrm{OEc})$ subdivisions of the $\mathrm{OE}$ after bilateral application of neurobiotin on the saccular epithelium. OE neurons lie on the midline between the medial longitudinal fasciculus (MLF) and the fourth ventricle (IV). OE dendrites (d) extend ventrolaterally toward the edge of the brain and prominent TH-ir fiber tracts run along the length of the $\mathrm{OE}$ dendrites. The medial efferent axon tract can be seen in a as a caudal continuation from Fig. $3 \mathrm{c}$ which connects to the OE somata (also see d). Arrowheads in c indicate single TH-ir cells associated with the rostral vagal lobe (XL). (d) In the sagittal plane a bundle of intensely labeled TH-ir axons can be seen entering the OE via the efferent tract (arrowhead). (e-h) High magnification images of robust TH-ir terminals and varicosities on and around OE somata and dendrites. TH-ir in this area appears highly localized to OE and its dendritic field. Scale bar $=200 \mu \mathrm{m}$ in $\mathbf{a}-\mathbf{c}, 80 \mu \mathrm{m}$ in $\mathbf{d}, 25 \mu \mathrm{m}$ in $\mathbf{e}$ and $16 \mu \mathrm{m}$ in $\mathbf{f}-\mathbf{h}$. From Forlano et al. (2014) 
Forlano et al. 2014). In addition to projecting to the saccule, the OE is reciprocally connected to the vocal prepacemaker nucleus (VPP) of the vocal pattern generator (VPG) and receives a corollary discharge when the VPG is activated (Chagnaud and Bass 2013).

\subsubsection{Saccule}

Because TH-ir fibers could be seen within the efferent bundle (EB) that includes the lateral OE axons which connect to nerve VIII (Figs. 3a, b and 5d-f), we investigated TH-ir within the saccule. Using double-label immunofluorescence for $\mathrm{TH}$ and otoferlin, labeled by the hair cell specific antibody (HCS-1), we were able to characterize TH-ir distribution within sections of the saccular epithelium (Forlano et al. 2014). Several large caliber TH-ir fibers are seen within the saccular branch of VIII proximal to the sensory macula. These fibers course past ganglion cells, bifurcate heavily, and mostly appear to form terminals and punctate-like structures proximal to the base of hair cells and within the layer that includes support cell nuclei (Figs. 6b, c and 7b).

\subsection{Origin of CA Fiber Innervation}

The origin of CA efferents to the saccule was revealed by identifying a small number of large, pear-shaped neurons in the diencephalon that were TH-ir and also consistently labeled with neurobiotin after saccular backfills (Fig. 6d-f) (Forlano et al. 2014). These TH-ir neurons reside in the periventricular posterior tuberculum (TPp) and are known to be dopaminergic in teleosts and homologous to DA A11 neurons in other vertebrates (Filippi et al. 2010; Kastenhuber et al. 2010; Ryu et al. 2006; Tay et al. 2011). All neurobiotin-filled TPp cells were TH-ir and backfilled cells were found on either side of the third ventricle regardless of which saccule was labeled, implying both ipsi-and contralateral projection patterns. We estimate that about only $5-10 \%$ of $\sim 300 \mathrm{TH}$-ir TPp neurons project to the saccule in midshipman. As mentioned above, TH-ir fibers of the same caliber seen in the saccular branch of VIII are also seen in LL nerves and it is highly likely that same TPp neurons innervate lateral line and other inner ear end organs (Forlano et al. 2014). Indeed, a study in larval zebrafish showed that these DA diencephalic neurons project to lateral line (Bricaud et al. 2001), and tract tracing studies in goldfish identified neurons in a similar position project to lateral line nerves (Puzdrowski 1989; Zottoli and Van Horne 1983). Prominent descending TH-ir tracts originating from TPp are obvious from sagittal and horizontal sections through the midshipman brain, and these fibers appeared to target the rostral and caudal OE in single-labeled tissue (Figs. 4d and 5). Whether the same DA neurons in TPp project to both the saccule and $\mathrm{OE}$ somata (and dendrites) is unknown at this time, but it is likely that much of the CA innervation of the auditory hindbrain originates from TPp. These projections form the bulk of the prominent medial longitudinal CA tract (mlct) and this tract courses through the SOv and some fibers from this tract appear to branch off 

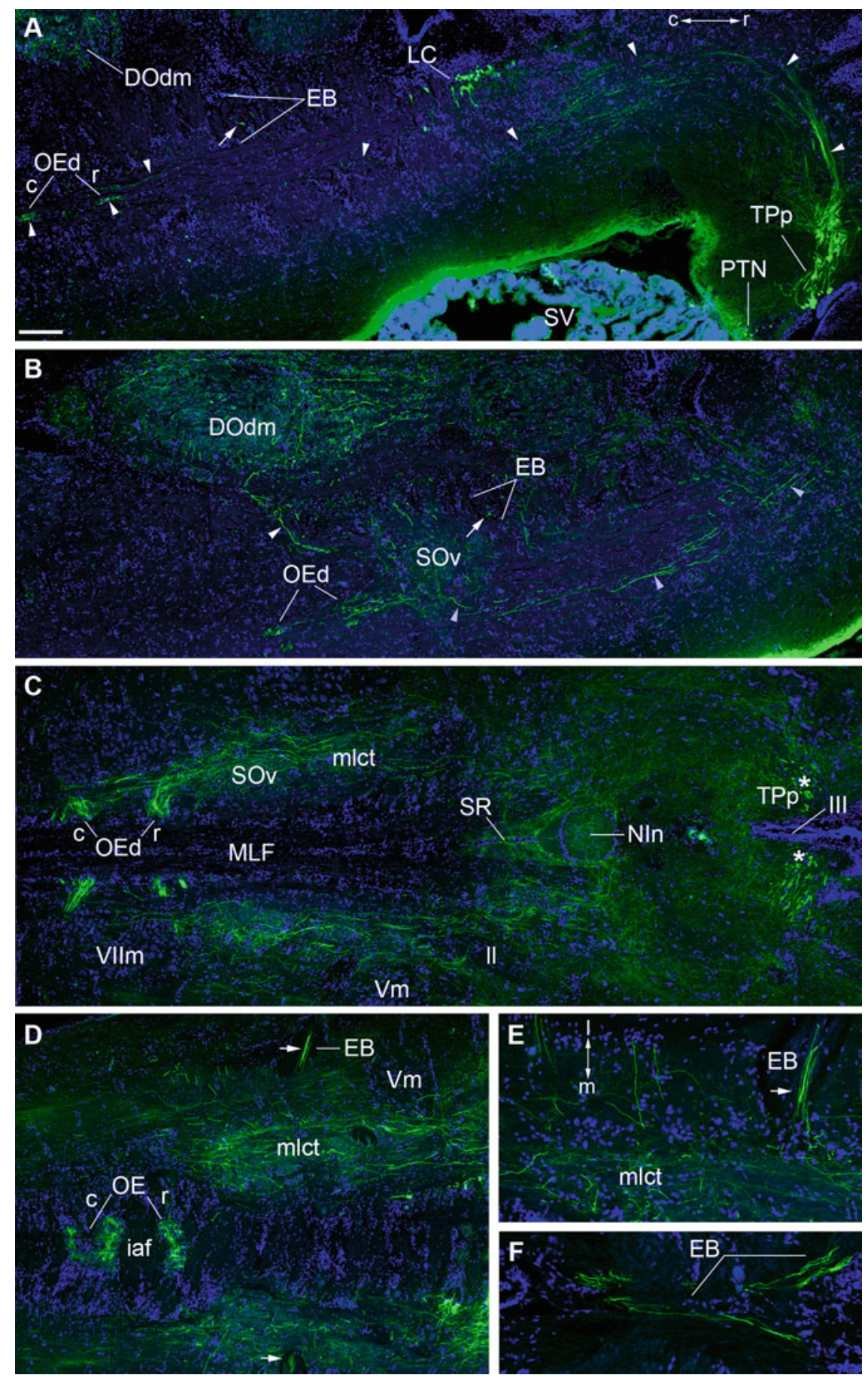

Fig. 5 Descending TH-ir projections (green) from the periventricular posterior tuberculum (TPp). Blue is DAPI nuclear stain. Rostral (r) is to the right in all images. (a) Composite parasagittal section showing large TPp TH-ir neurons which sit rostral to smaller TH-ir cells in the posterior tuberal nucleus (PTN) and send a thick tract of dorsal projections (arrowheads) that turns to descend 
and innervate dorsal DO areas such as dm (Figs. 3a-c and 5b; Forlano et al. 2014). In addition, at the level of the TPp in the diencephalon, fibers can clearly be seen originating in TPp and projecting dorsally into CP (Fig. 1D, E) as well as PAG, which has reciprocal connections with TPp and receives auditory information through the TS in the midbrain (Fig. 6a) (Forlano et al. 2014; Kittelberger and Bass 2013). Thus, the PAG is likely the conduit through which DA neurons in TPp receive auditory input (see below). In the diencephalon, aside from CP, PGl is also heavily innervated by TH-ir terminals (Fig. 2c). These fibers may originate from lateral projections of TPp or from more rostral ventral medial and ventrolateral thalamic TH-ir groups (VM/VL; Fig. 1C) (Forlano et al. 2014). Since TPp projections are also known to ascend to the ventral forebrain (Rink and Wullimann 2001; Tay et al. 2011), DA neurons from this area may also innervate various preoptic nuclei as well as the subdivisions of areas ventralis connected to the auditory thalamus (above), also these areas as well as AT likely receive input from local DA populations. The TS likely receives mixed CA input composed of both DA and NA fibers, as the locus coeruleus is known to project to TS (Ma 1994), and studies in other teleosts have reported dopamine beta hydroxylase (rate limiting enzyme in NA synthesis) as well as DA-ir in addition to TH-ir in this area (see below; Forlano et al. 2014).

\subsection{Comparisons to Other Fishes}

Outside of studies in mammals (mainly rodents), CA innervation of the peripheral auditory system has only been described in midshipman fish to date but we predict it is a conserved trait across vertebrates. Curiously, the robust TH-ir innervation

Fig. 5 (continued) and passes ventral to the locus coeruleus (LC) further into the hindbrain. Prominent terminations are seen within the rostral (r) and caudal (c) dendritic field (d) of the octavolateralis efferent nucleus (OE). (b) Composite parasagittal section lateral to a showing descending TH-ir fiber tracts which innervate ventral secondary octaval (SOv) and the dorsal medial descending octaval nuclei (DOdm). Arrows in $\mathbf{a}$ and $\mathbf{b}$ indicate cross-sections through TH-ir axons within the efferent bundle (EB). (c) Composite horizontal section showing TH-ir tracts from the caudal diencephalon to the level of the $\mathrm{OE}$ in the hindbrain. Asterisks $(*)$ indicate cross-sections through thick dorsal TH-ir projections from the TPp on either side of the third ventricle (III). The medial longitudinal catecholaminergic tract (mlct) is evident in this plane of section where a large subset of fibers turn sharply medial into the rostral and caudal OEd. TH-ir fibers also heavily innervate nucleus interpeduncularis (NIn) and superior raphe (SR). (d) Horizontal section dorsal to c showing robust TH-ir innervation of the medially located somata of the OE. Arrow indicates bundle of TH-ir axons within the lateral portion of the EB that will eventually merge with cranial nerve VIII. (e) A bundle of several robust TH-ir axons appear to branch off the mlct and continue laterally as seen in d (horizontal plane). (f) A more dorsal horizontal section to e shows TH-ir axons (of the same caliber as in e) converge medially within the descending EB tract. The EB serves as the conduit for the OE efferent fibers to reach VIII. Compare with transverse sections through the medulla in Figs. 3 and 4. Scale bar $=250 \mu \mathrm{m}$ in $\mathbf{a}-\mathbf{d}, 50 \mu \mathrm{m}$ in e and f. From Forlano et al. (2014) 

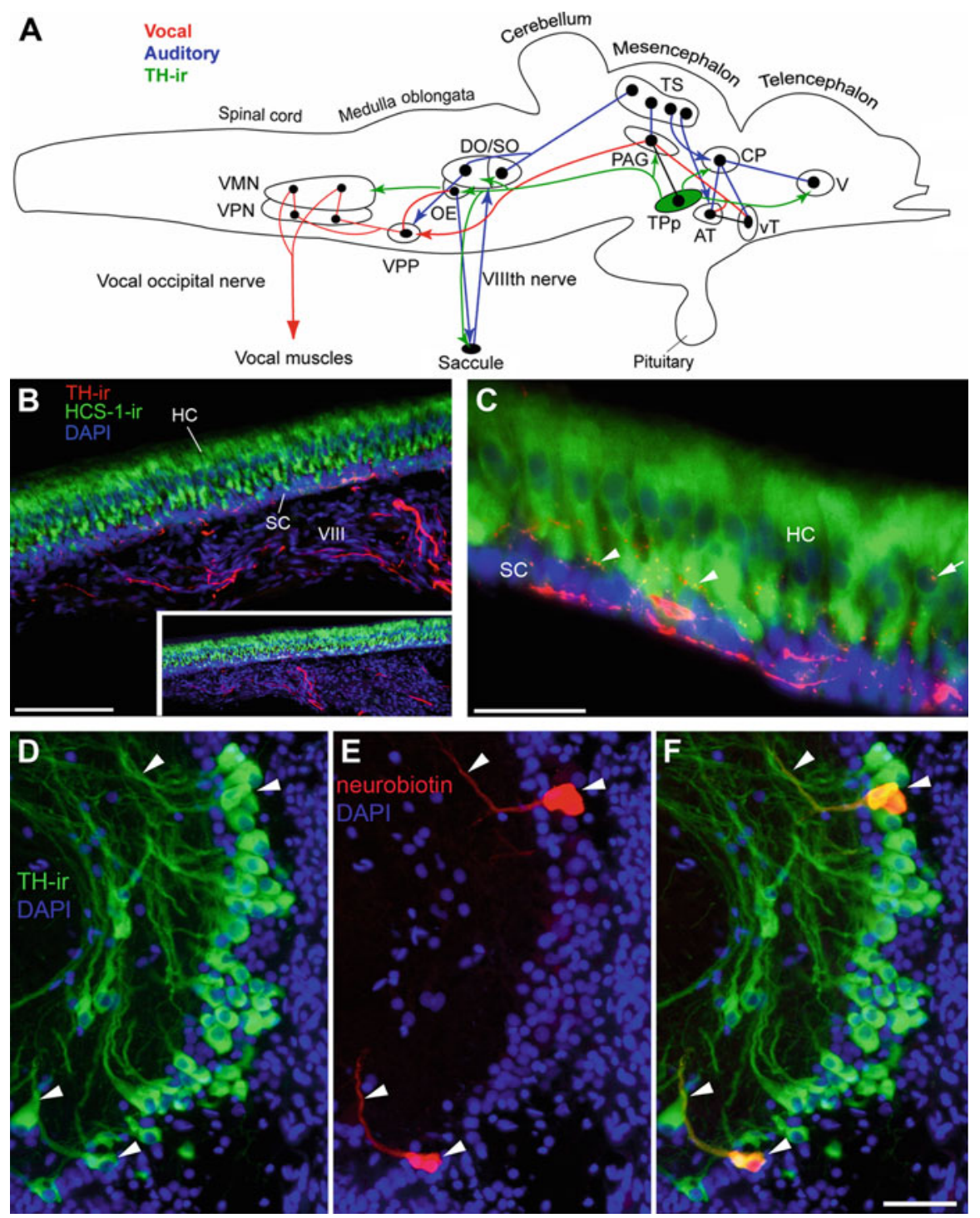

Fig. 6 (a) Schematic sagittal view of the brain showing vocal motor (red), and central auditory (blue) systems in batrachoidid fish (midshipman and toadfish) (modified from Bass and McKibben 2003; Kittelberger et al. 2006) with connectivity from large TH-ir neurons within periventricular posterior tuberculum (green, TPp). Solid dots represent somata, and lines represent axonal projection pathways. Two connected dots indicate reciprocal connections. Descending vocal motor pathways (see Bass and Baker 1990; Bass et al. 2000, 2001; Bass et al. 1994; Fine and Perini 1994; Goodson and Bass 2002; Kittelberger et al. 2006; Remage-Healey and Bass 2004). Preoptic (POA, not shown) and ventral (vT) and anterior (AT) tuberal nuclei in the hypothalamic forebrain project to the periaqueductal gray (PAG) in the midbrain which then connects to the vocal pattern generator (VPG) in the hindbrain-spinal cord. The VPG consists of vocal prepacemaker (VPP), pacemaker (VPN), and motor (VMN) nuclei. The VMN projects directly via occipital nerve roots to sound-producing muscle on the swim bladder. Central auditory system (see Bass et al. 2000, 2001; Bass et al. 1994). Social vocalizations are detected by the inner ear which projects via the VIIIth nerve to descending (DO) and secondary (SO) octaval nuclei in the hindbrain and further to the 
pattern of $\mathrm{OE}$ somata and dendrites seen in midshipman has not been reported in other teleosts. Perhaps this brain area has not been examined closely in most other species describing general CA fiber distribution, or our findings may reflect a character specialization of sonic teleosts. Interestingly, in the European eel, which is reported to produce sounds (Lagardere and Ernande 2004; Rountree et al. 2002), varicose DA-ir fibers as well as DA 1A/B and 2A/B receptors have been localized to OE (Kapsimali et al. 2000; Pasqualini et al. 2009; Roberts et al. 1989). There are, however, consistent reports of CA fiber projections throughout the central auditory system in fishes. Studies in a diverse array of species such as sturgeon (Acipenser), sea bass (Dicentrarchus), catfish (Clarias), stickleback (Gasterosteus), goldfish (Carrassius), zebrafish (Danio), African cichlid (Astatotilapia), European eel (Anguilla) electric fish (Apteronotus and Gnathonemus), and trout (Oncorhynchus) have reported TH-ir, DBH-ir and/or DA-ir fibers and terminals in hindbrain octaval nuclei, TS, CP, AT, and PGl (e.g., Adrio et al. 2002; Batten et al. 1993; Corio et al. 1991; Ekstrom et al. 1990; Ekstrom et al. 1986; Hornby and Piekut 1990; Kaslin

Fig. 6 (continued) auditory midbrain torus semicircularis (TS). Shown are nuclei interconnected with TS. The dorsal thalamic central posterior nucleus (CP) contains reciprocal connections with the ventral telencephalon (V; includes supracommissural division) and anterior hypothalamus (AT/ vT) (for nomenclature see Braford and Northcutt 1983). TS and CP also connect to vocal motor nuclei in the forebrain (AT, vT, POA, not shown) and midbrain (PAG and isthmal/tegmentum, not shown), while auditory-recipient octaval nuclei in the hindbrain connect to the VPG via the VPP (also see Bass et al. 1994; Goodson and Bass 2002). The octavolateralis efferent nucleus (OE) projects to the inner ear which includes the saccule, the main end organ of hearing (Bass et al. 1994, 2000; Weeg et al. 2005). OE contains reciprocal connections with the VPP (Chagnaud et al. 2011) and receives projections from PAG (Kittelberger and Bass 2013, not shown). Large, pearshaped TH-ir neurons from TPp send a massive dorsal turned descending tract into the hindbrain which appears to innervate DO, SO, and OE and likely VMN. A branch of this tract exits the brain via the efferent tract in the eighth nerve (VIII) to the inner ear. Other targets of TPp TH-ir neurons include CP and PAG. The PAG and TPp are reciprocally connected (Kittelberger and Bass 2013) but whether PAG projects onto TH-ir cells in TPp is not confirmed. TPp also has a robust ventral ascending $\mathrm{TH}$-ir projection although the exact innervation target in the ventral telencephalon (V) is undetermined. See above references for additional known connectivity. (b, c) TH-ir innervation of the saccule. (b) Section through the saccular epithelium (SE) including the attached branch of VIII. The hair cell layer (HC) is delineated using the hair cell specific antibody (HCS-1, green) which labels HC somata and can be distinguished from the basal support cells (SC) labeled by DAPI (blue) alone. Thick and smooth TH-ir fibers (red) course through VIII prior to terminating largely at the base of the HC layer. Inset is lower magnification of same section. (c) High magnification image showing thick TH-ir varicose fibers along the SC layer, fine-caliber terminals (arrowheads) at the base of the $\mathrm{HC}$ and less frequently terminals on the central portion of individual hair cells proximal to the nucleus (arrows). (d-f) Neurobiotin backfills of the saccule combined with $\mathrm{TH}$ immunofluorescence identify source of $\mathrm{TH}$-ir efferents to the saccular epithelium as a small population of large, pear-shaped cells in the periventricular posterior tuberculum (TPp). (d) TH-ir cells in the TPp just medial to the medial forebrain bundle and lateral and dorsal to the paraventricular organ. (e) Three neurobiotin-labeled neurons (two adjacent cells on top) after a saccular backfill. (f) Overlay of images in a and b. Arrowheads indicate same cells and filled axons. All neurobiotin-backfilled cells in this region were also TH-ir. Adapted from Forlano et al. (2014) 

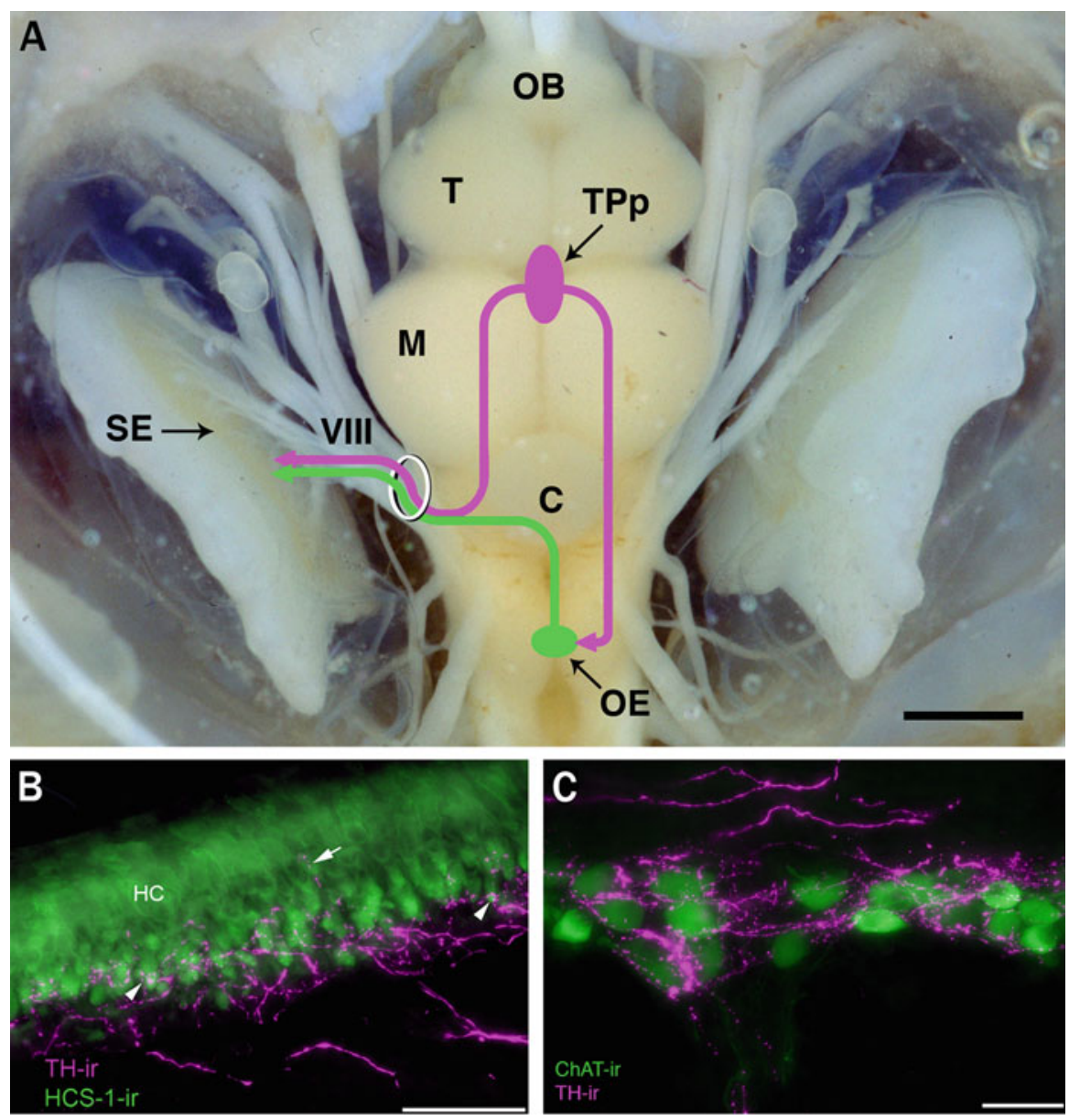

Fig. 7 (a) Dorsal view of midshipman brain and inner ear depicting the two efferent nuclei, the dopaminergic TPp (purple) and the cholinergic OE (green), which project to the saccular epithelium (SE). Solid lines indicate connections substantiated by tract tracing and immunohistochemically identified fiber tracts (Forlano et al. 2014). Fluorescent micrographs depict TH-ir innervation of midshipman saccule and OE. (b) TH-ir fibers (purple) enter the base of the SE and form punctate swellings (white arrowheads) around the base of hair cells (HC, green, identified with hair cell specific antibody HCS-1). Adapted from Forlano et al. (2014). (c) Punctate TH-ir fibers extensively wrap around $\mathrm{OE}$ neurons (green, identified with antibody for choline-acetyltransferase, ChAT). Abbreviations: $C$ cerebellum, $M$ midbrain, $O B$ olfactory bulb, $T$ telencephalon, VIII eighth nerve. Scale bar $=1.5 \mathrm{~mm}$ in $\mathbf{a}, 50 \mu \mathrm{m}$ in $\mathbf{b}, 25 \mu \mathrm{m}$ in $\mathbf{c}$

and Panula 2001; Ma 1994; O'Connell et al. 2011; Roberts et al. 1989; Sas et al. 1990; Vetillard et al. 2002). In addition, several studies in teleosts have demonstrated DAergic and/or NAergic receptor distribution in auditory nuclei which supports the auditory system as a CA target for sensory modulation. Vacher et al. (2003) showed $\mathrm{D}_{2}$ mRNA in TS (centralis and lateralis) in trout, and O'Connell et al. (2011) 
report $\mathrm{D}_{1 \mathrm{~A}}$ and $\mathrm{D}_{2}$ in $\mathrm{TS}, \mathrm{CP}$, and $\mathrm{AT}$ of the cichlid A. burtoni. In European eel, $\mathrm{D}_{1 \mathrm{~B}}$ and $\mathrm{D}_{2 \mathrm{~A} / \mathrm{B}} \mathrm{mRNA}$ expression is localized in TS and $\mathrm{D}_{1 \mathrm{~A} 2}$ and $\mathrm{D}_{2 \mathrm{~A} / \mathrm{B}} \mathrm{mRNA}$ in MG (Kapsimali et al. 2000; Pasqualini et al. 2009). Ampatzis and Dermon (2010) showed $\beta_{2}$ adrenergic receptor (AR) in CP, TS, PGl, MG and medial octaval nucleus (MON) in adult zebrafish which largely overlaps the distribution of $\alpha_{2 \mathrm{~A}} \mathrm{AR}$-ir in the same areas (Ampatzis et al. 2008). The red porgy (Pagrus) shows similar distributions of ARs in forebrain and midbrain, but hindbrain nuclei are not reported (Zikopoulos and Dermon 2005).

\section{Catecholaminergic Innervation of the Auditory System Varies with Reproductive State in Female Midshipman}

As summarized in Sect. 2.2, midshipman exhibit a dramatic seasonal change in frequency encoding and sensitivity at the level of the saccule that is mediated by a change in circulating steroid hormones (Sisneros 2009b). While an increase in number of hair cells and expression of BK channels are mechanisms which contribute to physiological changes to better encode the male advertisement call (Coffin et al. 2012; Rohmann et al. 2013), neurotransmitters such as dopamine may directly modulate peripheral and central auditory sensitivity (e.g., Gittelman et al. 2013; Ruel et al. 2001) as well as coordinate the behavioral response to acoustic social signals (Forlano et al. 2015b). Therefore, after we established that both the central and peripheral auditory system in midshipman are major targets of CA innervation, we next tested the hypothesis that $\mathrm{CA}$ innervation of the auditory system is seasonally plastic and dependent on reproductive state in females.

Gravid females were collected by hand from nests of type I males in the intertidal zone at low tide in June during the reproductive season or in deep offshore waters by otter trawl in December during the non-reproductive season when ovaries are regressed (Sisneros et al. 2004b). We then utilized quantitative fluorescent immunohistochemistry to measure TH-ir fiber density in six auditory nuclei that span the forebrain, midbrain, and hindbrain (Fig. 1). By double-labeling with a choline acetyltransferase (ChAT) antibody, we were able to quantify both TH-ir and ChAT-ir putative terminals on the sensory epithelium of the saccule of the inner ear. Using this method we could also analyze TH-ir innervation of somata and dendrites of the cholinergic OE (Forlano et al. 2015a). Summer females showed greater TH-ir fiber density in higher auditory processing areas such as CP and PGl (Fig. 8), while no seasonal differences were found in AT, TS or in SOv in the hindbrain. In contrast, winter females had greater TH-ir fiber density within the primary auditory hindbrain, specifically in a region spanning laterally within and between the dorsolateral division of descending octaval nucleus (DOdl) and the medial octavolateralis nucleus (MED) (Fig. 9). While DOdl receives direct input from the saccule, it is interconnected with MED, a lateral line recipient nucleus (Bass et al. 2000; Weeg and Bass 2000), and lateral line afferents are able to encode frequencies that overlap with the hum (Weeg and Bass 2002). Similar to CP and PGl, summer females 

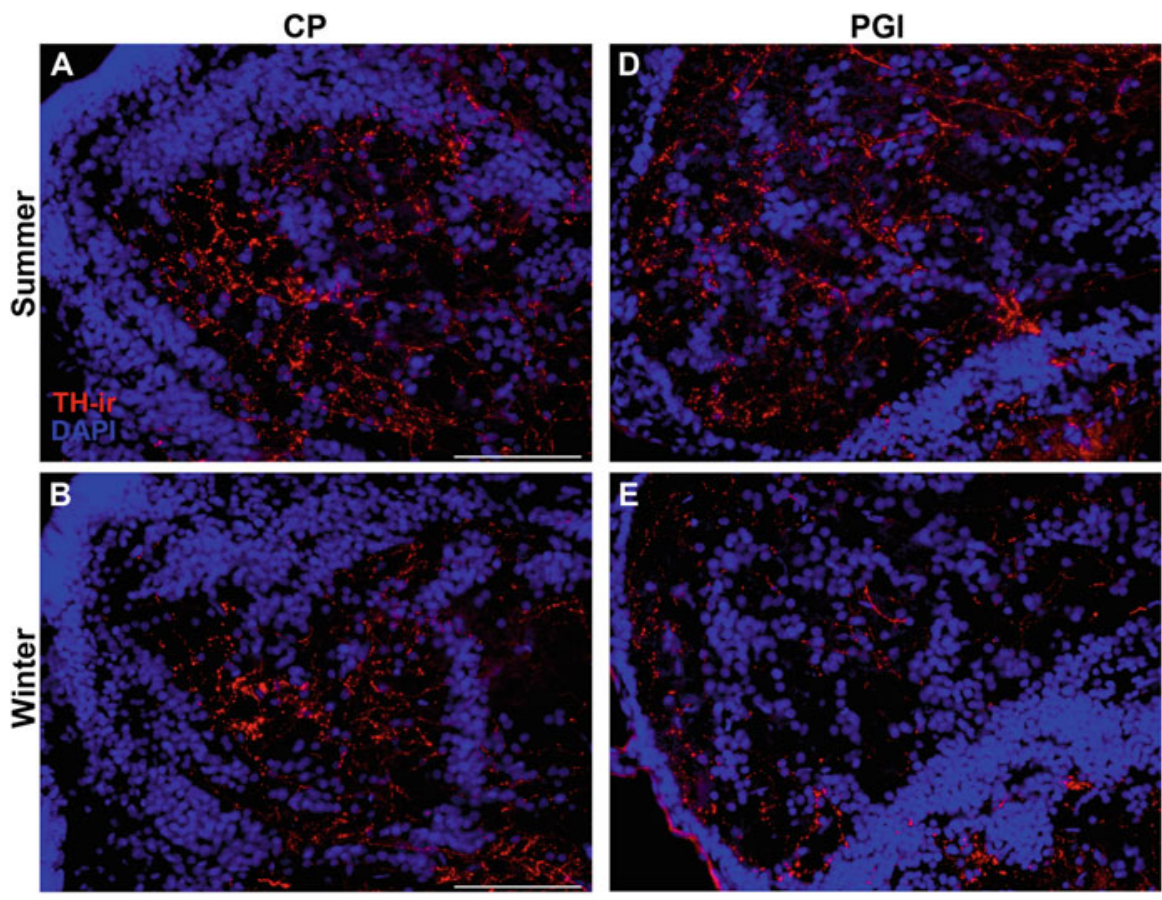

C

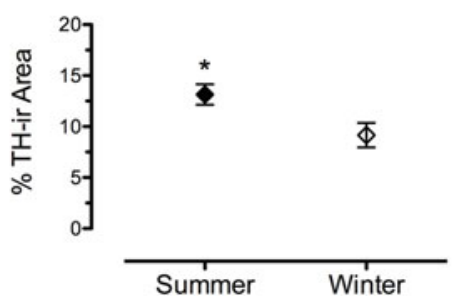

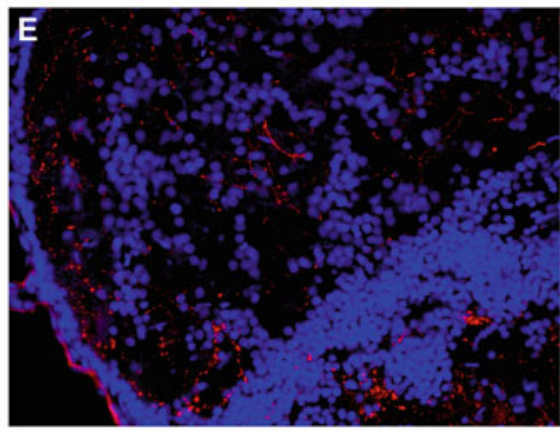

$\mathbf{F}$

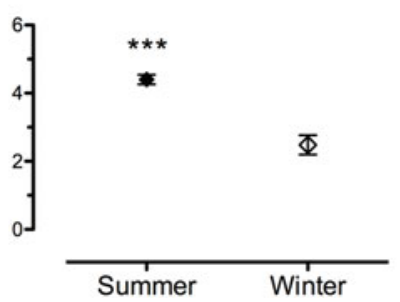

Fig. 8 Seasonal differences in TH-ir fiber density in forebrain auditory nuclei. (a, b) Central posterior nucleus of the thalamus $(\mathrm{CP})$ and $(\mathbf{d}, \mathbf{e})$ lateral division of nucleus preglomerulosus (PGl). Left edge in $\mathbf{a}$ and $\mathbf{b}$ is midline of brain. Left edge in $\mathbf{d}$ and $\mathbf{e}$ is lateral edge of brain. Data in $\mathbf{c}$ and f are represented as percent area of the nucleus that contains TH-ir (mean $\pm \mathrm{SE}$ ). ${ }^{*} p=0.03$; $* * * p=0.0003$. Scale bar $=100 \mu \mathrm{m}$. From Forlano et al. (2015a)

showed greater TH-ir fiber density within the OE nucleus, and more specifically, a greater percentage of CHAT-ir defined somata and dendritic area contacted by TH-ir fibers (Fig. 10). Interestingly, the seasonal pattern seen in the saccule was opposite to that found in the OE: winter, non-reproductive females had a greater number of TH-ir puncta as well as a greater area per TH-ir punctum, while no significant differences were found between seasons with regard to ChAT-ir puncta (Fig. 11). Since TH-ir neurons in TPp are known to project to several auditory nuclei as well as the $\mathrm{OE}$ and saccule, we also quantified this cell group between summer and winter females. While we did not find differences in number of $\mathrm{TH}$-ir neurons, we did 
Fig. 9 Seasonal difference in $\mathrm{TH}$-ir fiber density in the auditory hindbrain. (a, b) Transverse sections through the area that includes the dorsolateral division of the descending octaval nucleus (DOdl) and medial octavolateralis nucleus (MED). The left edge in $\mathbf{a}$ and $\mathbf{b}$ is the lateral part of the fourth ventricle. Data in $\mathbf{c}$ are represented as percent area of the analyzed region that contains $\mathrm{TH}$-ir (mean \pm SE). ${ }^{*} p=0.03$. Scale bar $=100 \mu \mathrm{m}$. From Forlano et al. (2015a)
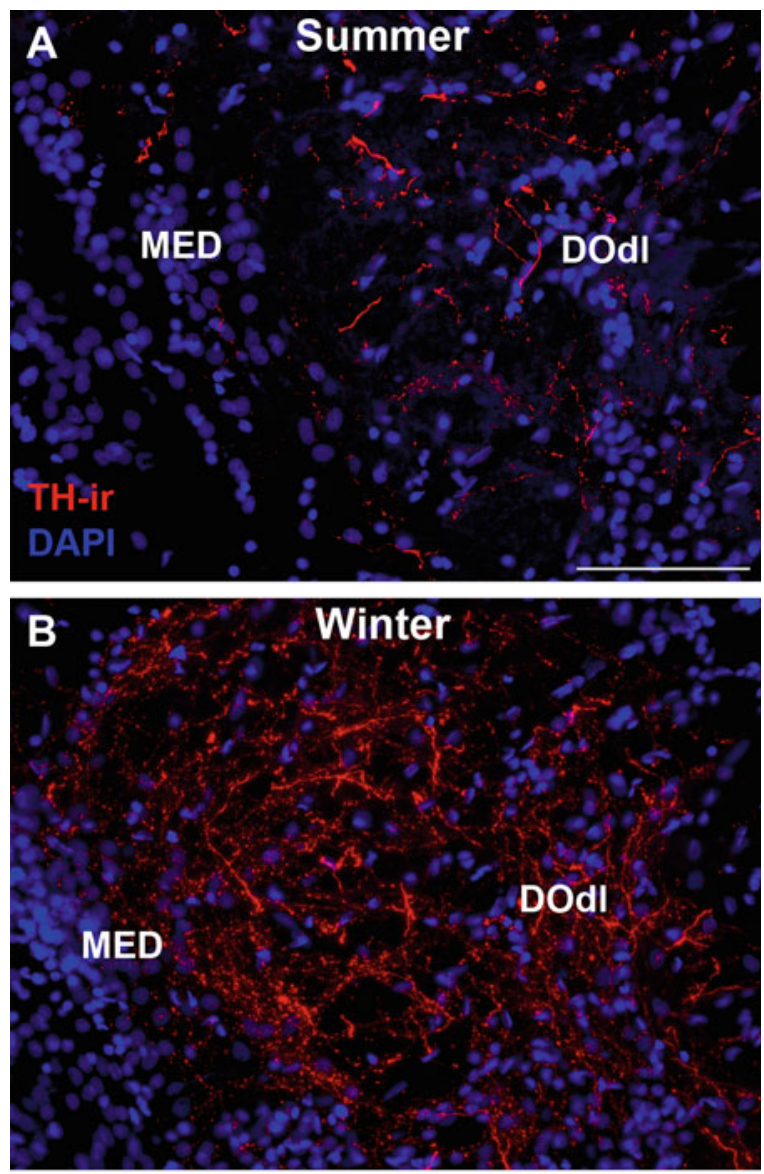

C

\section{DOdl+MED}

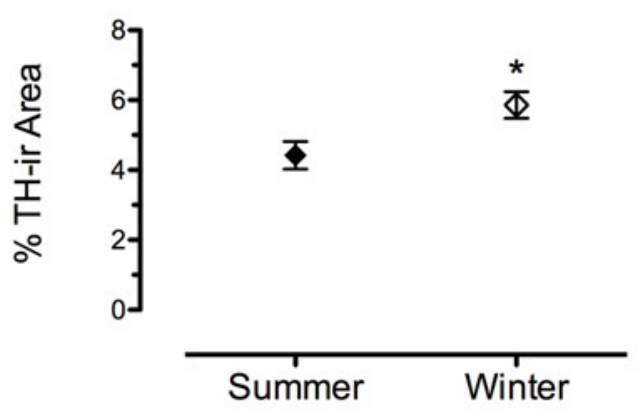




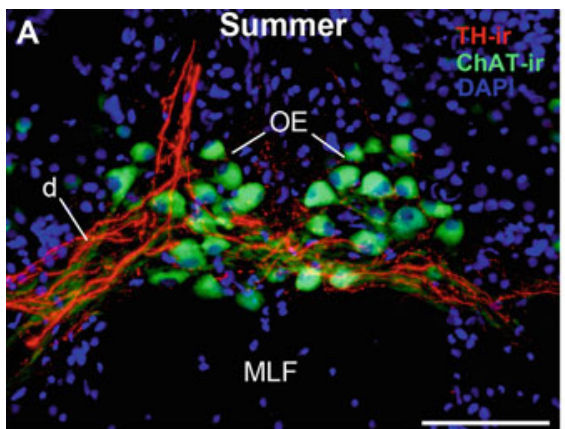

C

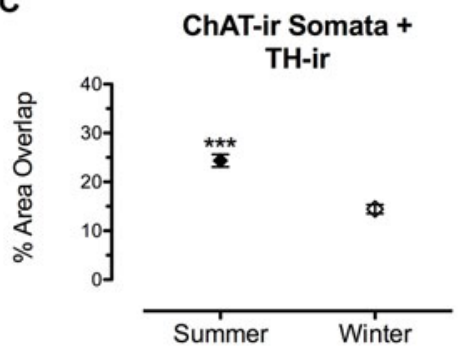

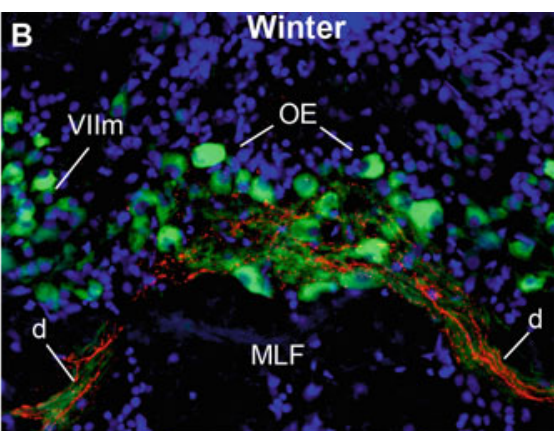

D

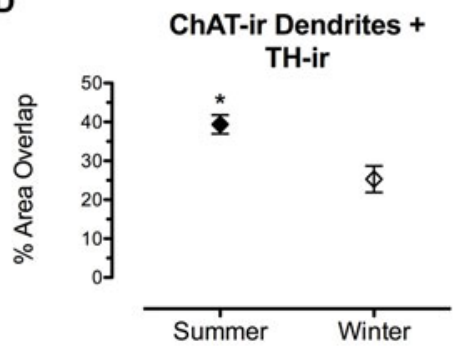

Fig. 10 Seasonal difference in TH-ir innervation of the cholinergic octavolateralis efferent nucleus (OE). (a, b) Transverse sections through the rostral OE showing TH-ir fibers and terminals on somata and dendrites (d) of OE neurons labeled by choline acetyltransferase (ChAT)-ir. Data in c and $\mathbf{d}$ are expressed as the percent area of ChAT-ir in the OE that is covered by TH-ir fibers (mean $\pm \mathrm{SE}$ ). $* p=0.01,{ }^{* * *} p=0.0001$. Abbreviations: $M L F$ medial longitudinal fasciculus, VIIm facial motor nucleus. Scale bar $=100 \mu \mathrm{m}$. From Forlano et al. (2015a)

demonstrate that TH-ir area of somata and proximal processes is greater in summer females, supporting this nucleus as a target of seasonal and/or steroid-mediated plasticity (Forlano et al. 2015a).

Overall these findings support a role for catecholamines as important modulators of auditory plasticity and behavior that varies with reproductive state in female midshipman. Since we did not measure DBH-ir, we are uncertain of the contribution of the NA system to the TH-ir fiber densities in central auditory nuclei that were measured. Therefore it is still plausible that there are seasonal differences in areas such as TS which receive a mixture of DA and NA input, but differences in a single catecholamine group is masked when total CA fiber density is combined. Seasonal changes in TH-ir innervation in forebrain (CP and PGl) and hindbrain (DOdl + MED) auditory areas may provide a modulatory substrate for seasonal changes in central auditory response properties which is unexplored at this time in midshipman.

Importantly, these findings provide neuroanatomical evidence that DA TPp neurons may seasonally modulate the sensitivity of the inner ear directly at the level of the hair cell, or indirectly by modulating the cholinergic OE (Forlano et al. 2015a). The effect of DA on hair cell or primary afferent physiology is unknown in fishes, 

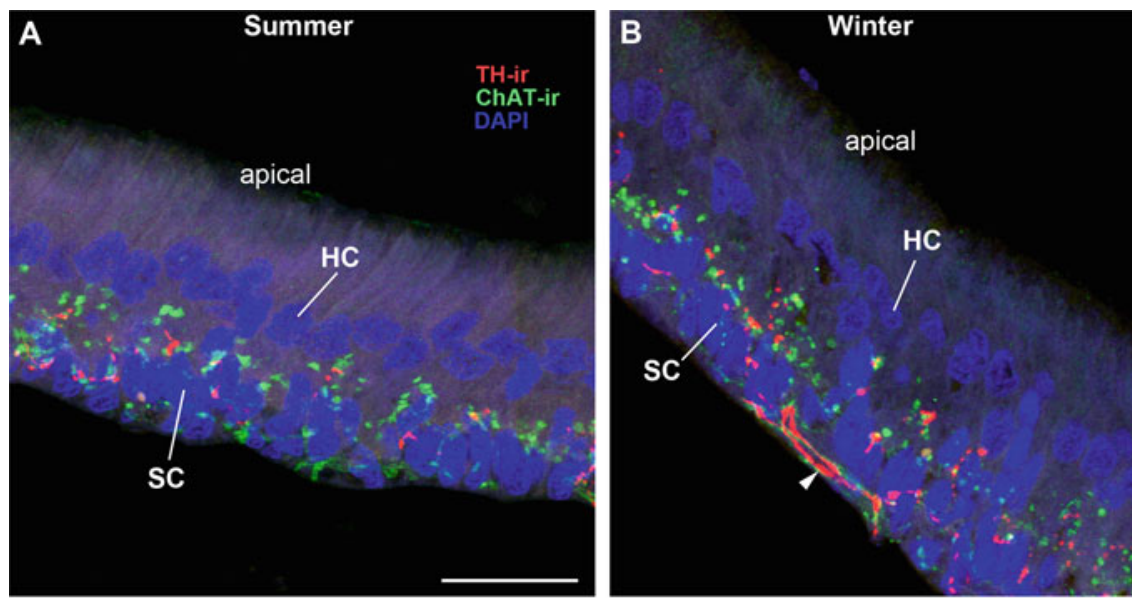

C

\section{D}
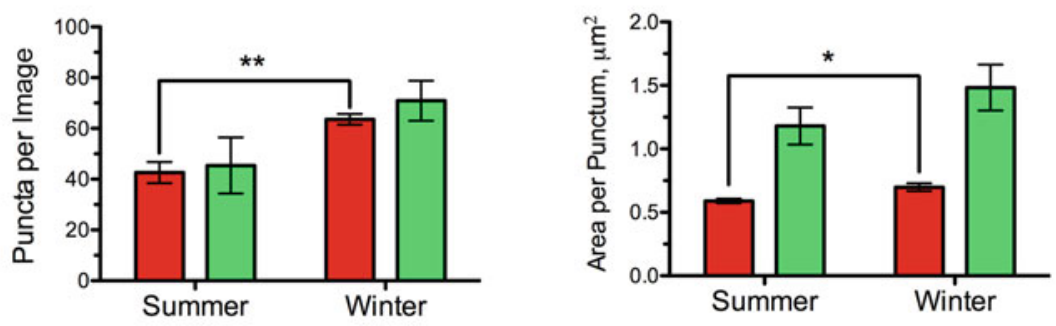

Fig. 11 Seasonal differences in dopaminergic but not cholinergic innervation of the saccule, the main end organ of hearing. (a, b) Transverse sections through the saccular epithelium. TH-ir and ChAT-ir puncta are largely concentrated at the base of hair cells and within the support cell layer. HC and SC labels point to DAPI-stained nuclei of individual hair cells and support cells, respectively. The rest of the hair cell is unlabeled and is a light purple background. Stereocillia (unlabeled) are located at the apical end of the hair cells. Quantification of numbers (c) and size (d) of putative TH-ir and ChAT-ir terminals (puncta) in the saccule (mean \pm SE). Arrowhead in b indicates an example of a thick, varicose TH-ir fiber along the base of the SC layer that was excluded from the puncta analysis. Colors in the graphs match TH-ir and ChAT-ir in the micrographs. $* p=0.017,{ }^{*} p=0.001$. Scale bar $=25 \mu \mathrm{m}$. From Forlano et al. (2015a)

but if similar to rodents, we would expect to see a largely inhibitory effect on auditory nerve physiology (Ruel et al. 2001; Ruel et al. 2007; Valdes-Baizabal et al. 2015). If this is the case, then a decrease in number of TH-ir terminals in the summer reproductive season may indicate reduced DA inhibition and therefore increase overall sensitivity of the saccule, consistent with seasonal physiological data recorded from primary afferents (Sisneros and Bass 2003). Ultimately, receptor subtype may confer a complex scenario of pre- and post-synaptic interactions of DA on saccular physiology (see Garrett et al. 2011; Maison et al. 2012). In addition, DA modulation of the saccule may be indirect via the cholinergic OE which is documented to have an inhibitory effect on fish saccular auditory hair cells (Furukawa 1981). 
If DA innervation has an inhibitory effect on OE firing, this would result in release of cholinergic inhibition in the saccule in the summer, and again, increased sensitivity in the reproductive season (Forlano et al. 2015a).

Although the functional significance of opposing plasticity in CA input at primary vs. higher auditory processing centers is unclear, we propose modulatory roles which may include optimizing signal detection in a noisy environment (see Tomchik and Lu 2006) (characteristic of the summer nesting grounds), increasing perception and salience of male vocalizations (e.g., Appeltants et al. 2002; Caras 2013; Lynch and Ball 2008; Maney 2013), and coordination of auditory responsiveness with the decision and subsequent motor response and to localize a potential mate's nest (Forlano et al. 2015a).

\section{Exposure to Advertisement Calls of Other Males Activates Dopaminergic and Noradrenergic Neurons in Type I Male Midshipman}

The rocky intertidal zone where midshipman nests are found in the summer reproductive season is a dynamic soundscape at night when type I males are actively courting female midshipman and defending their territories via advertisement and agonistic vocalizations, respectively (McIver et al. 2014). Male nests are often clumped together and vocalizations occur simultaneously (McIver et al. 2014; Sisneros et al. 2009) and therefore the perception of another male's mate call may modulate calling behavior in competition for females (Petersen et al. 2013). Indeed, in the closely related Gulf toadfish (Opsanus), a sound playback challenge of conspecific advertisement calls increases male calling rate (Remage-Healey and Bass 2005). In order to test the hypothesis that CA neurons are active in this naturalistic context in midshipman in response to conspecific social acoustic signals, we exposed type I male midshipman to a 30 min playback loop of five other male advertisement calls (hums) recorded in the field. Males were sacrificed after $120 \mathrm{~min}$ and brains were double-labeled for the immediate early gene (IEG) product cFos as a marker for neural activation together with TH using fluorescent immunohistochemistry (Petersen et al. 2013). This allowed us to quantify neural activation throughout the ascending auditory pathway as well as in CA neurons in males hearing other males vs. ambient noise conditions. Males exposed to the mate calls of other males showed significantly greater numbers of cFos-ir neurons in hindbrain (DOri), midbrain (TS), and forebrain (CP) auditory nuclei (Fig. 12) as well as in AT, an auditoryvocal integration site. Importantly, the percentage of TH-ir neurons in the TPp that were double-labeled with cFos was significantly greater in males exposed to hums over ambient noise (Fig. 13a-c). Furthermore, there was a significant positive correlation between numbers of cFos-ir in both $\mathrm{CP}$ and AT and percent colocalization of cFos in TH-ir TPp neurons (Fig. 14h, i) which supports functional connectivity and projections of TPp TH-ir fibers into these auditory nuclei (Forlano et al. 2014; 

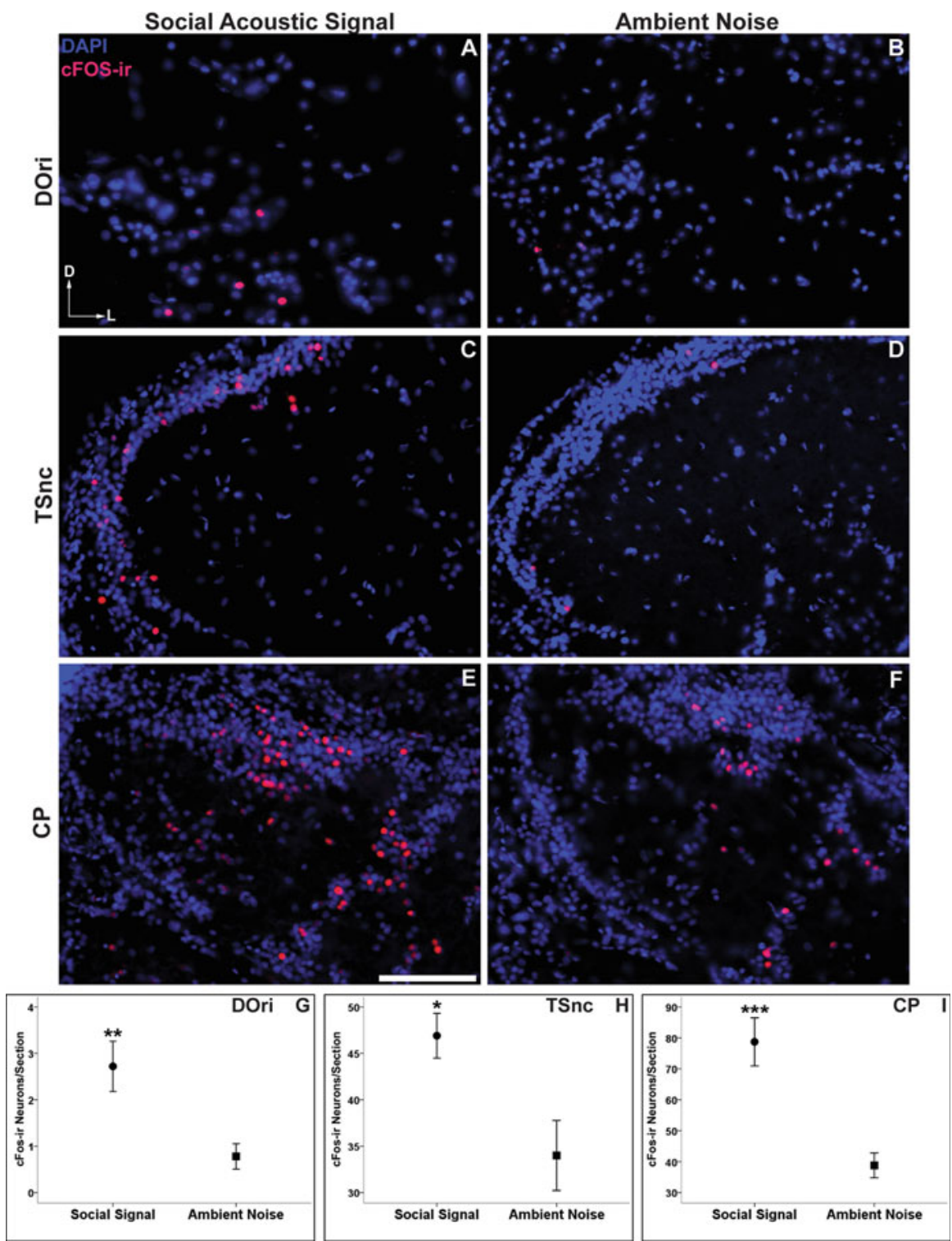

Fig. 12 cFos response to social acoustic signals (advertisement calls) in the ascending auditory pathway. Representative images of cFos-ir neurons (red/pink) of males who were exposed to social acoustic signals $(\mathbf{a}, \mathbf{c}, \mathbf{e})$ versus males exposed to ambient environmental noise $(\mathbf{b}, \mathbf{d}, \mathbf{f})$. $(\mathbf{a}, \mathbf{b})$ Rostral intermediate division of the descending octaval nucleus (DOri) within the medulla. (c, d) The periventricular nucleus centralis within the midbrain torus semicircularis (TSnc). (e, f) Compact division of the central posterior nucleus (CP) in the auditory thalamus. Scale bar $=100 \mu \mathrm{m}$. Arrows represent the dorsal (D) and lateral (L) orientation for each image. Data in g-i are represented as mean number of cFos-ir neurons per section $\pm \mathrm{SE}, * \mathrm{p}<0.05 * * \mathrm{p} \leq 0.01,{ }^{* * *} \mathrm{p}<0.001$. From Petersen et al. (2013) 

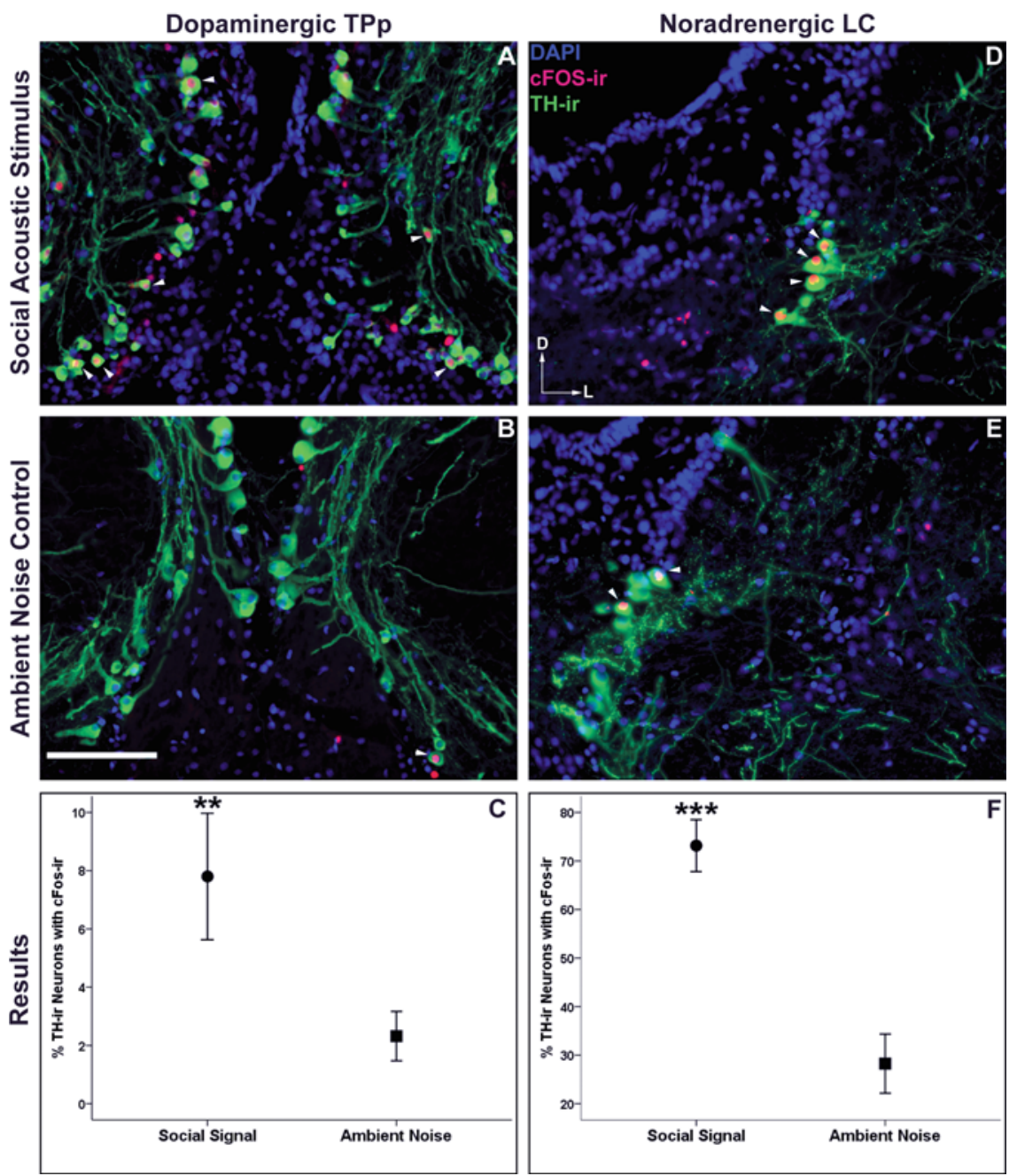

Fig. 13 cFos-ir colocalization with catecholaminergic (TH-ir) neurons. Arrowheads indicate cFos-ir colocalized to catecholaminergic neurons within the dopaminergic periventricular posterior tuberculum (TPp) (a, b) and the noradrenergic locus coeruleus (LC) (d, e) of males exposed to social acoustic signals and males exposed to ambient noise. Data in $\mathbf{c}$ and $\mathbf{f}$ are represented as mean percent colocalization \pm SE, $* * p \leq 0.01,{ }^{* * *} p<0.001$. Scale bar $=100 \mu \mathrm{m}$. Arrows represent the dorsal (D) and lateral (L) orientation for each image. From Petersen et al. (2013)

Petersen et al. 2013). Individual DA neurons in TPp may not only project to the saccule and hindbrain auditory nuclei, but also send ascending projections to the ventral telencephalon (i.e., Vd, Vv; see Rink and Wullimann 2001, 2002; Tay et al. 2011), and are therefore in a perfect position to affect primary auditory processing and higher brain function involved in behavioral decision making to salient auditory cues (Fig. 6A; Goodson and Kingsbury 2013; O'Connell and Hofmann 2011, 2012; Petersen et al. 2013). 
Locus Coeruleus

(Noradrenergic)
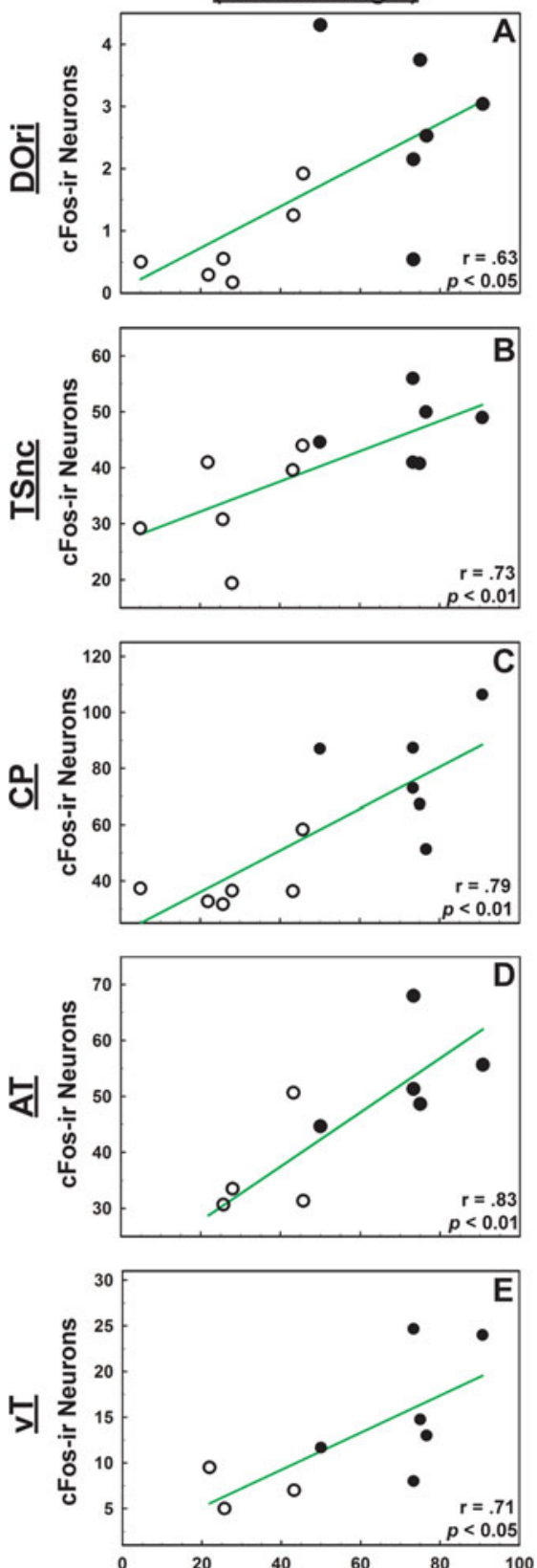

\section{$\%$ TH-ir Neurons with cFos-ir}

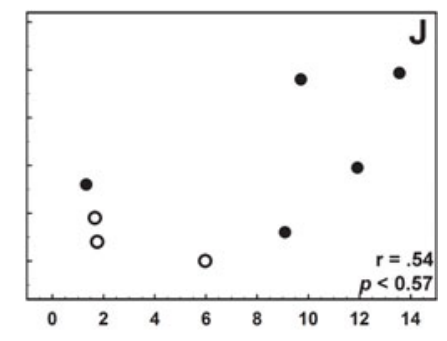

Fig. 14 Co-activation of auditory/vocal-acoustic nuclei and CA neurons: Pairwise correlations between numbers of cFos-ir neurons in auditory/vocal-acoustic nuclei and percent colocalization of cFos-ir within tyrosine hydroxylase (TH-ir) neurons of locus coeruleus (LC) (a-e) and the periventricular posterior tuberculum (TPp) (f-j). Closed circles are males exposed to social signals; open circles are males exposed to ambient noise; green trend lines indicate significant correlations $(p \leq 0.05)$. From Petersen et al. (2013) 
Like TPp neurons which provide the majority of far-reaching DA projections in teleosts, the LC contributes the majority of NA projections throughout the brain and TH-ir LC neurons show robust cFos-ir response to conspecific vocalizations in male midshipman (Fig. 13d-f). In addition, there were significant positive correlations between percent colocalization of cFos in TH-ir LC neurons and numbers of cFos-ir at all levels of the auditory system we investigated (Fig. 14a-e) which may reflect LC connectivity to those areas (Petersen et al. 2013). In songbirds, LC function is necessary for song-induced IEG expression in auditory forebrain and normal response to conspecific song (Appeltants et al. 2002; Lynch and Ball 2008; Pawlisch et al. 2011; Velho et al. 2012). Therefore, activation of CA neurons in TPp and LC may serve to coordinate appropriate behavioral responses to male competitors such as an increase in motivated vocal courtship (Petersen et al. 2013). In addition, TPp (and LC) activation may increase signal to noise at multiple levels of the central and peripheral auditory system as well as modulate reafferent suppression via $\mathrm{OE}$ control during calling behavior (Weeg et al. 2005).

\section{Conclusions and Future Directions}

Overall, these studies support a role for catecholamines in seasonal auditory plasticity and auditory-driven social behavior in midshipman fish and have provided new anatomical insights on catecholamines, and DA in particular, as important neuromodulators of auditory function in fishes. Based on our current knowledge, below are a list of important questions worthy of future investigations that will require neurophysiological, behavioral, gene expression, and further anatomical approaches to uncover function and mechanisms of CA action on audition and behavior in fishes. There remain a number of important questions that should be addressed in future work, several of which are briefly detailed below:

1. Where and via what receptors is dopamine acting in the midshipman saccule?

2. Does dopamine increase saccular hair cell sensitivity (lower threshold at higher frequencies)?

3. Does dopamine increase signal to noise processing at the level of the auditory primary afferents or hair cells?

4. Is catecholaminergic signaling important for female phonotaxis, motivation or ability to localize sound in noisy acoustic environments where midshipman court and breed?

Acknowledgements In terms of producing numerous foundational studies of fish auditory end organs at the morphological and functional level, Art Popper is truly a pioneer and set the groundwork for many of us interested in fish hearing. Work from Art's lab is inspirational in terms of scope and diversity of species that have been studied. PMF had the pleasure of getting to know Dick Fay personally during a summer spent at the Marine Biological Laboratory in Woods Hole, MA while collaborating with him and JAS. Dick's insights and contributions into the physiology, anatomy and behavior of hearing in fishes cannot be overstated. It was an honor to work with and learn from him on a daily basis as Dick is exemplary in his patience, kindness, and generosity on a scientific and personal level. 
Although JAS never had the opportunity to work with Art Popper, JAS has been greatly influenced by Art's research and career, and recently JAS has had to pleasure of co-organizing a major conference on the effects of noise on fish and aquatic life which has been a great experience. Art has been a great mentor and very generous with his time as he truly cares for the next generation of fish bioacoustic scientists. Dick Fay has always been a "gentlemen" scientist and JAS has been the fortunate recipient of his mentorship during a critical period of JAS's pre-tenure career. JAS is truly grateful for his friendship, advice, and great many discussions of fish hearing and auditory physiology.

We thank the numerous students from both the Forlano and Sisneros lab that contributed to studies described here, Midge Marchaterre for assistance with animal collections and Jonathan Perelmuter for help with figure 7. We also thank Carol Vines, Gary Cherr, Kitty Brown, and staff at the Bodega Marine Laboratory and Rob Dickie of AREAC, Brooklyn College for logistical support. This work was supported by NIH SC2DA034996 to PMF, National Science Foundation IOS-0642214 to JAS, PSC-CUNY Awards 64519-00 42 and 65650-00 43 jointly funded by The Professional Staff Congress and The City University of New York to PMF, Leonard and Claire Tow Travel Award to PMF and Brooklyn College and CUNY Research Foundation. Work conducted at the Marine Biological Laboratory, Woods Hole, MA was partially supported by MBL Faculty Research Fellowships to PMF and JAS.

\section{References}

Adrio F, Anadon R, Rodriguez-Moldes I (2002) Distribution of tyrosine hydroxylase (TH) and dopamine beta-hydroxylase (DBH) immunoreactivity in the central nervous system of two chondrostean fishes (Acipenser baeri and Huso huso). J Comp Neurol 448(3):280-297. doi:10.1002/cne.10256

Alderks PW, Sisneros JA (2013) Development of the acoustically evoked behavioral response in larval plainfin midshipman fish, Porichthys notatus. PLoS One 8(12), e82182. doi:10.1371/ journal.pone.0082182

Ampatzis K, Dermon CR (2010) Regional distribution and cellular localization of beta2adrenoceptors in the adult zebrafish brain (Danio rerio). J Comp Neurol 518(9):1418-1441. doi: $10.1002 / \mathrm{cne} .22278$

Ampatzis K, Kentouri M, Dermon CR (2008) Neuronal and glial localization of alpha(2A)-adrenoceptors in the adult zebrafish (Danio rerio) brain. J Comp Neurol 508(1):72-93. doi:10.1002/ cne. 21663

Appeltants D, Ball GF, Balthazart J (2001) The distribution of tyrosine hydroxylase in the canary brain: demonstration of a specific and sexually dimorphic catecholaminergic innervation of the telencephalic song control nulcei. Cell Tissue Res 304(2):237-259

Appeltants D, Del Negro C, Balthazart J (2002) Noradrenergic control of auditory information processing in female canaries. Behav Brain Res 133(2):221-235. pii: S0166432802000050

Bass AH (1996) Shaping brain sexuality. Am Sci 84(4):352-363

Bass AH, Baker R (1990) Sexual dimorphisms in the vocal control system of a teleost fish: morphology of physiologically identified neurons. J Neurobiol 21(8):1155-1168

Bass AH, Clark C (2003) The physical acoustics of underwater sound communication. In: Simmons AM, Popper AN, Fay RR (eds) Handbook of auditory research, vol 16. Springer, New York, pp 15-64

Bass AH, McKibben JR (2003) Neural mechanisms and behaviors for acoustic communication in teleost fish. Prog Neurobiol 69(1):1-26

Bass AH, Marchaterre MA, Baker R (1994) Vocal-acoustic pathways in a teleost fish. J Neurosci 14(7):4025-4039

Bass AH, Bodnar DA, Marchaterre MA (1999) Complementary explanations for existing phenotypes in an acoustic communication system. In: Hauser M, Konishi M (eds) Neural mechanisms of communication. MIT Press, Cambridge, pp 493-514 
Bass AH, Bodnar DA, Marchaterre MA (2000) Midbrain acoustic circuitry in a vocalizing fish. J Comp Neurol 419(4):505-531

Bass AH, Bodnar DA, Marchaterre MA (2001) Acoustic nuclei in the medulla and midbrain of the vocalizing gulf toadfish (Opsanus beta). Brain Behav Evol 57(2):63-79

Bass AH, Rose GJ, Pritz MB (2005) Auditory midbrain of fish, amphibians and reptiles: models systems for understanding auditory function. In: Winer JA, Schreiner CE (eds) The inferior colliculus. Springer, New York, pp 459-492

Batten TF, Berry PA, Maqbool A, Moons L, Vandesande F (1993) Immunolocalization of catecholamine enzymes, serotonin, dopamine and L-dopa in the brain of Dicentrarchus labrax (Teleostei). Brain Res Bull 31(3-4):233-252. pii: 0361-9230(93)90214-V

Berridge CW (2008) Noradrenergic modulation of arousal. Brain Res Rev 58(1):1-17. doi:10.1016/j.brainresrev.2007.10.013

Berridge CW, Waterhouse BD (2003) The locus coeruleus-noradrenergic system: modulation of behavioral state and state-dependent cognitive processes. Brain Res Brain Res Rev 42(1): 33-84. pii: S0165017303001437

Bodnar DA, Bass AH (1997) Temporal coding of concurrent acoustic signals in auditory midbrain. J Neurosci 17(19):7553-7564

Bodnar DA, Bass AH (1999) Midbrain combinatorial code for temporal and spectral information in concurrent acoustic signals. J Neurophysiol 81(2):552-563

Braford MR Jr, Northcutt RG (1983) Organization of the diencephalon and pretectum of the rayfinned fishes. In: Davis RE, Northcutt RG (eds) Fish neurobiology. University of Michigan Press, Ann Arbor, pp 117-164

Brantley RK, Bass AH (1988) Cholinergic neurons in the brain of a teleost fish (Porichthys notatus) located with a monoclonal antibody to choline acetyltransferase. J Comp Neurol 275(1):87-105

Brantley RK, Bass AH (1994) Alternative male spawning tactics and acoustic-signals in the plainfin midshipman fish Porichthys notatus Girard (Teleostei, Batrachoididae). Ethology 96(3):213-232

Brantley RK, Wingfield JC, Bass AH (1993) Sex steroid levels in Porichthys notatus, a fish with alternative reproductive tactics, and a review of the hormonal bases for male dimorphism among teleost fishes. Horm Behav 27(3):332-347

Bricaud O, Chaar V, Dambly-Chaudiere C, Ghysen A (2001) Early efferent innervation of the zebrafish lateral line. J Comp Neurol 434(3):253-261

Caras ML (2013) Estrogenic modulation of auditory processing: a vertebrate comparison. Front Neuroendocrinol 34(4):285-299. doi:10.1016/j.yfrne.2013.07.006

Chagnaud BP, Bass AH (2013) Vocal corollary discharge communicates call duration to vertebrate auditory system. J Neurosci 33(48):18775-18780. doi:10.1523/JNEUROSCI.3140-13.2013

Chagnaud BP, Baker R, Bass AH (2011) Vocalization frequency and duration are coded in separate hindbrain nuclei. Nat Commun 2:346. doi:10.1038/ncomms 1349

Coffin AB, Mohr RA, Sisneros JA (2012) Saccular-specific hair cell addition correlates with reproductive state-dependent changes in the auditory saccular sensitivity of a vocal fish. J Neurosci 32(4):1366-1376. doi:10.1523/JNEUROSCI.4928-11.2012

Cohen MJ, Winn HE (1967) Electrophysiological observations on hearing and sound production in the fish, Porichthys notatus. J Exp Zool 165:355-370

Corio M, Peute J, Steinbusch HW (1991) Distribution of serotonin- and dopamine-immunoreactivity in the brain of the teleost Clarias gariepinus. J Chem Neuroanat 4(2):79-95. pii: 0891-0618(91)90033-9

Edeline JM, Manunta Y, Hennevin E (2011) Induction of selective plasticity in the frequency tuning of auditory cortex and auditory thalamus neurons by locus coeruleus stimulation. Hear Res 274(1-2):75-84. doi:10.1016/j.heares.2010.08.005

Ekstrom P, Reschke M, Steinbusch H, van Veen T (1986) Distribution of noradrenaline in the brain of the teleost Gasterosteus aculeatus L.: an immunohistochemical analysis. J Comp Neurol 254(3):297-313. doi:10.1002/cne.902540304 
Ekstrom P, Honkanen T, Steinbusch HW (1990) Distribution of dopamine-immunoreactive neuronal perikarya and fibres in the brain of a teleost, Gasterosteus aculeatus L. comparison with tyrosine hydroxylase- and dopamine-beta-hydroxylase-immunoreactive neurons. J Chem Neuroanat 3(4):233-260

Endepols H, Walkowiak W, Luksch H (2000) Chemoarchitecture of the anuran auditory midbrain. Brain Res Brain Res Rev 33(2-3):179-198. pii: S0165017300000291

Fay RR, Edds-Walton PL (2008) Structures and functions of the auditory nervous system of fishes. In: Webb JF, Fay RR, Popper AN (eds) Fish bioacoustics, vol 32, Springer handbook of auditory research. Springer, New York, pp 49-97

Fettiplace R, Fuchs PA (1999) Mechanisms of hair cell tuning. Annu Rev Physiol 61:809-834

Filippi A, Mahler J, Schweitzer J, Driever W (2010) Expression of the paralogous tyrosine hydroxylase encoding genes Th1 and Th2 reveals the full complement of dopaminergic and noradrenergic neurons in zebrafish larval and juvenile brain. J Comp Neurol 518(4):423-438. doi: $10.1002 / \mathrm{cne} .22213$

Fine ML, Lenhardt ML (1983) Shallow-water propagation of the toadfish mating call. Comp Biochem Physiol A Comp Physiol 76(2):225-231

Fine ML, Perini MA (1994) Sound production evoked by electrical stimulation of the forebrain in the oyster toadfish. J Comp Physiol A 174(2):173-185

Forlano PM, Bass AH (2011) Neural and hormonal mechanisms of reproductive-related arousal in fishes. Horm Behav 59(5):616-629. doi:10.1016/j.yhbeh.2010.10.006

Forlano PM, Kim SD, Krzyminska ZM, Sisneros JA (2014) Catecholaminergic connectivity to the inner ear, central auditory, and vocal motor circuitry in the plainfin midshipman fish Porichthys notatus. J Comp Neurol 522(13):2887-2927. doi:10.1002/cne.23596

Forlano PM, Ghahramani ZN, Monestime CM, Kurochkin P, Chernenko A, Milkis D (2015a) Catecholaminergic innervation of central and peripheral auditory circuitry varies with reproductive state in female midshipman fish, Porichthys notatus. PLoS One 10(4), e0121914. doi: 10.1371/journal.pone.0121914

Forlano PM, Sisneros JA, Rohmann KN, Bass AH (2015b) Neuroendocrine control of seasonal plasticity in the auditory and vocal systems of fish. Front Neuroendocrinol 37:129-145. doi:10.1016/j.yfrne.2014.08.002

Furukawa T (1981) Effects of efferent stimulation on the saccule of goldfish. J Physiol 315:203-215

Garrett AR, Robertson D, Sellick PM, Mulders WH (2011) The actions of dopamine receptors in the guinea pig cochlea. Audiol Neurootol 16(3):145-157. doi:10.1159/000316674

Genova RM, Marchaterre MA, Knapp R, Fergus D, Bass AH (2013) Glucocorticoid and androgen signaling pathways diverge between advertisement calling and non-calling fish. Horm Behav 62(4):426-432. doi:10.1016/j.yhbeh.2012.07.010

Gittelman JX, Perkel DJ, Portfors CV (2013) Dopamine modulates auditory responses in the inferior colliculus in a heterogeneous manner. J Assoc Res Otolaryngol 14(5):719-729. doi:10.1007/s10162-013-0405-0

Goodson JL (2005) The vertebrate social behavior network: evolutionary themes and variations. Horm Behav 48(1):11-22

Goodson JL, Bass AH (2002) Vocal-acoustic circuitry and descending vocal pathways in teleost fish: convergence with terrestrial vertebrates reveals conserved traits. J Comp Neurol 448(3):298-322

Goodson JL, Kabelik D (2009) Dynamic limbic networks and social diversity in vertebrates: from neural context to neuromodulatory patterning. Front Neuroendocrinol 30(4):429-441. doi:10.1016/j.yfrne.2009.05.007

Goodson JL, Kingsbury MA (2013) What's in a name? Considerations of homologies and nomenclature for vertebrate social behavior networks. Horm Behav 64(1):103-112. doi:10.1016/j. yhbeh.2013.05.006

Hornby PJ, Piekut DT (1990) Distribution of catecholamine-synthesizing enzymes in goldfish brains: presumptive dopamine and norepinephrine neuronal organization. Brain Behav Evol 35(1):49-64 
Hurley LM, Devilbiss DM, Waterhouse BD (2004) A matter of focus: monoaminergic modulation of stimulus coding in mammalian sensory networks. Curr Opin Neurobiol 14(4):488-495. pii: S0959-4388(04)00096-0

Ibara RM, Penny LT, Ebeling AW, van Dykhuizen D, Cailliet G (1983) The mating call of the plainfin midshipman fish, Porichthys notatus. In: Noakes DLG, Lundquist DG, Helfman GS, Ward JA (eds) Predators and prey in fishes. Dr. W. Junk Publishers, The Hague, pp 205-212

Joshua M, Adler A, Bergman H (2009) The dynamics of dopamine in control of motor behavior. Curr Opin Neurobiol 19(6):615-620. doi:10.1016/j.conb.2009.10.001

Kapsimali M, Vidal B, Gonzalez A, Dufour S, Vernier P (2000) Distribution of the mRNA encoding the four dopamine $\mathrm{D}(1)$ receptor subtypes in the brain of the european eel (Anguilla anguilla): comparative approach to the function of $\mathrm{D}(1)$ receptors in vertebrates. J Comp Neurol 419(3): 320-343. doi:10.1002/(SICI)1096-9861(20000410)419:3<320::AID-CNE5>3.0.CO;2-F

Kaslin J, Panula P (2001) Comparative anatomy of the histaminergic and other aminergic systems in zebrafish (Danio rerio). J Comp Neurol 440(4):342-377. doi:10.1002/cne.1390

Kastenhuber E, Kratochwil CF, Ryu S, Schweitzer J, Driever W (2010) Genetic dissection of dopaminergic and noradrenergic contributions to catecholaminergic tracts in early larval zebrafish. J Comp Neurol 518(4):439-458. doi:10.1002/cne.22214

Kelly AM, Goodson JL (2015) Functional interactions of dopamine cell groups reflect personality, sex, and social context in highly social finches. Behav Brain Res 280:101-112. doi:10.1016/j. bbr.2014.12.004

Kirk EC, Smith DW (2003) Protection from acoustic trauma is not a primary function of the medial olivocochlear efferent system. J Assoc Res Otolaryngol 4(4):445-465. doi:10.1007/ s10162-002-3013-y

Kittelberger JM, Bass AH (2013) Vocal-motor and auditory connectivity of the midbrain periaqueductal gray in a teleost fish. J Comp Neurol 521(4):791-812. doi:10.1002/cne.23202

Kittelberger M, Land BR, Bass AH (2006) Midbrain periaqueductal gray and vocal pattering in a teleost fish. J Neurophysiol 96:71-85

Klepper A, Herbert H (1991) Distribution and origin of noradrenergic and serotonergic fibers in the cochlear nucleus and inferior colliculus of the rat. Brain Res 557(1-2):190-201. pii: 0006-8993(91)90134-H

Knapp R, Wingfield JC, Bass AH (1999) Steroid hormones and paternal care in the plainfin midshipman fish (Porichthys notatus). Horm Behav 35(1):81-89

Koppl C (2011) Evolution of the octavolateralis efferent system. In: Ryugo DK, Fay RR, Popper AN (eds) Auditory and vestibular efferents. Springer, New York, pp 217-259

Kossl M, Vater M (1989) Noradrenaline enhances temporal auditory contrast and neuronal timing precision in the cochlear nucleus of the mustached bat. J Neurosci 9(12):4169-4178

Lagardere JP, Ernande B (2004) Sounds recorded in salt marshes and attributed to the European eel. C R Biol 327(4):353-359

Lendvai B, Halmos GB, Polony G, Kapocsi J, Horvath T, Aller M, Sylvester Vizi E, Zelles T (2011) Chemical neuroprotection in the cochlea: the modulation of dopamine release from lateral olivocochlear efferents. Neurochem Int 59(2):150-158. doi:10.1016/j.neuint.2011.05.015

Lu Z (2011) Physiology of the ear and brain: how fish hear. In: Farrell AP (ed) Encyclopedia of fish physiology: from genome to environment. Academic, San Diego, pp 292-297

Lynch KS, Ball GF (2008) Noradrenergic deficits alter processing of communication signals in female songbirds. Brain Behav Evol 72(3):207-214. doi:10.1159/000157357

Ma PM (1994) Catecholaminergic systems in the zebrafish. II. Projection pathways and pattern of termination of the locus coeruleus. J Comp Neurol 344(2):256-269. doi:10.1002/cne.903440207

Maison SF, Liu XP, Eatock RA, Sibley DR, Grandy DK, Liberman MC (2012) Dopaminergic signaling in the cochlea: receptor expression patterns and deletion phenotypes. J Neurosci 32(1):344-355. doi:10.1523/JNEUROSCI.4720-11.2012

Maney DL (2013) The incentive salience of courtship vocalizations: hormone-mediated 'wanting' in the auditory system. Hear Res 305:19-30. doi:10.1016/j.heares.2013.04.011

Maney DL, Pinaud R (2011) Estradiol-dependent modulation of auditory processing and selectivity in songbirds. Front Neuroendocrinol 32(3):287-302. doi:10.1016/j.yfrne.2010.12.002 
McCormick CA (1999) Anatomy of the central auditory pathways of fish and amphibians. In: Popper A, Fay RR (eds) Comparative hearing: fish and amphibians. Springer, New York, pp 155-217

McCormick CA (2011) Auditory/lateral line CNS: anatomy. In: Farrell AP (ed) Encyclopedia of fish physiology: from genome to environment. Academic, San Diego, pp 283-291

McIver EL, Marchaterre MA, Rice AN, Bass AH (2014) Novel underwater soundscape: acoustic repertoire of plainfin midshipman fish. J Exp Biol 217:2377-2389. doi:10.1242/jeb.102772

McKibben JR, Bass AH (1998) Behavioral assessment of acoustic parameters relevant to signal recognition and preference in a vocal fish. J Acoust Soc Am 104(6):3520-3533

McKibben JR, Bass AH (1999) Peripheral encoding of behaviorally relevant acoustic signals in a vocal fish: single tones. J Comp Physiol A 184(6):563-576

McKibben JR, Bass AH (2001a) Effects of temporal envelope modulation on acoustic signal recognition in a vocal fish, the plainfin midshipman. J Acoust Soc Am 109(6):2934-2943

McKibben JR, Bass AH (2001b) Peripheral encoding of behaviorally relevant acoustic signals in a vocal fish: harmonic and beat stimuli. J Comp Physiol A 187(4):271-285

Mello CV, Pinaud R, Ribeiro S (1998) Noradrenergic system of the zebra finch brain: immunocytochemical study of dopamine-beta-hydroxylase. J Comp Neurol 400(2):207-228. doi:10.1002/ (SICI)1096-9861(19981019)400:2<207::AID-CNE4>3.0.CO;2-D

Niu X, Canlon B (2006) The signal transduction pathway for the dopamine D1 receptor in the guinea-pig cochlea. Neuroscience 137(3):981-990. doi:10.1016/j.neuroscience.2005.10.044

O'Connell LA, Hofmann HA (2011) The vertebrate mesolimbic reward system and social behavior network: a comparative synthesis. J Comp Neurol 519(18):3599-3639. doi:10.1002/ cne. 22735

O'Connell LA, Hofmann HA (2012) Evolution of a vertebrate social decision-making network. Science 336(6085):1154-1157. doi:10.1126/science.1218889

O'Connell LA, Fontenot MR, Hofmann HA (2011) Characterization of the dopaminergic system in the brain of an African cichlid fish, Astatotilapia burtoni. J Comp Neurol 519(1):75-92. doi:10.1002/cne.22506

Pasqualini C, Weltzien FA, Vidal B, Baloche S, Rouget C, Gilles N, Servent D, Vernier P, Dufour S (2009) Two distinct dopamine D2 receptor genes in the European eel: molecular characterization, tissue-specific transcription, and regulation by sex steroids. Endocrinology 150(3):1377-1392. doi:10.1210/en.2008-0578

Pawlisch BA, Stevenson SA, Riters LV (2011) alpha(1)-Noradrenegic receptor antagonism disrupts female songbird responses to male song. Neurosci Lett 496(1):20-24. doi:10.1016/j. neulet.2011.03.078

Petersen CL, Timothy M, Kim DS, Bhandiwad AA, Mohr RA, Sisneros JA, Forlano PM (2013) Exposure to advertisement calls of reproductive competitors activates vocal-acoustic and catecholaminergic neurons in the plainfin midshipman fish, Porichthys notatus. PLoS One 8(8), e70474. doi:10.1371/journal.pone.0070474

Puzdrowski RL (1989) Peripheral distribution and central projections of the lateral-line nerves in goldfish, Carassius auratus. Brain Behav Evol 34(2):110-131

Remage-Healey L, Bass AH (2004) Rapid, hierarchical modulation of vocal patterning by steroid hormones. J Neurosci 24(26):5892-5900

Remage-Healey L, Bass AH (2005) Rapid elevations in both steroid hormones and vocal signaling during playback challenge: a field experiment in Gulf toadfish. Horm Behav 47(3):297-305

Rink E, Wullimann MF (2001) The teleostean (zebrafish) dopaminergic system ascending to the subpallium (striatum) is located in the basal diencephalon (posterior tuberculum). Brain Res 889(1-2):316-330

Rink E, Wullimann MF (2002) Connections of the ventral telencephalon and tyrosine hydroxylase distribution in the zebrafish brain (Danio rerio) lead to identification of an ascending dopaminergic system in a teleost. Brain Res Bull 57(3-4):385-387

Riters LV (2012) The role of motivation and reward neural systems in vocal communication in songbirds. Front Neuroendocrinol 33(2):194-209. doi:10.1016/j.yfrne.2012.04.002 
Roberts BL, Meredith GE, Maslam S (1989) Immunocytochemical analysis of the dopamine system in the brain and spinal cord of the European eel, Anguilla anguilla. Anat Embryol (Berl) 180(4):401-412

Rogers PH, Cox M (1988) Underwater sound as a biological stimulus. In: Atema J, Fay RR, Popper AN, Tavolga WN (eds) Sensory biology of aquatic animals. Springer, New York

Rohmann KN, Bass AH (2011) Seasonal plasticity of auditory hair cell frequency sensitivity correlates with plasma steroid levels in vocal fish. J Exp Biol 214(Pt 11):1931-1942. doi:10.1242/jeb.054114

Rohmann KN, Deitcher DL, Bass AH (2009) Calcium-activated potassium (BK) channels are encoded by duplicate slo1 genes in teleost fishes. Mol Biol Evol 26(7):1509-1521. doi:10.1093/ molbev/msp060

Rohmann KN, Fergus DJ, Bass AH (2013) Plasticity in ion channel expression underlies variation in hearing during reproductive cycles. Curr Biol 23(8):678-683. doi:10.1016/j.cub.2013.03.014

Rountree RA, Perkins PJ, Kenney RD, Hinga KR (2002) Sounds of Western North Atlantic Fishes: Data rescue. Bioacoustics 12:242-244

Ruel J, Nouvian R, Gervais d'Aldin C, Pujol R, Eybalin M, Puel JL (2001) Dopamine inhibition of auditory nerve activity in the adult mammalian cochlea. Eur J Neurosci 14(6):977-986. pii: ejn 1721

Ruel J, Wang J, Rebillard G, Eybalin M, Lloyd R, Pujol R, Puel JL (2007) Physiology, pharmacology and plasticity at the inner hair cell synaptic complex. Hear Res 227(1-2):19-27. doi:10.1016/j.heares.2006.08.017

Ryu S, Holzschuh J, Mahler J, Driever W (2006) Genetic analysis of dopaminergic system development in zebrafish. J Neural Transm Suppl 70:61-66

Sas E, Maler L, Tinner B (1990) Catecholaminergic systems in the brain of a gymnotiform teleost fish: an immunohistochemical study. J Comp Neurol 292(1):127-162. doi:10.1002/ cne. 902920109

Schall U, Keysers C, Kast B (1999) Pharmacology of sensory gating in the ascending auditory system of the pigeon (Columba livia). Psychopharmacology (Berl) 145(3):273-282

Sisneros JA (2009a) Seasonal plasticity of auditory saccular sensitivity in the vocal plainfin midshipman fish, Porichthys notatus. J Neurophysiol 102(2):1121-1131. doi:10.1152/ jn.00236.2009

Sisneros JA (2009b) Steroid-dependent auditory plasticity for the enhancement of acoustic communication: recent insights from a vocal teleost fish. Hear Res 252(1-2):9-14. doi:10.1016/j. heares.2008.12.007

Sisneros JA, Bass AH (2003) Seasonal plasticity of peripheral auditory frequency sensitivity. J Neurosci 23(3):1049-1058

Sisneros JA, Marchaterre MA, Bass AH (2002) Otolithic endorgan projections of the inner ear in a vocal fish. Bioacoustics 12:137-139

Sisneros JA, Forlano PM, Deitcher DL, Bass AH (2004a) Steroid-dependent auditory plasticity leads to adaptive coupling of sender and receiver. Science 305(5682):404-407

Sisneros JA, Forlano PM, Knapp R, Bass AH (2004b) Seasonal variation of steroid hormone levels in an intertidal-nesting fish, the vocal plainfin midshipman. Gen Comp Endocrinol 136(1):101-116

Sisneros JA, Alderks PW, Leon K, Sniffen B (2009) Morphometric changes associated with the reproductive cycle and behaviour of the intertidal-nesting, male plainfin midshipman Porichthys notatus. J Fish Biol 74(1):18-36. doi:10.1111/j.1095-8649.2008.02104.x

Smith DW, Keil A (2015) The biological role of the medial olivocochlear efferents in hearing: separating evolved function from exaptation. Front Syst Neurosci 9:12. doi:10.3389/ fnsys.2015.00012

Tay TL, Ronneberger O, Ryu S, Nitschke R, Driever W (2011) Comprehensive catecholaminergic projectome analysis reveals single-neuron integration of zebrafish ascending and descending dopaminergic systems. Nat Commun 2:171. doi:10.1038/ncomms 1171

Tomchik SM, Lu ZM (2006) Modulation of auditory signal-to-noise ratios by efferent stimulation. J Neurophysiol 95(6):3562-3570 
Vacher C, Pellegrini E, Anglade I, Ferriere F, Saligaut C, Kah O (2003) Distribution of dopamine D-2 receptor mRNAs in the brain and the pituitary of female rainbow trout: an in situ hybridization study. J Comp Neurol 458(1):32-45

Valdes-Baizabal C, Soto E, Vega R (2015) Dopaminergic modulation of the voltage-gated sodium current in the cochlear afferent neurons of the rat. PLoS One 10(3), e0120808. doi:10.1371/ journal.pone. 0120808

Velho TA, Lu K, Ribeiro S, Pinaud R, Vicario D, Mello CV (2012) Noradrenergic control of gene expression and long-term neuronal adaptation evoked by learned vocalizations in songbirds. PLoS One 7(5), e36276. doi:10.1371/journal.pone.0036276

Vetillard A, Benanni S, Saligaut C, Jego P, Bailhache T (2002) Localization of tyrosine hydroxylase and its messenger RNA in the brain of rainbow trout by immunocytochemistry and in situ hybridization. J Comp Neurol 449(4):374-389

Weeg MS, Bass AH (2000) Central lateral line pathways in a vocalizing fish. J Comp Neurol 418(1):41-64

Weeg MS, Bass AH (2002) Frequency response properties of lateral line superficial neuromasts in a vocal fish, with evidence for acoustic sensitivity. J Neurophysiol 88(3):1252-1262

Weeg MS, Land BR, Bass AH (2005) Vocal pathways modulate efferent neurons to the inner ear and lateral line. J Neurosci 25(25):5967-5974

Zeddies DG, Fay RR, Alderks PW, Shaub KS, Sisneros JA (2010) Sound source localization by the plainfin midshipman fish, Porichthys notatus. J Acoust Soc Am 127(5):3104-3113. doi:10.1121/1.3365261

Zeddies DG, Fay RR, Gray MD, Alderks PW, Acob A, Sisneros JA (2012) Local acoustic particle motion guides sound-source localization behavior in the plainfin midshipman fish, Porichthys notatus. J Exp Biol 215(Pt 1):152-160. doi:10.1242/jeb.064998

Zikopoulos B, Dermon CR (2005) Comparative anatomy of alpha(2) and beta adrenoceptors in the adult and developing brain of the marine teleost the red porgy (Pagrus pagrus, Sparidae): [(3) $\mathrm{H}]$ clonidine and $[(3) \mathrm{H}]$ dihydroalprenolol quantitative autoradiography and receptor subtypes immunohistochemistry. J Comp Neurol 489(2):217-240. doi:10.1002/cne.20641

Zottoli SJ, Van Horne C (1983) Posterior lateral line afferent and efferent pathways within the central nervous system of the goldfish with special reference to the Mauthner cell. J Comp Neurol 219(1):100-111. doi:10.1002/cne.902190110 


\section{Index}

A

Abudefduf abdominalis, 231-232

AEP, 235

AEP recordings, 239, 243-244

electrophysiological recording methods, 239

recording experiments, 232

recording locations, 237

saccular potential recordings, 234-235, 238

saccular potentials, 243-244

single neuron recordings, 236, 239

Acoustic attraction, 264-265

Acoustic behaviors, 69, 72, 73

Acoustic communication, 94, 95, 97, 99-113

behavioral ecology of, 82-83

darters

acoustic repertoire, 113

audiograms, 106-108

behavioural context, sound structures, and acoustic properties, 97

phylogenetic hypothesis, 99-101

reproductive ecology, 95

signaling efficacy, 108-109, 112

signal-to-noise (S/N) ratio, 94

sound production mechanisms, 105-106

gobies

waveforms and spectrograms, 97

acoustic repertoire, 113

audiograms, 106-108

behavioural context, sound structures, and acoustic properties, 97, 102

phylogenetic hypothesis, 102-105

reproductive ecology, 97

signaling efficacy, 108-109, 112

sound production mechanisms, 105-106 tonal $v s$. pulsatile sound types, 113

waveforms and spectrograms, 97

intraspecific variations

size and somatic condition, 110-111

social context, 111-112

species identity, 112

nodding/pectoral fin motion, 94

sculpins

acoustic repertoire, 113

audiograms, 106-108

behavioural context, sound structures, and acoustic properties, 97

phylogenetic hypothesis, 101-103

reproductive ecology, 95

signaling efficacy, 108-109, 112

signal-to-noise $(\mathrm{S} / \mathrm{N})$ ratio, 94

sound production mechanisms, 105-106

waveforms and spectrograms, 97

signaling efficacy, 94, 108-109

swim bladder drumming sounds, 94

territoriality and mate attraction, 95

Acoustic ecology, 262-264

"Acoustic-lateralis" hypothesis, 127

"Acoustic-lateralis" model, 138

Acoustic responses, 258, 260-267

ear and lateral line

attraction, 264-265

behavioural response, hearing, 266

ecology, 262-264

farfield, 258

hearing, 258

nearfield, 258

particle and pressure detection, 266

physiological response, hearing, 265-266

research community, 267 
Acoustic responses (cont.)

tanks, sound propagation in, 262

underwater sound propagation, 260-262

Acoustic stimulus, 234, 287

farfield, 258

nearfield, 258

reception

anatomy, 61

ear and lateral line, 76

Acoustically evoked behavioral responses (AEBR), 167

Acquired hearing loss, 384-386

anthropogenic sound sources, 386-389

ototoxic drug-induced hair cell loss, 389-390

sound-induced hearing loss

AEP, 384

auditory masking, 386

goldfish, as experimental model, 384

intensity of sound stimuli vs. baseline hearing threshold level, 384

low and high frequency sounds, 385, 386

pressure component, 385

saccular hair cell loss, 384

SPL, 384

temporal patterns, 386

TTS, 384,385

AEBR. See Acoustically evoked behavioral responses (AEBR)

AEPs. See Auditory evoked potential (AEPs)

Al Tester, 36

Ambient acoustic noise, 83 sources of, 83

Ambient noise, 84-87

Anal fin retract sound, 69-72

Anterior octaval nucleus (AON), 209

Atlantic Molly (Poecilia mexicana), 189

Audiograms

cichlids, 333

thorny catfish, 331

Auditory, 273

Auditory capabilities

AEP methods, 229

behavioral and psychophysical methods, 228-229

goldfish, 230

Lusitanian toadfish, 230

oyster toadfish, 230

Auditory electrophysiology, 159

AEP recordings

Hawaiian sergeant damselfish, saccular potentials and, 243-244

AEP technique, 304
Auditory evoked potentials (AEPs), 77, 160, 190, 235-236, 239, 265

catfish, 328

hair cell damage, 384

Auditory physiology recording techniques

AEP and saccular potential recordings, 244,246

behavioral and psychological method, 245

otolithic endorgan, 248

potential sensory system, 247

primary afferent recordings, 244

single neuron recordings, 246

Auditory response, 258

Auditory sensitivity, 307-313

behavioral technique, 303

Chondrichthyes (cartilaginous fishes), 304

cichlids, 333

electrophysiology techniques, 303, 304

taxon-specific results, 304-306

Teleostomi/Osteichthyes (Bony Fishes), 308

Batrachoidiformes, 310-311

Clupeiformes, 307

Cypriniformes, 307-309

Gadiformes, 310

Perciformes, 311-313

Siluriformes, 309

Auditory startle response (ASR), 166-171

Auditory system, toadfish, 203

Auditory thresholds, 228

Avoidance conditioning, 163-164

B

Bannerfishes, 72

Behavioral audiogram, 245

Behavioral methods, 158

auditory function, 159

Behavioral repertoire oyster toadfish, 200

Behavioral techniques, 228, 229

Behaviorism, 15

Behavioural response hearing, 266

Békésy Laboratory, 32

Biomedical applications hair cell death and protection, 413-414 regeneration, 414-416

Birch Island, 15

Brain, 213-220

toadfish, auditory system, 212-213

DON roles, 213-218

octaval column, saccule targets, 218

TS, 219-220 
Butterflyfishes, 61, 63, 65-67, 69, 72, 76, 77, $79,81-87$

acoustic communication

ambient noise sources, 83

territories, hearing, 84-87

behavioral ecology of, 82-83

acoustic stimuli reception, ear and lateral line, 76

Chaetodon and swim bladder horns effect, 77, 79, 81-82

hydrodynamic article motion and sound pressure, 76, 77

anatomy, acoustic stimuli reception, 61

ear and proximity, 66, 67

LC, 61, 63

swim bladder, 63,65

diversity and evolution, 69

acoustic behavior and sound production mechanisms, 69, 72

genera of, 58

long-term haremic associations, 58

monogamous pairs, 58

sound characteristics, 73

sound production, evolution of, 74-76

\section{C}

Canal neuromasts, 259

Catfishes

vs. cichlids, 334-337

interfamilial comparison, 326-328

Cavefishes

AEP, 190, 191

amblyopsid cavefish and surface $F$. agassizii, 191

Atlantic molly (Poecilia mexicana), 189

auditory thresholds, 190

Fay, Richard, 192-193

hair cell density, reduction in, 191

high frequency hearing, loss of, 191

in subterranean habitats, 189

inner ear size and brain morphology, 191

lateral line, 192

lower auditory thresholds and greater frequency ranges, 189

non-visual sensory modalities, 189

otolith morphology, 190

otoliths morphology, 189

phylogenetic diversity, 188, 189

Popper, Arthur, 192-193

replicate ecological and evolutionary experiments, 188

sensory epithelia, 191
Chaetodon, 58, 61

and swim bladder effect, 77, 79, 81

behavior of, 58

buoyancy, 66

lateral line system, 81-82

LC in, 61, 68

sound production, 65

Chaetodon clades, 68, 74, 87

Chaetodon Ocellatus, tholichthys larvae of, 68

Chemical ototoxicity, 406-412, 416

inner ear and lateral line system, 413-414

aminoglycoside antibiotics, 408

biomedical applications see Biomedical applications

cisplatin, 408

environmental toxins, 416

evolutionary perspectives, 409-410

gentamicin, 408

larval zebrafish (Danio rerio), 408, 409

neuromasts, 407, 408

perception and behavior, 410-412

platinum-based compound, 408

single neuromasts label, 409

structure of, 406, 407

Cichlids, 332-334, 338

catfishes vs., 334-337

Classical conditioning, 164-166, 245

Clupeid fishes, hearing in, 5

Cochlear microphonics, 36

Comparative morphology, 4

Conductive hearing loss, 381

Constant stimuli method of, 175

Coral reefs, acoustic soundscape, 83-87 ambient noise sources, 83

territories, hearing in, 84-87

Cyanoacrylate gel, 277

Cynoscion regalis, swim bladder, 337

\section{D}

Damselfish (Pomacentridae), 261

DeepFin project, 349

Deep-sea fish ears, comparative morphology of, 5

Descending octaval nucleus (DON), 207-208, 220

brain, 213-218

Directional hearing and sound source localization, 125-130, 136-137

acoustic field measurements, 148

"acoustic-lateralis" model, 138

acoustic particle velocity, 140, 147-149 
Directional hearing and sound source localization (cont.)

acoustically small, 140

algorithmic approach, 139

arbitrary sinusoidal quantity, 142

behavioral studies, 130-136

directional unmasking, 129

direction-dependent masking, 128

early negative results, $125-126$

minimum audible angles, 127-128

$180^{\circ}$ ambiguity problem, $129-130$

phonotaxis experiments see Phonotaxis

experiments

re-evaluation of, 126-127

sound source distance discrimination, 129

swim bladder and lateral line, 136-137

computational model, 139

dipole source, 144, 147

inner ear, 124

local fluid velocity, 145

modes of hearing, 124, 125

monopole source, 140, 144

motion vector quantity, 140

multipole model, 139

near-field and far-field time-averaged intensity vectors, 147

orbital model, 139

orthogonal directions and arctangent algorithm, 140

particle velocity and time-averaged intensity, 144-146

phase model, 138

point cardioid source, 147

predicted values, 150

reactive oscillatory part, 141

resistive part, 141

scalar quantity, 140

sinusoidal signal, 141

time-averaged intensity, 142-144, 146-149

unbounded medium, 141

underwater sound and the acoustic cues, 123

Directional response pattern (DRP), 202

DON. See Descending octaval nucleus (DON)

Doradids, 328

$\mathbf{E}$

Ear

hearing, 210-212

Hawaiian fishes, analysis of, 66

toadfish, 203-205

Eight Point Sportsman's Club, 13

Electric shock, 163

Electrode lead, 276
Electrophysiological methods, 229

Electrophysiological recording methods, 249 accular potentials, comparison of, 239

F

Farfield, 287

Fay, Richard Rozzell

behavioral method, 16

dynamic properties, 17

early life, 13,15

faculty positions, 18

goldfish hearing, 16, 18

in laboratory, 14

multisensory interaction, 17

Perpetual Motion, 15

plainfin midshipman and sound source localization, 19

scientific conference, 14

shark hearing, 17

Fish auditory system, 295-302

DON roles, 213-218

morphological development embryology and early development, 297-300

functional significance, 302

postembryonic sensory hair cell, 300-302

teleost inner ear, 295-296

octaval column, saccule targets, 218

TS, 219-220

Fish hearing, 163-164, 166-173, 175-178, 303-313

AEPs, 160

areas of research, 179-180

auditory sensitivity see Auditory sensitivity

behavioral methods, 158

inner ear structure study, 158

noninvasive behavioral methods, 159

operant conditioning, 161-162

avoidance conditioning, 163-164

phonotaxis, 173-174

psychoacoustics experiments, 166, 174-175

constant stimuli method, 175

method of limits, 176

QUEST and ML-PEST, 177

staircase method, 176-177

stimulus presentation protocol, 175

threshold criteria, 177-178

reflex responses, 166

ASR, 166-171

PPI, 171-173

social communication, 313-314

techniques, 159

Forcipiger, head bob sound, 72

Fundulus heteroclitus. See Killifish 


\section{G}

Gas-filled cavities, 325

Goldfish(Carassius auratus)

classical conditioning, 165

dDON in, 208

otolithic endorgans of, 199

sound hearing, 161

\section{H}

Habituation, 169

Hair cell based mechanosensory lateral line, 274

Hawai'i Kai, 31-32

books, 41-44

Eniwetok and shark hearing, 36-41

first paper and descendants, 33-36

food, 46

hearing modes, 36

hearing specialist, curse of, 46-47

SHAR, 44-45

students, 45

Hawaiian fishes, analysis, ears of, 66

Hawaiian sergeant damselfish, 231-232

saccular potentials and AEP recordings, 243-244

Hawaiian sergeant fish, auditory physiology recording techniques, 245

Head bob acoustic behavior, 69

Head bob sound, 72

Hearing, 87, 258

behavioural response, 266

modes of, 36

physiological response, 265-266

thresholds, thorny catfish, 331

Hearing specialist, 46-47

Heniochus chrysostomus, 72

Hindbrain, 236, 239, 247

octaval nuclei, 236

Holocentridae, anterior swim bladder and posterior cranium situation, 334

Hydrodynamic mechanoreceptors, somatotopic organization, 81

Hydrodynamic particle motion, 76-77

\section{I}

Innate behavioral responses, 166-171

phonotaxis, 173-174

reflex responses, 166, 171-173

ASR, 166-171

PPI, 171-173

Inner ear diversity, 370-378, 383, 384

anabantiform fishes, 380

ancillary structures and modified orientation patterns, 380 auditory periphery evolution

developmental and genetic constraints, 384

driving factors, 383

sensory trade-offs, 384

spatial constraints, 383

bony fish species, 349-367, 370, 380, 382, 384

cichlid Etroplus maculatus, 381

ciliary bundle orientation patterns, 346 , 347, 378-379

Clown knifefish Chitala chitala, 380

cod Gadus morhua, 381

Cyprinodonotiforms, 345-344

DeepFin project, 349

Etroplus maculatus, 363, 378

Eutrigla gurnardus, 345-344

gobiiform fishes, 345-344

gross morphology, 346

Hawaiian ladyfish Elops hawaiensis (Elopidae), 381

Hemichromis guttatus, 363, 378

KS ratio, 382

Light of Phylogeny, 377, 382-383

macula types, 374-375, 380

methodological innovations, 381

micromechanical behavior, 382

modified orientation patterns, 380

non-teleost actinopterygii, 368-370

otoliths/otoconia, 346

otophysan ears, 345-344

otophysans and mormyrids, 380

otophysic connections, 348

Sarcopterygii, 349-368

Sarotherodon melanotheron, 363, 378

sciaenid species Micropogonias undulates and Cynoscion nebulosus, 381

sensory epithelia, 346

sound source $v s$. reradiated particle motion, 380

sound sources localization, 379-381

sound-exposure experiments, 382

Steatocranus tinanti, 363, 378

stimulation pathway, 348

teleostei

Elopomorpha, 370, 372-373

Euteleostomorpha, 374-378

Osteoglossomorpha, 371

Otomorpha, 371-373

Trichopsis vittata, 345-344

Inner ears

cichlid, 333

vs. swim bladders, 327

Instrumental conditioning, 161-162 
interfamilial comparison

catfishes, 326-328

Intermittent swimming strategy, 287

K

Kalmijn's guide approach hypothesis, 131

Killifish, experimental tank and testing apparatus, 158

$\mathbf{L}$

Lagena, 211

Lateral line

prey, detection of, 280

receptors, 259

toadfish, 285-286

Lateral line system, Chaetodon, swim bladder horns effect and LC, 81-82

Laterophysic connection (LC), 58, 61-63, 81-82 acoustic stimuli reception, lateral line, 81-82

Chaetodon, evolution, 68

types of, 61

Leiostomus xanthurus, swim bladder, 337

Lusitanian toadfish, saccular potentials and

AEP thresholds, 239

\section{M}

Magnocellular octaval nucleus (MON), 209, 218

Male's "boatwhistle" signal, 130

Marine Biological Laboratory (MBL), 18

Marine Resources Center (MRC), 201

Mauthner cells (M-cells), 166-167, 266

Mechanosensory lateral line, 258, 274

Mechanosensory systems, chemical ototoxicity

Medulla, ipsilateral DON and SO nuclei, 209

Method of limits, 176

Midbrain, 236, 239, 247

Midshipman fish (Porichthys notatus), behavioral studies of, 174

Midshipman fish model, 310

MON. See Magnocellular octaval nucleus (MON)

Mongolian gerbil (Meriones unguiculatus), PPI, 173

Multisensory integration, 267

Myripristis amaena, 334

\section{$\mathbf{N}$}

Nalgene experimental tank, 234

"N-down, one up" protocol, 178
Nearfield, 287

Neurobiotin, anterograde transport, 219

Neuromasts, 380

Next-generation sequencing (NGS) techniques, 395

Noninvasive behavioral methods, advantages of, 159

Nucleus ventrolateralis (NVL), 219

O

Octaval column, saccule targets, 218

Ontogeny development. See Fish hearing

Operant conditioning, 161-162

Opsanus tau

brain, 209

batrachoid fish, 275

saccular endorgan, 275

saccular nerve, 280

Oscar, hearing capability, determination, 161

Otolithic endorgan potentials, 248

Otophysans, 5

Otophysines, 325, 326

Oyster toadfish, 201

auditory physiology recording techniques, 244

\section{$\mathbf{P}$}

Particle motion, 286

Particle motion and pressure detection, 266-267

Peripheral auditory structure, 326-328, 334-337 catfishes vs. cichlids, 334-337 interfamilial comparison, 326-328

cichlids, 332-334

flatfishes or sculpins, 326

gas-filled cavities, 325

hearing, 324

holocentrids, 324

otophysines, 325

thorny catfishes, 328-332

Phase-locking, auditory afferents, 212, 214

Phonotaxis experiments, 173-174

behavioral tests, 133

climbing up, 131

dipole sound source, 134

eight mini-hydrophone array, 131, 132

hydrophones and acoustic particle motion, 135

J9 sound projector, 131, 132

Kalmijn's guide approach hypothesis, 131

light compass reaction, 131

male's "boatwhistle" signal, 130 
naïve female midshipman, 135

one and two choice tests, 131

plainfin midshipman, 131

radiation pattern, 134

US Navy J9 sound projector, 131

Physiological response, hearing, 265-266

Plainfin midshipman (Porichthys notatus), 131, 262, 267

saccular potential recordings, 234

Prepulse inhibition (PPI), 171-173

Primary afferent recordings, 244

Psychophysical methods, 245

\section{$\mathbf{R}$}

Radio telemetry, 274

Ray-finned bony fishes, 324

Rayleigh statistic, 237, 278

Recharging habitat and stage (RECHABS), 277

Reef effect, 260

Reflex responses, 166

\section{$\mathbf{S}$}

Saccular inputs, 206-207

Saccular otolith, 205

Saccular potentials and AEP recordings, Hawaiian sergeant damselfish, 243-244

recordings, 234-235, 238

Secondary octaval (SO) nuclei, medulla, 209

Seismic air guns, noise, 5

Sensorineural hearing loss, 381

Sensory hair cell damage and recovery, 383-390, 393-395

acquired hearing loss

anthropogenic sound sources, 386-389

ototoxic drug-induced hair cell loss, 389-390

sound-induced hearing loss, 383-387

anatomical specializations, 380

anthropogenic noise exposure, 392-393

causes of, 381-382

congenital hearing loss, 382-383

hair cell bundle loss, 381

regeneration

advantage, 395

AEP hearing thresholds, 395

gentamicin sulfate, 393

Microarray, 395

microRNA, 395

NGS techniques, 395

pathway regulation, 395

post exposure, 393, 394 post-acoustic trauma recovery, 395

post-exposure, 394

potential therapeutics, 395

rate of, 395

time course, 394, 395

superficial and canal neuromasts, 380

vestibular and lateral line deficits, 391-392

Sensory hair cells, 198

Shaker system, 202

Sharpening ratio (SR), 214, 215

Signal to noise ratio (SNR), 84

Single neuron recordings

A. abdominalis, 239

auditory hindbrain and midbrain, 236-237

tuning curves, 246

Soliloquy, 53

Sound localization, 274

toadfish, 282-284, 286

Sound pressure, 259

hydrodynamic particle motion and, 76-77

Sound pressure levels (SPL), 277, 384

Sound production, $69,72,73,84-87$

Abudefduf abdominalis, 231

evolution, butterflyfishes, 74-76

Sound propagation

in natural settings, 265

in tanks, 262

underwater, 260-262

Soundscape analysis, 108

Spike 2 software, 235-237

Staircase method, 176-177

Startle response, kinematics of, 168

Startle-escape response, 167

Stimulus presentation protocol, 175

Superficial neuromasts, 259

Swim bladder, 63, 65, 337

cichlid, 333

Cynoscion regalis, 337

ear and proximity, 66, 67

horns, Chaetodon and effect of, 77, 79, 81

inner ears vs., 327

Leiostomus xanthuru, 337

T

Tail slap locomotor behavior, 72

Tail-flip response, 127

Tangential octaval nucleus (TON), 209, 218

Telemetry tag, 275-278

effectiveness of, 279

prey, lateral line detection of, 280

Teleosts

inner ear of, 273

swim bladder of, 65 
Temporary threshold shifts (TTS), 384, 385

Thorny catfishes, 328-332 intrafamilial study, 338

Threshold criteria, 177-178

Toadfish, 198, 203-213

auditory system, 203

AON function, 209

AON function of, 209

brain, 212-213

DON, 207-208

ear, 203-205

ear hearing, 210-212

MON/TON, 209

saccular inputs, 206-207

batrachoid fish, 275

behavioral repertoire, 200

boatwhistle, 275

detection distance, 286-287

gas bladder, 221

lateral line, 285-286

MRC, 201

MS-222 dose response curve, 279

orthogonal semi-circular canals and otolithic endorgans, 200

physiological studies, 202-203

preliminary experiments, 288

prey, lateral line detection of, 280

Rayleigh statistic, 278

secondary octaval populations, nuclei, 221

self-generated movement, 287-288

sensory hair cells, 198

sensory roles, 220

sound, 200

sound localization, 274, 282-284, 286

telemetry tag, 275-278

tract-tracing studies, 201 utricle, 280-282

vector strength and spike rate, 278

TON. See Tangential octaval nucleus

Torus semicircularis (TS), 219-220, 236

Transmission electron microscopy (TEM) studies, 410

Tunica externa, 65

Tunica interna, 63

\section{$\mathbf{U}$}

US Navy J9 sound projector, 131

Utricle, 280-282

V

Vector detection, 130

Vestibular, 273

von Békésy, Georg, 16

W

Waterproof connector, 276

Weberian ossicles, catfish, 328

$\mathbf{Z}$

Zebrafish (Danio rerio)

ASR vs.PPI, 168

auditory thresholds, 167, 168

experimental paradigm, 167

kinematics of, 168-169

ontogeny, 169

PPI, 173

startle responses of, 168

thresholds for, 170 